\title{
A UNIDADE ÁGUA CLARA NO CONTEXTO DO GRUPO AÇUNGUI: UM MODELO TRANSPRESSIVO DE COLISÃO OBLÍQUA NO NEOPROTEROZÓICO PARANAENSE
}

\author{
ELVO FASSBINDER
}

Orientador: Prof. Dr. Rômulo Machado

TESE DE DOUTORAMENTO

COMISSÃO JULGADORA

Nome

Assinatura

Presidente:

Prof. Dr. Rômulo Machado

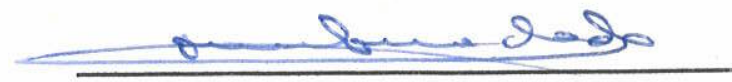

Examinadores:

Prof. Dr. Ginaldo A.da C.Campanha

Prof. Dr. Antonio Romalino S.F.Cesar

Prof. Dr. Alberto Pio Fiori

Prof. Dr. Carlos Alberto Rosière

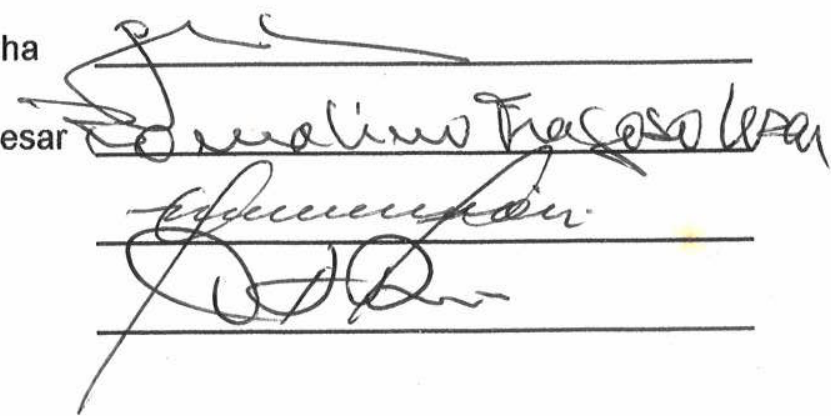




\title{
UNIVERSIDADE DE SĀO PAULO \\ INSTITUTO DE GEOCIENCIAS
}

\section{A UNIDADE ÁGUA CLARA NO CONTEXTO DO GRUPO AÇUNGUI: UM MODELO TRANSPRESSIVO DE COLISÃO OBLÍQUA NO NEOPROTEROZÓICO PARANAENSE}

\author{
Elvo Fassbinder
}

Orientador: Prof. Dr. Rômulo Machado

TESE DE DOUTORAMENTO

Programa de Pós-Graduação em Geoquímica e Geotectônica

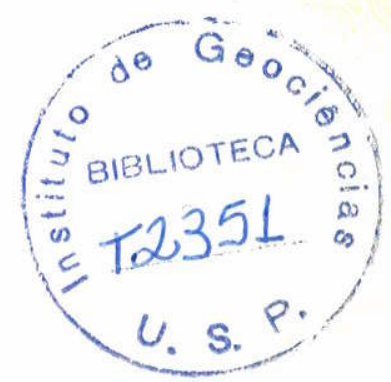

SÃO PAULO

1996 
AO amigo JOSÉ HENRIQUE GODOY SIGUEL

(in memoriam);

Aos meus pais EDA e BRENO,

minha esposa NADIA e ao meu filho NICOLAS. 


\section{INTRODUÇÃO}

1.1 OBJETIVOS 2

1.2 LOCALIZAÇ̃̃o dA ÁREA

1.3 MATERIAIS E MÉTODOS UTILIZADOS 4

1.3.1 PESQUISA BIBLIOGRÁFICA

1.3.2 TRABALHOS DE FOTOINTERPRETAÇÃO

1.3.3 ATIVIDADES DE CAMPO 4

1.3.3.1 BASES CARTOGRÁFICAS E AEROFOTOGEOLÓGICAS 4

1.3.3.2 BASES GEOLÓGICAS DE APOIO

1.3.3.3 AMOSTRAGEM

1.3.4 ATIVIDADES DE LABORATÓRIO

1.3.4.1 PREPARAÇÃO E ANÁLISE DE LÂMINAS DELGADAS 5

1.3.4.2 TRATAMENTO ESTATÍSTICO DOS DADOS ESTRUTURAIS ? 6

$\begin{array}{ll}\text { 1.3.4.3 ISÓTOPOS } & 6\end{array}$

1.3.4.4 APRESENTAÇÃO DOS RESULTADOS

$\begin{array}{ll}\text { 1.4 AGRADECIMENTOS } & 7\end{array}$

\section{CONCEITOS BÁSICOS}

2.1 MODELO TRANSPRESSIONAL

2.1.1 INTRODUÇÃO

\subsection{CONCEITUAÇ̃̃o}

2.2.1 CARACTERISTICAS DE UMA ESTRUTURA TRANSPRESSIONAL/

TRANSTRACIONAL IDEAL

2.2.1.1 ESTRUTURAS DÚCTEIS

a) PORCÃO INFERIOR DA ESTRUTURA (RAIZ)

b) PORCYIO NTERMEDI.ARIA

c) PORÇAO SIPERIOR DA ESTRLTURA

$\begin{array}{ll}\text { 2.2.1.2 ESTRUTURAS DÚCTEIS-RÚPTEIS E RÚPTEIS } & 15\end{array}$ 
2.3 EVOLUÇÃO dOS CONHECIMENTOS A PARTIR DOS CONCEITOS DE

SANDERSON \& MARCHINI (1984) 16

2.4 COLISÕES OBLÍQUAS $\quad 20$

2.4.1 MODELO DE SANDERSON \& MARCHINI (1984) 20

2.4.1.1 COLISÃO COM ÂNGULO $>45^{\circ}\left(\alpha^{-1}<1\right)$

2.4.1.2 COLISÃO COM ÂNGULO $=45^{\circ}\left(\alpha^{-1}=1\right)$

2.4.1.3 COLISÃO COM ÂNGULO $<45^{\circ}\left(\alpha^{-1}>1\right) \quad 22$

2.4.2 MODELO DE TIKOFF \& TEYSSIER (1994) 22

2.4.2.1 INTRODUÇÃO

2.4.2.2 PARÂMETROS 23

2.4.2.3 RELAÇÕES ENTRE OS ELIPSÓIDES DE DEFORMAÇÃO INSTANTANEA

2.4.2.4 QUANTIFICAČ̃̃ DAS ZONAS TRANSPRESSIONAIS NOS DOMÍNIOS DE
CISALHAMENTO PURO E TRANSCORRENTE

2.4.2.5 RELAÇÃO ENTRE O MOVIMENTO DE PLACAS E A DEFORMAÇÃO EM
ZONAS TRANSPRESSIONAIS

2.4.2.6 DEFORMAÇÃO INSTANTANEA E O MOVIMENTO RELATIVO DAS
PLACAS

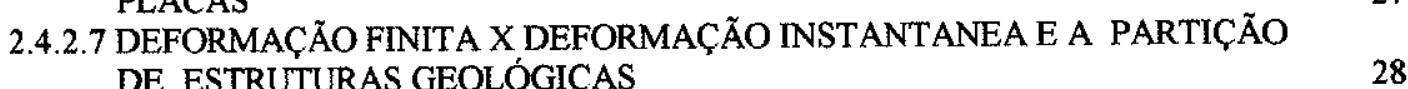

a) TRANSPRESSIONAL COM COMPONENTE PRINCIPAL TRANSCORRENTE 28

b) TRANSPRESSIONAL COM CISALHAMENTO PURO COMO COMPONENTE PRINCIPAL 28

2.4.2.8 FALHAS TRANSCORRENTES DISCRETAS EM ZONAS

TRANSPRESSIONAIS

2.5 SIMETRIA LITO-ESTRUTURAL AO LONGO DE UMA ESTRUTURA EM FLOR POSITIVA

2.6 MÉTOdOS DE CÁLCULO DA VARIAÇÃO DE VOLUME EM ZONAS

TRANSPRESSIONAIS/TRANSTRACIONAIS

31

\section{EVOLUÇÃO DOS CONHECIMENTOS GEOLÓGICOS ANTERIORES}

3.1 FASE HISTÓRICA

3.2 FASE DE ESTUDOS SISTEMÁTICOS 33

3.2.1 DEFINIÇÕES BÁSICAS

3.2.2 RECONHECIMENTO 33

3.2.2.1 ESTADO DO PARANÁ

3.2.2.2 VALE DO RIO RIBEIRA DE IGUAPE

3.2.3 FASE ATUAL $\quad 35$

3.2.4 DISCUSSÃO CRÍTICA DA GEOLOGIA REGIONAL 38

3.3 SINTESE DO QUADRO ESTRATIGRÁFICO EVOLUTIVO 
3.4 MODELOS TECTÔNICOS REGIONAIS

3.4.1 MODELO DE HASUI et al. (1986) 53

3.4.2 MODELO DE SOARES (1987) 53

3.4.3 MODELO DE CAMPANHA et al (1987) 55

3.4.4 MODELO DE REIS NETO (1994)

\section{GEOLOGIA DA ÁREA}

\subsection{INTRODUÇÃO}

4.2 ASSOCIAÇÕES LITOLÓGICAS

4.2.1 SEQUÊNCIA SERRINHA

$\begin{array}{ll}\text { 4.2.2 SEQUÊNCIA SÃO SLVESTRE } & 60\end{array}$

4.3 ANÁLISE DAS ESTRUTURAS NA ESCALA MESOSCÓPICA

4.3.1 INTRODUÇ̃̃O $\quad 61$

4.3.2 PERFIS RIO DA LOMBA E RIO DA BARRA 62

4.3.3 ANÁLISE DA DEFORMAÇÃO E DO METAMORFISMO 62

4.3.3.1 CISALHAMENTO PRINCIPAL DO SISTEMA TRANSPRESSIVO

a) FOLIAÇÕES $S-C_{(1)}$

b) DOBRAS

c) $\mathrm{Li} S s$

d) LINEAÇÕES (MINERAIS E DE ESTIRAMENTO)

e) DOBRAS SUAVES E ABERTAS

4.3.4 ANÁLISE GEOMÉTRICA REGIONAL 83

4.3.4.1 PERFIL RIO DA LOMBA 83

4.3.4.2 SUMARIZAÇÃO DOS DADOS DO PERFIL NO RIO DA BARRA

4.3.4.3 PADRÃO CINEMÁTICO DO SISTEMA TRANSPRESSIVO DÚCTIL.

$\begin{array}{ll}\text { NA ESCALA MESOSCÓPICA } & 90 \\ & 91\end{array}$

$\begin{array}{ll}\text { 4.3.4.4 SISTEMA TRANSCORRENTE } & 91 \\ & 92\end{array}$

$\begin{array}{lr}\text { a) DOBRAS ESCALONADAS } & 92 \\ \text { b) SISTEMA DE REATIVAÇÃO } & 94\end{array}$

4.3.4.5 OUTRAS DEFORMAÇÕES 94

4.3.5 MODEILIZAÇÃO E DISCUSSÃO DOS DADOS ESTRUTURAIS DA

FORMAÇÃO ÁGUA CLARA 96

4.4 ANÁLISE DAS ESTRUTURAS NA ESCALA MICROSCÓPICA

4.4.1 INTRODUÇÃO 96

4.4.2 SISTEMA DE DEFORMAÇÃO $\mathrm{SD}_{1}$

4.4.2.1 LINEAÇÕES $\quad 99$

4.3 SISTEMA DE DEFORMAÇÃO SD
z 
4.4.4 SISTEMA DE DEFORMAÇÃO $\mathrm{SD}_{3}$

4.5 ISÓTOPOS

4.5.1 INTRODUÇ̃̃OO 120

4.5.2 RESULTADOS DAS ANÁLISES DAS COMPOSIÇÕES ISOTÓPICAS 120

4.5.3 DISCUSSÃO DOS RESULTADOS 123

4.5.3.1 AMBIENTE DE SEDIMENTAÇÃO 123

4.5.4 ISÓTOPOS ESTÁVEIS COMO INDICADORES TEMPORAIS 125

$\begin{array}{lr}4.5 .5 \text { CORRELAÇÕES } & 128\end{array}$

4.6 AMBIENTES DE SEDIMENTAÇÃO

4.6.1 NA UNIDADE SÃO SILVESTRE (FORMAÇÃO ÁGUA CLARA) 129

4.6.2 NO GRUPO AÇUNGUI (FORMAÇ̃̃ES CAPIRÚ, VOTUVERAVA
E ITAIACOCA)

4.6.2.1 BASE DO GRUPO AÇUNGUI TRADICIONAL

4.6.2.2 PORÇÃO INTERMEDIÁRIA DA BACIA AÇUNGUI

$\begin{array}{ll}\text { 4.6.2.3 TOPO DO GRUPO AÇUNGUI } & 137\end{array}$

a) DUPLICAÇÃo TECTÔNICA DA BACIA AÇUNGUI

b) CICLOS DE SEDIMENTAÇÃO PARA A BACIA AÇUNGUI $\quad 138$

4.7 CORRELAÇÃo da FORMAÇÃo ÁGUA CLARA COM O GRUPO AÇUNGUI

$4.7 .11^{\circ}$ SISTEMA DE DEFORMAÇ̃̃O $\left(\mathrm{SD}_{1}\right) \quad 142$

4.7.2 $2^{\circ}$ SISTEMA DE DEFORMACุÃO $\left(\mathrm{SD}_{2}\right)$

$4.7 .33^{\circ}$ SISTEMA DE DEFORMAÇÃO

5. MODELO TECTÓNICO

$\begin{array}{lr}\text { S.1 INTRODUÇÃO } & 147\end{array}$

5.2 MODELOS ESTRUTURAIS PROPOSTOS E PROBLEMAS PENDENTES

5.3 O CINTURÃo RIBEIRA NO CONTEXTO REGIONAL 152

5.4 PORÇÃo CENTRAL da ZONA dE CISALHAMENTO (TRANSPRESSIONAL) 156

5.5 DISCUSSÃo SOBRE A DISPOSIÇão SIMÉTRICA DAS UNIDADES

$\begin{array}{lr}\text { 5.6 COLUNA ESTRATIGRÁFICA ORIGINAL } & 170\end{array}$

5.7 LOCALIZAÇÃo DO GRUPO ACUNGUI NA ESTRUTURA TRANSPRESSIONAL 173 
5.8 MECANISMOS DE GERAÇÃO DA FOLIAÇÃo $\mathrm{S}_{1} / \mathrm{S}_{\text {o }}$

5.8.1 MECANISMO CLÁSSICO DE "BUCKLING"

5.8.2 CISALHAMENTO SIMPLES, NO SENTIDO DE RAMSAY(1980)

5.9 CONTATO ENTRE AS UNIDADES

175

5.10 INTENSIDADE DA TRANSPRESSÃO

6. EVOLUÇÃO GEOLÓGICA

7. CONCLUSÕES

8. GLOSSÁRIO

8.1 FASE DE DEFORMAÇÃo

8.2 SISTEMA DE DEFORMAÇÃO

8.3 SUPERPOSIÇÃO CINEMÁTICA

\section{LISTA DE FIGURAS}

FIGURA 1.1 - LOCALIZAÇÃO DA ÁREA ESTUDADA.

FIGURA 2.1 - MODELO DE TRANSPRESSÃO.

FIGURA 2.2 - DIAGRAMA LOGARITMICO DE FLINN

FIGURA 2.3 - ORIENTAÇÃO DO ELIPSÓIDE DE DEFORMAÇÃO FINITA PARA TRANSPRESSÃO/ TRANSTRAÇÃO. E OS CAMINHOS DA DEFORMAÇÃO NO ESPACO K- $\gamma$ 
FIGURA 2.4 - ORIENTAÇÃO DA DIREÇÃO MÁXIMA INSTANTÂNEA DE ESTIRAMENTO $\left(\varepsilon_{1}\right)$ COM A VARIAÇÃO DO $W_{K}$ PARA TRANSPRESSÃO E TRANSTRAÇÃO

FIGURA 2.5 - DIAGRAMA MOSTRANDO A ORIENTAČ̃̃O DE ESTRUTURAS DENTRO O MODELO TRANSPRESSIONAL/TRANSTRACIONAL.

FIGURA 2.6 - DOIS TIPOS DE TRANSPRESSÃO, COM PREDOMÍNIO DE CISALHAMENTO PURO E CISALHAMENTO SIMPLES RESPECTIVAMENTE, DISTINGUIDOS PELA ORIENTAÇÃO DOS EIXOS DE DEFORMAÇÃO INSTANTÂNEO.

FIGURA 2.7 - RELAÇÃO ENTRE O KINEMATIC VORTICITY NUMBER E O EIXO $\theta$

FIGURA 2.8 - RELAÇÃO ENTRE O FLOW APOPHYSES, EIXOS DE DEFORMAÇÃO INSTANTÂNEA, E LINHAS DE FLUXO

FIGURA 2.9 - RELAÇÃO ENTRE O ÂNGULO $\alpha$ DA CONVERGÊNCIA DE PLACAS E O ÂNGULO $\theta$.

FIGURA 2.10 - COMPARTIMENTAÇÃO LITO-ESTRUTURAL GERADA POR UMA ESTRUTURA-EM-FLOR

FIGURA 3.1 - CONDIÇÕES TECTONO-METAMÓRFICAS EM QUE AS FOLIAÇÕES DOS GRUPOS SETUVA E AÇUNGUI FORAM DESENVOLVIDAS

FIGURA 4.1 - REPRESENTAÇÃO ESQUEMÁTICA DA PRESENÇA DE CISALHAMENTO

FIGURA 4.3 - DESENHO ESQUEMÁTICO DO ESTILO DE DEFORMAÇÃO PRESENTE NA FORMAÇÃO ÁGUA CLARA

FIGURA 4.4 - DESENHO ESQUEMÁTICO DE UMA DOBRA-FALHA GERADA POR DEFORMAÇÃO DÚCTIL, MOSTRANDO SUAS RELAÇÕES COM AS FOLIAÇÕES S-C $(1)$.

FIGURA 4.5 - DOBRAS GERADAS POR CISALHAMENTO NO AFL. ED 100.

FIGURA 4.6 - DOBRAS GERADAS POR CISALHAMENTO NO AFLORAMENTO ED 120(3).

FIGURA 4.7 - DESENHOS ESQUEMÁTICOS DE CAMADAS DE ROCHAS CARBONÁTICAS IMPURAS INTENSAMENTE DEFORMADAS NO AFLORAMENTO ED 111.

FIGURA 4.8 - DIAGRAMA SCHMIDT-LAMBERT COM A DISTRIBUIÇÃO DOS EIXOS DE DOBRAS FECHADAS A ISOCLINAIS

FIGURA 4.9 - DIAGRAMA MOSTRANDO A DISPOSIÇÃO DOS EIXOS DE DOBRAS NO QUADRANTE NOROESTE, ROTACIONADAS PARA O QUADRANTE SUDESTE

FIGURA 4.10 - DIAGRAMA CONFECCIONADO A PARTIR DE DADOS ESTRUTUTAIS OBTIDOS NOS AFLORAMENTOS ED 100 - 101 E 102

FIGURA 4.11 - MODELO DE DEFORMAÇÃO POR CISALHAMENTO SIMPLES.

FIGURA +.12 - DIAGRAMA COM GUIRLANDA DE PÓLOS DA FOLIAÇÃO $\mathrm{S}_{r} / / \mathrm{S}_{\curvearrowright}$. EIXO ß. PLANO AXIAL E LINEAÇÕES DE INTERSECÇÃO

FIGURA 4.13 - DOBRA-FALHA GERADA EM CONDIÇÕES RÚPTEIS-DÚCTEIS (AFLORAMENTO ED 127). 
FIGURA 4.14 - REPRESENTAÇÃO GRÁFICA DAS ESTRUTURAS DA FIG 4.13

(AFLORAMENTO ED 127).

FIGURA 4.15 - DOBRA ISOCLINAL GERADA PELO CISALHAMENTO PRINCIPAL,

REDOBRADA POR DOBRAS ABERTAS, COM ELXOS NE-E.

FIGURA 4.16 - DESENHO ESQUEMÁTICO DE UMA DOBRA ABERTA NA BASE, QUE PASSA PARA DOBRA SUAVE NO TOPO.

FIGURA 4.17 - DIAGRAMA MOSTRANDO UMA DOBRA SUAVE

FIGURA 4.18 - DIAGRAMA COM 535 PÓLOS DA FOLIAÇÃO $\mathrm{S}_{C}$, DO PERFIL RIO DA LOMBA

FIGURA 4.19 - DIAGRAMA MOSTRANDO A DISTRIBUIÇÃO DE 24 EIXOS ESTATÍSTICOS

DE DOBRAS SUAVES/ABERTAS (PERFIL RIO DA LOMBA)

FIGURA 4.20 - DIAGRAMA MOSTRANDO A DISPOSIÇÃO DOS EIXOS DE DOBRAS MEDIDOS NOS AFLORAMENTOS DO PERFIL RIO DA LOMBA.

FIGURA 4.21 - DISTRIBUIÇÃO DE 86 LINEAÇÕES DE INTERSECÇÃO DA FOLIAÇÃO

$S_{S}$ SOBRE A $S_{C}$, NO PERFIL RIO DA LOMBA.

FIGURA 4.22 - INTEGRAÇÃO DOS PÓLOS DA FOLIAÇÃO S SO PERFIL RIO DA BARRA.

FIGURA 4.23 - REPRESENTAÇÃO CICLOGRÁFICA DOS DIVERSOS EIXOS ESTATÍSTICOS

OBTIDOS NO PERFIL RIO DA BARRA.

FIGURA 4.24 - REPRESENTAÇÃO ESTEROGRÁFICA DAS LI ${ }_{S c}^{S s}$ COLETADAS NO PERFIL

RIO DA BARRA.

FIGURA 4.25 - REPRESENTAÇÃO DE 126 EIXOS DE DOBRAS DO PERFIL RIO DA BARRA

FIGURA 4.26 - GEOMETRIA DAS ZONAS DE CISALHAMENTO TRANSCORRENTES NOS ESTADOS DO PARANÁ E SUL DE SÃO PAULO.

FIGURA 4.27 - EVIDÊCIAS DE UMA DIREÇÃO DE DOBRAMENTOS COM EIXOS N-NW NA ÁREA DE SÃO PEDRO/SÃO SILVESTRE

FIGURA 4.28 - DESENHO ESQUEMÁTICO DAS DEFORMAÇÕES PRESENTES NA ÁREA

DE SÃO PEDRO/SÃO SILVESTRE

FIGURA 4.29 - DIAGRAMA $\delta{ }^{13} \mathrm{C}_{\text {PDB }} \times \delta^{18} \mathrm{O}_{\text {SMOW }}$ DE ROCHAS CARBONÁTICAS DO PRÉCAMBRIANO PARANAENSE

FIGURA 4.30 - DIAGRAMA $\delta{ }^{18} \mathrm{O}_{\mathrm{PDB}} \mathrm{X} \quad \delta^{13} \mathrm{C}_{\mathrm{PDB}}$ DAS FORMAÇÕES ÁGUA CLARA,

VOTUVERAVA E CAPIRÚ

FIGURA 4.31 - DISTRIBUIÇÃO TEMPORAL DOS VALORES DE $\delta^{18} \mathrm{O}$ PARA AS

FORMAÇÕES ÁGUA CLARA. VOTUVERAVA E CAPIRÚ

FIGURA 4.32 - MAPA DOS COMPARTIMENTOS TECTÔNICOS DO PRÉ-CAMBRIANO

PARANAENSE

FIGURA 5.1 - O CINTURÃO RIBEIRA OU ATLÂNTICO. SEGUNDO PROPOSIÇÃO

DE ENDO \& MACHADO (1993).

FIGURA 5.2 - ESTRUTURAÇÃO DO CENTRO DA ZONA DE CISALHAMENTO

TRANSPRESSIONAL

FIGURA 5.3 - DISPOSIÇÃO DAS UNIDADES DO GRUPO AÇUNGUI EM TORNO DO MACIÇO TRÊS CÓRREGOS 
FIGURA 5.4 - DIAGRAMA DE ${ }^{207} \mathrm{~PB} /{ }^{204} \mathrm{~PB} \mathrm{X}^{206} \mathrm{~PB} /{ }^{204} \mathrm{~PB}$ MOSTRANDO A COMPOSIÇÃO ISOTÓPICA DO PB PARA OS COMPLEXOS CUNHAPORANGA E TRÊS CÓRREGOS.

FIGURA 5.5 - SECÇ̃̃O ESQUEMÁTICA, MOSTRANDO A DISPOSIÇÃO DAS UNIDADES DO GRUPO AÇUNGUI, EXPOSTAS POR UMA ESTRUTURA EM FLOR, POSITIVA.

FIGURA 5.6 - COLUNA PROPOSTA PARA O PRÉ-CAMBRIANO DOS ESTADOS DO PARANÁ E SUL DE SÃO PAULO.

FIGURA 5.7 - REPRESENTAÇÃO, NO DIAGRAMA DE FLINN, DE VALORES DE K PROVENIENTES DAS FORMAÇÕES ÁGUA CLARA, VOTUVERAVA E ANTINHA

FIGURA 5.8 - RESULTADOS OBTIDOS POR KOPS (1994) NO DIAGRAMA DE HOSSACK QUE RELACIONA OS VALORES DE INTENSIDADE DE DEFORMAÇÃO (ES) E TIPOS DE ELIPSÓIDES DE DEFORMAÇÃO (v), PARA AS FORMAÇÕES ÁGUA CLARA, VOTUVERAVA E ANTINHA.

\section{LISTA DE QUADROS}

QUADRO 2.1 - SÍNTESE DAS CARACTERÍSTICAS ESTRUTURAIS PRESENTES NUMA ESTRUTURA TRANSPRESSIONAL SEGUNDO SANDERSON \& MARCHINI (1984)

QUADRO 2.2 - SINTESE DAS CARACTERÍSTICAS ESTRUTURAIS PRESENTES EM ZONAS DE TRANSPRESSÃO E TRANSTRAÇÃO SEGUNDO FOSSEN \& TIKOFF (1993)

QUADRO 3.1 - COLUNA LITOESTRATIGRÁFICA PROPOSTA POR CAMPANHA (1991) PARA OS ESTADOS DO PARANÁ E SUL DE SÃO PAULO

QUADRO 3.2 - RELAÇÃO DE AUTORES QUE RECONHECERAM CONTEMPORANEIDADE E/OU SUPERPOSIÇÃO CRONOLÓGICA ENTRE AS UNIDADES QUE COMPÕEM O GRUPO AÇUNGUI.

QUADRO 3.3 - COLUNA LITOESTRATIGRÁFICA PROPOSTA POR FIORI (1990. 1992)

PARA O GRUPO AÇUNGUI, À NORTE DA CIDADE DE CURITIBA.

QUADRO 4.1 - SUMARIZAÇÃO DOS DADOS ESTRUTURAIS DO PERFIL RIO DA LOMBA FORMAC̨ÃO ÁGUA CLARA.

QUADRO +.2 - SUMARIZAÇÃO DOS DADOS ESTRUTURAIS DO PERFIL RIO DA BARRA FORMAÇÃO ÁGUA CLARA.

QUADRO 4.3 - ORDENAMENTO DOS DIVERSOS TIPOS DE ESTRUTURAS SEDIMENTARES EM FUNÇÃO DA HETEROGENEIDADE E HOMOGENEIDADE APARENTE DAS ROCHAS. SEGUNDO HUMBERT (1976) MODIFICADO 
QUADRO 4.4 - ORDENAMENTO DAS ESTRUTURAS DE TIPOS DE GRÃOS EM FUNÇÃO DE SUA APARENTE HOMOGENEIDADE OU HETEROGENEIDADE (HUMBERT, 1976) MODIFICADO.

QUADRO 4.5 - COMPILAÇÃO DAS COLUNAS ESTRATIGRÁFICAS EXISTENTES NOS DIVERSOS BLOCOS TECTÔNICOS DO GRUPO AÇUNGUI.

QUADRO 4.6 - SÍNTESE SOBRE AS CARACTERÍSTICAS MAIS IMPORTANTES DA FORMAÇÃO ÁGUA CLARA E DO GRUPO AÇUNGUI

QUADRO 4.7 - PRINCIPAIS ASSOCIAÇÕES MINERAIS PRESENTES NAS FORMAÇÕES ÁGUA CLARA, VOTUVERAVA E CAPIRÚ.

QUADRO 5.1 - PRINCIPAIS CARACTERÍSTICAS GEOQUIMICAS, ISOTÓPICAS E GEOCRONOLÓGICAS DO COMPLEXO TRÊS CÓRREGOS, SEGUNDO REIS NETO (1994).

QUADRO 5.2 - PRINCIPAIS CARACTERÍSTICAS GEOQUIMICAS, ISOTÓPICAS E GEOCRONOLÓGICAS DO COMPLEXO CUNHAPORANGA, SEGUNDO REIS NETO (1994).

QUADRO 5.3 - CARACTERÍSTICAS GEOLÓGICAS E PETROGRÁFICAS DO COMPLEXO CUNHAPORANGA, SEGUNDO REIS NETO (1994).

QUADRO 5.4 - CARACTERÍSTICAS GEOLÓGICAS E PETROGRÁFICAS DO COMPLEXO TRÊS CÓRREGOS, SEGUNDO REIS NETO (1994).

\section{LISTA DE TABELAS}

TABELA 3.1 - EVOLUÇÃO DOS MODELOS TECTÔNICOS A PARTIR DAS IDÉIAS GEOSSINCLINAIS, AULACOGÊNICAS E A TECTÔNICA DE "NAPPES", SEGUNDO DIVERSOS AUTORES

TABELA 3.2 - CARACTERIZAÇÃO DE DIVERSOS SITIOS TECTÔNICOS SEGUNDO O MODELO DE TECTÔNICA DE PLACAS . SEGUNDO DIVERSOS AUTORES

TABELA 4.1 - VALORES ISOTÓPICOS $\mathrm{DE}^{13} \mathrm{C} \mathrm{E}^{18} \mathrm{O}(\%)$ DE ROCHAS CARBONÁTICAS PRÉ-CAMBRIANAS DO GRUPO AÇUNGUI E SIMILARES

TABELA 4.2 - VALORES MÉDIOS DAS COMPOSIÇÕES ISOTÓPICAS DE $\delta^{13} \mathrm{C}$ E $\delta^{18} \mathrm{O}(\%)$ DE ROCHAS CARBONÁTICAS

TABELA 4.3 - ASSINATURA ISOTÓPICA DE $\delta^{18} \mathrm{O}_{\mathrm{PDB}}$ DOS DIFERENTES PERÍODOS DO PROTEROZÓICO, A PARTIR DE ANÁLISES DO NORDESTE BRASILEIRO

TABELA 5.1 - VALORES DE RAZÕES DE DEFORMAÇÃO ENCONTRADOS POR SPOLADORE (1993) E KOPS (1994) NAS FORMAÇÕES ÁGUA CLARA. VOTUVERAVA E ANTINHA. NO GRUPO AÇUNGUI. 


\section{LISTA DE FOTOGRAFIAS}

FOTOGRAFIA 4.1 - NIVEL ESTRATIGRÁFICO DE METAMARGAS INTENSAMENTE DEFORMADAS ENTRE ROCHAS POUCO DEFORMADAS

FOTOGRAFIA 4.2 - DETALHE DA FOTOGRAFIA ANTERIOR, MOSTRANDO DOBRAS INTRAFOLIAIS ASSIMÉTRICAS

FOTOGRAFIA 4.3 - DOBRAS GERADAS EM METAMARGAS DA FORMAÇÃO ÁGUA CLARA, COM SIGNIFICATIVO ESPESSAMENTO E ALONGAMENTO DOS ÁPICES

FOTOGRAFIA 4.4 - DETALHE DA FOTOGRAFIA 4.3. OBSERVAR A GEOMETRIA HETEROGÊNEA DAS DOBRAS

FOTOGRAFIA 4.5 - ZONA DE CISALHAMENTO JUSTAPONDO UM NIVEL (SUPERIOR) DOBRADO, AO LADO DE OUTRA COM AUSÊNCIA DE DOBRAS (PARTE INFERIOR DA DOBRA)

FOTOGRAFIA 4.6 - DETALHE DA FOTOGRAFIA 4.5, MOSTRANDO A DIFERENÇA GEOMÉTRICA DAS ESTRUTURAS DA PARTE SUPERIOR DA FOTO EM RELAÇÃO AQUELA SITUADA NA SUA PARTE INFERIOR

FOTOGRAFIA 5.1 - MOSÁICO DE FOTOGRAFIAS MOSTRANDO AS ESTRUTURAÇÕES DAS ZONAS DE CISALHAMENTO LANCINHA E MORRO AGUDO

\section{LISTA DE FOTOMICROGRAFIAS}

FOTOMICROGRAFIA +.1 - CISALHAMENTO LATERAL DIREITO GERADA AO LONGO DE PLANOS $\mathrm{Ss}_{1} E \mathrm{Ss}_{2}$, MARCADOS POR MINERAIS DE QUARTZO E ANFIBÓLIO

FOTOMICROGRAFIA 4.2 - AS FOLIAÇÕES $\mathrm{Ss}_{1}$ E Sc ${ }_{1}$ PRESERVADAS EM MICROLITONS, NA PARTE SUPERIOR DA FOTOGRAFIA

FOTOMICROGRAFIA 4.3 - DETALHE DA RELAÇÃO ENTRE AS FOLIAÇÕES Ss $s_{1} \mathrm{E} \mathrm{Sc}_{1}$, PRESERVADAS NO MICROLITON DA FOTOMICROGRAFIA 4.2 FOTOMICROGRAFIA 4.4 - RECRISTALIZAÇÃO DE QUARTZO AO LONGO DOS PLANOS DA FOLIAÇÃO $\mathrm{Sc}_{1}$. E A PRESERVAÇÃO DOS CRISTAIS DE QUARTZO SOBRE OS PLANOS $S s_{1}$.

FOTOMICROGRAFIA 4.5 - CRISTAIS DE QUARTZO COM RAZÕES DE ESTIRAMENTO DA ORDEM DE 3 A 5:1. EM FASE DE RECUPERAÇÃO/ RECRISTALIZAÇ̃̃O 
FOTOMICROGRAFIA 4.6 - CRISTAIS DE GRANADA GERADAS EM CONDIÇÕES CEDO CINEMÁTICAS, APRESENTANDO ROTAÇÃO HORÁRIA

FOTOMICROGRAFIA 4.7 - DETALHE DA FOLIAÇÃO INTERNA NA GRANADA DA MICROFOTOGRAFIA ANTERIOR

FOTOMICROGRAFIA 4.8 - GRANADA SIN-CINEMÁTICA, ENGLOBANDO UMA FOLIAÇÃO MARCADA POR QUARTZO ESTIRADO E TREMOLTTA/ ACTINOLITA, COM ROTAÇÃO HORÁRIA ASSOCIADA

FOTOMICROGRAFIA 4.9 - DETALHE DA FOTOMICROGRAFIA 4.8, MOSTRANDO A ROTAÇÃO HORÁRIA DO CRISTAL DE GRANADA

FOTOMICROGRAFIA 4.10 - ROTAÇÃO HORÁRIA EM DUAS GRANADAS CEDO A SINCINEMÁTICAS

FOTOMICROGRAFIA 4.11 - CRISTAIS DE GRANADA CEDO A SIN-CINEMÁTICAS, DESENVOLVIDOS SOBRE A FOLIAÇÃO $\mathrm{Sc}_{1}$, E DISPOSTOS DE FORMA PARALELA AO ACAMAMENTO SEDIMENTAR RELIQUIAR (So)

FOTOMICROGRAFIA 4.12 - SOMBRA DE PRESSÃO FORMADA AO LADO DE CRISTAL DE GRANADA CEDO A SIN-CINEMÉTICO, OCUPADA POR QUARTZO E ANFIBÓLIO

FOTOMICROGRAFIA 4.13 - IDEM FOTOMICROGRAFIA 4.12

FOTOMICROGRAFIA 4.14 - GRANADA SIN A TARDI-TECTÔNICA, CRESCENDO SOBRE A FOLIAČ̃̃O $\mathrm{Sc}_{1}$, PORÉM SEM SOFRER ROTAÇÃO

FOTOMICROGRAFIA 4.15 - IDEM FOTOMICROGRAFIA 4.14

FOTOMICROGRAFIA 4.16 - FOLIAÇÃO S-C $C_{(1)}$ PRESERVADA NA FORMA DE MINERAIS DE DIOPSÍDIO E BIOTITAS,, DISPOSTAS PERPENDICULARMENTE A FOLIAÇÃO DE TRANSPOSIÇÃO

FOTOMICROGRAFIA 4.17 - MINERAIS DE GRANADA ESTIRADOS SEGUNDO O PLANO DA FOLIAÇÃO $S_{2} s_{2}$ E ASSOCIADAS A MINERAIS DE BIOTITA E ANFIBÓLIO

FOTOMICROGRAFIA 4.18 - IDEM FOTOMICROGRAFIA 4.17

FOTOMICROGRAFIA 4.19 - MINERAIS DE GRANADA ESTIRADOS NUMA RELAÇÃO DE 8 A 10:1 E DISPOSTOS SEGUNDO O PLANO $\mathrm{Sc}_{2}$

FOTOMICROGRAFIA 4.20 - IDEM FOTOMICROGRAFIA 4.19

FOTOMICROGRAFIA 4.21 - CRISTAL DE GRANADA COM DUAS FASES DE CRESCIMENTO CINEMÁTICO: CEDO E SIM. COM RELEVO ALTO; E TARDI A PÓS-CINEMÁTICO, COM RELEVO MODERADO E NEOCRISTALIZAÇÃO ESTÁTICA

FOTOMICROGRAFIA 4.22 - IDEM FOTOMICROGRAFIA 4.21 
FOTOMICROGRAFIA 4.27 - ÁPICE DE DOBRA CERRADA A ISOCLINAL, COM TRANSPOSIÇÃO PLANO AXIAL EVIDENCIADOS PELOS MINERAIS DE QUARTZO ESTIRADOS

FOTOMICROGRAFIA 4.28 - DETALHE DA FOTOMICROGRAFIA 4.27, MOSTRANDO A PASSAGEM DE DIOPSÍDIO PARA TREMOLITA/ACTINOLITA

FOTOMICROGRAFIA 4.29 - CRISTAIS DE TREMOLITA/ACTINOLITA RETROMETAMORFISADOS

FOTOMICROGRAFIA 4.30 - VISÃO GERAL DA SUPERFÍCIE AXIAL DA DOBRA DA FOTOMICROGRAFIA 4.29, COM RODS EM SEU ÁPICE

FOTOMICROGRAFIA 4.31 - DETALHE DA FOTOMICROGRAFIA 4.30, MOSTRANDO O ESTIRAMENTO DE MINERAIS DE QUARTZO SOBRE A FOLIAÇÃO PLANO AXIAL, COM RELAÇÕES DE 3 A 5:1

FOTOMICROGRAFIA 4.32 - FOLIAÇÃO PLANO AXIAL MARCADA POR MINERAIS DE TREMOLITA/ACTINOLITA

FOTOMICROGRAFIA 4.33 - RELAÇ̃̃o ENTRE AS FOLIAÇÕES S-C (1) $_{(1)}$ E S-C ${ }_{(2)}$, MARCADAS POR MINERAIS DE DIOPSÍDIO E BIOTITA

FOTOMICROGRAFIA 4.34 - DETALHE DA FOTOMICROGRAGIA 4.33

FOTOMICROGRAFIA 4.35 - CISALHAMENTO $\mathrm{Sc}_{2}$ QUE REATIVA A MATRIZ ESTRUTURAL ANTERIOR

FOTOMICROGRAFIA 4.36 - IDEM A FOTOMICROGRAFIA 4.35

FOTOMICROGRAFIA 4.37 - DESENVOLVIMENTO DAS FOLIAÇÕES $\mathrm{Ss}_{2}$ E Sc $c_{2}$, INDICANDO DESLOCAMENTO ANTI-HORÁRIO

FOTOMICROGRAFIA 4.38 - PARALELISMO DA FOLIAÇÃO Ss $s_{2}$ SEGUNDO OS PLANOS DA FOLIAÇÃO Ss $s_{2}$

FOTOMICROGRAFIA 4.39 - INDICADOR CINEMÁTICO DE UM MINERAL DE QUARTZO, COM SENTIDO DE TRANSPORTE ANTI-HORÁRIO ASSOCIADO.

AO LONGO DA FOLIAÇÃO $\mathrm{Sc}_{2}$

FOTOMICROGRAFIA 4.40 - MINERAIS DE BIOTITA FORMANDO ESTRUTURAS TIPO "ESPINHA DE PEIXE", INDICANDO SUPERPOSIÇÃO DE DEFORMAÇ̃̃O COM SENTIDOS DE TRANSPORTE OPOSTOS AO LONGO DE UMA IDÊNTICA DIREÇÃO

FOTOMICROGRAFIA 4.41 - DISPOSIÇÃO OBLIQUUA DAS FOLIAÇÕES S-C(3) COM RELAÇÃO AO ACAMAMENTO SEDIMENTAR RELIQUIAR E AS FOLIAÇÕES $\mathrm{Sc}_{1} \mathrm{E} \mathrm{Sc}_{2}$

FOTOMICROGRAFIA 4.42 - FOLIAÇÃO S-C $C_{3,3}$ TRANSPONDO A MATRIZ ESTRUTURAL ANTEIOR

FOTOMICROGRAFIA 4.43 - MINERAIS COM COR DE INTERFERÊNCIA ESCURA FORMAM A FOLIAÇÃO S-C $\mathrm{C}_{(3)}$. AQUELES COM COR MAIS CLARA CONSTITUEM A FOLIAÇÃO $S s_{1}$ PRETÉRITA, ROTACIONADA E TRANSPOSTA. COM SENTIDO DE DESLOCAMENTO HORÁRIO 
FOTOMICROGRAFIA 4.44 - DETALHE DE MINERAIS DE GRANADA NEOCRISTALIZADAS SOBRE OS PLANOS DAS FOLIAÇÕES Ss $\mathrm{E} \mathrm{Ss}_{3}$

FOTOMICROGRAFIA 4.45 - VISÃO MAIS ABRANGENTE DA FOLIAÇÃO S-C $\mathrm{C}_{(3)}$ E DOS

MINERAIS DE GRANADA, OS QUAIS APARECEM NA ASSOCIAÇÃO MINERAL EXTINTA

FOTOMICROGRAFIA 4.46 - ESTRATIFICAÇÃO SEDIMENTAR RELIQUIAR, MARCADA POR NÍVEIS COM OCORRÊNCIA DE DIVERSOS MINERAIS

FOTOMICROGRAFIA 4.47 - IDEM FOTOMICROGRAFIA 4.46

\section{LISTA DE ANEXOS}

ANEXO I - COLUNAS ESTRATIGRÁFICAS DO PRÉ-CAMBRIANO DOS ESTADOS DO PARANÁ E SUL DE SÃo PAULO

ANEXO II - MAPA FOTOGEOLÓGICO DA REGIÃO DE SÃO PEDRO - SÃO SILVESTRE ANEXO IIIA - MAPA DE PONTOS 


\section{RESUMO}

As litologias do Grupo Açungui, situadas no Estado Paraná, foram deformadas num regime transpressivo, em consequência de uma convergência oblíqua de placas. A deformação sofreu partição segundo as componentes de cisalhamento puro (thrust faults) e cisalhamento simples (transcorrências), ambas em regime de deformação dúctil. A componente de cisalhamento puro, melhor desenvolvida nas litologias da Formação Água Clara, gerou os sistemas de deformação $\mathrm{SD}_{1}, \mathrm{SD}_{2}$ e $\mathrm{SD}_{3}$. Destes sistemas, o $\mathrm{SD}_{1}$ é penetrativo, gerando foliações $\mathrm{Ss}_{(1)}$ e $\mathrm{Sc}_{(1)}$, dobras cerradas a isoclinais, lineações minerais e de estiramento. $\mathrm{O}$ sistema $\mathrm{SD}_{2}$, com as foliações $\mathrm{Ss}_{(2)}$ e $\mathrm{Sc}_{(2)}$, reativou e reorientou o sistema anterior $\left(\mathrm{SD}_{1}\right)$. E o sistema $\mathrm{SD}_{3}$ é composto pelas foliações $\mathrm{Ss}_{(3)}$ e $\mathrm{Sc}_{(3)}$. Estes sistemas sofreram superposição cinemática, com transportes para sul $\left(\mathrm{SD}_{1}\right)$, norte $\left(\mathrm{SD}_{2}\right)$ e sul $\left(\mathrm{SD}_{3}\right)$, respectivamente.

A segunda componente da partição, de cisalhamento simples, desenvolveu-se nas demais litologias do Grupo Açungui, na sequência da história deformacional. Foram geradas novas estruturas, além da reorientação daquelas pré-existentes. Seguiu-se um periodo de transtração, com a colocação de granitos nos Complexos Três Córregos e Cunhaporanga (?). Este período foi sucedido por um novo evento transpressional, agora de natureza rúptil/dúctil, sendo também acompanhado por partição da deformação. Ao longo da componente de cisalhamento simples, predominante, desenvolveram-se os lineamentos transcorrentes da Lancinha, Morro Agudo, Itapirapuã, Ribeira, entre outros, além de dobras escalonadas e demais estruturas de Riedel. Ao longo desta componente, ocorreu a rotação do eixo $\mathrm{X}$ do elipsóide de deformação finita, passando de uma posição horizontal para vertical. Esta rotação da deformação somou-se aquela da componente de cisalhamento puro, gerando uma estrutura-em-flor, positiva. Esta estrutura alçou, no seu centro, com maior intensidade, o Complexo Três Córregos e a Formação Água Clara, diminuindo de intensidade em direção às suas bordas, expondo a Formação Votuverava, a sudeste, e mais afastadas destas, as Formações Capirú e Itaiacoca, nas bordas sudeste e noroeste, respectivamente.

A coluna estratigráfica original do Grupo Açungui, com a Formação Água Clara na base, seguida da Formação Votuverava e, no topo, as Formações Capirú e Itaiacoca, sofreram inversão tectônica ao longo da estrutura-em-flor, positiva. Os dados de isótopos estáveis de ${ }^{18} \mathrm{O}$ sugerem um intervalo de 400-450 Ma para a sedimentação destas unidades, com idade próxima de 1.3Ga, para a Formação Água Clara, de $0,90 \mathrm{Ga}$ para a Formação Votuverava e, próxima de $0.70 \mathrm{Ga}$, para as Formações Capirú e Itaiacoca. 


\section{A B S TRACT}

The lithological units of the Açungui Group, in the state of Paraná, were deformed in a transpressive regime as a consequence of an oblique plate colision. Both thrust faults and simple shearing took place in a ductile deformation regime. Pure shearing which was better developed in the Água Clara Formation generated $\mathrm{SD}_{1}, \mathrm{SD}_{2}$ and $\mathrm{SD}_{3}$ deformation systems; $\mathrm{SD}_{1}$ is penetrative, with $\mathrm{Ss}_{1}$ and $\mathrm{Sc}_{1}$ foliations, close to isoclinal folds, mineral and stretching lineations; $\mathrm{SD}_{2}$, with $\mathrm{Ss}_{2}$ and $\mathrm{Sc}_{2}$ foliations, reactivated and reoriented the $\mathrm{SD}_{1}$ system and $\mathrm{SD}_{3}$ is made up of $\mathrm{Ss}_{3}$ and $\mathrm{Sc}_{3}$ foliations. These systems underwent a kinematic superposition, with Southward $\left(\mathrm{SD}_{1}\right)$, Northward $\left(\mathrm{SD}_{2}\right)$ and again Southward $\left(\mathrm{SD}_{3}\right)$ transport.

Following the sequence of deformation events, the second component of the partition, consisting of simple shearing, developed in the remaining lithologies of the Açungui Group. Besides the reorientation of the existent structures, new ones were generated. A period of transtension thus followed, with the emplacement of granites in the Três Córregos and Cunhaporanga (?) Complexes. This period was succeeded by a new transpression event which had a ruptile/ductile behavior while a partition of the deformation also happened. Besides en échelon folding and other Riedel's structures, transcurrent faults (e.g. Lancinha, Morro Agudo, Itapirapuã, Ribeira) developed along the dominant simple shearing component. It was along this component that the finite deformation ellipsoid $\mathrm{X}$ axis rotated, changing for horizontal to vertical position. This rotation of the deformation added up to that of the pure shearing component, generating a positive flower structure, which uplifted, in its center, the Três Córregos Complex and the Agua Clara Formation. Towards the structure limits, the Votuverava Formation was exposed at Southeast, and Capirú and Itaiacoca Formations at Southeast and Northwest, respectively.

The original stratigraphy of the Açungui Group, with the Agua Clara Formation in the base, folowed by the Votuverava Formation and with Capiru and Itaiacoca Formations on top, experienced a tectonic inversion throughout the positive flower structure. Stable isotopes of ${ }^{18} \mathrm{O}$ data suggest an interval of 400-450 Ma for thes sedimentation of these units, with ages of 1.3 $\mathrm{Ga}$ for the Água Clara Formation, $0.90 \mathrm{Ga}$ for Votuverava and around 0.70 Ga for Capirú and Itaiacoca Formations. 


\section{INTRODUÇÃO}

Este trabalho se originou a partir dos projetos desenvolvidos pelo Convênio UFPRMINEROPAR, no periodo de 1984 - 1988, coordenados pelo Prof. Dr. Alberto Pio Fiori. A investigação geológica sobre as supra-crustais do pré-cambriano Paranaense, sobretudo do Grupo Açungui, avançou significativamente neste período (Fiori et al., 1984; Góis et al., 1985, Fassbinder et al., 1985; Fiori, 1985; Fiori et. al., 1987a,b,c e Soares, 1987). Porém, a relação do Grupo Açungui com a Formação Água Clara continuou ainda uma questão polêmica. Embora Marini et al. (1967) a tenha definido como uma formação ocupando o topo do Grupo Açungui, Pontes $(1981,1982)$ a interpretou como fazendo parte da base do referido Grupo, enquanto Fritzsons Jr et al. (1982) preferiram colocá-la no Grupo Setuva, atribuindo-lhe a um ciclo geotectônico anterior (Proterozóico Médio). Esta linha de raciocínio foi seguida pôr Soares (1987), que estabeleceu um modelo para os Grupo Setuva evoluído no Proterozóico Médio, e para o Grupo Açungui, no Proterozóico Superior.

Os avanços registrados no campo teórico da geologia estrutural, sobretudo na área da mecânica da deformação, incluindo a introdução dos conceitos de cisalhamento Simples (Ramsay, 1967, 1980; Ramsay e Graham, 1970; Ramsay e Huber, 1983, 1987; Simpson e Schmidt, 1983, entre outros), de cavalgamentos de baixo ângulo (Boyer e Elliot, 1982; Butler, 1982; Lister e Snoke, 1984; Boyer, 1986, entre outros), de transpressão (Harland, 1971; Sanderson \& Marchini, 1984; Fossen \& Tikoff, 1993) e de partição da deformação (Richard \& Cobbold, 1990; Pinet \& Cobbold, 1992; Tikoff \& Teyssier, 1994), modificou substancialmente os parâmetros com os quais as unidades geológicas foram interpretadas na década de 80 . Neste sentido, a investigação da relação da Formação Água Clara com o Grupo Açungui, bem como a busca de um modelo tectônico alternativo para as supra-crustais do pré-cambriano paranaense, se constituíram na motivação principal para a realização deste trabalho. 


\subsection{OBJETIVOS}

Os objetivos principais deste trabalho foram:

a) Caracterizar o padrão estrutural da Formação Água Clara nas suas diferentes escalas (macroscópica, mesoscópica e microscópica);

b) Comparar a Formação Água Clara com o Grupo Açungui em termos estruturais, metamórficos, sedimentares e estratigráficos, assim como estabelecer possíveis relações entre estas unidades;

c) Estabelecer um modelo tectônico alternativo para o Grupo Açungui e correlatos, visando responder questões não respondidas pelos modelos ora disponíveis.

\subsection{LOCALIZAÇÃo DA ÁREA}

Como estratégia de estudo, foram selecionadas vários perfis geológicos, visando equacionar os objetivos acima propostos (Figura 1.1). Tais perfis situam-se a norte e noroeste de Curitiba, correspondendo aos do Rio da Lomba e Rio da Barra, os quais foram utilizados pôr Pontes $(1981,1982)$ e Pontes \& Salazar (1982), como área padrão para definição das litologias da Fácies São Silvestre (Formação Água Clara), na região de São Pedro - São Silvestre. Adicionalmente, para comparação com o Grupo Açungui, foram estudados os perfis Rio Branco do Sul - Voturuvú, ao longo da estrada que vai de Rio Branco a localidade de Canelão, abrangendo litologias clássicas da Formação Votuverava; perfil Tunas - Cerro Azul, em litologias da Formação Votuverava, com ênfase no contato entre os metassedimentos Açungui e as rochas graníticas do Complexo Três Córregos. Além disso, com o propósito de uma correlação regional, foram realizados estudos sistemáticos em afloramentos das Formações Água Clara, Votuverava, Capirú e Itaiacoca, ao longo da área demarcada na Figura 1.1 e representadas no Anexo IIIA (Mapa de Pontos). 


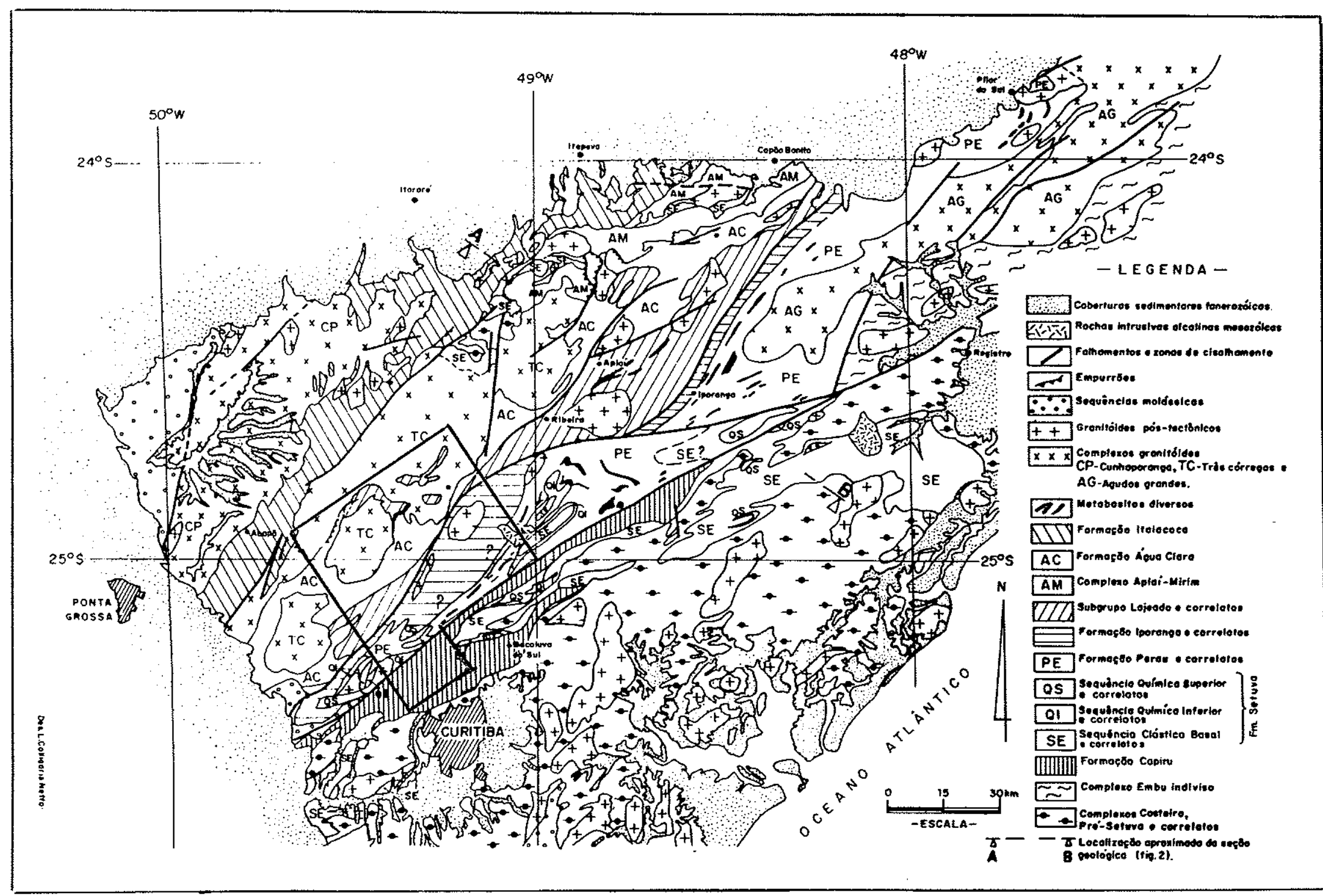

Figura 1.1 - Localização da Árca cstudada. Fontc: Campanha ct al. (1987). Área de estudos 


\subsection{MATERIAIS E MÉTODOS UTILIZADOS}

Este trabalho foi desenvolvido no período de 1990/1996, no qual foram empregados diversos métodos e técnicas específicas, como segue:

\subsubsection{PESQUISA BIBLIOGRÁFICA}

Levantamento da bibliografia regional, com ênfase nas proposições estratigráficas e modelos tectônicos existentes, visando dar ao leitor uma perspectiva histórica do quadro de evolução dos conhecimentos geológicos disponiveis na região. Esta atividade gerou o Anexo I, no qual foram compiladas 40 colunas estratigráficas.

\subsubsection{TRABALHOS DE FOTOINTERPRETAÇÃO}

Foram realizados trabalhos de fotointerpretação de imagens de satélite Landsat, na escala 1:100.000, fotografias aéreas, na escala 1:70.000, da USAF, objetivando delimitar as litologias da Formação Água Clara e seu contexto fotogeológico. O resultado desta atividade resultou no Anexo II (Mapa Fotogeológico da Região de São Pedro - São Silvestre).

\subsubsection{ATIVIDADES DE CAMPO}

Os trabalhos de campo foram desenvolvidas no período de 120 dias. Compõem, basicamente, as seguintes atividades:

\subsubsection{BASES CARTOGRÁFICAS E AEROFOTOGEOLÓGICAS}

As principais bases cartográficas utilizadas, foram:

- Levantamento aerofotogeológico da COMEC, escala 1:50.000 (4 folhas), 1:20.000 (16 folhas); e 1:10.000 (4 folhas);

- Folhas topográficas do Ministério do Exército, escala 1:50.000 (Folhas de Cerro Azul e Tunas);

- Fotografias aéreas do ITC-PR, escala 1:25.000 (60 fotografias);

\subsubsection{BASES GEOLÓGICAS DE APOIO}

Constaram de:

- Cartas Geológicas da Comissão da Carta Geológica do Paraná, escala 1:70.000; 
- Mapas Geológicos do Projecto Integração e Detalhe Geológico no Vale do Ribeira, escala

1:100.000. (Cerro Azul, Curitiba, Campo Largo e Piraí do Sul:

- Mapas do Projecto Leste do Paraná, escala 1:100.000;

- Mapa Geológico-Estrutural da Região de Rio Branco do Sul, escala 1;100.000 (Fiori, 1989).

\subsubsection{AMOSTRAGEM}

Obtenção de dados estruturais, metamórfico, sedimentares, estratigráficos, com base nas relações de campo ao longo de perfis pré-determinados, principalmente em leitos de rios, onde as rochas carbonáticas da Formação Água Clara são melhor preservadas do intemperismo. Assim, foram:

- descritos 264 afloramentos;

- coletados 1.200 dados de foliações metamórficas;

- medidos 286 atitudes de eixos de dobras;

- medidos 175 lineações de intersecção;

Estes dados foram obtidos através de 8 perfis básicos (Anexo IIIA) e alguns afloramentos distribuídos na região de ocorrência da Formação Água Clara e do Grupo Açungui.

Atenção especial foi dada as amostras orientadas, com vista aos estudos cinemáticos posteriores. Assim, foram coletadas 200 amostras orientadas.

\subsubsection{ATIVIDADES DE LABORATÓRIO}

As atividades de laboratório constaram da preparação e descrição de lâminas delgadas, tratamento estatístico dos dados estruturais, sedimentares e metamórficos, discussão e apresentação dos resultados.

\subsubsection{PREPARAÇÃO E ANÁLISE DE LAMINAS DELGADAS}

As amostras foram inicialmente cortadas, em fatias orientadas, no setor de laminação da UFPr. Aqui, estabeleceu-se cortes em três direções, em fatias com dimensões adequadas para as observações pretendidas, num total de 190 cortes. As amostras foram posteriormente montadas no setor de laminação do IG-USP, das quais resultaram 120 lâminas delgadas orientadas.

A seguir procedeu-se a análise destas lâminas delgadas e amostras de rochas correspondentes, em 3 dimensões, realizando as correlações das estruturas entre as escalas 
microscópica, mesoscópica e macroscópica, tentando entender os mecanismos de deformação presentes nestas escalas. Desta atividade resultou 48 fotomicrografias, descritas na sequência do trabalho.

Após o entendimento das microestruturas e associações minerais presentes nas lâminas delgadas, procedeu-se a reorientação das amostras em caixas de areia e posterior medição, com bússola de geólogo, das novas estruturas e estruturas não corretamente interpretadas no campo. Estes dados deixaram de ser coletados no campo tendo em vista a baixa luminosidade presente no leito dos rios, os quais normalmente encontravam-se circundados pôr matas ciliares ou matas de dimensões maiores.

Os dados microtectônicos foram compilado em quadros de sumarização das estruturas tectônicas e microtectônicas, como uma ferramenta auxiliar no entendimento de suas geometrias e cronologias.

\subsubsection{TRATAMENTO ESTATISTIICO DOS DADOS ESTRUTURAIS}

O tratamento estatístico dos dados de foliações metamórficas, lineações minerais e de intersecção e eixos de dobras, obtidos nas escalas macro, meso e microscópica, foram realizados em diagramas do tipo Schmidt-Lambert. Para tanto, foram realizados estudos em conjuntos de afloramentos com comportamento aparentemente homogêneo da deformação e em afloramentos individualizados, na tentativa de entender a geometria das estruturas e fazer uma correlação com aquelas identificadas em lâminas delgadas. Nesta atividade foram elaborados 73 estereogramas na Formação Água Clara (Quadros I e II).

Procedeu-se, ainda, a análise das associações minerais presentes nas diversas lâminas e suas relações com as estruturas tectônicas presentes nas diversas escalas.

\section{I.3.4.3 ISÓTOPOS}

Realizou-se 20 análises de isótopos de ${ }^{13} \mathrm{C}$ e ${ }^{18} \mathrm{O}$ das Formações Água Clara, Capirú e Votuverava. Tais análises foram realizadas no laboratório do Centro de Energia Nuclear na Agricultura (CENA), em Piracicaba, S.P., visando caracterizar o ambiente de sedimentação em que estas formações foram geradas e sua possivel localização no tempo geológico. 


\subsubsection{APRESENTAÇÃO DOS RESULTADOS}

Os dados obtidos no campo e em laboratório foram acrescidos àqueles disponíveis na literatura. Assim, foi possível realizar uma discussão entre as feições geológicas presentes na Formação Água Clara, com aqueles do Grupo Açungui. Estes resultados convergiram em torno de um modelo tectônico alternativo para o Grupo Açungui e correlatos, qual, possivelmente, se constitua num avanço no conhecimento geológico da região próxima a Curitiba.

\subsection{AGRADECIMENTOS}

Gostaria de expressar o meu profundo agradecimento a todas pessoas que diretamente ou indiretamente me ajudaram na elaboração deste trabalho.

Ao Prof. Dr. Rômulo Machado, pela amizade, incentivo e orientação em todas as fases do trabalho, sobretudo pela detalhada correção do texto final. E pôr ter se disponibilizado em trabalhar nas drenagens das localidades de São Pedro e São Silvestre, de dificil acesso e caminhamento. A sua família, nas pessoas da sua esposa, $D^{\text {ra }}$. Luci, e aos filhos Tariana e Tiago, pelo carinho.

Aos amigos Romalino Fragoso Cesar, Augusto Pedreira, José Roberto Góis e Augustinho Rigotti, pelas participações nas etapas de campo e discussões teóricas altamente proveitosas e solução de problemas de informática;

Ao Prof. Dr. Alberto Pio Fiori, pelo exemplo de dedicação a pesquisa científica e pelo incentivo e participação na minha formação geológica na graduação, mestrado e doutorado;

Ao CNPq, pela concessão de bolsa de estudos no período de 1990-1993;

A FAPESP (Fundação de Amparo à Pesquisa do Estado de São Paulo), pela concessão de auxílio financeiro de campo, através do processo $n^{\circ}$ 90/2047-2;

Aos amigos José Henrique Godoy Siguel (in memoriam), Juliano de Mio, Rodoilton Stevanato, pelo incentivo;

Aos Professores Dr. Paulo Cesar Soares, Dr. Benjamin Bley de Brito Neves, Dr. Georg Robert Sadowski, Dr. Marcos Egydio da Silva, pelo incentivo e espírito científico motivador;

Aos Professores Coriolano de Marins e Dias Neto e Dr. Emerson Carneiro Camargo peio incentivo e apoio profissional; 
Aos Professores José Manoel dos Reis Neto, pelo auxílio nos primeiros contatos com a pós-graduação do IG-USP, e ao Prof. Vicente V.A. Girardi, pelas gestões para concessão da bolsa de doutoramento;

Aos geólogos da MINEROPAR, em especial a Gil Piekarz e Oscar Salazar pelo auxílio material e logístico nas etapas de campo da região de São Pedro/São Silvestre, bem como funcionários e geólogos que participaram do Projeto Ouro de São Pedro, pela acolhida e convivência na região;

Ao convênio UFPR-MINEROPAR, coordenado pelo Prof. Dr. Alberto Pio Fiori no período 1984-1990, que contou com a participação dos colegas José Roberto Góis, Eduardo Salamuni, Paulo Kops, Luiz Gaspar, Celso Fumagalli, Amim Katbeh, Renata Moro, Angelo Spoladore, entre outros, pôr ter gerado um ambiente de iniciação científica contagiante, o qual viria a frutificar com várias dissertações de mestrado e teses de doutorado nos Institutos de Geociências da UNESP - Rio Claro, e da USP - São Paulo;

Ao Comitê de Gestão do Sistema Geologia (Departamento de Geologia - UFPr), coordenado pelo Prof. Renato Eugênio de Lima, o qual propiciou condições favoráveis para a conclusão deste trabalho;

As bibliotecárias do IG-USP, da MINEROPAR, e da UFPR, em especial a Srta. Eliane Maria Stroparo;

Ao desenhista, Sr. Oto Laurentino Rosa, pelo zelo na elaboração de mapas e desenhos;

Ao setor da laminação do IG-USP, pelo gentil atendimento e pelo trabalho minucioso desenvolvido pôr seus funcionários na confecção de lâminas delgadas orientadas;

Ao pessoal da Gráfica do IG-USP, pelos serviços de sua impressão gráfica;

Ao Sr. Adelar Dosso Pasa, pelo apoio na troca do motor do carro, avariado na região de São Pedro;

Ao amigo José Roberto Góis pela ajuda nas diversas etapas de campo, mesmo com prejuizos financeiros, tendo sido também envolvido num acidente com o seu próprio carro nas "curvas de São Pedro".

Finalmente, ao Instituto de Geociências, que me acolheu como aluno de mestrado e doutorado. 


\section{CONCEITOS BÁSICOS}

\subsection{MODELO TRANSPRESSIONAL}

\subsubsection{INTRODUÇÃO}

Embora sistemas transcorrentes constituam-se num mecanismo geralmente reconhecido no Paleozóico Superior atuante no fechamento de uma deformação progressiva pré-cambriana, relacionada a cisalhamento de baixo ângulo, (gerados em rampa frontal (Fiori, 1990) ou rampa obliqua (Ebert et al., 1988 ; Soares et al., 1990), este padrão deformacional de alto ângulo pode ser aplicado a cinturões transcorrentes antigos, conforme sugerido por Reading (1980) e Tikoff \& Teyssier (1994).

A aplicação generalizada do modelo clássico da Tectônicas de Placas concebido por Dewey \& Bird (1970), com subducção-colisão, encontra dificuldades na explicação de certos aspectos presentes em diversos cinturões orogênicos pré-cambrianos. Neste sentido, Reading (1980) sugeriu que o modelo de Cinturões Orogênicos Transcorrentes ou Zonas Móveis Transcorrentes (transtração $\Rightarrow$ preenchimento de bacias $\Rightarrow$ transpressão $\Rightarrow$ deformação/ soerguimento $\Rightarrow$ erosão) pode se constituir num modelo alternativo (ou complementar) ao ciclo de Wilson, o qual envolve expansão do assoalho oceânico $\Rightarrow$ subducção $\Rightarrow$ colisão continental $\Rightarrow$ cadeia orogênica $\Rightarrow$ erosâo.

$O$ modelo de cinturões orogênicos transcorrentes se diferencia basicamente do modelo de subducção por apresentar conservação da litosfera envolvida, não ocorrendo nem consumo e nem acresção de crosta oceânica. Desta forma, a ausência de indícios significativos de crosta oceânica no Pré-Cambriano dos Estados do Paraná e sul de São Paulo seria satisfatoriamente explicada. Por outro lado, a expressiva granitogênese da região, onde apenas no Estado do Paraná são reconhecidos cerca de 45 corpos intrusivos, poderia representar um zoneamento ígneo gerado ao longo de uma zona de cisalhamento transtracional/ transpressional, e não relacionar-se, obrigatoriamente, a um suposto arco magmático ou arco de ilhas. Por outro lado, a presença, na Faixa Ribeira, de estruturas de baixo ângulo com direção sudeste (foliações metamórficas, eixos de dobras, lineações de estiramento mineral, etc) e de falhas transcorrentes com direção nordeste, podem ser convenientemente explicadas pela partição da deformação, conforme modelo de Tikoff \& Teyssier (1994). 


\subsection{CONCEITUAÇÃO}

O conceito de transpressão foi desenvolvido na década de 70 por Harland (1971), para descrever a deformação registrada ao longo da convergência oblíqua de placas tectônicas. Este termo foi definido pelo autor, como sendo a combinação de regime de transcorrência com regime compressivo. Considerou, ainda, que regimes transpressivos ocorrem em zonas de compressão oblíqua. Posteriormente, o conceito foi ampliado por Sanderson \& Marchini (1984) como sendo "um cisalhamento de empurrão ou transcorrente, acompanhado por encurtamento horizontal transversal e um alongamento vertical ao longo do plano de cisalhamento, dentro de uma zona limitada por falhas". Os autores acentuam que o modelo transpressivo envolve a combinação de cisalhamento puro e cisalhamento simples. Neste sentido, a ocorrência de um ou outro mecanismo de forma isolada, se constitui num caso especial. Para Fiori (1995-inédito), a transpressão representa um modelo de deformação em zonas transcorrentes, relacionada a um processo de cisalhamento simples seguido de um encurtamento perpendicular ao plano de cisalhamento, e de um alongamento na vertical, ao longo do mesmo plano. A transtração envolve um alongamento da zona de cisalhamento e um encurtamento na vertical, ao longo do plano.

O embasamento moderno para a teoria transpressional em zonas de colisão obliquas de placas tectônicas foi dado por Sanderson \& Marchini (1984), os quais forneceram uma solução de deformação finita que prediz a orientação de linhas e planos para um dado elipsóide de deformação finita. Estes conceitos serão utilizados para estabelecer as características de uma estrutura transpressional ideal, como segue.

\subsubsection{CARACTERÍSTICAS DE UMA ESTRUTURA TRANSPRESSIONAL/ TRANSTRACIONAL IDEAL}

Diversas estruturas podem estar presentes ao longo de uma estrutura transpressional, materializada na forma de uma estrutura em flor positiva (Tabela 2.1). O comportamento da deformação pode ser igualmente materializado através de estruturas dúcteis no nivel estrutural inferior (Mattaeur, 1972), ou rúpteis, no nivel superior. 


\begin{tabular}{|c|c|c|c|c|c|c|c|c|c|c|c|c|c|c|}
\hline \multicolumn{2}{|c|}{ DLAGRAMM DE FLINN } & \multicolumn{4}{|c|}{ CARACTERISTICAS DEFORMACIONANS } & \multicolumn{8}{|c|}{ CARACTERISTICAS CINEMATICAS } & \multirow{2}{*}{$\begin{array}{l}\text { VARIA } \\
\text { GÃO DE } \\
\text { Volume }\end{array}$} \\
\hline $\begin{array}{l}\text { AREAS DO } \\
\text { ERAFICO }\end{array}$ & $\begin{array}{l}\alpha^{-1} \\
\text { ou } \\
k \\
(* 1)\end{array}$ & $\begin{array}{l}\text { CARACTE- } \\
\text { KISTICAS } \\
\text { DEFORMA- } \\
\text { CIONAIS }\end{array}$ & $\begin{array}{l}\text { TIPO DE } \\
\text { ELLIPSÓEDE }\end{array}$ & $\begin{array}{l}\text { TEC- } \\
\text { TóN1- } \\
\text { Cos }\end{array}$ & $\begin{array}{l}\text { EIXOS } \\
\text { DEFOR- } \\
\text { MAGÁAO }\end{array}$ & $\begin{array}{l}\text { EAXOS } \\
\text { VER- } \\
\text { TICAS } \\
\text { (2) }\end{array}$ & $\begin{array}{l}\text { PLANO } \\
X Y \\
\text { (FOLLA- } \\
\text { CÃO) }\end{array}$ & $\begin{array}{l}\text { LINEAGR̆o } \\
\text { MINERAL } \\
\text { (EIXOX) }\end{array}$ & $\begin{array}{l}\text { PLANO } \\
x z \\
\text { (*3) }\end{array}$ & $\begin{array}{l}\text { LI WTERR. } \\
\text { SECG:10 } \\
\text { (4) }\end{array}$ & $\begin{array}{l}\text { TIPO DE } \\
\text { FALHA OU } \\
\text { ZONA } \\
\text { CISALHA- } \\
\text { MENTO }\end{array}$ & $\begin{array}{l}\text { NIVEL } \\
\text { ESTRU- } \\
\text { TURAR }\end{array}$ & $\begin{array}{l}\text { TRANS- } \\
\text { PORTE }\end{array}$ & \\
\hline $\begin{array}{l}x Y=a \\
\text { (ORDENADA) }\end{array}$ & $\begin{aligned} \alpha^{-1}=\infty \\
k=\infty\end{aligned}$ & $\begin{array}{l}\text { INIENSO } \\
\text { ESTIRAMEN- } \\
\text { TO ANIAL } \\
\text { (exceyão) }\end{array}$ & $\begin{array}{l}\text { PROL_ATO ou } \\
\text { INIAXIAL } \\
\text { ESTIRADO }\end{array}$ & I. & $\mathbf{X}>\mathbf{Y}=\mathbf{Z}$ & $z$ & $\begin{array}{l}\text { HORIZON. } \\
\text { TAL. }\end{array}$ & $\begin{array}{l}\text { HORI- } \\
\text { ZONIAL }\end{array}$ & VERTICAL & $\begin{array}{l}\text { FOLIACÁ } \\
\text { MAL. } \\
\text { DESEN- } \\
\text { VOLVIDA }\end{array}$ & $\begin{array}{l}\text { REVERSA } \\
\text { DE BAIXO } \\
\text { ANGULO A } \\
\text { EXTENSIO- } \\
\text { NAL }\end{array}$ & $\begin{array}{l}\text { TOPO DA } \\
\text { ESTRT- } \\
\text { TURA EM } \\
\text { FLOR }\end{array}$ & $\begin{array}{l}\text { HOREON- } \\
\text { TAL, PARA- } \\
\text { LELOA } \\
\text { ZONA TRANS. } \\
\text { PRESSIONAL. }\end{array}$ & \multirow[t]{2}{*}{$(1+\Delta)>1$} \\
\hline $\begin{array}{l}\text { ENTRE A } \\
\text { RETA } K=1 \\
\text { EA ORDEMADA }\end{array}$ & $\begin{array}{l}\alpha^{-1}>1 \\
\infty>k>1\end{array}$ & $\begin{array}{l}\text { ESTRRAMEN- } \\
\text { To + } \\
\text { CISALHA. } \\
\text { MENTO } \\
\text { SIMPLES }\end{array}$ & PROLATO & $\begin{array}{l}\text { L-SC } \\
\text { A } \\
\text { SC-L }\end{array}$ & & $\begin{array}{l}z \\
\text { ov } \\
y\end{array}$ & $\begin{array}{l}\text { VARLACAAO } \\
\text { ENTRE } \\
\text { VERTICAL } \\
\text { E } \\
\text { HORIZON- } \\
\text { TAL }\end{array}$ & $\begin{array}{l}\text { HORI- } \\
\text { ZONTAL }\end{array}$ & $\begin{array}{l}\text { VARIACAOO } \\
\text { ENIRE } \\
\text { VERTICAL } \\
\text { E HORI- } \\
\text { ZONTAL }\end{array}$ & $\begin{array}{l}\text { VARIACCAO } \\
\text { ENTRE } \\
\text { VERTICAL E } \\
\text { HORI- } \\
\text { ZONIAL }\end{array}$ & & & & \\
\hline RETA $k=1$ & $\begin{aligned} \alpha^{-1} & =1 \\
k & =1\end{aligned}$ & $\begin{array}{l}\text { DEFORMA- } \\
\text { CÃ̃o } \\
\text { PLANA } \\
\text { (excesấ) }\end{array}$ & & sc & $X>Y>Z$ & Y & VERTICAL & $\begin{array}{l}\text { HORI- } \\
\text { ZONTAL }\end{array}$ & $\begin{array}{l}\text { HORIZON- } \\
\text { TAL }\end{array}$ & VERTICAL & $\begin{array}{l}\text { TRANSCOR- } \\
\text { RENTE }\end{array}$ & $\begin{array}{l}\text { ZONA } \\
\text { INTER } \\
\text { MEDIÁ- } \\
\text { RIA }\end{array}$ & $\begin{array}{l}\text { HORIZON TAL, } \\
\text { PARA LE-LO A } \\
\text { ZONA TRANS } \\
\text { PRESSIONAL. }\end{array}$ & $(1+\Delta)=1$ \\
\hline $\begin{array}{l}\text { ENTRE A } \\
\text { RETA } K=1 \\
\text { EA ABCISSA }\end{array}$ & $\begin{array}{l}a^{-1}<1 \\
1>b>0\end{array}$ & $\begin{array}{l}\text { ACHATA- } \\
\text { MENTO + } \\
\text { CISALHA- } \\
\text { MENTO } \\
\text { SIMPLES }\end{array}$ & OBLATO & $\begin{array}{l}\text { SC-S } \\
\text { A } \\
\text { S-SC }\end{array}$ & & $\begin{array}{l}\mathbf{y} \\
\text { ov } \\
\mathrm{x}\end{array}$ & $\begin{array}{l}\text { SEMPRE } \\
\text { VERTICAL }\end{array}$ & $\begin{array}{l}\text { VARLACAO } \\
\text { ENIRE } \\
\text { HORIZON- } \\
\text { TAL E } \\
\text { VERTICAL }\end{array}$ & $\begin{array}{l}\text { HORIZON- } \\
\text { TAL }\end{array}$ & $\begin{array}{l}\text { VARIAÇAO } \\
\text { ENTRE } \\
\text { HORIZON- } \\
\text { TAL E } \\
\text { VERTICAL }\end{array}$ & & & & \multirow[t]{2}{*}{$(1+\Delta)<1$} \\
\hline $\begin{array}{l}Y / Z=b \\
\text { (ABCISSA) }\end{array}$ & $\begin{aligned} \alpha^{-1} & =0 \\
k & =0\end{aligned}$ & $\begin{array}{l}\text { INTENSO } \\
\text { ACHATA- } \\
\text { MENTO ANIAL } \\
\text { (exreepäo) }\end{array}$ & $\begin{array}{l}\text { OBLATO ou } \\
\text { INIAXIAL } \\
\text { ACHATADO }\end{array}$ & $s$ & $\mathbf{X}=\mathbf{Y}>\mathbf{Z}$ & $\mathrm{x}$ & $\begin{array}{l}\text { SEMPRE } \\
\text { VERTICAL }\end{array}$ & VERTICAL & VERTICAL & $\begin{array}{l}\text { AUSENTE } \\
\text { (OCORRE } \\
\text { APENAS } 1 \\
\text { FOLLAÇĀO }\end{array}$ & EMPURRĀO & $\begin{array}{l}\text { RAIZ DA } \\
\text { ESTRU- } \\
\text { TURA EM } \\
\text { FLOR }\end{array}$ & $\begin{array}{l}\text { VERTICAL, } \\
\text { PERPENDICU- } \\
\text { LAR A ZONA } \\
\text { TRANSPRES- } \\
\text { SNA }\end{array}$ & \\
\hline
\end{tabular}

Quadro 2.1 - Síntese das características estruturais presentes numa estrutura transpressional, segundo Sanderson \& Marchini(1984) modificado.

$\left.{ }^{*} \cdot 1\right) \quad \alpha^{-1}=$ encurtamento verificado através da zona transpressional;

(*2) Sanderson \& Marchini (1984) fixaram um dos eixos principais do elipsóide de deformação como VERTICAL em cada um dos campos do gráfico;

(*3) Plano (X-Z) ideal para leitura dos indicadores cinemáticos:

(*) LINEAÇÃO DE INTERSECÇÃO da foliação Ss sobre o plano da Sc (paralela ao eixo Y do elipsóide de deformação). 


\subsubsection{ESTRUTURAS DÚCTEIS}

O comportamento da deformação e dos indicadores cinemáticos se apresentam de forma distinta ao longo de uma estrutura transpressional (Ver Quadro 2.1). Desta forma, as porções inferior, intermediária e superior da referida estrutura serão analisadas individualmente, como segue.

\section{a) PORÇÃO INFERIOR DAS ESTRUTURAS (RAIZ)}

A deformação se manifesta essencialmente por mecanismos de achatamento dos minerais e objetos (elipsóides oblatos), ao longo de falhas de empurrão de alto ângulo a verticais, com transporte de alto ângulo a vertical perpendicular a faixa transpressional. Estão associados:

\ lineações minerais verticais;

■ foliação gerada por achatamento;

ausência de foliações S-C e lineações de intersecção de foliações.

Seguindo na coluna transpressional, feições de achatamento transicionam para feições de cisalhamento simples, podendo ocorrer ou não a coexistência entre estes dois tipos de deformação. Podem, ocorrer associados os seguintes tipos de estruturas:

曰 falhas de empurrão que transicionam para falhas transcorrentes;

$\square \quad$ lineações minerais obliquas;

\ surgimento gradativo de foliações S-C em substituição a foliações de achatamento puro, acompanhado de uma lineação de intersecção oblíqua.

No início do processo deformativo registra-se, nesta porção da estrutura, intenso achatamento que evolui para o processo de fluxo por difusão, envolvendo a transferência de elementos químicos a partir dos grãos minerais e seus contatos. Dentro deste processo, a dissolução por pressão se constitui no mecanismo mais conhecido, gerando a desestabilização de minerais em zonas de intenso stress (transpressional) seguido da migração de seus íons para áreas de menor pressão (transtracional). Desta forma, o aumento da pressão acarreta uma 
diminuição da largura da zona de cisalhamento e, como conseqüência, conduz a uma diminuição de sua área.

Este processo é particularmente importante na dissolução e concentração de minerais de interesse econômico, a exemplo da fluorita, bário, ouro, etc.

\section{b) PORÇÃO INTERMEDIÁRIA}

$\mathrm{Na}$ porção intermediária da estrutura transpressional, a deformação passa a ser comandada por mecanismos de cisalhamento simples, onde o eixo $\mathrm{Y}$ do elipsóide de deformação tem valor unitário (deformação plana).

Neste nivel da estrutura ocorrem falhas essencialmente transcorrentes, com transporte paralelo a zona transpressional. Encontram-se associadas as seguintes estruturas:

\footnotetext{
■ lineações minerais subhorizontais;

$\square$ pares de foliações S-C;

■ lineações de intersecção da foliação Ss sobre a foliação Sc, com disposição subverticais (paralelas ao eixo Y do elipsóide deformação);
}

Nesta porção da estrutura ocorre conservação do volume original das rochas (1+ $\Delta)=1$. Porém, a zona de cisalhamento poderá funcionar como condutora de soluções, interligando as zonas de dissolução (transpressão) com aquelas receptoras (transtração), onde ocorrerá precipitação.

\section{c) PORÇÃO SUPERIOR DA ESTRUTURA}

A deformação essencialmente plana presente na porção intermediária da estrutura transiciona e/ou coexiste com o início de estiramento, típico de elipsóides prolatos, no início da porção superior da estrutura. As falhas transcorrentes transformam-se progressivamente em falhas reversas de baixo ângulo (falhas obliquas), culminando com falhas direcionais de baixo ângulo, onde o estiramento mineral passa a se constituir na feição mais importante. $O$ plano $\mathrm{XY}$ (foliação) passa a uma disposição de médio ângulo, enquanto a lineação mineral continua horizontal a subhorizontal. As feições de cisalhamento simples vão gradativamente perdendo importância, e com elas as lineações de interseç̧ão, dando lugar ao aparecimento de uma lineação de estiramento mineral mais proeminente. 
No topo da estrutura, um estiramento mineral subhorizontal passa a ser a feição estrutural mais importante (tectonito L). Falhas reversas e direcionais, ambas de baixo ângulo, dão lugar a estiramento puro acompanhado de extensão nas abas da estrutura, com transporte perpendicular (paralelo ?) a faixa transpressional.

Nesta porção da estrutura ocorre um aumento da largura da zona transpressional, resultando num aumento de área $(1+\Delta>1)$. A queda da pressão propicia a criação de um regime extensional, ainda em condições de deformação progressiva, com geração de lineação de estiramento mineral, coexistindo com descontinuidades. Estas descontinuidades são representados por espaços de natureza transtracionais, os quais são normalmente preenchidos pelo aporte de soluções provenientes de regiões de maior pressão (transpressionais), ricas em quartzo, calcita, ouro, fluorita, etc.

Porém, situações em que a deformação produz essencialmente achatamento, transcorrência ou estiramento, constitue-se em casos excepcionais, estando presentes em porções muito restritas da estrutura, respectivamente nas porções inferior, intermediária e superior da mesma. A situação deformacional predominante é aquela em que ocorre a combinação de mecanismos de cisalhamento simples e de achatamento ao longo de falhas de empurrão (e/ou transcorrentes) de médio ângulo, situadas na raiz da estrutura (elipsóides oblatos); ou falhas transcorrentes combinadas ou transicionando para falhas reversas de baixo ângulo, com estiramento mineral associado (elipsóides prolatos), presentes na porção intermediária da estrutura.

A combinação dos transportes tectônicos verificados nas porções inferior, intermediária e superior da estrutura, indicam uma geometria helicoidal para a estrutura em flor, idêntica a tulip structure descrita por Naylor et al. (1986) para falhas sintéticas.

Desta forma, o comportamento da deformação ao longo de uma estrutura transpressional apresenta características específicas nas suas diferentes porções, podendo ser caracterizada pelos seguintes indicativos (Quadro ).

प caimento ou obliqüidade das lineações minerais e de estiramento mineral;

ఐ disposição subvertical da foliação de achatamento (tectonitos "S"), subvertical da foliação SC (Cisalhamento Simples) e subhorizontal da foliação com predominio de estiramentos (tectonitos "L");

$\square$ presença de lineações de intersecção da foliação Ss sobre a foliação Sc;

ఐ tipos de elipsóides presentes (oblatos, prolatos); 
variação de volume presente nas rochas numa zona de cisalhamento em relação à mesma rocha pré-deformada. Esta relação pode ser expressa pela equação:

$$
(1+\Delta<1), \quad(1+\Delta=1), \text { ou } \quad(1+\Delta>1)
$$

\subsubsection{ESTRUTURAS DÚCTEIS-RÚPTEIS E RÚPTEIS}

No campo da deformação dúctil-rúptil e rúptil, as falhas de empurrão presentes na porção inferior apresentam estrias de atrito verticais, as quais passam sucessivamente a obliquas e horizontais na zona de ocorrência das falhas transcorrentes. Os ressaltos, com disposição ortogonal das estrias, assumem disposições horizontais até verticais, respectivamente.

A dissolução por pressão limita-se as zonas de moagens de minerais, nas imediações das falhas de empurrão. Estes fluídos são carreados, a exemplo das zonas dúcteis, para zonas de transtração, onde irão formar veios ou permitir a nucleação e concentração de neominerais em fraturas extensionais.

\subsubsection{OUTRAS ESTRUTURAS TRANSPRESSIONAIS/TRANSTRACIONAIS}

A compartimentação geométrica da deformação presente ao longa de estruturas transpressionais pode variar dependendo de diversos fatores, como aqueles relacionados ao regime de esforços (posição, tipo, intensidade e tempo), ou ainda, a reologia, morfotectônica, temperatura de metamorfismo, presença de fluidos, pressão confinante; forma, dimensão e mergulho dos estratos sedimentares (Sadowski, 1983; Ebert et al., 1988). Desta forma, as camadas sedimentares podem ser ejetadas ao longa da estrutura em flor, levando a inversões de camadas no topo da estrutura, ou produzindo o alçamento de blocos tectônicos com exposição de litologias mais antigas no centro da estrutura. 


\subsection{EVOLUÇÃO DOS CONHECIMENTOS A PARTIR DOS CONCEITOS DE SANDERSON \& MARCHINI (1984)}

Fossen \& Tikoff (1993) utilizaram a matriz de deformação geral tridimensional idealizada por Tikoff \& Fossen (1993) e aplicaram o caso da tectônica transpressional e transtracional. Assim, os primeiros autores identificaram, numa zona transpressional, simultaneamente, cisalhamento simples vertical (Transcorrência na direção do eixo $x$ ) (Figura 2.1), combinado com cisalhamento puro no plano y-z (Thrust faults segundo Tikoff \& Teyssier, 1994), dando origem a um único estágio de deformação.

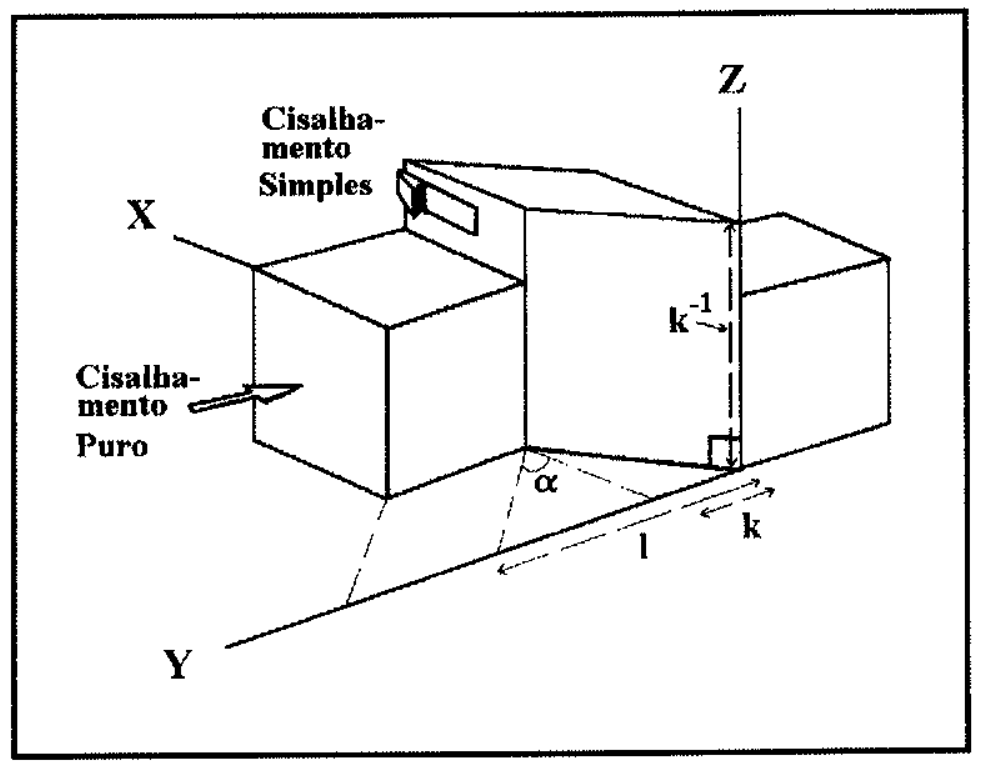

Figura 2.1 - Modelo de transpressão.

Ocorre a convergência obliqua de dois blocos rígidos (blocos escuros) num sistema de referências $(x, y, z)$, definindo um zona transpressional (bloco branco). $\mathbf{k}^{-1}$ (elongação) e k (extensão), compóem as componentes de cisalhamento puro, situadas sobre os eixos $z$ e $y$, respectivamente; $\alpha$, ângulo de convergência.

Fonte: Tikoff \& Teissier (1994) modificado.

Fossen \& Tikoff (1993) retrabalharam o modelo de Sanderson \& Marchini (1984), estabelecendo no Diagrama de Flinn logaritmico, campos onde são registrados deformações transpressionais e transtracionais (Figura 2.2) (Quadro 2.2). Nestes campos ocorre, por definição, respectivamente redução e aumento de volume em relação a reta $k=1$, onde a 


\begin{tabular}{|c|c|c|c|c|c|c|c|}
\hline $\begin{array}{l}\text { ÁREAS NO } \\
\text { GRAFICO DE } \\
\text { FLINN }\end{array}$ & $\begin{array}{l}\mathbf{k} \\
\mathbf{e} \\
\gamma\end{array}$ & $\begin{array}{c}\text { CAMPOS DE } \\
\text { DEFORMAÇÃO } \\
\text { NO GRÁFICO DE } \\
\text { FLINN }\end{array}$ & DEFINIÇÕES & $\begin{array}{c}\text { TIPOS DE } \\
\text { DEFORMAÇÃO }\end{array}$ & FABRIC & $\begin{array}{c}\text { EIXOS } \\
\text { PRINCIPA } \\
\text { IS } \\
\text { VERTICAI } \\
\mathbf{S}\end{array}$ & $\begin{array}{c}\text { EIXOS } \\
\text { PRINCIP } \\
\text { AIS } \\
\text { HORIZO } \\
\text { NTAIS }\end{array}$ \\
\hline $\begin{array}{c}\text { EIXOZ Z } \\
\text { (ORDENADAS) }\end{array}$ & $\mathbf{k}>1$ & TRANS- & $\begin{array}{l}\text { O eixo maior do elipsóide de } \\
\text { deformação é sempre }\end{array}$ & CONSTRICCIONAL & $\mathbf{L}(\mathbf{S})$ & $\mathbf{z}$ & $X$ e $Y$ \\
\hline \begin{tabular}{|c|} 
ENTRE A RETA \\
$k=1$ E O EIXO \\
$z$ \\
\end{tabular} & $\gamma \neq \mathbf{0}$ & TRAÇĀO & horizontal(Eixo $X$ ou $\lambda_{1}$ ) & & & & \\
\hline RETA $k=1$ & $\mathbf{k}=1$ & & O eixo $X$ é horizontal & & & $\mathbf{Y}$ & $X \in Z$ \\
\hline $\begin{array}{c}\text { ENTRE A RETA } \\
\mathrm{k}=1 \mathrm{E} \text { O EIXO } \\
\mathrm{X}\end{array}$ & $k>1$ & TRANS- & $\begin{array}{l}\text { Uma variaçâo do eixo X entre } \\
\text { horizontal até vertical (switches) }\end{array}$ & ACHATAMENTO & $\mathbf{S}(\mathbf{L})$ & & \\
\hline \begin{tabular}{|c|} 
EIXO X \\
(ABCISSA)
\end{tabular} & $\gamma \neq \mathbf{0}$ & PRESSÃO & $\begin{array}{c}\text { O eixo X é sempre vertical } \\
\text { para altas deformaçôes } \\
\text { transpressionais. }\end{array}$ & & & $\mathbf{x}$ & Y e Z \\
\hline
\end{tabular}

Quadro 2.2 - Síntese das caracteristicas estruturais presentes em zonas de transpressão e transtração, segundó Fossen \& Tikoff (1993). 
deformação é plana (volume constante) e divide os referido campos. A presença das deformações por cisalhamento puro foram anotadas por $\mathbf{k}$, e de cisalhamento simples por $\gamma$, no referido diagrama.

Os autores definiram a variável Wk (kinematic vorticity number) que combina deformação coaxial (k) e cisalhamento simples $(\gamma)$. Por definição o vorticity numbers varia entre 0 e 1 , onde $\mathrm{W}_{\mathrm{k}}=0$ marca a presença de cisalhamento puro, e $\mathrm{W}_{\mathrm{k}}=1$ para cisalhamento simples (Figura 2.3), aprimorando conceitualmente os campos da deformação onde ocorre transpressão, transcorrência e transtração em relação a Figura 2.2 .

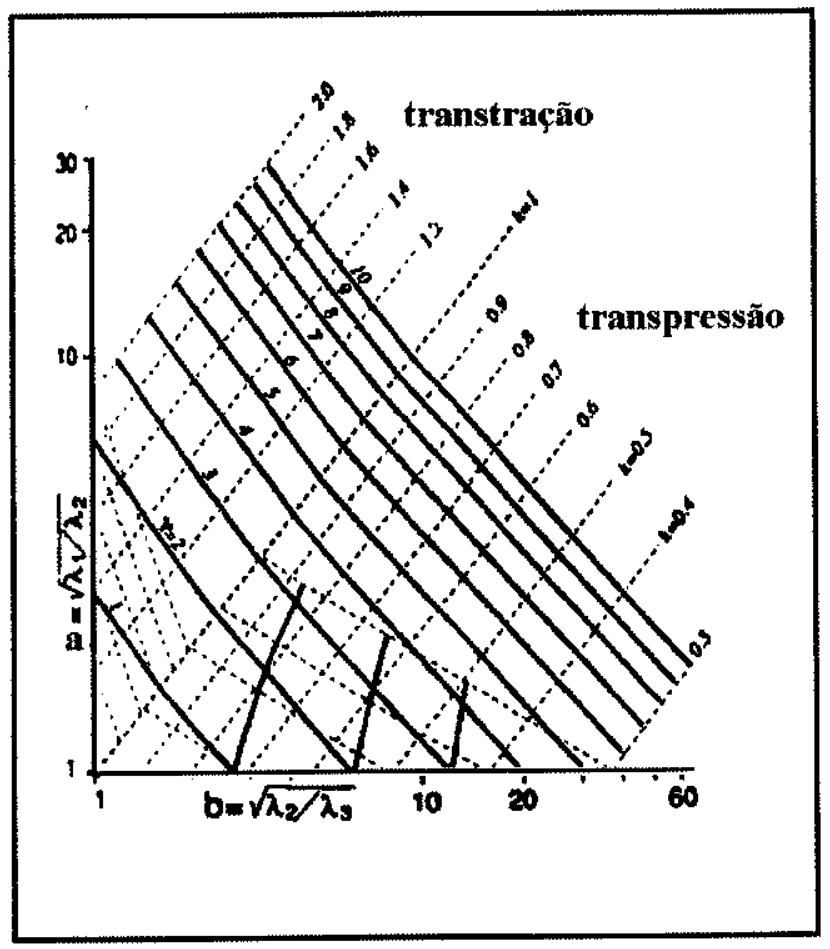

Figura 2.2 - Diagrama logarítmico de Flinn, segundo Fossen \& Tikoff (1993) modificado.

Os autores avançam no conceito de transpressão, estabelecendo um método para estimar o vorticity number $W_{k}$ da deformação. Sabendo-se a direção do eixo de estiramento máximo instantâneo $\left(\varepsilon_{1}\right)$ e a direção da margem da zona de cisalhamento, é possível obter o total relativo de cisalhamento simples e cisalhamento puro utilizando-se o gráfico da Figura 2.4, abaixo. 

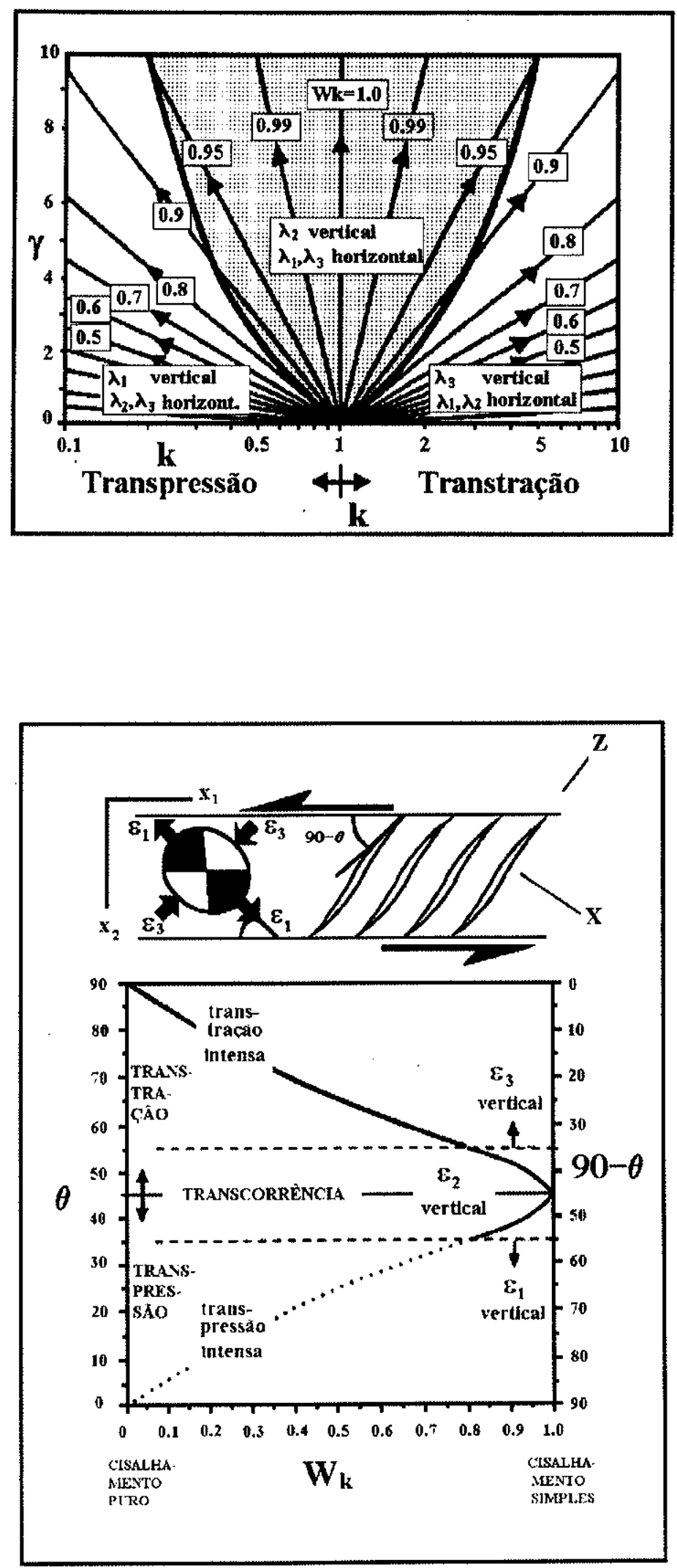

Figura 2.3 - Orientação do elipsoide de deformação finita para transpressão/transtração, e os caminhos da deformação para uma vorticity deformations constante no espaço $\mathrm{k}-\gamma$, segundo Fossen \& Tikoff (1993).
Figura 2.4 - Orientação da direção máxima instantânea de estiramento $\left(\varepsilon_{1}\right)$ com a variação do $W_{k}$ para transpressão $\mathrm{e}$ transtração, e a variação do ângulo $\theta$, e X e $Z$ são os eixos máximo $\mathrm{e}$ mínimo do elipsóide de deformação. 
O eixo de estiramento máximo pode ser obtido através de gashes, eixos de dobras escalonadas, estiramentos minerais, etc.

Este gráfico é, em alguns casos, também aplicado a feições em grandes escalas, tais como falhas extensionais, sistema de enxames de diques, falhas de cavalgamento, eixos de dobras, ambos formados em zonas de transpressão-transtração, as quais sofrem sucessivas rotações com o desenvolvimento de deformações progressivas.

\subsection{COLISÕES OBLÍQUAS}

\subsubsection{MODELO DE SANDERSON \& MARCHINI (1984)}

Sanderson \& Marchini(1984) descreveram diversas estruturas secundárias geradas em função da obliqüidade da colisão entre dois continentes, com base nas definições originais de Harland (1971) (Figura 2.5) .

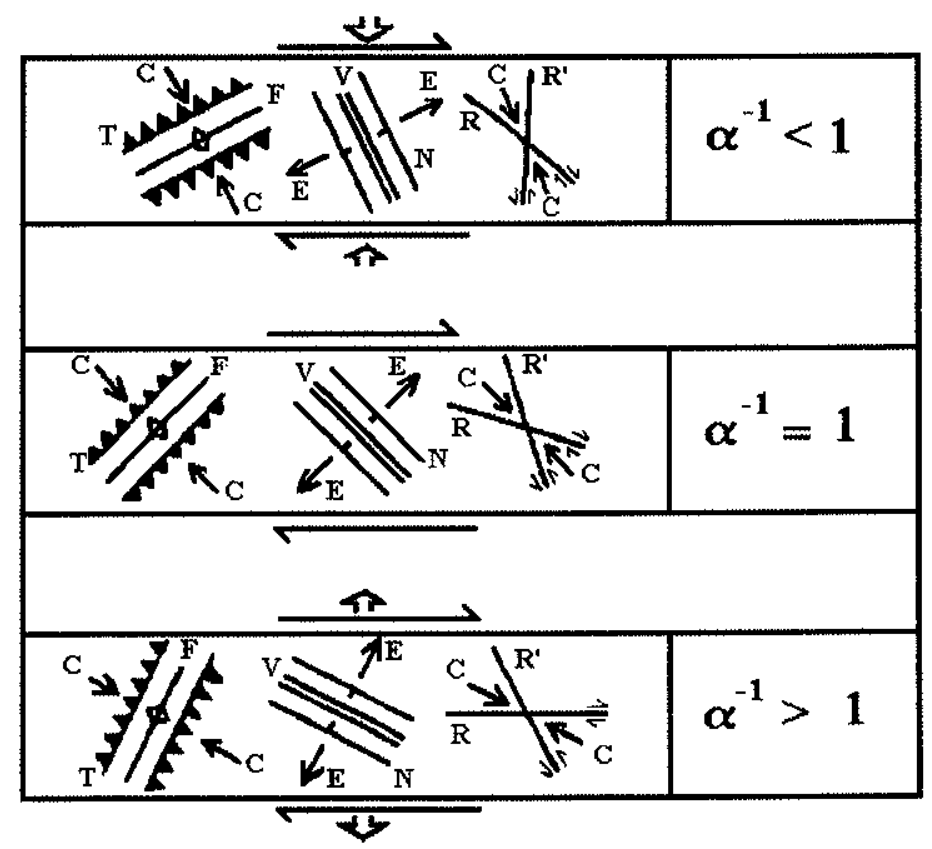

Figura 2.5 - Diagrama mostrando a orientação de estruturas dentro o modelo transpressional/transtracional.

(a) $\left(\alpha^{-1}\right)$ ou $(l+\Delta)<1 \Rightarrow$ modelo transpressional:

(b) $\left(\alpha^{-1}\right)$ ou $(I+\Delta)=1 \Rightarrow \bmod$. cisalhamento

(c) $\left(\alpha^{-1}\right)$ ou $(I+\Delta)>1 \Rightarrow$ modelo transtrativo.

\section{LEGENDA}

$C=$ eixo de compressão (Z);

$\boldsymbol{E}=$ eixo de extensão $(X)$;

$N=$ falhas normais;

$T=$ falhas de empurrão;

$\boldsymbol{R}, \boldsymbol{R}^{\prime}=$ falhas sintéticas $\boldsymbol{e}$ antitéticas; $\quad V=$ veios;

$F=$ eixos de dobras.

Sanderson \& Marchini (1984). 


\subsubsection{COLISÃO COM ÂNGULO $>45^{c}\left(\alpha^{-1}<1\right)$}

A colisão entre dois blocos continentais, gerada de forma ligeiramente oblíqua (ângulos superiores à $45^{\circ}$ ), desenvolve principalmente estruturas transpressionais e, secundariamente, transtracionais, conforme ilustrado pela Figura 2.5a. As principais características são:

\ Predominio de deformação por achatamento(elipsóide oblato), com $\mathrm{k}$ ou $\alpha^{-1}<1$;

■ Clivagem com forte mergulho e lineação de estiramento que pode ser vertical ou horizontal (eixo x);

■ Dobras e empurrões dispõem-se inicialmente com baixo ângulo da margem da zona transpressional;

Falhas normais, diques, veios e outras estruturas extensionais possuem disposição inicial de alto ângulo com a zona transpressional. Estas estruturas apresentam importância secundária em relação as dobras e empurrões;

■ Espaçamento crustal e soerguimento vertical;

$\square$ Redução de volume nas elipses de deformação $(1+\Delta)<1$.

\subsubsection{COLISÃO COM ÂNGULO $=45^{c}\left(\alpha^{-1}=1\right)$}

Desenvolve-se essencialmente deformação não coaxial ao longo de zonas de cisalhamento transcorrentes (deformação plana), quando as colisões entre blocos continentais fazem um ângulo ao redor de $4^{\circ}\left(\mathrm{k}\right.$ ou $\left.\alpha^{-1}=1\right)$ (Figura $\left.2.5 \mathrm{~b}\right)$. Esta condições angulares de deformação se constituem numa exceção entre as zonas transpressionais/ transtracionais, visto que o volume original da rocha na zona de cisalhamento é conservado, não ocorrendo, portanto, aumento ou redução de área da elipse envolvida $(1+\Delta=1)$.

Neste caso, nota-se a seguinte relação geométrica das estruturas com a zona de cisalhamento:

$\square$ Domos e falhas de empurrão apresentam um valor angular inicial moderado com a zona de cisalhamento; 
■ As estruturas extensionais, falhas normais, diques, veios, etc, com disposição subortogonal às estruturas anteriores, também exibem uma relação angular inicial moderada com a zona de cisalhamento.

■ As falhas sintéticas são subparalelas a zona de cisalhamento, enquanto que as antitéticas possuem alto ângulo.

\subsubsection{COLISÃO COM ÂNGULO $<45^{c} \quad\left(\alpha^{-1}>1\right)$}

Em colisões essencialmente tangenciais, com ângulos menores que $45^{\circ}$ com a borda da zona de cisalhamento (Figura 2.5c), desenvolvem-se estruturas predominantemente extensionais, como segue:

ఐ Deformação por constrição (elipsóide prolato), com $\mathrm{k}>1$;

छstiramento horizontal, com clivagem apresentando forte mergulho até horizontal;

$\square$ Dobras e empurrões dispostos com alto ângulo em relação a zona transtrativa, constituindo-se em estruturas secundárias do sistema;

■struturas extensionais (falhas normais, diques, veios, etc), dispõem-se inicialmente com baixo ângulo em relação a borda da zona deformada;

■ Afinamento crustal, subsidência e desenvolvimento de bacias.

Pode ocorrer, ainda, a superposição de estruturas, quando rochas deformadas por achatamento no nível estrutural inferior da estrutura são alçadas para a posição intermediária, sendo neste nível sujeitas a um segundo regime deformacional, de natureza transcorrente, com cisalhamento simples associado (deformação plana).

\subsubsection{MODELO DE TIKOFF \& TEYSSIER (1994)}

\subsubsection{INTRODUÇत्AO}

Em regiões com convergência obliqua de placas, a deformação geralmente sofre partição segundo as componentes transcorrente (strike-slip) e de contração (contractional), segundo Tikoff \& Teyssier (1994) (Ver Figura 2.1). A partição da deformação foi descrita em diversos cinturões orogênicos antigos como o de Cordillera por Oldow et al., 1989; Sierra Nevada por Tikoff \& Teyssier, 1993; Hercynides, Vauchez \& Nicolas, 1991. 
Tikoff \& Teyssier (1994) propõem que o movimento das placas controlam primariamente a deformação de orógenos. Acrescentam que a partição cinemática da deformação pode explicar a maior parte dos orógenos paralelos as margens deformadas e dos orógenos com estruturas perpendiculares, ambos em cinturões orogênicos transpressionais.

\subsubsection{PARAMETROS}

Os autores estabeleceram três parâmetros principais, ou seja, o ângulo de convergência entre placas (movimento relativo das placas), deformação instantânea e deformação finita. Com o cálculo da sua exata relação, Tikoff \& Teyssier (op. cit.) podem prever o tipo e orientação das estruturas geológicas em zonas e convergência oblíqua de placas.

\subsubsection{RELAÇÕES ENTRE OS ELIPSÓIDES DE DEFORMAÇÃO INSTANTÂNEA E FINITA}

Os autores decompuseram a matriz de deformação geral utilizada por Tikoff \& Fossen (1993), o que permitiu que as deformações instantânea e finita pudessem ser correlacionadas. Estabeleceram a relação $\left.\left.\mathbf{s}_{1}\right\rangle \mathbf{s}_{2}\right\rangle \mathbf{s}_{3}$ para os eixos de deformação (ou estiramento) instantâneo, idêntica a relação dos eixos de deformação finita $\left.\left.\lambda_{1}\right\rangle \lambda_{2}\right\rangle \lambda_{3}$ ou $\left.X>Y\right\rangle Z$. Porém, nem sempre os eixos destes elipsóides são paralelos. No caso da deformação coaxial predominar num ambiente de transpressão, a componente de cisalhamento puro domina ambas deformações instantânea e finita, ocorrendo uma pequena rotação dos eixos $\mathrm{Y}$ e $\mathrm{Z}$, adquirindo uma disposição paralela e perpendicular, respectivamente, ao plano de cisalhamento com deformação infinita (Figura 2.6), devido a natureza não coaxial da componente de cisalhamento simples.

Enquanto que, nos campos transpressionais nos quais a deformação não coaxial predomina, não ocorre uma correspondência entre os eixos de deformação finita e instantânea. No início da deformação os eixos de ambos elipsóides de deformação começam paralelos. Depois de alguns incrementos de deformação, o eixo $\mathrm{X}$ muda como eixo $\mathrm{Y}$, tornando-se vertical, enquanto que os eixos do elipsóide de deformação instantânea permanecem constantes. Por este motivo estes eixos são normalmente correlacionadas aos eixos do elipsóide de tensão, igualmente constantes durante uma determinada deformação progressiva. Os autores determinaram, ainda, que a componente de cisalhamento puro instantânea, embora de igual incremento em relação ao cisalhamento simples, causa uma maior deformação finita, devido a sua natureza coaxial. Desta forma torna-se mais eficiente no acumulo de deformação finita, gerando uma rotação progressiva 


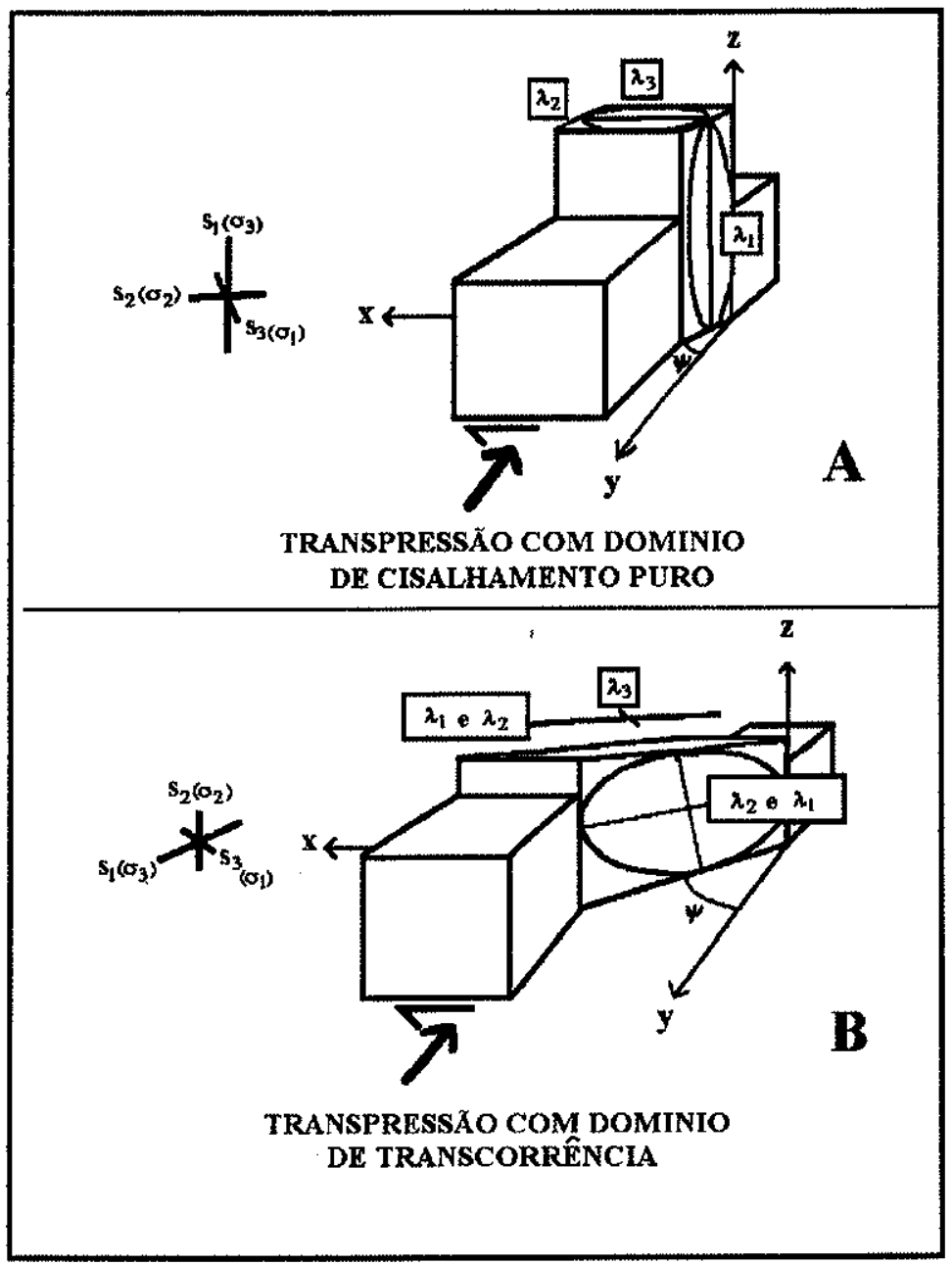

Figura 2.6 - Dois tipos de transpressão, com predomínio de cisalhamento puro e cisalhamento simples respectivamente, distinguidos pela orientação dos eixos de deformação instantâneo.

Fonte: Tikoff \& Teyssier (1994)

do eixo $\mathrm{X}$ desde uma posição horizontal até vertical. Estas mudanças são importantes para prever a disposição das estruturas geológicas numa zona transpressional.

\subsubsection{QUANTIFICAÇ̃OO DAS ZONAS TRANSPRESSIONAIS NOS DOMÍNIOS DE}

\section{CISALHAMENTO PURO E TRANSCORRENTE}

Para distinguir quantitativamente entre os domínios transpressionais de transcorrência $\mathrm{e}$ cisalhamento puro (Figura 2.7 ), Tikoff \& Teyssier (1994) utilizaram a variável $\mathrm{W}_{\mathrm{k}}$ (kinematic vorticity number) de Truesdell, 1953. Segundo os autores, este número simples registra a razão, não linear, das componentes de cisalhamento puro e cisalhamento simples durante a transpressão.

Desta forma, a transpressão dominada por cisalhamento simples (transcorrência) é definida quando $1>W_{k}>0.81$ e $35^{\circ}\left\langle\theta<45^{\circ}\right.$, enquanto que para transpressão formada basicamente por cisalhamento puro (Thrust faults), $\left.0.81 \geq \mathrm{W}_{\mathrm{k}}\right\rangle 0^{\circ}$ e $0^{\circ}\left\langle\theta\left\langle 35^{\circ}\right.\right.$, onde $\theta$ representa o angulo entre $\mathrm{s}_{1} \mathrm{e}$ a margem da zona transpressional. 
A mudança dos domínios transcorrente para cisalhamento puro, além de implicar em ângulos $(\theta)$ menores que $35^{\circ}$, o eixo $\mathrm{X}$ muda para $\mathrm{Y}$ no plano horizontal, e no plano vertical, $\mathrm{o}$ eixo y muda para o eixo $\mathrm{X}$.

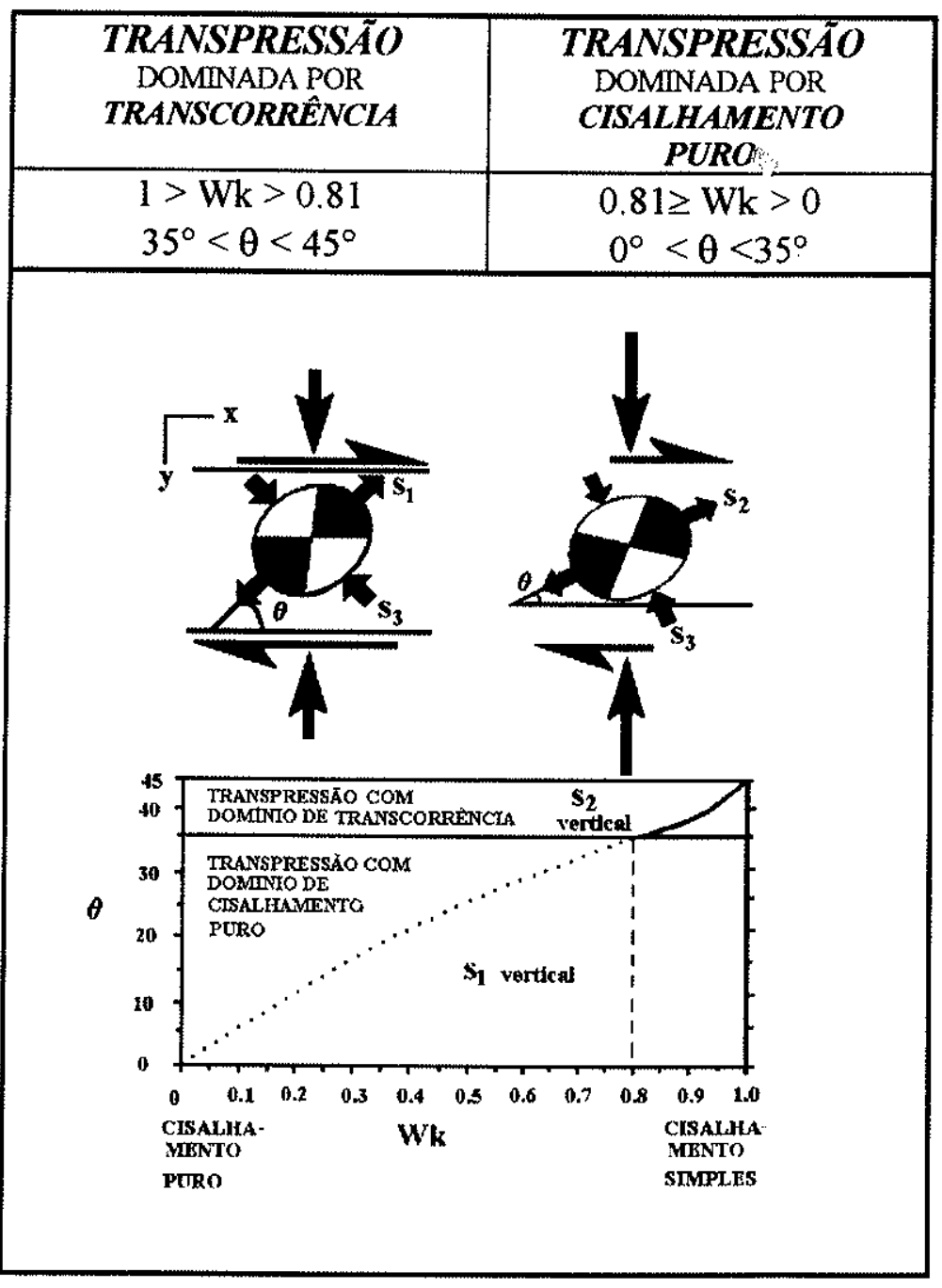

Figura $2.7 \quad$ Relação entre o $k i$ nematic vorticity number e o eixo $\theta$, este ultimo medido entre 0 eixo máximo instantâneo horizontal e a borda da zona transpressional, segundo Fossen \& Tikoff, 1993. 
2.4.2.5 RELAÇÃO ENTRE O MOVIMENTO DE PLACAS E A DEFORMAÇÃO EM ZONAS TRANSPRESSIONAIS

Segundo Tikoff \& Teyssier (op. cit.) a relação entre movimento de placas e deformação pode ser quantificada ao assumir que as bordas de placas são sistemas transpressionais em zonas de convergência obliquas, com movimento transformante puro e convergência normal, como termos extremos do campo deformacional (Figura 2.8). O vetor de movimento o relativo de placa deve ser paralelo ao flow apophysis contracional, ou seja, na direção do maior gradiente de velocidade contracional.

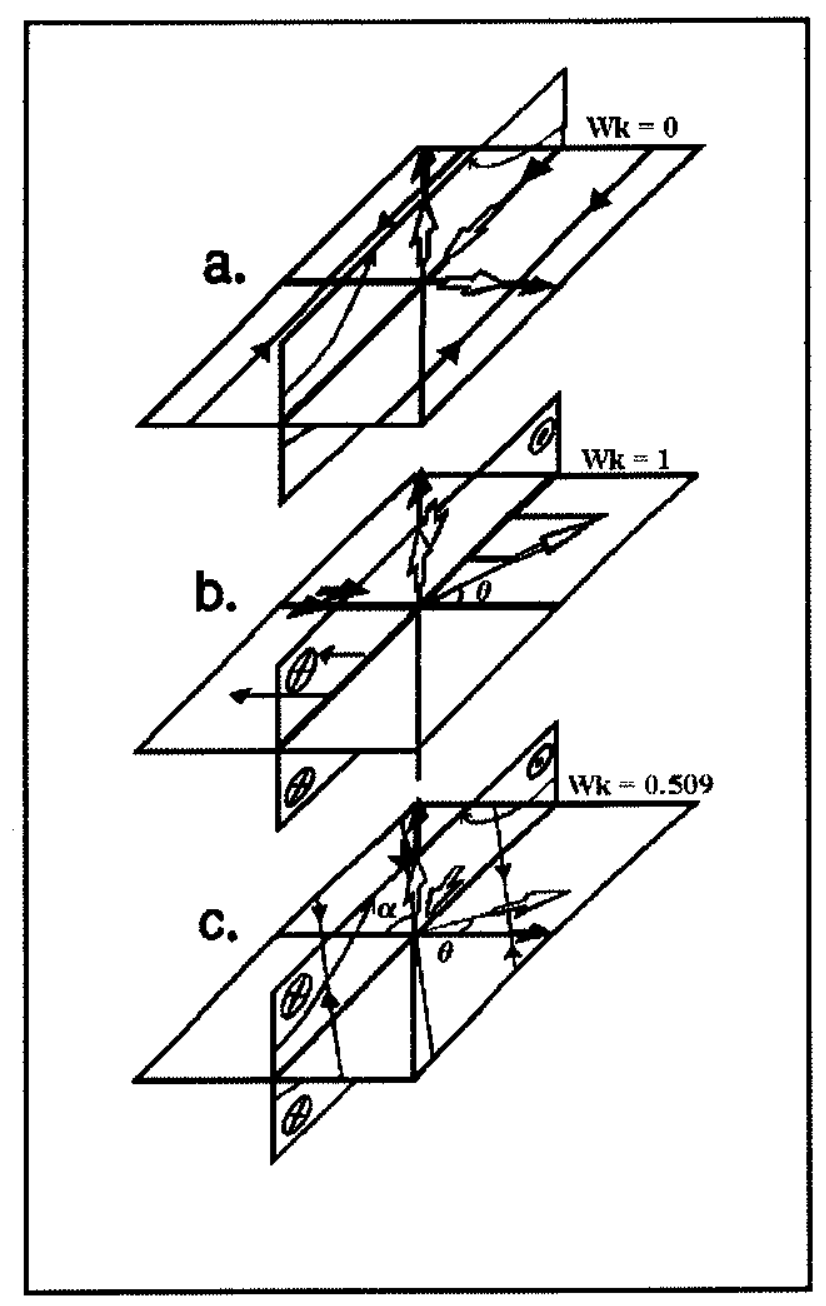

Figura 2.8 - Relação entre o flow apophyses (flexa preta), eixos de deformação instantânea (flexa branca), e linhas de fluxo (linhas finas com flexas), para:

a) Cisalhamento Puro

b) Cisalhamento Simples $\left(W_{k}\right.$ $=1$ );

c) Caso particular de transpressão $(\mathrm{Wk}=0.509)$.

$\alpha$ é o ângulo entre o contractional flow apophysis e o eixo X. Observar que os eixos de flow apophysis não precisam ser mutuamente perpendiculares, a exemplo dos elipsóides de deformação instantânea, finita ou de tensão. 


\subsubsection{DEFORMAÇÃO INSTANTÂNEA E OMOVIMENTO RELATIVO DAS PLACAS}

Segundo Tikoff \& Teyssier (1994) é possível predizer a exata relação ente a orientação dos eixos de estiramento instantâneo e a direção de movimento relativo das placas (Figura 2.9).

Assim, para uma convergência pura, a direção relativa de movimento de placa e o eixo mínimo de deformação instantânea $\left(\mathrm{s}_{3}\right)$ coincidem $\left(\alpha=90^{\circ}, \theta=0^{\circ}\right)$. Enquanto que numa deformação com transcorrência pura, $\alpha=0^{\circ}$ e $\theta=45^{\circ}$. Observar que o ângulo $\alpha$ pode variar de zero a $90^{\circ}$ devido a rotação do eixo $X$ do elipsóide de deformação desde uma posição horizontal, quando ocorre transcorrência pura $\left(\alpha=0^{\circ}\right)$, até uma posição vertical $\left(\alpha=90^{\circ}\right)$, quando ocorre cisalhamento puro. A variação do ângulo entre o eixo máximo de deformação instantânea horizontal e a margem da placa é de $45^{\circ}$. Assim, quando este ângulo é de $45^{\circ}$ ocorre transcorrência pura, e quando é de zero graus, ocorre convergência pura, conforme o gráfico da Figura 2.9.

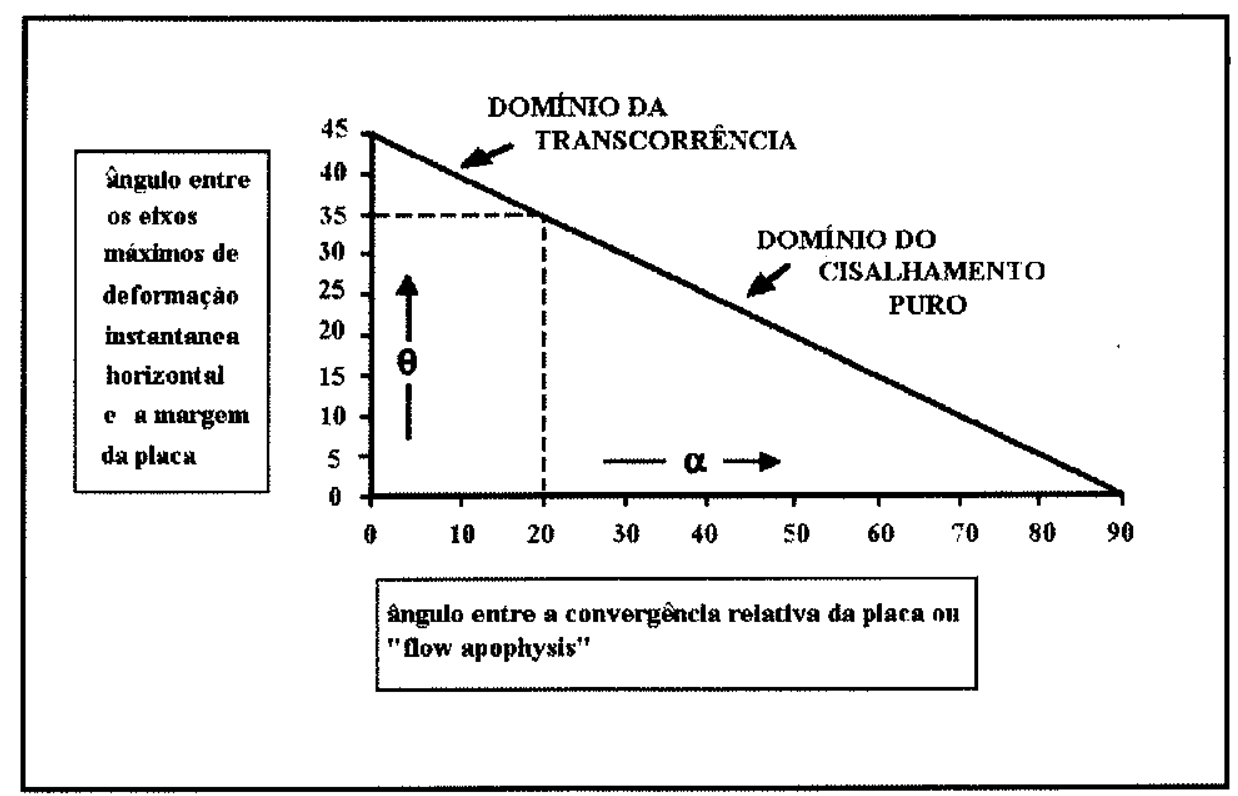

$\alpha=0$ angulo entre 0 contractional flow apophysis e o eixo $X$;

$\theta=0$ ângulo entre o eixo de deformação máxima instantâneo horizontal $\left(s_{1}\right.$ na transcorrência e $s_{2}$ no cisalhamento puro, ambos em ambiente transpressional) e a margem da placa.

Figura 2.9 - Relação entre o angulo $\alpha$ da convergência de placas (direção do contractional flow apophysis) e o angulo $\theta$. 


\subsubsection{DEFORMAÇÃO FINITA X DEFORMAÇÃO INSTANTÂNEA E A PARTIÇÃO DE ESTRUTURAS GEOLÓGICAS}

\section{a) TRANSPRESSIONAL, COM COMPONENTE PRINCIPAL TRANSCORRENTE}

Se falhas são formadas somente como o resultado da deformação instantânea, todas as falhas em domínios transcorrentes transpressivos devem ser verticais, para acomodar o deslocamento transcorrente. Porém, como falhas verticais não podem acomodar a componente de cisalhamento puro (contracional) imposta pela deformação finita, devem ser geradas falhas de cavalgamento (thrust faults), com direção próxima ou paralela ao orógeno, gerando a partição da deformação. Uma vez formadas falhas transcorrentes e de cavalgamento, ambas permanecem ativas simultaneamente para acomodar as componentes de cisalhamento simples e cisalhamento puro da deformação que venham a ocorrer durante um processo de deformação progressiva. Para que estas falhas possam se instalar é necessário que os eixos de deformação instantânea $s_{1}$ e $s_{3}$ sejam horizontais. porém, com o transcorrer da deformação, o eixo $\mathrm{X}$ passa de uma posição horizontal para uma segunda vertical, embora os eixos $s_{1}$ e $s_{3}$ continuam horizontais. Desta forma o marcador da deformação finita, tais como clastos boudinados, veios, elongação de fósseis, lineações de estiramento provavelmente mostrem extensão vertical, ao mesmo tempo em que eixos de deformação instantânea (e campo de tensões) são consistentes com o movimento transcorrente predominante.

\section{b) TRANSPRESSÃO COM CISALHAMENTO PURO COMO COMPONENTE PRINCIPAL}

Nestes sítios formam-se primeiro falhas de cavalgamento (Thrust faults), em resposta a aplicação da deformação instantânea. Porém, estas falhas não são bem orientadas para acomodar o movimento transcorrente, imposto pelas condições de convergência obliqua transpressional. Portanto, falhas transcorrentes são formadas em resposta a deformação finita, gerando novamente partição da deformação.

\subsubsection{FALHAS TRANSCORRENTES DISCRETAS EM ZONAS TRANSPRESSIONAIS}

O efeito da componente de cisalhamento puro é registrado na deformação interna dos blocos situados entre falhas, na forma de espessamento crustal e relevo topográfico. Ao passo que 
a componente transcorrente pode sofrer partição em deformação interna e deslocamento sobre falhas discretas e assim resultar em transporte paralelo ao orógeno. Para cada componente do movimento transcorrente que gera discretas falhas transcorrentes, o kinematic vorticity (Wk) dentro da zona transpressional deve decrescer, e com isto a zona transpressional torna-se gradativamente mais contracional. Assim, o papel da componente de cisalhamento puro deve crescer, considerando-se os segmentos deformados como homogêneos.

Para movimentos de placas dominados por convergência normal a moderadamente oblíquos, o Wk da zona transpressiva decresce linearmente com o aumento da partição da componente transcorrente. Para movimentos de placas dominados por transcorrência, o Wk da zona transpressional decresce mais rapidamente numa maneira não linear, conforme demostrado graficamente por Tikoff \& Teyssier (1994).

\subsection{SIMETRIA LITO-ESTRUTURAL AO LONGO DE UMA ESTRUTURA-EM-FLOR POSITIVA}

Ao longo de uma estrutura transpressional forma-se uma compartimentação litológica simétrica em relação ao centro da estrutura (Figura 2.10). Esta simetria é formada, em perfil, pelo alçamento de niveis estruturais e estratigráficos mais profundos no centro da estrutura na forma de escamas, lascas, cavalos (horses) ou fatias de rochas, no sentido empregado por Dahlstron (1970), Boyer \& Elliot (1982) e Butler (1982). À medida em que o observador se afasta do centro da estrutura em direção as suas margens, estas litologias vão sendo substituídas por outras menos deformadas e/ou metamorfisadas, até desaparecer o efeito transpressivo, e a coluna estratigráfica original permanecer inalterada. Esta simetria pode se igualmente verificada em planta, onde conjuntos litológicos passam a ter com disposição lenticular ou blocos alongados, sendo delimitados por falhas de empurrão e/ou transcorrentes, com disposição paralela ao centro da estrutura transpressional. A justaposição lateral de blocos ou unidades geológicas pode colocar lado a lado unidades com maior ou menor grau de deformação e metamorfismo na porção interna da estrutura, ou mesmo unidades indeformadas na parte externa da estrutura. Falhas de empurrão mostram mergulho centripeto em relação ao centro da estrutura, entre as quais pode ocorrer rochas do embasamento, alçadas por transpressão. Além disso, no centro da estrutura pode, muitas vezes, ocorrer a intrusão de corpos graníticos, os quais mostram suas 


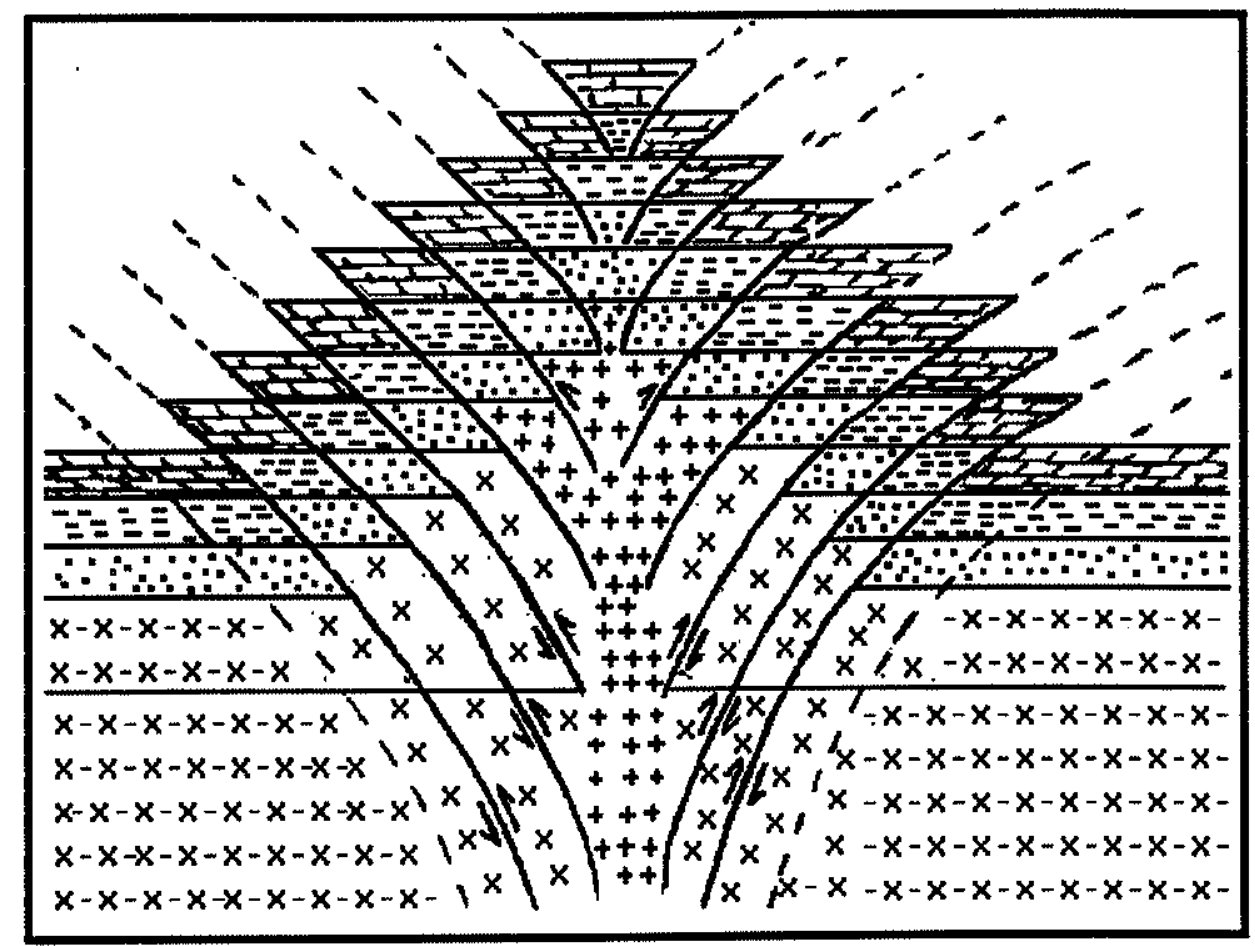

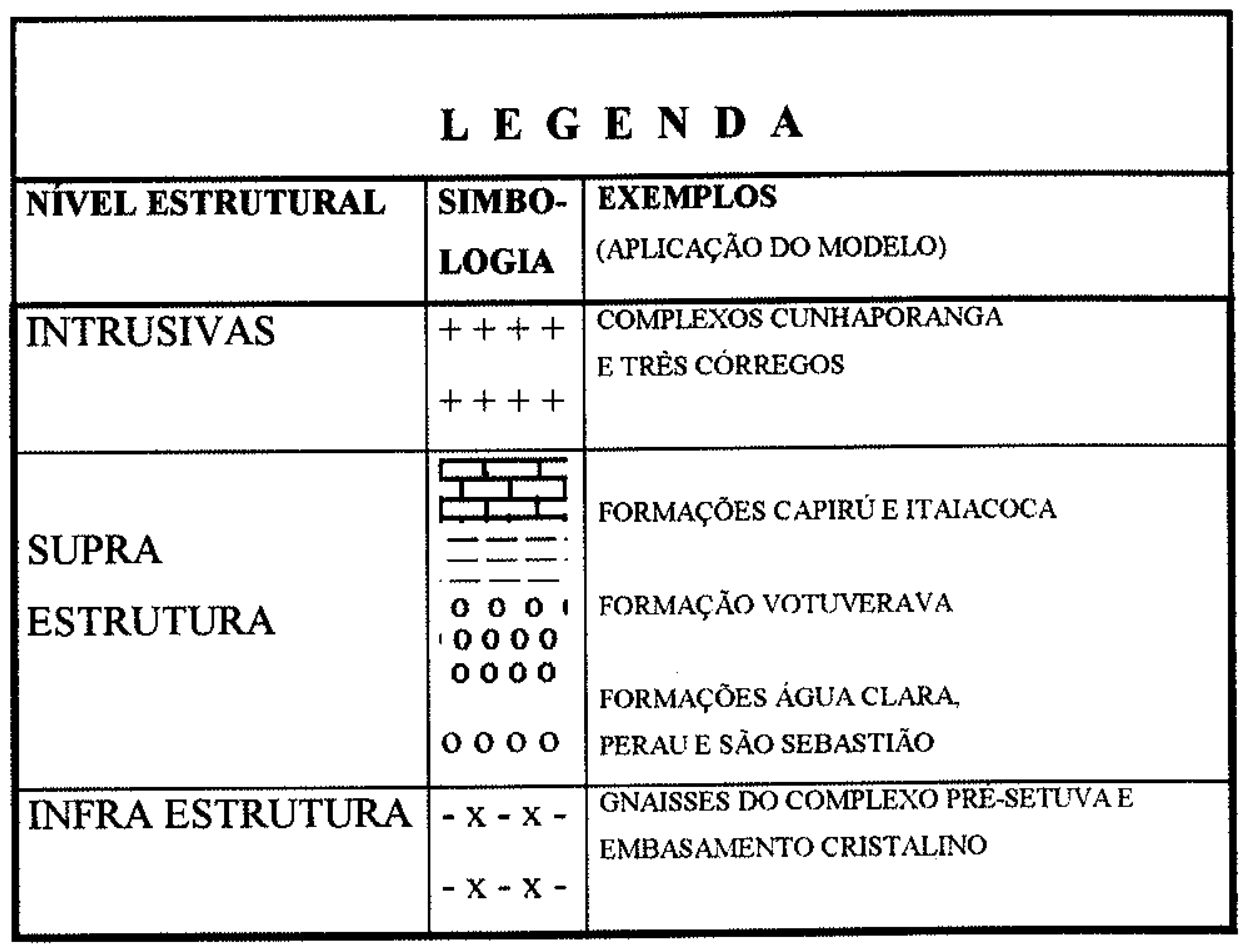

Figura 2.10 - Compartimentação lito-estrutural gerada por uma estrutura-em-flor positiva. Observar a colocação de rochas graníticas no centro da estrutura num periodo transtracional. 
bordas fortemente tectonizados, e o seu interior pode apresentar orientação magmática de cristais porfiríticos, indicativo do mecanismo tectônico vigente durante a sua intrusão.

\subsection{MÉTODOS DE CÁLCULO DA VARIAÇÃO DE VOLUME EM ZONAS TRANSPRESSIONAIS/TRANSTRACIONAIS}

$\mathrm{Na}$ conceituação original de zonas transpressionais e transtracionais de Harland (1971) e Sanderson \& Marchini (1984), os autores utilizaram o parâmetro da variação de volume desta zonas $(1+\Delta)$ como um elemento fundamental. Neste sentido, o cálculo da variação de volume é essencial para caracterizar este tipo de estrutura. Diversos métodos de cálculo da variação de volume em estruturas bandadas dúcteis foram reunidos por Fiori (1996). Entre estes métodos, destacam-se:

■ Cálculo da variação de volume $(1+\Delta)$ em função da deflexão de linhas com diferente orientação;

ఐ Cálculo da variação de volume em função da deflexão de uma única linha dentro da zona de cisalhamento, conhecendo-se $\theta^{\prime}$;

■ Cálculo da variação de volume, conhecendo-se a deformação no interior de duas camadas (Q = camada rica em quartzo; $\mathrm{M}=$ camada rica em mica);

■ Cálculo da variação de volume, conhecendo-se a deformação no interior e fora da zona de cisalhamento. 


\section{EVOLUÇÃO DOS CONHECIMENTOS GEOLÓGICOS ANTERIORES}

\subsection{FASE HISTÓRICA}

As rochas metamórficas de baixo a médio graus aflorantes no Estado do Paraná e sul do Estado de São Paulo, vêm despertando interesse de diversos pesquisadores desde o final do século passado. Coube a Derby (1878) a proposição da primeira coluna litoestratigráfica para a região, com a definição de Séries Cristalofilianas e não Cristalofilianas no Estado do Paraná. A estas séries foi atribuído as denominações de Série Açungui e Complexo Cristalino respectivamente por Oliveira $(1916,25,27)$. Essa proposta de caracterização litoestratigráfica foi estendida a outros estados da federação, juntamente com a definição das Séries São Roque (Moraes Rego, 1933), Brusque e Porongos (Carvalho \& Pinto, 1937), ou ainda, Minas por Oliveira \& Leonardo (1943). A seguir Maack (1947) reuniu as Séries Açungui, Brusque e Minas no Sistema Espinhaço, como unidades supracrustais, mantendo o Complexo Cristalino (ou Complexo Brasileiro) como unidade infracrustal, de forma análoga ao que foi proposto por Oliveira (op. cit.), referindo-se as Séries Não Cristalofilianas de Derby (1878) (Anexo 1 Colunas estratigráficas do Pré-Cambriano dos Estados do Paraná e sul de São Paulo - Ver encadernação no final do trabalho).

As Séries Açungui e São Roque foram reconhecidas no vale do Rio Ribeira de Iguape por Carvalho \& Pinto (1937) e Martins (1938). Porém, a denominação Açungui para esses litotipos foi preterida por diversos autores.

Leonardos (1934) introduziu a designação de Formação Iporanga para os conglomerados da região homônima, porém mais tarde (Leonardos, 1941) substituiu esta denominação por Série Ribeira, com base na observação de uma maior área de exposição ao longo do rio Ribeira de Iguape. 


\subsection{FASE DE ESTUDOS SISTEMÁTICOS \\ 3.2.1 DEFINIÇÕES BÁSICAS}

A Série Açungui clássica definida por Oliveira $(1916,25,27)$ na região situada nos arredores da cidade de Curitiba, foi ampliada e subdividida nas Formações Votuverava, Capirú e Setuva por Bigarella \& Salamuni $(1956,1958)$, sendo denominada de Grupo por Marini et al. (1967), oportunidade em que a Formação Água Clara foi definida no topo do Grupo Açungui, a partir do seu desmembramento da Formação Votuverava.

Fazem parte, ainda, dessa fase de definições básicas, a definição da Formação Itaiacoca por Almeida (1956,1957), entre as regiões de Castro (PR) e Itapeva (SP), com base nos estromatólitos reconhecidos pelo autor em 1944. Inseriu-se ainda neste contexto, o trabalho clássico de Petri \& Suguio (1969), que considera as Formações Itaiacoca, Votuverava e Capirú como sendo contemporâneas e correlacionáveis lateralmente dentro do Grupo Açungui, com base em dados de sedimentação.

\subsubsection{RECONHECIMENTO}

\subsubsection{ESTADO DO PARANÁ}

Essa fase se caracterizou pelo desenvolvimento de trabalhos geralmente de cunho local, onde tentativas de correlação não foram bem sucedidas. Nesta fase foram geradas, inúmeras colunas estratigráficas, incluíndo redefinições de unidades em termos de posicionamento estratigráfico e geotectônico. Esta fase foi caracterizada pelo decréscimo do número de unidades que compunham o Grupo Açungui. Iniciou-se com o desmembramento da Formação Setuva por Marini (1970), a qual foi elevada a Grupo por Popp et al. (1979), sendo então atribuída a um ciclo geotectônico anterior em relação ao Grupo Açungui (Proterozóico Médio por Cordeiro da Silva et al. 1981, ou Proterozóico inferior por Batolla Jr. et al. 1981). Idêntica trajetória foi dada a Formação Água Clara, passando do topo do Grupo Açungui (Marini et al. 1967) para a base (Pontes, 1981), sendo posteriormente retirada do referido grupo e incluida no topo do Grupo Setuva por Fritzsons et al. (1982). 
A Formação São Sebastião, apesar de ter sido definida como pré-Açungui por Veiga \& Salomão (1980), foi posteriormente incorporada na base do Grupo Açungui por Cordeiro da Silva et al. (1981) e, novamente, recolocada na sua posição original por Piekarz (1981).

Tentativas para restringir ainda mais o Grupo Açungui foram feitas por Chiodi Filho (1984), que incorporou a Formação Itaiacoca ao Grupo Setuva. Hasui (1986) enfeixou a Formação Votuverava no Grupo Ribeira (antigo Grupo Setuva situado a NW da Falha da Lancinha); e Soares (1987) considerou a Formação Antinha (parte da antiga Formação Votuverava) como uma bacia pós-Açungui. Porém, estas alterações, em grande parte, não foram assimiladas pela comunidade geológica.

Tudo indica que o Grupo Açungui deva aumentar novamente em extensão e número de unidades, com a sua elevação a Super Grupo por Hasui (1989), seguido por Souza (1990, 1992), Campanha (1991) e Reis Neto (1994).

\subsubsection{VALE DO RIO RIBEIRA DE IGUAPE (Sul do Estado de São Paulo)}

Foram realizadas várias tentativas no sentido de estender as definições clássicas propostas para o Grupo Açungui no Estado do Paraná por Bigarella \& Salamuni(1956,1958), Marini et al.(1967), Petri \& Suguio(1969), entre outras, para o Estado de São Paulo. Destacam-se as proposições de Melcher et al. (1973), Hasui (1973), Algarte et al. (1974), Morgental et al. (1975), Paiva et al. (1977), Silva et al. (1977, 1978), Campanha et al. (1985, 1986), Campanha (1991), entre outros.

Hasui (1975a, 1975b) e Hasui \& Sadowski (1976) separaram o Grupo São Roque (ao norte da Falha de Taxaquara) do Grupo Açungui, ao sul, com base em critérios estruturais. Propuseram a subdivisão do Grupo Açungui em Complexo Pilar (ectinitos) e Complexo Embú (migmatitos), com passagens amplamente transicionais entre eles. Consideraram, ainda, que o Complexo Embú poderia incluir porções do embasamento pré-Açungui, não facilmente separáveis. O Complexo Embú foi posteriormente estendido para os Estados de São Paulo (Hasui et al., 1978), Rio de Janeiro e Espírito Santo (Hasui et al., 1981 e Hasui et al., 1984b), e em direção ao Vale do Ribeira até Sete Barras (SP), terminando ao norte do lineamento CubatãoItapeúna (Hasui et al., 1981 e Hasui et al., 1984b). 
A inclusão de migmatitos no Grupo Açungui, embora reconhecido com amplas passagens transicionais para os ectinitos, difere substancialmente da definição básica de Bigarella e Salamuni (op. cit.), os quais reconheceram basicamente metassedimentos de baixo grau metamórfico, geralmente com estruturas sedimentares preservadas, em seções tipo situadas no Estado do Paraná.

\subsubsection{FASE ATUAL}

Nessa fase foram formuladas propostas de estudos sistemáticos das unidades préCambrianas, voltadas para o entendimento do controle estrutural destes litotipos e suas relações com o respectivo ambiente de sedimentação. Neste sentido, foram realizados trabalhos por Fiori et al. $(1985,1987)$ e Fiori $(1990,1992)$ na região situada a norte de Curitiba. O autor subdividiu as Formações Capirú, Votuverava e Antinha em diversos conjuntos litológicos (Ver Anexo 1).

Seguem-se alguns esquemas de ordenamento das unidades geológicas em âmbito regional, abrangendo os Estados do Paraná e São Paulo (Hasui et al., 1984a; Hasui, 1986, 1989; e Campanha, 1991).

Campanha (op. cit.) enfeixou o Grupo Itaiacoca, Formação Água Clara, Grupo Votuverava, Formação Capirú e o Grupo Setuva no Super Grupo Açungui, com disposição das unidades de noroeste para sudeste, fazendo um empilhamento litoestratigráfico nessa ordem, desde a unidade de topo até a base, voltando as definições originais de Bigarella \& Salamuni (1956, 1958), Marini et al. (1967) e Ebert (1971) (Quadro e Anexo 1).

O Grupo Votuverava foi subdividido por Campanha (op. cit.) nas seguintes unidades (Ver Quadro):

(1) Sub Grupo Lajeado - Composto pelas Formações Betari (basal), Bairro da Serra, Água Suja, Mina de Furnas, Serra da Boa Vista, Passa Vinte e Gorutuba (topo), aflorantes entre as cidades de Apiai e Iporanga, seguindo a proposição clássica de Barbosa (1941), as denominações formais de Campos Neto (1983), Hasui et al. (1984a) e Campanha (1985).

No Estado do Paraná o Sub Grupo Lajeado corresponde a Formação Antinha de Dias \& Salazar $(1983,1987)$, a qual foi subdividida por Fiori $(1990,1992)$ nos conjuntos litológicos Tacaniça (basal), Capivara e Voturuvú (topo). 


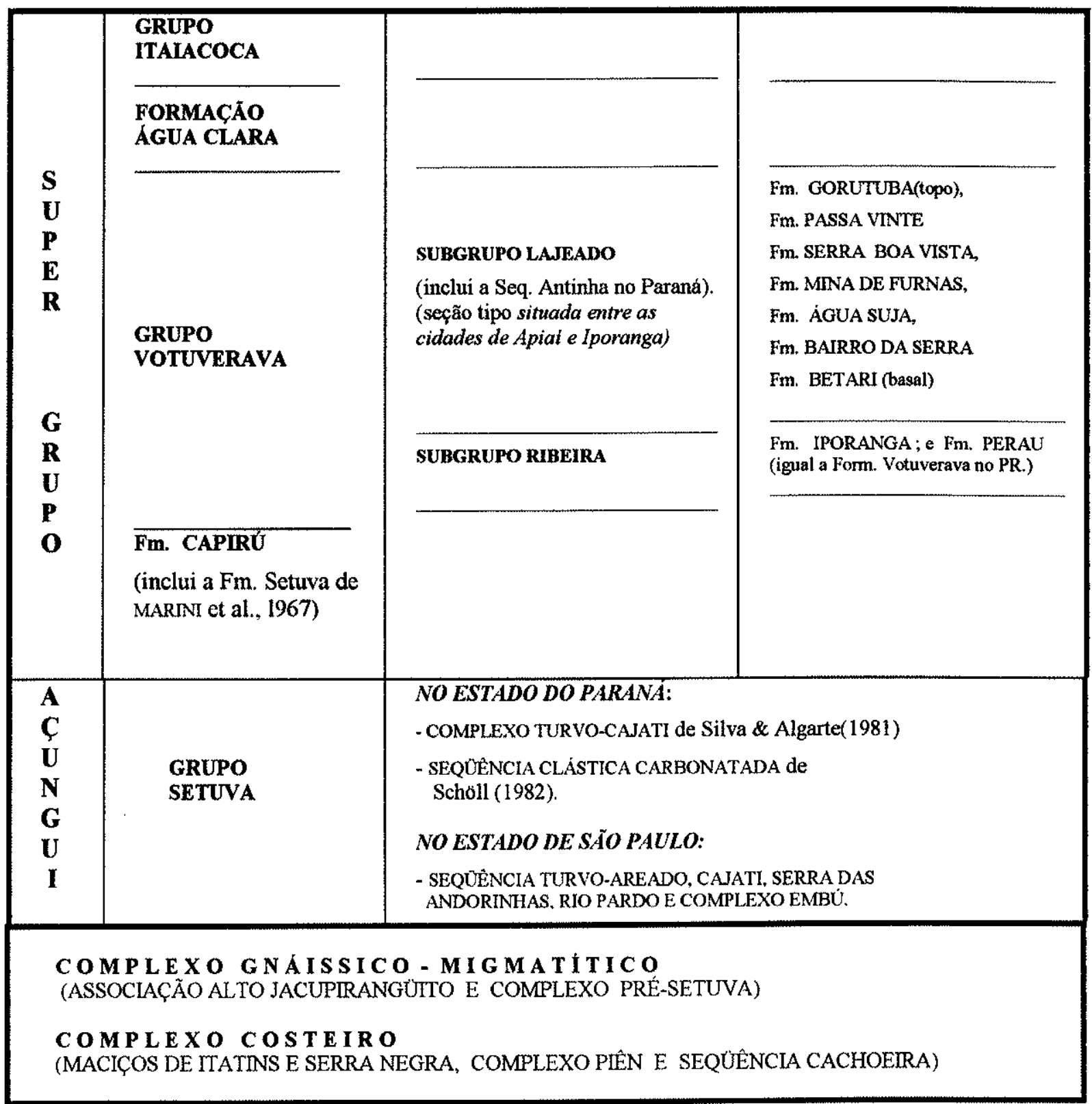

Quadro 3.1 - Coluna litoestratigráfica proposta por Campanha (1991) para os Estados do Paraná e sul de São Paulo. A disposição das unidades geológicas é de noroeste para sudeste, desde o Grupo Itaiacoca até o Grupo Setuva. respectivamente.

(2) Sub Grupo Ribeira - É constituido pelas Formação Iporanga (metaconglomerados de baixo grau metamórfico), que no Estado do Paraná corresponde ao Conjunto Litológico Bromado de Fiori $(1990,1992 a, 1992 b)$; a Formação Perau, que corresponde a Formação Votuverava clássica no Estado do Paraná. A denominação "Perau" foi atribuída por Piekarz 
(1981) a um conjunto de litologias que afloram na Mina do Perau cuja deformação e metamorfismo são relativamente maiores do que as da Formação Votuverava clássica. Além disso forma-se uma associação litológica particular. Estas características, aparentemente, estão ausentes nos litotipos aflorantes a oeste da cidade de Iporanga. É provável que as litologias identificadas como Formação "Perau" por Campanha (op cit), no vale do Ribeira, tenham correspondência com àquelas agrupadas nos Conjuntos Litológicos Saivá (topo), Coloninha e Bromado (base) por Fiori (op cit) para a Formação Votuverava clássica no Estado do Paraná.

A Formação Capirú, subdividida nos Conjuntos Litológicos Morro Grande (topo), Rio Branco e Juruqui (base) por Fiori $(1990,1992)$, parece não ter correspondente no Vale do Rio Ribeira de Iguape.

O Grupo Setuva, colocado na base do Super Grupo Açungui por Campanha (op cit), reeditando a coluna litoestratigráfica de Bigarella \& Salamuni $(1956,1958)$ e Marini et al. (1967), é composto por litologias com maior grau de metamorfismo e deformação, quando comparado com a unidade Votuverava clássica do Estado do Paraná.

A tendência atual de alguns pesquisadores em voltar a incluir o Grupo Setuva no Super Grupo Açungui, admitindo uma mesma idade de sedimentação e metamorfismo desta unidade em relação as unidades Itaiacoca, Votuverava Capirú e Água Clara, carecem, ainda, de dados geológicos confiáveis, os quais possam confirmar ou não a hipótese de trabalho sugerida por Campanha (op cit), pois existem nítidas diferenças de deformação e metamorfismo da unidade Setuva em relação as demais unidades. A Formação Água Clara, por outro lado, parece pertencer ao Grupo ou Super Grupo Açungui, haja visto as similaridades de sedimentação com a Formação Votuverava, pois ambas são consideradas de águas profundas, tendo igualmente composição sedimentar margosa/carbonática e pelítica; registram-se ainda similaridades estruturais com as Formações Capirú e Votuverava, diferenciando-se apenas pela maior intensidade de deformação nas litologias da Formação Água Clara; em termos metamórficos, ocorre um aumento de pressão e temperatura nas associações minerais, variando da fácies xisto verde baixo (Formações Capirú e Votuverava) até xisto verde médio e alto (Formação Água Clara), conforme verificações de Fassbinder et al. (1993,1994) (Ver Capítulo 4.5 - Correlação com o Grupo Açungui). Em algumas situações pontuais foi detectado a fácies anfibolito em rochas básicas, conforme verificado por Pontes (1981). 


\subsubsection{DISCUSSÃO CRÍTICA DA GEOLOGIA REGIONAL}

Um exame dos trabalhos anteriores regionais, levou a constatação de alguns problemas, como segue:

(1) Constante mudança de hierarquias das unidades ou conjuntos litologicos, agrupados em torno das denominações Açungui e Setuva.

A unidade Açungui passou da hierarquia de Série (Oliveira, 1916, 1925, 1927) para Grupo (Marini et al., 1967) e Super Grupo (Hasui et al., 1989). As unidades Itaiacoca, Votuverava e Capirú acompanharam igualmente essa tendência, com a formalização de Formação (Bigarella \& Salamuni 1956, 1958), Fácies (Schöll et al. 1980), Grupo (Hasui et al., 1984, 1989), ou ainda, de Complexo por Soares (1987).

Por outro lado, Fiori $(1990,1992)$ subdividiu as Formações Capirú e Votuverava nos Conjuntos Litológicos Morro Grande - Rio Branco - Juruqui e Saivá - Coloninha - Bromado respectivamente, as quais poderiam, por sua vez, corresponder a novas Formações, e o Super Grupo proposto por Hasui (1989) teria que ser elevada a uma hierarquia superior (hierarquia de "Super"-Super Grupo, e assim sucessivamente).

(2) Aspecto da contemporaneidade ou sucessão sedimentar das unidades do Grupo Açungui.

A discussão sobre a idade relativa entre as unidades que compõem o Grupo Açungui remonta aos trabalhos da década de 50. As colunas estratigráficas elaboradas por Bigarella \& Salamuni $(1956,58)$, e o posterior desmembramento da Formação Água Clara a partir da Formação Votuverava por Marini et al., (1967), mostram um empilhamento estratigráfico das unidades geológicas. Assim, os autores reconhecem um empilhamento estratigráfico das unidades de noroeste para sudeste, do topo para base, das Formações Água Clara, Votuverava, Capirú e Setuva. Essa tendência foi seguida por diversos autores, entre eles Campanha (1991), o qual retoma as colunas de Bigarella \& Salamuni (op. cit.) e Marini et al. (op. cit.) (Ver relação de autores no Quadro 3.2).

Porém, uma segunda alternativa de apresentação das unidades litológicas foi proposta por Petri \& Suguio (1969), com a proposição da contemporaneidade de sedimentação entre as 
Formações Itaiacoca, Votuverava e Capirú. Esta hipótese de trabalho foi adotada por Ebert (1971), o qual, por sua vez, considerou como contemporâneas as Formações Capirú, Votuverava e Água Clara, assumindo uma idade de sedimentação mais antiga para a Formação Setuva, colocando esta última na base do Grupo Açungui. Com a retirada da Formação Setuva do Grupo Açungui por Marini (1970) e a sua elevação para Grupo por Popp et al. (1979), juntamente com a atribuição de idades do Proterozóico Médio por Cordeiro da Silva (1981) e Fritzsons Jr. et al. (1982), a discussão da contemporaneidade da sedimentação ficou centrada nas Formações Capirú, Votuverava, Antinha e, mais recentemente, Água Clara, no Grupo Açungui.

Entre os diversos autores que consideraram contemporâneas algumas ou o conjunto das unidades que compõem o Grupo Açungui (Ver Quadro 3.2), Fiori $(1990,1992)$ apresentou uma nova distribuição para as litologias do Grupo Açungui. A partir dos domínios clássicos de ocorrência das Formações Antinha, Votuverava e Capirú, situadas respectivamente nos Blocos tectônicos C (noroeste da Zona de Cisalhamento Morro Agudo), D (entre as Zonas de Cisalhamento Morro Agudo e Lancinha), e E (sudeste da Zona de Cisalhamento Lancinha), o autor identificou correlações litológicas presentes em mais de um desses blocos tectônicos. Assim, Fiori (op. cit.) reconheceu os Conjuntos Litológicos Saivá, Coloninha e Bromado no domínio Clássico da Formação Votuverava (Bloco D), e identificou similaridades com os Conjuntos Litológicos Tacaniça no Bloco $\mathrm{C}$ e Juruqui, no Bloco E. Dessa forma, a Formação Votuverava passou a ser reconhecida nos blocos tectônicos $\mathrm{C}, \mathrm{D}$ e E, em sequências consideradas como basais, pelo autor, no Grupo Açungui (Quadro 3.3).

A Formação Capirú, com clássica ocorrência no Bloco E, ficou restrita ao Conjunto Litológico Rio Branco, porém com similaridades com o Conjunto Litológico Capivara, situado no Bloco C. Assim, a Formação Capirú passou a ter representantes litoestratigráficos nos blocos $\mathrm{C}$ e E. No topo da coluna, os Conjuntos Litológicos Morro Grande e Vuturuvú foram desmembrados das Formações clássicas Capirú, (bloco E), e Antinha, (bloco C). Dessa forma, esses 2 conjuntos litológicos passaram a se constituir em núcleos isolados nas sinformas de Morro Grande e Vuturuvú, sem que $o$ autor se referisse a alguma outra unidade estratigráfica existente na literatura.

Esta proposição formulada por Fiori (op. cit.), com base em estudos estruturais e sedimentares, passou a considerar uma maior distribuição lateral das Formações Votuverava e 


\begin{tabular}{|c|c|}
\hline $\begin{array}{llr}\text { Realizaram } & \text { empilhamento } & \text { lito } \\
\text { estratigráfico das unidades do Grupo } \\
\text { Açungui. }\end{array}$ & $\begin{array}{l}\text { Sedimentação contemporânea entre } \\
\text { algumas ou todas as unidades do Grupo } \\
\text { Açungui. }\end{array}$ \\
\hline $\begin{array}{l}\text { - Bigarella \& Salamuni }(1956,58) \\
\text { - Marini et al. (1967) } \\
\text { - Fuck et al. (1971) } \\
\text { - Popp et al. (1979) } \\
\text { - Pontes (1981) } \\
\text { - Cordeiro da Silva (1981) } \\
\text { - Pontes (1982) } \\
\text { - Schöll et al. (1982) } \\
\text { - Campos Neto (1983) } \\
\text { - Dias \& Salazar (1983,87) } \\
\text { - Chiodi Filho (1984) } \\
\text { - Hasui et al. (1984) } \\
\text { - Takahashi et al. (1984,86) } \\
\text { - Trein et al. (1985) } \\
\text { - Campanha et al. (1985,86) } \\
\text { - Souza (1990,92) } \\
\text { - Almeida (1990) } \\
\text { - Campanha (1991) }\end{array}$ & $\begin{array}{l}\text { - Petri \& Suguio (1969) } \\
\text { - Ebert (1971) } \\
\text { - Marini (1970) } \\
\text { - Schöll et al. (1980) } \\
\text { - Piekarz (1981) } \\
\text { - Fritzsons Jr. et al. (1982) } \\
\text { - Piekarz (1984) } \\
\text { - Hasui (1986) } \\
\text { - Soares (1987) } \\
\text { - Hasui (1989) } \\
\text { - Fiori (1990,92). }\end{array}$ \\
\hline
\end{tabular}

Quadro 3.2 - Relação de autores que reconheceram aspectos estruturais e sedimentares que indicaram contemporaneidade e/ou superposição cronológica entre as unidades que compõem o Grupo Açungui.

Fonte: Colunas litoestratigráficas compiladas no Anexo 1. 


\begin{tabular}{|c|c|c|c|}
\hline 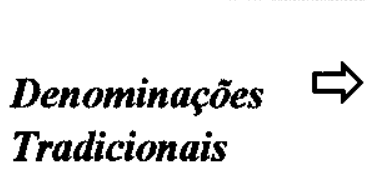 & $\begin{array}{l}\text { Bloco } C \\
\text { Fm. ANTINHA }\end{array}$ & $\begin{array}{l}\text { Bloco D } \\
\text { Fm. } \\
\text { VOTUVERAVA }\end{array}$ & $\begin{array}{l}\text { Bloco E } \\
\text { Fm. CAPIRÚ }\end{array}$ \\
\hline & $\begin{array}{l}\text { CONJUNTO } \\
\text { LITOLOGICO } \\
\text { VUTURUVU } \\
\text { (Parte do domínio } \\
\text { clássico da Fm. } \\
\text { Antinha). }\end{array}$ & & $\begin{array}{l}\text { CONJUNTO } \\
\text { LITOLÓGICO } \\
\text { MORRO } \\
\text { GRANDE }\end{array}$ \\
\hline $\begin{array}{l}\text { Formacão } \\
\text { CAPIRÚ }\end{array}$ & $\begin{array}{l}\text { CONJUNTO } \\
\text { LITOLOGICO } \\
\text { CAPIVARA }\end{array}$ & & $\begin{array}{l}\text { CONJUNTO } \\
\text { LITOLOGICO } \\
\text { RIO BRANCO } \\
\text { (parte do domínio } \\
\text { clássico da Fm. } \\
\text { Capirú) }\end{array}$ \\
\hline $\begin{array}{l}\text { Formacão } \\
\text { VOTUVERAVA }\end{array}$ & $\begin{array}{l}\text { CONJUNTO } \\
\text { LITOLOGGCO } \\
\text { TACANIÇA }\end{array}$ & $\begin{array}{l}\text { CONJUNTO } \\
\text { LITOLógICo } \\
\text { SAIVÁ }\left({ }^{*}\right) \\
\text { CONJUNTO } \\
\text { LITOLÓGICO } \\
\text { COLONINHA (*) } \\
\text { CONJUNTO } \\
\text { LITOLÓGICO } \\
\text { BROMADO (*) } \\
\left(\left(^{*}\right) \text { domínio clássico }\right. \\
\text { da Fm. Votuverava) }\end{array}$ & \begin{tabular}{|l|} 
CONJUNTO \\
LITOLOGICO \\
JURUQUI
\end{tabular} \\
\hline $\begin{array}{c}\hat{\mathrm{U}} \\
\frac{\text { Empilhamento }}{\text { litoestratigráfico }} \\
\frac{\text { proposto. }}{}\end{array}$ & \multicolumn{3}{|c|}{ CONJUNTOS LITOLÓGICOS PROPOSTOS } \\
\hline
\end{tabular}

Quadro 3.3 - Coluna litoestratigráfica proposta por Fiori (1990 e 1992) para o Grupo Açungui, à norte da cidade de Curitiba.

Capirú, presente em praticamente todos os blocos tectônicos que seccionam o pré-Cambriano do Estado do Paraná. Além disso, o autor considerou a Formação Votuverava como basal do Grupo Açungui, sobreposta pela Formação Capirú, e pelos Conjuntos Litológicos Morro Grande e 
Vuturuvú. Esta ordem de empilhamento estratigráfico segue uma ordem inversa ao das colunas de Bigarella \& Salamuni (1956,58), Schöll et al,, (1982) e Chiodi Filho (1984), pois estes colocaram a Formação Votuverava no topo das citadas colunas; Marini et al., (1976), Fuck et al. (1971), Popp et al., (1979) a colocaram próxima ao topo, logo abaixo da Formação Água Clara. Seguindo nessa mesma ordem, Campanha (1991) entendeu o Grupo Itaiacoca como ocupando o topo da coluna, seguido pela Formação Água Clara, Grupo Votuverava, Formação Capirú, e Grupo Setuva na base. É provável que esses autores tenham reconhecido, na verdade, uma estratigrafia estruturalmente invertida ou alterada a partir da sua disposição sedimentar original, a qual foi, provavelmente, identificada por Fiori $(1990,92)$.

Por outro lado, a grande maioria das camadas litológicas das Formações Capirú e Votuverava apresentam estruturas sedimentares com disposição normal, ou seja, sem inversões estratigráficas. Esta característica pode estar associado ao fato de que as estruturas do tipo duplex apresentam flancos normais com maior incidência estatística comparada com flancos invertidos, presentes normalmente em porções terminais da estrutura, onde a falha da base do empurrão gera dobras-falha do tipo antiformais, com flancos de forte mergulho, até invertidos (Boyer, 1986). É provável que a maioria desses flancos invertidos, de pequena escala, tenham sido erodidos no Grupo Açungui, uma vez que as falhas, as quais as referidas dobras estão associadas, geram zonas de anisotropia preferencialmente afetadas pela ação do intemperismo.

A identificação de uma tectônica de baixo ângulo ( tipo duplex), no sentido proposto por Boyer \& Elliot (1982), por Fiori et al. (1987) e Fiori $(1989,1990,1992$ a) nas litologias das Formações Capirú e Votuverava, a norte da cidade de Curitiba, abre a possibilidade de que ocorram diversas repetições de um mesmo nivel estratigráfico ao longo de uma mesma seção geológica, ou sobreposições de horizontes estratigráficos e/ou estruturais mais antigos ou mais deformados, sobre horizontes mais jovens ou menos deformados, na forma de fatias tectônicas empilhadas e imbricadas, seguindo a concepção de Dahlstron (1970).

A ausência de estudos estruturais em escala de semi-detalhe e de detalhe, com identificação de escamas ou lascas de empurrão (Thrust Shets), ou ainda, de cavalos (Horses) (Boyer \& Elliot, op. cit.), com suas respectivas estratigrafias internas, levou a diversos autores a criar denominações locais para prováveis repetições de um mesmo horizonte estratigráfico e/ou estrutural, o qual fora definido por outros autores em áreas adjacentes. A criação do Super Grupo Açungui e Super Grupo Ribesita por Hasui (1989) e a conservação da hierarquia de super grupo para a primeira unidade por Campanha (1991), Reis Neto (1994), foi uma forma de 
evitar a complicação na literatura. Esta proliferação de colunas estratigráficas, dentro das quais 41 colunas foram compiladas apenas neste trabalho, podem se visualizadas no Quadro do Anexo 1. Estas colunas diferem em termos de nomenclatura, posição estratigráfica ocupada pelos mesmos conjuntos litológicos, idade de sedimentação e/ou metamorfismo, hierarquização de unidades geológicas, etc. As razões disso já apontados nos itens (1) e (2), somam-se ainda os seguintes aspectos:

(1) Abrangência localizada de várias colunas estratigráficas;

(2) Negligência de muitos pesquisadores sobre a discussão dos trabalhos anteriores;

(3) Mudanças estratigráficas radicais, sem definição clara dos critérios utilizados e tampouco de uma argumentação baseada em dados geológicos ou geocronológicos que suportem a nova proposta . Além disso, assumem-se muitos pressupostos, muitas vezes aceitos pela comunidade cientifica, porém sem terem sido publicados.

(4) Periodo na geologia em que foi muito utilizada a técnica de correlação estrutural, onde se admitia que um certo estilo de dobras com uma foliação plano-axial associada, definida como fase de deformação ou de dobramento, era critério para se definir como pertencente ou não a um determinado ciclo geotectônico (Ciclo Brasiliano, Uruaçuano ou Transamazônico). Porém, com a introdução de novos conceitos sobre cisalhamento simples, incluíndo estruturas de cavalgamentos, passou-se a admitir que o desenvolvimento de estruturas tectônicas (planares ou lineares), incluindo a geração de dobras e falhas, com feições penetrativas ou não, desenvolvidas em diversas escalas, poderiam estar associadas a um mesmo regime tectônico. A este conjunto de feições estruturais, Fiori (1990) denominou de "Sistema de Deformação".

A ocorrência de uma foliação, muitas vezes pouco penetrativa, porém generalizada numa mesma unidade, foi utilizada como critério para atribuir idades mais antigas a uma determinada litologia. Neste sentido, Campanha (1991) assinala que a presença de diferentes estilos estruturais poderiam indicar um posicionamento espacial distinto dentro de um mesmo orógeno, sem implicar, obrigatoriamente, num posicionamento temporal distinto. 
(5) A não aplicação do conceito de níveis estruturais de Mattauer (1972) por muitos autores. A elevação do grau metamórfico da fácies xisto verde baixo, em algumas unidades (Formações Capirú e Votuverava), para a fácies xisto verde médio a alto em outras (Formação Água Clara), foi utilizado como critério para separá-las como unidades temporalmente distintas, seja dentro de um mesmo ciclo geotectônico ou até mesmo de ciclos geotectônicos distintos (Reis Neto \& Soares, 1987; Soares et al., 1993, entre outros).

A desobediência no uso do Código de Nomenclatura Estratigráfico, se reflete no fato de que poucos autores definiram formalmente as unidades estratigráficas por eles propostos, conforme já assinalado por Campanha (1991).

(7) A falta do emprego de metodologias com maior rigor científico, incluindo discussão dos trabalhos anteriores com maior objetividade.

$\mathrm{O}$ aprofundamento da análise mais detalhada da Anexo 1 mostra que todas as colunas podem ser agrupadas em torno dos Grupos Açungui e Setuva (ou Ribeira), e ainda dos Complexos Pré-Setuva e Cristalino (ou Complexos Apiai-Mirim e Costeiro de Hasui, 1986) (observar as linhas limitrofes da referida tabela).

A determinação de uma camada guia para a base do Grupo Açungui parece ser uma questão central a ser resolvida no atual estágio de conhecimentos. Campanha (op. cit.) sugere a adoção de uma camada guia de quartzitos na base da Formação Perau, a qual acha-se sobreposta aos gnaisses da Formação Setuva, assim como outro nivel de quartzitos ou metaconglomerados na base da Formação Iporanga ou de camadas correlatas (Seqüência Bromado de Fiori, 1990).

Campanha (1991) entende por Formação Setuva o Complexo Pré-Setuva de Fritzsons Jr. et al., 1982 e de Biondi, 1983; e Formação Perau, pelo Grupo Setuva e parte do Grupo Açungui (Formação Votuverava) dos referidos autores. Campanha (op. cit.) reconhece, ainda, uma transição entre os xistos e filitos no anticlinal do Setuva, os quais no opinião do autor, pertencem a Formação Perau. Porém, diversos pesquisadores identificam uma importante discordância estrutural entre os filitos e xistos acima referidos, culminando com o reconhecimento da Falha do Setuva por Fiori et al. (1987), Althoff (1989) e Fiori (1990). Estes autores interpretaram a referida estrutura como uma falha de descolamento em duplex, com a geração de uma tectonofácies, localmente denominada Setuva. 
A inclusão, no que seria a Bacia Açungui original, de unidades como a Formação São Sebastião (Veiga \& Salomão, 1980), Grupo Setuva (Schöll et al., 1982) e Formação Perau (Piekarz, 1981), fica ainda na dependência de dados analíticos e estratigráficos consistentes, embora, com base nos dados ora disponíveis, possa-se considerar que as Formações Capirú e Votuverava (Iporanga e Lajeado) representem as porções superiores da citada bacia Açungui.

Por outro lado, vários autores, dentre eles Hasui et al., 1984c; Fiori et al. 1985, 1987; Fiori, 1990; Soares, 1987 tem demonstrado a existência de contatos tectônicos, transposições, lenticularizações, recristalizações internas, dificultando deste modo o empilhamento estratigráfico original e tornando assim enganosa muitas das proposições estratigráficas existentes na literatura, conforme já assinalado por Campanha (1991). Neste sentido, correlações a médias ou longas distâncias (por exemplo, unidades situadas nos arredores de Curitiba com aquelas situadas na região de Apiaí-Iporanga) são impraticáveis, ou no mínimo, passíveis de discussões. É provável que uma litoestratigrafia clássica, seguindo as recomendações do código de nomenclatura estratigráfica seja aplicável apenas em áreas restritas como, por exemplo, no interior de lascas de empurrão (horses de sistemas de leques embricados e duplex - Boyer \& Elliot, 1982; Butler, 1982, entre outros). É verdade, também, que os regimes deformacionais não se mantêm constantes ao longo de grandes distâncias. E, por último, a superposição da extensa zona de cisalhamento direcional de alto ângulo Lancinha-Cubatão-Além Paraíba (Campanha, 1980; Silva, 1981,1996; Fiori, 1985a, Fassbinder, 1990; Fassbinder et al. (1994) e Hackspacher (1996), constitui-se num complicador estratigráfico adicional, modificando as relações estratigráficas originais e gerando uma geometria característica de zonas de cisalhamento de alto ângulo com duplex de Riedel associados.

\subsection{SÍNTESE DO QUADRO ESTRATIGRÁFICO EVOLUTIVO}

A primeira tentativa em situar a Formação Água Clara numa coluna estratigráfica foi efetuada por Marini et al., 1967 (in: Bigarella et al., 1967). Os autores verificaram que as litologias desta unidade repousam "em aparente discordância" (?) "sobre a Formação Votuverava, a partir de relações estruturais (a foliação principal possui direção NE e mergulhos para NW). Desta forma, os autores posicionaram a Formação Água Clara no topo do Grupo Açungui (Ver Quadro 3.1), tendo em vista a sua localização geográfica à NW das Formações Votuverava e Antinha. 
Marini (1970) verificou que o único critério que pudesse indicar uma discordância entre as Formações Água Clara e Votuverava era estrutural. O autor descreveu o contato como sendo feito por "aparente falha". Manteve a Formação Água Clara no topo do Grupo Açungui, porém, considerou-a contemporânea com a Formação Votuverava (Ver Anexo 1).

A interpretação de Marini et al. (op. cit.) e Marini(op. cit.) foi corroborada por Ebert (1971), Fuck et al. (1971) e Popp et al. (1979).

A identificação de metassedimentos típicos de águas profundas na fácies São Silvestre (basal da Formação Água Clara) levou Pontes $(1981,1982)$ a posicionar a Formação Água Clara na base do Grupo Açungui ( $V e r$ Anexo 1), embora a fácies Serrinha (esta de topo) apresentasse estruturas sedimentares indicativas de águas rasas. É provável que essas últimas características serviram de suporte para as interpretações de Marini et al. (op. cit.) e Marini (op. cit.). Mas a ocorrência de dobras isoclinais quase sempre rompidas e com metamorfismo na fácies xisto verde alto, início do grau médio, na região de São Silvestre/São Domingos, indicaria um incremento da intensidade de deformação e do grau metamórfico em relação as Formações Capirú e Votuverava, embasando assim a interpretação de Pontes (op. cit.). Estas características levaram este autor a sugerir que a Formação Água Clara pudesse pertencer a um ciclo tectônico anterior (Proterozóico médio ?).

Veiga \& Salomão (1980) e Piekarz (1981) descreveram a Formação São Sebastião e a Seqüência Perau, respectivamente, com características litológicas, estruturais e metamórficas idênticas aquelas verificadas por Pontes $(1981,1982)$ na Formação Água Clara.

Porém, Fritzsons Jr. et al. (1982) retiraram a Formação Água Clara da base do Grupo Açungui, situando-a no topo do Grupo Setuva, não esclarecendo, entretanto, os critérios que os levaram a fazer esta importante modificação estratigráfica. Para a Formação Perau, tida pelos autores como basal no Grupo Setuva, atribuíram idade Transamazônica (ou Proterozóico Médio), com base em 5 idades $\mathrm{Rb} / \mathrm{Sr}$ convencionais, distribuídas entre $1.201 \pm 31 \mathrm{Ma}$ e $2.146 \pm 92 \mathrm{Ma}$ (Batolla Jr. et al., 1981 in: Fritzsons Jr. et al., op. cit.). Desta forma, passou-se a atribuir uma idade do Proterozóico Médio para Formação Água Clara, sem que alguma datação radiométrica tenha sido efetuada em suas litologias. Além disso, as relações com a definição original do Grupo Setuva não foram esclarecidas. Esta linha de interpretação foi seguida por Biondi (1983), Piekarz (1984), Chiodi Filho (1984), Hasui et al. (1984), Reis Neto \& Soares (1987), Soares (1987) e Soares et al. (1993). Porém, Campanha (1991) voltou a posicionar a Formação Água Clara próxima ao topo da coluna litoestratigráfica do Grupo Açungui, logo abaixo do Grupo 
Itaiacoca (Ver Quadro 3.1), reeditando assim as discussões levantadas por Marini et al. (1967) e Marini (1970).

Reis Neto \& Soares (1987) procuraram caracterizar as micro estruturas presentes nos Grupos Setuva e Açungui, utilizando como critérios a intensidade do metamorfismo e a quantidade de foliações presentes, juntamente com o tipo de deformação e o regime tectonotermal em que cada foliação se desenvolveu. Os autores descreveram uma foliação cisalhante desenvolvida no Grupo Setuva (regime essencialmente dúctil e metamorfismo de fácies anfibolito, zona da estaurolita), e uma segunda, desenvolvida no Grupo Açungui (regime dúctil a dúctil/rúptil, e metamorfismo de fácies xisto verde, nas zonas da clorita e/ou biotita (Figura 3.1). Os autores interpretaram estas duas foliações como tendo sido geradas em ciclos geotectônicos distintos, respectivamente, no Proterozóico Médio e Proterozóico Superior.

O critério da associação de uma determinada foliação e um certo grau metamórfico para definir as condições tectono-termais de um determinado ciclo geotectônico foi utilizado desde Bigarella \& Salamuni $(1956,1958)$ até meados de 1985, por diversos autores. Porém, com a introdução da conceituação de cisalhamento simples por Ramsay (1967,1980), Ramsay \& Graham (1970), Ramsay \& Huber (1983, 1986), Simpson \& Schmidt (1983), entre outros; cavalgamentos e retrocavalgamentos por Boyer \& Elliot (1982), Butler (1982), Lister \& Snoke (1984), Boyer (1986), entre outros (ver a aplicação dessa metodologia em Fiori, 1990), passouse a verificar que diversas estruturas podem ser geradas por um único processo de deformação. Se este processo for uma deformação contínua, diversas estruturas vão sendo progressivamente impressas nas rochas, aparecendo assim varias relações de superposição. Neste sentido, Fiori (op. cit.) descreveu as foliações $S_{s}$ e $S_{c}\left(S_{1}\right)$ e dobras $D_{1}$, geradas por cavalgamentos, foliações $S_{2}$ $\left(S_{c}\right)$ e dobras $D_{2}$ formadas por retrocavalgamentos, as quais teriam sido geradas quase contemporâneas; somam-se, ainda, estruturas associadas as zonas de cisalhamento de alto ângulo do lineamento Lancinha-Itapeúna-Cubatão (zona de cisalhamento principal, zonas de cisalhamento sintéticas e antitéticas e dobras escalonadas), geradas por um processo de deformação contínua a partir dos cavalgamentos e retrocavalgamentos, durante o Proterozóico Superior.

A ação deformadora das falhas de baixo ângulo (cavalgamentos e retrocavalgamentos), teria produzido o transporte tectônico de um pacote litológico sobre o outro, e um 


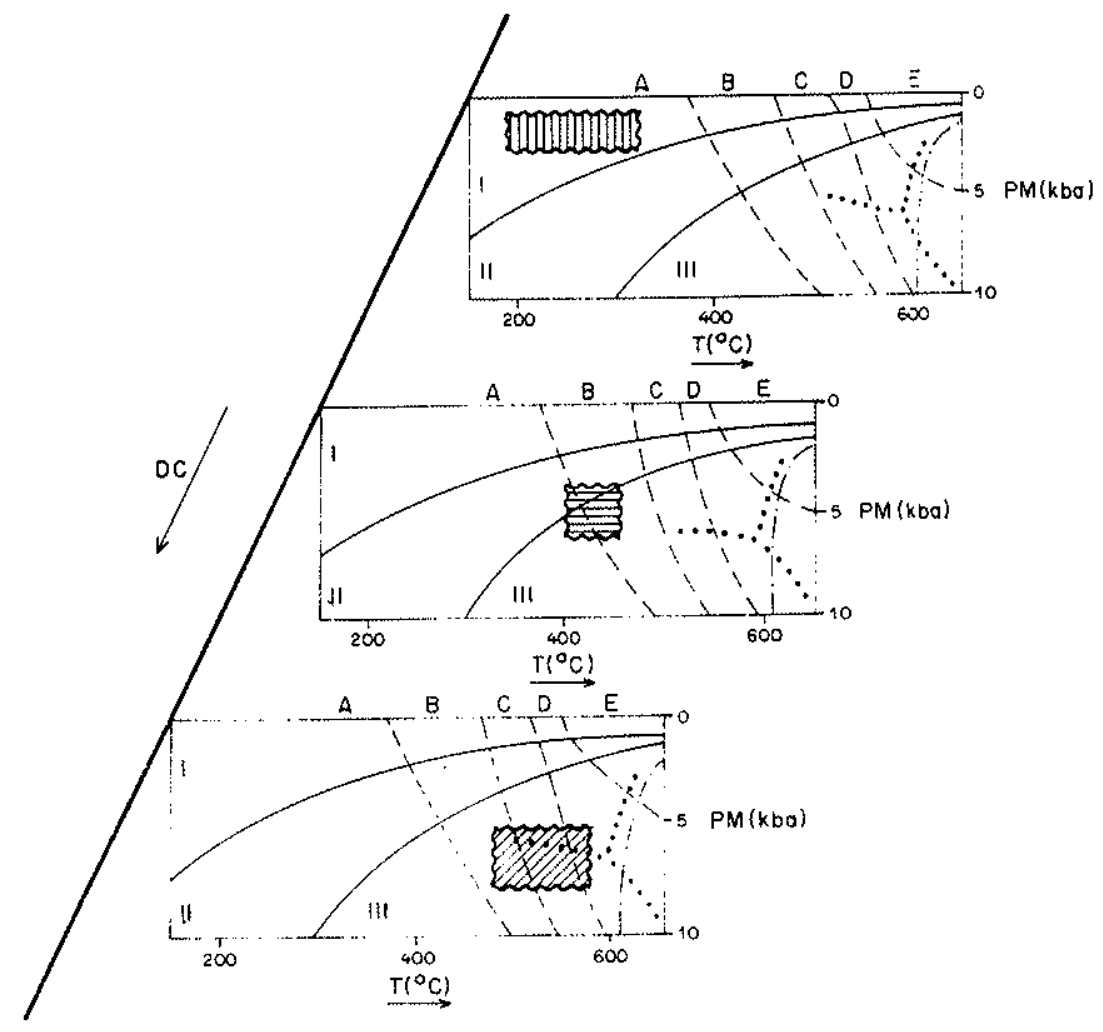

DC Deformaçăo Cisathante.

$T$. Temperatura.

- - Curva de fusāo de grancióides

PM. Pressāo Móxima. ricos em $\mathrm{H}_{2} \mathrm{O}$.

.... Campo de establidaze dos $\mathrm{Al}_{2} \mathrm{SiO}_{5}$.

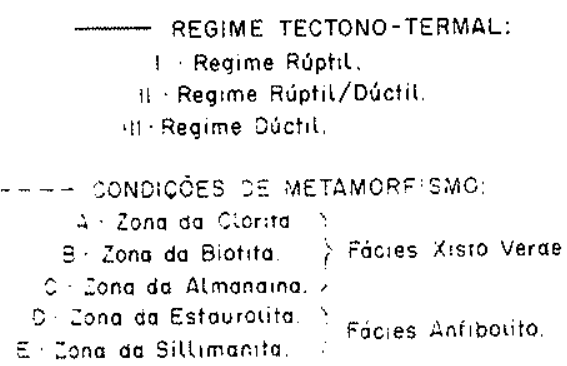

SAMPO SE FORMAÇĀO DOS DIFERENTES TIPOS SE MICRC ESTRUTURAS.

MTMT! Stç. Folıaçâo Antinha e Camarinho.

Sa1. Foliagão do Grudo Acunqul.

Ss:1 Foliaçấc do Grudo Seruva

Figura 3.1 - Condições tectono-metamórficas em que as foliações dos Grupos Setuva e Açungui formạ desenvolvidas. segundo a interpretação de Reis Neto \& Soares (1987). 
empilhamento parcial destas unidades, introduzindo assim dificuldades no estudo destas sequências, cujos aspectos principais são os seguintes:

(1) Falta de continuidade lateral e vertical entre as diversas sequências deposicionais do Grupo Açungui e da Formação Água Clara, devido a presença de falhas de cavalgamento na base e no topo destas unidades. Além disso, a ação de zonas de cisalhamento de alto ângulo gerou blocos tectônicos que foram transportados direcionalmente, por diversos quilômetros, com movimento lateral direito ao longo da direção N50-60E.

(2) Provável repetição de camadas na coluna estratigráfica em algumas regiões e ausência em outras, devido ao empilhamento estrutural das unidades, não obedecendo a coluna original de deposição, com unidades mais antigas colocadas sobre unidades mais jovens, porém, ambas associadas a um determinado ciclo sedimentar;

(3) Deformação heterogênea, a qual afeta certos níveis da estratigrafia original, deformandoos mais ou menos intensamente, enquanto em outros níveis são preservadas as estruturas sedimentares, com a deformação podendo ser muito pequena, ou mesmo ausente. Esta mecânica pode gerar significativas descontinuidades estruturais, justapondo pacotes intensamente deformados com outros de menor deformação;

(4) Ausência de transições metamórficas entre as unidades. A ação das falhas de baixo ângulo justapôs blocos com diferentes graus metamórficos, eliminando assim, em muitas situações, prováveis zonas de transição metamórfica. Um exemplo típico desta situação pode ser observado entre a Seqüência São Silvestre e a Formação Votuverava, as quais foram metamorfisadas respectivamente na parte superior do grau baixo (fácies xisto verde alto) a grau médio, e porção inferior do grau baixo (fácies xisto verde baixo). Em outras situações, unidades com o mesmo grau metamórfico foram empilhadas, como parece ser o caso das Formações Capirú e Votuverava no Grupo Açungui, conforme verificado por Fiori (1990).

Na revisão da vasta bibliografia sobre o Pré-Cambriano Paranaense, fica evidente a não utilização do modelo de niveis estruturais de Mattauer (1973) pelos diversos autores que elaboraram colunas estratigráficas locais, exceção feita aos trabalhos de Soares (1987) e Fiori (1990). Diferenças de ductilidade e intensidade de deformação, número de foliações e grau 
metamórfico, mesmo com diferenças pouco significativas, tem sido utilizado tradicionalmente como parâmetro para definir unidades geológicas e situá-las em diferentes ciclos geotectônicos.

\subsection{MODELOS TECTÔNICOS REGIONAIS}

Diversos modelos tentaram explicar as feições geológicas presentes na faixa Ribeira, na altura dos Estados do Paraná e sul de São Paulo. As idéias geossinclinais (Melfi et al. 1965; Almeida. 1967; Marini et al. 1967; Petri \& Suguio 1969; Marini 1970; e Wernick et al. 1978), foram sucedidas pelo modelo aulacogênico (IPT 1982; Hasui 1982 e Chiodi Filho et al. 1984) (Tabela 3.1), a qual, por sua vez, deu lugar ao modelo da Tectônica de Placa (Tabela 3.2).

Dentro do modelo da tectônica de placas, o trabalho de Ebert (1971) se constituiu num marco pioneiro, com a proposição de uma tectônica de nappes para a região do anticlinal do Setuva, onde o autor identificou elementos estruturais que apontavam para uma aloctonia pronunciada das unidades geológicas. Embora o modelo de tectônicas de placas estivesse em vias de formalização na Europa e Estados Unidos na década de 60 e início de 70, o trabalho de Ebert (op. cit.) pode ser incluído nesta abordagem, tendo em vista características idênticas entre o modelo de nappes e aquele de placas tectônicas.

$\mathrm{Na}$ década de 80 foi retomada a idéia da aloctonia, com a identificação de uma generalizada foliação não coaxial nas litologias dos Grupos Açungui e Setuva por Hasui et al. (1984 a,b,c, 1986, 1989), Fiori et al. (1984, 1987c), Soares (1987), Ebert (1988), Fiori (1990, $1992 \mathrm{a}, \mathrm{b})$, entre outros. O reconhecimento dessas feições estruturais, juntamente com os aspectos paleogeográficos e magmáticos, levou diversos autores a elaborar modelos de tectônica placas, inspirados nos modelos Himalaiano e Andino, entre os quais destacam-se os de Hasui (1986), Campanha et al. (1987), Soares (1987), Fiori (1990), Campanha (1991) e Reis Neto (1994).

Entre os resultados obtidos pelos autores, o reconhecimento dos Complexos Cunhaporanga e Três Córregos como sendo um arco magmático, parece se constituir no único elemento convergente. É provável que a divergência na interpretação dos diversos sítios tectônicos esteja associada em grande parte ao sentido da subduç̧ão postulado pelos autores Soares (op. cit.), e Fiori(op. cit.) de W/NW $\Rightarrow$ E/SE; Campanha et al. (op. cit.), Campanha (op. cit.) e Reis Neto (op. cit.) de $\mathbf{E} / \mathbf{S E} \Rightarrow \mathbf{W} / \mathbf{N W}$; ou ainda, Hasui (op. cit.) e Ebert et al. (op. cit.) de $\mathbf{S} \Rightarrow \mathbf{N}$. 


\begin{tabular}{|c|c|c|c|c|}
\hline \multicolumn{5}{|c|}{ MODELO GEOSSINCLINAL } \\
\hline AUTOR & UNDADE & CLASSIFICACÃO & SUBDIVISĀO & CARACTERÍSTICAS \\
\hline MELFI ET AL (1965) & GRIPO AÇUINGUT & GEOSSINCLINEO & & -IMPLANTADO NA BORDA SE DE UM CRÁTON, LOCALIZADO SOB A BACIA DO PARANÁ. \\
\hline ALMEIDA (1967) & $\begin{array}{l}\text { GRUPOS BRUSQLE } \\
\text { EACINGI } \\
\end{array}$ & $\begin{array}{l}\text { ORTO- } \\
\text { GEOSSENCLINEO }\end{array}$ & & $\begin{array}{l}\text {-OS GRUPOS ACUNGUI E BRUSQUE ATRIBÚDOS AO GBOSSINCLINEOO PARABB, NO CICLO } \\
\text { BACALANO. }\end{array}$ \\
\hline MARINT ET AL (1967) & GRUPO AÇINGU & ORTO- & EUGEOSSINCLINEO & $\begin{array}{l}\text {-GRANDE ESPESSURA DE SEDIMENTOS INTENSAMENTE DOBRADOS. } \\
\text { - MAGMATISMO OFIOLITICO (BÁSTCO) E GRANITICO ASSOCIADO. }\end{array}$ \\
\hline PETRI \& SLGUTO (1969) & $\begin{array}{l}\text { Fms. ITAACOCA, } \\
\text { VOTVERAVA E } \\
\text { CAPRER. }\end{array}$ & & MOGEOSSINCLINEO & $\begin{array}{l}\text {-DEPÓSTTOS TIPO PLATAFORMA CONTINENTAL, EM MAR RASO, EPICONTINENTAL; } \\
\text {-AREA FONTE STYUADA A NW. }\end{array}$ \\
\hline MARINI 1970 & IDEM & & MIOGEOSSINCLINEO & ÁREA FONTE: STTUADA A SE. \\
\hline WERNICK ET AL A1978) $^{2}$ & FAXXA RIREIRA & GEOSSINCLINAL & & 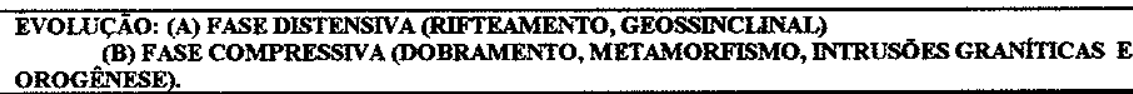 \\
\hline
\end{tabular}

\begin{tabular}{|c|c|c|c|}
\hline \multicolumn{4}{|r|}{ MODELO DE AULACÓGENO } \\
\hline AUTTOR & UNDADES & PROPOSICŌES & CARACTERISTICAS \\
\hline \multirow{3}{*}{$\begin{array}{l}\text { IPT, 1982 } \\
\text { (in: CAMPANHA, 1991) } \\
\text { HASUI (1982) }\end{array}$} & \multirow{3}{*}{$\begin{array}{l}\text { FARIS } \\
\text { APAII } \\
\text { SÁOROQIE }\end{array}$} & AULACOGENO & 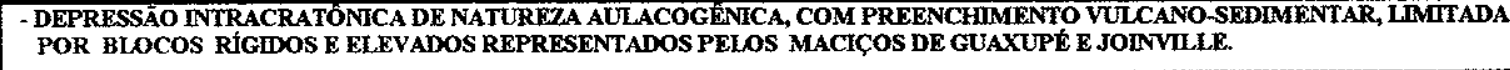 \\
\hline & & $\begin{array}{l}\text { GEOSSINCLINEO } \\
\text { INTRACRATÓNICO }\end{array}$ & $\begin{array}{l}\text { - MODELO ALTERNATTVO PARA EXPLICAR O METAMORFISMO, DEFORMAÇÃO E GRANDE QUANTDADE DE GRANTTOS, COM } \\
\text { NCOMPATVERIS O MODELO DE AULACÓGENO. }\end{array}$ \\
\hline & & $\begin{array}{l}\text { TECTONACA DE } \\
\text { PLACAS }\end{array}$ & $\begin{array}{l}\text { COM O DESLOCAMENTO DE PLACAS E ABERTERA DE OCRANOS RESTRTOS; } \\
\text { CONSDERAM FALTA DE ELEMENTOS PARA ASSUNIR ESAE MODELO PARA O PRE-CAMBRIANO PAULUSTA }\end{array}$ \\
\hline \multirow[b]{2}{*}{$\begin{array}{l}\text { CHIODI FIL.HO } \\
\text { ET AL. (1984) }\end{array}$} & \multirow{2}{*}{$\begin{array}{l}\text { GRUPO SETUVA } \\
\text { Fms. ITACACOCA- } \\
\text { AGUACLARA. } \\
\text { PERAU ES Seq. } \\
\text { TURVO CAJATI }\end{array}$} & AULACÓGENO & -DEPOSICÁA EM TORNO DE 1.400 MA;; -POSTERIOR METAMORFISMO E DEFORMAÇÄO. \\
\hline & & $\begin{array}{l}\text { RIFTES } \\
\text { LOCALIZADOS } \\
\Rightarrow \text { SINÉCLISES. }\end{array}$ & $\begin{array}{l}\text {-DEPOSICĀO EM RIFTS LOCALIZADOS; } \\
\text { - EVOLUCAO PARA SINECLSES; } \\
\text {-NA CONTINUDADE, DEFORMACĀO E METAMORFISMO NO CICLO BRASLIANO. }\end{array}$ \\
\hline
\end{tabular}

\begin{tabular}{|c|c|c|c|}
\hline \multicolumn{4}{|c|}{ TECTÔNICA DE "NAPPES" } \\
\hline AUTOR & UNIDADE & PROPOSTCÃO & CARACTERISTICAS \\
\hline EBERT (1968) & GRIPO AÇUNGUI & TECTONNICA DE NAPPES & 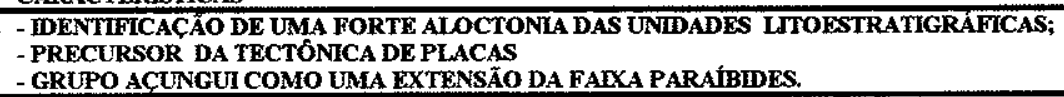 \\
\hline
\end{tabular}

Tabela 3.1 - Evolução dos modelos tectônicos a partir das idéias geossinclinais, aulacogênicas e a tectônica de "nappes", segundo diversos autores. 


\begin{tabular}{|c|c|c|c|c|c|c|c|c|c|c|}
\hline \multicolumn{11}{|c|}{ MODELO DE TECTÔNICA DE PLACAS } \\
\hline AITOR & MODELO & $\begin{array}{l}\text { PLACAS } \\
\text { ENVOIVDDAS }\end{array}$ & $\begin{array}{r}\text { BACLA } \\
\text { RETRO } \\
\text { ARCO (1) }\end{array}$ & $\begin{array}{l}\text { ARCO } \\
\text { MAGMA- } \\
\text { TICO Q }\end{array}$ & $\begin{array}{c}\text { BACIA } \\
\text { ANTE } \\
\text { ARCO (3) }\end{array}$ & COMPLEX & $\begin{array}{l}\text { DE SUBDUCCĀO } \\
\text { (4) }\end{array}$ & $\begin{array}{c}\text { SUTURA } \\
\text { (5) }\end{array}$ & $\begin{array}{l}\text { SENTIDO DE } \\
\text { SUBDUC- } \\
\text { CĀO/COLI- } \\
\text { SĀO } 6 \\
\end{array}$ & $\begin{array}{c}\text { PLACA } \\
\text { SUBDUCTADA } \\
\varnothing\end{array}$ \\
\hline $\begin{array}{l}\text { CAMPANHA } \\
\text { et al. (1987) } \\
\text { CAMPANHA } \\
\text { (1991) }\end{array}$ & $\begin{array}{l}\text { SUBDIICCÃO DO } \\
\text { TIPO B } \\
\text { (PLACAS } \\
\text { OCEANICA. } \\
\text { CONTINENTAL) } \\
\quad \text { E } \\
\text { POSTERIOR } \\
\text { COLISAO DE } \\
\text { BIOCOS } \\
\text { CONTINENTAIS }\end{array}$ & 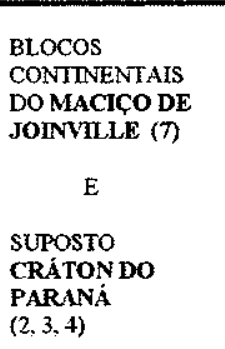 & $?$ & $\begin{array}{l}\text { MACIÇO } \\
\text { CATAS } \\
\text { ALTAS }\end{array}$ & $\begin{array}{l}\text { SUB } \\
\text { GRUPO } \\
\text { LAJEADO }\end{array}$ & $\begin{array}{l}\text { FAXX INTERNA: } \\
\text { OFIÓLITOS } \\
\text { + LASCAS DE } \\
\text { FLYSCH } \\
\text { + RXS METAMÓRF. } \\
\text { + MEELANGES TEC- } \\
\text { TONNICAS. } \\
\\
\text { Fms. IPORANGA } \\
\text { E PERAU } \\
\text { (VOTUVERAVA NO } \\
\text { PARANÁ). }\end{array}$ & $\begin{array}{l}\text { FAIXA EXTERNA OU } \\
\text { BACIA T: } \\
\text { INTERAMENTE DE } \\
\text { FLYSCH, COM PORÇÕES } \\
\text { MENORES } \\
\text { DE RXS ÍGNEAS. } \\
\text { (FOSSA. ABISSAL) } \\
\text { Fm. PPORANGA } \\
\text { (DEPÓSTIOS DO TIPO } \\
\text { WLDFLYSCH }\end{array}$ & $\begin{array}{l}\text { LINEAMENTO } \\
\text { FIGUEIRA } \\
\text { (SÃOPAULO) } \\
\text { LINEAMENTO } \\
\text { MORRO } \\
\text { AGUDO } \\
\text { (PARANA) }\end{array}$ & $\begin{array}{l}\text { PLACA } \\
\text { OCEÂNICA } \\
\text { SUBDUCTA- } \\
\text { DA DE } \\
\text { SE } \Rightarrow \text { NW }\end{array}$ & $\begin{array}{l}\text { MACICCO DE } \\
\text { JOINVLLLE } \\
\\
\text { FM. CAPIRÚ- } \\
\text { (SEDIMENTOS } \\
\text { LITORÂNEOS) } \\
\text { FM. SETUVA } \\
\text { (PLATAFORMA } \\
\text { CONTINENTAL/ } \\
\text { EMBASAMENTo }\end{array}$ \\
\hline HASII (1986) & $\begin{array}{l}\text { COLISÃO } \\
\text { CONTINENTAL } \\
\text { (1 OROKIENESE } \\
\text { ARQUEANA) }\end{array}$ & $\begin{array}{l}\text { BLOCO SĀO } \\
\text { PAULO } \\
\text { (A NORTE) } \\
\text { BIOCO VTTÓRIA } \\
\text { (A SUL) } \\
\end{array}$ & ? & ? & $?$ & & $?$ & $\begin{array}{l}\text { LINEAMENTO } \\
\text { LANCINIAA } \\
\text { ? }\end{array}$ & $\begin{array}{l}\text { SUL } \Rightarrow \\
\text { NORTE }\end{array}$ & - \\
\hline $\begin{array}{l}\text { SOARES } \\
(1987)\end{array}$ & 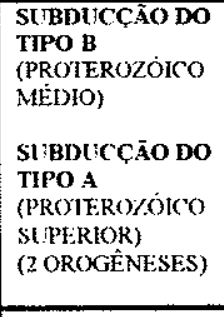 & $\begin{array}{c}\text { CRÁTON DO } \\
\text { PARANA } \\
\text { E } \\
\\
?\end{array}$ & $\begin{array}{l}\text { BACIA } \\
\text { SETUVA } \\
\text { (PROTE- } \\
\text { ROZÓICO } \\
\text { MÉDIO) } \\
\\
\text { BACIA } \\
\text { ACIINGUI } \\
\text { (PROTERO- } \\
\text { ZÓICO } \\
\text { SUPERIOR) } \\
\end{array}$ & $\begin{array}{l}\text { COMPLE- } \\
\text { XOS } \\
\text { CUNHAPO- } \\
\text { RANGA } \\
\text { E } \\
\text { TRÊS } \\
\text { CÓRREGOS }\end{array}$ & $\begin{array}{l}\text { ENCOBER- } \\
\text { TA PELA } \\
\text { BACIA } \\
\text { DO } \\
\text { PARANA }\end{array}$ & ENCOBERTA PELA E & CIA DOPARANÁ & $\begin{array}{l}\text { ENCOBERTA } \\
\text { PELA BACIA } \\
\text { DO PARANÁ }\end{array}$ & $\mathbf{W} \Rightarrow \mathbf{E}$ & $\begin{array}{l}\text { PLACA } \\
\text { PARANá }\end{array}$ \\
\hline FIORI (1990) & $\begin{array}{l}\text { SL IBDI ICCĀO } \\
\text { TIPO B } \\
\text { (1 OROGÊNESE) }\end{array}$ & $\begin{array}{l}\text { CONTINENTE } \\
\text { SIIUADO A SE, } \\
\text { E ARCO MAGM- } \\
\text { TICOA NW }\end{array}$ & $\begin{array}{l}\text { BACLA } \\
\text { AÇUNGU }\end{array}$ & $\begin{array}{l}\text { BATÓLITOS } \\
\text { CUNHAPO- } \\
\text { RANGAE } 3 \\
\text { CÓRREGOS }\end{array}$ & $?$ & & ? & ? & $\mathbf{W} \Rightarrow \mathbf{E}$ & $?$ \\
\hline $\begin{array}{l}\text { REIS NETO } \\
\text { (1994) }\end{array}$ & $\begin{array}{l}\text { SUBBDICCĀ̄O } \\
\text { TIPO B } \\
\text { (3 OROCEENESES) }\end{array}$ & ? & $?$ & $\begin{array}{l}\text { CUNHAPO- } \\
\text { RANGA } \\
(750-650 \mathrm{MA}) \\
\text { TRÉS } \\
\text { CÓRREGOS } \\
(650-550 \mathrm{MA})\end{array}$ & $?$ & & $?$ & $\begin{array}{l}\text { LINEAMENTO } \\
\text { ITAPIRAPUĀ }\end{array}$ & $\mathbf{E} \Rightarrow \mathbf{W}$ & $?$ \\
\hline
\end{tabular}

Tabela 3.2 - Caracterização de diversos sítios tectônicos segundo o modelo de tectônica de placas, segundo diversos autores 


\subsubsection{MODELO DE HASUI et al. (1986)}

Hasui et al. (1986) propôs uma zona de sutura ao longo do lineamento Lancinha, com cavalgamento do bloco Vitória sobre o bloco São Paulo e transporte tectônico para norte (Ver Tabela 3.2) parece não se verificar. Este modelo é de dificil aplicação e os trabalhos posteriores tem demonstrado a sua fragilidade. Mesmo com a identificação de indicadores cinemáticos que confirmam um transporte para norte nesse trabalho, a zona de cisalhamento Lancinha se constitui numa importante zona de cisalhamento direcional, de alto ângulo. As feições estruturais associadas a esta zona de cisalhamento foram caracterizadas por Fiori (1985 a,b,c), e confirmadas por Fassbinder (1990) e Fassbinder et al. (1992, 1994), Kops et al. (1993), com a identificação de estruturas secundárias compatíveis com o modelo de Riedel ao longo do seu traçado.

\subsubsection{MODELO DE SOARES (1987)}

O modelo proposto por Soares (1987), postula uma bacia do tipo back arc Setuva, de idade do Proterozóico Médio, a qual teria sofrido a superposição da bacia Açungui, igualmente gerado em idêntico sítio tectônico, agora em tempos do Proterozóico Superior. $O$ autor admite uma subducção inicialmente do tipo $\mathrm{B}$, a qual teria evoluído para subducção o tipo $\mathrm{A}$, de oeste para leste, com a sutura situada provavelmente sob a Bacia do Paraná; o arco e ilha/magmático seria representado pelos Complexos Graníticos Cunhaporanga e Três Córregos (Ver Tabela 3.2). A existência das bacias Setuva e Açungui, com caracteristicas estruturais e de sedimentação distintas, geradas no Proterozóico médio e superior, respectivamente, não parecem ser compativeis com os dados ora disponíveis. Os dados estruturais, de metamorfismo e sedimentação, indicam a existência de uma única bacia, com a seqüência Perau, Formações São Sebastião e Água Clara compondo o nível estratigráfico basal, conforme demonstrado no presente trabalho. Neste sentido, discussões prévias foram desenvolvidas por Fiori (1990), Salamuni (1991), Salamuni et al. (1992 a,b), Fassbinder et al. (1993,1994), Spoladore (1993), Kops (1994) Reis Neto (1994) e Monteiro et al. (1994).

A interpretação da bacia Açungui como de natureza de back-arc foi corroborada por Fiori (1990) e Spoladore (1993). Porém, a falta de uma pronunciada sedimentação de origem 
vulcanogênica, gerada a partir da erupção ou da erosão da parte superior do suposto arco vulcânico/magmático Cunhaporanga - Três Córregos são argumentos contra esta interpretação. Dados recentes de datação das rochas metavulcânicas (traquitos) da Formação Abapã (Grupo Itaiacoca), através dos métodos $\mathrm{Pb} / \mathrm{Pb}$ e $\mathrm{Rb} / \mathrm{Sr}$, forneceram idades em torno de $1.250 \pm 100 \mathrm{Ma}$. (Reis Neto 1994). Idênticas idades foram obtidas pelo autor para sills básicos (metadoleritos) e mármores da Formação Bairro dos Campos (Grupo Itaiacoca), através do método $\mathrm{Pb} / \mathrm{Pb}$, com idades de $1.083 \pm 252 \mathrm{Ma}$. e $1.123 \pm 350 \mathrm{Ma}$. respectivamente; o Complexo Granítico Cunhaporanga forneceu idade $\mathrm{Rb} / \mathrm{Sr}$ de $746 \pm 45 \mathrm{Ma}$. (Reis Neto, op. cit.), possivelmente associado a um arco magmático. Portanto, a sedimentacão do Grupo Itaiacoca e, possivelmente, do Grupo Açungui, ocorreu no mesoproterozóico, enquanto a provável tectônica colisional ocorreu apenas no neoproterozóico. Por outro lado, feições de campo indicam sedimentação do tipo plataformal para as Formações Capirú e Itaiacoca, as quais foram antecedidos por sedimentos gerados em condições relativamente mais profundas, onde predominam turbiditos para a Formação Votuverava, e compondo a base da bacia, sequências de areias, turbiditos carbonáticos distais, com contribuições vulcanogênicas juntamente com formação ferrífera e mineralizações de $\mathrm{Ba}-\mathrm{Cu}-\mathrm{Pb}-\mathrm{Zn}-\mathrm{Au}-\mathrm{Ag}$ (compativeis com um modelo exalativo), além de uma seqüência de pelitos intercalados por anfibolitos na Formação Água Clara.

Os sedimentos do Grupo Açungui (entendido como tendo em sua base as sequências Perau/São Sebastião e Água Clara), apresentam características de águas calmas, com sedimentos bem retrabalhados e abundantes estruturas sedimentares preservadas, ao lado de raras brechas sedimentares e sedimentos gerados em condições de tectonismo ativo. Além disso, ocorrem poucas evidências de sedimentos vulcanogênicos nas porções superiores da bacia, compreendido pelas Formações Lajeado/Antinha, Capirú e Votuverava. Estas características apontam para uma sedimentação em uma típica bacia de margem continental passiva, conforme sugeriu Campanha (1991).

Idêntico ambiente foi sugerido por Reis Neto (1994) para os metarenitos feldspáticos da Formação Abapã, o qual não encontrou registro de verdadeiros lito-arenitos, que pudessem conferir ambiente de arco magmático/vulcânico imaturo. Desta forma, interpretou tais sedimentos como originados a partir do retrabalhamento de uma crosta continental pré-existente, situada no interior do continente ou de blocos continentais soerguidos num possivel estágio rift de geração da bacia Itaiacoca e, provavelmente, da bacia Açungui. 


\subsubsection{MODELO DE CAMPANHA et al. (1987)}

Um modelo de Tectônica de Placas alternativo foi proposto por Campanha et al. (1987) e Campanha (1991). Os autores descrevem uma subducção do tipo B de SE para NW (Ver Tabela 3.2), a qual teria evoluído para uma colisão continental (tipo A), compatível com um dos transportes tectônicos verificado nesse trabalho, de NW para SE. Porém, os autores interpretaram a Formação Perau (Formação Votuverava clássica no Estado do Paraná) como constituíndo a faixa interna de um complexo de subducção (cunha de acresção), com rochas básicas intercaladas nos metapelitos da seqüência Perau e Formação Votuverava. Contudo a deformação destas unidades é muito baixa não ultrapassando a relação de $3: 1$ (eixos $\mathrm{X}$ e $\mathrm{Z}$ do elipsóide de deformação) (Spoladore 1993; Fiori, comunicação verbal), exibindo sombras de pressão incipientes do tipo pirita, com pequena ductilidade, além de freqüentes estruturas sedimentares preservadas, geralmente com indicação de topo normal das camadas sedimentares. A Formação Iporanga foi interpretadas pelos autores sendo com depósito do tipo Wildflysch, correspondendo a faixa externa do suposto complexo de subduçãa, ou seja, a uma bacia do tipo $\mathrm{T}$ (Trench) segundo a conceituação de Kingston et al. 1983, ou ainda, a uma bacia de Fossa Abissal.

A interpretação dos conglomerados Iporanga no Estado de São Paulo e Bromado (Paraná) como depósitos gerados a partir de falhamentos ativos (wildflysch), é, no mínimo, questionável, tendo por base apenas as diferentes opiniões existentes na literatura. Esta discussão teve início na década de 40, quando Barbosa (1948) observou que os depósitos de conglomerados eram provenientes de fases erosivas posteriores à primeira fase de dobramento e de metamorfismo da Série Açungui, atribuindo-lhes ambiente costeiro. A discussão sobre uma possivel origem glacial desses metaconglomerados, proposta por Leonardos (1941) e reeditada por Soares (1987), persiste até hoje, embora Barbosa (1948) já tenha concluído que a suposta origem glacial de seus seixos não suporta um exame mais detalhado. $O$ autor não reconheceu formas típicas de "ferro de engomar", assinalando que a sua distribuição é tipicamente conglomerática e não tilítica, aspecto este que é reforçado pela natureza dos seixos, constituída essencialmente de quartzo e quartzito. Sugeriu, ainda, que as estrias e o alongamento dos seixos eram de origem tectônica, e que o seu depósito era do tipo "sedimentos orogênicos", e não de uma "moraine", conforme proposto por Leonardos (1941). 
A tentativa de Soares (1987) em identificar sedimentos glaciogênicos no pré-Cambriano do Paraná é oportuna, tendo em vista registros de um evento glacial à nível mundial no neoproterozóico (Eorola, 1994). Porém, a interpretação destes depósitos como turbiditos proximais parece ser mais coerente, com retrabalhamento de seixos de rios e dos turbiditos previamente depositados, num processo autofágico, ao longo de canyons que seccionam uma plataforma.

Campanha et al. (1987) e Campanha (1991) postularam, ainda, a existência de uma sutura entre as Formações Iporanga e Lajeado, materializada possivelmente pelo lineamento Figueira. Dados de campo mostram que esse lineamento é de alto ângulo, de pequena expressão, deformando rochas numa largura métrica a poucas dezenas de metros, com movimentação lateral direita, constituindo-se assim numa provável estrutura de Riedel do tipo $\mathrm{X}$ ou $\mathrm{P}$, ou ainda, numa falha de empurrão, associada ao lineamento Lancinha-Cubatão, conforme proposto por Fassbinder (1990) e Fassbinder et al. (1994). No Estado do Paraná, as Formações Iporanga e Perau correspondem a Formação Votuverava clássica, proposta por Bigarella \& Salamuni $(1956,58)$ e atualmente reduzida aos litotipos aflorantes entre os lineamentos Lancinha e Morro Agudo. A zona de sutura proposta por Campanha et al. (op. cit.) e Campanha (op. cit.), corresponde, nessa região, à zona de cisalhamento Morro Agudo: Novamente os dados de campo indicam para esse lineamento, características direcionais, podendo se constituir numa falha de empurrão e/ou transcorrente, associada ao Sistema de Cisalhamento Lancinha, com características transpressivas, conforme discussões de Fiori (1985), Fassbinder (1990), Spoladore (1993) e Kops et al. (1993).

Por outro lado, o não reconhecimento de associações metamórficas de alta pressão nesse modelo, tanto no Estado de São Paulo como no Estado do Paraná, constitui-se num problema reconhecido inclusive pelos autores. Nesse sentido, Spoladore (1993) identificou na região de Bromado, nas imediações do lineamento de Morro Agudo, paragêneses minerais em metamargas da Formação Água Clara, geradas com temperaturas de aproximadamente $450^{\circ}$ e pressões entre 2 e $4 \mathrm{~kb}$. Para as Formações Votuverava e Antinha, Spoladore (op. cit.) reconheceu condições de $\mathrm{P}$ e $\mathrm{T}$ ainda menores. Neste sentido, até o presente momento não se tem registros do desenvolvimento de paragêneses de alta pressão, que pudessem sugerir a presença de uma sutura na região.

Um segundo argumento que se contrapõe ao modelo de Campanha et al. (op. cit.) e Campanha (op. cit.), relaciona-se à disposição lateral das Formações Iporanga e Perau 
(Formações Votuverava clássica) com relação a uma possível sutura gerada através de uma subducção e, posterior, colisão de sudeste para noroeste. Admitindo-se que a Seqüência Lajeado corresponda a depósitos de uma bacia do tipo abissal, e que a Formação Perau se constitua num complexo de subducção (cunha de acresção), a geometria destas unidades, em relação a referida sutura (Lineamentos Figueira e Morro Agudo), exigiria uma subducção de NW para SE, ou seja, contrário ao modelo proposto pelos autores.

Além disso, os sills básicos e de corpos anfibolíticos presentes na Formação Votuverava e na Seqüência Perau, não são necessariamente indicativos da presença de crosta oceânica subductada, conforme será discutido mais adiante.

A ausência de evidências concretas de subducções do tipo B na Faixa Ribeira, durante o ciclo Brasiliano, levou Campanha et al. (1994) a reformular os modelos de 1987 e 1991, e propor dois ciclos metamórfico, corroborando assim com o modelo de Soares (1987).

Desta forma, Campanha (op. cit.) propuseram uma abertura oceânica a partir de rifteamento no início do Proterozóico Médio, com base numa datação de $\mathrm{Rb} / \mathrm{Sr}$ em sills básicos presentes na Seqüência Rio das Pedras (Formação Perau no Estado de São Paulo, ou Votuverava no Paraná), com idade de $1.745 \pm 13,8 \mathrm{Ma}(\mathrm{Ro}=0,7089 \pm 0,0001)$. Sugerem, ainda, para o Proterozóico médio, o desenvolvimento de arco de ilhas e posterior colisão continental/arco de ilhas, com base na remobilização de fluidos de chumbo (hidrotermais) por volta de 1,3 - 1,4 Ga. No Proterozóico Superior, durante o Ciclo Brasiliano, teria se desenvolvido na faixa Ribeira um forte evento termal, com metamorfismo de média pressão (Barroviano) por volta de 0,7 - 0,75 Ga., seguido de um extenso magmatismo granitóide e cisalhamento transcorrente $(0,6-0,5 \mathrm{Ga})$. Estas características foram vinculadas, pelos autores, a uma subducção/colisão presente no cinturão Dom Feliciano.

Porém, a datação de 1.745 Ma pode estar sujeito a erro de interpretação, pois os pontos amostrados não apresentam uma boa distribuição sobre a isócrona. Por outro lado, as datações de $\mathrm{Pb}$ e $\mathrm{Sr}$ em galenas, baritas e calcitas em depósitos estratiformes (tipo Perau) e veios hidrotermais (tipo Panelas ou Furnas-Lajeado) na região do vale do Ribeira (Tassinari et al. 1990), podem representar a idade de sedimentação das Sequências Perau e São Sebastião, e não necessariamente um evento de remobilização metamórfica como sugerido por Campanha et al. (op. cit.) e Tassinari et al. (op. cit.). 


\subsubsection{MODELO DE REIS NETO (1994)}

Um quarto modelo elaborado por Reis Neto (1994), propõe uma subducção de SE para NW, gerando as orogêneses Cunhaporanga e Três Córregos, através de uma possivel sutura registrada ao longo do lineamento de Itapirapuã (Ver Tabela 3.2). $\mathrm{O}$ modelo de Reis Neto (op. cit.), está embasado na conceituação teórica de Sengor (1990), tendo por base apenas o magmatismo granítico cálcio-alcalino dos Complexos Cunhaporanga e Três Córregos, e de uma possível sutura, a qual corresponde, na verdade, a um lineamento com características essencialmente direcionais, conforme caracterização efetuada por Fiori (1985). 


\section{GEOLOGIA DA ÁREA}

\subsection{INTRODUÇÃO}

Neste capítulo serão analisadas as estruturas da Formação Água Clara nas escalas mesoscópica e microscópica, através de análise geométrica e cinemática. Esta análise estrutural será correlacionada com aquelas presentes nas Formações Capirú e Votuverava, verificando-se que ocorre correspondência entre as mesmas.

Será, ainda, realizado uma análise dos ambientes de sedimentação, suportada por dados de isótopos estáveis de oxigênio e carbono. Estes dados indicam uma cronologia na sedimentação da Bacia Açungui, estando a Formação Água Clara situada na base, seguida pela Formação Votuverava e, no topo, as Formações Capirú e Itaiacoca, estas últimas depositadas de forma contemporânea. Os dados de isótopos estáveis, relações de campo e geocronológicos disponíveis na literatura, indicam uma provável idade de sedimentação do neoproterozóico inferior para o Grupo Açungui.

\subsection{ASSOCIAÇÕES LITOLÓGICAS}

\subsubsection{SEQUENCLA SERRINHA}

A Sequência Serrinha é constituída por metacalcários cinza escuros, maciços, com aparente ausência de estruturas internas (foliações metamórficas ou estruturas sedimentares). Suas rochas apresentam, algumas vezes, pirita disseminada.

Pontes (1981) relata a presença de gretas de contração e outras estruturas de águas rasas nas litologias da Sequência Serrinha. Já as estruturas sedimentares da Sequência São Silvestre indicam ambiente de águas profundas, conforme discussões no Capítulo 4.5 (Ambientes de Sedimentação). Esta discordância entre os ambientes de deposição destas unidades, sugere a existência de um hiato sedimentar e possivelmente temporal entre suas deposições.

As características de deposição em ambientes de água rasa da Sequência Serrinha, além da similaridade litológica com pacotes carbonáticos adjacentes (Sequências Saivá e Voturuvú) indicam uma provável correlação entre seus termos litológicos. Estas observações sugerem que a Sequência Serrinha possa ser desmembrada da Formação Água Clara, permanecendo nesta Formação apenas a Sequência São Silvestre, como uma entidade litológica individualizável. Os 
trabalhos de Campanha (1991), Almeida (1990), entre outros, não descrevem litologias correlacionáveis a Sequência Serrinha nos domínios da Formação Água Clara no Estado de São Paulo. Esta verificação reforça a hipótese que a Formação Água Clara seja composta apenas por litologias geradas em ambiente de águas profundas. Assim a Sequência Serrinha pode ser correlata as Formações Capirú, Votuverava e Itaiacoca, sobreposta a Sequência São Silvestre.

\subsubsection{SEQUÊNCIA SÃO SILVESTRE}

É constituída basicamente por metacalcários. Predominam níveis bandados impuros, com alternância de níveis cinza escuros e cinza claros, decimétricos a centimétricos, algumas vezes com tons marrons ou esverdeados. A estrutura é tipicamente bandada e reflete uma estrutura sedimentar plano-paralela. No topo dos leitos bandados, ocorrem finas intercalações milimétricas a centimétricas de calcários pelíticos, cinza escuros, os quais registram, em geral, lineações de intersecção, além do desenvolvimento de minerais micáceos.

Os calcários puros são subordinados e ocorrem entre os níveis bandados. Possuem cor cinza escura, com espessuras decimétricas a métricas.

$\mathrm{O}$ dois tipos de metacalcários são geralmente calcíticos, e apresentam sulfetos (pirita e calcopirita) dispostos ao longo das superficies de foliação, ou disseminados aleatoriamente na rocha, em concentrações variáveis de um lugar para outro.

Ocorrem, ainda, níveis métricos de quartzitos cinza claros, contendo granada de cor rosa clara disposta ao longo dos planos de foliação, ou de forma aleatória. Estas granadas, de composição manganesifera, conferem à rocha cor violácea típica, formando leitos rítmicos, centimétricos, alternando cores creme e cinza, quando intemperizadas.

Uma característica marcante na Formação Água Clara é a alternância de níveis centimétricos, de tons cinza claro a cinza escuro, creme ou violáceo, marrom e esverdeado, seja nos termos carbonáticos puros, seja nos impuros.

Estão presentes, ainda, calcarenitos e rochas metabásicas esporádicas. Estas últimas foram interpretadas por Pontes (1981) como sendo tufos almofadados. Porém, a ocorrência isolada na área estudada de apenas um afloramento intemperizado impossibilitou uma melhor definição deste tipo litológico.

São registrados, ainda, a ocorrência de metabasitos, na forma de possiveis sills, aflorantes sempre na forma de blocos ou de matacões ao longo de drenagens. 
São comuns ocorrências de concreções ferruginosas supergênicas, provenientes da alteração de piritas e de granadas ricas em moléculas de espessartita. Os metachert descrito por Pontes $(1981,1982)$, não foram identificados neste trabalho.

\subsection{ANÁLISE DAS ESTRUTURAS NA ESCALA MESOSCÓPICA}

\subsubsection{INTRODUÇÃO}

Na unidade São Silvestre, doravante denominada de Formação Água Clara (por entendermos que a unidade Serrinha é correlata as Formações Capirú, Votuverava e Itaiacoca, portanto, sobreposta a Formação Água Clara) distinguem-se basicamente três sistemas de deformação. O termo "sistema de deformação" é aqui utilizado no sentido de Fiori (1990), pelo seu significado mais amplo, abrigando todas as estruturas formadas num mesmo regime tectônico, compreendendo diversas estruturas planares e lineares, dobras e falhas em diversas escalas, desenvolvidas de forma contemporânea ou quase. Ainda, segundo esse conceito, algumas dessas estruturas nem sempre são penetrativas na área, podendo ocorrer de forma localizada, ora associada a alguma estrutura maior, ora representando anomalias do desenvolvimento estrutural regional. O termo "fase de deformação" foi reservado por Fiori (op. cit.) para designar um evento único, penetrativo e característico dentro da evolução estrutural da área, e será mantido com o mesmo sentido neste trabalho.

Foram realizados 4 perfis básicos, com coleta de dados estruturais: Rio da Lomba e Rio da Barra, ambos na Formação Água Clara; e os perfis Rio Branco do Sul - Voturuvú e Tunas Cerro Azul, no Grupo Açungui (Anexos III-A e II).

Nestes perfis foram coletados amostras orientadas, as quais foram laminadas em até 3 cortes cada uma, segundo os planos X-Z, X-Y e Y-Z. Tais amostras foram, posteriormente estudadas, visando a caracterização de seus aspectos geométricos, cinemáticos e metamórficos: Os resultados foram descritos segundo os Sistemas de Deformação SD $_{1}$, com as foliações $\mathrm{Ss}_{1-}$ $\mathrm{Sc}_{1}$, microdobras e lineações associadas; o Sistema de Deformação $\mathbf{S D}_{2}$ (par de foliações $\mathrm{S}_{(2)} \mathrm{C}_{(2)}$, microdobras, lineações) e o Sistema de Deformação $\mathbf{S D}_{3}$, com o desenvolvimento principalmente do par de foliações $\mathrm{S}_{-\mathrm{C}_{(3)}}$, e redução granulométrica dos minerais gerados nos eventos anteriores, com pronunciada recristalização. $\mathrm{Na}$ escala mesoscópica, os dados estruturais foram submetidos a uma análise geométrica e interpretação cinemática. 


\subsubsection{PERFIS RIO DA LOMBA E RIO DA BARRA}

Foram levantados alguns perfis básicos, entre eles o do Rio da Lomba e do Rio da Barra, ambos na Formação Água Clara, e ainda os perfis Rio Branco do Sul -Vuturuvú e Tunas - Cerro Azul, no Grupo Açungui (Ver Anexo III-A). Durante a realização destes perfis, foi efetuada uma coleta sistemática de amostras orientadas, assim como dos dados estruturais, os quais serão analisados no decorrer deste capítulo.

O perfil Rio da Lomba foi realizado no rio homônimo, situado na margem direita do Rio Açungui, para jusante, próximo das localidades de São Pedro/São Silvestre, na região que limita os municípios de Rio Branco do Sul e Campo Largo. Foram descritos 535 dados de foliação, 75 eixos de dobras e 86 lineações de intersecção (75 afloramentos), Os dados foram tratados em diagrama Schmidt-Lambert encontram-se sumarizados no Quadro 4.1.

O perfil Rio da Barra foi realizado no rio de mesmo nome, agora na margem esquerda do Rio Açungui, também para jusante. Foram obtidos 139 dados de foliações, 126 eixos de dobras e 12 lineações de intersecção. Estes dados foram igualmente tratados em estereogramas e encontram-se tabelados no Quadro 4.2 .

\subsubsection{ANÁLISE DA DEFORMAÇÃO E DO METAMORFISMO}

\subsubsection{CISALHAMENTO PRINCIPAL DO SISTEMA TRANSPRESSIVO \\ (Sistema de Deformação $S D_{l}$ )}

Esta deformação imprimiu nas rochas da Formação Água Clara foliações penetrativas, dobras fechadas a isoclinais e lineações de intersecção e de estiramento mineral. Trata-se de uma deformação gerada por mecanismos de cisalhamento simples e com características de deformação heterogênea. Desta forma, alguns níveis estratigráficos podem apresentar-se intensamente deformados, enquanto que outras, situados em suas imediações (acima, abaixo ou ao lado deste nível), podem apresentar deformações muito baixas, ou até mesmo quase indeformados, preservando parcialmente ou totalmente as estruturas sedimentares. 


\begin{tabular}{|c|c|c|c|c|c|c|c|c|c|c|c|c|c|c|c|c|}
\hline \multirow{2}{*}{$\begin{array}{c}\text { PONTO } \\
\text { No }\end{array}$} & \multicolumn{3}{|c|}{ GUIRLANDAS } & & \multicolumn{3}{|c|}{ MICRO-EIXOS } & \multirow{2}{*}{ 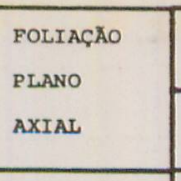 } & \multicolumn{3}{|c|}{ 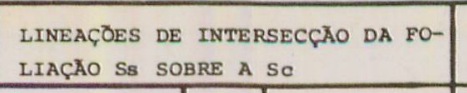 } & \multicolumn{4}{|c|}{ 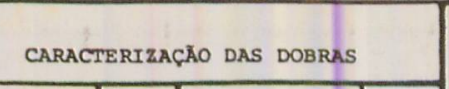 } & \multirow{2}{*}{ OBSERVACOES } \\
\hline & \begin{tabular}{|l} 
PLANCOS \\
seDTos (SC) \\
\end{tabular} & \begin{tabular}{|l} 
No 05 \\
Potos
\end{tabular} & $\begin{array}{l}\text { I DE DADOS } \\
\text { DAS ISOCCURVA } \\
\end{array}$ & & \begin{tabular}{|l|} 
MICRO-EIXOS \\
ESTATISTICOOS
\end{tabular} & \begin{tabular}{|l|l|} 
NS D D \\
DADOSO
\end{tabular} & \begin{tabular}{|l|} 
I DE DADDS \\
DAS ISOCCURVAS \\
\end{tabular} & & $\begin{array}{c}\text { II Estarts } \\
\text { TICO }\end{array}$ & \begin{tabular}{|l|l|} 
NQ D \\
DADOS \\
\end{tabular} & \begin{tabular}{|l|} 
I DE DADOS \\
DAS ISOCURV \\
\end{tabular} & $\begin{array}{c}\text { VERGES } \\
\text { CIA } \\
\end{array}$ & 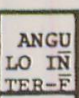 & \begin{tabular}{|l|l} 
TIPO & \\
\end{tabular} & \begin{tabular}{|l|} 
cir. \\
con.
\end{tabular} & \\
\hline \multirow{2}{*}{$\begin{array}{c}100 \\
\mathrm{a} \\
102\end{array}$} & & & & & 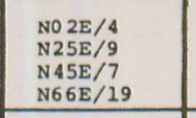 & 4 & & & $\begin{array}{l}\mathrm{N} 88 \mathrm{~B} / 13 \\
\mathrm{~S} 8 \mathrm{BE} / 12 \\
\end{array}$ & $\begin{array}{l}3 \\
3 \\
\end{array}$ & $\begin{array}{l}1,28 \\
1,22 \\
\end{array}$ & SE & - & 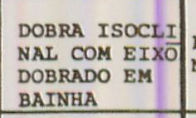 & \begin{tabular}{|l|} 
BAI- \\
MHA
\end{tabular} & \multirow{2}{*}{ 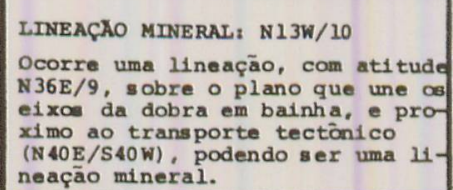 } \\
\hline & \begin{tabular}{|l|}
$\mathrm{N} 28 \mathrm{~B} / 16 \mathrm{SE}$ \\
$\mathrm{N} 22 \mathrm{~W} / 76 \mathrm{SW}$ \\
\end{tabular} & $\frac{5}{6}$ & $\frac{1,2, \ldots, 58}{1,2,3,4 t}$ & $\begin{array}{l}5888 / 5 \\
570 E / 14\end{array}$ & - & \begin{tabular}{|l|}
- \\
- \\
\end{tabular} & - & - & - & $\begin{array}{ll}- \\
-\end{array}$ & - & $\frac{3}{3}$ & $\begin{array}{l}3 \\
?\end{array}$ & \begin{tabular}{|l|} 
SUIAVEE \\
SUAVE \\
\end{tabular} & \begin{tabular}{|l|}
$\mathrm{CIL}$ \\
$\mathrm{CIL}$
\end{tabular} & \\
\hline \multirow{3}{*}{203} & - & - & - & - & väricos: NW & 12 & - & - & $\mathrm{N} 78 \mathrm{E} / 12$ & 1 & 10 & - & - & BAXNAB & BaI & \multirow{3}{*}{ 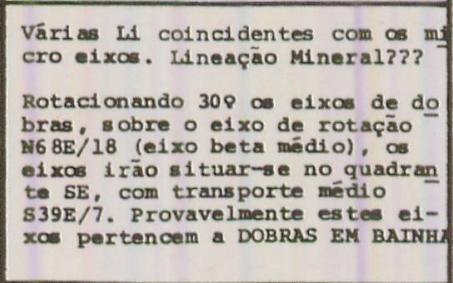 } \\
\hline & 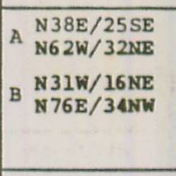 & 68 & $1,2, \ldots, 88$ & 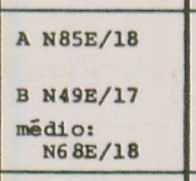 & - & - & - & - & - & $\begin{array}{ll}- \\
-\end{array}$ & - & $\begin{array}{c}\mathrm{s}-\mathrm{sB} \\
-\end{array}$ & $\begin{array}{l}1966 \\
136\end{array}$ & $\begin{array}{l}\text { SUAVE/ABBRTA } \\
\text { SUAVE/ABERTA }\end{array}$ & crr & \\
\hline & - & - & - & - & N218/36 & \begin{tabular}{|l}
- \\
\end{tabular} & - & - & $\ldots$ & -1 & - & - & - & - & - & \\
\hline $106^{\circ}$ & N5 5 W/ 0 ans & 13 & $1,2, \ldots, 100$ & - & - & - & - & - & - & - & - & - & - & - & - & \\
\hline 107 & N28w/17sw & 11 & $1,2, \ldots, 6 \mathrm{~B}$ & N6 $6 \mathrm{~W} / \mathrm{B}$ & - & - & - & - & - & -1 & - & $?$ & $?$ & $=$ & $\mathrm{cr}$ & \\
\hline 208 & \$3368/16SE & 5 & $1,2,34$ & พ6 $678 / 7$ & 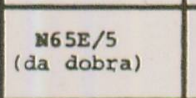 & 1 & 18 & $\mathrm{B} 70 \mathrm{E} / 6 \mathrm{5NW}$ & - & -1 & - & $\mathrm{se}$ & 2 & SUAvE & $\mathrm{crs}$ & \\
\hline \multirow[t]{3}{*}{$\begin{array}{c}109 \\
a \\
118\end{array}$} & - & - & - & - & 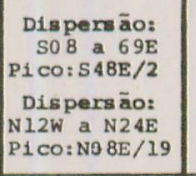 & 32 & $1,2, \ldots, 68$ & - & 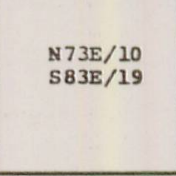 & ${ }^{10}$ & $1,2,3,4:$ & - & - & - & - & \multirow{3}{*}{ 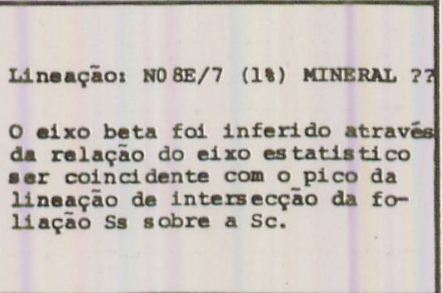 } \\
\hline & \begin{tabular}{|l|l|} 
N228W/16WE \\
\end{tabular} & 38 & $1,5,10, \ldots 3 i^{\prime}$ & $5828 / 12$ & - & - & - & - & - & -1 & - & - & - & - & $\mathrm{crI}$ & \\
\hline & - & - & - & - & - & - & - & - & N35E/07 & -1 & $1,2 \mathrm{t}$ & - & - & - & - & \\
\hline 119 & - & - & - & - & - & - & - & - & $\$ 708 / 09$ & 12 & $1,2, \ldots, 50$ & - & - & - & - & \\
\hline $\begin{array}{c}2 \\
221 \\
121\end{array}$ & N56 W/26nE & 35 & $1,5 \ldots, 218$ & $\begin{array}{l}\text { A N698/13 } \\
\text { B } \mathrm{k} 25 \mathrm{~W} / 07\end{array}$ & - & - & - & - & - & - & $=$ & $?$ & $\begin{array}{l}3 \\
3\end{array}$ & $?$ & $\begin{array}{ll}\mathrm{cm} \\
\mathrm{cm}\end{array}$ & \\
\hline & - & - & - & - & \$1664//5 & 2 & - & - & - & -1 & - & $=$ & $=$ & $=$ & $\mathrm{cr}$ & \\
\hline & - & - & - & - & N100 / 29 & 1 & - & If $5 / 50 \mathrm{om}$ & $\$ 748 / 12$ & 7 & $1,2,3,40$ & - & - & - & - & \\
\hline 122 & 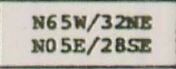 & 2 & 10 & $\mathrm{N698/24}$ & $\$ 700 / 19$ & 1 & 10 & 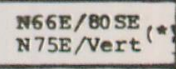 & - & - & - & $\mathrm{ss}$ & 166 & sonss & $\mathrm{cm}$ & 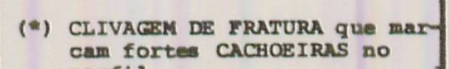 \\
\hline & $\$ x 0 \mathrm{w} / 20 \mathrm{~kg}$ & 16 & $1,3, \ldots, 98$ & $\mathrm{~N} 18 \mathrm{BW} / 15$ & - & - & - & s1aw/78sm & - & -1 & - & - & - & $\operatorname{senvE}$ & $\mathrm{cm}$ & \\
\hline 123 & R55T/17nTE & 9 & $1,3,5,70$ & \$228/16 & - & - & - & - & - & - & - & - & - & $\operatorname{senve}=$ & $\mathrm{cr}$ & \\
\hline & - & - & - & - & - & - & - & $=$ & M78E $/ 09$ & 20 & $1,2, \ldots, \pi$ & - & - & - & - & Lineaçăo Neneral: \&4SZ/10 \\
\hline & 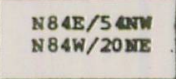 & ${ }^{30}$ & $1,4,7, \ldots, 16$ & $\begin{array}{l}\text { N79E/5 ou } \\
\text { SCIE/AB }\end{array}$ & $\mathrm{s} 78 \mathrm{E} / 9$ & 5. & $1,2,3,41$ & w $77 \mathrm{E} / 58 \mathrm{BSE}$ & 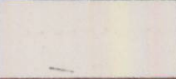 & 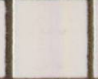 & - & $\mathrm{N}-\mathrm{NW}$ & $\begin{array}{r}146 \\
30\end{array}$ & sUAvE & $\begin{array}{c}\mathrm{cr}_{\mathrm{Cos}} \\
\mathrm{cos}\end{array}$ & \\
\hline & \begin{tabular}{|l}
$\substack{\mathrm{N} 20 \mathrm{E} / 8 \mathrm{8SE} \\
\mathrm{N} 74 \mathrm{~W} / 16 \mathrm{KE}}$ \\
\end{tabular} & 4 & 1,21 & $\mathrm{~N} 28 \mathrm{E} / 12$ & $\mathrm{N2} 2 \mathrm{E} / 14$ & 2 & 1,21 & M558/60sw & - & - & - & $\mathrm{sE}$ & 216 & ABRreta & $\mathrm{crx}$ & \\
\hline & - & $\therefore-$ & - & - & - & - & - & - & 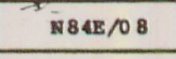 & 2 & 1.20 & - & - & - & - & \\
\hline & N666//4NE & 6 & $1,2, \ldots, 66$ & 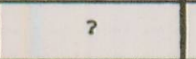 & - & - & - & - & - & -1 & - & 3 & - & 2 & - & \\
\hline & - & - & - & - & - & - & - & - & \$7TR/18 & 6 & $1,2, \ldots, 60$ & - & - & - & - & \\
\hline 127 & 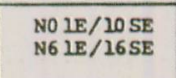 & 51. & $1,3, \ldots, 150$ & $s 79 E / 10$. & $\begin{array}{l}\mathrm{SBOE} / 72 \\
\mathbb{N} 72 \mathrm{E} / 12\end{array}$ & 2 & 19 & $\mathrm{~N} 75 \mathrm{~W} / 70 \mathrm{NB}$ & - & - & - & s-sw & 165 & suave & cII & \\
\hline & $=$ & - & - & - & - & - & - & - & $x 728 x / 12$ & 1 & 10 & - & - & $\ldots$ & - & \\
\hline 128 & 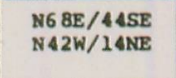 & 16 & $1,3,5,7$ & $\mathrm{NB2E} / 10$ & $\begin{array}{l}\mathbb{N} 766 / 8 \\
\mathbb{N} 01 E / 4\end{array}$ & 3 & 1,20 & N85W/49NE & $=$ & $=$ & $=$ & sor & 130 & SUAVE/ABRRe & $\mathrm{cr}$ & \\
\hline & - & - & - & - & NBQE/4 & 4 & $1,2,30$ & N85E/80NW & - & -1 & - & - & - & $\operatorname{senve}$ & cII & $\begin{array}{l}\text { Oangulo entre as } 2 \text { cononentra- } \\
\text { cinges }\end{array}$ \\
\hline & - & - & - & - & No66/1 & 6 & $1,2,3,40$ & мо ов/ $/ 90$ & $\cdots$ & - & - & - & - & sunve & $\mathrm{crm}$ & 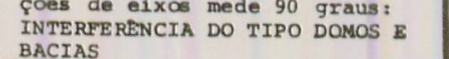 \\
\hline & - & - & - & - & - & - & - & - & $\mathrm{N} 72 \mathrm{2} / \mathrm{14}$ & 5 & $1,2,3,40$ & - & - & - & - & \\
\hline $\begin{array}{l}129 \\
137\end{array}$ & N50W/12NE & 44 & $1,5, \ldots, 250$ & 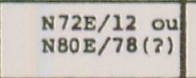 & - & - & - & - & - & - & - & $?$ & $?$ & SUAVE & $\begin{array}{l}\mathrm{cr} \\
\text { cor }\end{array}$ & 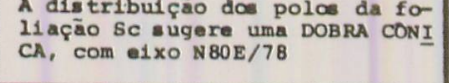 \\
\hline & - & - & - & - & - & - & - & - & $850 \% / 08$ & 4 & $1,2,31$ & - & - & - & - & \\
\hline 139 & 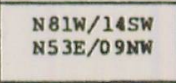 & 25 & $1,3, \ldots, 116$ & 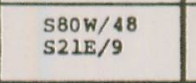 & - & - & - & 2 & $\Xi$ & $=$ & $\bar{Z}$ & 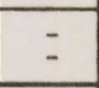 & \begin{tabular}{|l|}
45 \\
\end{tabular} & $\operatorname{sunvE}^{2}$ & cons & 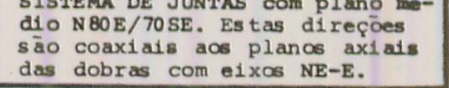 \\
\hline & - & - & - & - & - & - & - & - & M56E/09 & 5 & $1,2,30$ & - & - & - & - & \\
\hline $\begin{array}{l}\begin{array}{l}140 \\
2 \\
145\end{array} \\
145\end{array}$ & N886W/16NE & 15 & $1,3,5,7,91$ & \$66W/5 & - & - & - & - & - & -1 & - & 2 & 23 & sUNVE & $\mathrm{crI}$ & \\
\hline & - & - & - & - & \$12n/9 & 1 & ${ }^{10}$ & N12W/7TNE & - & -1 & - & - & - & - & - & \\
\hline $\begin{array}{l}138 \mathrm{a} \\
145^{\circ}\end{array}$ & 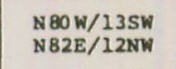 & $₫$ & $1,3 \ldots, 120$ & $L w / 70$ & - & - & - & - & - & - & - & $=$ & 27 & $=$ & con & \\
\hline & - & - & - & - & - & - & - & - & N62E/03 & 2 & 10 & - & - & - & - & \\
\hline 149 & 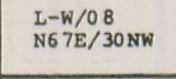 & 11 & $1,2, \ldots, 60$ & N59E/3 & - & - & - & - & - & -1 & - & $\mathrm{N}-\mathrm{N} w$ & 157 & SUAvE & cIL & \\
\hline & - & - & - & - & - & - & - & - & $\begin{array}{l}\begin{array}{l}N 65 E / 14 \\
\text { N5TE/25 }\end{array} \\
\end{array}$ & 4 & 1,21 & - & \begin{tabular}{|l|}
- \\
\end{tabular} & - & - & \\
\hline 150 & 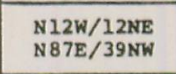 & & & N70E/11 & - & - & - & - & - & - & - & $\mathrm{s}-\mathrm{sE}$ & 180 & SUAVE & cri & $\begin{array}{l}\text { Ocorre uma dis } \\
\text { entre o e el xoe }\end{array}$ \\
\hline $\begin{array}{l}250 \\
159\end{array}$ & 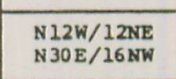 & 22 & $1,2, \ldots, 66$ & $\begin{array}{l}\mathrm{N} 1338 / 4 \\
\text { No } 0 \mathrm{~kW} / 2\end{array}$ & - & - & - & - & - & - & - & - & 153 & suave & cIL & 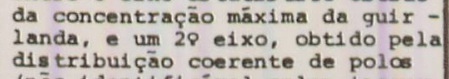 \\
\hline & 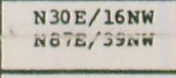 & & 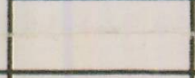 & N773w/15 & - & - & - & - & - & - & - & $s-s w$ & 196 & suave & $\mathrm{crr}$ & 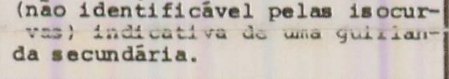 \\
\hline & - & - & - & - & - & - & - & - & N6 TE/06 & 3 & 1,21 & - & - & - & - & \\
\hline 160 & \begin{tabular}{|l}
$\mathrm{N} 87 \mathrm{~F} / 16 \mathrm{NW}$ \\
$\mathrm{N} 20 \mathrm{~W} / 5 \mathrm{NSNE}$
\end{tabular} & 16 & $1,3,58$ & м0 7w/15 & - & - & - & - & - & - & - & w & 130 & SOAVE & cII & \\
\hline 61- & N76E/30NM & 23 & $1,3, \ldots, 98$ & $\mathrm{~s} 28 \mathrm{~g} / 48$ & - & - & - & - & - & - & - & - & 15 & - & con & \\
\hline & - & - & - & - & - & - & - & - & N6 $64 \mathrm{E} / 9$ & 2 & 1,20 & - & - & - & - & \\
\hline $\begin{array}{l}\text { a } \\
171\end{array}$ & N7 3E/25NW & 29 & $1,4,8, \ldots, \ldots i$ & 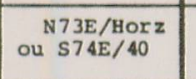 & - & - & - & - & - & - & - & 3 & - & - & $\begin{array}{l}\operatorname{crl} \\
\text { CoN }\end{array}$ & \\
\hline 172 & 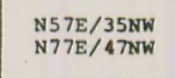 & 11 & $1,2,3,48$ & $540 E / 30$ & - & - & - & - & - & - & - & $=$ & 25 & & con & \\
\hline $\begin{array}{l}173 \\
176\end{array}$ & \begin{tabular}{|l}
$\mathrm{N} 73 \mathrm{E} / \mathrm{ANWW}$ \\
$\mathrm{N} 73 \mathrm{E} / \mathrm{TSSE}$
\end{tabular} & 24 & $1,3, \ldots, 98$ & \begin{tabular}{|l|l} 
N73E/Horz & \\
\end{tabular} & - & - & - & - & - & - & - & $s-s 8$ & 66 & FECAADA & $\mathrm{crz}$ & \\
\hline 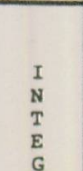 & - & - & - & - & 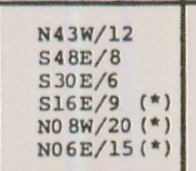 & & 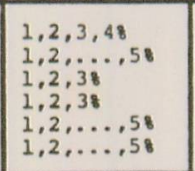 & - & 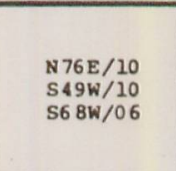 & & $\left|\begin{array}{c}1,5, \ldots \ldots, 20 . \\
1,38 \\
18\end{array}\right|$ & - & - & - & & 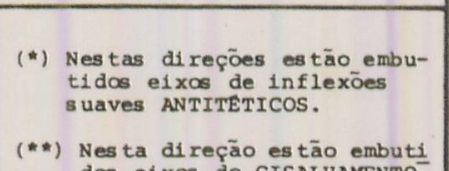 \\
\hline 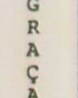 & $\mathrm{N} 61 \mathrm{~W} / 16 \mathrm{WE}$ & 535 & ${ }^{1,20} \ldots \ldots$ & 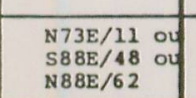 & $\begin{array}{l}\mathrm{N} 77 \mathrm{E} / \mathrm{9} \\
\mathrm{SBOE} / \mathrm{B}\end{array}$ & 75 & $\begin{array}{r}1,2,3,48 \\
18\end{array}$ & - & $\cdots$ & 86 & - & $=$ & \begin{tabular}{l|l}
2 \\
50 \\
40
\end{tabular} & \begin{tabular}{|l|} 
SUAVE/ABERRAA \\
\end{tabular} & $\begin{array}{l}\text { cin } \\
\text { con } \\
\text { con }\end{array}$ & $\begin{array}{l}\text { dos } \\
\text { PRI } \\
\text { VAL } \\
\text { VAL }\end{array}$ \\
\hline 告 & - & - & - & - & 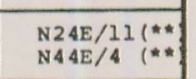 & & $\begin{array}{r}1,2,3,48 \\
1,28\end{array}$ & $\bar{z}$ & N35E/07 & & - & - & - & - & - & 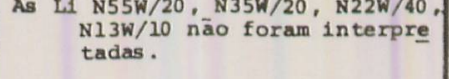 \\
\hline & - & - & - & - & 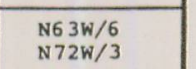 & & $1,2,3,4:$ & - & - & & - & - & - & - & & \\
\hline
\end{tabular}


Quadro 4.2

\begin{tabular}{|c|c|c|c|c|c|c|c|c|c|c|c|c|c|c|c|c|}
\hline \multirow{2}{*}{$\begin{array}{l}\text { PONTO } \\
\text { No }\end{array}$} & \multicolumn{4}{|c|}{ GUIRIANDAS } & \multicolumn{3}{|c|}{ NICRO-EIXOS } & \multirow{2}{*}{$\begin{array}{l}\text { FOLIAÇAO } \\
\text { PLANO } \\
\text { AXIAL }\end{array}$} & \multicolumn{3}{|c|}{$\begin{array}{l}\text { LINEAÇOES DE INTERSECÇAO DA } \\
\text { FOLIAÇAO SS SOBRE A SC }\end{array}$} & \multicolumn{4}{|c|}{ CARACTERIZAÇÃO DAS DOBRAS } & \multirow{2}{*}{ OBSERVA\& $O E S$} \\
\hline & $\begin{array}{l}\text { FLANCOS } \\
\text { IEDIOS (SC) }\end{array}$ & $\begin{array}{l}\text { NQ DF } \\
\text { POLOS }\end{array}$ & $\begin{array}{l}8 \text { DE DADOS } \\
\text { DAS ISOCURVAS }\end{array}$ & & $\begin{array}{l}\text { MICRO-EIXOS } \\
\text { ESTATISTICOS }\end{array}$ & $\begin{array}{l}\text { No } \\
\text { PADOS }\end{array}$ & \begin{tabular}{|l|} 
DE DADOS \\
DAS ISOCURVA
\end{tabular} & & $L \underset{\text { TICO }}{\text { ESTATIS }}$ & $\begin{array}{l}\text { NO DE } \\
\text { DADOS }\end{array}$ & $\begin{array}{l}8 \text { DE DADOS } \\
\text { DAS ISOCURVAS }\end{array}$ & $\begin{array}{l}\text { VERGEN } \\
\text { CIA }\end{array}$ & $\mid \begin{array}{ll}\operatorname{ANGGO} \\
\mathrm{LO} \\
\mathrm{TER}-\overline{\mathrm{N}}\end{array}$ & TIPO & $\begin{array}{l}\operatorname{CIL} \\
\operatorname{coN}\end{array}$ & \\
\hline $\begin{array}{c}177 \\
e \\
178\end{array}$ & $\begin{array}{l}\text { N52W/25NE } \\
\text { N42E/18SE }\end{array}$ & 7 & $1,2,38$ & S86E/13 & $\begin{array}{l}\text { S80E/09(*) } \\
(\mathrm{N85E} / 24)\end{array}$ & 2 & 18 & $\begin{array}{l}\text { N8OW/72SW }(* *) \\
\text { (DIQUE) }\end{array}$ & - & - & - & $?$ & $1: 37$ & SUAVE & CII & $\begin{array}{l}\text { o Ponto } 177 \text { faz contato com o } \\
\text { Grant to Tres Córregos. } \\
\text { (*) Eixo de dobra Fech ada. } \\
\text { (**) Dique afanitico a microgra- } \\
\text { nular, de cor cinza es cura, } \\
\text { de largura de } 0,5 \text { metros. }\end{array}$ \\
\hline \multirow{2}{*}{\begin{tabular}{r|r}
182 \\
$a$ \\
184
\end{tabular}} & & - & - & - & - & - & - & - & N65W/0 8 & 3 & $1,2,38$ & - & - & - & - & \\
\hline & N71W/31NE & 11 & $1,2, \ldots, 88$ & (A) N 70 W/Hor. & N6 3W/05 & 1 & 18 & - & - & - & $=$ & 3 & $?$ & SUAVE (?) & CIL & \\
\hline $\begin{array}{c}190 \\
a \\
193\end{array}$ & $\begin{array}{l}\text { N71W/32NE } \\
\text { N77E/39NW }\end{array}$ & 16 & $1,2, \ldots, 68$ & $\begin{array}{l}\text { (A) N70W/03 } \\
\text { (A') S85W/06 } \\
\text { (B) N24E/32 }\end{array}$ & $\bar{z}$ & $\bar{z}$ & $\bar{z}$ & $\bar{z}$ & $\overline{-}$ & $\bar{z}$ & $\bar{z}$ & $?$ & $?$ & $\begin{array}{l}\text { SUAVE } \\
\text { SUAVE }\end{array}$ & $\begin{array}{l}\text { CIL } \\
\text { CII }\end{array}$ & $\begin{array}{l}\text { Dispersão entre os elxos beta } A \\
\text { e } A^{\prime} \text { de } 25 \text { graus. } \\
\text { Eixo derado por dispersão (B) }\end{array}$ \\
\hline \multirow{2}{*}{$\begin{array}{c}179 \\
a \\
193\end{array}$} & - & - & - & - & - & - & - & - & $\mathrm{N} 69 \mathrm{w} / 06$ & 4 & $1,2,38$ & - & .. & - & - & \multirow{2}{*}{$\begin{array}{l}\text { O elxo es tatistico (B) fol } \\
\text { a partir da dispersao da gais } \\
\text { da com eixo estatistico (A) } \\
\text { Angulo entre os eixos A e B: }\end{array}$} \\
\hline & $\mathrm{N} 76 \mathrm{~W} / 32 \mathrm{NE}$ & 48 & $1,3, \ldots, 298$ & $\begin{array}{l}\text { (A) } \mathrm{N6} 8 \mathrm{WW} / 04 \\
\text { (B) } \mathrm{N} 24 \mathrm{E} / 29\end{array}$ & $\mathrm{~N} 63 \mathrm{~W} / 5$ & 1 & 18 & - & $=$ & $=$ & $\overline{-}$ & $?$ & $?$ & SUAVE & CIL & \\
\hline \begin{tabular}{c|}
194 \\
$a$ \\
197
\end{tabular} & - & - & - & - & - & - & - & - & N85W/0 8 & 2 & 18 & - & - & - & - & \\
\hline $\begin{array}{r}198 \\
202\end{array}$ & $\mathrm{~N} 82 \mathrm{~W} / 32 \mathrm{NE}$ & 27 & $1,5, \ldots, 208$ & $\mathrm{~N} 10 \mathrm{E} / 42$ & - & -1 & - & - & - & - & - & - & .. & - & CIL & $\begin{array}{l}\text { O elxo es tatis tico apresent. } \\
\text { mexgulho elevado com relack } \\
\text { queles de DOBRAS ESCALONADA. }\end{array}$ \\
\hline \multirow{2}{*}{$\begin{array}{l}203 \\
a \\
209\end{array}$} & - & - & - & - & - & - & - & - & $N 40 E / 14$ & 1 & 18 & - & .. & - & - & \\
\hline & $\begin{array}{l}\mathrm{N} 84 \mathrm{E} / 27 \mathrm{NW} \\
\mathrm{N} 48 \mathrm{~W} / 12 \mathrm{NE}\end{array}$ & 21 & $1,2, \ldots, 78$ & $\mathrm{~S} 80 \mathrm{E} / 70$ & $\begin{array}{l}\text { No } 5 E / 41 \\
\text { S20W/38 }\end{array}$ & 2 & 28 & - & - & - & - & - & $: 10$ & - & CON & \\
\hline \multirow{2}{*}{213} & - & - & - & - & - & - & - & - & $\mathrm{N} 48 \mathrm{E} / 30$ & 1 & 18 & - & - & - & - & \\
\hline & $\mathrm{N} 12 \mathrm{~W} / 32 \mathrm{NE}$ & 3 & $1,2,38$ & $\mathrm{~N} 48 \mathrm{E} / 27$ & - & - & - & - & - & - & - & $?$ & 7 & $?$ & CIL & \\
\hline $210 \mathrm{a}$ & $\begin{array}{l}\mathrm{N} 14 \mathrm{~W} / 24 \mathrm{NE} \\
\mathrm{N} 16 \mathrm{~W} / 76 \mathrm{NE}\end{array}$ & 16 & $1,2,3, \ldots, 78$ & N32W/09 & - & - & - & - & - & - & - & șw-w & 73 & - & CON & \\
\hline \multirow{2}{*}{219} & - & - & - & - & - & - & - & - & N6 $3 E / 11$ & 2 & 18 & - & -. & - & - & \\
\hline & $\mathrm{N} 76 \mathrm{E} / 24 \mathrm{NW}$ & 8 & $1,2,3,48$ & N71W/13 & $\begin{array}{l}\mathrm{N} 83 \mathrm{E} / 10 \\
\mathrm{~S} 84 \mathrm{~W} / 08\end{array}$ & 120 & $\begin{array}{l}1,5, \ldots, 328 \\
1,5,10,128\end{array}$ & - & - & - & - & - & $:$ & SUAVE & CIL & \\
\hline \multirow{2}{*}{$\begin{array}{l}\text { IN- } \\
\text { TE- } \\
\text { GRA } \\
\text { CRAO }\end{array}$} & - & - & - & - & - & - & - & - & N6 $7 w / 06$ & 12 & $1,2,38$ & - & - & - & - & \multirow[b]{2}{*}{ (*) Provavelmente. } \\
\hline & $\mathrm{N} 78 \mathrm{~W} / 36 \mathrm{NE}$ & 139 & $1,5, \ldots, 208$ & $\mathrm{~N} 80 \mathrm{E} / 15$ & $\begin{array}{l}\mathrm{N} 83 \mathrm{E} / 09 \\
\mathrm{S21W/30}\end{array}$ & 126 & $\begin{array}{l}1,5,9, \ldots, 29 \\
1,5,98\end{array}$ & - & - & -- & - & $?$ & $p$ & SUAVE (*) & CII & \\
\hline
\end{tabular}

NA COLUNA DA CARACTERIZAÇÃO DAS DOBRAS: CIL - DOBKA CILINDRICA; CON - DOBRA CONICA

SUAVE/ABERTA - LIMITE ENTRE DOBRA SUAVE E ABERTA (120 graus)

COLUNA ANGULO INTER-FLANCO - QUANDO SE TRATA DE DOBRAS CONICAS,

FORNECIDO O 2NGULO DE ABERTURA

DAS DOBRAS (ANGULO ENTRE O EIXO E

UM FLANCO DA IOBRA). 


\section{$L E G E N D A$ dos quadros 4.1 e 4.2}

\begin{tabular}{|c|c|}
\hline $\mathrm{C}_{\mathrm{st}}$ & $\begin{array}{l}\text { Cisalhamento Principal como resultado da componente de Cisalhamento puro dentro de um } \\
\text { Sistema Transpressivo; }\end{array}$ \\
\hline $\mathrm{D}_{\mathrm{st}}$ & $\begin{array}{l}\text { Dobras Suaves a Abertas (até fechadas), com eixos NE-E, associadas a componente de } \\
\text { Cisalhamento Simples de um Sistema Transpressivo. }\end{array}$ \\
\hline $\mathrm{ST}_{\text {Princ }}$ & $\begin{array}{l}\text { Sistema Transcorrente Principal, com movimento lateral direito associado: (D) Dobras } \\
\text { Escalonadas;(A) Falhas/Fraturas e suaves inflexões de litologias ao longo de } \\
\text { direções antitéticas; (componente de cisalhamento simples de um Sistema } \\
\text { Transpressivo; }\end{array}$ \\
\hline $\mathrm{ST}_{\text {Reat }}$ & $\begin{array}{l}\text { Reativação do Sistema Transcorrente, com movimento lateral esquerdo associado; } \\
\text { (D) Dobras suaves escalonadas, num Sistema Transpressivo. }\end{array}$ \\
\hline
\end{tabular}

a) Foliações $\mathrm{S}-\mathrm{C}_{(1)}$

De uma maneira geral constitui-se numa feição penetrativa e bem desenvolvida em todas as litologias estudadas. Nas rochas estudas, distingue-se uma primeira foliação, a qual dispõe-se, em geral, de forma paralela ou subparalela ao acamamento sedimentar. Este acamamento é marcado pela alternância centimétrica a métrica de níveis de mármore calcítico, ora mais puro ou mais impuros (meta-margas), além da presença de níveis quartzosos, granatíferos e de finas intercalações de metapelitos. Esta foliação, identificada neste trabalho como uma estrutura $\mathrm{Sc}_{(1)}$, apresenta uma lineação de intersecção situada sobre sua superficie, igualmente penetrativa, gerada pela intersecção de uma segunda, disposta de forma oblíqua a anterior, qualificada de estrutura $\mathrm{Ss}_{(1)}$.

Em níveis muito deformados, a foliação $\mathbf{S s}_{(\mathbf{1})}$ foi paralelizada a $\mathbf{S c}_{(1)}$, denotando um acentuado deslocamento ao longo desta superfície. A estes níveis associam-se dobras cerradas/isoclinais, dobras em bainha, dobra redobradas, estiramento mineral intenso, além de uma associação mineral característica. Em outros níveis, quando a deformação é menor, ocorrem estruturas $\mathbf{S c}_{(1)}$ típicas, com a inflexão da foliação $\mathbf{S s}_{(1)}$ ao longo dos planos de cisalhamento $\mathrm{Sc}_{(1)}$, constituindo-se assim num indicador cinemático seguro. Estas feições foram identificadas com segurança nos afloramentos ED 100, 141, 204, 205, 219, entre outros, conforme desenhos esquemáticos das Figuras 4.1 e 4.2, indicando transporte tectônico para sul. Esta heterogeneidade da deformação preservou estruturas sedimentares em alguns níveis litológicos, tais como estratificações plano-paralelas. Por outro lado, quando a deformação é muito intensa, aparecem 


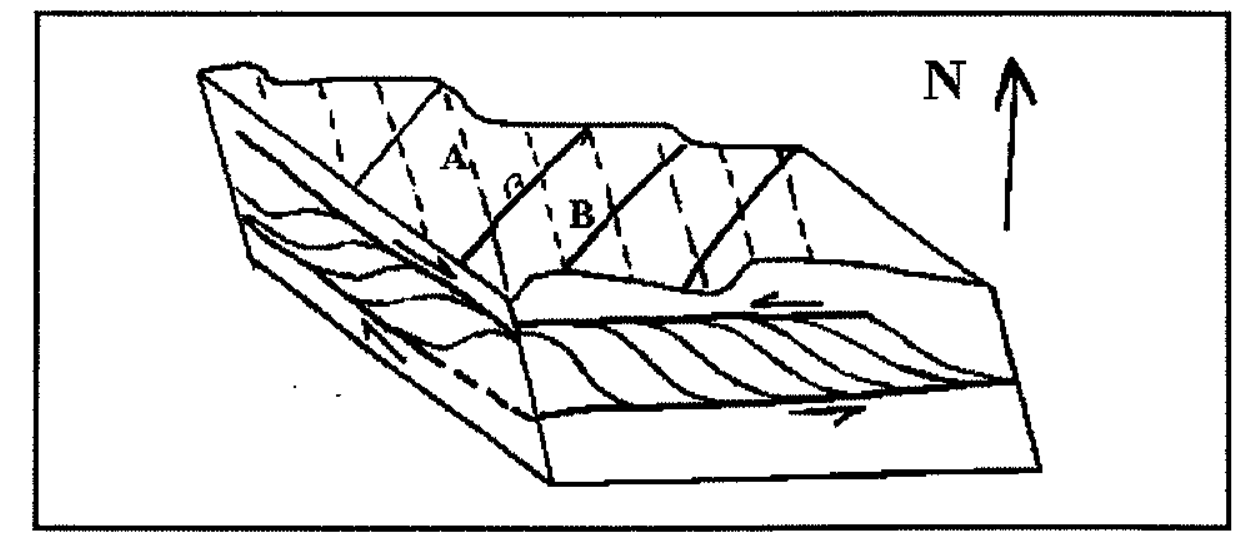

Figura 4.1 - Representação esquemática da presença de cisalhamento simples no afloramento ED 100, com transporte tectônico par sul, paralela a subparalela a lineação mineral $\mathrm{N} 13 \mathrm{~W} / 10^{\circ}$ (escala de afloramento)
A - Lineação mineral, $\mathrm{N} 13 \mathrm{~W} / 10^{\circ}$
B - Lineação de intersecção da foliação Ss sobre a Sc, N35E/10 .

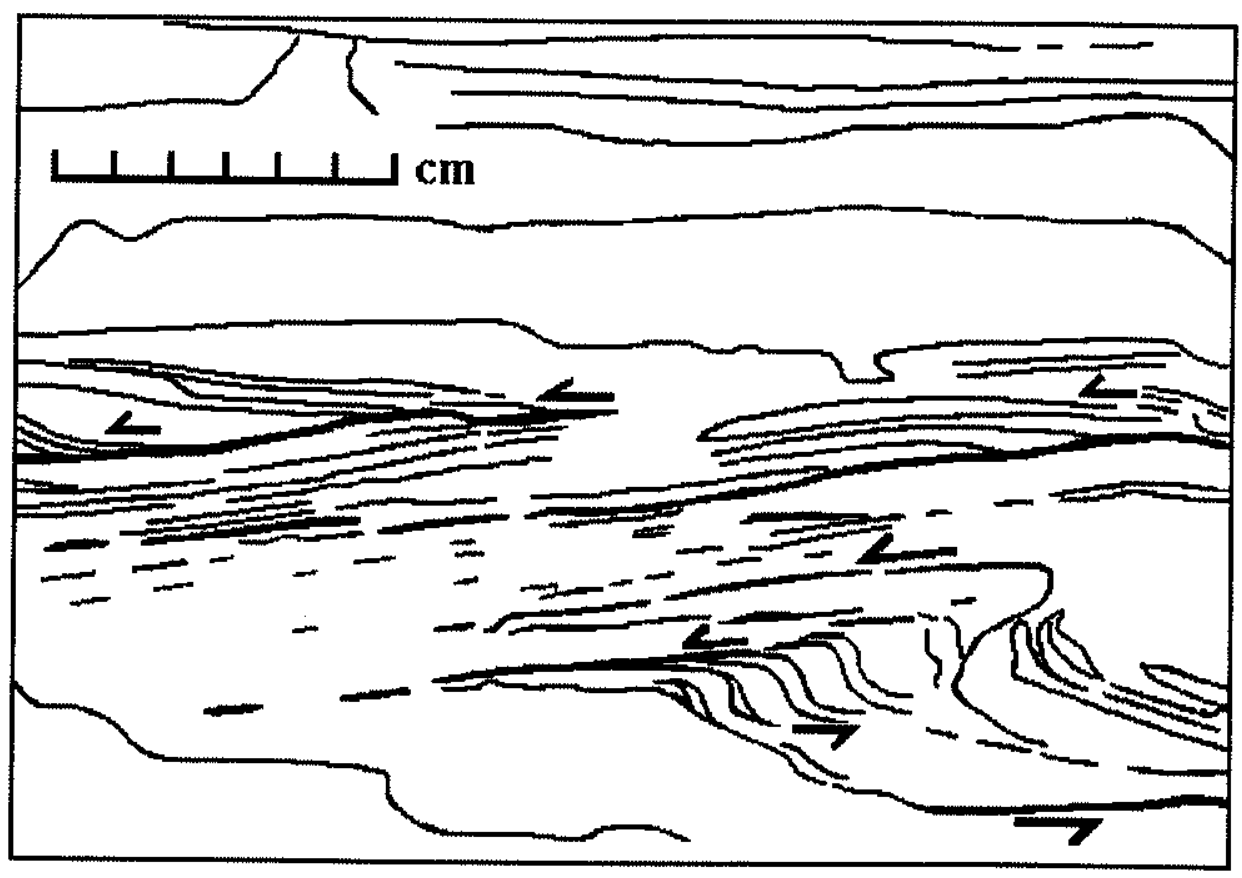

Figura 4.2 - Estruturas S-C associadas ao cisalhamento principal do sistema transpressivo. Desenho obtido a partir de amostra sem orientação do afloramento ED 204.

feições com desenvolvimento de possíveis dobras em bainha, a exemplo de que é representado na Figura 4.3. Estas feições apresentam-se na escala decimétrica a métrica, podendo evoluir para importantes zonas de cisalhamento da ordem de dezenas de metros de largura. 


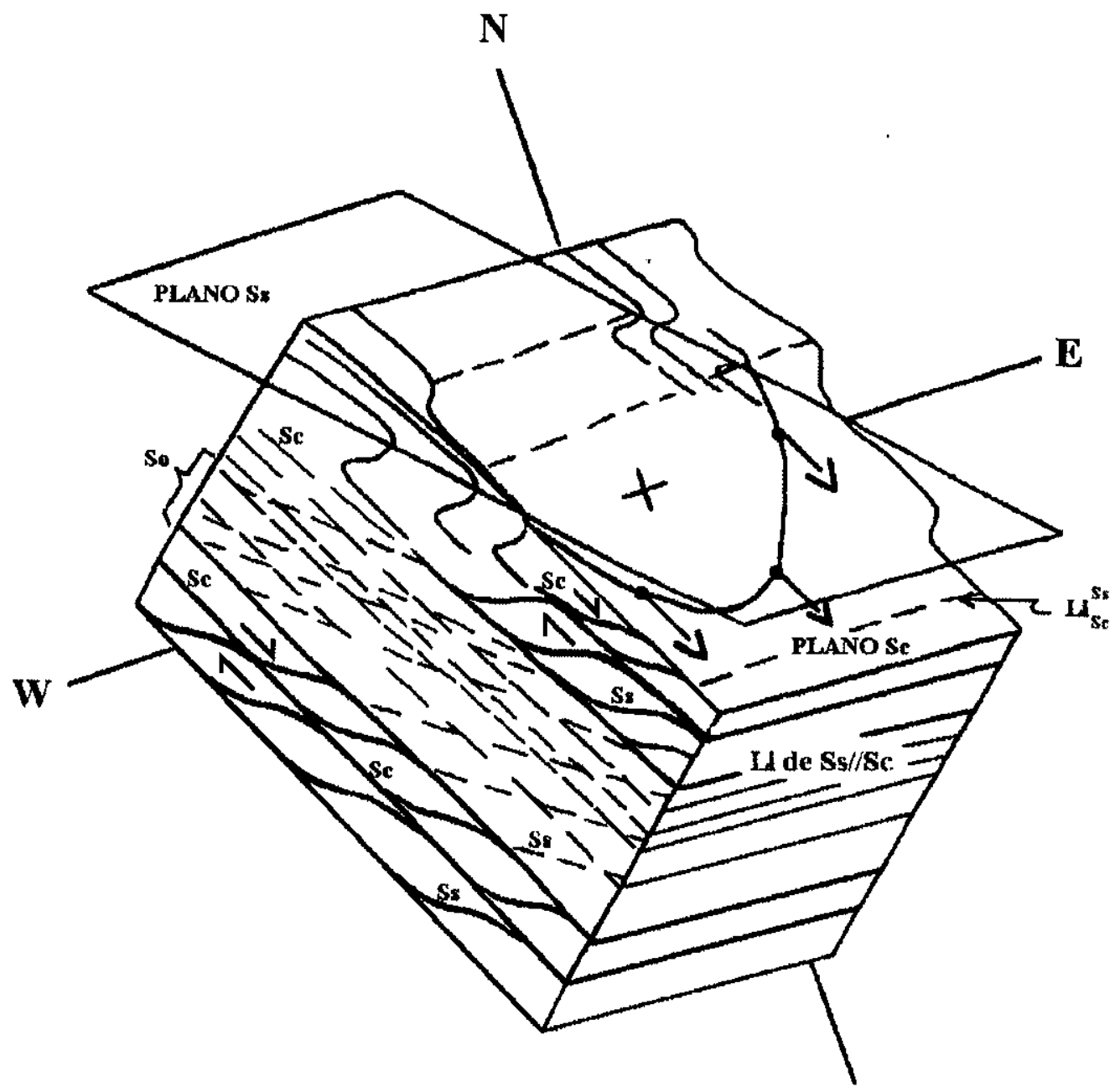

Figura 4.3 - Desenho esquemático do estilo de deformação presente na Formação Água Clara, com dobras-falha. cisalhamento e, possivelmente, dobras em bainha, indicando transporte tectônico para S-SE. Salienta-se que, para facilitar a visualização, diagrama foi construido com o plano principal de cisalhamento e demais estruturas compressivas. caindo para sudeste.

Numa terceira situação, a deformação é relativamente mais fraca do que a das deformações anteriores, produzindo pequeno deslocamento entre pacotes rochosos ao longo das superfícies de cisalhamento. Neste caso, as duas foliações são oblíquas e formam um ângulo ao redor de $30^{\circ}$. $\mathrm{Na}$ análise das relações de superposição destas duas superficies de cisalhamento $\left(\mathrm{Ss}_{1}\right.$ e $\left.\mathrm{Sc}_{1}\right)$, muitas vezes é difícil determinar a relação cronológica de geração 
ângulo ao redor de $30^{\circ}$. $\mathrm{Na}$ análise das relações de superposição destas duas superfícies de cisalhamento $\left(\mathrm{Ss}_{1}\right.$ e $\left.\mathrm{Sc}_{1}\right)$, muitas vezes é dificil determinar a relação cronológica de geração entre as mesmas, dificuldade encontrada por Fiori (Comunicação verbal) em todo o Grupo Açungui.

$\mathrm{O}$ conjunto de foliações, referidas como $\mathrm{SC}_{(1)}$, caracteriza-se muitas vezes como uma clivagem ardosiana, a qual é marcada pelo desenvolvimento de finas palhetas de biotita, muscovita e sericita. Por outro lado, este mesmo conjunto de estruturas, na presença de minerais micáceos melhor desenvolvidos, passa-se a se constituir numa xistosidade, ocasião em que os filossilicatos passam a ser visiveis a olho nú.

Podem estar presentes, ainda, sulfetos como pirita, calcopirita e possivelmente, ouro, este último detectado através de geoquímica de sedimentos de corrente (Mineropar, inédito). Estes minerais, de provável origem sedimentar, migraram, em parte, através de descontinuidades das rochas, em consequência da deformação por cisalhamento simples e concentrando-se ao longo de foliações metamórficas ou de zonas de alivio de tensão (direção do eixo $\mathrm{X}$ do elipsóide de deformação).

É interessante observar que na Formação Água Clara, especificamente a Fácies São Silvestre de Pontes (1981), quando bordeja o Complexo Três Córregos, a foliação $\mathrm{Sc}_{(1)}$ ocorre com disposição geralmente subhorizontal. Pode ocorrer, ainda, em núcleos antiformais, conforme será discutido no decorrer do trabalho. Por outro lado, em domínios clássicos do Grupo Açungui e correlatos (Formações Capirú, Votuverava, Itaiacoca) esta foliação apresenta mergulhos de alto ângulo $\left(>60^{\circ}\right)$ a subverticais, na maioria dos afloramentos (70\% das situações). Estas observações de campo serão analizadas de forma mais detalhada durante o trabalho.

As relações geométricas entre as foliações $\mathrm{Ss}_{(1)}$ e $\mathrm{Sc}_{(1)}$, juntamente com a natureza cisalhante deste última em relação à primeira, constituiu-se num critério seguro na determinação do transporte tectônico para sul na maioria dos afloramentos. Os valores angulares entre estas foliações, variaram em torno do ângulo médio de $30^{\circ} \pm 15$, o qual é compativel com o valor determinado teoricamente por Simpson (1983) e Simpson \& Schmidt (1986).

\section{b) Dobras}

Estas estruturas ocorrem na escala decimétrica/centimétrica, tendo sido registradas na escala de afloramento. São dobras de perfis fechados a isocinais, mostrando espessamento de charneiras e adelgaçamento de flancos. A superficie axial normalmente não é retilínea, aspecto 
este comum em dobras geradas por cisalhamento. Possuem uma geometria cilíndrica e, possivelmente, cônica (ou entre cilíndrica e cônica ?). São estruturas dúcteis, limitadas a um determinado nível litológico, os quais foram deformados com maior intensidade do que os demais níveis.

Estas dobras são caracteristicamente limitadas por planos de foliações de natureza cisalhante $\left(\mathrm{Sc}_{1}\right)$, os quais normalmente rompem um dos seus flancos (dobras-falha). Esta estrutura possui, de maneira geral, uma disposição paralela ao acamamento metassedimentar (Figura 4.4), conforme verificado nos afloramentos 127 e 204.

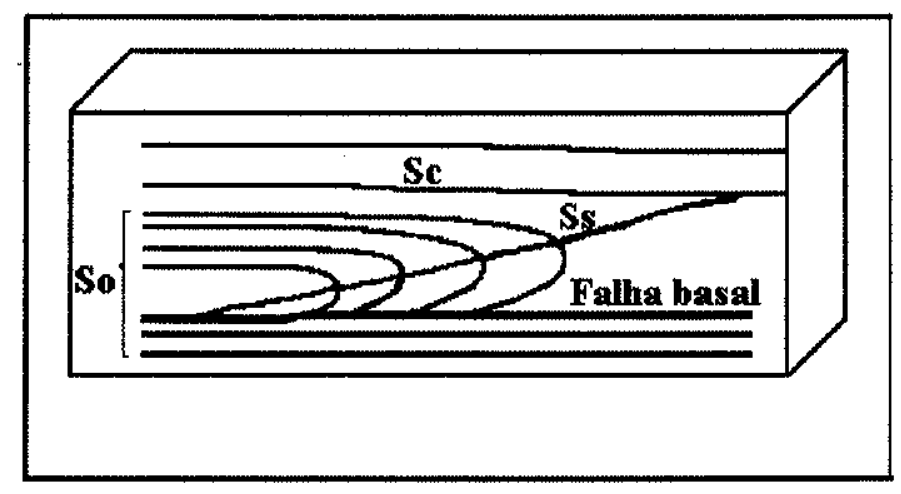

Figura 4.4 - Desenho esquemático de uma dobra-falha gerada por deformação dúctil, mostrando suas relações com as foliações $\mathrm{S}-\mathrm{C}_{(1)}$.

A superficie dobrada é o acamamento sedimentar, com a foliação plano axial passando a se constituir numa estrutura $\mathrm{Ss}$, a qual sofre inflexão ao longo superficie de cisalhamento ( $\mathrm{Sc}$ ), conforme indicado no desenho acima.

Estas estruturas se constituem num indicador cinemático seguro, indicando em geral sentido de transporte para sul.

Estes níveis deformados podem variar desde espessura centimétricalmétrica até decamétricalhectométrica, na forma de descontinuidades que podem evoluir para zonas de cisalhamento, zonas de descolamento ou de falhas. Estas estruturas não foram reconhecidas, neste trabalho, nas imagens de satélite ou fotografia aérea . Porém, são esperadas nesta escala, pois foram identificadas nas escalas meso e microscópica. Além disso, Fiori (1990) reconheceu estas estruturas no Grupo Açungui, mais precisamente nos arredores de Curitiba, em mapas litoestruturais (Fiori \& Salamuni, 1995). A geometria destes dobramentos podem ser vistos, ainda, nos desenhos das Figura 4.5 e Figura 4.6, obtidos de amostras devidamente cortadas. 
indicação de transporte tectônico para sul. Tais dobras são limitas por superficies de cisalhamento (Fotografia 4.2 e Figura 4.7A), com o aparecimento de dobras redobradas, formando padrões de interferência do tipo do tipo 1 ("caixa de ovos") de Ramsay (1967). Podem evoluír para dobras acilíndricas, muitas vezes na forma de dobras em bainhas (Figura 4.7B), assim

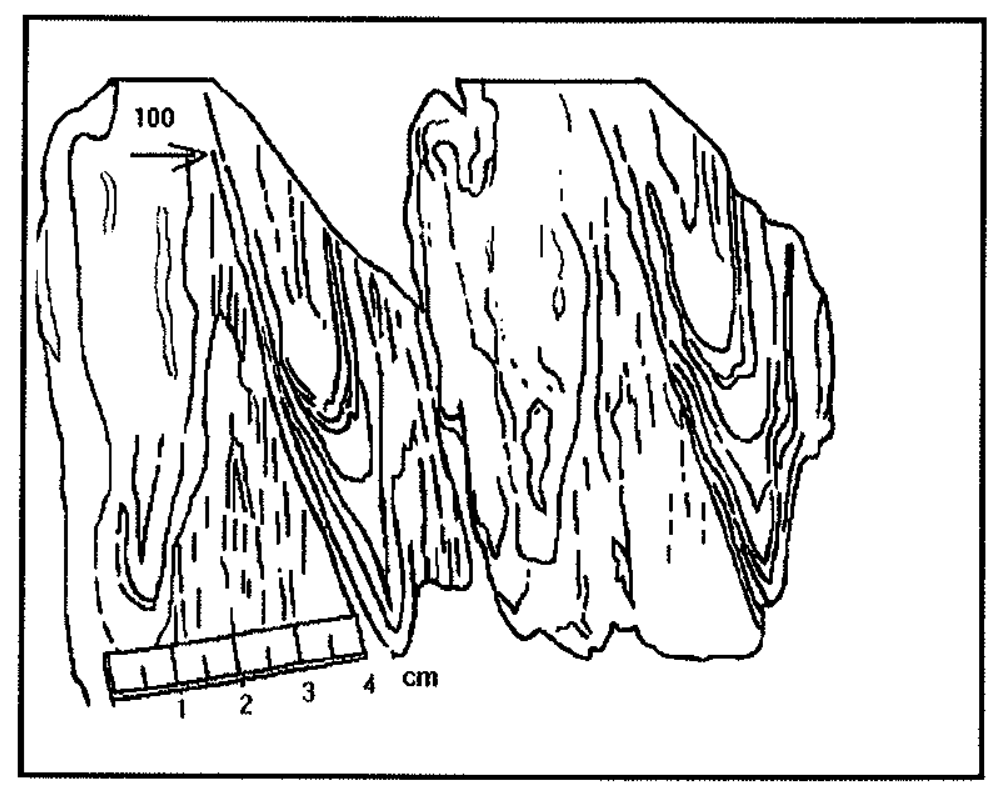

Figura 4.5 - Dobras geradas por cisalhamento no Afl. ED 100. Trata-se de deformação dúctil, com o rompimento de um dos flancos da dobra.

Desenho obtido a partir de fotografia de corte de serra,em amostra de mão.

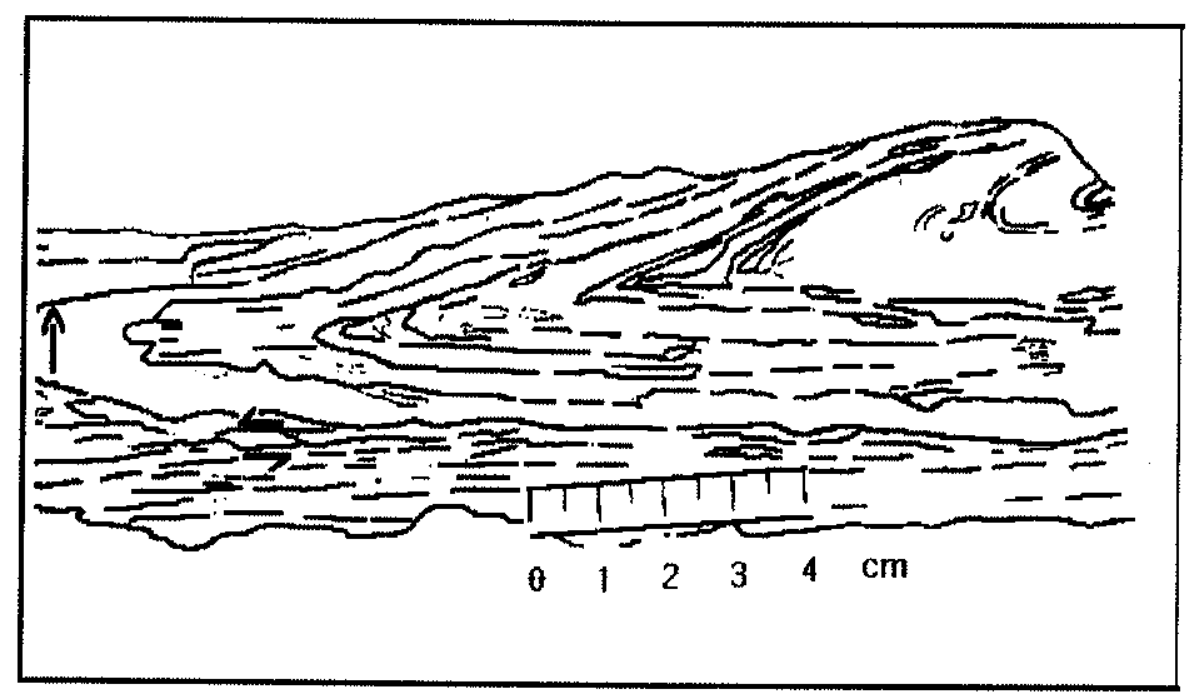

Figura 4.6 - Dobras geradas por cisalhamento no afloramento ED $120(3)$. 
como veios de quartzo discordantes da foliação principal, deformados de forma progressiva, sugerindo a interveniência de mecanismos de deformação progressiva sobre estas rochas (Figura 4.7C)

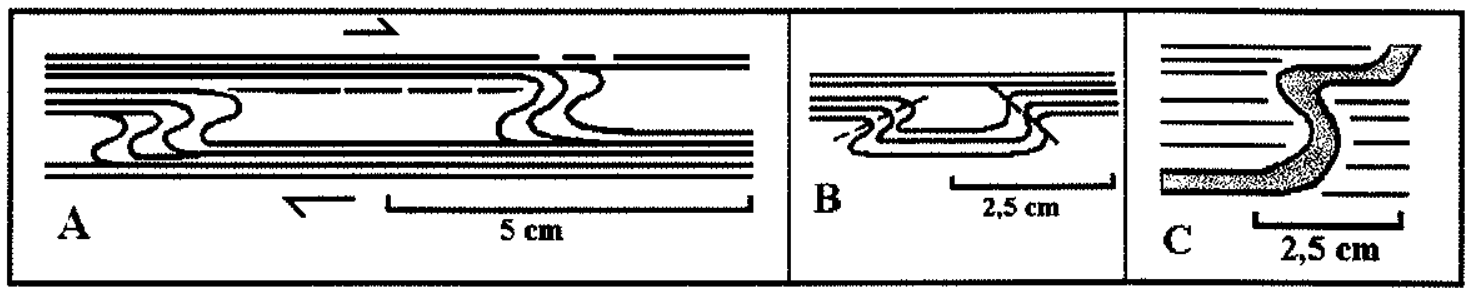

Figura 4.7 - Desenhos esquemáticos de camadas de rochas carbonáticas impuras intensamente deformadas no afloramento ED 111.

A - Dobras com indicador cinemático, com transporte para sul;

B - Feições de possíveis dobras em bainha, mostrando a seç̧̃̃o Z-Y do elipsóide de deformação;

C - Veio de quartzo disposto de forma discordante com relação as estruturas mais deformadas, sofrendo dobramento de forma menos intensa na sequência da história deformacional da rocha.

A presença de frequentes dobras fechadas a isoclinais nesta faixa de considerável deformação (Afloramento ED 111) permitiu a confecção de um estereograma com 32 eixos de dobras (Figura 4.8). A análise do estereograma permitiu identificar dois setores de dispersão dos eixos, um no quadrante sudeste entre S08-69E, com um pico estatístico S48E/02 ${ }^{\circ}$ associado, o qual possui continuidade no quadrante noroeste, situado entre $\mathrm{N} 24 \mathrm{~W}$ e N64W, com concentração máxima N48W/horizontal. E uma segunda concentração, situada entre $\mathrm{N} 12 \mathrm{~W} / 02^{\circ}$ a $\mathrm{N} 24 \mathrm{E}$ noroeste, com um máximo em N08E $/ 19^{\circ}$. É provável que as concentrações máximas $\mathrm{N} 48 \mathrm{~W} /$ horizontal e $\mathrm{N} 08 / 19^{\circ}$ mostrem uma trajetória de migração centrípeta sobre a borda noroeste do diagrama, mostrando um estágio de evolução de dobras em bainhas. Embora não tenham sido identificadas lineações minerais ou de estiramento mineral, é provável que o transporte tectônico desta dobras tenha ocorrido no sentido de noroeste para sudeste, ou até de norte para sul, provavelmente coincidentes com o transporte identificado por Fiori (1990) para o Grupo Açungui.

Em zonas em que esta deformação é menos acentuada, os eixos destas dobras parecem ter comportamento geométrico idêntico ao do afloramento anterior. Isto ocorre no afloramento ED 


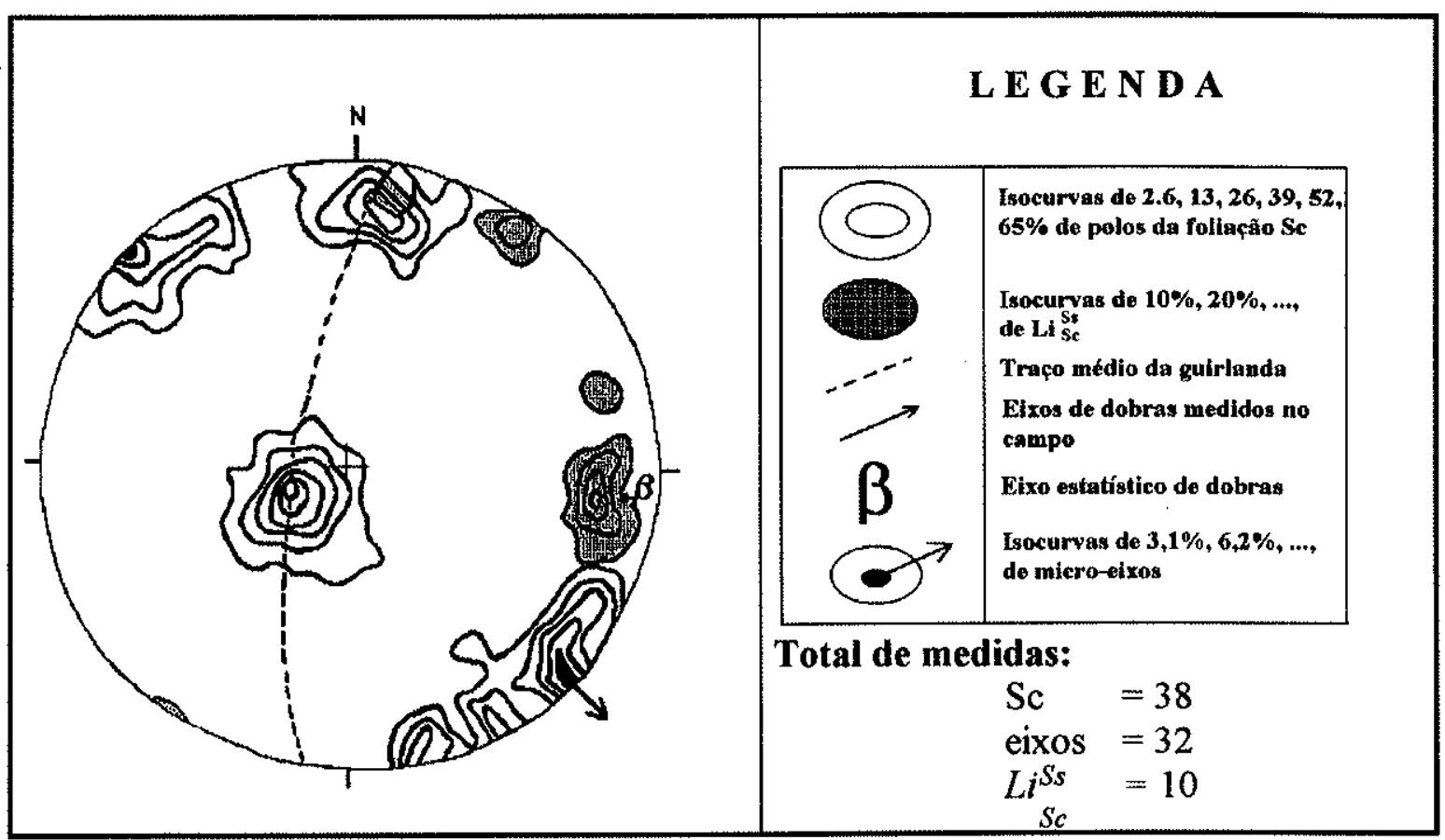

Figura 4.8 - Diagrama Schmidt-Lambert com a distribuição dos eixos de dobras fechadas a isoclinais do afloramento ED 111, além dos pólos da foliação Sc paralela a So, eixo estatístico $\beta$ e a Li ${ }_{S c}$, correspondente aos afloramentos ED 109 a 118.

103, onde os eixos situam-se nos quadrantes NW-NE. Tendo em vista que estas estruturas foram dobradas por dobras de perfis suaves a abertos, (ângulo interflancos ao redor de $33^{\circ}$ ), foi efetuado o desdobramento destas estruturas segundo um eixo de rotação $\mathrm{N} 68 \mathrm{E} / 18^{\circ}$ (eixo $\beta$ médio das dobras). Após as operações de rotação, os eixos de dobras anteriores passaram a ocupar uma nova posição no diagrama no quadrante SE, indicando um transporte idêntico ao do afloramento anterior (ED 111 , Figura 4.9).

Transporte similar foi também verificado nos afloramentos ED 100, 101 e 102, onde as lineações minerais com pequeno ângulo de caimento situadas no flanco de uma dobra cerrada a isoclinal, no quadrante N-NW, indicam transporte para S-SE (Figura 4.10), com vários eixos dispostos num plano no quadrante NE, sugerindo uma possível dobra cônica, com transporte para S-SW, conforme ilustrado no desenho esquemático da figura.

Considerando a disposição dos eixos de dobras nos diagramas das Figura 4.8, Figura 4.9 e Figura 4.10, juntamente com a ductilidade com que estas estruturas foram geradas, nota-se que os eixos geométricos (b) das dobras tendem a se dispor paralelos ao eixo $\mathrm{X}$ do elipsóide de deformação, sugerindo, em alguns locais, a formação de dobras em bainha. 


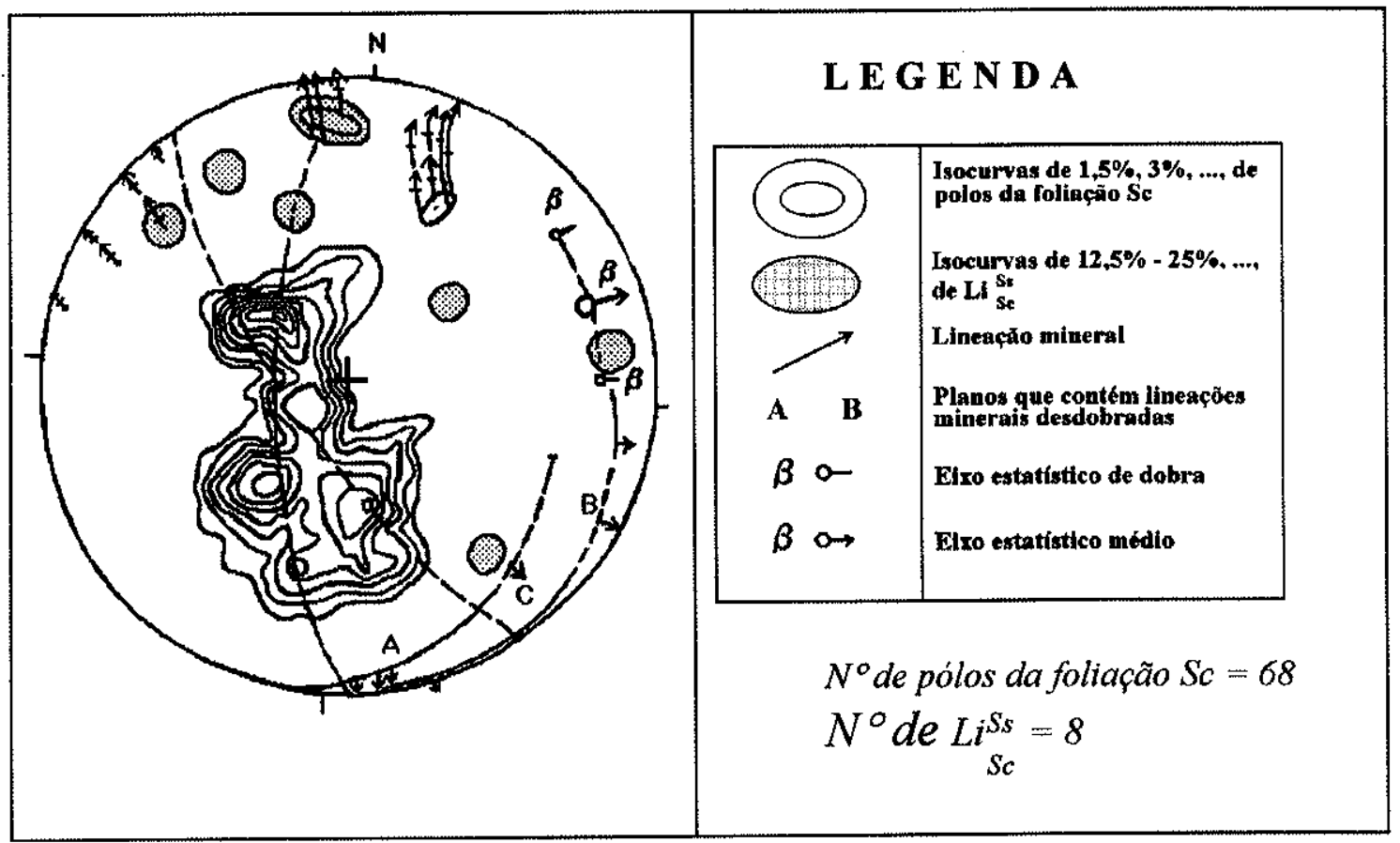

Figura 4.9 - Diagrama mostrando a disposição dos eixos de dobras do quadrante noroeste, rotacionadas para o quadrante sudeste. Além disso, o diagrama mostra a distribuição dos pólos da foliação $\mathrm{Sc}_{1} / / \mathrm{S}_{\mathrm{o}}$, eixo de dobras estatístico, e a lineação Li $_{S c}^{S s}$ (Afloramento ED 103).

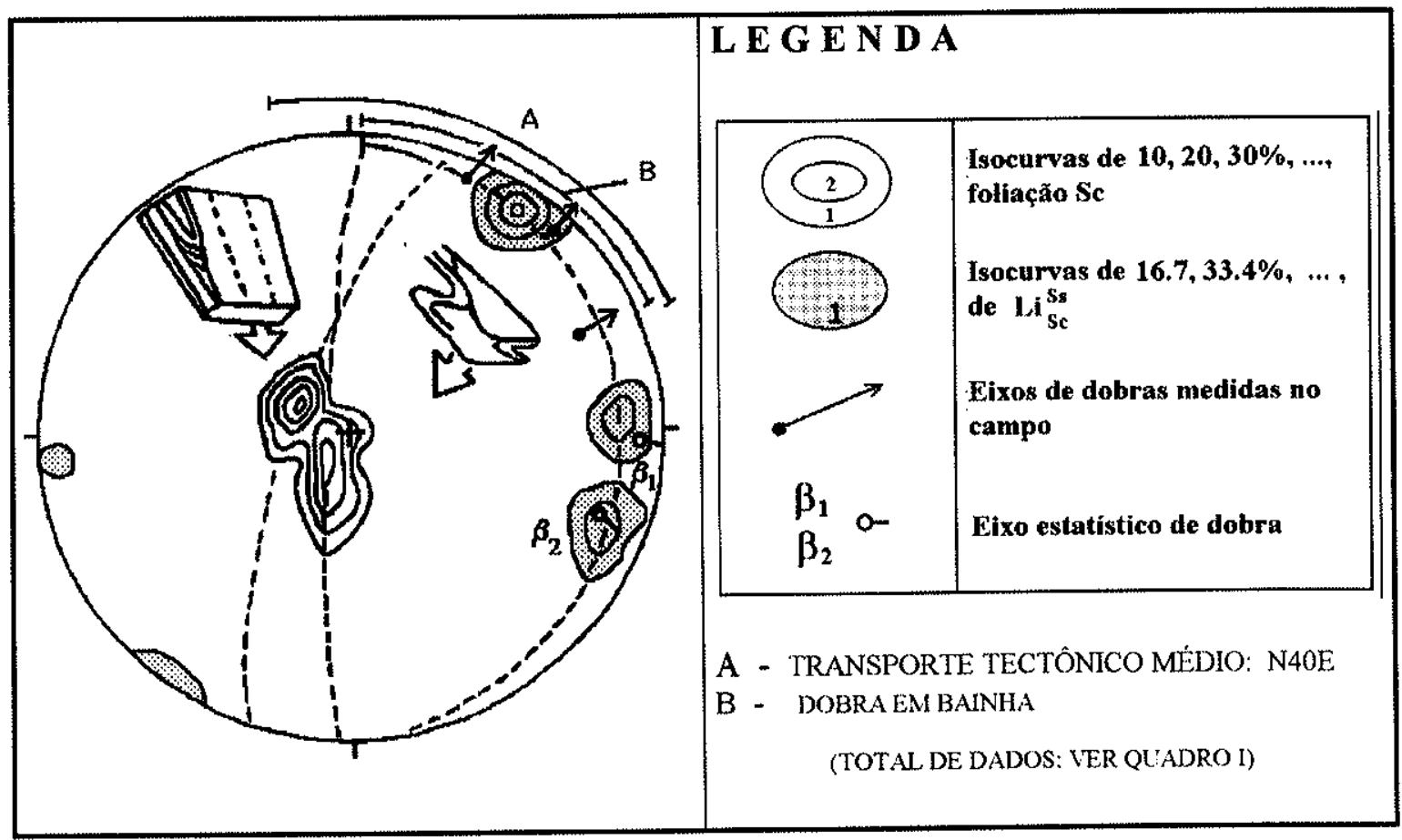

Figura 4.10 - Diagrama Schimdt - Lambert confeccionado a partir de dados estruturais obtidos nos afloramentos ED $100-101$ e 102. 
As Fotografias 4.3 e 4.4 mostram variações de estilos das dobras, com alguns niveis sendo fortemente espessados nas zonas de charneiras destas dobras, enquanto em outros, de maior viscosidade, este espessamento é menor ou até inexistente. Este último reflete assim variações de contraste de viscosidade entre as camadas, variações de espessuras das camadas competentes, ou mesma variação na proporção das camadas menos competentes, conforme discutido por Ramsay \& Huber (1983).

O estilo (ou morfologia) dessa dobras são também ilustradas nas Fotografias 4.5 e 4.6, onde coexiste dobras da mesma geração, com perfis apertados a isoclinais e com charneiras pouco (aguda) e muito desenvolvidas (arredondados), mostrando um descolamento (décollement). na base dessas estruturas, segundo à foliação principal. Isto pode ser interpretado como a geração contemporanea de dobras e zonas de cisalhamento.

c) $\mathrm{Li}_{S c}^{S s}$

Mesmo em zonas de cisalhamento com taxas de deformação menos acentuadas, ocorre o desenvolvimento dos pares SC de foliações, pois tratam-se de estruturas penetrativas em toda a região (Ver Figura 4.3). Embora as foliações Ss e Sc sugiram relações de superposição, elas foram desenvolvidas de forma quase concomitante (Simpson, 1986). Mesmo que não ocorra a inflexão da foliação Ss ao longo dos planos Sc, por falta de movimento ao longo desta última, estas duas foliações podem ser consideradas como pertencentes a zonas de cisalhamento maiores. Desta forma, as referidas foliações podem ser consideradas contemporâneas embora a geração da Ss seja ligeiramente anterior a Sc. Para efeitos de análise, a intersecção da foliação Ss sobre uma superficie Sc, pode ser esperado teoricamente numa direção perpendicular ao transporte tectônico, conforme ilustrado na Figura 4.11.

Considerando que o transporte tectônico obtido em escala mesoscópica para as litologias da Formação Água Clara é para os quadrantes SW-S-SE, portanto a grosso modo para sul, a lineação de intersecção de Ss sobre Sc esperada é NE-E, ou seja, a $90^{\circ}$ da direção de transporte. Os diagramas das Figuras $4.10,4.12$ e 4.14 mostram esta relação geométrica, a qual é confirmada nos diagramas sinópticos dos perfis do Rio da Lomba e Rio da Barra, que serão discutidos mais adiante. 


\section{LEGENDA DAS FOTOGRAFIAS DE $N^{\text {os }} 4.1$ a 4.6}

Fotografia 4.1 - Nível estratigráfico de metamargas intensamente deformado, com $0,5 \mathrm{~m}$ de espessura, entre rochas pouco deformadas. Afloramento ED 111.

Fotografia 4.2 - Detalhe da Fotografia 4.1, mostrando dobras intrafoliais assimétricas, como um aspecto da deformação presente no referido nivel litológico.

Fotografia 4.3 - Dobras geradas em metamargas da Formação Água Clara, com significativo espessamento e alongamento dos ápices (charneira). Pedreira de mármores calcíticos do Sumidouro, município de Tunas - Pr.

Fotografia 4.4 - Detalhe da Fotografia 4.3. Observar a geometria heterogênea das dobras, caracteristico de zonas de grande fluxo de materiais, comum no nivel estrutural inferior de Mattauer (1967).

Fotografia 4.5 - Zona de cisalhamento justapondo um nivel(superior) dobrado. ao lado de outra com ausência de dobras (parte inferior da dobra). Pode tratar-se, ainda, de uma zona de alto fluxo (deformação) de materiais, ao lado de um nivel com menor fluxo ou deformação, no qual aparecem dobras, sem que exista uma zona de descolamento entre estas duas zonas (Pedreira do Sumidouro).

Fotografia 4.6 - Detalhe da Fotografia 4.5. mostrando a diferença geométrica das estruturas da parte superior da foto em relação aquela situada na sua parte inferior. 


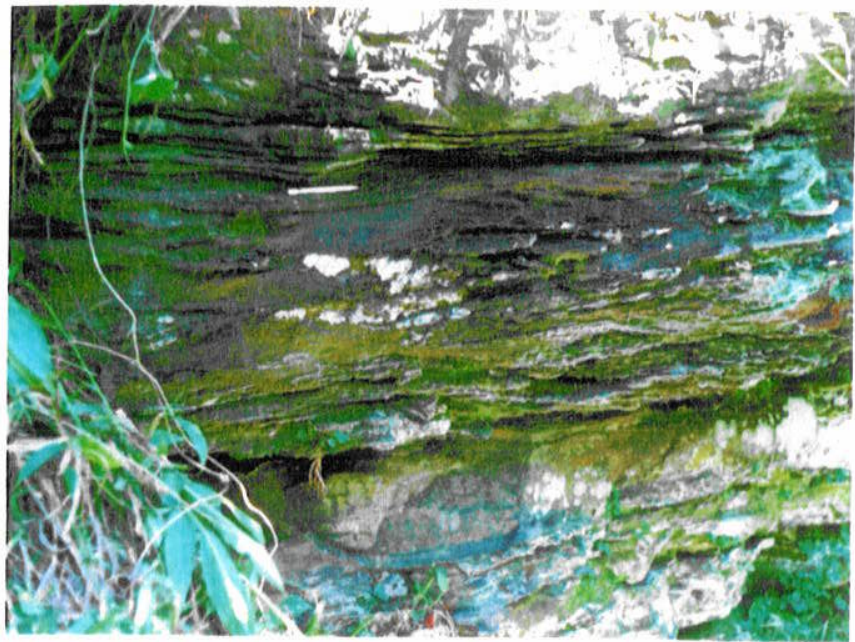

FOTO 4.1

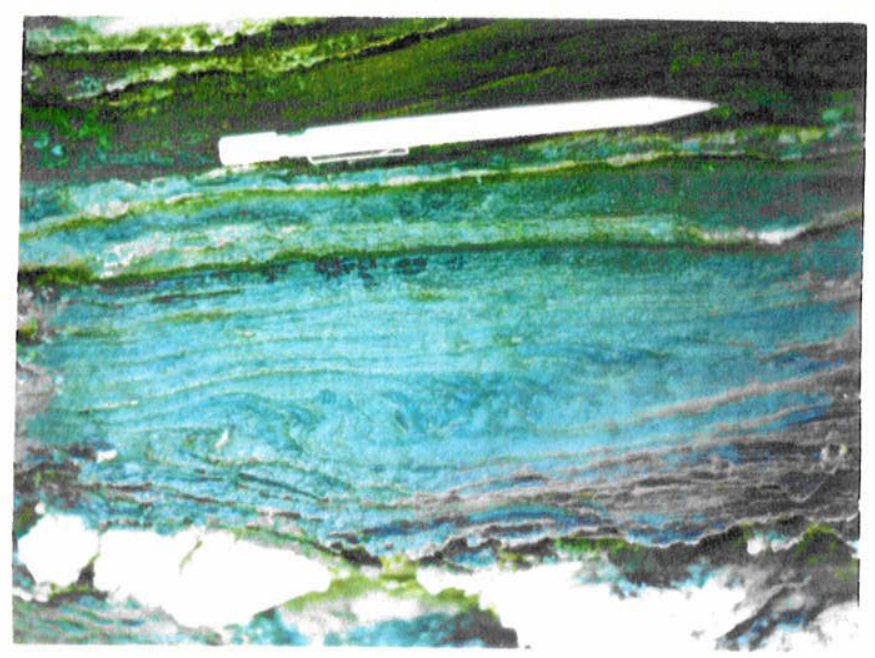

FOTO 4.2

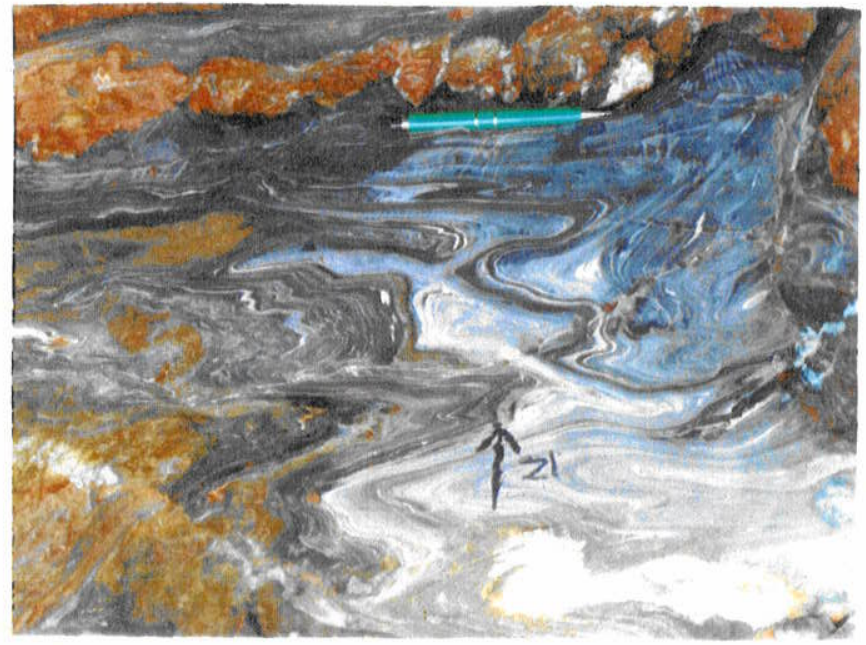

FOTO 4.3

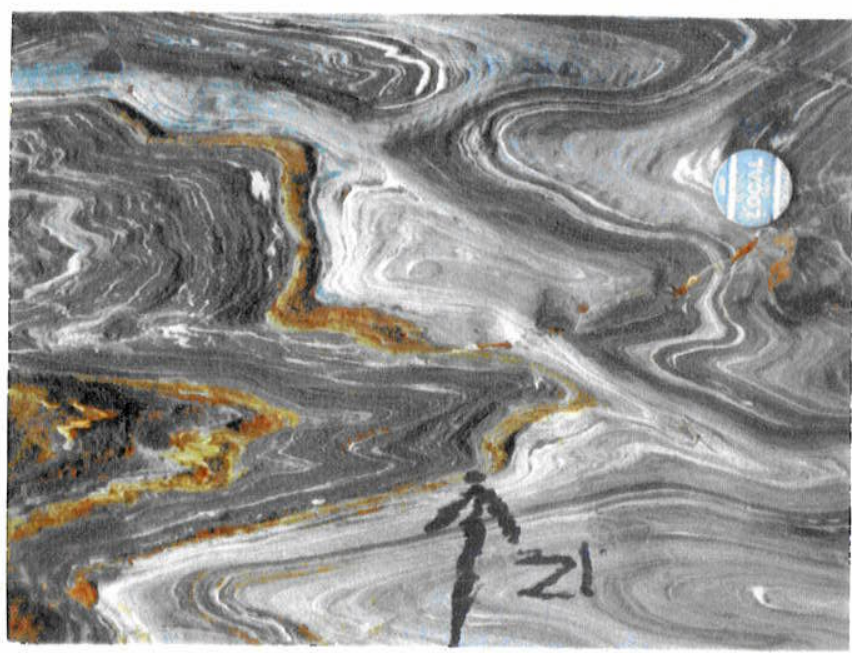

FOTO 4.4

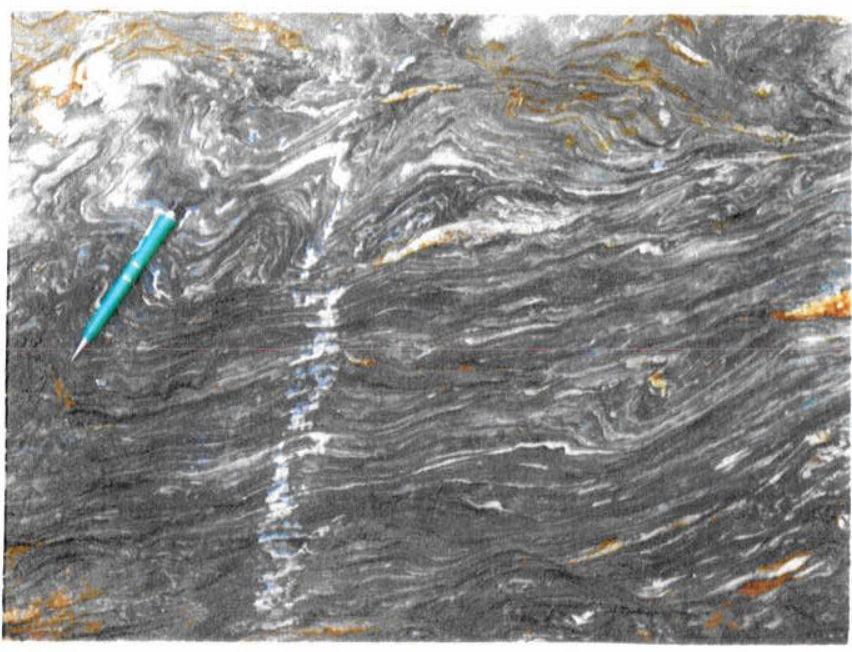

FOTO 4.5

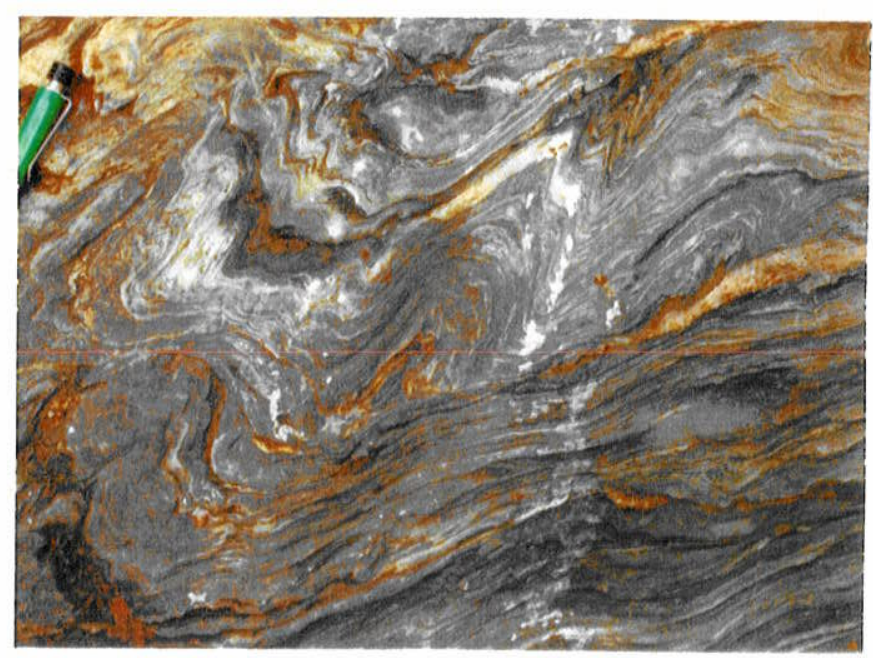

FOTO 4.6 


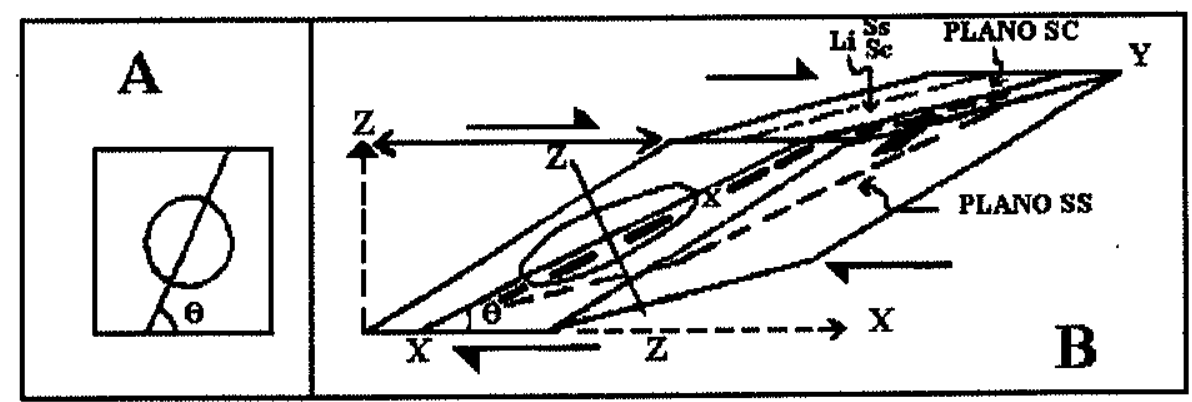

Figura 4.11 - Modelo de deformação por cisalhamento simples.

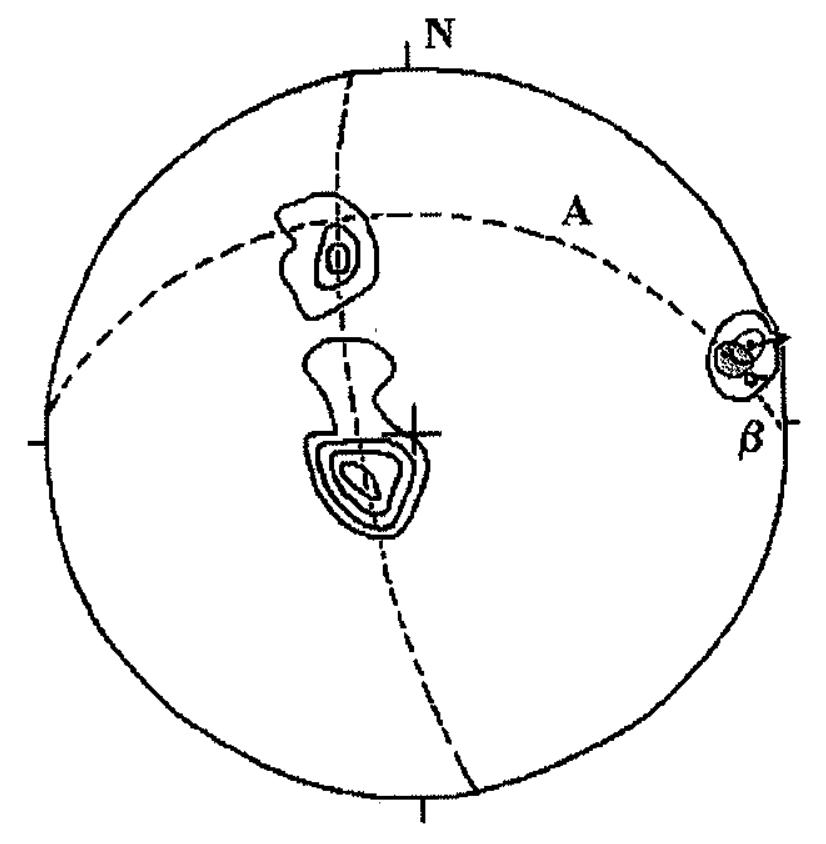

LE G E N D A

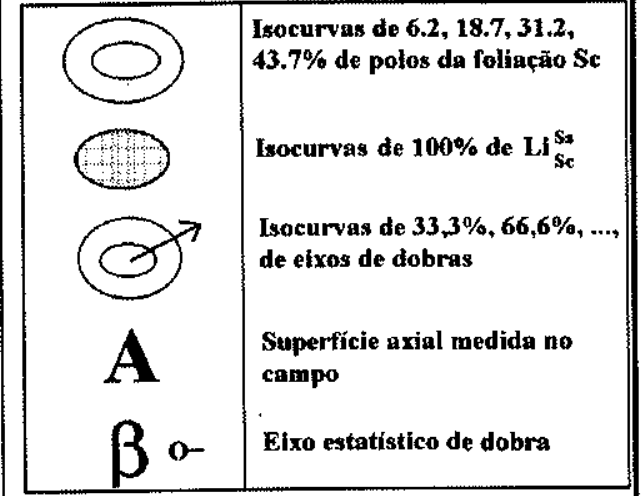

Total de medidas:

polos da foliação $\mathrm{Sc}=16$

eixos $\quad=03$

$\mathrm{Li}^{\mathrm{Ss}} \quad=02$

Figura 4.12 - Diagrama Schmidt-Lambert com guirlanda de pólos da foliação $\mathrm{Sc} / \mathrm{So}$, com flancos médios N64E/44SE e N42W/14NE; eixo $\beta, N 82 E / 10^{\circ}$, próximo do eixo medido no campo, N76E $/ 08^{\circ}$; plano axial, N85W/49NE; e Li ${ }_{S c}^{S s}, \mathrm{~N} 76 \mathrm{E} / 12^{\circ}$ (Afloramento ED 128).

d) Lineações (minerais e de estiramento)

Estas estruturas foram de dificil identificação na escala mesoscópica (amostras de mão), devido a granulação muito fina das metamargas, e das intercalações metacarbonáticas, 
metareníticas e metapelíticas. Entretanto, estas estruturas foram devidamente identificadas na escala microscópica, com base no estudo de lâminas delgadas de amostras orientadas.

De uma maneira geral, o transporte tectônico para sul, na escala mesoscópica foi determinado pela relação das foliações $\mathrm{SC}$, lineações de intersecções, dobras-falha e dobras em bainha. Algumas lineações minerais identificadas com segurança possuem direção $\mathrm{N} 13 \mathrm{~W} / 10^{\circ}$, N05W $/ 19^{\circ}$ (ED 103); N01E $/ 05^{\circ}$ (ED 128); N13E/07 (ED 109); S38E/01 ${ }^{\circ}, \mathrm{N} 38 \mathrm{E} / 10^{\circ}$ e $\mathrm{N} 33 \mathrm{E} / 07^{\circ}(\mathrm{ED} 100)$ e $\mathrm{N} 45 \mathrm{E} / 10^{\circ}$ (ED 124).

A identificação de lineação de estiramento mineral foi extremamente dificultada em função do predomínio da composição carbonática da unidade, assim como a inexistência (ou ausência) de seixos ou objetos favoráveis ao aparecimento deste tipo de estrutura.

Estão presentes, ainda, estruturas lineares formadas pela orientação de rods, com atitudes de $\mathrm{S} 45 \mathrm{E} / 11^{\circ}$ e S29E $/ 04^{\circ}$, respectivamente.

\section{e) Dobras suaves a abertas}

As foliações $\mathrm{Ss}_{(1)}$ e $\mathrm{Sc}_{(1)}$ são em geral afetadas por dobras de perfis abertos a suaves, formando guirlandas que exibem frequentemente uma concentração única de pólos, conforme pode ser observado nos Quadro 4.1 e Quadro 4.2. São registrados também diagramas com a repartição de pólos em duas concentrações, permitindo assim uma melhor definição do plano AC de simetria da dobra e, consequentemente o cálculo do ângulo interflanco (Ver Quadro 4.1). Um exemplo típico desta estrutura ocorre no afloramento ED 128 , onde a referida dobra apresenta flancos médios com atitudes N68E/44SE e N42W/14NE, e eixo estatístico $(\beta)$ de $\mathrm{N} 82 \mathrm{E} / 10^{\circ}$, com clivagem plano-axial de N85W/49NE (Figura 4.12).

$\mathrm{O}$ eixo da dobra medido em campo $\left(\mathrm{N} 80 \mathrm{E} / 08^{\circ}\right)$, é coincidente com a geometria estatística obtida. A dobra define uma vergência para sul.

Estas dobras evoluem para dobras/falhas, conforme ilustrado na Figura 4.13 (afloramento ED 127), deformado em condições rúpteis/dúcteis.

Estas dobras, associadas com falhamentos, mostram-se mais suaves com amplificação do comprimento de onda e decréscimo da amplitude, à medida que se afastam do falhamento. Na ausência de indicadores cinemáticos na superficie da falha, interpretou-se com base na geometria das dobras, de um lado e de outro do bloco, como sendo uma falha de empurrão, de oeste para leste. Os dados estruturais desta estrutura, lançados mo estereograma, com um total de 51 medidas da foliação $\mathrm{Sc}_{(1)}$, definem guirlanda com eixo estatístico de $\mathrm{S} 79 \mathrm{E} / 10^{\circ}$, situado na 


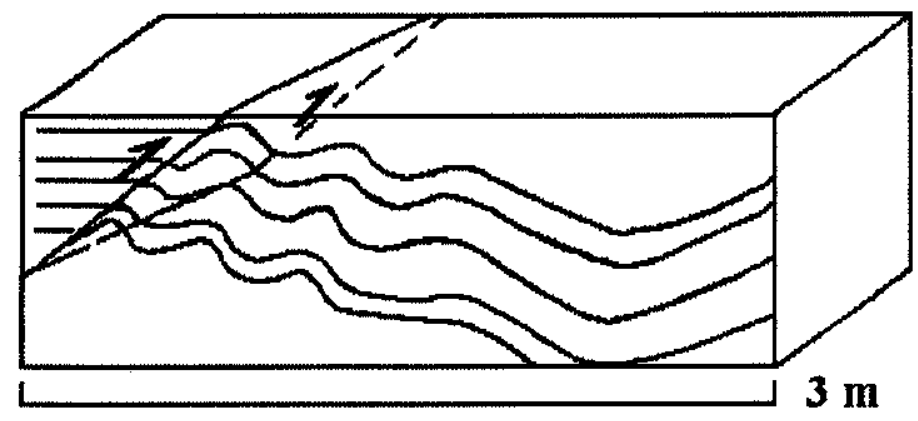

Figura 4.13 - Dobra-falha gerada em condições rúpteisdúcteis, disposta de forma paralela à lineação de intersecção (Ss sobre Sc). (Afloramento ED 127).

superficie axial da dobra (N75W/70NE), e coincide com o eixo medido campo, cujo valor é de $\mathrm{S} 80 \mathrm{E} / 07^{\circ}$ (Figura 4.14). A relação geométrica dobra/falha mostra um valor angular de $90^{\circ}$ entre o plano da falha (N55W/35NE) e o plano AC de simetria da dobra. Um outro eixo de dobra medido

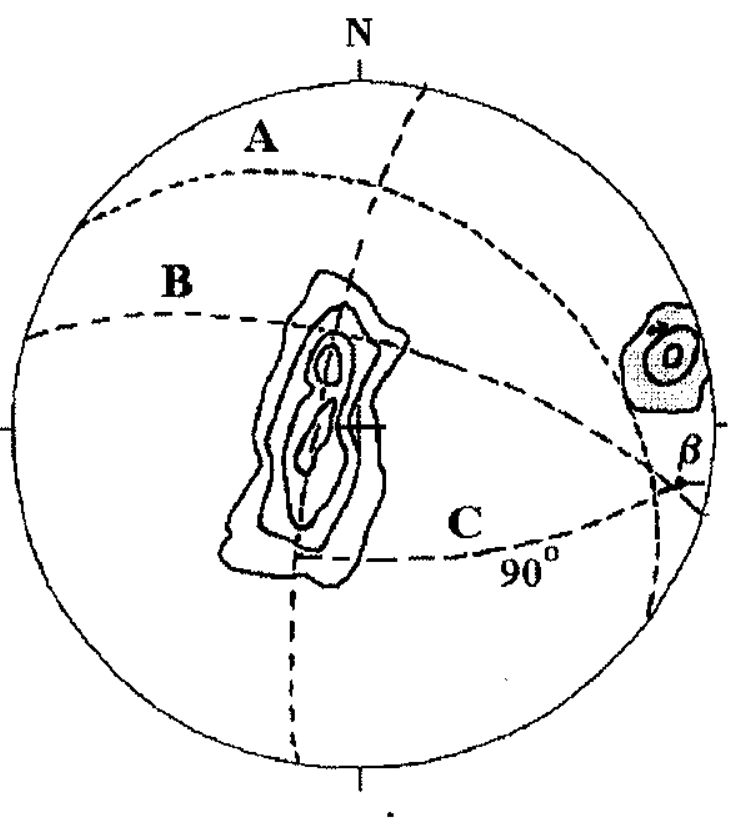

\section{E G E N D A}

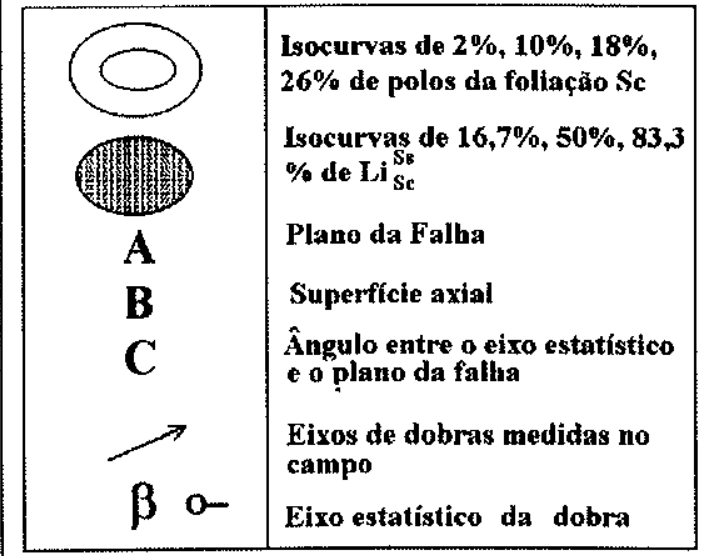

Total de medidas:

Foliação Sc $=51$

$\mathrm{LiSSS}_{S C}=6$

Sc

Figura 4.14 - Representação gráfica em diagrama Schmidt-Lambert das estruturas da FIG 4.13. correspondentes ao afloramento ED 127. 
no afloramento, com atitude de $\mathrm{N} 72 \mathrm{E} / 12^{\circ}$, apresenta uma dispersão de $23^{\circ}$ em relação ao anterior.

O transporte tectônico ocorrido nestas estruturas, geradas em condições rúpteis-dúcteis, é no sentido S-SW, coincidente, de uma forma geral, com o transporte verificado no cisalhamento principal, de natureza dúctil.

As feições rúpteis destas estruturas foram também verificadas no afloramento ED 122 , onde um sistema de juntas, com atitude N75E/subvertical, apresenta geometria próxima da superficie axial das dobras aqui consideradas, com direção N66E/80SE.

Nota-se que esta direção NE-E se repete nas diversas condições de ductilidade. Em condições dúcteis aparecem, com esta direção, lineações de intersecção da foliação Ss sobre a Sc, com disposição ortogonal ao transporte tectônico (dobras em bainha, dobras isoclinais, cisalhamentos e lineações minerais). As foliações $\mathrm{Ss}$, $\mathrm{Sc}$ e a $\mathrm{Li} S \mathrm{Ss}_{\mathrm{Sc}}$ dispõem-se, de forma sistemática, com baixos mergulhos ao longo dos perfis Rio da Lomba e Rio da Barra.

Segue-se, em condições menos dúctil a rúptil-dúctil a geração de dobramentos suaves a abertos, com eixos estatísticos NE-E, os quais evoluem para falhas de médio ângulo. Posteriormente, em condições rúpteis, ocorreu a formação de clivagens de fraturas/falhas, as quais condicionam diversas cachoeiras ao longo do perfil.

Esta coaxialidade entre as estruturas, refletindo estruturas dúcteis até rúpteis, indica que houve um prosseguimento do cisalhamento durante a ascensão do pacote de rochas da Formação Água Clara, desde níveis crustais mais inferiores, até mais superiores.

Desta forma, espera-se uma transição entre estruturas dúcteis de baixo ângulo, situadas nas bordas do Complexo Granítico Três Córregos, passando a dobras-falha rúpteis/dúcteis $\left( \pm 50^{\circ}\right.$ de mergulho), até falhas de alto ângulo, as quais podem corresponder ao registro das falhas transcorrentes (Lancinha, Morro Agudo, Itapirapuã, entre outras). Estas estruturas, além de apresentarem-se com diferente ductilidade e disposição espacial nos diferentes níveis estruturais, foram submetidos a prováveis mecanismos de partição da deformação, segundo conceituação de Tikoff \& Teyssier (1994). Através desta mecânica desenvolveram-se thrust faults como o resultado da atuação da componente de cisalhamento puro e, transcorrência, a partir da componente de cisalhamento simples. Dentro desse contexto, as falhas de baixo ângulo identificadas por Fiori et al. (1987c), Soares (1987), Fiori $(1990,1992,1993)$, e Fiori \& Gaspar (1993) correspondem a componente de cisalhamento puro atuante num regime de transpressão. 
Este regime pode explicar a disposição das foliações metamórficas, com mergulhos superiores a $50^{\circ}$, na maioria dos afloramentos do Grupo Açungui.

De uma maneira geral, os niveis litológicos com deformação muito intensa são localizados, sendo subordinados aos domínios com deformação menos intensa ou até indeformados, estes últimos apresentando estruturas primárias. Mesmo assim, as estruturas tectônicas constituem-se numa feição marcante e penetrativa, mostrando que as deformações afetaram tanto a Formação Água Clara quanto o Grupo Açungui.

Evidências da superposição de estruturas dobradas podem ser observadas no afloramento ED $208 \mathrm{C}$, onde uma dobra isoclinal foi redobrada de forma aberta, com geração de foliação plano-axial associada, a qual é ressaltada pela presença de alinhamentos de sulfetos como pirita e calcopirita em seus planos (Figura 4.15).

Porém, a interpretação da existência de dobras suaves a abertas de forma generalizada, com base de guirlandas de estereogramas pode, muitas vezes, ser incorreta. Feições semelhantes a dobras abertas, interpretadas como dobramento tipo flexural, podem ser produzidas pela lenticularização da foliação, geradas por cisalhamento simples, ou através de fluxo com diferentes viscosidades, gerando transportes com diferentes velocidades ao longo da estruturação tectônica de uma unidade geológica. Estas feições podem, assim, gerar feições de dobras abertas, as quais desaparecem lateralmente ao longo do pacote litológico (Figura 4.16, Afloramento ED 124). Na

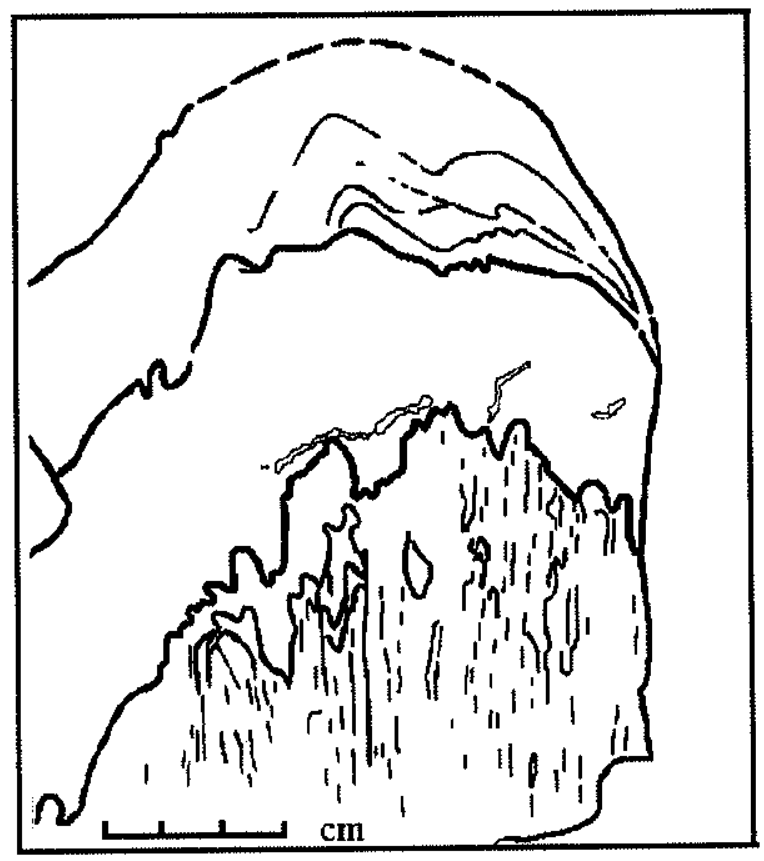

Figura 4.15 - Dobra isoclinal gerada pelo cisalhamento principal, redobrada por dobras abertas, com eixos NE-E.

Afloramento ED 208C 


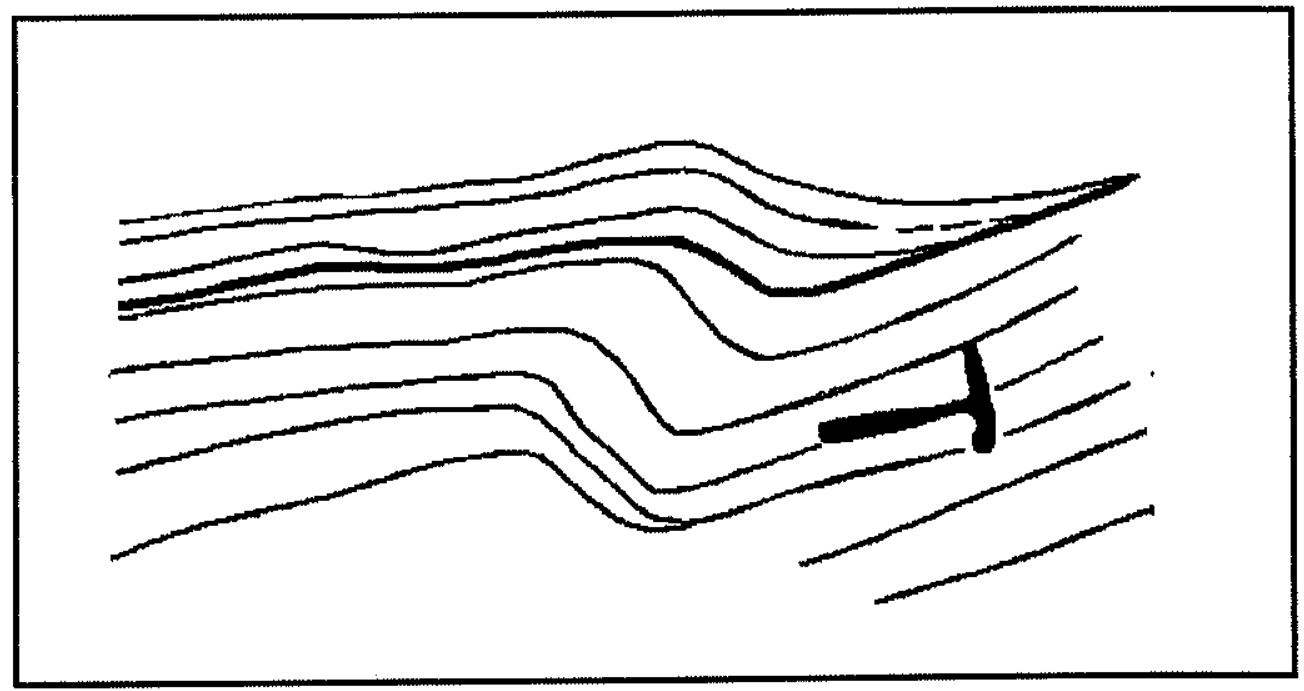

Figura 4.16 - Desenho esquemático de uma dobra aberta na base, passa para dobra suave no topo. Esta estrutura é associada ao evento de cisalhamento principal, e pode ser facilmente confundida com as dobras abertas regionais, tardias.

base do desenho esquemático, a dobra apresenta-se de forma aberta, evoluindo para o topo do afloramento para dobramento suave, tendendo a desaparecer em direção ao topo.

E por último, uma dobra aberta com um dique em posição plano axial, situada a cerca de 100 metros do contato da Formação Água Clara com o Complexo Três Córregos, sugerindo uma possível relação genética entre esta estrutura o referido complexo. A análise geométrica desta dobra mostra um eixo estatístico com atitude $\mathrm{S} 86 \mathrm{E} / 13^{\circ}$, o qual é compatível com os eixos encontrados no campo, de $\mathrm{S} 80 \mathrm{E} / 09^{\circ}$ e $\mathrm{N} 85 \mathrm{E} / 24^{\circ}$. A atitude de $\mathrm{N} 80 \mathrm{~W} / 72 \mathrm{SW}$, obtida para o referido dique, é muito próximo dos valores das foliações plano-axiais para as dobras abertas identificadas na região (Figura 4.17).

A correspondência geométrica desta dobra com o padrão regional, sugere a existência de uma relação entre a deformação tardia do pulso principal de deformação regional e a colocação dos corpos graníticos no Complexo Três Córregos, responsável pela atual configuração dos Lineamentos Lancinha, Morro Agudo e Itapirapuã. 


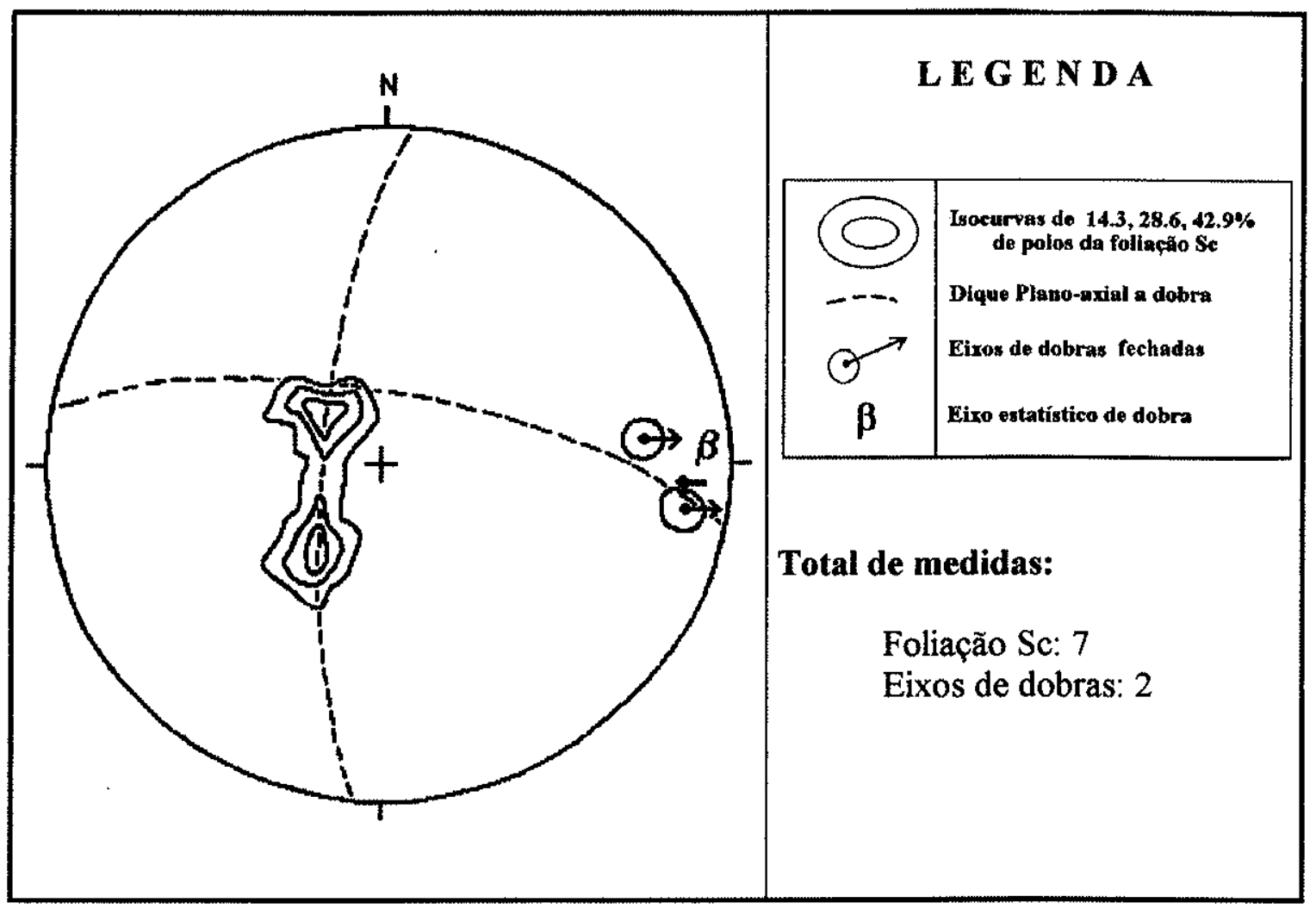

Figura 4.17 - Diagrama Schmidt-Lambert mostrando uma dobra suave (ângulo interflanco de $137^{\circ}$ ), eixo $\beta \mathrm{S} 86 \mathrm{E} / 13^{\circ}$, contendo um dique plano-axial, este último com largura de 0,5 metros.

\subsubsection{ANÁLISE GEOMÉTRICA REGIONAL}

As diversas estruturas tectônicas identificadas ao longo dos perfis do Rio da Lomba e Rio da Barra e, em outros locais, na região de São Pedro/São Silvestre descritos no item anterior, serão analisados, levando em consideração o contexto regional.

\subsubsection{PERFIL RIO DA LOMBA}

As dobras abertas foram analisadas a partir do tratamento estatistico de 535 pólos da foliação $\mathrm{Sc}_{(1)}$, em diagramas Schmidt-Lambert, o qual sugeriu uma guirlanda de dobramento cilíndrico (Figura 4.18). O eixo estatístico ( $\beta$ ), com atitude $N 73 E / 11^{\circ}$, é idêntico ao resultado obtido na compilação de 16 eixos $\beta$ na Figura 4.19. Nota-se neste último diagrama, uma concentração máxima de $\mathrm{N} 70 \mathrm{E} / 09^{\circ}\left(7 \%\right.$ dos dados) e, outra, secundária, de $\mathrm{S} 83 \mathrm{E} / 09^{\circ}(3 \%)$. 


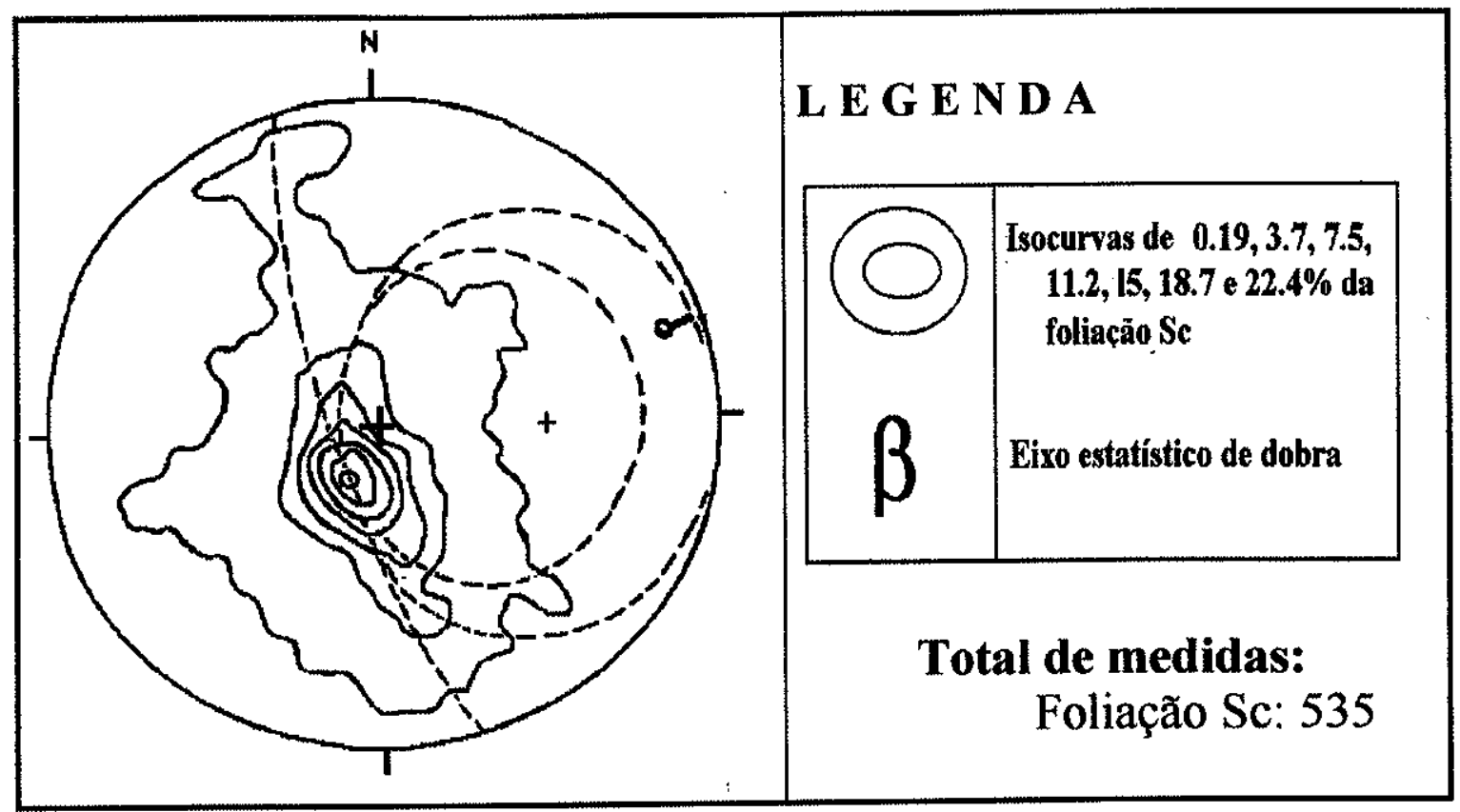

Figura 4.18 - Diagrama Schmidt-Lambert de 535 pólos da foliação Sc coletada no perfil do Rio da Lomba. A guirlanda sugere a presença de dobras cilíndricas, com eixo $\beta$, ao redor de $\mathrm{N} 73 \mathrm{E} / 11^{\circ}$. A distribuição dos pólos sugere, ainda, uma dobra cônica com eixo estatístico de $\mathrm{S88E} / 48^{\circ}$ (abertura de $50^{\circ}$ ) ou $\mathrm{N88E} / 62^{\circ}$, com abertura de $40^{\circ}$.

A leitura da distribuição dos pólos de $\mathrm{Sc}_{(1)}$ no diagrama da Figura 4.18 sugere, ainda, uma geometria cônica, para a estrutura com eixos de $\mathrm{S} 88 \mathrm{E} / 48^{\circ}$ (abertura interflancos de $50^{\circ}$ ) de $\mathrm{N} 88 \mathrm{E} / 62^{\circ}$ (abertura de $40^{\circ}$ ), respectivamente. Esta geometria, embora não seja predominante, aparece em diagramas dos aforamentos ED 124, 129 a 137, 138 a 139, 138 a 145, 161 a 163, 164 a 171 e 172. Isto sugere, em alguns locais, a ocorrência de dobras cônicas.

Analisando, ainda, o diagrama da Figura 4.19, é possível observar uma considerável dispersão dos eixos estatísticos, dos quais cinco deles situa-se no quadrante sudeste (conjunto de afloramentos $\mathrm{ED} 124,138$ a 145,161 a 163,164 a 171 e 172) com atitudes de $\mathrm{S} 41 \mathrm{E} / 48^{\circ}, \mathrm{L}$ $\mathrm{W} / 70^{\circ}, \mathrm{S} 28 \mathrm{E} / 48^{\circ}, \mathrm{S} 74 \mathrm{E} / 40^{\circ}$ e $\mathrm{S} 40 \mathrm{E} / 30^{\circ}$. Próximo a distribuição dos dados anteriores, ocorrem dois eixos, com atitude média $\mathrm{N} 80 \mathrm{E} / 78^{\circ}$ (ED 129 a 137). Nota-se, ainda, no quadrante NW duas concentrações, com atitudes médias de $\mathrm{N} 14 \mathrm{~W} / 15^{\circ}$ e $\mathrm{N} 68 \mathrm{~W} / 08^{\circ}$. Apenas o eixo da guirlanda dos afloramentos ED 138 e 139 (Ver Quadro 4.1) situou-se o quadrante SW, com atitude $\mathrm{S} 80 \mathrm{~W} / 48^{\circ}$. 


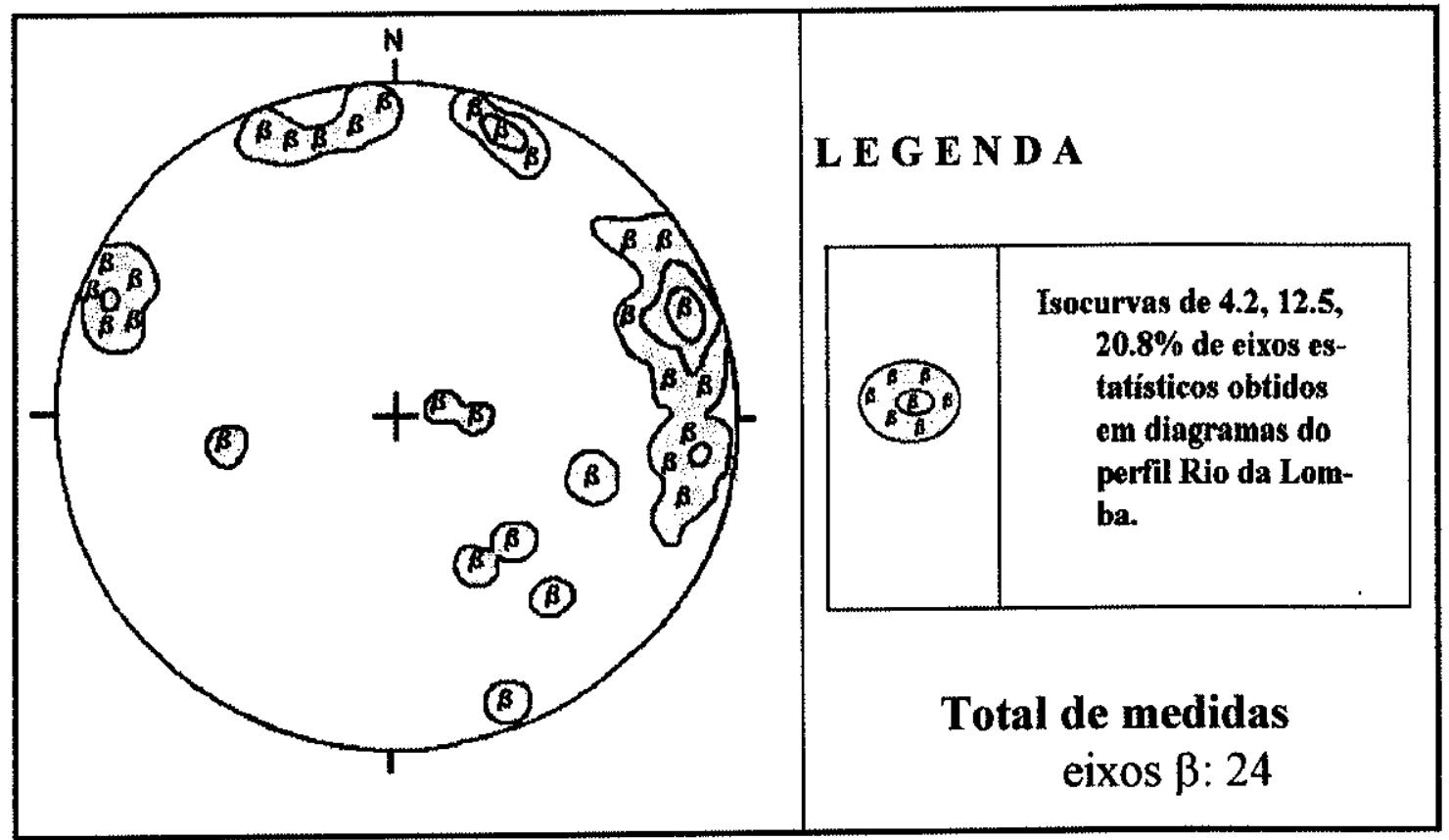

Figura 4.19 - Diagrama mostrando a distribuição de 24 eixos estatísticos de dobras suaves/ abertas obtidos nos diversos diagramas do perfil Rio da Lomba e tabulados no Quadro 4.1

A dispersão desses eixos no quadrante sudeste, coincide com a direção no transporte tectônico do cisalhamento principal do Sistema Transpressivo, indicando novamente, coaxialidade entre as dobras geradas pelos sistemas de Deformação $\mathrm{SD}_{1}$ e $\mathrm{SD}_{2}$, as quais diferem, portanto, do nivel estrutural em que foram geradas. Assim, as dobras suaves estão relacionadas a um nivel estrutural mais superior do que as estruturas dúcteis (dobras fechadas a isoclinais, dobras em bainha, foliações Ss e Sc), porém foram desenvolvidas num mesmo campo de "stress" tectônico. Porém, a distribuição média dos dois eixos $\beta$ cônicos da Figura 4.18, acha-se levemente deslocada da média dos eixos estatísticos cônicos dos diversos diagramas plotados na Figura 4.19. Apenas dois dos eixos se aproximam desta média (afloramentos ED 129 a 137. 138 a 145), enquanto que os demais (afloramentos ED 124, 161 a 163, 164 a 171 e 172) giram em torno de um eixo médio com atitude $\mathrm{S} 40 \mathrm{E} / 38^{\circ}$. Padrões idênticos são observados no diagrama da Figura 4.20 , onde foram lançados eixos de dobras coletados no campo. As dobras fechadas/isoclinais e, em bainha, geradas durante o evento de cisalhamento principal ( $64 \%$ dos dados), apresentam concentrações máximas com direções $\mathrm{S} 48 \mathrm{E} / 08^{\circ}$ (5 medidas), $\mathrm{S} 30 \mathrm{E} / 06^{\circ}(3), \quad \mathrm{S} 16 \mathrm{E} / 09^{\circ}(3), \quad \mathrm{N} 43 \mathrm{~W} / 09^{\circ}(4)$, 


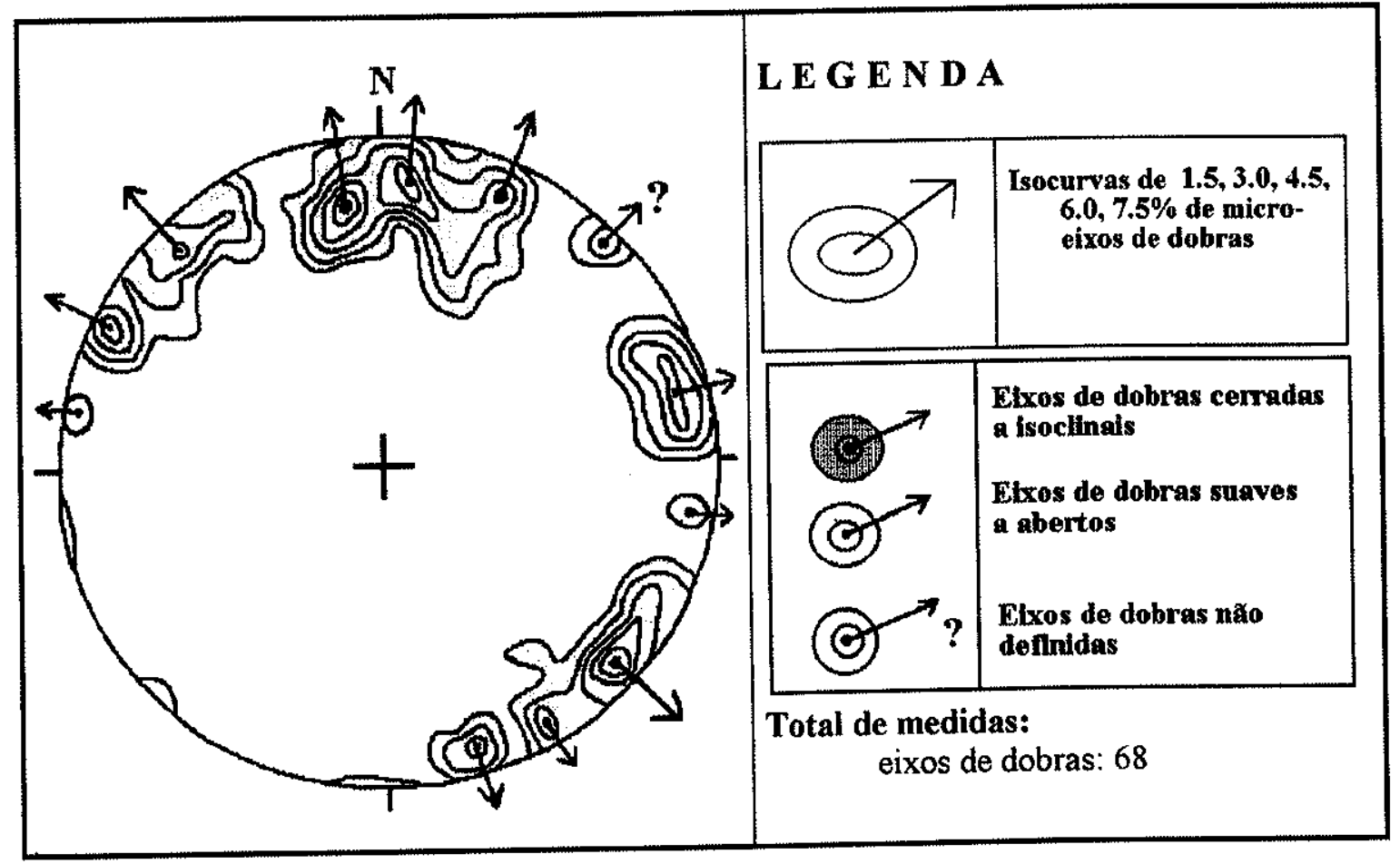

Figura 4.20 - Diagrama mostrando a disposição dos diversos eixos de dobras medidos nos afloramentos do perfil Rio da Lomba.

$\mathrm{N} 24 \mathrm{E} / 10^{\circ}$ (4), N06E/14 $(5), \mathrm{N} 08 \mathrm{~W} / 20^{\circ}$ (5) e $\mathrm{N} 45 \mathrm{E} / 04^{\circ}$ (2); as dobras suaves/abertas apresentam uma única concentração, $\mathrm{N} 77 \mathrm{E} / 09^{\circ}$ (4 medidas), coincidente com o eixo $\beta$ (Ver Figura 4.20), este último com direção N73E/11 $1^{\circ}$.

O exame do comportamento das lineacões de interseccão $\left(\mathbf{L i}_{S c}^{S s}\right)$ na secção Rio da Lomba, com 86 dados, apresenta uma concentração máxima de $\mathrm{N} 77 \mathrm{E} / 09^{\circ}$ ( $25 \%$ dos dados) (Figura 4.21 ), situada próximo ao eixo da dobra cilíndrica $\left(\mathrm{N} 73 \mathrm{E} / 11^{\circ}\right)$. Porém, para que estas estruturas tivessem relações genéticas, ou seja, tivessem sido geradas no mesmo momento da história deformacional, seria esperado que lineações de intersecção também se dispusessem de forma paralela aos eixos de dobras cônicas, o que não ocorre. É provável que as dobras suaves/abertas, com eixos NE-E, tenham sido geradas no estágio inicial do processo de deformação progressiva. Com a intensificação dos esforços estas dobras passaram assumir geometrias fechadas a isoclinais, que evoluem para dobras em bainha, com direção SE-S, a qual é idêntica a direção de transporte obtida pelos demais indicadores cinemáticos (relação 


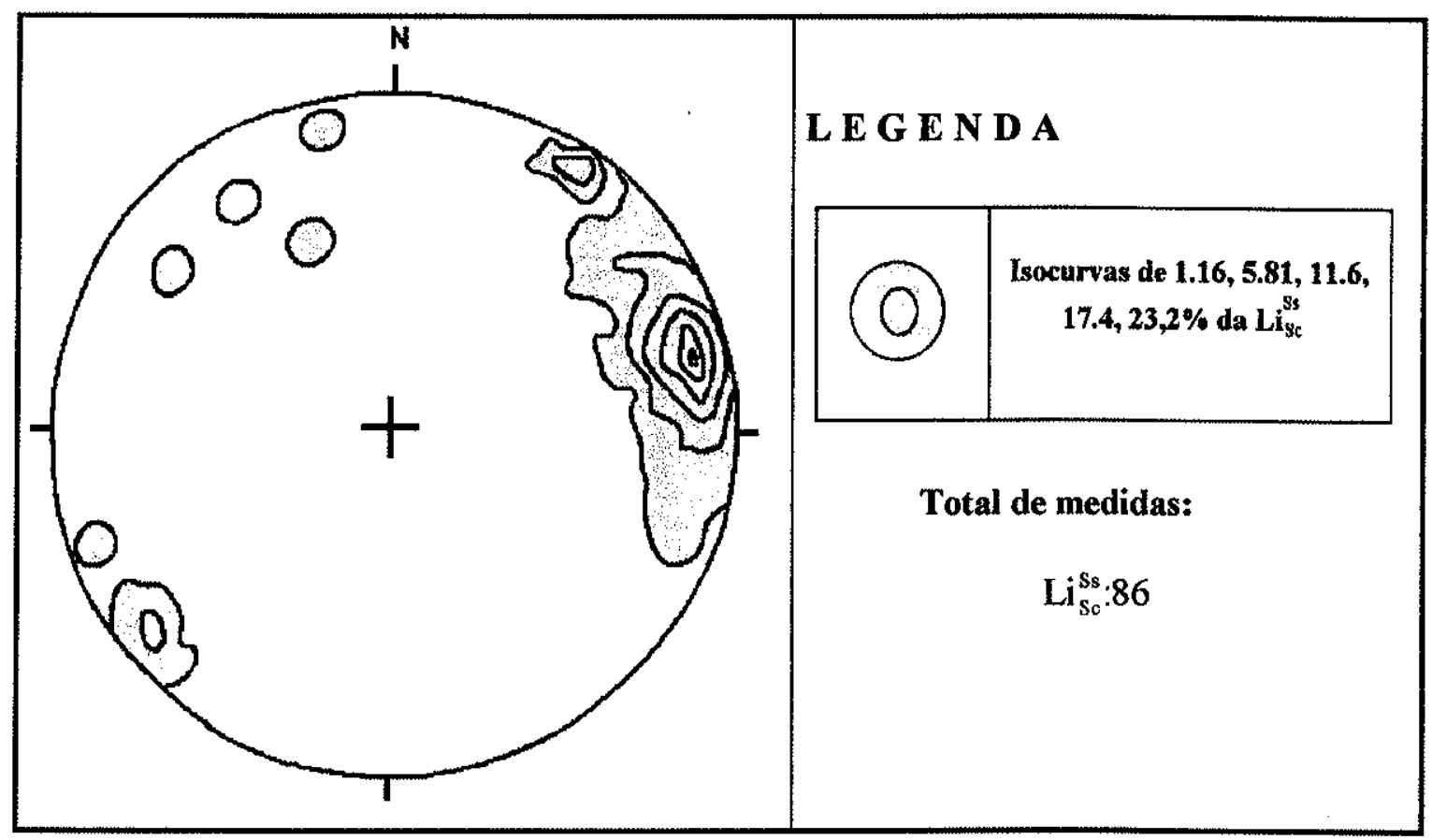

Figura 4.21 - Distribuição de 86 lineações de intersecção da foliação Ss sobre a Sc, no perfil Rio da Lomba, com uma concentração máxima de dados em torno de N77E $/ 09^{\circ}$ (25 atitudes), e concentrações secundárias de $\mathrm{S} 49 \mathrm{~W} / 09^{\circ}$ e $\mathrm{N} 35 \mathrm{E} / 07^{\circ}$ reșpectivamente, com 3 e 2 lineações.

entre as foliações $\mathrm{Ss}, \mathrm{Sc}$, dobras-falha, rotação e lineação mineral, $\underset{S c}{\mathrm{Li}_{S c}^{S s}}$, etc.). As estruturas associadas à deformação $\mathrm{SD}_{1}$, foram obliteradas pela transposição ocorrida durante a história deformacional, por ocasião da superposição de um novo pulso transpressivo, agora de natureza transcorrente.Estas feições podem ser observadas pelo predomínio das foliações subverticalizadas no Grupo Açungui e correlatos, existência de dobras sem raiz (rootless folds) de escala decimétrica a métrica, e pela presença de fechamentos de dobras na escala regional apenas em torno dos lineamentos Lancinha, Morro Agudo e Itapirapuã, interpretadas a partir de fotografias áreas e estereogramas com integração regional das foliações $\mathrm{Ss}_{1}$ e $\mathrm{Sc}_{1}$. Durante a última fase, presente nas litologias da Formação Água Clara, foram formados as dobras tardias (suaves a abertas), com eixos de direção NE-E, N-NW e NW-W, os quais são descontínuas na escala nível regional, e apresentam uma certa superposição dos diagramas com os eixos de dobras relacionadas à fase principal de deformação. 


\subsubsection{SUMARIZAÇÃO DOS DADOS DO PERFIL NO RIO DA BARRA}

Os resultados obtidos no Perfil do Rio da Barra são idênticos aos obtidos no Perfil do Rio da Lomba, apesar da menor quantidade de dados.

A análise dos diagramas da foliação $S_{\mathrm{s}}\left(S_{1}\right)$ (140 pólos) (Figura 4.22), indica a presença de uma dobra cilíndrica, com eixo estatístico de $\mathrm{N} 80 \mathrm{E} / 15^{\circ}$, próximo do eixo encontrado no perfil Rio da Lomba $\left(\mathrm{N} 73 \mathrm{E} / 11^{\circ}\right)$ (Ver Figura 4.18).

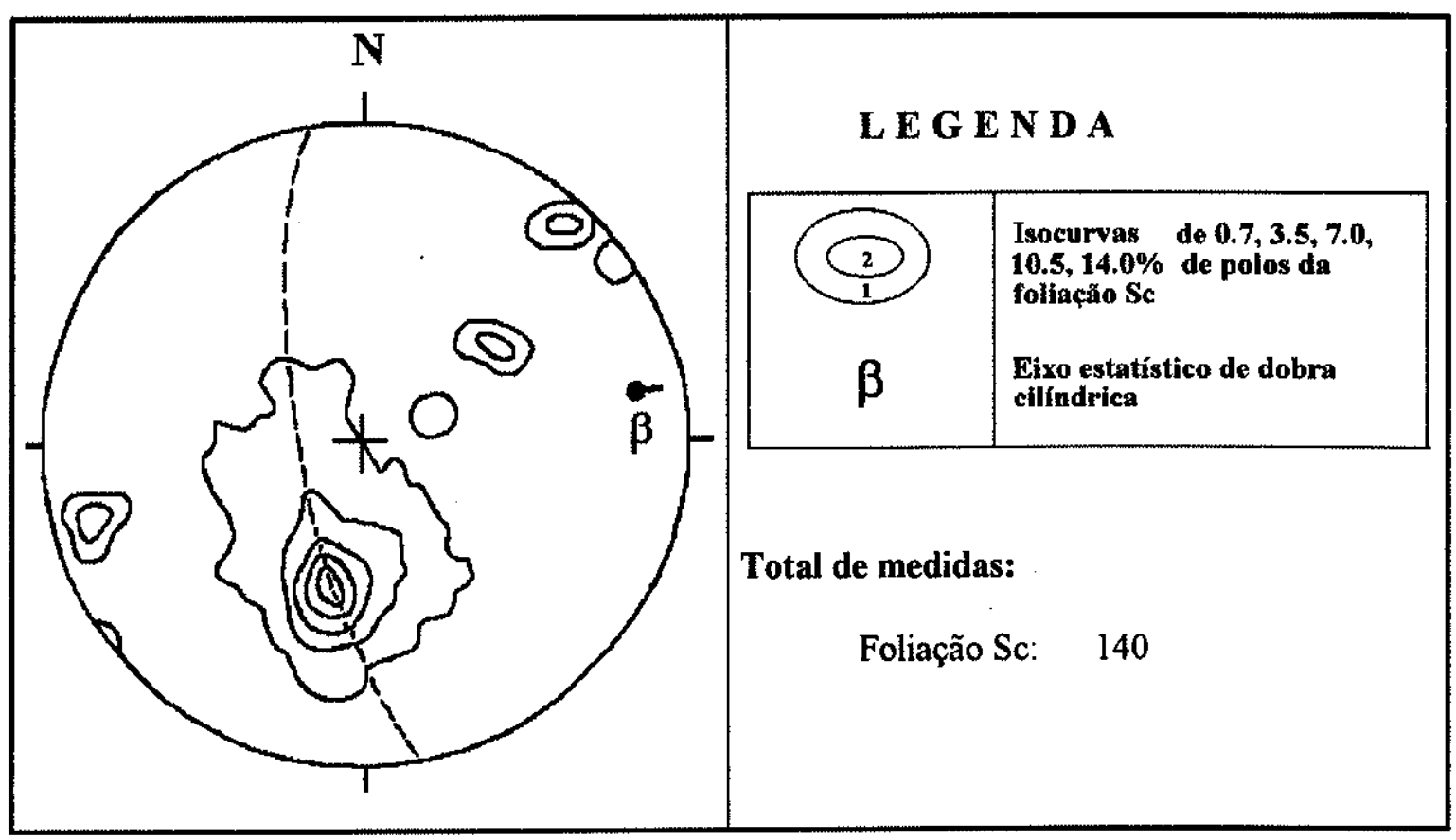

Figura 4.22 - Integração dos pólos da foliação Ss do perfil Rio da Barra. Os pólos estão organizados numa guirlanda de dobra cilíndrica, com eixo estatístico, $\mathrm{N} 80 \mathrm{E} / 15^{\circ}$.

Porém, o tratamento estatístico dos diversos eixos $\boldsymbol{\beta}$ de dobras tabulados no Quadro 4. 2 (Figura 4.23), revelou uma concentração de $\mathrm{N} 70 \mathrm{~W} / 04^{\circ}$ (3 eixos), com uma variada distribuição de eixos estatísticos de dobras cilíndricas, com atitudes de $\mathrm{S} 86 \mathrm{~W} / 06^{\circ}, \mathrm{S} 86 \mathrm{E} / 13^{\circ}, \mathrm{N} 48 \mathrm{E} / 28^{\circ}$, $\mathrm{N} 24 \mathrm{E} / 32^{\circ}, \mathrm{N} 10 \mathrm{E} / 42^{\circ}$ e $\mathrm{N} 33 \mathrm{~W} / 10^{\circ}$ (ambos com um eixo), além do eixo da dobra cônica, $\mathrm{S} 80 \mathrm{E} / 70^{\circ}$. Esta dispersão de eixos indica a presença de dobramentos tardios, com eixos $\mathrm{N}-\mathrm{NE}$, subhorizontais. Mesmo assim, é esperado que houvesse coincidência entre o eixo estatístico da Figura 4.23 e os diversos eixos representativos das guirlandas apontadas no quadro 4.2 . 


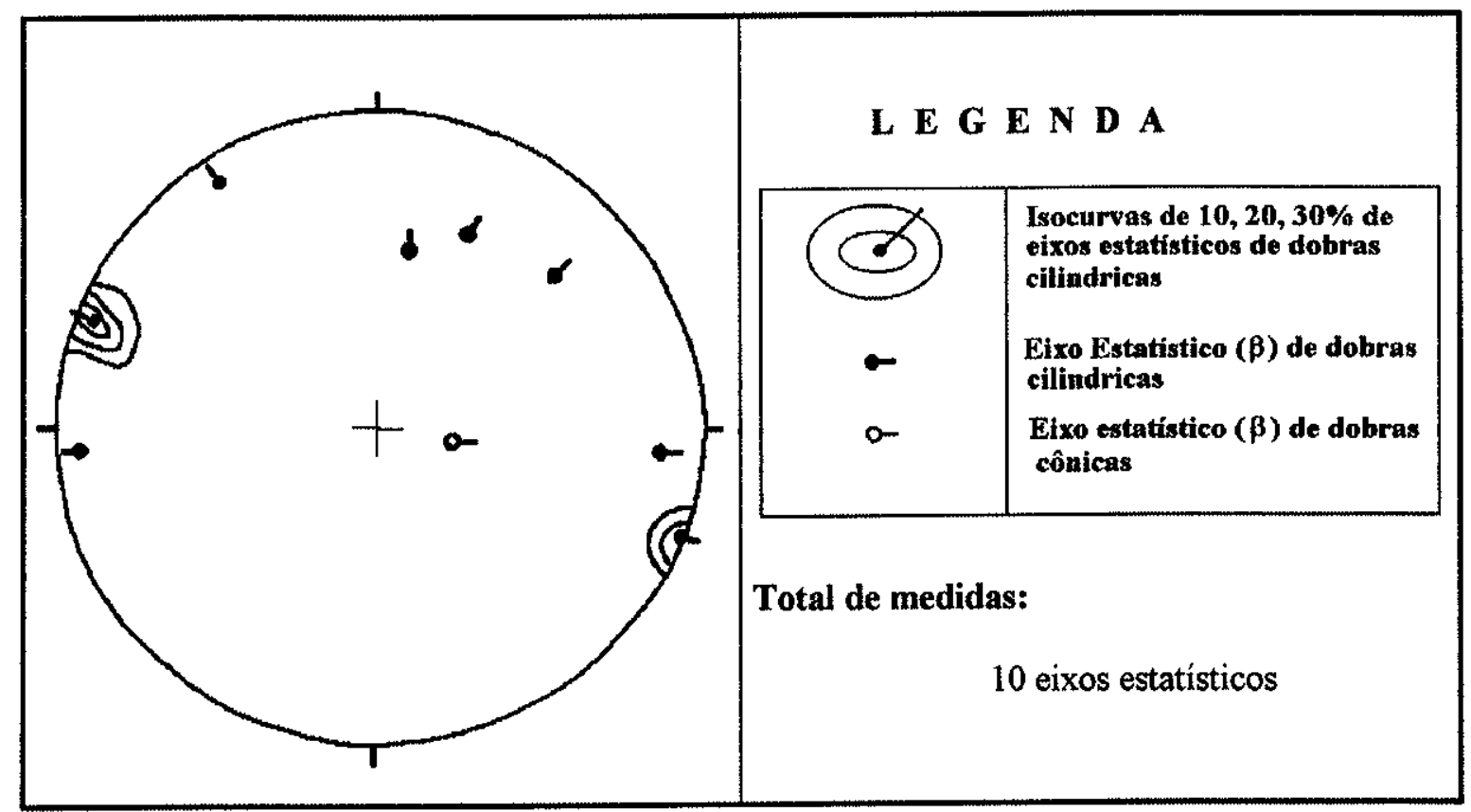

Figura 4.23 - Representação ciclográfica dos diversos eixos estatísticos representativos das guirlandas construídas ao longo do perfil Rio da Barra, e listadas no quadro 4.2.

Esta divergência de resultados pode ser devido a pequena quantidade de dados obtidos ao longo do perfil.

As lineações de intersecção ( $\mathrm{Li}_{S c}^{S s}$ ) formam uma concentração de N67W/06 ${ }^{\circ}$ (Figura 4.24), próximo daquele obtido para os eixos estatísticos das dobras suaves/abertas do diagrama da Figura 4.23. A correlação geométrica entre as lineações de intersecção da Fase $\mathrm{SD}_{1}$ e os eixos de dobras suaves, relacionados a fase $\mathrm{SD}_{4}$, também se verifica neste perfil, a exemplo do perfil Rio da Lomba. (A fase $\mathrm{SD}_{4}$ está relacionada as reativações tardias das transcorrências, ou associada a intrusão de corpos graniticos no Complexo Três Córregos). As três lineações de intersecção situadas no quadrante NE (Ver Figura 4.24) são incongruentes com os demais. O pequeno número de lineações obtidas no perfil (13) é insuficiente para uma discussão mais conclusiva sobre o assunto. O diagrama dos eixos de suaves, referente ao afloramento ED 219 (Figura 4.25), onde foram coletadas 120 medidas, embora com uma certa dispersão dos dados, mostra uma concentração principal dos eixos ao redor de $\mathrm{N} 83 / 09^{\circ}$, evidenciando novamente este dobramento suave, com eixos NE-E.

A Figura 4.25 apresenta, ainda, uma concentração de três eixos, com atitude $\mathrm{S} 21 \mathrm{~W} / 30^{\circ}$, que foge da orientação dos demais eixos medidos. 


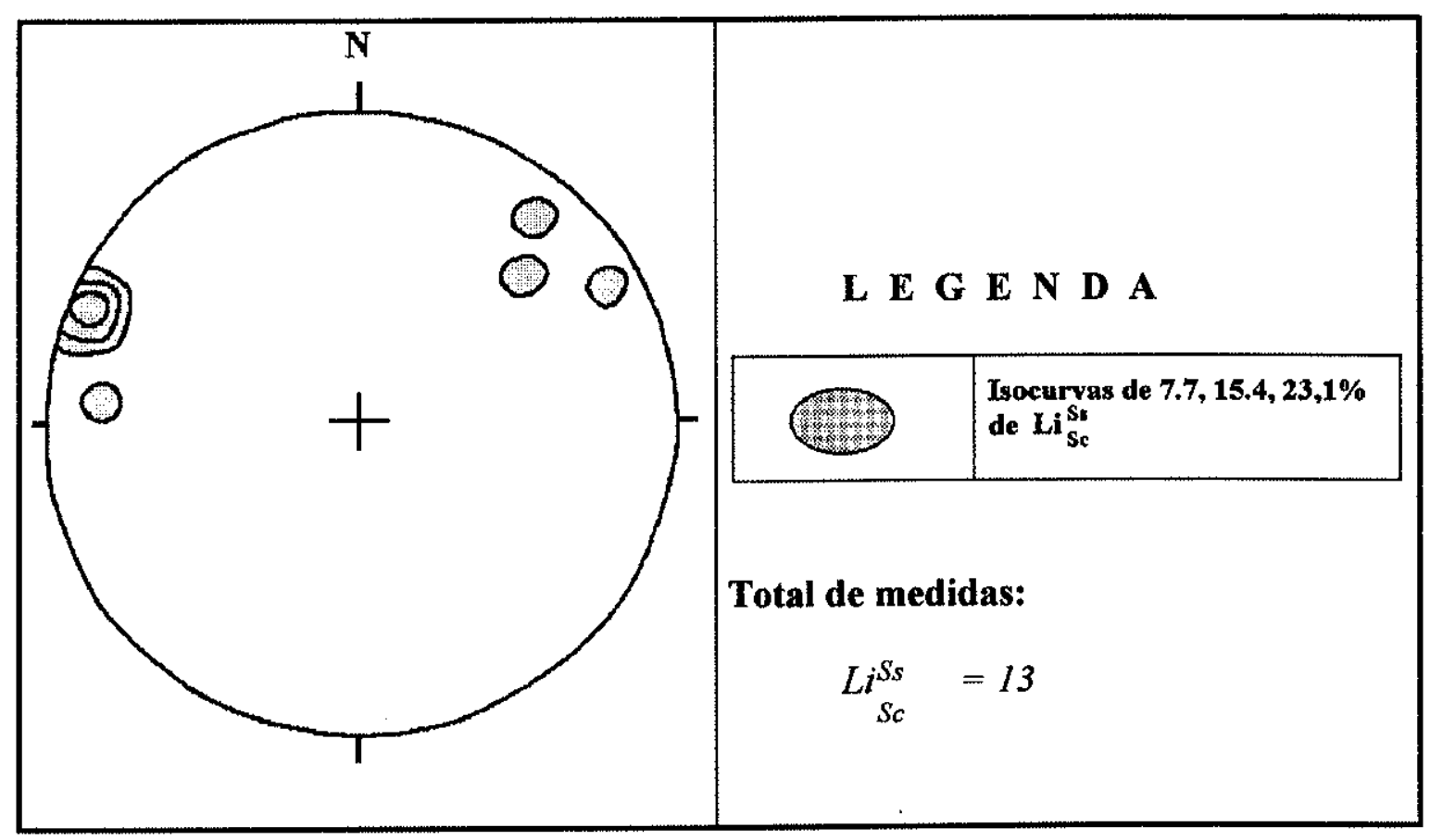

Figura 4.24 - Representação estereográfica das $\mathrm{Li}_{S_{c}}^{S s}$ coletadas no perfil Rio da Barra. Concentração máxima: $\quad \mathrm{N} 67 \mathrm{~W} / 06^{\circ}(23.1 \%$ dos dados).

Em resumo, neste capítulo procurou-se dar uma visão integrada do conjunto de afloramentos analisados, através de diagramas sinópticos das diferentes feições estruturais planares e lineares observadas na região. Estas são no geral coerentes e homogêneos, e as dispersões apresentadas refletem, na realidade, uma variação geométrica regional das estruturas. Finalmente, o estudo do comportamento geométrico de afloramentos contínuos permite um entendimento mais pormenorizado das estruturas, por consequência, um melhor entendimento do seu quadro cinemático. Além disso, este tipo de estudo constitui-se num pré-requisito para o estudo de microtectônica.

\subsubsection{PADR TO CINEMȦTICO DO SISTEMA TRANSPRESSIVO DÚCTIL, NA ESCALA MESOSCÓPICA}

O padrão cinemático verificado através de estruturas dúcteis, como dobras cerradas/isoclinais (com um dos flancos geralmente rompido), dobras em bainha, relação entre as foliações $\mathrm{Ss}_{1} \mathrm{eSc}_{1}$, indicam transporte para S-SE para a componente de cisalhamento puro do 


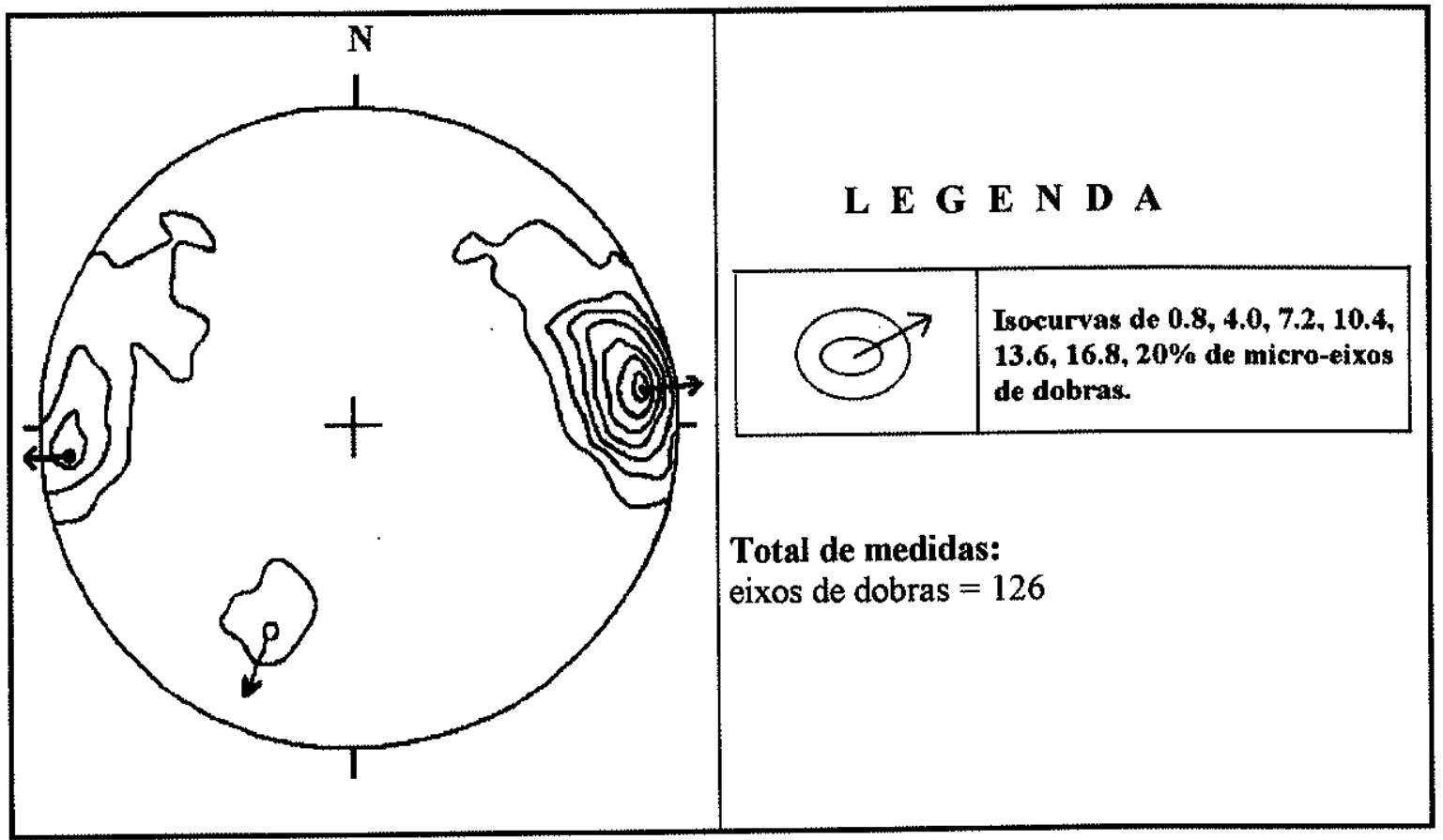

Figura 4.25 - Representação de 126 eixos de dobras do perfil Rio da Barra, dos quais 120 pertencem ao afloramento 219 .

Concentração máxima: N83E $/ 09^{\circ}$ (20\% dos dados);

Concentração Secundária: $\mathrm{S} 21 \mathrm{~W} / 30^{\circ} \quad(7,2 \%$ dos dados $)$.

sistema transpressivo. Esta componente foi gerada pelo processo de partição da deformação, conforme modelo teórico de Tikoff \& Teyssier (1994). Este transporte é idêntico aquele verificado no Grupo Açungui (Formações Votuverava e Capirú) por Fiori et al. (1987a,b,c). Porém, na escala microscópica, foram detectado mais duas direções de transporte, as quais serão descritas e discutidas na sequência do trabalho.

\subsubsection{SISTEMA TRANSCORRENTE}

Os últimos pulsos de deformação do sistema transpressivo, reconhecidos na bibliografia como Sistema Transcorrente, foram mal desenvolvidos nas litologias da Formação Água Clara, principalmente na região de São Pedro/São Silvestre. Este fato se deve, provavelmente, a presença das rochas graníticas do Complexo Três Córregos que funcionaram como um anteparo 
rigido, protegendo as litologias desta unidade, dispostas às suas bordas, das deformações que ocorriam mais afastadas deste. Este aspecto pode ser observado na Figura 4.26, onde fica evidente um decréscimo da deformação a partir do centro da Zona de Cisalhamento Lancinha até o citado complexo.

Embora a deformação transcorrente não seja penetrativa na área, alguns dos seus efeitos foram observados na região estudada, como segue:

\section{a) Dobras Escalonadas}

Esta dobras podem são observadas de forma localizada, pelo padrão de dispersão dos elementos geométricos das dobras em estereogramas de afloramentos ou de integração ao longo dos perfis realizados. Assim, ao longo do perfil Rio da Lomba, nos afloramentos ED 123 e 124, foram identificadas dobras suaves a abertas, com vergência para SE, com eixos estatísticos $\mathrm{N} 22 \mathrm{E} / 16^{\circ}$ e $\mathrm{N} 28 \mathrm{E} / 12^{\circ}$, respectivamente. No afloramento ED 124 identificou-se uma dobra aberta, com eixo estatístico $\mathrm{N} 28 \mathrm{E} / 12^{\circ}$, e ângulo interflancos de $114^{\circ}$. No perfil Rio da Barra, estas interferências estão igualmente presentes, conforme verificado nos dados da foliação $\mathbf{S c}_{(1)}$ obtidos entre os afloramentos ED 179 e 193, onde o eixo estatístico tem valor de N24E/29 . Ambos os eixos são muito próximos do valor médio regional obtido por Fassbinder $(1990,1994)$

para as dobras escalonadas do Sistema Transcorrente Lancinha, cujo valor obtido foi N30E/subhorizontal.

Em outras situações a dispersão da foliação pretérita não chega a se reorganizar numa nova guirlanda, com indicação de um outro eixo. Apenas chega a interferir e, raramente, desorganizar as estruturas pretéritas, facilmente visualizadas nos estereogramas.

Estes redobramentos de natureza transcorrente raramente podem ser observados em escala de afloramento, ou em amostra de mão. Geralmente são perceptíveis numa escala maior, quando os dados $\left(\mathrm{Sc}_{(1)}\right)$ de diversos afloramentos são compilados num mesmo diagrama, geralmente envolvendo distâncias superiores a 100 metros ao longo de perfis. 


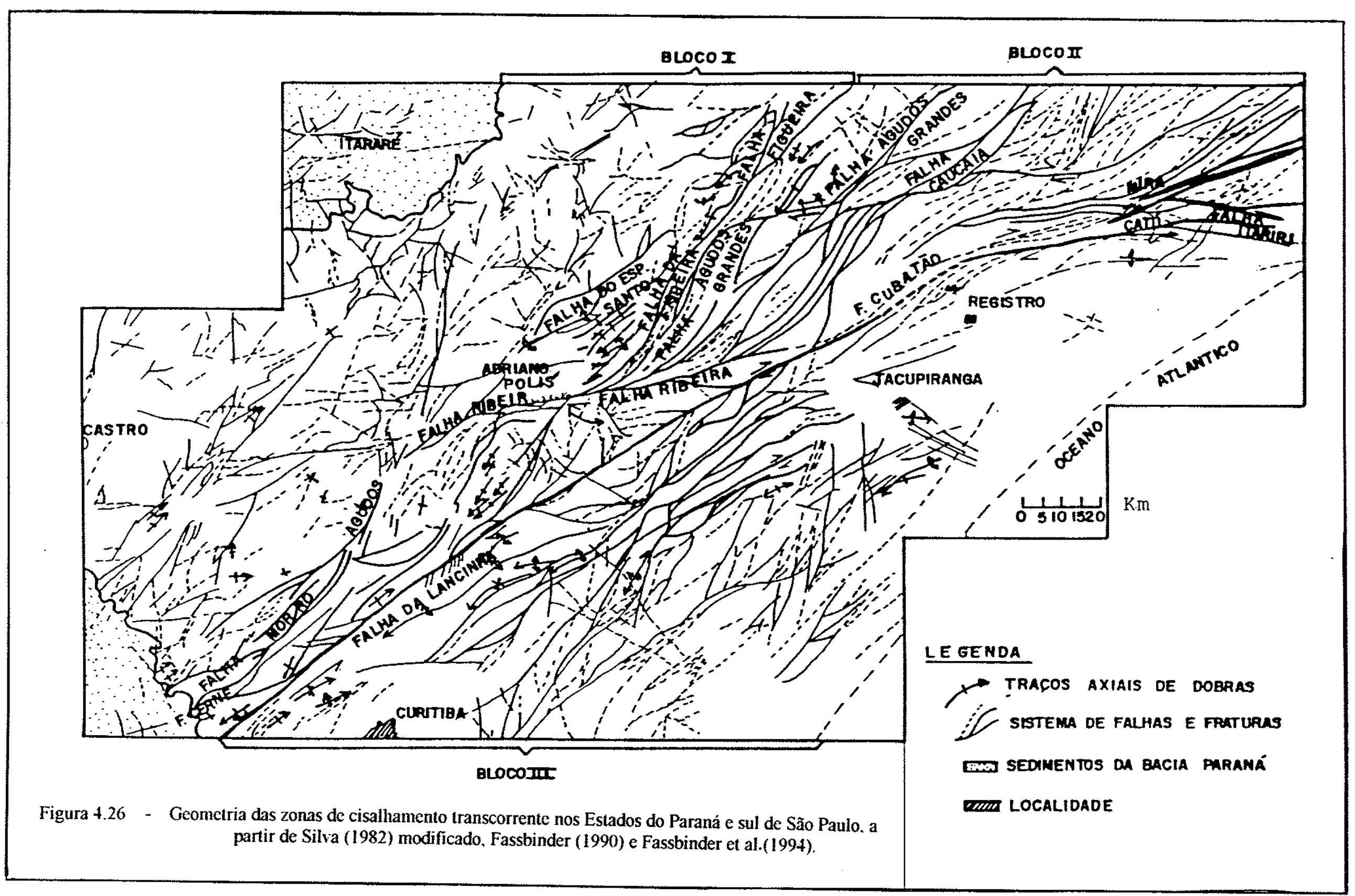


b) Sistema de Reativação

Estão presentes ainda, dobras suaves, com eixos estatísticos $(\beta) \mathrm{N} 64 \mathrm{~W} / 08^{\circ}, \mathrm{N} 66 \mathrm{~W} / 05^{\circ} \mathrm{e}$ $\mathrm{N} 73 \mathrm{~W} / 15^{\circ}$, referente aos afloramentos 107,140 a 145 e 150 a 159 , respectivamente.

A dispersão dos pólos da foliação $\mathrm{Sc}$, ao longo de guirlandas nos diagramas, sugere eixos $\beta$ com direção NW-W. Tais evidências são mais pronunciadas nos afloramentos 150 a 159 , onde foi possível determinar, para estas estruturas, um provável ângulo inter-flancos de $146^{\circ}$.

Estas direções de dobramentos suaves, com eixos $\beta$ com direção NW-W, estão associadas, provavelmente, a esforços atuantes na reativação lateral esquerda dos lineamentos transcorrentes do Pré-Cambriano Paranaense (Ver Fassbinder, 1990 e Fassbinder et al., 1994).

\subsubsection{OUTRAS DEFORMAÇÕES}

Uma última clivagem de fratura, identificada na área de estudos, apresenta direção média N14W/78SW. A uma primeira vista, esta direção poderia ser interpretada como uma estrutura antitética, associada ao sistema de lineamentos transcorrentes, com movimento lateral direito associado, a exemplo das Falhas da Lancinha, Morro Agudo, Itapirapuã, entre outras (Fiori, 1985a; Soares, 1987; Fassbinder, 1990 e Fassbinder et al., 1994b). Porém, uma análise mais detalhada mostrou que se trata, na verdade, de uma clivagem com disposição plano axial à dobras suaves a abertas, de caráter local (ED 119 a 121, 122 e 160) (Figura 4.27B). Ocorre uma distribuição regular dos pólos da foliação $\mathrm{Sc}_{(1)}$ em torno desta nova guirlanda, a qual apresenta um ângulo interflancos de $130^{\circ}$ (Figura 4.27B). Mas nem sempre estas guirlandas ficam bem caracterizadas, sendo muitas vezes apenas sugestivas, como ocorre nas Figuras 4.27A e B.

Este padrão de eixos situa-se à aproximadamente $90^{\circ}$ dos eixos das dobras com direção N85E $/ 10^{\circ}$ (Ver Figura 4.27B). Embora os dois dobramentos apresentem uma disposição suave a aberta dos seus flancos, foi reconhecida o padrão de interferência do tipo 1 de Ramsay (1967) no afloramento ED 132, no qual as superficies axiais apresentaram direções de N10W/90 e N80E/80NW. 


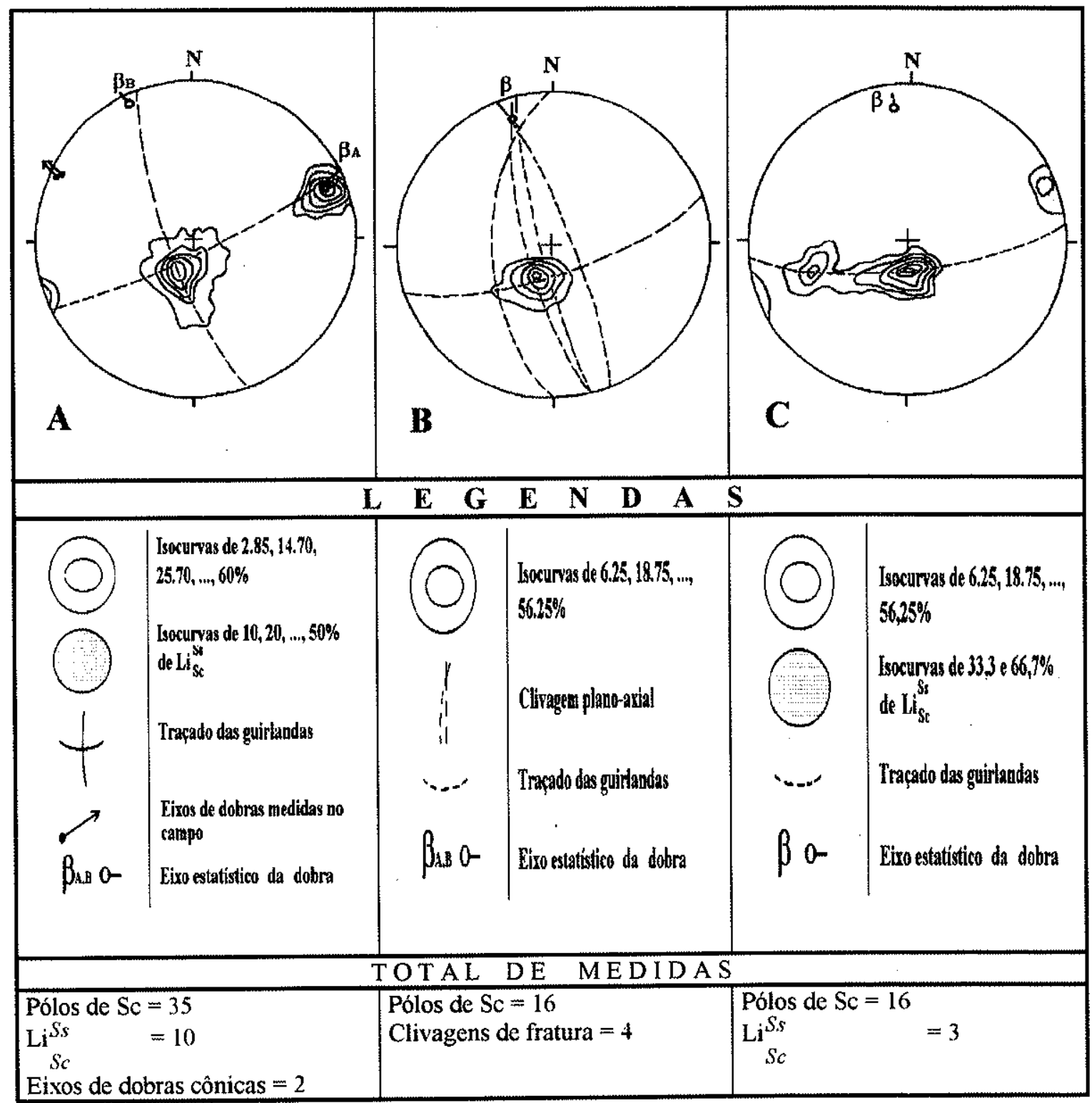

Figura 4.27 - Evidências de uma direção de dobramentos com eixos N-NW na área de São Pedro/ São Silvestre.

A - Eixo de dobra estatística com direção de $\mathrm{N} 25 \mathrm{~W} / 07^{\circ}$. Observar que o eixos estatísticos das dobras suaves/abertas e a $\mathbf{L i}_{S c}^{S s}$ estão situados na direção de N69E/ $13^{\circ}$. ou seja, a $90^{\circ}$ do eixo estatístico anterior (Afloramento ED 119 a 121 ).

B - Clivagens de fratura plano axial as dobras suaves a abertas. locais, com eixo estatístico $\mathrm{N} 18 \mathrm{~W} / 15^{\circ}$ (Afloramento ED 122A).

C - Guirlandas de dobras suaves. com eixo estatístico N07W/15 (Afloramento ED 160). 


\subsubsection{MODELIZAÇÃo E DISCUSSÃO DOS DADOS ESTRUTURAIS DA FORMAÇÃO ÁGUA CLARA}

As estruturas com baixo ângulo [foliações, lineações minerais, eixos de dobras e boudins, descritas neste capítulo e confirmadas através de detalhamento na escala microscópica (Capítulo 4.3)], correspondem a componente de cisalhamento puro de um sistema transpressional.

Neste sistema transpressional ocorreu partição da deformação segundo duas componentes. A primeira, acima referida, foi instalada perpendicular as margens continentais, em colisão oblíqua, gerando o encurtamento da Bacia Açungui através de falhas de baixo ângulo (thrust faults). A componente de cisalhamento simples (transcorrente) foi a responsável pela instalação de uma foliação subverticalizada (cerca de $70 \%$ das foliações do Grupo Açungui), muitas vezes associada a dobras/falhas ou a dobras em processo de transposição, juntamente com as demais estruturas secundárias de Riedel, descritas por Fassbinder (1990) e Fassbinder et al. (1994b). Esta componente transcorrente não é significativa nas litologias da Formação Água Clara na região de São Pedro/São Silvestre, devido, provavelmente, ao predomínio da componente de Cisalhamento Puro.

Este evento transpressivo teria, ainda, exposto diferentes níveis estratigráficos, de metamorfismo e estruturais da bacia, através do seu alçamento em torno de uma estrutura-emflor positiva, com diferentes intensidades (Ver FIG 2.4). Esta ação deformativa expôs, no centro da referida estrutura, litologias das suas porções mais profundas, enquanto na borda da mesma aparecem as porções mais superiores, onde o efeito transpressivo torna-se reduzido. A ação dos processos intempéricos e erosivos, nas litologias com esta estruturação tectônica, gerou a exposição de diferentes porções desta coluna estratigráfica ao longo dos diferentes blocos tectônicos.

\subsection{ANÁLISE DAS ESTRUTURAS NA ESCALA MICROSCÓPICA} 4.4.1 INTRODUÇÃO

Os trabalhos de microtectônica permitiram identificar três pares de foliações SC, os quais correspondem, de uma forma geral, as foliações analisadas no Capítulo 4.2. Estas estruturas acham-se representadas esquematicamente na Figura 4.28, e serão descritas a seguir. 


\subsubsection{SISTEMA DE DEFORMAÇÃO $\mathrm{SD}_{1}$}

O sistema de deformação $\mathrm{SD}_{1}$ é aqui referido como o evento de deformação principal que afetou as litologias da Formação Água Clara. Este sistema corresponde ao Sistema de Cavalgamentos Açungui (SCA) de Fiori (1990,1992a,b).

$\mathrm{O}$ estilo do $\mathrm{SD}_{1}$, com base nas estruturas observadas em afloramentos e lâminas delgadas orientadas, acha-se relacionado a uma tectônica transpressional, da forma como foi empregado por Machado \& Endo (1993).

As principais estruturas desenvolvidas durante a vigência deste regime tectônico são os conjuntos de foliações $\mathrm{Ss}_{1}, \mathrm{Sc}_{1}$, dobras em escalas meso e microscópicas, juntamente com diversas estruturas lineares. Todas essas estruturas acham-se relacionadas a um processo de deformação por cisalhamento simples, aqui atribuídas a um regime de deformação progressiva.

\subsubsection{PLANOS DE FOLIAÇÃ̃ $\mathrm{Ss}_{1}$ e $\mathrm{Sc}_{1}$}

O par de foliações $S-C_{(1)}$ é bem desenvolvido e penetrativo na região de São Pedro - São Silvestre, onde afloram litologias da Formação Água Clara.

A foliação $\mathrm{Ss}_{1}$ dispõe-se de forma oblíqua ao acamamento sedimentar reliquiar, enquanto a foliação $\mathrm{Sc}_{1}$ disposta de forma paralela, formando ângulos de até $30^{\circ}$ entre elas, com indicação de movimentação lateral direita (Figura 4.28). A utilização da terminologia cinemática lateral direita ou esquerda objetiva apenas a caracterização geométrica das foliações, visto que se constitui numa nomenclatura intrínseca de foliações dispostas com alto ângulo. Neste sentido, a sua utilização para foliações de baixo ângulo para os horizontes litoestruturais presentes na área de estudo, pode resultar em erros, pois uma mesma trama estrutural pode fornecer indicação de movimentos horários ou anti-horários, dependendo do corte, que está sendo observado na amostra (Ver discussões no item 4.2.1.5 - Transporte Tectônico).

As foliações $\mathrm{Ss}_{1}$ e $\mathrm{Sc}_{1}$ foram preservadas em determinados niveis litológicos (Fotomicrografia 4.1), na forma de microliton, em meio a trama estrutural superposta. Exemplo de um microliton deste par de foliações pode ser observado na parte inferior da Fotomicrografia 4.2 , onde as porções superior e inferior são limitadas por concentrações horizontais de minerais como biotita e tremolita/actinolita, marcadores de uma foliação superposta $\left(\mathrm{Sc}_{2}\right)$. A foliação $\mathrm{Ss}_{1}$, preservada faz contatos com aquela superposta com ângulos maiores do que $30^{\circ}$. Na parte central do microliton, o par $\mathrm{Ss}_{1}-\mathrm{Sc}_{1}$ preservou sua geometria original, na forma de uma foliação 


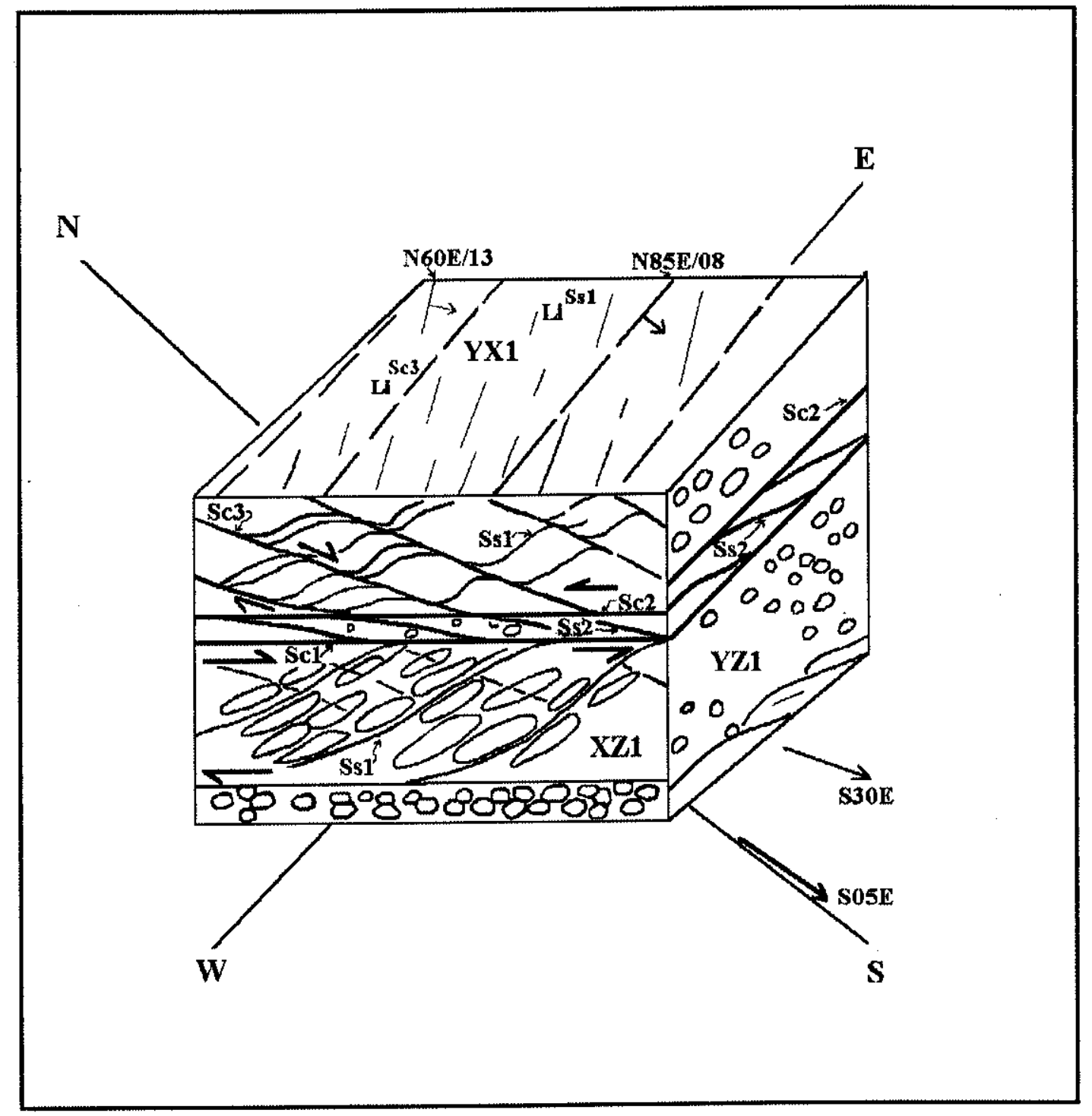

Figura 4.28 - Desenho esquemático das deformações presentes na Área de São Pedro/ São Silvestre. em litologias da Formação Água Clara. identificadas com base nos trabalhos de microtectônica.

$\mathrm{Sc}_{(1)}$ na porção central, reorientando a foliação $\mathrm{Ss}_{1}$, a qual se dispõe com ângulos menores do que $30^{\circ}$. Os detalhes das feições internas do microliton pode ser observado na Fotomicrografia 4.3.

A foliação $\mathrm{Sc}_{1}$ pode aparecer reorientando a foliação $\mathrm{Ss}_{\mathrm{l}}$, ou apresentar uma recristalização de quartzo em seus planos, desestabilizando localmente cristais equigranulares 
estirados, gerados de forma quase contemporânea, porém num momento cedo cinemático em relação a $\mathrm{Sc}_{1}$, dispondo-se ao longo da foliação $\mathrm{Ss}_{1}$ (Fotomicrografia 4.4 e Fotomicrografia 4.5 ).

$\mathrm{O}$ estiramento de quartzo ao longo da foliação $\mathrm{Ss}_{1}$ foi congelada dentro de cristais de granada, os quais sofreram rotações com o prosseguimento da deformação. Essas feições podem ser observadas nas Fotomicrografias 4.6 e 4.7, onde pode ser observado rotação horária cedo cinemática da granada, com presença de cristais de quartzo levemente estirados na parte central e ausência deste estiramento e de extinção ondulante nos cristais das bordas; rotação sincinemática de cristais de granada, ilustrada pelas Fotomicrografias 4.8 e 4.9 , com preservação no seu interior de anfibólio e quartzo, com este último apresentando uma maior deformação e extinção ondulante.

Nos cristais de granada cedo a sin-cinemáticos, a deformação gerou sombras de pressão, que foram ocupadas por cristais de quartzo neocristalizados (Fotomicrografia 4.10; ver Fotomicrografia 4.6), tremolita/actinolita (Fotomicrografias 4.11, 4.12 e 4.13), além de biotita. $O$ crescimento de cristais de granada tardi a pós-cinemáticos pode ser observado nas Fotomicrografias 4.14 e 4.15 . O desenvolvimento deste mineral ocorreu de forma estática sobre a foliação $\mathrm{Sc}_{1}$, esta última formada por quartzo, biotita e anfibólios (tremolita/actinolita). A existência de inclusões de quartzo estirados no interior da granada, contrastam com os cristais de quartzo não estirados na porção externa da mesma. Este aspecto soma-se a forma discordante do cristal de granada com relação aos cristais de biotita marrom circundantes (Ver Fotomicrografia 4.14), ressaltando, assim, as características tardi a pós-tectônicas deste cristal de granada.

De uma forma geral, as principais associações minerais desenvolvidas sobre a foliação $\mathrm{Ss}_{1}$ são constituídas por diopsídio, granada, biotita e quartzo; sobre a foliação $\mathrm{Sc}_{1}$ verifica-se o desenvolvimento de uma idêntica associação mineral, sendo acrescida apenas de clinozoisita.

\subsubsection{LINEAÇÕES}

A existência de lineações de intersecção da foliação $\mathrm{Ss}$, sobre a foliação $\mathrm{Sc}_{1}$ pode ser recuperada em domínios menos deformados pela superposição dos eventos superpostos $\mathrm{SD}_{2} \mathrm{e}$ $\mathrm{SD}_{3}$. São comuns situações em que as lineações de intersecção da superfície $\mathrm{Ss}_{\mathfrak{3}}$, sobre as superficies de $\mathrm{Sc}_{3}$ e $\mathrm{Sc}_{1}$, cortam as lineações geradas por $\mathrm{Sc}_{1}$, conforme esquematizado na Figura 4.28. 
Fotomicrografia 4.1 - Cisalhamento lateral direito gerado ao longo de planos $\mathrm{Ss}_{1} \mathrm{e} \mathrm{Sc}_{1}$, marcados por minerais de quartzo e anfibólios, respectivamente. Afloramanento ED 158, amostra 01, corte 2; aumento na objetiva, 2.5x e ocular, 12.5x; luz natural e nicois normais.

Fotomicrografia 4.2 - As foliações $\mathrm{Ss}_{1} \mathrm{eSc}_{1}$ preservadas em microlitons, na parte inferior da foto. Observar as feições de arrasto e dobramento da foliação $\mathrm{Ss}_{1}$ pela superposição da Foliação $\mathrm{Sc}_{2}$. Afloramento ED 202, corte 2; aumento na objetiva, 2.5x e ocular, 12.5x; luz polarizada e nicóis cruzados.

Fotomicrografia 4.3 - Detalhe da relação entre as foliações $\mathrm{Ss}_{1}$ e $\mathrm{Sc}_{1}$, preservadas no microliton da Fotomicrografia 4.2. Afloramento ED 202, corte 2; aumento na objetiva, $6.3 x$ e ocular, 12.5x; luz polarizada e nicóis cruzados.

Fotomicrografia 4.4 - Recristalização de quartzo ao longo dos planos da foliação $\mathrm{Sc}_{1}$, e a preservação dos cristais de quartzo sobre os planos $\mathrm{Ss}_{1}$. Afloramento ED 198, amostra 1; aumento na objetiva, 6.3x e ocular, 12.5x; luz polarizada e nicóis cruzados.

Fotomicrografia 4.5 - Cristais de quartzo com razões de estiramento da ordem de 3 a 5:1, em fase de recuperação/ recristalização. Observar a presença da foliação $\mathrm{Sc}_{3}$, disposta com direção NW-SE na fotomicrografia. Ambas as foliações apresentam tremolita/actinolita associadas. Afloramento ED 125, corte 1; aumento na objetiva, 6.3x e ocular, 12.5x; luz polarizada e nicóis cruzados.

Fotomicrografia 4.6 - Cristal de granada gerada em condições cedo cinemáticas, apresentando rotação horária. Afloramento ED 175; aumento na objetiva, 2,5x e ocular, 12.5x; luz polarizada e nicóis cruzados. 


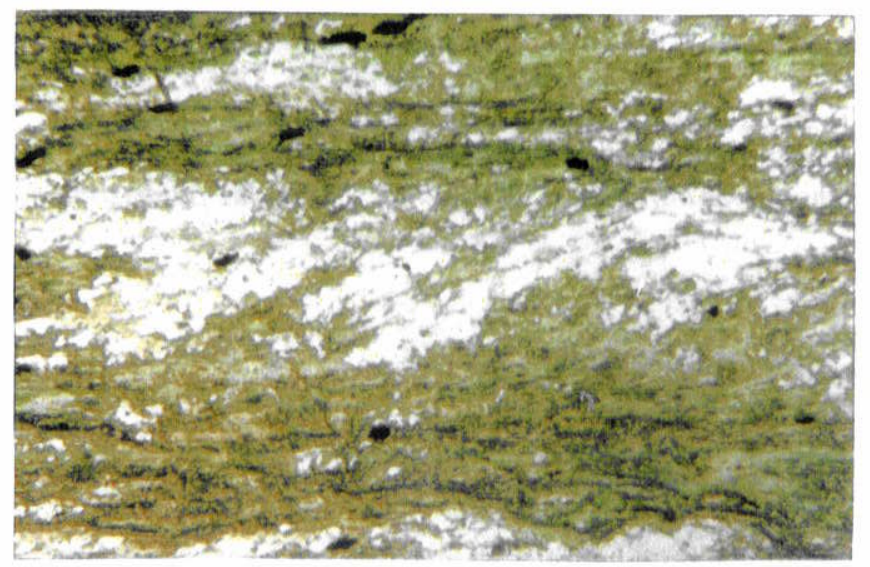

FM 4.1

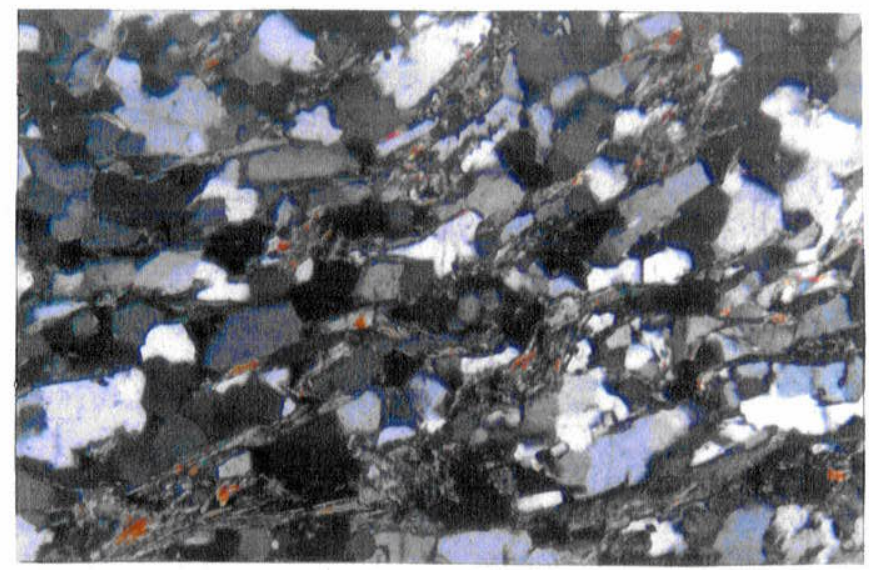

FM 4.3

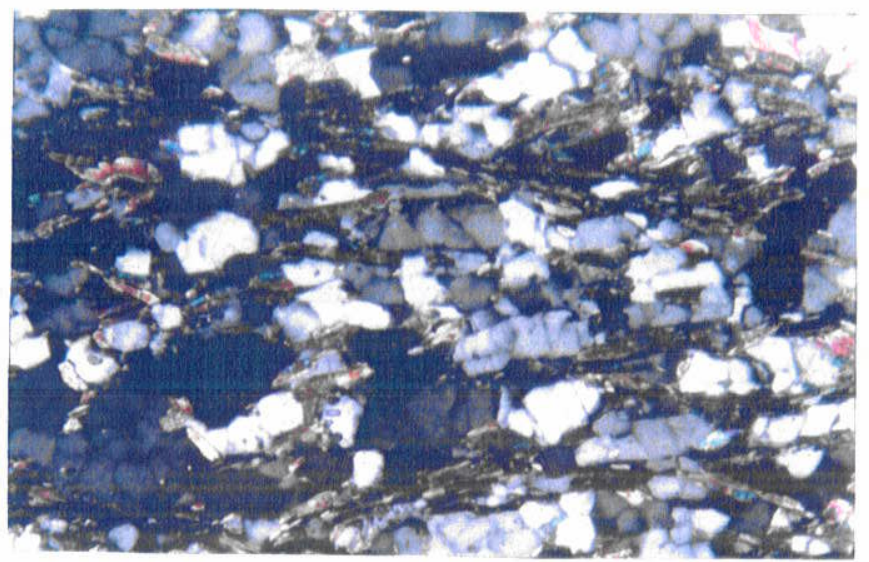

FM 4.5

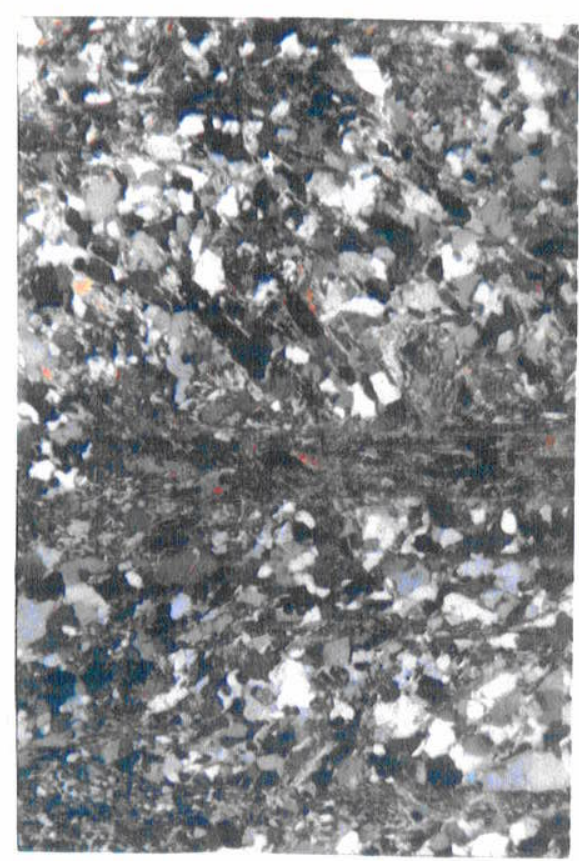

FM 4.2

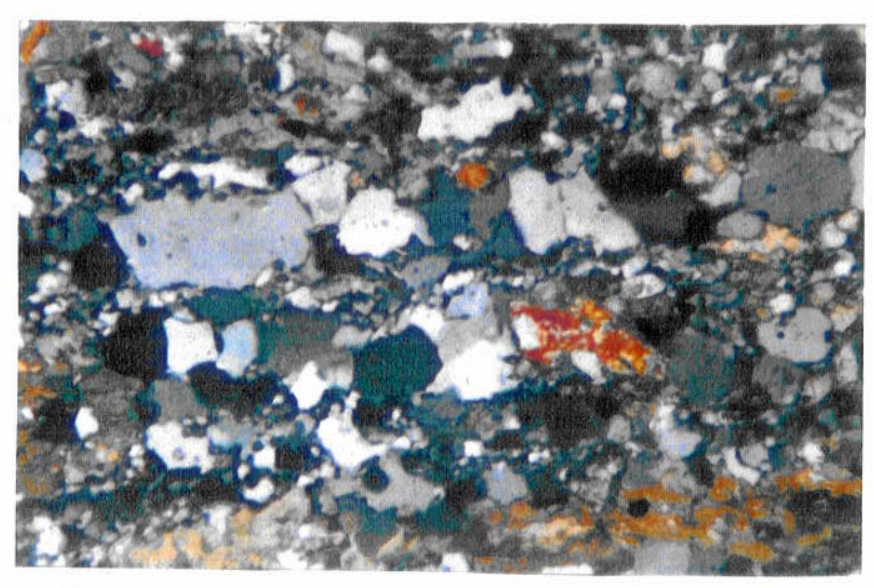

FM 4.4

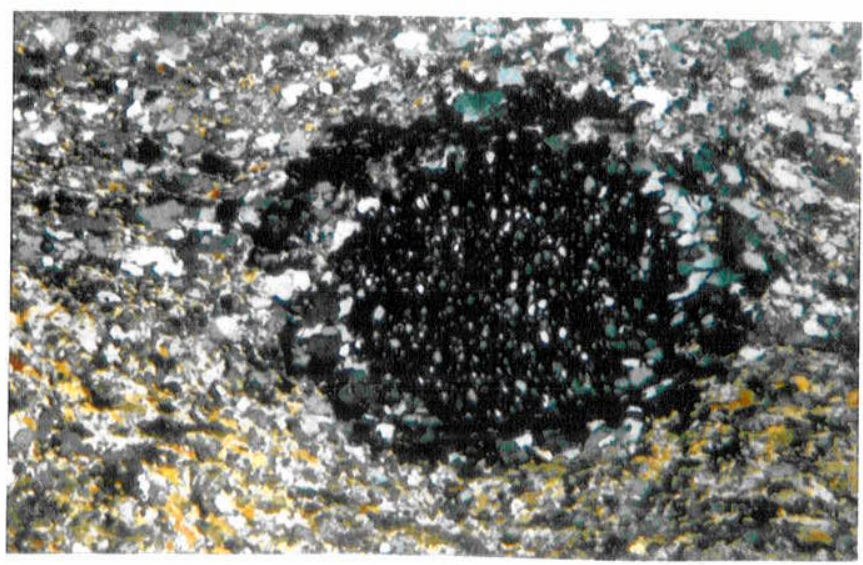

FM 4.6 
Fotomicrografia 4.7 - Detalhe da foliação interna na granada da fotomicrografia anterior. Observar o quartzo com uma deformação muito pequena, e ausência de extinção ondulante. Afloramento ED 175; aumento na objetiva, $6.3 x$ e ocular, 12.5x; luz polarizada e nicóis cruzados.

Fotomicrografia 4.8 - Granada sin-cinemática, englobando uma foliação marcada por quartzo estirado e tremolita/actinolita, com rotação horária associada. Afloramento ED 106, amostra 2; aumento na objetiva, 2.5x e ocular, 12.5x; luz polarizada e nicóis cruzados.

Fotomicrografia 4.9 - Detalhe da Fotomicrografia 4.8, mostrando a rotação horária do cristal de granada. Afloramento ED 106, amostra 2; aumento na objetiva, 6.3x e ocular, $12.5 x$; luz polarizada e nicóis cruzados.

Fotomicrografia 4.10 - Rotação horária em duas granadas cedo a sin-cinemáticas. Observar a sombra de pressão, formada por minerais de quartzo neocristalizados na porção oeste da fotomicrografia. Afloramento ED 175; aumento na objetiva, $2.5 x$, e ocular, $12.5 x$; luz polarizada e nicóis cruzados.

Fotomicrografia 4.11 - Cristais de granada cedo a sin-cinemáticos, desenvolvidos sobre a foliação $\mathrm{Sc}_{1}, \mathrm{e}$ dispostos de forma paralela ao acamamento sedimentar reliquiar (So). Observar a presença de clinozoisita sobre os planos de $\mathrm{Sc}_{1}$, com cor de interferência anômala (azul índico). Afloramento ED 199, amostra 1, corte 2; aumento na objetiva, $2.5 x$ e ocular, 12.5x; luz polarizada e nicois cruzados. 


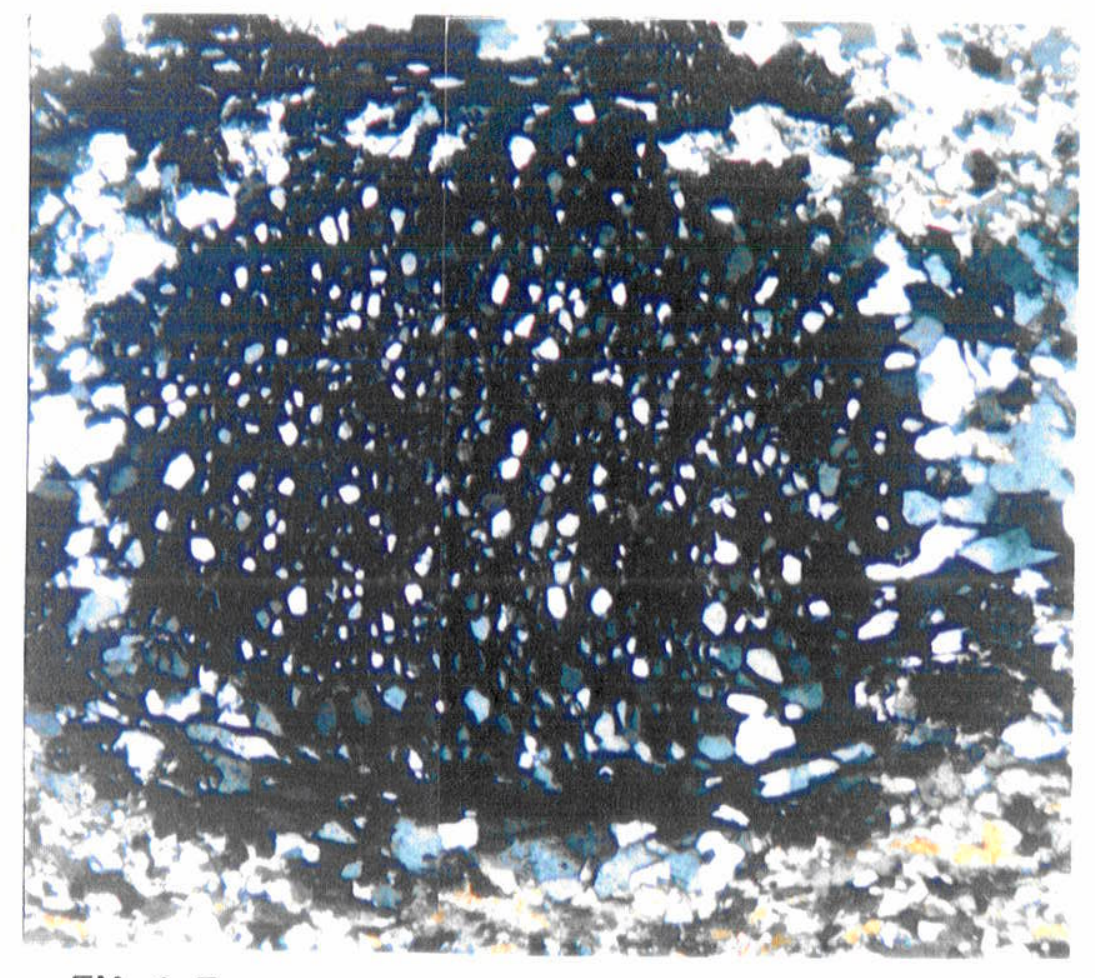

FM 4.7

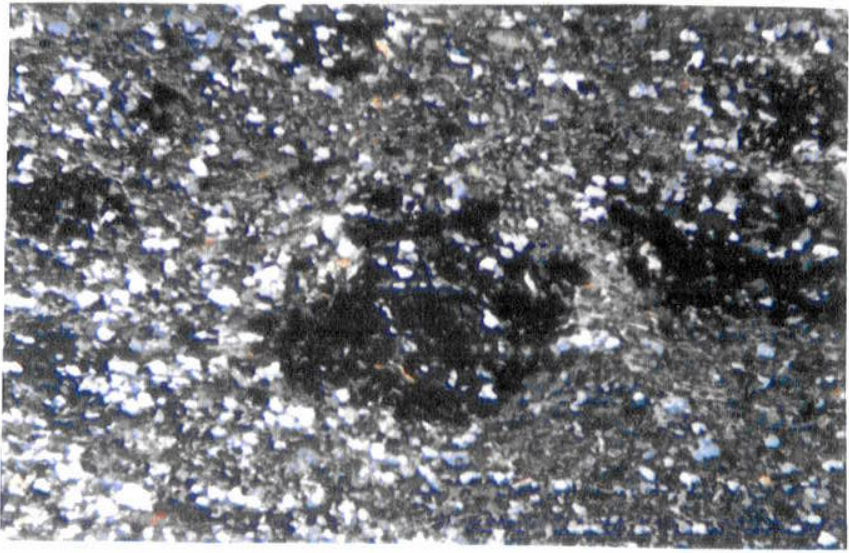

FM 4.8

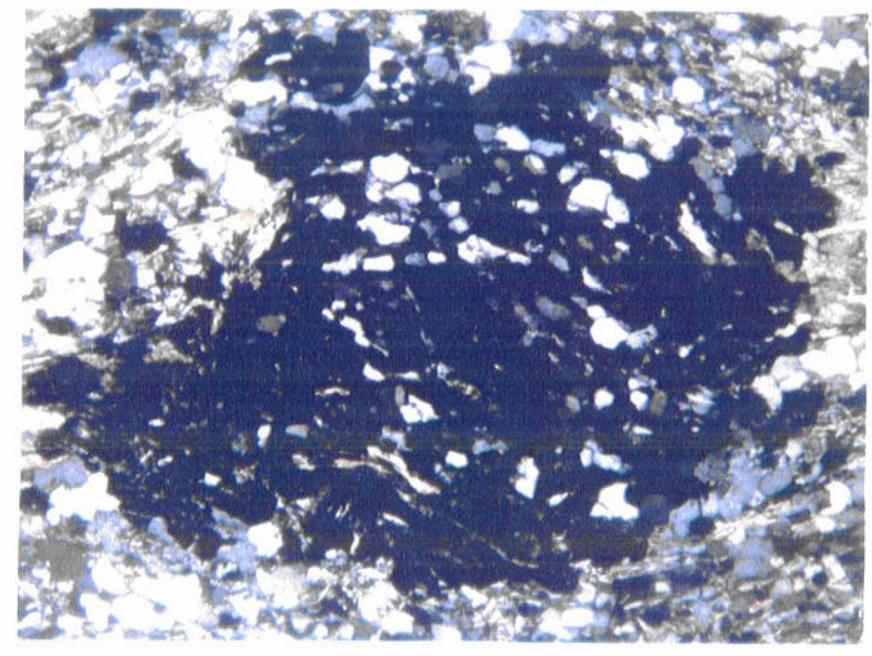

FM 4.9

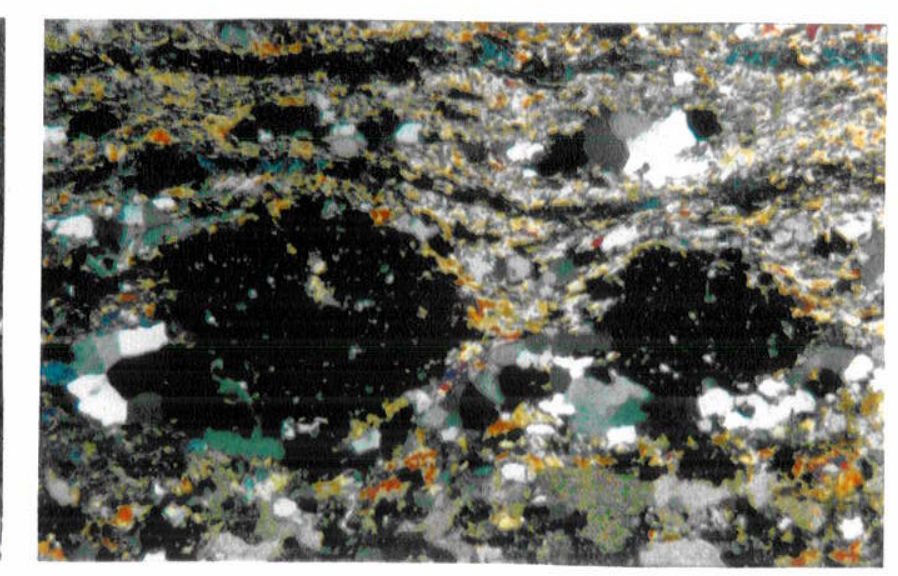

FM 4.11

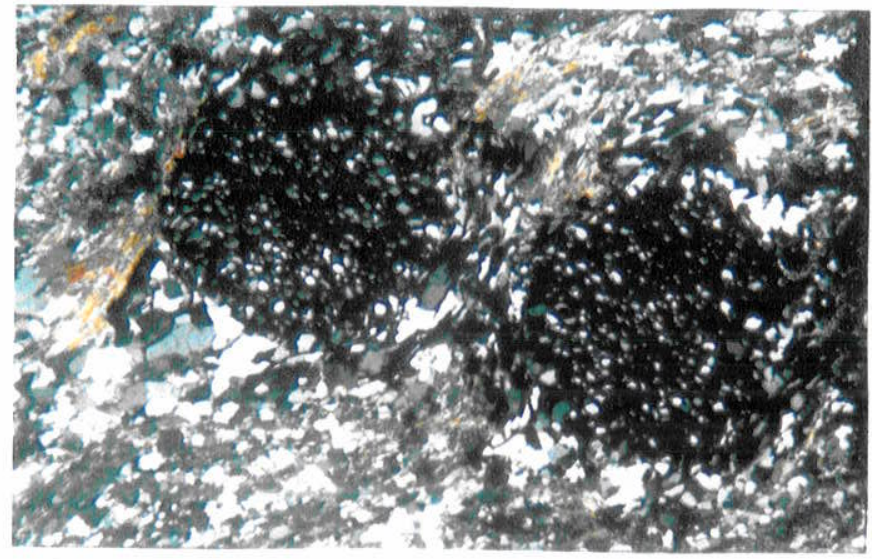

FM 4.10 
Por outro lado, lineações de estiramento mineral são marcadas pela deformação de cristais de quartzo, numa razão de 3 a 5:1, respectivamente, para os eixos $\mathrm{X}$ e $\mathrm{Z}$ do elipsóide de deformação. Porém, no campo, estas lineações de estiramento mineral são de difícil identificação, devido a granulação fina dos níveis quartzosos intercalados nas metamargas e nos metacalcários.

\subsubsection{OUTRAS ESTRUTURAS}

Dobras, em escala de lâmina, associadas ao Sistema $\mathrm{SD}_{1}$, são de dificil recuperação, devido a superposição de estruturas geradas nos eventos $\mathrm{SD}_{2}$ e $\mathrm{SD}_{3}$. Dobras geradas no evento $\mathrm{SD}_{2}$ apresentam, em algumas situações, cristais de diopsídio em seus flancos, preservados do retrometamorfismo generalizado que transformou piroxênios em anfibólios (série tremolita/ actinolita) (Afloramento ED 120, amostra 3) (ver item 4.2.2, com a descrição do sistema de deformação na escala mesoscópica). Em outras situações, a foliação $\mathrm{SC}_{(1)}$ pode ser recuperada no interior de boudins ou em micrólitons resultantes do processo de deformação por cisalhamento simples, durante o evento $\mathrm{SD}_{2}$ (Fotomicrografia 4.16).

De uma forma geral, a foliação $\mathrm{S}-\mathrm{C}_{(1)}$ apresenta as seguintes características:

1. Quartzo estirado, parcial ou totalmente recristalizado, muitas vezes com recuperação/ recristalização de grãos, ou ainda em cristais idiomórficos, com extinção ondulante;

2. Presença de cristais de diopsídio, muitas vezes em secções basais sobre o plano $\mathrm{XZ}$ (elipsóide de deformação) do Sistema de Deformação $\mathrm{SD}_{2}$;

3. Cristais de granada rotacionados, contendo inclusões de quartzo;

4. Cristais de microclínio, intensamente deformados, pelos eventos $\mathrm{SD}_{1}$ e $\mathrm{SD}_{2}$, e, possivelmente, pelo $\mathrm{SD}_{3}$, com geração de estruturas do tipo ribbon.

5. Cristais de plagioclásio, associados possivelmente ao evento $\mathrm{SD}_{1}$, embora possam também pertencer aos eventos $\mathrm{SD}_{2}$ ou $\mathrm{SD}_{3}$;

6. O retrometamorfismo generalizado presente no evento $\mathrm{SD}_{2}$, modificou substancialmente as paragênese geradas no evento anterior $\left(\mathrm{SD}_{1}\right)$, preservando alguns minerais como diopsídio, granada, microclínio e, provavelmente, plagioclásio. 


\subsubsection{SISTEMA DE DEFORMAÇÃO $\mathrm{SD}_{2}$}

Um segundo sistema de deformação se desenvolveu sobre os planos de anisotropia da foliação pretérita $\mathrm{Sc}_{1}$ (ver esquema na Figura 4.28). Este sistema afetou litologias da Formação Água Clara de forma heterogênea, gerando estruturas com redobramento das foliações $\mathrm{Ss}_{1}$ e $\mathrm{Sc}_{1}$, incluíndo dobras cerradas a isoclinais do tipo strain slip, com flancos rompidos, foliações $\mathrm{Ss}_{2} \mathrm{e}$ $\mathrm{Sc}_{2}$ e estruturas lineares de dificil individualização.

\subsubsection{DOBRAS}

A nível de lâmina delgada foram identificadas foliações dobradas por mecanismos de strain slip, com foliação plano axial mostrando uma geometria com a foliação anterior, indicativa de transporte tectônico para norte. Tais estruturas dobram as foliações $\mathrm{Ss}_{1}$ e $\mathrm{Sc}_{1}$, podendo evoluir para uma foliação de transposição. Durante este processo de transposição, ocorreu o desenvolvimento de um novo par de foliações $\mathrm{S}-\mathrm{C}_{(2)}$, com biotita e granada neocristalizadas sobre o plano da foliação $\mathrm{Ss}_{2}$ (Fotomicrografias 4.17 e 4.18), podendo ser rotacionadas e paralelizadas à foliação $\mathrm{Sc}_{2}$ (Fotomicrografias 4.19 e 4.20).

Cristais de granada com relevo moderado, idêntico àqueles evidenciadas nas Fotomicrografias 19 e 20, foram também observados como cristais sobrecrescidos cedo a sincinemáticos ao evento $\mathrm{SD}_{1}$, congelando e rotacionando uma foliação metamórfica anterior, presente no seu interior (Fotomicrografias 21 a 26). Este estágio de sobrecrescimento confere condições de desenvolvimento tardi-cinemático em relação ao evento $\mathrm{SD}_{1}$.

Esse sobrecrescimento ná formação das granadas apresenta, ainda, as seguintes características:

1. Relevo sensivelmente menor, descrito como moderado neste trabalho, em relação aos cristais de granada formados nos estágios de crescimento cedo a sin-cinemáticos. $\mathrm{O}$ relevo desta fase tardi-cinemática é muito próximo daquele verificado nos cristais de anfibólio;

2. Crescimento estático sobre a foliação metamórfica $\mathrm{Sc}_{1}$, sugerindo ausência de deformação não-coaxial durante esta fase;

3. Neoformação de granadas, exibindo reações de borda com outros minerais. Presença de granadas isótropas, sem vestígios de foliação anterior, mostrando discordância nas bordas com a foliação metamórfica externa. 
Fotomicrografia 4.12 - Sombra de pressão formada ao lado de cristal de granada cedo a sin-cinemático, ocupada por quartzo e anfibólio (mineral com cor verde). Minerais de biotita marrom foram neocristalizados sobre os planos da foliação Sc, . Afloramento ED 194; aumento na objetiva, 6.3x e ocular, 12.5x; luz natural e nicóis normais.

Fotomicrografia 4.13 - Idem Fotomicrografia 4.12, com luz polarizada e nicóis cruzados.

Fotomicrografia 4.14 - Granada sin a tardi-tectônica, crescendo sobre a foliação $\mathrm{Sc}_{1}$, porém sem sofrer rotação, e apresentando relevo alto. A foliação $\mathrm{Sc}_{1}$ apresenta minerais de anfibólio (Tremolita/actinolita), biotita, quartzo e opacos associados a seus planos. Afloramento ED 199, amostra 5, corte 2; aumento na objetiva, 6.3x e ocular, 12.5x; luz natural e nicóis normais.

Fotomicrografia 4.15 - Idem Fotomicrografia 4.14, com luz polarizada e nicóis cruzados.

Fotomicrografia 4.16

- Foliação $S-C_{4}$ preservada na forma de minerais de diopsidio (secçð̃es basais no centro da fotomicrografia) e biotitas, dispostas perpendicularmente a foliação de transposição em dobras do tipo "strain slip". Afloramento ED 103, amostra 4, corte 1; aumento na objetiva, 6.3x e ocular, 12.5x; luz polarizada e nicóis cruzados.

Fotomicrografia 4.17 - Minerais de granada estirados segundo o plano da foliação $\mathrm{Ss}_{2}$ e associados a minerais de biotita e anfibólio. Observar o relevo moderado dos minerais de granada.

Afloramento ED 103, amostra 4, corte 1; aumento na objetiva, 6.3x, e ocular, 12.5x; luz natural e nicóis normais.

Fotomicrografia 4.18 - Idem Fotomicrografia 4.17. com luz polarizada e nicóis cruzados. 


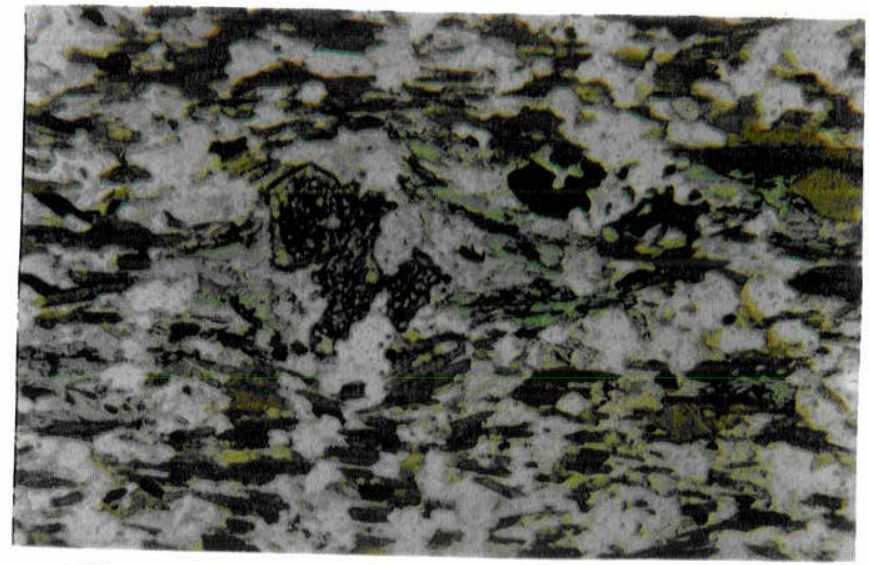

FM 4.12

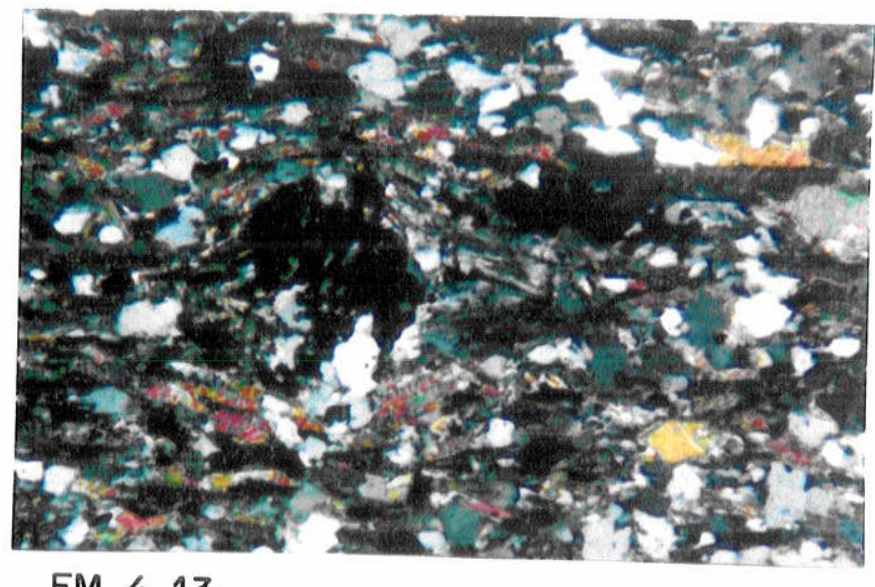

FM 4.13

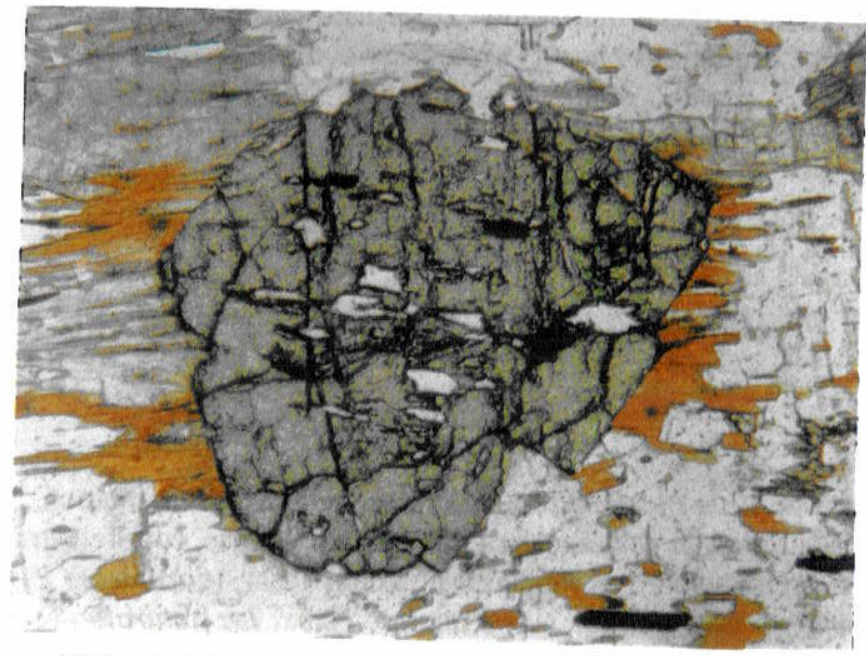

FM 4.14

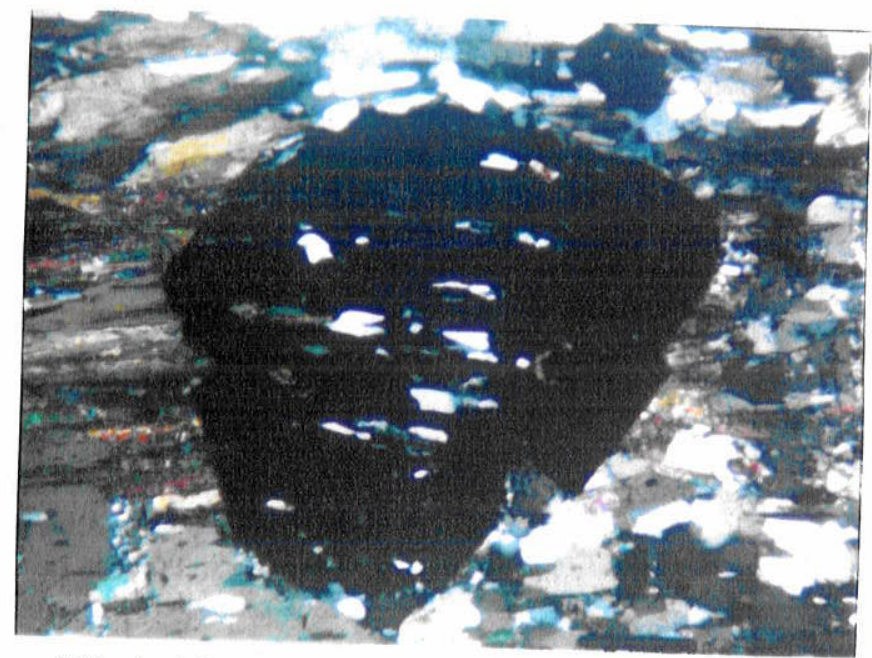

FM 4.15

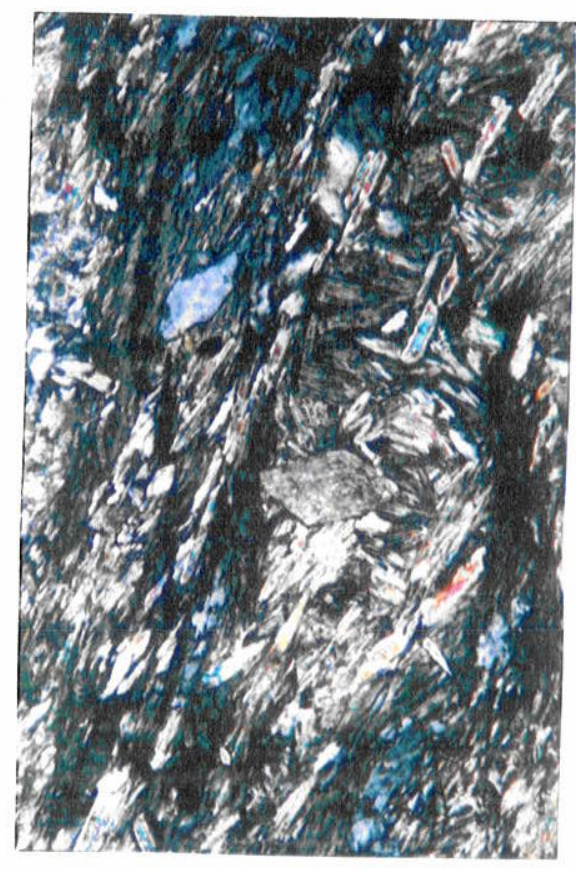

FM 4.16

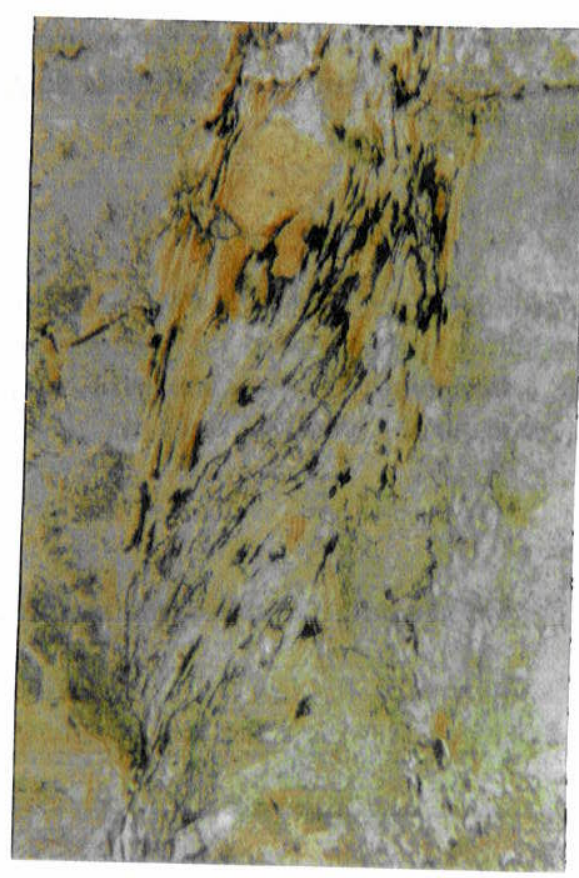

FM 4.17

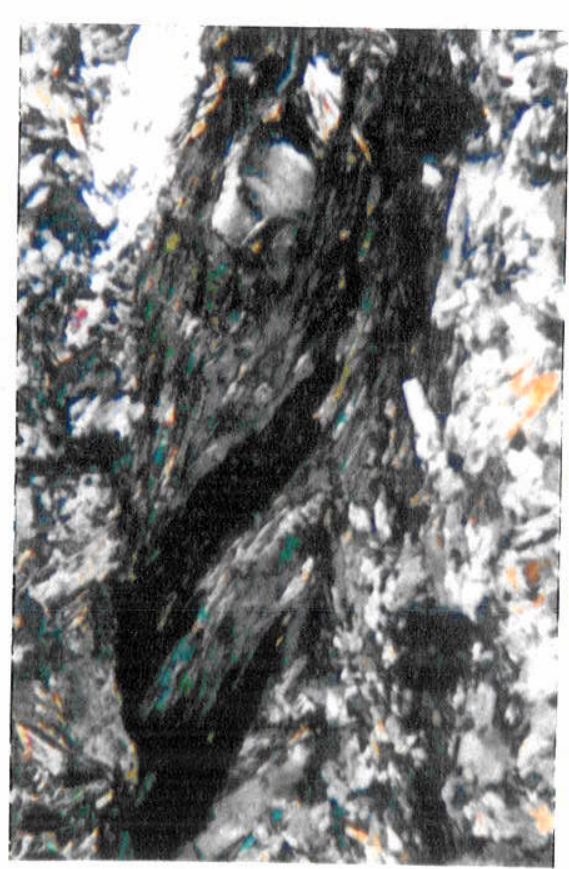

FM 4.18 
Fotomicrografia 4.19

Minerais de granada estirados numa relação de 8 a 10:1 e dispostos segundo o plano $\mathrm{Sc}_{2}$. Observar minerais de microclínio dispostos segundo as folią̧⿸厃s $\mathrm{Ss}_{\uparrow}$ e $\mathrm{Sc}_{\uparrow}$. Afloramento ED 103, amostra 4, corte 1; aumento na objetiva, 6.3x, e ocular, 12.5x; luz natural e nicóis normais.

Fotomicrografia 4.20 - Idem Fotomicrografia 4.19 com luz polarizada e nicóis cruzados.

Fotomicrografia 4.21 - Cristal de granada com duas fases de crescimento cinemático: cedo a sim. com relevo alto; e tardi a pós-cinemático, com relevo moderado e neocristalização estática. A associação mineral é composta, ainda, por biotitas, tremolita/ actinolita e quartzo. Afloramento ED 199, amostra 5, corte 2; aumento na objetiva, 2.5x e ocular, 12.5x; luz natural e nicóis normais.

Fotomicrografia 4.22 - Idem Fotomicrografia 4.21, com luz polarizada e nicóis cruzados.

Fotomicrografia 4.23

Cristal de granada com duas fases de crescimento. A $1^{\circ}$ fase, cedo a sin-cinemática, com relevo alto, rotaciona uma foliação metamórfica interna; e a $2^{\circ}$ fase, com relevo moderado, cresceu de forma estática sobre as foliações metamórficas. Afloramento $E D$ 199, amostra 5, corte 2; aumento na objetiva, 2.5x e ocular, 12.5x; luz natural e nicóis normais.

Fotomicrografia 4.24 - Idem Fotomicrografia 4.23, com luz polarizada e nicóis cruzados. A associação mineral presente na lâmina é constituída de granada, anfibólio (tremolita/actinolita), quartzo e biotita.

Fotomicrografia 4.25 -

Idem Fotomicrografias 23 e 24. Observar minerais de tremolita/actinolita com hábito fibro-radial no canto sudoeste da fotomicrografia. Ocorrem, ainda, biotita, quartzo e opacos. Afloramento ED 199, amostra 5, corte 1; aumento na objetiva, 2.5x e ocular, 12.5x; luz natural e nicóis normais.

Fotomicrografia 4.26 - Idem Fotomicrografia , com luz polarizada e nicóis cruzados. 
109

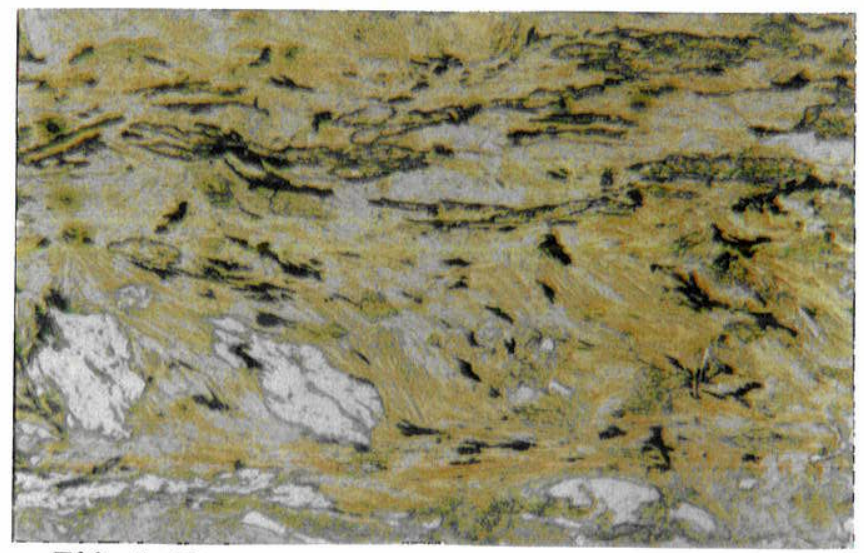

FM 4.19

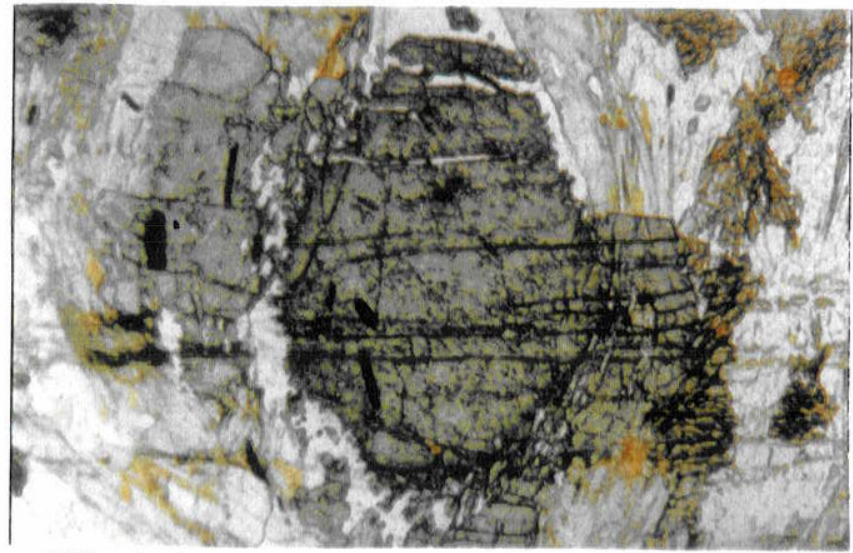

FM 4.21

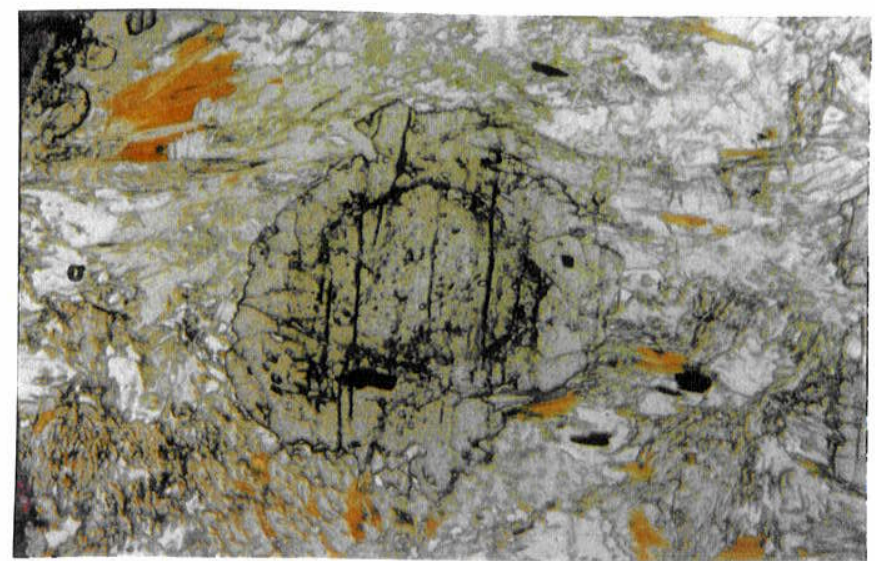

FM 4.23

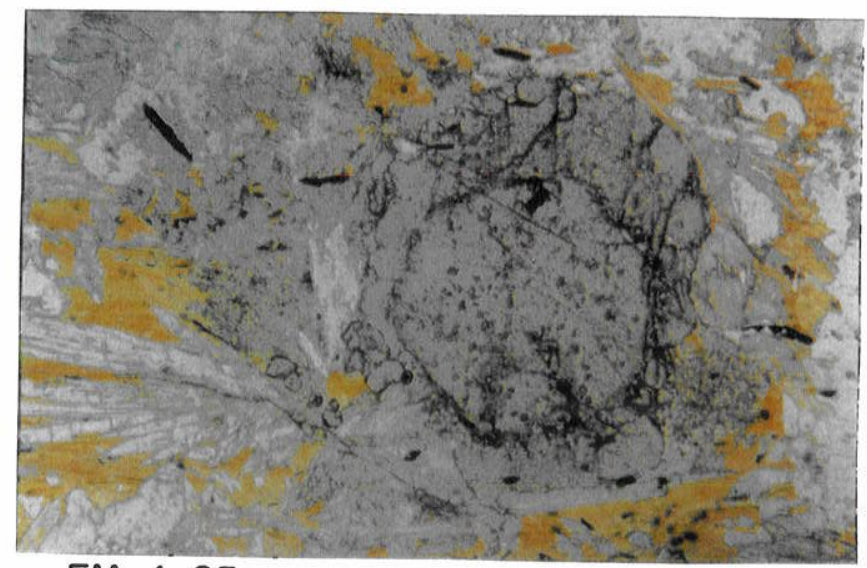

FM 4.25
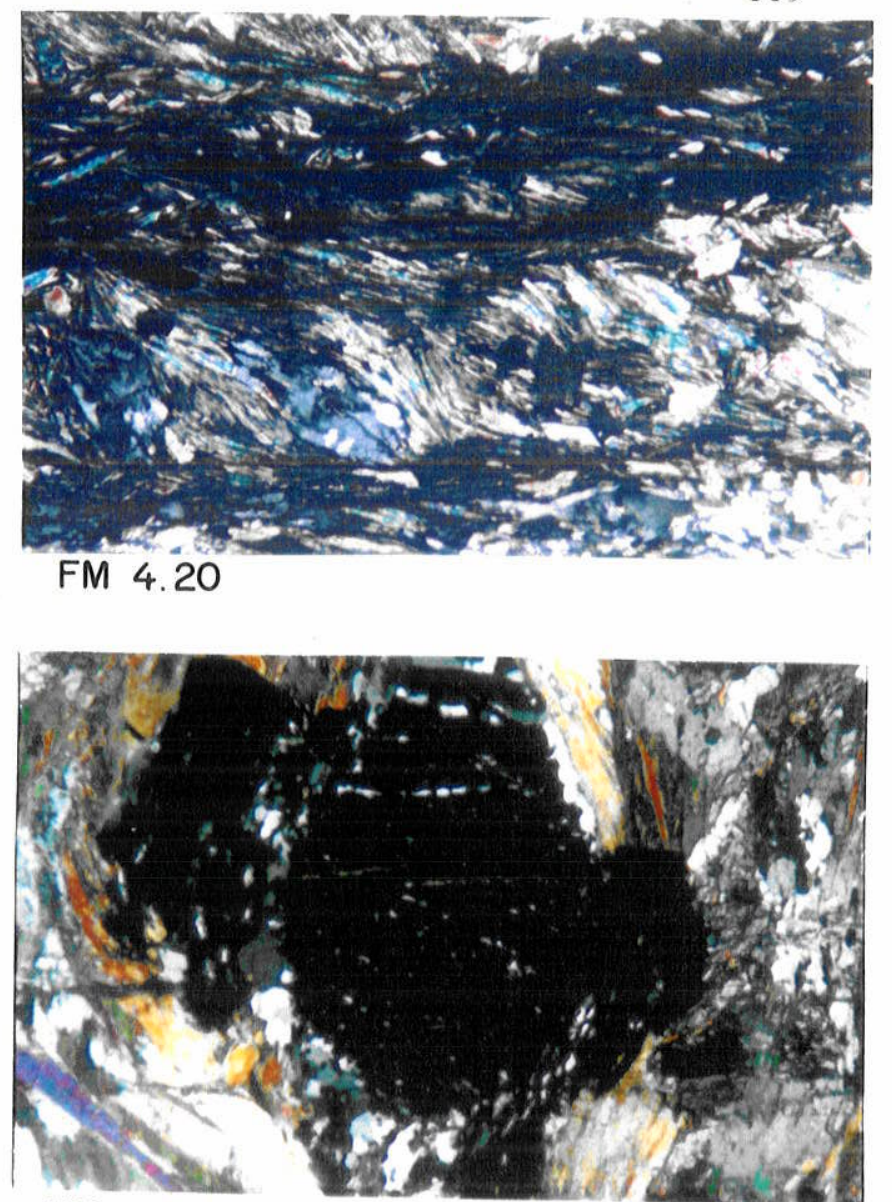

FM 4.22

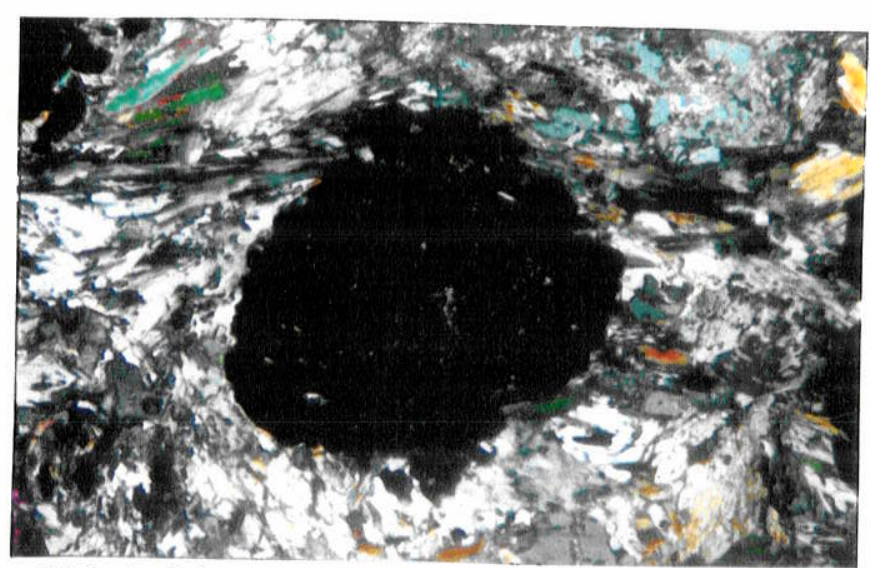

FM 4.24

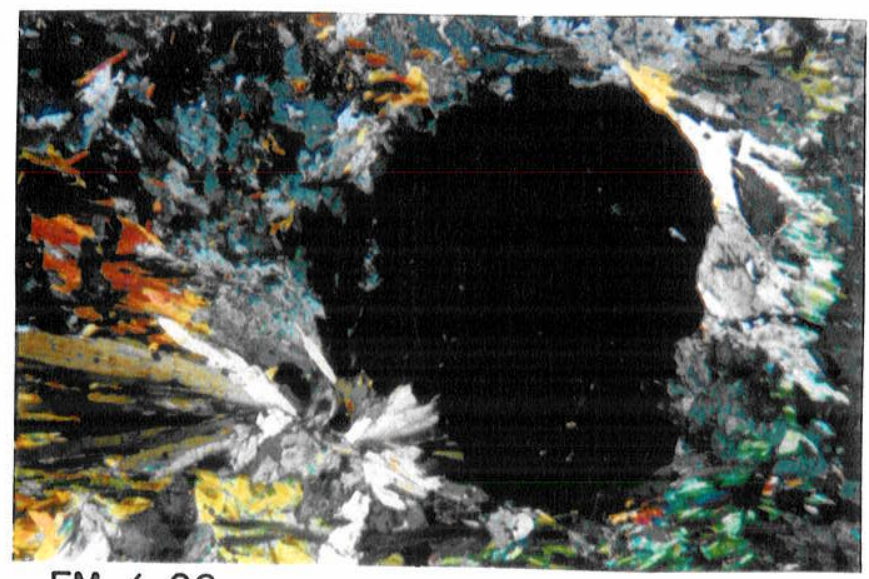

FM 4.26 
Foram, ainda, identificadas dobras cerradas a isoclinais, com rompimento num dos flancos. Estas estruturas dobram foliações anteriores $\left(\mathrm{Ss}_{1}-\mathrm{Sc}_{1}\right)$, preservando muitas vezes núcleos de diopsídio, evidenciando assim o registro de condições metamórfica mais elevada do que uma paragênese principal de rochas, a qual encontra-se associada a um generalizado retrometamorfismo. A passagem de diopsídio para tremolita/actinolita, presente em diversas lâminas, pode ser observada nas Fotomicrografias n ${ }^{\text {os }} 27$ e 28 , obtidas na zona de charneira de uma dobra cerrada (afloramento $\mathrm{n}^{\circ} 120$ ). Nos flancos da mesma dobra, a foliação anterior pode ser também reconhecida, embora com paragênese retrometamórfica, pela presença de cristais de anfibólio em processo de reorientação segundo a foliação plano axial de transposição (Fotomicrografia 29). $\mathrm{O}$ aspecto geral dessa estrutura pode ser visualizada na Fotomicrografia 30 , onde ocorre o espessamento de charneira da dobra, através da dissolução por pressão do quartzo nos seus flancos, e consequente, migração para o seu ápice, formando estruturas do tipo rods, que são posteriormente deformadas.

As Fotomicrografias 29 e 30 registram, ainda, a intensa foliação de transposição, com associação de quartzo, tremolita/actinolita e biotita. $O$ estiramento de quartzo apresenta uma relação média entre 3 e 5:1, respectivamente, para os eixos $X$ e $Z$ do elipsóide de deformação (Fotomicrografia 31), sendo relativamente superior a média regional de 2:1 observada por Fiori (comunicação verbal) nas Formações Capirú e Votuverava, a norte de Curitiba.

A disposição plano axial da tremolita/actinolita pode ser visualizada sobre um cristal de microclínio, arranjada ao longo da clivagem, com disposição norte-sul na lâmina orientada (Fotomicrografia 32). O microclínio associa-se aos minerais que formavam a foliação $\mathrm{S}-\mathrm{C}_{(1)}$ no flanco da dobra, ficando preservado do retrometamorfismo que transformou a maior parte dos minerais.

A relação de truncamento entre diopsídio, marcador da foliação $\mathrm{S}-\mathrm{C}_{(1)}$, com a biotita e tremolita/actinolita, pertencentes a foliação $\mathrm{S}-\mathrm{C}_{(2)}$, pode ser observada nas Fotomicrografias 33 e 34 (afloramento ED 100.2). 
Fotomicrografia 4.27 - Ápice de dobra cerrada a isoclinal, com transposição plano axial evidenciado pelos minerais de quartzo estirados e dispostos na direção norte-sul da fotomicrografia. Observar à direita da referida foto, a passagem de diopsídio (com cor de interferência amarela) para tremolita/actinolita, com cor esbranquicada, na borda do cristal. $A f l$. $E D$ 120, amostra 3; aum. na objetiva, 6.3x e ocular, 12.5x; luz polarz. e nicois $X$.

Fotomicrografia 4.28

Detalhe da Fotomicrografia 4.27, mostrando a passagem de diopsídio para tremolita/actinolita no lado direito da fotomicrografia, marcado com cores de interferência amarelo e esbranquiçado, respectivamente. Afloramento ED 120, amostra 3; aum. na objetiva, 10x e ocular, 12.5x; luz polarz. e nicóis cruzados.

Fotomicrografia 4.29

Cristais de tremolita/actinolita retrometamorfisados, sendo reorientados a partir da foliação pretérita de um dos flancos da dobra para uma posição plano axial, com orientação norte-sul na fotomicrografia. Afloramento ED 120, amostra 3; aum. na objetiva, 6.3x e ocular, 12.5x; luz polarz. e nicóis cruzados.

Fotomicrografia 4.30 - Visão geral da superficie axial da dobra da Fotomicrografia 4.29, com "rods" em seu ápice. Observar a foliação plano axial marcada por minerais de quartzo estirados, biotita e tremolita/actinolita.

Fotomicrografia 4.31 - Detalhe da Fotomicrografia 4.30, mostrando o estiramento de minerais de quartzo sobre a foliação plano axial, com relações de 3 a 5:1 (relação dos eixos $x / z$ do elipsóide de deformação). Afloramento ED 120, amostra 3; aumento na objetiva, $6.3 x$ e ocular. 12.5x; luz polarizada e nicóis cruzados.

Fotomicrografia 4.32 - Foliação plano axial marcada por minerais de tremolita/actinolita, com cor de interferência marrom amarelada, com orientação norte-sul sobre um mineral de microclínio. Afl. ED 120, amostra 3; aumento na objetiva, 6.3x e ocular, 12.5x; luz polarizada e nicóis cruzados.

Fotomicrografia 4.33 - Relação entre as foliações $\mathrm{S}-\mathrm{C}_{(1)}$ e S-C $\mathrm{C}_{(2)}$, marcadas por minerais de diopsidio e biotita, respectivamente. Afl. ED 100, corte 2; aumento na objetiva, 2.5x e ocular, 12.5x; luz polarizada e nicóis cruzados.

Fotomicrografia 4.34 - Detalhe da Fotomicrografia 4.33. com aumento da objetiva de 10x 


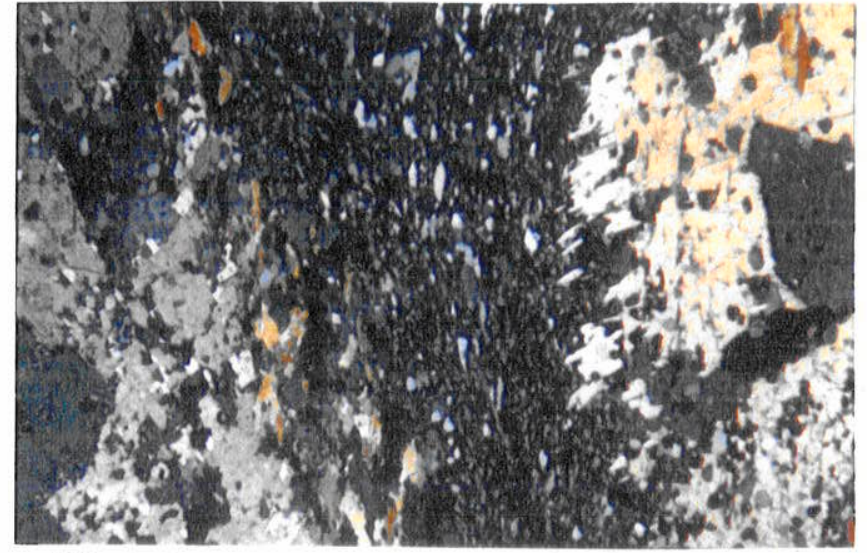

FM 4.27

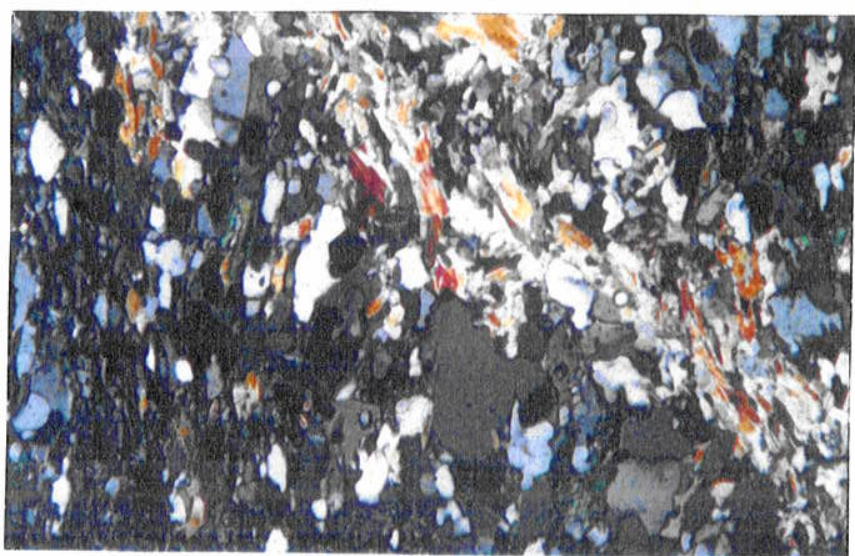

FM 4.29

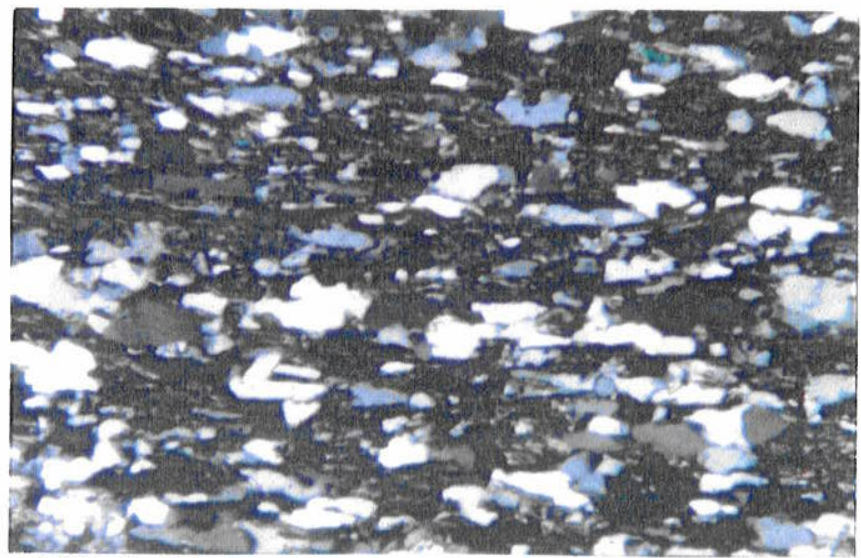

FM 4.31

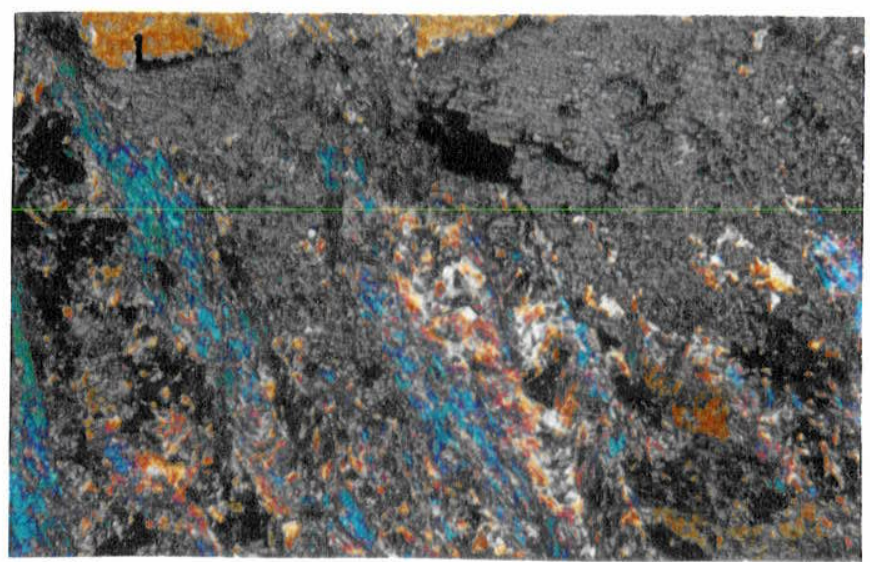

FM 4.33

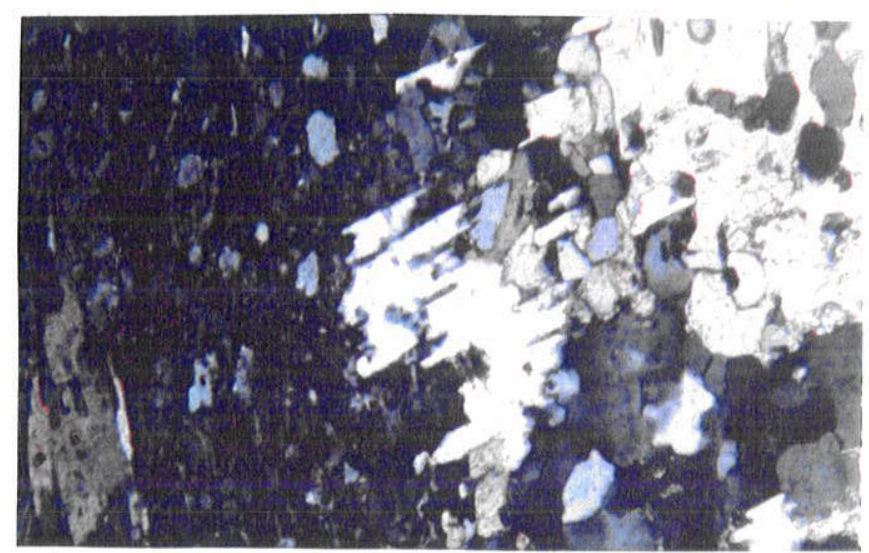

FM 4.28

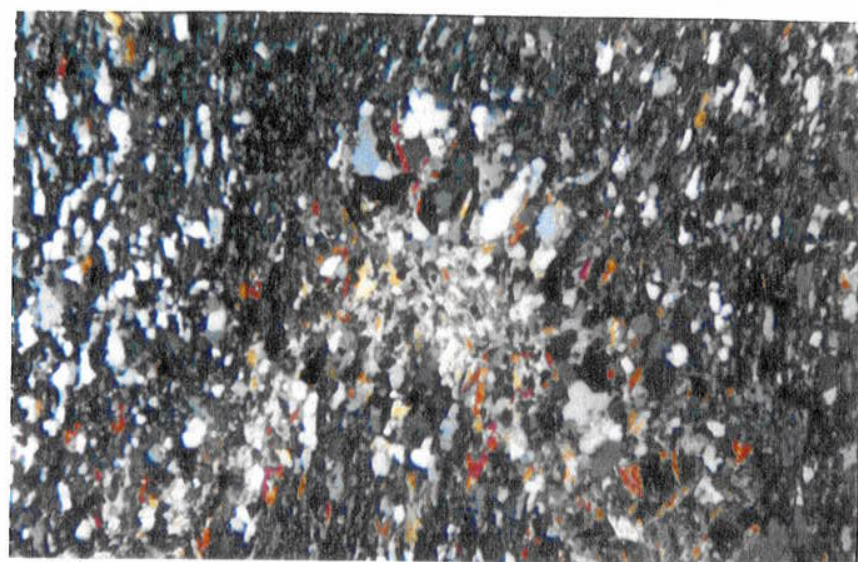

FM 4.30

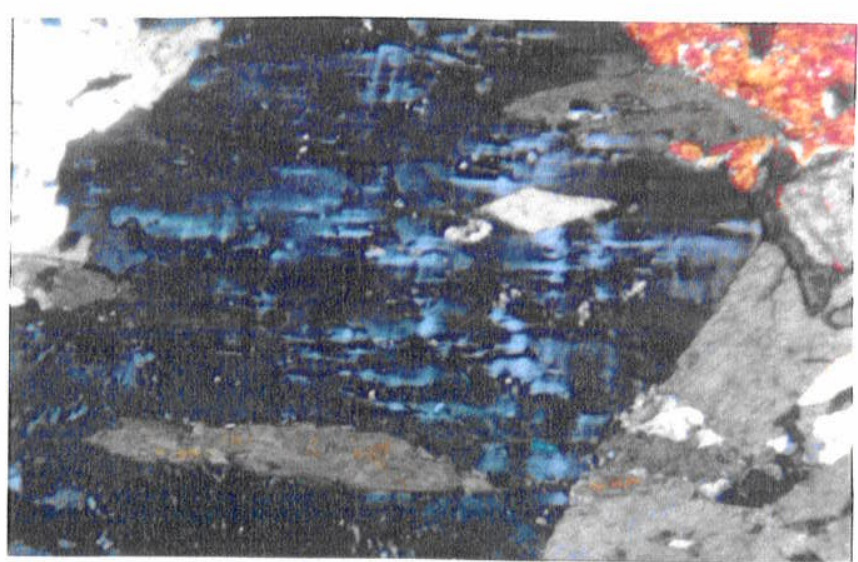

FM 4.32

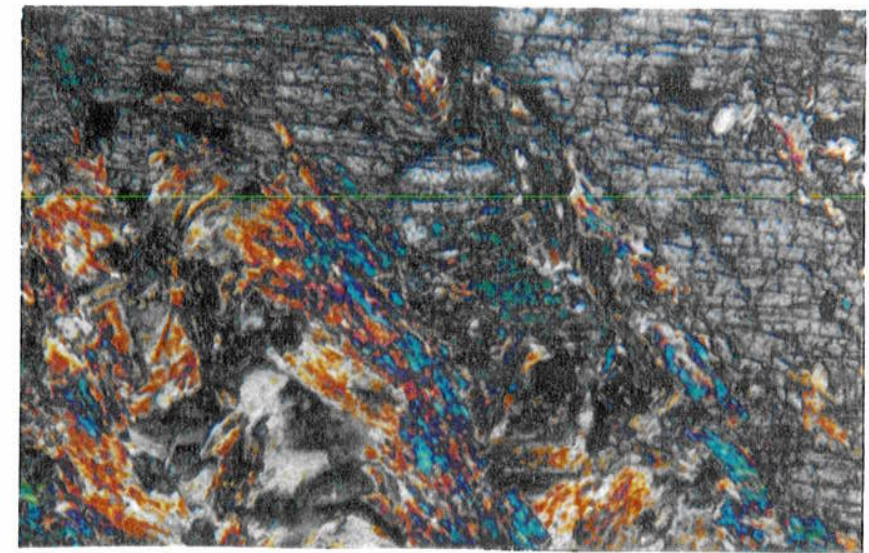

FM 4.34 


\subsubsection{FOLIAÇÕES $\mathrm{Ss}_{2}$ e $\mathrm{Sc}_{2}$}

Em geral, o par de foliações $S-C_{(2)}$ se constitui na estrutura de penetratividade principal na rocha, desenvolvida em zonas milimétricas (escala de lâmina delgada) sobre anisotropias geradas pela foliação $\mathrm{Sc}_{1}$, pretérita. Muitas vezes, ocorre a reorientação da foliação $\mathrm{Ss}_{1}$, sendo marcada por feições de arrastos (ver fotomicrografia $n^{\circ} 4.2$ ), os quais podem evoluir para microdobras desarmônicas. Mesmo quando essas novas foliações são bem desenvolvidas, é possível, ainda, visualizar porfiroclastos de diopsídio rotacionados em meio a nova trama estrutural (Fotomicrografias 4.35 e 4.36). Na Fotomicrografia 4.36, sob nicóis cruzados, é possível visualizar a extinção dos minerais da fotomicrografia anterior. Afloramento ED 120, amostra 3; aumento na objetiva, 2.5x e ocular, 12.5x; luz polarizada e nicóis cruzados, situados sobre a foliação $S_{2}$ (ver as duas faixas escuras na referida fotomicrografia), indicando características óticas idênticas para esses minerais, sugerindo, portanto, sua contemporaneidade. $O$ contraste entre os minerais extintos, com aqueles coloridos, indicam, da mesma forma, sobreposição de uma paragênese mais jovem, $S_{2}$, sobre outra mais antiga, $S-C_{(1)}$.

Um novo par de foliações, gerado por processo de deformação não-coaxial, pode se desenvolver ao longo dessa nova direção estrutural. Assim, minerais como biotita e anfibólio (principalmente tremolita/actinolita), com idênticas características óticas, são encontradas ao longo das foliações $\mathrm{Ss}_{2}$ e $\mathrm{Sc}_{2}$, conforme pode ser visto na Fotomicrografia 4.37. Aqui a relação geométrica entre as foliações, evidencia sentido de movimento tectônico para norte. Esses indicadores cinemáticos não devem ser confundidos com aqueles que fazem parte da trama estrutural anterior, com sentido de movimento tectônico para sul associado, agora quase totalmente reequilibrada nas condições metamórficas relacionadas ao evento $\mathrm{SD}_{2}$.

A foliação $\mathrm{Ss}_{2}$ ocorre, muitas vezes, disposta de forma subparalela a paralela aos planos $\mathrm{Sc}_{2}$, com seus minerais arranjados nesta nova direção, exibindo uma forte orientação mineral (biotita, tremolita/actinolita e quartzo) (Fotomicrografia 4.38).

A concentração de esforços, de relativa intensidade sobre zonas de anisotropia da foliação $S-C_{(1)}$, além de gerar um paralelismo, provocou um estiramento mineral dos grãos de quartzo, com razão de deformação $X: Z$ idêntica ao da foliação de transposição plano axial de dobras cerradas (ver fotomicrografias 30 e 31 ).

$\mathrm{O}$ sentido de transporte tectônico para norte, verificado nas foliações $\mathrm{Sc}_{2}$, é idêntico ao observado nas dobras geradas por mecanismos de strain slip (ver subitem 4.2.1.3(a) - Sistema de Deformação $\mathrm{SD}_{2}$ ), ou, ainda, as Fotomicrografias 4.37 e 4.39 ). O sentido de transporte 
levógiro se dispõe, de uma forma geral, próximo a $180^{\circ}$ do movimento lateral direito, este último associado às estruturas $\mathrm{SD}_{1}$.

Esta superposição cinemática, com sentidos opostos de transporte, ao longo de uma mesma direção, pode gerar estruturas do tipo "espinha de peixe" (Fotomicrografia 4.40), usualmente reconhecidas em rochas sedimentares.

As lineações de interseç̧ão geradas pela foliação $\mathrm{Ss}_{2}$ sobre os planos $\mathrm{Sc}_{1}$ e $\mathrm{Sc}_{2}$ são de dificil individualização, devido ao caráter localizado do sistema de deformação SD2(?), e ao paralelismo frequente entre as foliações do par $\mathrm{S}-\mathrm{C}_{(2)}$. Entretanto, como as lineações de estiramento mineral $\mathrm{Ss}_{2}$ apresentam disposição paralela a subparalela ao das foliações $\mathrm{Ss}_{1} \mathrm{em}$ zonas em que a deformação é mais intensa, torna-se dificil sua separação, pois ambas associações minerais foram geradas em idênticas condições de pressão e temperatura, na fácies xisto-verde alto de Winkler (1977).

\subsubsection{SISTEMA DE DEFORMAÇÃO $\mathrm{SD}_{3}$}

As estruturas do Sistema de Deformação $\mathrm{SD}_{3}$ superpõem-se àquelas dos sistemas $\mathrm{SD}_{1} \mathrm{e}$ $\mathrm{SD}_{2}$, dispondo-se de forma oblíqua as foliações $\mathrm{Sc}_{1}$ e $\mathrm{Sc}_{2}$, com ângulos menores do que $40^{\circ}$ (ver Figura 4.28 e Fotomicrografia 4.41).

$\mathrm{Na}$ escala de lâmina observa-se desde uma simples orientação mineral, associada ou não a uma foliação discreta, a qual pode evoluir para uma foliação mais intensa, chegando a crenular e, muitas vezes, a transpor a foliação $\mathrm{Ss}_{1}$ (ver Figura 4.28). Em geral, essa foliação se desenvolve apenas nos domínios mais incompetentes, na presença da foliação $\mathrm{Ss}_{1}$. Quando atinge níveis mais competentes, onde predominam as foliações $\mathrm{Sc}_{1}, \mathrm{Ss}_{2}$ e $\mathrm{Sc}_{2}$, a foliação $\mathrm{S}_{3}$ sofre refração, diminuindo progressivamente o seu ângulo com essas estruturas planares e com os níveis litoestruturais.

Ao longo das estruturas planares geradas por transposição, no evento $\mathrm{SD}_{3}$, ocorre um forte arrasto da foliação pretérita $\mathrm{Ss}_{1}$ (Fotomicrografias 4.41 a 4.45 ), e o desenvolvimento de um par de foliações $\mathrm{Ss}_{3}-\mathrm{Sc}_{3}$, com sentido de deslocamento horário (Ver Fotomicrografia 4.42). O ângulo formado entre as foliações $\mathrm{S}_{3} \mathrm{e} \mathrm{Sc}_{3}$, nesta última fotomicrografia, é de cerca de $10^{\circ}$, mostrando que a foliação $\mathrm{Ss}_{3}$ está em processo de paralelização com $\mathrm{Sc}_{3}$, evidenciando assim o registro da deformação. Assume-se, aqui, que o ângulo de $10^{\circ}$ não seja aparente.

Esse conjunto de foliações $\left(\mathrm{Ss}_{3}-\mathrm{Sc}_{3}\right)$, por sua vez, faz um ângulo ao redor de $40^{\circ}$ com a foliação $\mathrm{Ss}_{1}$, anterior, conforme ilustra a Fotomicrografia 4.42, mostrando uma nítida 
Fotomicrografia 4.35 - Cisalhamento $\mathrm{Sc}_{2}$ que reativa a matriz estrutural anterior. Observar minerais de diopsídio em secçőes basais, preservados da foliação $\mathrm{Ss}_{1}$. Af. ED 125, corte 2; aumento na objetiva, 10x e ocular, 12.5x; luz natural e nicóis normais.

Fotomicrografia 4.36 - Idem a Fotomicrografia 4.35, com luz polarizada e nicóis X.

Fotomicrografia 4.37 - Desenvolvimento das foliaç̃es $\mathrm{Ss}_{2} \mathrm{e} \mathrm{Sc}_{\curlywedge}$, indicando deslocamento anti-horário. Afloramento ED 202, corte 2; aumento na objetiva, $6.3 x$ e ocular, $12.5 x$; luz polarizada e nicóis cruzados.

Fotomicrografia 4.38 - Paralelismo da foliação $\mathrm{Ss}_{2}$ segundo os planos da foliação $\mathrm{Sc}_{2}$. Afloramento ED I25, corte 2; aumento na objetiva, 2.3x e ocular, 12.5x; luz polarizada e nicóis cruzados.

Fotomicrografia 4.39 - Indicador cinemático de um mineral de quartzo, com sentido de transporte anti-horário associado, ao longo da foliação $\mathrm{Sc}_{2}$. A foliação $\mathrm{Sc}_{\text {, }}$, originalmente horizontal, sofreu uma pequena rotação anti-horária nessa fotomicrografia, objetivando a busca de uma melhor cor de interferência dos minerais. Afloramento ED 202, corte 2; aumento na objetiva, 6.3x e ocular, 12.5x; luz polarizada e nicóis cruzados.

Fotomicrografia 4.40 - Minerais de biotita formando estruturas tipo "espinha de peixe", indicando superposição de deformações com sentidos de transporte opostos ao longo de uma idêntica direção. Afloramento ED 100, amostra B; aumento na objetiva, 10x e ocular, 12.5x; luz polarizada e nicóis cruzados.

Fotomicrografia 4.41 - Disposição obliqua das foliações S-C $\mathrm{C}_{(3)}$ com relação ao acamamento sedimentar reliquiar e as foliaçðes $\mathrm{Sc}_{1}$ e $\mathrm{Sc}_{2}$, sofrendo refração ao longo de niveis mais competentes. no centro da fotomicrografia. Afloramento ED 125, corte I; aumento na objetiva, 2.5x e ocular, 12.5x; luz polarizada e nicóis cruzados. 


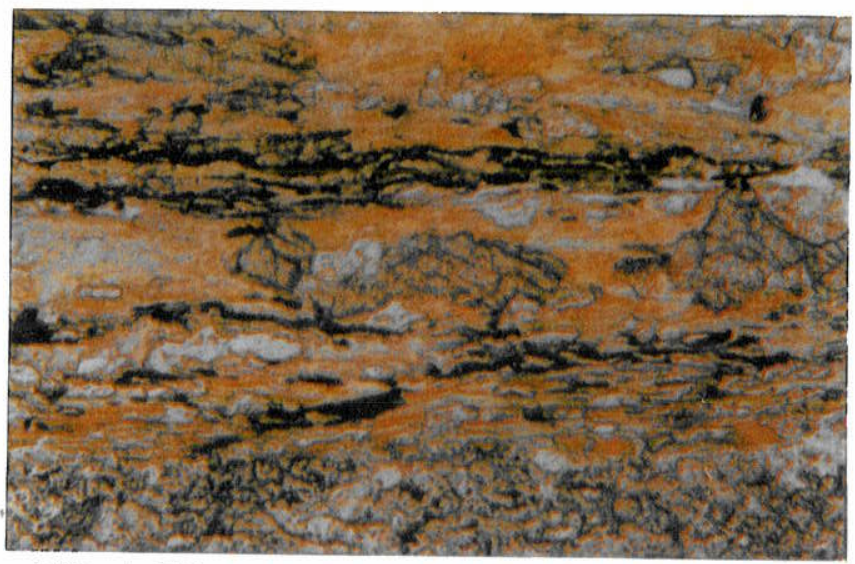

FM 4.35

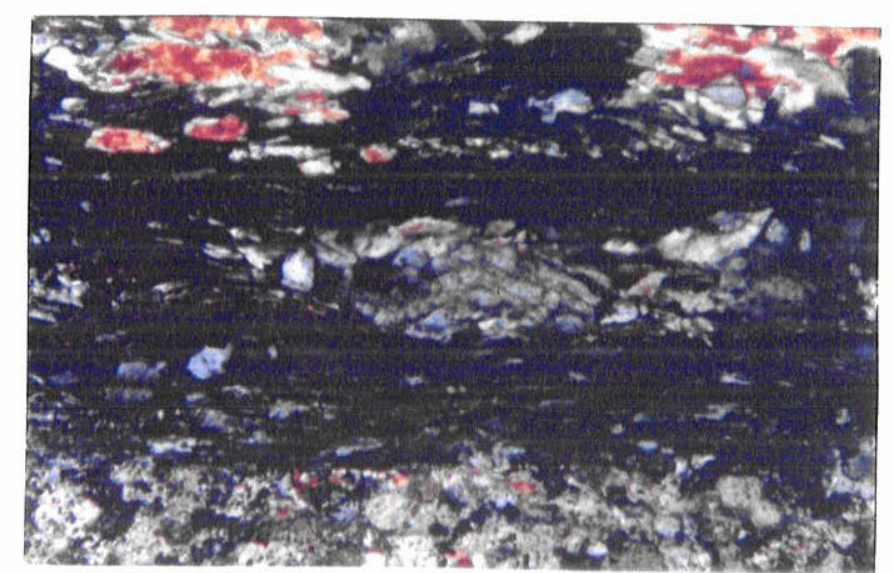

FM 4.36

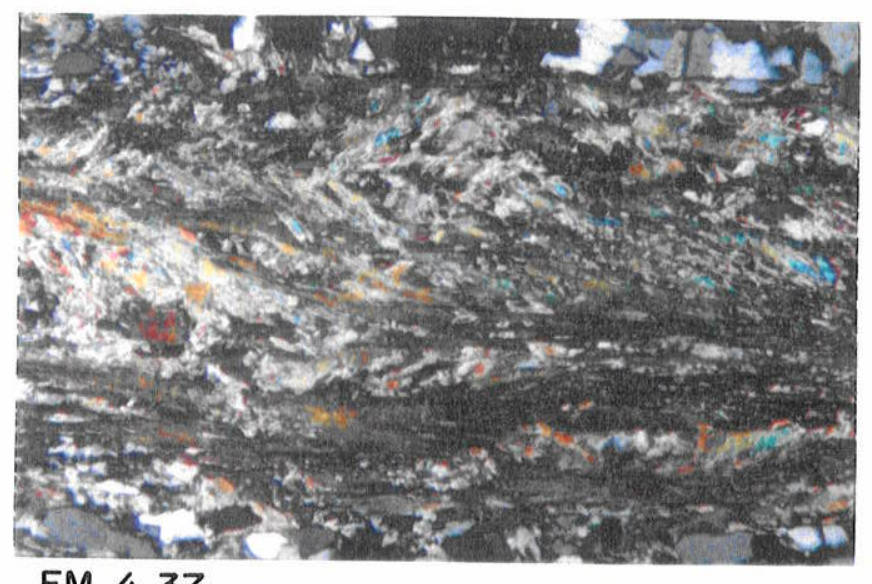

FM 4.37

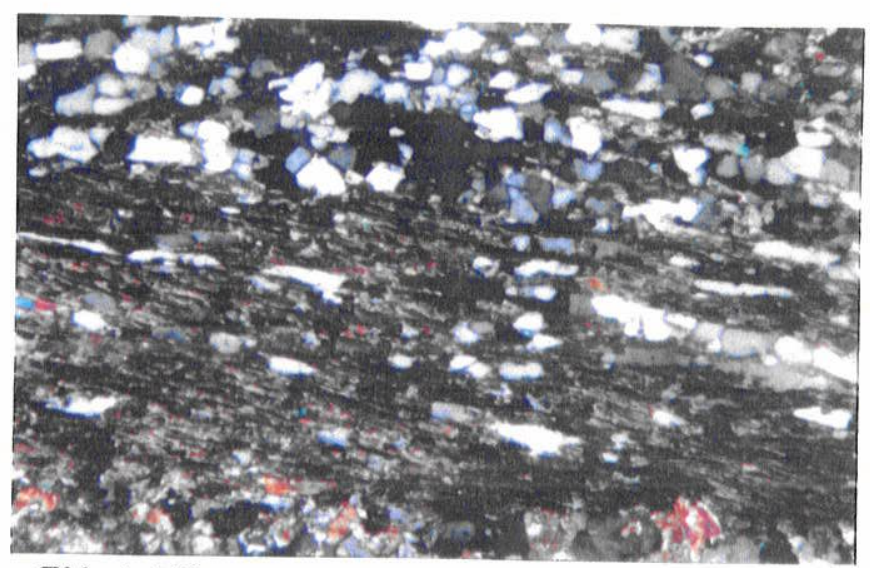

FM 4.38

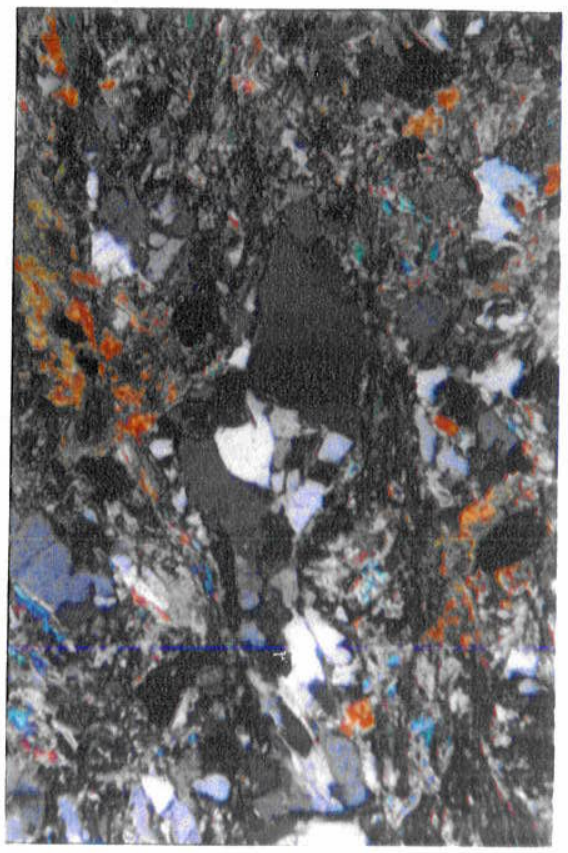

FM 4.39

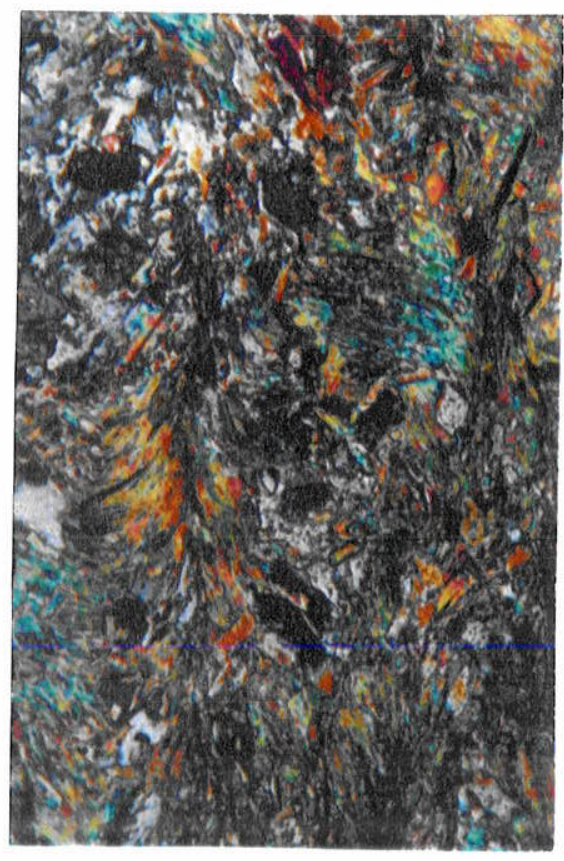

FM 4.40

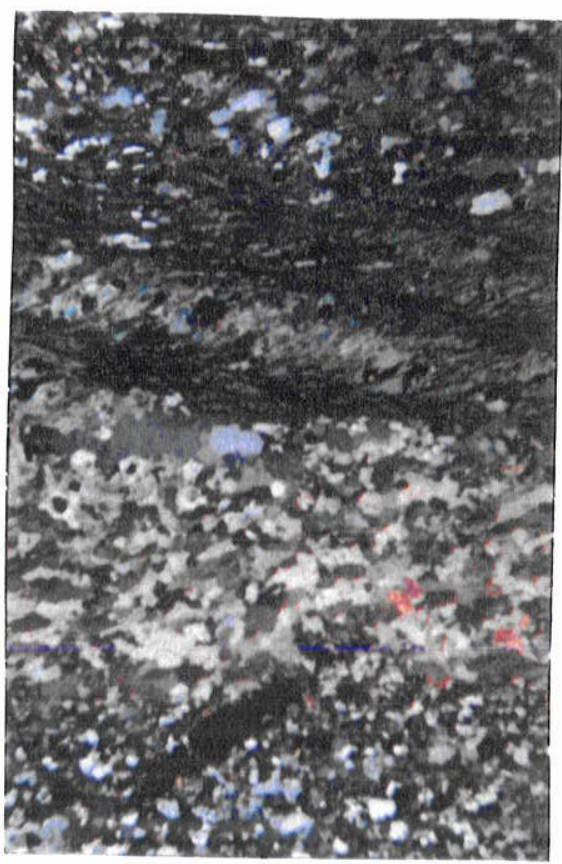

FM 4.41 
superposição desse conjunto sobre a trama estrutural mais antiga acima referida. Essa discordância entre as características dessas foliações pode ser observada também pela granulação dos minerais. Assim, ao longo da foliação $\mathrm{Ss}_{1}$, minerais de quartzo apresentam tamanho de 0,2 $\mathrm{mm}$, com as biotitas sendo bem desenvolvidas, juntamente com diopsídio e clinozoisita. Porém, sobre os planos das foliações $\mathrm{S}-\mathrm{C}_{(3)}$ ocorre uma pronunciada redução granulométrica associada com neocristalização, com cristais de quartzo sendo inferiores a $0,025 \mathrm{~mm}$, juntamente com biotitas recristalizadas de granulometria ainda menor, materializando assim uma fina xistosidade.

Nesta associação mineral gerada no evento $\mathrm{SD}_{3}$ (quartzo, biotita, diopsídio, clinozoizita) aparece, ainda, granada neocristalizada na foliação $S-C_{(3)}$, exibindo um relevo moderado (Ver Fotomicrografias 4.44 e 4.45). Estes minerais estão associados provavelmente as granadas tardi a pós-tectônicas ao $\mathrm{SD}_{1}$ (ver fotomicrografias $\mathrm{n}^{\circ} \mathrm{s} 21$ a 26).

Desta forma, a associação de granadas (com relevo moderado), quartzo e biotita em tamanhos menores, colocam essa foliação $\mathrm{S}-\mathrm{C}_{(3)}$ como tendo sido gerada em condições tarditectônicas, e sob condições de pressão e temperatura mais brandas do que as associações minerais geradas nos eventos $\mathrm{SD}_{1}$ e $\mathrm{SD}_{2}$, porém, ainda dentro da fácies xisto-verde alto de Winkler (1977).

$\mathrm{O}$ par de foliações $\mathrm{S}-\mathrm{C}_{(3)}$ desenvolveu, ainda, uma lineação de intersecção sobre os planos da foliação $\mathrm{Sc}_{1}$ e $\mathrm{Sc}_{2}$ (ver Figura 4.28), as quais são penetrativas na região de São Pedro - São Silvestre. Trata-se de uma lineação mais espaçada, que, em geral, trunca uma lineação de intersecção mais antiga, gerada pela foliação $\mathrm{Ss}_{1}$.

\subsubsection{RECUPERAÇÃO DO ACAMAMENTO SEDIMENTAR ORIGINAL}

Os sistemas de deformação $\mathrm{SD}_{1}$ e $\mathrm{SD}_{2}$ impuseram as litologias da Formação Água Clara estruturas planares dispostas de forma paralela ao antigo acamamento sedimentar. Assim, o acamamento original, constituído por estratificações plano-paralelas centimétricas a métricas, com variações da composição granulométrica e química, teve um aumento de anisotropia com a instalação das foliações $\mathrm{Sc}_{1} \mathrm{e} \mathrm{Sc}_{2}$, de forma paralela a estrutura anterior. Desta forma, a estrutura mais proeminente observada no campo é o plano de acamamento sedimentar, agora deformado e transposto, além de transformado pelo metamorfismo. Assim, o acamamento reliquiar pode ser, muitas vezes, recuperado em escala de lâmina, pela alternância de níveis milimétricos, com evidentes variações composicionais entre estes niveis, onde predominam minerais de granada, diopsídio, tremolita/actinolita, quartzo, biotita, mais ou menos deformados (Fotomicrografias 4.46 e 4.47). 
Fotomicrografia $4.42 \quad-\quad$ Foliação $S-C_{(3)}$ transpondo a matriz estrutural anterior. A foliação $\mathrm{Ss}_{1}$ é marcada por
quartzo, tremolita/ actinolita e biotitas com granulometria sensivelmente maior, com quartzo, tremolita/ actinolita e biotitas com granulometria sensivelmente maior, com relação aos minerais de quartzo e biotita neocristalizadas nos planos da foliação $\mathrm{Ss}_{3}$. Inclinação da foliação $\mathrm{S}-\mathrm{C}_{(3)}$ exagerada. Afloramento $E D$ 131, amostra 2; aumento na objetiva, 10x e ocular, 12.5x; luz polarizada e nicóis cruzados.

Fotomicrografia 4.43 - Minerais com cor de interferência escura formam a foliação S- $\mathrm{C}_{(3)}$, enquanto que aqueles com cor mais clara constituem a foliação $\mathrm{Ss}_{1}$ pretérita, rotacionada $\mathrm{e}$ transposta, com sentido de deslocamento horário. A foliação $\mathrm{S}-\mathrm{C}_{(3)}$ foi horizontalizada na fotomicrografia, a partir de mergulhos reais entre 30 e $40^{\circ}$. Afloramento ED 125 , corte l; aumento na objetiva, $6.3 x$ e ocular, $12.5 x$; luz polarizada e nicóis cruzados.

Fotomicrografia 4.44

Detalhe de minerais de granada neocristalizadas sobre os planos das foliações $\mathrm{Ss}_{3} \mathrm{e}$ $\mathrm{Ss}_{3}$, com relevo moderado. A foliação superposta foi horizontalizada na fotomicrografia para se obter uma melhor iluminação dos minerais. Afloramento ED 125, corte 1; aumento na objetiva, 10x e ocular, 12.5x; luz normal e nicóis cruzados.

Fotomicrografia 4.45 - Visão mais abrangente da foliação $S-C_{(3)}$ e dos minerais de granada, os quais aparecem na associação mineral extinta. Afloramento ED 125, corte I; aumento na objetiva, 6.3 e ocular, 12.5; luz polarizada e nicóis cruzados.

Fotomicrografia 4.46

Estratificação sedimentar reliquiar, marcada por niveis com ocorrências de minerais de quartzo e anfibólios: granada idiomórfica e quartzo; e num $3^{\circ}$ nivel, com anfibólios (tremolita/actinolita). Afloramento ED 199, amostra 5, corte A; aumento na objetiva, 2.5x e ocular, 12.5x; luz natural e nicóis normais.

Fotomicrografia 4.47 - Idem a Fotomicrografia 4.46. com luz polarizada e nicóis cruzados. 
For.

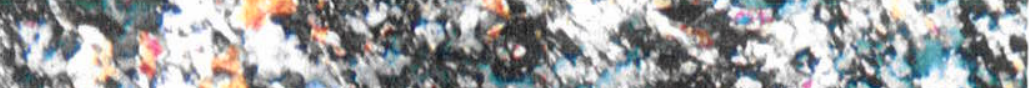

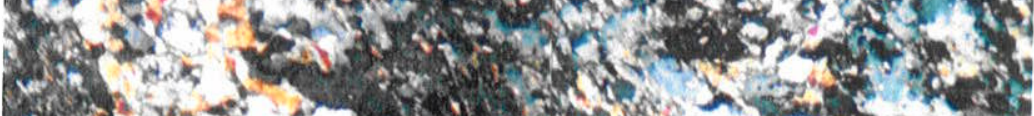

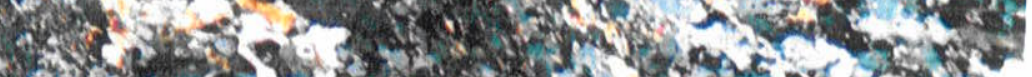

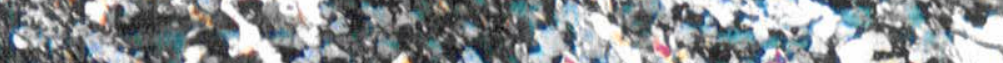

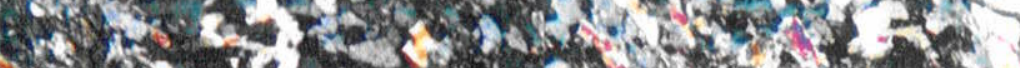

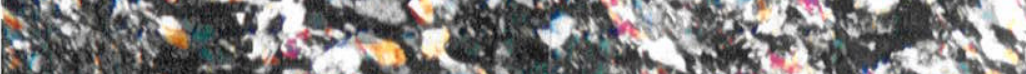

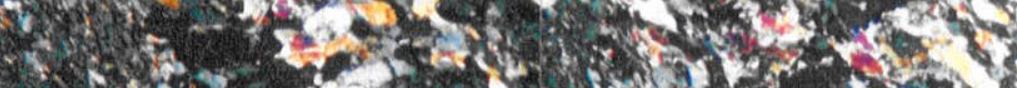

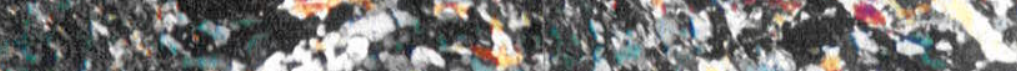

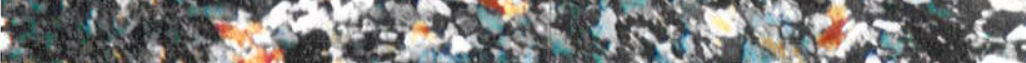

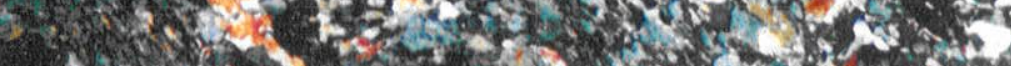
A 5 3

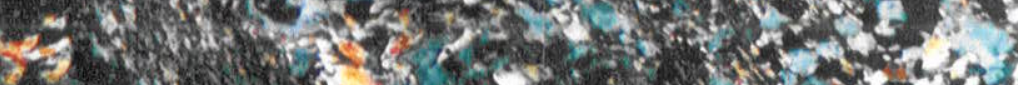

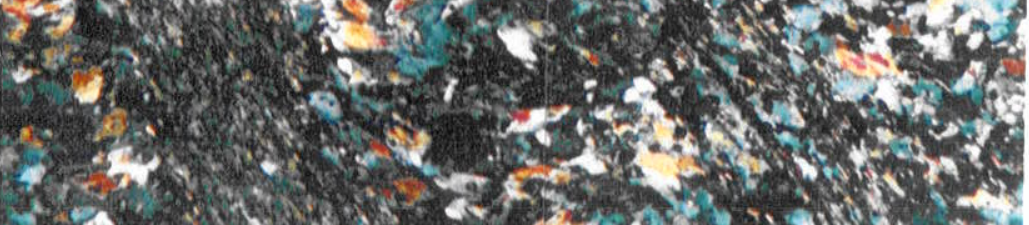

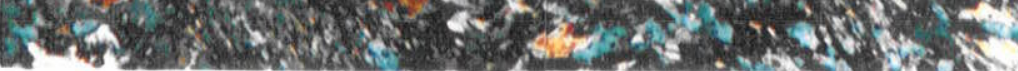

FM 4.42

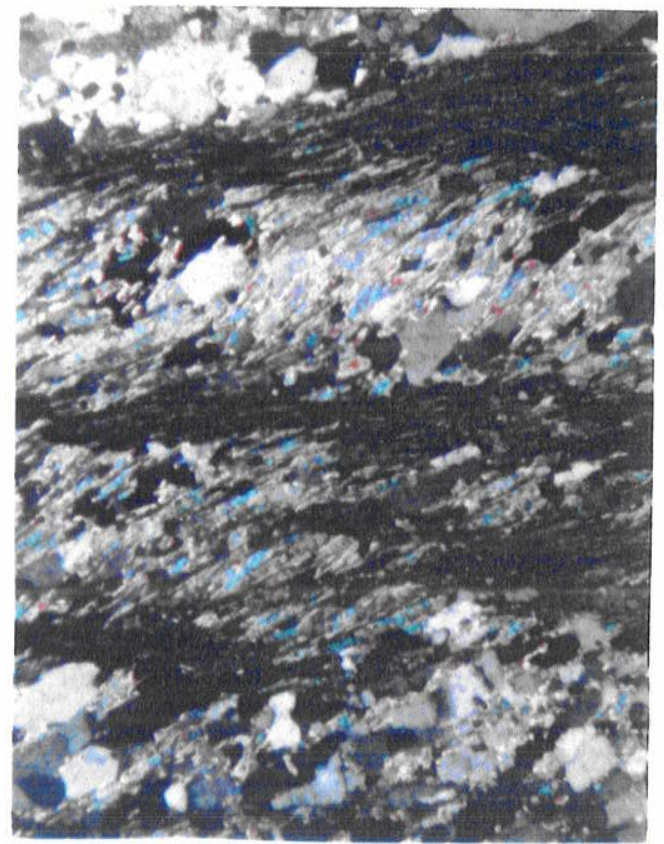

FM 4.43

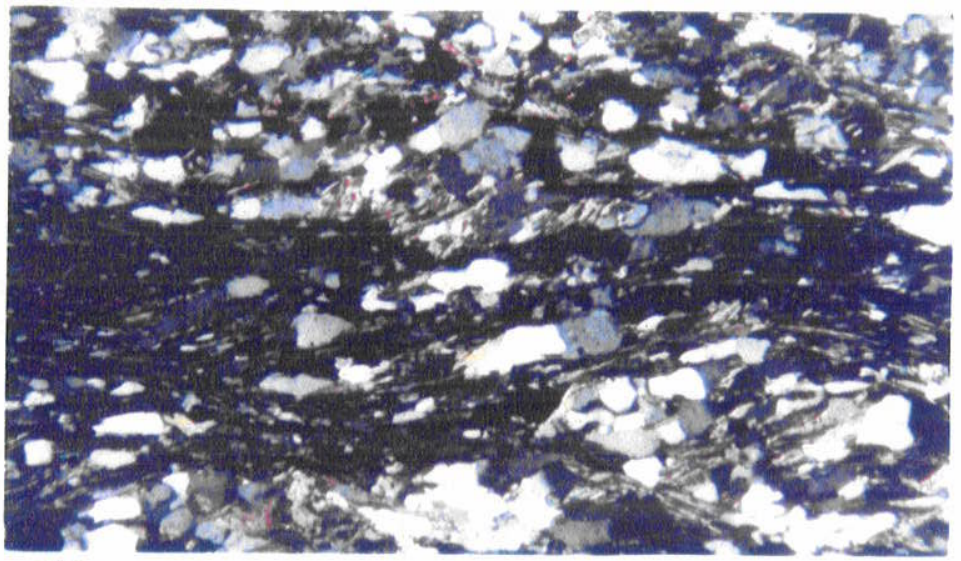

FM 4.45

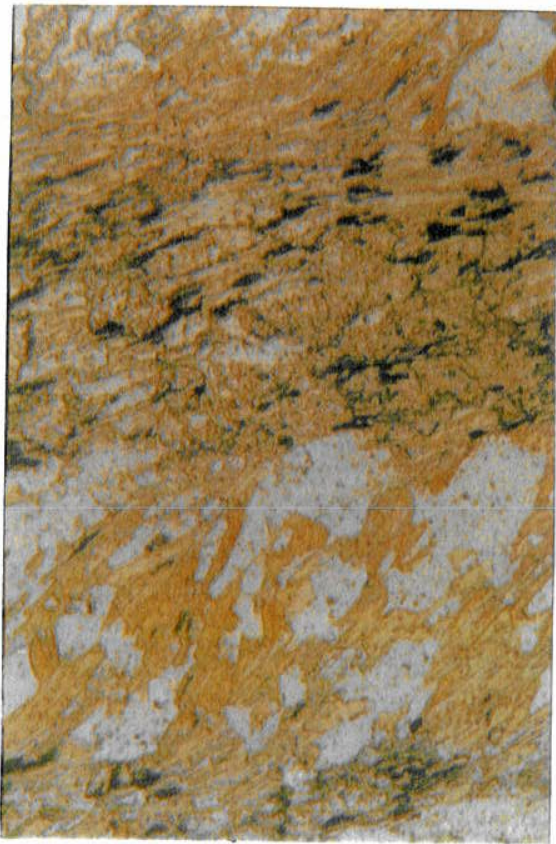

FM 4.44

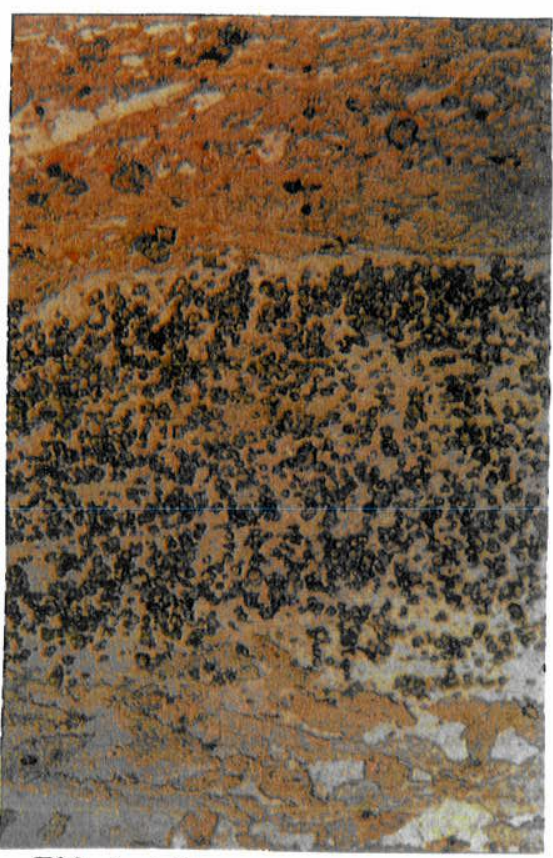

FM 4.46

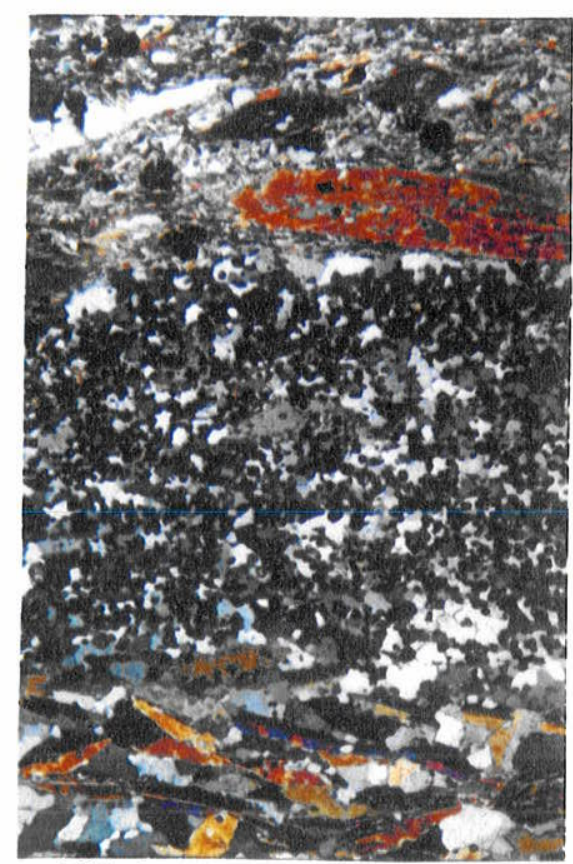

FM 4.47 


\subsection{ISÓTOPOS}

\subsubsection{INTRODUÇ̃̃O}

O estudo dos isótopos estáveis de carbono e oxigênio tem sido empregados como indicadores de paleotemperatura de águas oceânicas, gênese e ambientes de deposição de carbonatos, assim como um geotermômetro para determinar a temperatura do último equilíbrio isotópico entre os minerais (Urey, 1948; McCrea, 1950; Croig, 1953; Epstein \& Mayeda, 1953; Keith \& Weber, 1964; Schidlowski et al., 1975; Kaufman et al. 1991 entre outros). Este método tem sido empregado, também, para datar rochas pré-cambrianas, conforme proposição de Torquato (1980).

Entende-se por isótopos estáveis aqueles átomos cujos núcleos contém o mesmo número de protons, porém com diferentes número de neutrons, e que não são prontamente radioativos ou instáveis.

Os isótopos de um elemento (no caso Carbono e Oxigênio) podem sofrer fracionamento (ou segregação/separação). A quantidade segregada e seu comportamento podem ser medidos e analisados, fornecendo subsídios para o estudo do ambiente em que eles foram depositados.

O princípio utilizado para entender o significado das análises estabelece que durante a formação dos sedimentos carbonáticos, estes estariam em equilibrio com as águas do ambiente deposicional. Assim, os valores dos isótopos de carbono e de oxigênio refleteriam, portanto, as condições originais e alterações pós-deposicionais ou metamórficas.

\subsubsection{RESULTADOS DAS ANÁLISES DAS COMPOSIÇÕES ISOTÓPICAS}

Foram analisadas 20 amostras para ${ }^{13} \mathrm{C}$ e ${ }^{18} \mathrm{O}$ nos padrões internacionais de referência PDB (Bellemnitella Americana da Formação Pee Dee) e SMOW (Standard Mean Ocean Water, Craig 1961), as quais estão distribuídas em 9 amostras da Formação Água Clara (mármores calcíticos), 7 amostras da Formação Votuverava (metacalcários calcíticos), e 4 da Formação Capirú (metacalcários dolomíticos) (Tabela 4.1). Para o cálculo das médias e desvio padrão foi utilizado a planilha Excel.

Estas amostras foram processadas no laboratório do CENA (Centro de Energia Nuclear na Agricultura - Campus de Piracicaba, Universidade de São Paulo), e nas quais utilizou-se as conversões de $\delta_{\mathrm{SMOW}}=1.008 \delta_{\mathrm{PDB}}+30.86$ ou $\delta_{\mathrm{PDB}}=0.97006 \delta_{\mathrm{SMOW}}-29.94 \%$ (Kawashita, 1996). 


\begin{tabular}{|c|c|c|c|c|c|}
\hline \multirow{2}{*}{$\begin{array}{c}\text { UNIDADE } \\
\text { GEOLÓGICA }\end{array}$} & \multirow[t]{2}{*}{ AMOSTRA } & \multicolumn{3}{|c|}{$\begin{array}{l}\text { COMPOSIÇÓES } \\
\text { ISOTOPICAS } \% \text { \%o) }\end{array}$} & \multirow[b]{2}{*}{ PETROGRAFICA } \\
\hline & & $\delta^{13} \mathrm{C}_{(\mathrm{PDB})}$ & $\delta^{18} \mathrm{O}_{(\mathrm{PDB})}$ & $\delta^{18} \mathrm{O}_{\text {SMOW }}$ & \\
\hline \multirow{11}{*}{$\begin{array}{l}F O R M A C ̧ A O \\
A G U A C L A R A\end{array}$} & ED 69 & -2.06 & -13.54 & 17.20 & \multirow{11}{*}{$\begin{array}{l}\text { MÁRMORES } \\
\text { CALCÍTICOS }\end{array}$} \\
\hline & ED $70 B$ & -2.77 & -10.79 & 19.98 & \\
\hline & ED 122 & -3.10 & -14.57 & 16.16 & \\
\hline & ED 125 & -2.82 & -12.00 & 18.76 & \\
\hline & ED 129(4) & -3.33 & -12.08 & 18.68 & \\
\hline & ED 186 & -335 & -10.81 & 19.96 & \\
\hline & ED 201 & -2.75 & -10.67 & 20.10 & \\
\hline & ED 207 & -3.36 & -1128 & 19.48 & \\
\hline & ED 208(2) & -1.81 & -11.24 & 19.52 & \\
\hline & Média & -281 & -1189 & 18.87 & \\
\hline & Desvio Padrão & 0.56 & 1.35 & & \\
\hline \multirow{9}{*}{$\begin{array}{l}\text { FORMACÃO } \\
\text { VOTUVERAVA }\end{array}$} & $\mathrm{ED} 324 \mathrm{H}$ & 0.85 & -8.31 & 22.48 & \multirow{9}{*}{$\begin{array}{l}\text { METACALCÁRIOS } \\
\text { CALCÍTICOS }\end{array}$} \\
\hline & ED 324C & 1.41 & -7.10 & 23.70 & \\
\hline & $\mathrm{ED} 324 \mathrm{~J}$ & 123 & -683 & 23.97 & \\
\hline & ED $325 \mathrm{M}$ & 0.77 & -9.53 & 21.25 & \\
\hline & ED 336B & 0.97 & -6.39 & 24.41 & \\
\hline & ED 352A & 0.83 & -9.97 & 20.80 & \\
\hline & ED $63 \mathrm{~B}$ & 1.07 & -795 & 22.84 & \\
\hline & Média & 1.02 & -8.01 & 22.78 & \\
\hline & Desvio Padrão & 0.23 & 136 & & \\
\hline \multirow{6}{*}{$\begin{array}{l}\text { FORMAÇ̃O } \\
\text { CAPIR } \mathscr{U}\end{array}$} & ED 311 & 1.03 & -5.35 & 25.46 & \multirow{6}{*}{$\begin{array}{l}\text { METACALCÁRIOS } \\
\text { DOLOMÍTICOS }\end{array}$} \\
\hline & ED 313 & 117 & -4.86 & 25.96 & \\
\hline & ED 316 & 1.12 & -2.40 & 28.44 & \\
\hline & ED 317 & 1.08 & -2.66 & 28.18 & \\
\hline & Média & 1.10 & \multirow[t]{2}{*}{$\$$} & & \\
\hline & Desvio Padrão & 0.06 & & & \\
\hline
\end{tabular}

\begin{tabular}{|l|l|c|c|}
\hline \multicolumn{3}{|c|}{ MEDLA E DESVIO PADRÂO DOS DADOS DA FORMACÃO CAPIRU } \\
\hline \multirow{3}{*}{$*$} & Discriminação das análises & Média & Desvio Padrão \\
\hline \multirow{2}{*}{ Considerando as 4 análises } & -3.82 & 1.50 \\
\cline { 2 - 4 } & Considerando as análises ED 311 e ED 313 & -5.11 & 0.35 \\
\cline { 2 - 4 } & Considerando as análises ED 316 e ED 317 & -2.53 & 0.18 \\
\hline
\end{tabular}

Tabela 4.1 - Valores isotópicos de ${ }^{1.3} \mathrm{C} \mathrm{e}{ }^{18} \mathrm{O}(\%)$ de rochas carbonáticas pré-cambrianas do Grupo Açungui e similares.

Estas análises foram efetuadas como o objetivo de identificar a assinatura isotópica de cada unidade geológica analisada, comparar os resultados entre si, tendo em vista que a Formação Água Clara poderia ser uma unidade da Bacia Açungui e não como uma bacia individualizada préAçungui, conforme proposto por Soares (1987). Neste sentido, analisar a potencialidade do 
método para datar as referidas rochas carbonáticas, pareceu ser uma contribuição importante a partir dos dados dos isótopos estáveis.

$\mathrm{Na}$ Tabela 4.2, foram calculados os valores médios para as composições isotópicas do ${ }^{13} \mathrm{C}$ e ${ }^{18} \mathrm{O}$, para as Formações Água Clara, Votuverava e Capirú, utilizando-se o grau de liberdade estatística de 95\% para o desvio padrão e valores críticos de Student's (t) de 2.26, 2.36, 2.78 e 4.30 para 9, 7, 4 e 2 análises, respectivamente (Cheeny, 1983).

\begin{tabular}{|l|c|c|}
\hline \multicolumn{1}{|c|}{ UNIDADE GEOLOGICA } & $\delta^{13} \mathrm{C}$ (PDB) & $\delta^{18} \mathrm{O}$ (PDB) \\
\hline FORMAÇAिO ÁAUA CLARA & $-2.82 \pm 0.42$ & $-11.89 \pm 1.02$ \\
\hline FORMAÇÄO VOTUVERAVA & $1.02 \pm 0.21$ & $-08.01 \pm 1.21$ \\
\hline FORMAÇAO CAPIRU & $1.10 \pm 0.08$ & \\
\hline
\end{tabular}

\begin{tabular}{|l|l|c|}
\hline \multicolumn{2}{|c|}{$\delta^{18}$ O(PDB) DA FORMACÃO CAPIRÚ } \\
\hline \multirow{3}{*}{$* \begin{array}{c}\text { Discriminação das análises } \\
\text { Considerando as 4 análises }\end{array}$} & $\delta^{18} \mathbf{O}$ (PDB) \\
\cline { 2 - 3 } & Considerando as análises ED 311 e ED 313 & $-3.82 \pm 2.09$ \\
\cline { 2 - 3 } & Considerando as análises ED 316 e ED 317 & $-5.11 \pm 1.05$ \\
\hline
\end{tabular}

Tabela 4.2 - Valores médios das composições isotópicas de $\delta{ }^{13} \mathrm{C}$ e $\delta^{18} \mathrm{O}(\%)$ de rochas carbonáticas do pré-cambriano paranaense.

As variações em torno das médias das análises de ${ }^{13} \mathrm{C}$ estão dentro de padrões aceitáveis, com um variação máxima de \pm 0.42 . Para o ${ }^{18} \mathrm{O}$ esta variação aumentou para \pm 1.02 ( média de -11.89) na Formação Água Clara, e \pm 1.21 (média de -8.01) na Formação Votuverava. Estes valores aumentam ainda mais na Formação Capirú, para \pm 2.09 , muito próximo da sua média, de -3.82 .

Numa tentativa em aumentar o grau de confiabilidade das médias de $\delta{ }^{18} \mathrm{O}$ na Formação Capirú, efetuou-se uma divisão dos dados em dois agrupamento (Ver Tabela 4.2). Obteve-se, assim, valores de $-5.11 \pm 1.05$ e $-2.53 \pm 0.18$, os quais serão discutidos na sequência. 


\subsubsection{DISCUSSÃO DOS RESULTADOS}

\subsubsection{AMBIENTE DE SEDIMENTAÇÃO}

$\mathrm{Na}$ análise dos grande ambientes de rochas carbonáticas proposto por Weber et al (1964) (Figura 4.29, abaixo), verifica-se que todas as amostras analisadas situaram-se no campo dos carbonatos marinhos pré-cambrianos metamorfisados, campo III de Borschthevski et al 1981 (apud Frascá, 1992).

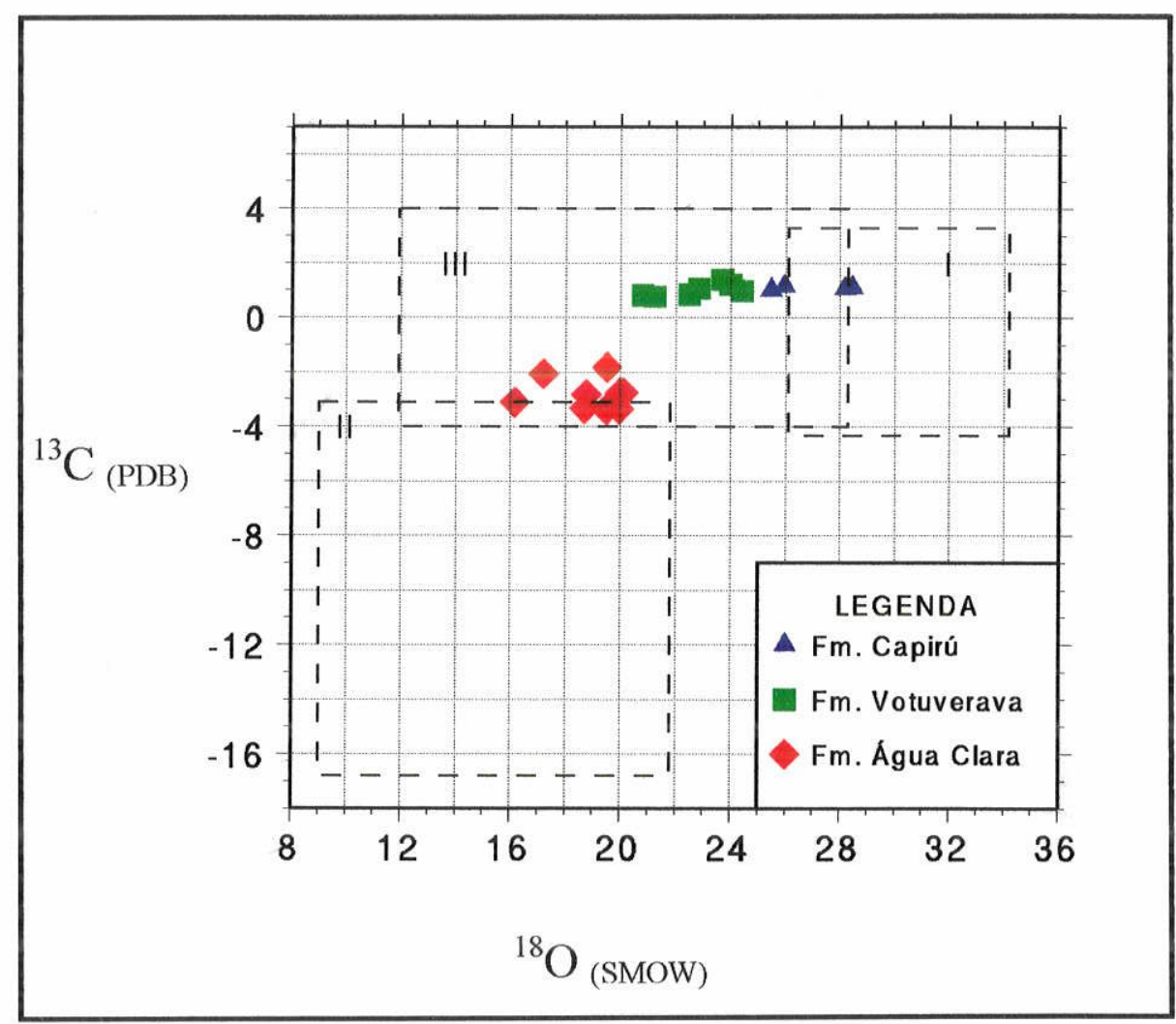

Figura 4.29 - Diagrama $\delta^{13} \mathrm{C}_{\mathrm{PDB}} \times \delta^{18} \mathrm{O}_{\mathrm{SMOW}}$ de rochas carbonáticas do Pré-Cambriano Paranaense:

I - carbonatos marinhos; II - carbonatos de água doce;

III - carbonatos marinhos pré-cambrianos metamorfisados.

Os dados da Tabela 4.1 foram lançados num gráfico que mostra o comportamento dos isótopos ${ }^{13} \mathrm{C} \times{ }^{18} \mathrm{O}$, correspondente as Formações Água Clara, Votuverava e Capirú (Figura $4.30)$. 


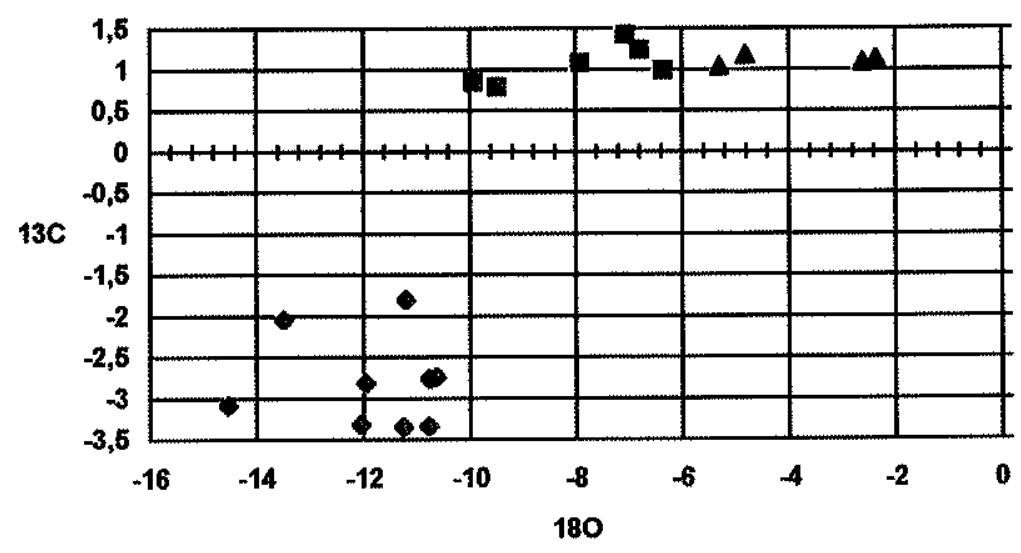

๑Fm. Agua Clara EFm. Votuverava AFm. Caplrú

Figura 4.30 - Diagrama $\delta^{18} \mathrm{O}_{\mathrm{PDB}} \times \quad \delta^{13} \mathrm{C}_{\mathrm{PDB}}$ de mármores calcíticos da Formação Água Clara, metacalcários calcíticos da Formação Votuverava e metacalcários dolomíticos da Formação Capirú (Grupo Açungui).

A análise do gráfico da Figura 4.30, permite separar dois grupos distintos de amostras, um com valores de isótopos de ${ }^{13} \mathrm{C}$ positivos e outro com valores negativos. Tais grupos apresentam os seguintes intervalos de isótopos de ${ }^{13} \mathrm{C}$ e de ${ }^{18} \mathrm{O}$ :

\begin{tabular}{|c|c|}
\hline GRUPO I & $-3.5 \%{ }_{00}\left\langle\delta^{13} \mathrm{C}<-1.5 \%\right.$ e $-15^{\circ} \%_{00}\left\langle\delta^{18} \mathrm{O}<-10 \%\right.$ \\
\hline GRUPO II & $0.5 \%{ }_{00}\left\langle\delta^{13} \mathrm{C}\left\langle 1.5 \%\right.\right.$ e $\quad-10 \%{ }_{00}\left\langle\delta^{18} \mathrm{O}<-2 \%\right.$ \\
\hline
\end{tabular}

No Grupo I encontram-se as amostras da Formação Água Clara, enquanto no Grupo II, encontram-se as amostras das Formações Votuverava e Capirú. Embora as amostras da Formação Capirú sejam de composição dolomítica, situam-se próximo daquelas de composição calcítica da Formação Votuverava, definido apenas por um pequeno enriquecimento de isótopo de ${ }^{18} \mathrm{O}$. Estes valores mais positivos em $\delta^{18} \mathrm{O}$ nos metacalcários dolomíticos da Formação Capirú em relação aos metacalcários calcíticos da Formação Votuverava é esperado, pois os dolomitos devem ser mais pesados neste isótopo.

A coerência entre os dados do Grupo II é compatível com a cogeneticidade entre ambos, evidenciando um equilíbrio isotópico na maioria das suas análises. 
A variação do ${ }^{13} \mathrm{C}$ do Grupo I até o Grupo II, desde valores de -3.5 até 1.5 , pode significar variações locais do ambiente de sedimentação, conforme proposto por Frascá (1992) para explicar fenômeno idêntico observado nos metacalcários do Grupo São Roque e do Subgrupo Lajeado.

$\mathrm{O}$ fracionamento isotópico de $\delta^{13} \mathrm{C}$ e $\delta^{18} \mathrm{O}$ da calcita em relação a dolomita não foi analisado, devido a ausência destes dois tipos de análises em amostras de ambas unidades. Este estudo poderia fornecer subsídios para determinação da temperatura de equilíbrio isotópico final. Da mesma forma, não foram realizados estudos sobre o fracionamento do $\delta^{16} \mathrm{O}$ e $\delta^{18} \mathrm{O}$ nos referidos carbonatos, o que poderia fornecer informações de geotermometria, uma vez que este tipo de análise não havia sido previsto neste trabalho.

\subsubsection{ISÓTOPOS ESTÁVEIS COMO INDICADORES TEMPORAIS}

Alguns autores têm utilizado o $\delta^{16} \mathrm{O}$ como indicadores de idades geológicas, pois as rochas geologicamente mais velhas mostram um aumento progressivo no conteúdo deste isótopo, na razão $\delta^{18} \mathrm{O} / \delta^{16} \mathrm{O}$, causado por um contínuo reequilíbrio pós-deposicional com águas meteóricas isotopicamente leves (Veizer \& Hoefs, 1976).

Em contrapartida, o isótopo $\delta^{18} \mathrm{O}$ pode ser também utilizado para obtenção de indicadores de idades geológicas para carbonatos do pré-cambriano. Assim Torquato (1980) estabeleceu valores médios de $\delta^{18} \mathrm{OPBB}_{\mathrm{PD}}$ para o proterozóico superior, médio e inferior, a partir da análise de 836 amostras de rochas pré-cambrianas, e da comparação destes resultados com aqueles disponiveis na literatura mundial (Tabela 4.3).

O valor de $13.39 \pm 1.96 \%$, obtido por Torquato (1980) para o proterozóico médio do Nordeste Brasileiro, não coincide com o valor médio de $-10.84 \pm 3,41 \%$, utilizada na escala mundial para este mesmo período, porém encontra-se contida no intervalo previsto nesta escala.

Adaptando os valores de Torquato (op. cit.) para uma escala gráfica, teremos os valores médios ${ }^{18} \mathrm{O}$ das Formações Água Clara, Votuverava e Capirú distribuídos ao longo do tempo geológico, conforme indicado pela Figura 4.31.

Os metacalcários dolomíticos da Formação Capirú situam-se no neoproterozóico médio, algo em torno de $0.71 \mathrm{Ga}$, considerando-se a média isotópica de $-5.11 \pm 1.05 \%$ (Ver Tabela 4.2). Esta idade aparentemente nova se deve ao enriquecimento natural de ${ }^{18} \mathrm{O}$ nos metacalcários dolomíticos em relação aos calcíticos. Se houvesse sido analisado um metacalcário calcítico desta 


\begin{tabular}{|l|c|}
\hline \multicolumn{1}{|c|}{ PERIODO GEOLOGICO } & $\begin{array}{c}\text { VALORES MÉDIOS DE } \boldsymbol{~}^{\mathbf{1 8}} \mathbf{O}_{\mathrm{PDB}} \\
\text { (Torquato, 1992). }\end{array}$ \\
\hline PROTEROZOICO SUPERIOR & $-6.65 \pm 2,75 \%$ \\
\hline PROTEROZOICO MEDIO & $-13.39 \pm 1,96 \%$ \\
& (Escala Mundial: $-10.84 \pm 3.41 \%$ ) \\
\hline PROTEROZOICO INFERIOR & $-16.75 \pm 2.66 \%$ \\
\hline
\end{tabular}

Tabela 4.3 - Assinatura isotópica de $\delta^{18} \mathrm{O}_{\mathrm{PDB}}$ dos diferentes períodos do Proterozóico, a partir de análises do Nordeste brasileiro. (Fonte: Torquato, 1980)

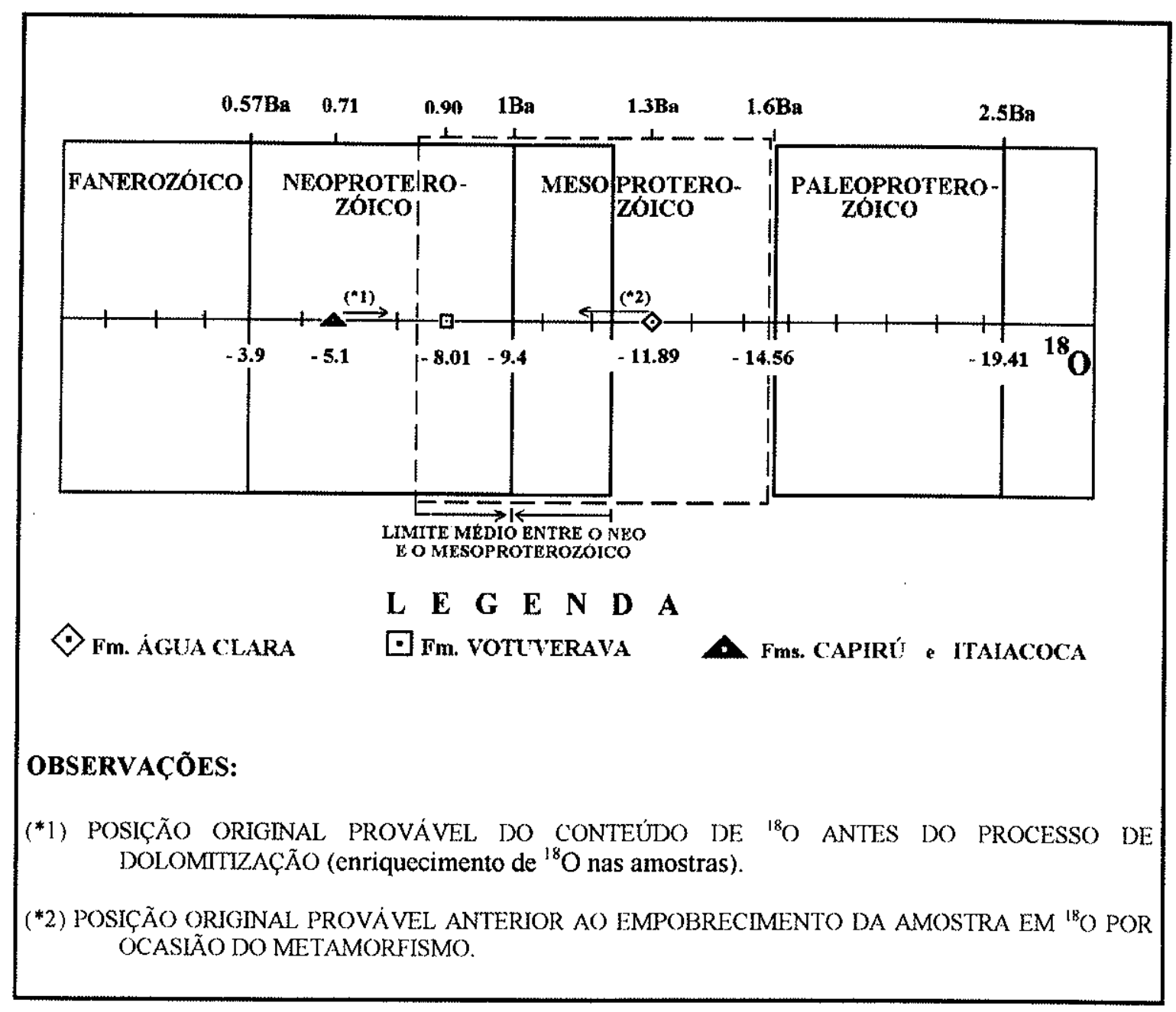

Figura 4.31 - Distribuição temporal dos valores de $\delta^{18} \mathrm{O}$ para as Formações Água Clara, Votuverava e Capirú. 
formação, é provável que a média isotópica de ${ }^{18} \mathrm{O}$ teria se deslocado para uma posição algo mais mediana do neoproterozóico, conforme sugerido no Gráfico da Figura 4.31. Este fenômeno de enriquecimento pode ser também observado nos dados de isotópicos de Frascá (1992), pois a autora obteve para a Formação Itaiacoca valores de $-5.60 \pm 2.17 \%$ para $\delta^{18} \mathrm{O}_{c c}(\mathrm{cc}=$ composição calcítica) e $-4.72 \pm 1.91 \%$ para $\delta^{18} \mathrm{O}_{\mathrm{DO}}$ (Do $=$ composição dolomítica), embora o erro em torno destas médias seja elevado. Desta forma, a segunda média obtida na Tabela 4.2 , de $-2.53 \pm 0.18$ $\%$, pode ser descartada, pois, segundo esta média, a sedimentação da Formação Capirú iria se situar no Fanerozóico Inferior. Sabe-se, por relações de campo e dados geocronológicos, que esta relação temporal não se verifica, devendo ter sido construída, provavelmente, por dados com imperfeições de laboratório. Analisando, assim, as informações de isótopos estáveis, somados aos dados de sedimentação e tectônicos, os quais sugerem uma contemporaneidade na sedimentação das Formações Capirú e Itaiacoca, em margens opostas da Bacia Açungui.

Os valores de $\delta^{18} \mathrm{O}_{\mathrm{cc}}$ para os metacalcários calcíticos das Formações Votuverava e Água Clara situaram-se na porção inferior do Proterozóico Superior e superior do Proterozóico Médio, respectivamente. Os dados sugerem a ocorrência ou de um intervalo na sedimentação destas três unidades geológicas ou que possa estar associadas a pulsos de subsidência distintos (três) no contexto de evolução tectono-sedimentar da mesma bacia. Desta forma, a Formação Água Clara estaria situada na base da coluna estratigráfica, a Formação Votuverava numa porção mediana, enquanto a Formação Capirú, estaria no topo.

$\mathrm{O}$ valor de $-11.89 \pm 1.02 \%$ para $\delta^{18} \mathrm{O}$ e de $-2.82 \pm 0.42 \%$ para $\delta^{13} \mathrm{C}$ nos carbonatos da Formação Água Clara podem indicar empobrecimento nestes isótopos devido a reações de descarbonatação, as quais promoveram a liberam $\mathrm{CO}_{2}$, relativamente enriquecido em isótopos de ${ }^{13} \mathrm{C}$ e ${ }^{18} \mathrm{O}$, levando os valores de $\delta^{13} \mathrm{C}$ e $\delta^{18} \mathrm{O}$ do carbono residual a se tornarem mais negativos, conforme já assinalado por Frascá (1992). É provável que estas reações de descarbonatação atuaram sobre os litotipos da Formação Água Clara, uma vez que o metamorfismo situou-se na fácies xisto verde alto a início da fácies anfibolito. Desta forma, estes valores não refletem as condições de sedimentação da Formação Água Clara, as quais, após retiradas as influências do metamorfismo, poderiam situar-se mais próximo ou mesmo na da porção inferior do Proterozóico Superior, no Gráfico da Figura 4.31.

A ampla distribuição entre os valores de $\delta^{13} \mathrm{C}$, desde $-3.5 \%$ até $1.5 \%$ nas Formações Água Clara, Votuverava e Capirú (Ver Figura 4.30) podem também refletir as mudanças globais na composição isotópica da água do mar durante o Proterozóico Superior, segundo Kaufman et al. (1991), podendo a sedimentação ter-se processado numa mesma bacia sedimentar, em 
diferentes pulsos subsidentes, conforme referido anteriormente. Durante o intervalo tectônico, quando a bacia não era mais uma receptora de sedimentos em potencial, a composição isotópica da água do mar teria se modificado por influência de fatores climáticos, embora as variações dos isótopos de ${ }^{13} \mathrm{C}$ reflitam apenas o ambiente de sedimentação e não a relação temporal entre estas sedimentações.

Variações idênticas entre os isótopos de oxigênio e de carbono presentes no Grupo Açungui foram também identificadas por Kaufman et al. (1991) no Super Grupo Damara, na Namíbia, em rochas seguramente reconhecidas como pertencentes ao Proterozóico Superior. Desta forma, a hipótese de que a Formação Água Clara pertença a uma bacia do Proterozóico Médio, gerada num ciclo tectônico pré-Brasiliano, embora pouco provável, não pode ainda ser descartada. Em resumo, os dados aqui obtidos reforçam a hipótese de que a Formação Água Clara pertença a Bacia Açungui, formando a sua base, sendo seguido pelas Formações Votuverava e Capirú, no topo.

\subsubsection{CORRELAÇÕES}

Dados de $\delta^{13} \mathrm{C}$ e $\delta^{18} \mathrm{O}$ obtidos no pré-cambriano do Estado de São Paulo apresentam assinaturas isotópicas muito próximas as análises obtidas no pré-cambriano paranaense, permitindo deste modo correlações. Com base nestes isótopos, a Sequência Lajeado apresentou valores $\delta^{13} \mathrm{C}_{\mathrm{cc}}=1.27 \pm 1.33 \%$ e $\delta^{18} \mathrm{O}_{\mathrm{cc}}=7.37 \pm 1.27 \%$ (Frascá, 1992), os quais são muito próximos dos valores obtidos para a Formação Votuverava, com valores de $1.01 \pm 0.21 \% \mathrm{e}$ $-8,01 \pm 1.21 \%$ obtidos para $\delta^{13} \mathrm{C}_{\mathrm{cc}}$ e $\delta^{18} \mathrm{O}_{\mathrm{cc}}$, respectivamente. Este modo, a continuidade física entre estas duas unidades é reforçada pelos dados isotópicos. Contudo, as diferenças de metamorfismo e de deformação observadas nestas unidades, ao longo dos Estados do Paraná e São Paulo, podem ser atribuídos as diferentes intensidades com que a tectônica deformadora ficou registrada nestas litologias.

A Formação Itaiacoca, também analisada por Frascá (op. cit.) no Estado de São Paulo, pode ser também correlacionada com a Formação Capirú, no Estado do Paraná. Os valores isotópicos da Formação Itaiacoca de $1.02 \pm 0,90 \%$ e $-4.72 \pm 1,91 \%$ para $\delta^{13} \mathrm{C}_{\mathrm{DO}}$ e $\delta^{18} \mathrm{O}_{\mathrm{DO}}$, estão próximos dos valores obtidos neste trabalho na Formação Capirú, com valores de $1.1 \pm 0.08 \%$ e $-5.11 \pm 1.05 \%$. 
Desta forma, as sedimentações das Formações Itaiacoca e Capinu teriam sido processadas nas margens ocidental e oriental da Bacia Açungui, respectivamente, tendo em vista que estas unidades geológicas apresentam estruturas sedimentares comuns, incluíndo litotipos e presença de estromatólitos de águas rasas, as quais são feições típicas de plataformas continentais.

Entretanto, na Formação Água Clara e Mármores Tapagem do Estado de São Paulo, Frascá (op. cit.) encontrou valores de $-1.40 \%$ e $-1.04 \%$ para $\delta^{13} \mathrm{C}_{c c},-8.02 \%$ e -13.13 $\%$ para $\delta^{18} \mathrm{O}_{\mathrm{cc}}$, enquanto que no Estado do Paraná estas litologias apresentam valores de -2.82 $\pm 0.42 \%$ e $-11.89 \pm 1.02 \%$ para $\delta^{13} \mathrm{C}_{\mathrm{cc}}$ e $\delta^{18} \mathrm{O}_{\mathrm{cc}}$, respectivamente. Apesar da comparação entre os isótopos destes estados mostrarem uma idêntica escala de valores, existem diferenças significativas entre elas que necessitam ser melhor investigadas.

\subsection{AMBIENTES DE SEDIMENTAÇÃO}

\subsubsection{NA UNIDADE SÃo SILVESTRE (FORMAÇÃo ÁGUA CLARA)}

As litologias da Formação Água Clara apresentam uma estrutura laminar planohorizontal conspícua em toda área estudada. Trata-se da alternância de níveis centimétricos a métricos, essencialmente carbonáticos, com níveis granatíferos, quartzosos, intercalados com níveis de metamargas contendo diopsídio, muitas vezes retrometamorfisado para tremolita/actinolita.

As combinações de conteúdo entre os sedimentos carbonáticos e quartzosos variam desde termos essencialmente quartzíticos até carbonáticos.

Essas alternâncias composicionais marcam bem a estratificação sedimentar reliquiar $\left(\mathrm{S}_{\mathrm{o}}\right)$, que pode ser recuperável em níveis litoestruturais relativamente preservados da deformação e das transformações mineralógicas.

Ocorrem indícios de escavação e/ou erosão do topo de níveis turbidíticos, os quais parecem ter sido preenchidos por um fluxo sedimentar subsequente. Além disso, estão presentes estratificações gradacionais, presentes em diversas amostras.

Essas estruturas indicam uma origem clástica para os sedimentos da Formação São Silvestre. A alternância laminar plano-horizontal, monótona, de niveis centimétricos de composição carbonática, areno-carbonática, culminando no topo da sequência deposicional com um nível pelítico milimétrico, transformado pelo metamorfismo em minerais como biotita, raras moscovitas, sugerem uma estrutura do tipo turbidito distal (níveis D e E de Bouma, 1962, cujo conceito foi ampliado por Walker,1975,1977,1978, e Lowe, 1982). 
Segundo Humbert $(1976 \mathrm{a}, \mathrm{b})$, a estrutura laminar plano-horizontal indica uma máxima ordem com sedimentos bem selecionados, retrabalhados e organizados em estratos (Quadro 4.3). A nível dos grãos minerais individuais pode ser observado uma forte heterogeneidade aparente, pois cada grão sedimentar apresenta uma história deposicional e uma organização própria no contexto do pacote sedimentar, gerado pelas condições hidrodinâmicas vigentes na época da deposição.

A textura micrítica parece estar presente nos níveis carbonáticos mais puros, os quais são caracterizados por um material de granulação fina, fosco, e com cor variando de cinza a quase preto. Em carbonatos com este tipo de textura podem ser esperados impurezas detríticas silicosas, argilosas e silticas, as quais se acumulam em águas tranquilas, onde as lamas calcárias tendem a se precipitar, conforme observações de Suguio (1980). Nesse sentido, a presença de sedimentos químicos do tipo chert podem estar presentes, porém não foram confirmados com segurança.

Foram, ainda, identificados grãos de quartzo com um máximo de arredondamento, e em fase de recuperação/recristalização, submetidos ao metamorfismo térmico gerado pela introdução de corpos graníticos tardi a pós-tectônicos no Complexo Três Córregos. A ausência de esforços tectônicos dirigidos sobre esses grãos de quartzo é algo marcante, constituíndo-se num núcleo preservado da deformação, indicando uma possivel origem química para os mesmos.

A presença de uma tectônica distensiva pode ser também verificada pela presença de falhas normais sin-sedimentares, associadas a uma sedimentação calma. A presença de sulfetos, entre eles pirita e calcopirita, em parte alteradas para crostas limoníticas, além de ouro, são indicativos da vigência de características sedimentares de uma bacia restrita, de ambiente euxínico, em condições redutoras, estáveis.

As evidências alóctones e autóctones dos sedimentos presentes na fácies São Silvestre (Formação Água Clara), levam a concluir por uma sedimentação de águas profundas do tipo turbidítico (sedimentação alóctone), com períodos em que o aporte turbidítico deu lugar a sedimentação química, com características alóctones.

$\mathrm{O}$ estudo do arcabouço granular dos carbonatos, com a análise da estrutura interna dos grãos e o aspecto microscópico de suas bordas ficou inviabilizado devido as fortes transformações mineralógicas impostas pela recristalização, as quais modificaram os constituintes originais da sedimentação. Assim, as partículas aloquímicas como oólitos, pisólitos, bioclastos, litoclastos (intraclastos, pellets), isoclastos, agregoclastos, além dos constituintes ortoquímicos, como micrito (calcita microcristalina), e da matriz singenética e epigenética, não puderam ser 
MAXIMA ORDEM

FORTE HETEROGENEIDADE APARENTE

(1) ESTRUTURA LAMINAR PLANO-HORIZONTAL

(2) ESTRUTURA LAMINAR ONDULADA

(3) ESTRUTURA LAMINAR HORIZONTAL realçada pela orientação preferencial de certos constituintes.

(4) ESTRUTURA LAMINAR OBLÍQUA

(5) ESTRUTURA LAMINAR LENTICULARIZADA

(6) ESTRUTURA LAMINAR MESCLADA

(7) ESTRUTURA EM POCHES

(estrutura em forma de bolsa)

(8) ESTRUTURA ESPONGIFORME

(9) ESTRUTURA HOMOGÊNEA

(11) ESTRUTURA COM FORTE ISOTROPIA

MAXIMA DESORDEM

FORTE HOMOGENEIDADE APARENTE

Quadro 4.3 - Ordenamento dos diversos tipos de estruturas sedimentares em função da heterogeneidade e homogeneidade aparente das rochas. segundo Humbert (1976) modificado. 
diferenciados. $O$ reconhecimento destes tipos de partículas pode indicar a presença de estruturas com forte heterogeneidade ou homogeneidade aparente, conforme Quadro 4.4, proposto por Humbert (1976a).

É provável que ações de transformações sinsedimentares de grãos calcários (denominado por Humbert,1976a de biosedimentologênese), associadas às ações de transformações sedimentares e pós-sedimentares (diagênese), geraram uma homogeneização intragranular e/ou global da rocha em calcário microcristalino ou cristalino. Porém, a origem dos sedimentos carbonáticos, a partir de famílias de vazas calcárias e calcários criptocristalinos, e famílias de areias calcárias e de calcários granulares não foi recuperado. Isso se deve a forte recristalização e estiramento verificado nos grãos carbonáticos durante o metamorfismo regional, e ao metamorfismo termal, este último gerado pela intrusão dos corpos graniticos no Complexo Três Córregos, próximo aos litotipos aflorantes da Formação Água Clara, conforme discutido anteriormente.

A observação dos minerais através de microscópio ótico, com aumentos de $43,75 x$, $81,75 x$ e $125 x$, revelou grãos poligonais, com contatos entre os grãos de $120^{\circ}$, gerando textura granoblástica poligonal ou em mosáico. A recristalização total desses minerais não permitiu diferenciar as partículas sedimentares originais do seu cimento, não justificando o uso de terminologias como criptocristalino, microcristalino ou cristalino, utilizados para descrever constituintes minerais muito finos (micrito) ou o cimento da rocha.

Por outro lado, é possível, também, que os sedimentos carbonáticos fossem compostos, em sua maioria, por micritos, não havendo a presença pronunciada de partículas aloquímicas como ooclastos, bioclastos, litoclastos, agregadoclastos e isoclastos. Segundo essa última hipótese, o processo de homogeneização presente durante a diagênese não teria atuado de forma a modificar a textura original de seus constituintes, no caso criptocristalinos.

A presença especifica de estruturas biogênicas também não foi recuperado. Embora os bioclastos sejam componentes importantes nos calcários modernos, parecem estar ausentes nos calcários pré-cambrianos. Admitindo uma idade de sedimentação para a unidade São Silvestre similar àquela sugerida por Reis Neto (1994) para a Grupo Açungui, de 1.1 - 1.3 Ga. (admitindo que a Formação Água Clara constitua a base do referido grupo), é provável que apenas as algas se desenvolveram em grandes colônias naquela época, na forma de esteiras algais ou estromatólitos, uma vez que o seu apogeu ocorreu por volta de $1.1 \mathrm{Ga}$., permitindo um registro significativo nas rochas. Porém, considerando que os estromatólitos normalmente se desenvolvem próximo das costas continentais, onde encontram condições de águas rasas e limpas com boa 
ESTRUTURAS COM FORTE

HETEROGENEIDADE APARENTE

\section{(1) OOCLASTOS}

com empacotamento regular e com contorno puro.

(2) OOCLASTOS

empacotamento regular e com contorne suave ou leve.

(3) OOCLASTOS

com empacotamento irregular de origem orgânica provável ou presumida.

(4) OOCLASTOS

com empacotamento muito irregular de origem

orgânica provável ou presumida.

(5) LITOCLASTOS

(6) BIOCLASTOS

(7) AGREGADOS

ou compostos de grãos.

(8) ISOCLASTOS

Grãos com uma estrutura com forte isotropia

(isoclasto) e com contorno puro.

(9) ISOCLASTOS

Grãos com um estrutura com forte isotropia (isoclastos)

e com isotropia suave ou leve.

ESTRUTURAS COM FORTE

HOMOGENEIDADE APARENTE

Quadro 4.4 - Ordenamento das estruturas de tipos de grãos em função de sua aparente homogeneidade ou heterogeneidade. (Humbert. 1976) modificado. 
oxigenação, boa iluminação e temperaturas em torno de $20^{\circ} \mathrm{C}$, entre outras condições básicas, como ocorreu durante a sedimentação das Formações Itaiacoca e Capirú, situadas respectivamente nas bordas noroeste e sudeste da Bacia Açungui. Entretato, a sedimentação da Unidade São Silvestre se desenvolveu em condições essencialmente de águas profundas, num ambiente inadequado para o desenvolvimento de estromatólitos, o que é reforçado pela não identificação de nenhum registro desta estrutura fóssil.

Em termos estratigráficos, a Formação Água Clara se apresenta estruturada basicamente em três pacotes litológicos, tendo uma unidade quartzítica na base, seguida por outra de composição carbonática pura a impura e outra unidade terrígena (filitos) e anfibolitos no topo, como pode ser observado no anticlinal do Perau. Porém, estas três unidades nem sempre ocorrem em todas as exposições da Formação Água Clara. Assim ocorre nas bordas sudestes e noroeste do Complexo Granítico Três Córregos, onde estão melhor representados os termos carbonáticos, com os termos pelíticos e arenosos sendo mal desenvolvidos.

\subsection{2 - NO GRUPO AÇUNGUI (FORMAÇÕES CAPIRÚ, VOTUVERAVA E ITAIACOCA)}

No Grupo Açungui tradicional, compreendido pelas Formações Capirú, Votuverava e Itaiacoca, repetem-se os intervalos sedimentares presentes na Formação Água Clara. Ocorrem sedimentos clásticos grosseiros que transicionam para sedimentos finos na base, seguidas por termos carbonáticos calcíticos, os quais passam para dolomíticos na sequência ascendente da coluna, e no topo voltam a ocorrer sedimentos clásticas com granulometria média a fina (rochas psamíticas e pelíticas) e raras psefíticas (Quadro 4.5).

\subsubsection{BASE DO GRUPO AÇUNGUI TRADICIONAL}

Os litotipos clásticos presentes logo acima da Formação Água Clara, compreendidos por metaconglomerados, metarenitos finos e metassiltitos e raros metargilitos foram agrupados por Fiori (1990) nos Conjuntos Litológicos Coloninha e Bromado, no Bloco D, Tacaniça, no Bloco D, e por Reis Neto (1994) na Formação Abapã, no Bloco B, podendo corresponder aos filitos do Conjunto Litológico Juruqui, no bloco E. Esta compartimentação tectônica em blocos foi proposta por Góis et al. (1985, modificado) (Figura 4.32). 


\begin{tabular}{|c|c|c|c|c|}
\hline & & \multicolumn{2}{|c|}{ BLOCOS ALCCADOS POR TRANSPRESSÃO } & \multirow[b]{2}{*}{ BLOCOE } \\
\hline & BLOCOB & BLOCOC & BLOCO D & \\
\hline $\begin{array}{l}\text { SEDIMENTAÇÃO GERANDO } \\
\text { A Formação } \\
\text { ITAIACOCA NA BORDA } \\
\text { NW DA BACIA AÇUNGUI E } \\
\text { A Formação CAPIRÚ } \\
\text { NA BORDA SE. } \\
\text { (TOPO DO Grupo AÇUNGUI) }\end{array}$ & 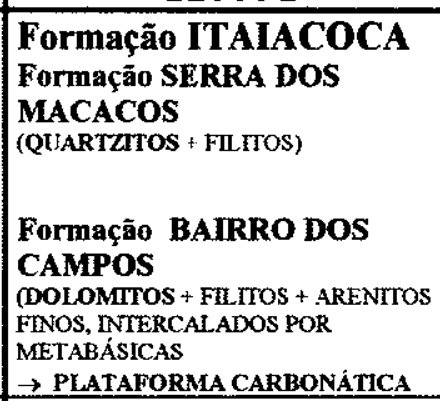 & 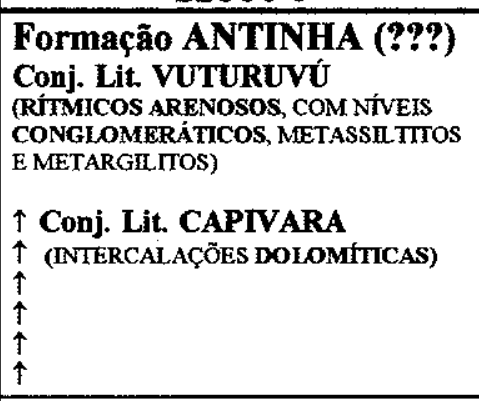 & $\begin{array}{l}\text { CONJUNTO LITOLÓGICO } \\
\text { ERODIDO } \\
\text { (ARENITOS + QUARTZITOS QUE FORAM } \\
\text { ERODDOS NOS BLOCOS SORRGUIDOS } \\
\text { POR TRANSPRESSAO). } \\
\text { CONJUNTO LITOLÓGICO } \\
\text { ERODIDO } \\
\text { MARMOORES DOLOMITICOS FORAM } \\
\text { ERRDIDOS) }\end{array}$ & \begin{tabular}{|l} 
Formação CAPIRÚ \\
Conj. Lit. MORRO GRANDE \\
(QUARTZTIOS + PELITOS) \\
\\
$\downarrow$ Conj. Lit. RIO BRANCO \\
$\downarrow$ (METADOLOMITOS NTERCALA- \\
$\downarrow$ DOS POR NIVEIS CALCITCOS). \\
$\downarrow$ \\
$\downarrow$ \\
$\downarrow$ \\
$\downarrow$ \\
$\downarrow$
\end{tabular} \\
\hline $\begin{array}{l}\text { SEDIMENTAÇÃO DAS } \\
\text { FormaÇÕes ABAPÃ E } \\
\text { VOTUVERA VA. } \\
\\
\text { (PORÇÃO INTERMEDIÁRIA } \\
\text { DO GRUPO AÇUNGUI) }\end{array}$ & 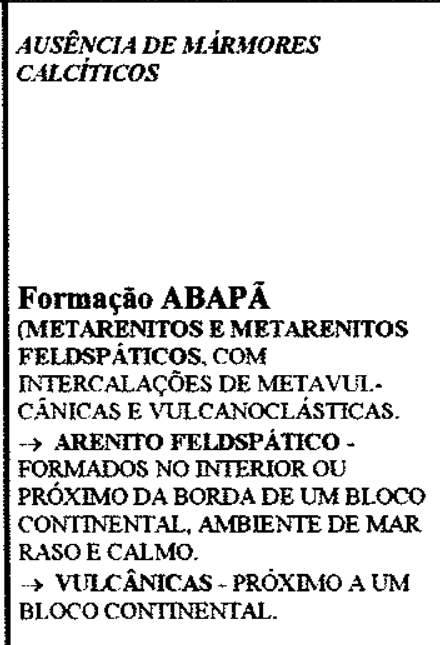 & 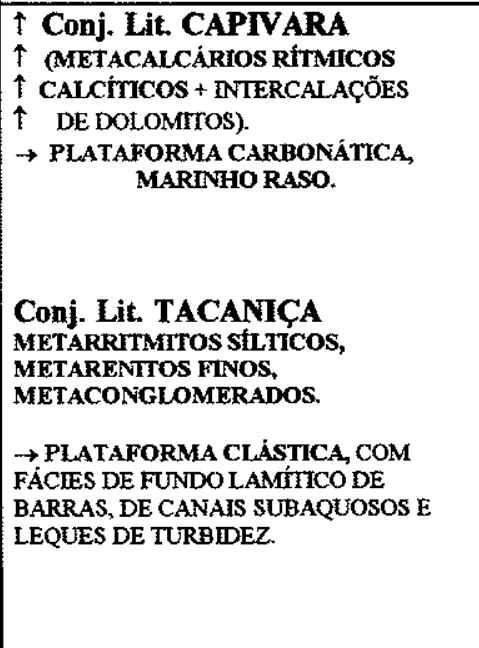 & 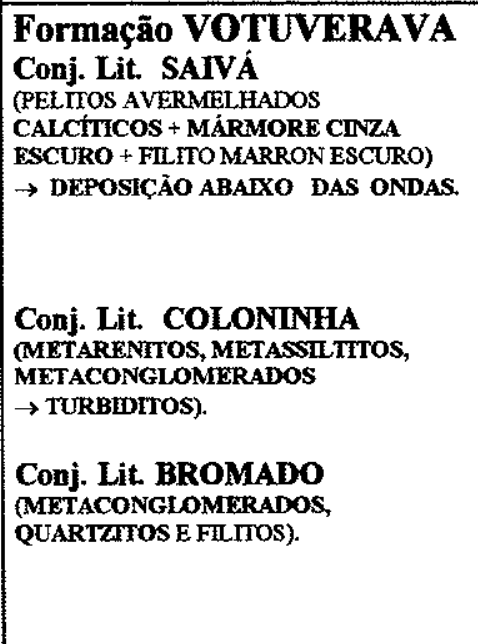 & $\begin{array}{l}\downarrow \text { Conj. Lit. RIO BRANCO } \\
\downarrow \text { (INIRRCALAÇÓES DE NIVRIS } \\
\downarrow \text { CALCIIICOS) } \\
\text { COnj. Lit. JURUQUI } \\
\text { PRESENÇA DE FILITOS. }\end{array}$ \\
\hline $\begin{array}{l}\text { SEDIMENTAÇÃO DA } \\
\text { Formação ÁGUA } \\
\text { CLARA. } \\
\text { (BASE DO GRUPO AÇUNGUI) }\end{array}$ & $\begin{array}{l}\text { Formação AGUA CLARA } \\
\text { (AICAADO POR TRANSPRESSÃO) } \\
\text { BORDA NW DO COMPLEXO } 3 \\
\text { CORREGOS }\end{array}$ & $\begin{array}{l}\text { Formação ÁGUA CLARA } \\
\text { (EXPPOSTO EM ANTICLINAL E POR } \\
\text { TRANSPRESSAO). } \\
\text { - UNDADERE TIRRRIGENA } \\
\text { - UNDADE CARBONÁTICA } \\
\text { - ????? }\end{array}$ & 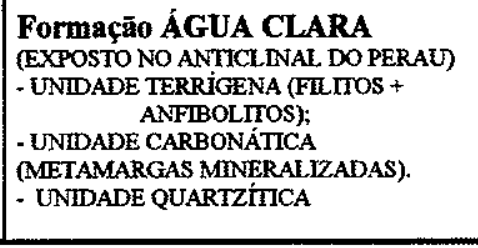 & $\begin{array}{l}\text { Grupo SETUVA } \\
\text { (ANTICLINAL DO SETUVA) } \\
\text { RELACCóES COM A FORMACÃo } \\
\text { ÁGUA CLARA DESCONHECDAS. }\end{array}$ \\
\hline
\end{tabular}

Quadro 4.5 - Compilação das colunas estratigráficas existentes nos diversos blocos tectônicos do Grupo Açungui. ABREVIAÇÃO: Conj. Lit. = Conjunto Litológico. Fontes: Fiori (1990), Lima et al. (1993) e Reis Neto (1994). 


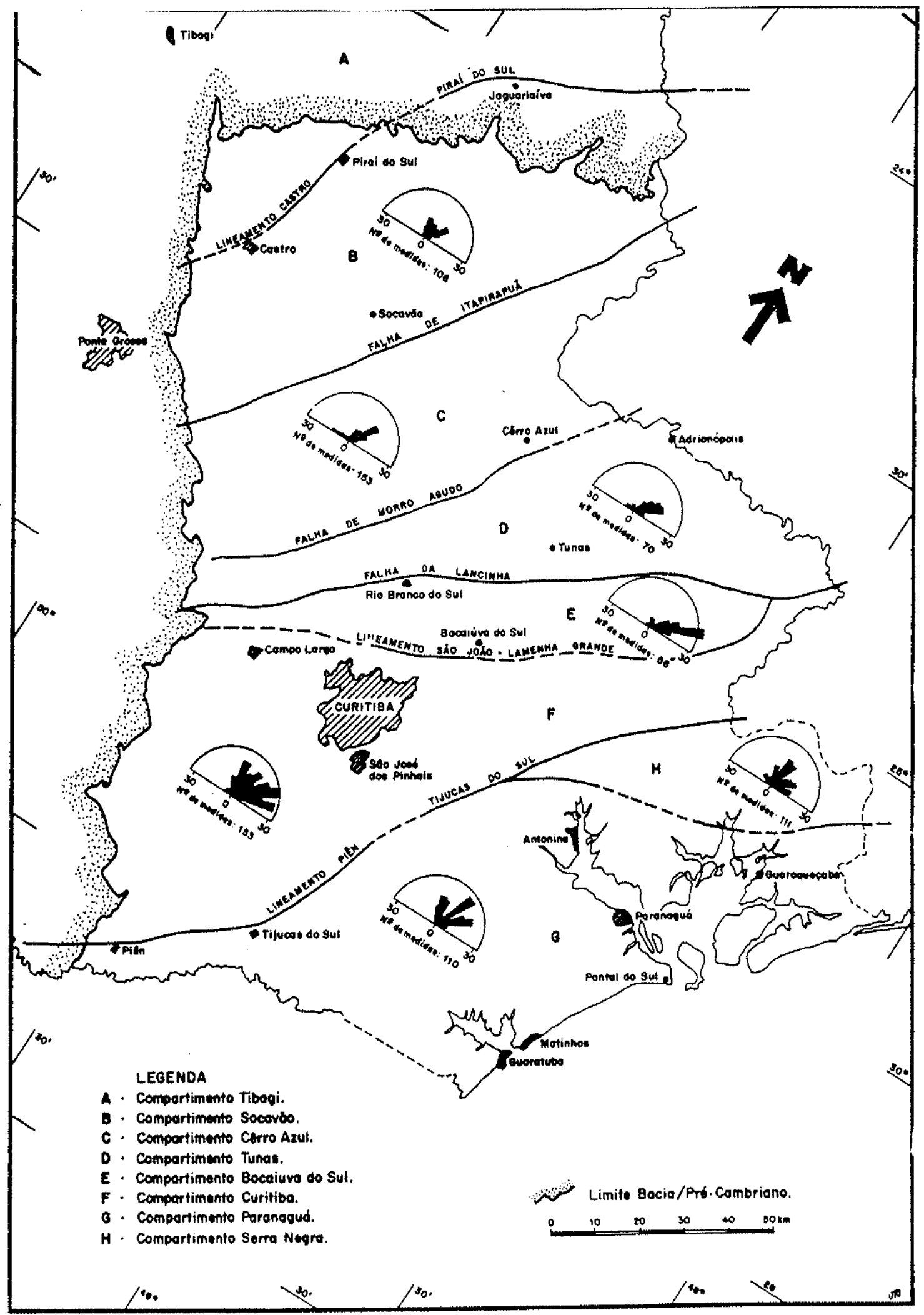

Figura +.32 - Mapa dos Compartimentos tectònicos do pré-cambriano paranaense . idealizado por Góis et al,(1985). 


\subsubsection{PORÇÃO INTERMEDIÁRIA DA BACIA AÇUNGUI}

$\mathrm{Na}$ porção intermediária da coluna estratigráfica, ocorrem os mármores calcíticos, agrupados nos Conjuntos Litológicos Saivá, no Bloco D, Capivara, no bloco C, estando provavelmente ausentes na Faixa Itaiacoca (Bloco B), e no bloco E, constituindo-se em pequenas intercalações no Conjunto Litológicos Rio Branco. Estes mármores calcíticos passam para mármores dolomíticos na sequência ascendente da coluna estratigráfica, estando representados pelos Conjuntos Litológicos Rio Branco e Capivara, nos blocos E e C respectivamente; na Faixa Itaiacoca, pela Formação Bairro dos Campos de Lima et al. (1993) e Reis Neto (1994), a qual possivelmente foi erodida no Bloco $\mathrm{D}$, em consequência de sua ascensão tectônica da mesma por intermédio de esforços transpressivos.

\subsubsection{TOPO DO GRUPO AÇUNGUI}

No topo da coluna estratigráfica aparecem metarenitos, com intercalações de metaconglomerados e metapelitos. Foram enfeixados pelos Conjuntos Litológicos Morro Grande, no bloco E, Vuturuvú, no bloco C, Formação Serra dos Macacos, na Faixa Itaiacoca (bloco B), estando igualmente ausentes no bloco $\mathrm{D}$ por efeito de erosão.

Comparando-se os intervalos ou ciclos sedimentares presentes na Formação Água Clara com aqueles do Grupo Açungui, nota-se que a sedimentação da primeira é essencialmente carbonática, com os sedimentos clásticos ocorrendo de forma subordinada, enquanto que no Grupo Açungui, os sedimentos detriticos compõem a parcela principal da sedimentação, com os carbonatos ocorrendo intercalados como fina camadas ou lentes.

Embora as formações tradicionais ocorrem em blocos distintos, com as Formações Capirú, no Bloco E, a Votuverava, no D, a Antinha (?), no C, e Itaiacoca no bloco B, é possivel homogeneizar as nomenclaturas numa coluna estratigráfica comum para todos os blocos. Assim, a Formação Água Clara estaria compondo a base da Bacia Açungui, seguida pela Formação Votuverava, e no topo a Formações Capirú e Itaiacoca.

Esta análise vertical dos pacotes sedimentares necessita obrigatoriamente de uma análise das composições, interdigitações e extensões laterais das sequências sedimentares. De uma forma geral, estas unidades apresentam as seguintes caracteristicas:

a) A Formação Capirú ocupa a margem sudeste da Bacia Açungui, com sequências terrígenas e carbonáticas típicas de plataforma continental. 
b) A Formação Votuverava está situada numa porção mais profunda da bacia, constituída de sedimentos clásticos mais finos, estruturados, em grande parte, na forma de turbiditos distais (termos D e E de Bouma,1962).

c) A Formação Água Clara ocupa uma porção ainda mais profunda da bacia, onde o aporte de sedimentos clásticos teria sido substituído, em grande parte, por sedimentos carbonáticos, igualmente com estruturas de turbiditos distais. Esta unidade está situada na base do Grupo Açungui, com vulcânicas associadas, marcando possivelmente a abertura da referida bacia. Estão presentes, ainda, intrusão de corpos básicos, agora anfibolitizadas, na forma de sills, idêntico as ocorrências presentes nas Formações Votuverava e Itaiacoca.

d) E a Faixa Itaiacoca, situada na margem noroeste da Bacia Açungui, marca novamente a presença de sedimentos costeiros ou de margem continental, num ambiente de mar calmo e raso. Associam-se a este ambiente rochas vulcânicas, descritas por Reis Neto (1994) como integrando a Formação Abapã.

A verificação de dois intervalos ou ciclos sedimentares na Bacia Açungui, bem como uma coerência entre os ambientes deposicionais denotada por intermédio de uma análise lateral das sequências, permite formular duas hipóteses de trabalho:

\section{a) DUPLICAÇÃO TECTÔNICA DA BACIA AÇUNGUI}

Os idênticos intervalos sedimentares presentes no Grupo Açungui tradicional (Formações Capirú, Votuverava e Itaiacoca), e na Formação Água Clara, poderiam corresponder a um único intervalo sedimentar, porém duplicado através de processos tectônicos. A presença da Formação Água Clara em todos os blocos tectônicos, ou seja, na base das Formações Votuverava, Antinha e Itaiacoca e, provavelmente, Capirú, poderia ser explicada como sendo o produto de uma duplicação estratigráfica ao longo de uma falha de cavalgamento (baixo ângulo), ocorrida nos estágios iniciais de encurtamento da Bacia Açungui. Porém, não existem dados de campo que apontem para esta hipótese de trabalho.

\section{b) CICLOS DE SEDIMENTAÇÃO PARA A BACIA AÇUNGUI}

Teriam ocorrido dois intervalos ou ciclos de sedimentação na Bacia Açungui: um primeiro, compondo a Formação Água Clara, com as unidades quartzitica $\rightarrow$ carbonática $\rightarrow$ terrigena (da base para o topo). Teria ocorrido um hiato na sedimentação, com possível erosão, seguindo-se um novo ciclo sedimentar com mudança da área fonte, agora com aporte de 
sedimentos principalmente detríticos, novamente com sedimentos clásticos compondo as litologias da base, seguindo-se um intervalo carbonático, e fechando o ciclo, um novo aporte de sedimentos clásticos. Ou, ainda, em três ciclos distintos, com as sedimentações das Bacias Água Clara, na base do Grupo Açungui, seguida pela Votuverava e, no topo, a Capirú/Itaiacoca, com base na distribuição temporal de suas análises de isótopos de ${ }^{18} \mathrm{O}$.

É interessante observar que estes ciclos sedimentares (clásticas - carbonáticas - clásticas) encontram correspondentes em todos os blocos tectônicos, com variações da espessura dos aportes sedimentares em alguns termos, às vezes com pequenas modificações na composição dos sedimentos, aspecto este característico de fontes sedimentares distintas. Desta forma, haveria uma coluna estratigráfica única para todos os blocos, na qual a Formação Água Clara estaria na base, seguida pela Formação Votuverava, com as Formações Capirú/Itaiacoca no topo, estas últimas correlatas. Porém, o diferente nível de exposição desta coluna estratigráfica, bem como sua compartimentação em blocos tectônicos distintos, levou diversos autores a propor inúmeras colunas, com nomenclaturas próprias das diversas situações geográficas.

A esta estruturação sedimentar, discutida com base nestas duas hipóteses, teria sido afetada por um evento de deformação transpressional, conforme discussões no Capítulo 4.3.5 (Modelização e Discussão dos dados Estruturais da Formação Água Clara). Com o desenvolvimento das estruturas transpressivas, ocorreu o alçamento de diferentes níveis estratigráficos em torno de uma estrutura-em-flor positiva (Ver Figura 2.4). Esta justaposição de unidades sedimentares aparentemente diferentes, devido ao diferente nível de exposição da coluna estratigráfica original ao longo dos diversos blocos, induziu muitos pesquisadores a admitir uma coluna estratigráfica e uma história deposicional particular para as litologias de cada bloco tectônico, o que, na verdade, parece pouco provável.

\subsection{CORRELAÇÃo dA FORMAÇÃo ÁGUA CLARA COM O GRUPO AÇUNGUI}

Comparando-se a Formação Água Clara com o Grupo Açungui em termos estruturais, metamórficos e de ambiente de sedimentação, ficam transparentes importantes similaridades (Fassbinder et al. 1994) (Quadro 4.6): 


\begin{tabular}{|c|c|c|c|c|c|c|}
\hline \multicolumn{2}{|c|}{ FORMAÇÃO ÁGUA CLARA } & \multicolumn{4}{|c|}{ GRUPO AÇUNGUI } & \\
\hline ASPECTOS ESTRUTURAIS & METAMORFISMO & \multicolumn{2}{|c|}{ ASPECTOS ESTRUTURAIS } & \multicolumn{2}{|c|}{ METAMORFISMO } & \\
\hline 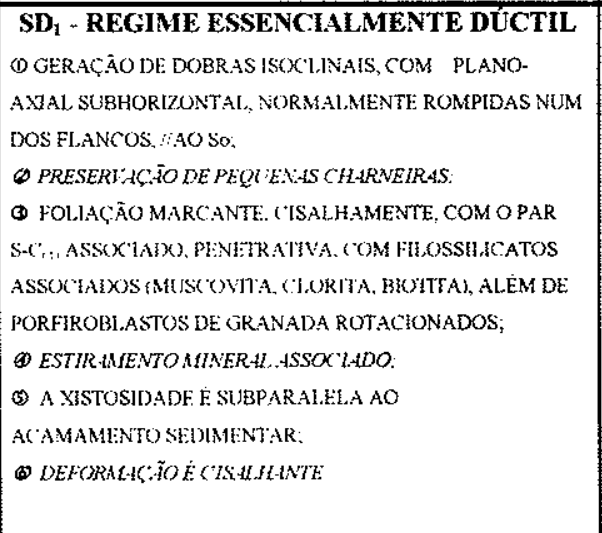 & 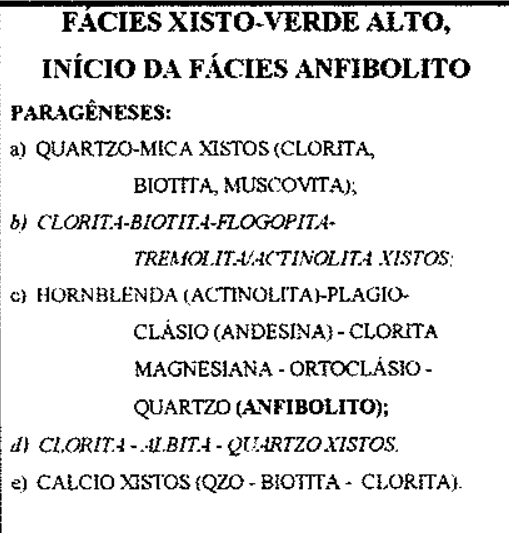 & \multicolumn{2}{|c|}{ 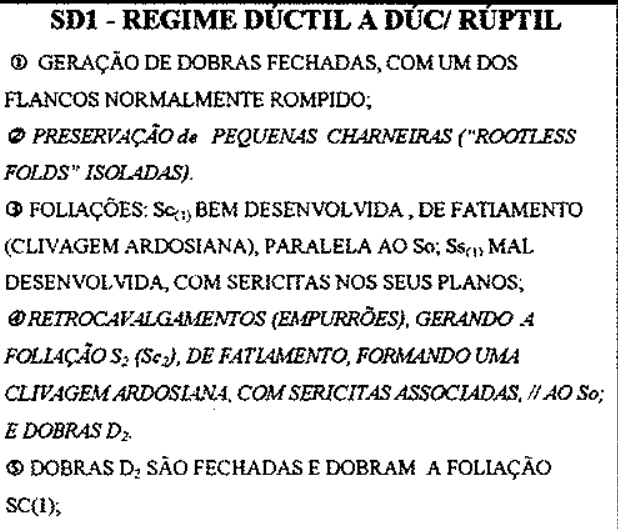 } & $\begin{array}{l}\text { FÁCIES } \\
\text { CLORI } \\
\\
\text { MINERAIS D } \\
\text { - CLORITA } \\
\text { - ERIDOTO } \\
\text { - ACTINOLIT } \\
\text { - CIANITA. }\end{array}$ & $\begin{array}{l}\text { STO-VERDE, ZONA DA } \\
\text { E INICIO DA ZONA DA } \\
\text { BIOTITA } \\
\text { ENÓSIICOS: }\end{array}$ & $\begin{array}{l}\downarrow \\
\downarrow \\
\downarrow \\
\downarrow \\
\downarrow \\
\downarrow \\
\downarrow \\
\downarrow \\
\downarrow \\
\downarrow \\
\downarrow \\
\downarrow \\
\downarrow\end{array}$ \\
\hline 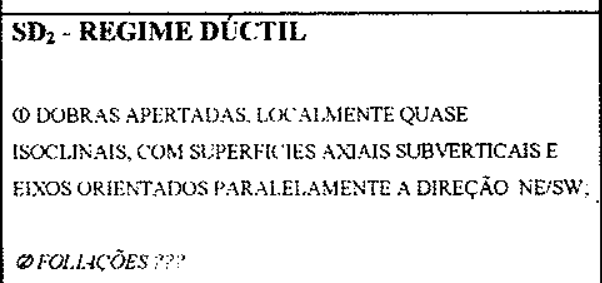 & 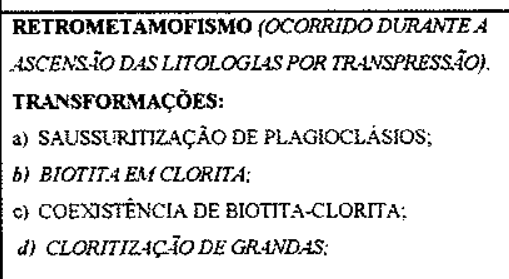 & \multicolumn{2}{|c|}{ 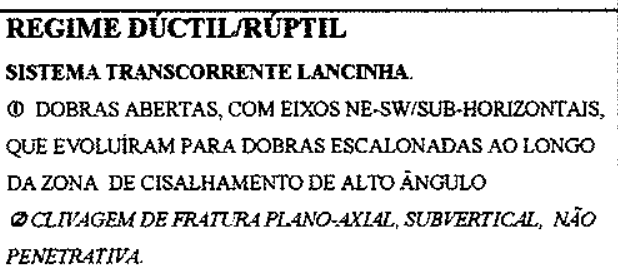 } & \multicolumn{2}{|c|}{$\begin{array}{c}\text { FÁCIES XISTO VERDE, ZONA DA } \\
\text { CLORITA A ANQUIMETAMÓRFICO } \\
(?)\end{array}$} & $\begin{array}{l}\downarrow \\
\downarrow \\
\downarrow \\
\downarrow \\
\downarrow \\
\downarrow\end{array}$ \\
\hline 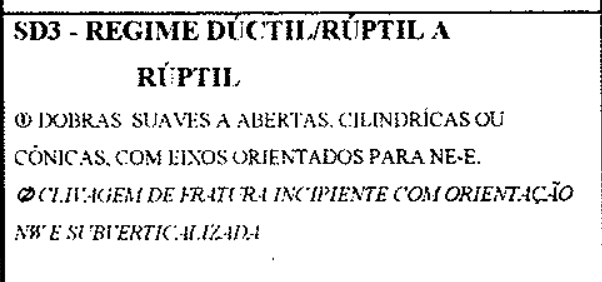 & 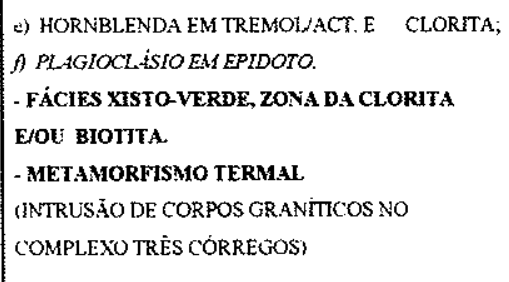 & \multicolumn{2}{|c|}{ 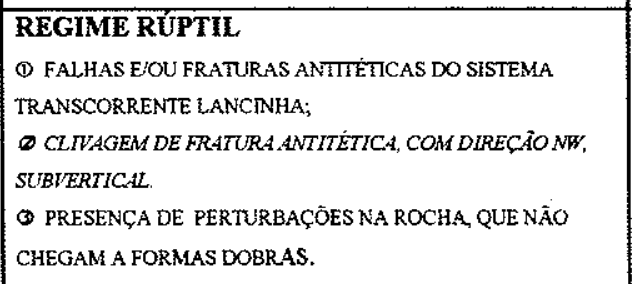 } & \multicolumn{2}{|r|}{ AUSENTE (?) } & $\begin{array}{l}\downarrow \\
\downarrow \\
\downarrow \\
\downarrow \\
\downarrow \\
\downarrow\end{array}$ \\
\hline AMBIENTE DE SEDIMENTAÇÃO $\Rightarrow$ & $\begin{array}{l}\text { MARINHO PROFUNDO, TURBDITICO, } \\
\text { COM ATVDADE VLCÁNICA ASSOCIADA. }\end{array}$ & $\begin{array}{l}\text { FORMAÇAOO VOTUVERAVA } \\
\text { SISTEMA TURBDITICO DE } \\
\text { AGUAS } \pm \text { PROFUNDAS }\end{array}$ & $\begin{array}{l}\text { FORMAÇĀO CAPI } \\
\text { PLATAFORMA CAR } \\
\text { TERRIGENA DE ÁG }\end{array}$ & $\begin{array}{l}\text { BONÁTICA } \\
\text { UAS RASAS }\end{array}$ & $\begin{array}{l}\text { SEQUÉNCIA ANTINHA } \\
\text { DEPÓSITOS PLATAFOR } \\
\text { MASS. }\end{array}$ & $\begin{array}{l}\downarrow \\
\downarrow \\
(*)\end{array}$ \\
\hline
\end{tabular}

Quadro 4.6 - Síntese sobre as características mais importantes da Formação Água Clara e do Grupo Açungui. Muitos eventos estruturais colocadas neste quadro em ordem cronológica, podem ter se desenvolvido de forma contemporânea, dentro de um sistema de deformação..

$\left(^{*}\right)$ Indica DEFORMAÇÃO PROGRESSIVA, a partir do paroxismo até o resfriamento total do Orógeno Ribeira, nos arredores de Curitiba. 
a) A deformação em ambas unidades é do tipo cisalhante, gerada por esforços transpressionais, com ocorrência de partição da deformação. A componente de cisalhamento puro gerou o cavalgamentos e retrocavalgamentos, os quais foram propostos por Fiori (1990) na região de Rio Branco do Sul, Bocaiúva do Sul e Bateias (município de Campo Largo).

b) Esta deformação foi gerada num campo essencialmente dúctil, na Formação Água Clara, com dobras isoclinais quase sempre rompidas num de seus flancos, com um par de foliações SC penetrativo, além de estiramentos e lineações minerais e lineações de interseç̧ão de foliações. Contudo, no Grupo Açungui (Formações Votuverava, Antinha, Capirú/Itaiacoca) ocorre uma deformação dúctil a rúptil/dúctil, com as dobras associadas ao evento $\mathrm{SD}_{1}$, sendo normalmente fechadas, raramente cerradas, ocorrendo igualmente um par de foliações $\mathrm{SC}$, porém menos desenvolvido, com um estiramento mineral pequeno.

c) O estiramento mineral quantificado por Spoladore (1993) forneceu valores de deformação cisalhamento $(\gamma)$ da ordem de 3,0 para a Formação Água Clara, de 1,2 a 2,5 para a Formação Votuverava, e ao redor de 1,0 (nulo) para a Formação Antinha. Observações de campo mostram relações de deformação na ordem de 5 para $X$ e de 1 para $Z$, relações estas que podem chegar até 10 para $X$ e 1 para $Z$ na Formação Água Clara, enquanto no Grupo Açungui a média situa-se em torno de 2 ou 3 para $X$ e 1 para $Z$. Estes dados mostram que todas as unidades do Grupo Açungui sofreram algum tipo de deformação, e que existe uma transição da deformação entre suas unidades. Assim, o Formação Água Clara com valores mais elevados de deformação ocupa a base da coluna estratigráfica, seguida pela Formação Votuverava, e no topo as Formação Antinha e, provavelmente, a Formações Capirú e Itaiacoca, onde ocorre um decréscimo acentuado da deformação, excetuando-se as zonas de cisalhamento identificadas por Fiori et al. $(1987 \mathrm{a}, \mathrm{b})$, onde ocorrem valores anômalos com relação ao back ground regional.

d) Verifica-se uma equivalência entre os sistemas de deformação presentes nas diversas formações (Água Clara, Votuverava, Capirú/Itaiacoca). O número de fases de deformação pode variar, geradas por possíveis redistribuições dos vetores do campo de stress a partir de anteparos tectônicos; interferências entre diferentes zonas de cisalhamentos; interferência entre fases de dobramentos distintos, geradas por influência do comportamento da deformação em diferentes níveis estruturais e diferentes competências das rochas; ascensão do orógeno, ocorrendo 
superposição de foliações, num regime de deformação progressiva (exemplo: deformações essencialmente de achatamento oriundas da raiz da estrutura, sofrendo superposição de deformações transcorrentes). Assim, as equivalências identificada foram:

\subsection{1 $1^{\circ}$ SISTEMA DE DEFORMAÇÃO $\left(\mathrm{SD}_{1}\right)$}

\begin{tabular}{|c|c|c|}
\hline & NA FORMAÇÃo ÁGUA CLARA & $\begin{array}{c}\text { NO GRUPO ACUNGUI } \\
\text { (FORMAÇÖES VOTUVERAVA e CAPIRÚ) }\end{array}$ \\
\hline 1. & $\begin{array}{l}\text { Dobras isoclinais, com um dos flancos normalmente } \\
\text { rompido, com superficie axial subhorizontal. }\end{array}$ & $\begin{array}{l}\text { Dobras fechadas, raramente apertadas, igualmente } \\
\text { com um dos flancos rompidos, transpostas, com } \\
\text { estruturas do tipo ROOTLESS. }\end{array}$ \\
\hline 2. & 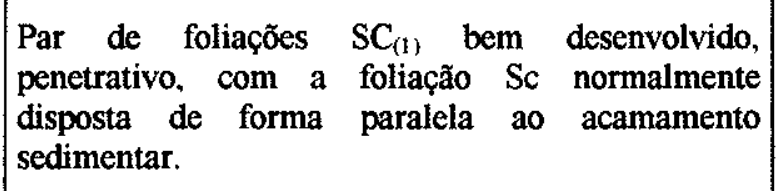 & $\begin{array}{l}\text { Presença das foliaçóes } \mathrm{SC}_{(1)} \text {, porém com a foliação } \mathrm{Ss} \\
\text { mal desenvolvida. A foliação } \mathrm{Sc} \text { situa-se, geralmente, } \\
\text { de forma paralela ao So, de forma similar a Formação } \\
\text { Água Clara. }\end{array}$ \\
\hline 3. & $\begin{array}{l}\text { Estiramento mineral pronunciado, com valores de } \\
\gamma=3,0 \\
\text { (Spoladore, 1993). }\end{array}$ & $\begin{array}{l}\text { Estiramento mineral menos desenvolvido. } \\
\gamma=1,2 \text { a } 2,5 \text { para a Formação Votuverava, e } \\
\gamma=1,0 \text { para a Formação Antinha. (Spoladore, 1993). }\end{array}$ \\
\hline 4. & $\begin{array}{l}\text { Lineação de interseç̧ão das Foliação Ss sobre a Sc } \\
\text { bem desenvolvida e penetrativa, com direção média } \\
\text { de } \mathrm{N} 80 \mathrm{E} / 13^{\circ}\end{array}$ & $\begin{array}{l}\text { Lineação de intersecção da foliação Ss sobre a Sc, mal } \\
\text { desenvolvida. }\end{array}$ \\
\hline 5. & $\begin{array}{l}\text { Transporte tectônico com sentido SUL (S30E), } \\
\text { verificado pela relação entre as foliações SC, dobras } \\
\text { falha. assimetria de dobras (?), rotação de } \\
\text { porfiroblastos (clastos), e pelas dobras em bainha. }\end{array}$ & $\begin{array}{l}\text { Transporte tectônico para S-SE, idêntico aquele } \\
\text { verificado por Fiori ct al. (1987a.b), Soares (1987) e } \\
\text { Fiori (1990). }\end{array}$ \\
\hline
\end{tabular}




\subsection{2 $2^{\circ}$ SISTEMA DE DEFORMAÇÃO $\left(\mathrm{SD}_{2}\right)$}

\begin{tabular}{|c|c|c|}
\hline & NA FORMAÇÃO ÁGUA CLARA & $\begin{array}{c}\text { NO GRUPO AÇUNGUI } \\
\text { (FORMAÇÓES VOTUVERAVA e CAPIRÚ) }\end{array}$ \\
\hline 1. & $\begin{array}{l}\text { Geração de um par de foliações } \mathrm{SC}_{(2)} \text {, identificado em } \\
\text { escala microscópica, menos penetrativo do que a } \\
\text { foliação } \mathrm{SC}_{(1)} \text {. }\end{array}$ & $\begin{array}{l}\text { Presença da foliação } S_{2} \text {, identificada por Fiori et al. } \\
\text { (1987a,b) em escala mesoscópica. }\end{array}$ \\
\hline 2. & Transporte tectônico para NORTE. & Transporte tectônico para norte (Fiori, 1990). \\
\hline 3. & $\begin{array}{l}\text { As foliaçðes } \mathrm{SC}_{(2)} \text { utilizam a anisotropia gerada pela } \\
\text { foliação } \mathrm{SC}_{(1)} \text {, ou seja, a foliação } \mathrm{Sc}_{2} \text { utiliza o mesmo } \\
\text { plano de deformação da foliação } \mathrm{Sc}_{(1)} \text {, porém com } \\
\text { sentido de transporte oposto em relação a esta última. }\end{array}$ & $\begin{array}{l}\text { Esta estrutura foi interpretada por Fiori et al. } \\
\text { (1987a,b) e Fiori(1990) como retrocavalgamento ou } \\
\text { pela superposição das deformaçøes de duas rampas } \\
\text { frontais de cisalhamento. }\end{array}$ \\
\hline 4. & $\begin{array}{l}\text { Desorganização parcial da trama estrutural pretérita } \\
\left.\text { (foliação } \mathrm{SC}_{(1)}\right) \text {, com redobramento e reorientação da } \\
\text { foliação } \mathrm{Ss}_{1} \text {, rotação de porfiroclastos, e instalą̧ão de } \\
\text { um novo par de foliaçðes }\left(\mathrm{SC}_{(2)}\right) \text {. }\end{array}$ & $\begin{array}{l}\text { A foliação } S_{2} \text { não foi descrita em escala microscó- } \\
\text { pica. }\end{array}$ \\
\hline 5. & $\begin{array}{l}\text { Lineaçð̃es de interseç̧ão não foram recuperadas com } \\
\text { segurança. }\end{array}$ & $\begin{array}{l}\text { Lineaçð̃es de intersecção não foram descritas por } \\
\text { Fiori (op. cit.). }\end{array}$ \\
\hline
\end{tabular}

\subsection{3 $3^{\circ}$ SISTEMA DE DEFORMAÇÃO}

\begin{tabular}{|c|c|c|}
\hline & NA FORMAÇÃO ÁGUA CLARA & $\begin{array}{l}\text { NO GRUPO ACUNGUI } \\
\text { (FORMAÇÓES VOTUVERAVA e CAPIRÚ) }\end{array}$ \\
\hline 1. & $\begin{array}{l}\text { Superposição de um } 3^{\circ} \text { par de foliações. } \mathrm{SC}_{(3)} \\
\text { ocorrendo a foliação } \mathrm{Sc}_{3} \text { de forma mais } \\
\text { pronunciada. porém descontínua. porém presente } \\
\text { em toda a área (?). }\end{array}$ & $\begin{array}{l}\text { Pode corresponder as deformações de alto ângulo } \\
\text { presentes no Grupo Açungui, como clivagem de } \\
\text { fratura, brechas, protomilonitos, dobras escalonadas, } \\
\text { intenso fraturamento. }\end{array}$ \\
\hline 2: & Trunca e reorienta a foliação $\mathrm{Ss}_{1}$. & $\begin{array}{l}\text { Última deformação pronunciada que deixou } \\
\text { registros nas rochas do Grupo Açungui. }\end{array}$ \\
\hline 3. & $\begin{array}{l}\text { Lineações de intersecção presentes de forma muito } \\
\text { penetrativa em toda a área. com média estatística } \\
\mathrm{N} 85 \mathrm{E} / 10^{\circ} \text { (Esta lineação pode ser, na verdade. a } \mathrm{Li} \\
\left.\mathrm{Ss} \text { gerada no evento } \mathrm{SD}_{4}\right) \text {. }\end{array}$ & Feição não penetrativa no Grupo Açungui. \\
\hline
\end{tabular}




\section{CONTINUAÇÃO DO $3^{\circ}$ SISTEMA DE DEFORMAÇÃO}

\begin{tabular}{|c|c|c|}
\hline & NA FORMAÇÃO ÁGUA CLARA & $\begin{array}{c}\text { NO GRUPO ACUNGUI } \\
\text { (FORMAÇOES VOTUVERAVA e CAPIRÚ) }\end{array}$ \\
\hline 4. & Geração de dobras suaves, com eixo $\beta \mathrm{N} 85 \mathrm{E} / 10^{\circ}$ & $\begin{array}{l}\text { As dobras escalonadas apresentam uma direção média, } \\
\mathrm{N} 30 \mathrm{E} \text { no Grupo Açungui. Ocorre, assim, uma } \\
\text { diferença de } 55^{\circ} \text { desta em relação aos eixos de dobras } \\
\text { suaves presentes na Formação Agua Clara. }\end{array}$ \\
\hline 5. & $\begin{array}{l}\text { Pode significar um pulso subsequente da } \\
\text { deformação progressiva transpressional na } \\
\text { Formação Agua Clara, com um mergulho } \\
\text { ligeiramente superior as foliaç̃es } \mathrm{SC}_{(1)} \text { e } \mathrm{SC}_{(2)} \text {. } \\
\text { Pode significar, também, deformações associadas as } \\
\text { intrusões de corpos graníticos no Complexo Três } \\
\text { Córregos. }\end{array}$ & $\begin{array}{l}\text { Deformaç̃es transcorrentes presentes de forma } \\
\text { generalizada em todo o Grupo Açungui. Estas feiç̃os } \\
\text { parecem estar ausentes na Formação Água Clara, com } \\
\text { exceção de algumas reorientaçð̃es de guirlandas de } \\
\text { pólos, sugerinđo eixos } \beta \text { médios de N30E. }\end{array}$ \\
\hline
\end{tabular}

e) Uma deformação mais intensa na Formação Água Clara e outra progressivamente menor no Grupo Açungui, indica uma transição da deformação a partir da Formação Água Clara para a Formação Votuverava, e desta para a Formação Capirú/Itaiacoca, idêntico as conclusões obtidas a partir das análise de deformação. Esta deformação pode ser observada de forma evidente no Anticlinal do Perau, ao longo da estrada que conduz a mina de mesmo nome, onde a deformação e metamorfismo decrescem a partir da Formação Água Clara até a Formação Votuverava.

f) O metamorfismo presente nos metassedimentos da Formação Água Clara situa-se na fácies xisto verde alto, o qual pode chegar no inicio do grau médio em rochas metabásicas, conforme descrição de Pontes $(1981,1982)$. Nas Formações Votuverava, Capirú/Itaiacoca este metamorfismo decresce para a fácies xisto verde, zona da clorita e início da biotita.

As principais associações minerais diagnósticas identificados por Pontes (1981,1982), Pontes \& Salazar (1982), Reis Neto \& Soares (1987) e por este trabalho para as Formações Água Clara, Votuverava e Capinu (Grupo Açungui) estão relacionadas no Quadro 4.7. 


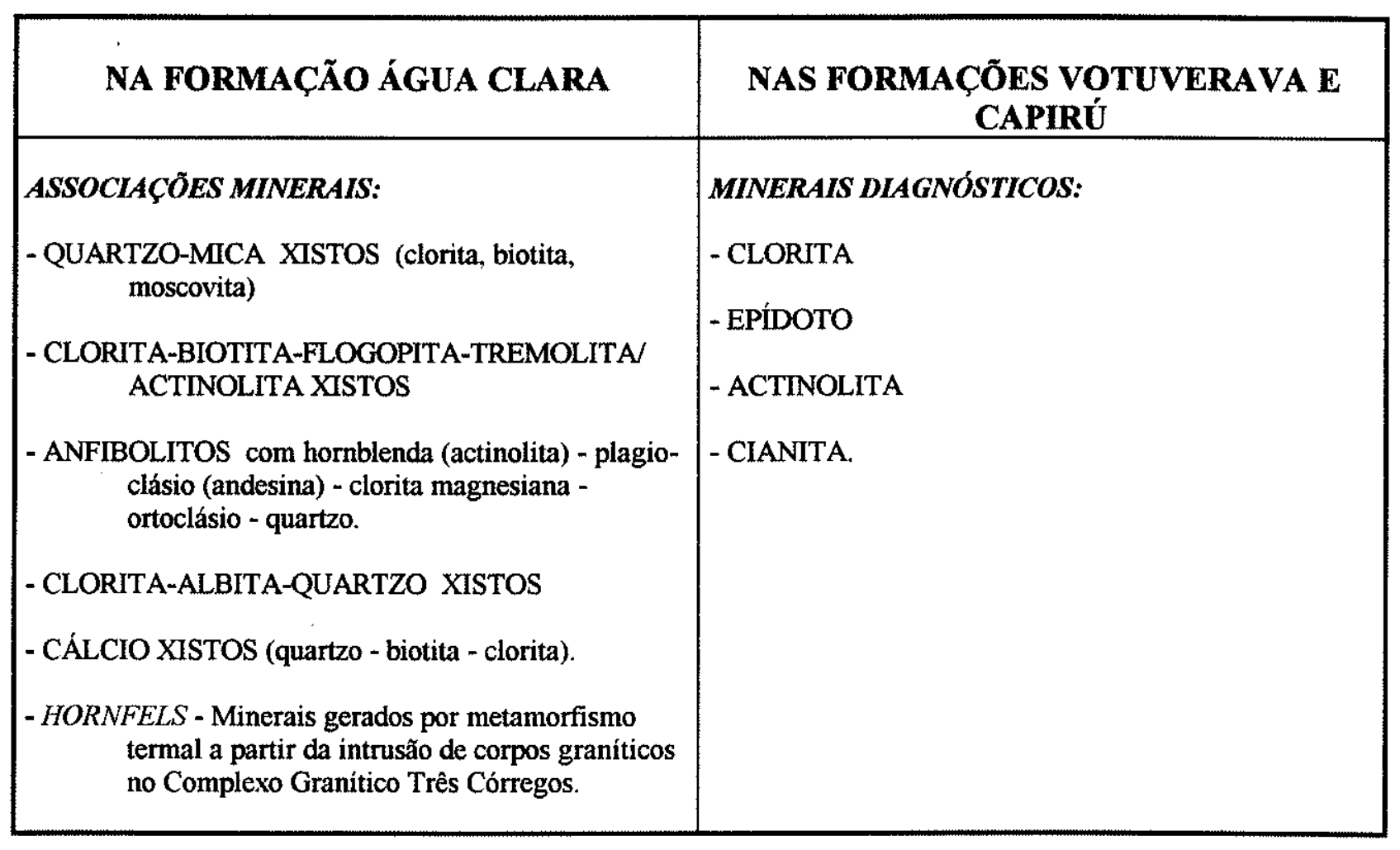

Quadro 4.7 - Principais associações minerais presentes na Formações Água Clara, Votuverava e Capirú.

A proximidade entre as fácies metamórficas presentes na Formação Água Clara e no Grupo Açungui (entendido pelas Formações Votuverava e Capirú), sendo a primeira um grau metamórfico ligeiramente superior em relação a segunda, mostra novamente uma transição entre as unidades em referência, agora de natureza metamórfica. Esta transição não é melhor caracterizada devido as restritas exposições da Formação Água Clara, normalmente inserida em blocos tectônicos individualizados por meio de falhas de empurrão (cavalgamento?), o que não permite o rasteamento lateral das isotermas.

g) O retrometamorfismo presente em larga escala nas litologias da Formação Água Clara representa um periodo da transpressão em que extensos pacotes litológicos foram alçados através da coluna transpressional (estrutura-em-flor positiva), desestabilizando as paragêneses geradas na fácies xisto-verde alto, inicio da fácies anfibolito em estruturais mais profundos. Estas litologias quando atingiram um idêntico nivel estrutural com aquele em que o Grupo Açungui foi 
metamorfisado, as paragêneses das duas unidades tornaram-se parcialmente equivalentes. Neste retrometamorfismo pode ser observado as seguintes transformações:

(1) Saussuritização de plagioclásios;

(2) Biotita em clorita;

(3) Coexistência de biotita-clorita;

(4) Cloritização de granadas;

(5) Hornblenda em tremolita/actinolita;

(b) Plagioclásio em epídoto.

h) O ambiente de sedimentação parece indicar novamente uma semelhança entre as unidades em referência. Enquanto as Formações Capirú e Itaiacoca mostram sedimentações tipicamente plataformais de águas rasas, com abundantes estruturas estromatolíticas, a Formação Votuverava foi formada por uma sedimentação mais distal, conforme exemplificado pelos pacotes significativos de turbiditos do tipo A-D, segundo a classificação de Bouma (1962). A Formação Água Clara parece se constituir numa fácies mais distal do que da Formação Votuverava, ocorrendo uma considerável contribuição turbidítica, situada nos intervalos C-E de Bouma (op. cit.). Admitindo a hipótese de uma continuidade lateral na sedimentação das Formações Votuverava e Água Clara, em algum ponto da Bacia Açungui, desfigurada por meio de uma possível tectônica de baixo ângulo inicial (a qual evoluiu para a partição da deformação $e$ o alçamento das litologias em torno de estrutura em flor positiva), fica evidente uma mudança na área fonte, com a substituição de aporte de material detrítico por carbonático. Segundo esta hipótese teria ocorrido uma duplicação da coluna estratigráfica original, conforme discussões na item anterior. 


\section{MODELO TECTÔNICO}

\subsection{INTRODUÇÃO}

A aplicação de modelos de subduç̧ão para a Faixa Ribeira no Pré-Cambriano Superior apresenta diversos problemas, conforme apontados no item 3.4 - Modelos Tectônicos Regionais (Capitulo 3 - Evolução dos conhecimentos geológicos anteriores).

Um dos maiores problemas é a transposição de modelos, previamente formulados para explicar as feições geológicas presentes nas cadeias modernas, tipo Himalaia e Andes, e adaptados para tempos pré-cambrianos. A história geológica das cadeias proterozóicas não apresentam necessariamente a mesma história de evolução das cadeias de montanhas modernas, embora estas últimas sirvam de exemplo na falta de parâmetros mais confiáveis que passam ser usados no pré-Cambriano.

A falta de evidências da ocorrência de uma acentuada subducção do tipo Andino, e com conseqüente colisão continente-continente, podem ser observadas pela ausência de diversas feições, como metamorfismo de alta pressão, peridotitos ou ofiólitos mantélicos, prisma de acresção suturas, magmatismo cálcio-alcalino restrito.

A presença de um extenso magmatismo cálcio-alcalino e alcalino foi explicado por Nardi (1994) na forma de uma evolução da granitogênese associada a subducção, para um magmatismo sin-transcorrência (cálcio-alcalino/shoshonítico/alcalino supersaturado em sílica). $\mathrm{O}$ autor discutiu critérios geoquímicos indicativos de fontes mantélicas modificadas por consumo de crosta oceânica, a qual teria evoluído durante o evento alcalino para magmatismo intra-placa (sintranscorrência), com maior contribuição astenosférica, principalmente nas áreas mais estáveis, junto ao embasamento.

Por outro lado, as amplas indicações isotópicas de retrabalhamento de material paleoproterozóico e/ou arqueano (?), durante o Brasiliano, levaram Hartmann et al. (1994) a propor uma tectônica de plumas mantélicas para o Cinturão Dom Feliciano. Embora o modelo seja muito genérico e não forneça respostas satisfatórias as feições estruturais/ metamórficas, traduz a busca por mecanismos tectônicos alternativos ao modelo de Tectônica de Placas convencional.

Estas indicações isotópicas de retrabalhamento da crosta mais antiga foram igualmente observadas por Mantovani et al. (1987), Cordani et al. (1988), Chemale Jr. et al. (1994), Ebert et al. (1994) entre outros. Esses dados levaram Ebert et al. (op. cit.) a reconhecer que pouca crosta continental juvenil parece ter sido gerada durante o evento Brasiliano, indicando que a colisão 
continental envolveu, no máximo, um oceano de dimensões muito restritas. Desta forma, os autores propuseram um modelo de fusão parcial do manto superior durante o espessamento das margens transpressionais dos blocos colididos, delimitados por profundas zonas de cisalhamento transpressionais. Os autores acrescentaram, ainda, que o regime transpressional, atuando sobre as raizes orogênicas, constitui-se num importante motor de migração de rochas plutônicas de níveis crustais profundos até superiores, através de zonas de cisalhamento.

Esta tectônica transpressional foi proposta também por Machado \& Endo (1993) e Endo \& Machado (1993), englobando todo o Cinturão de Cisalhamento Paraíba do Sul, e mais genericamente para o cinturão Ribeira na altura do Estado do Rio de Janeiro, como sendo um evento térmico-deformacional responsável pela estruturação das principais feições estruturais e associações metamórficas. Dentro desse modelo, Machado \& Endo (1994) propuseram, ainda, que a inversão dos regimes cinemáticos de lateral direito para lateral esquerdo teria criado condições para a implantação de ambiente transtracional, o qual teria propiciado a ascensão e colocação de magmas graníticos no referido cinturão.

Este modelo transpressional vem parcialmente de encontro ao modelo proposto por Campanha (1980), Silva (1981, 1996), Fiori (1985 a,b,c), Fiori et al. (1987c), Fassbinder et al. (1987), Ebert et al. (1988, 1993), Fassbinder (1990), Spoladore \& Ebert (1993), Kops (1994), Hackspacher (1994) os quais reconheceram também uma tectônica transpressiva, porém, no final do ciclo Brasiliano, a qual teria evoluido por cisalhamento de baixo ângulo, a partir de rampas frontais (Fiori et al., 1987c; Fiori, 1990), ou rampas obliquas (Ebert et al., 1988, 1993), num regime de deformação progressiva.

O mecanismo de transcorrência transpressional é referido, por Ebert \& Hasui (1989), como sendo "o soerguimento dos núcleos gnáissicos (é) relacionado inicialmente a um aquecimento e um desiquilibrio isostático causado pelo espessamento crustal durante uma tectônica tangencial horizontal (cavalgamento do Bloco Vitória sobre o São Paulo). Estas massas ascendentes não só sofreram mas também interagiram com a evolução tectônica das antiformas. Elas parecem ter servido de rampas laterais através das quais os deslocamentos horizontais passaram gradualmente a atuar em superficies cada vez mais inclinadas, superficialmente expressas por zonas transcorrentes", ou seja, "... a convergência crustal subhorizontal passou gradualmente a ser absorvida por movimentos direcionais transcorrentes". Os autores acrescentam, ainda, que os núcleos gnáissicos dômicos foram expostos através de estrutura-em-flor positiva, expondo litologias de niveis crustais médios (>20 km). 
Embora Ebert et al. (1994) tenha conferido um menor valor a tectônica de baixo ângulo (rampas obliquas associadas a uma colisão obliqua $E-W$ de blocos continentais na faixa Ribeira), diversos autores reconhecem evidências de uma tectônica pré-transpressional (Heilbron et al., 1994; Tupinambá \& Trouw, 1994; Souza Neto et al., 1994, entre outros), em oposição a uma tectônica puramente transpressiva. Desta forma, a questão atualmente em pauta versa sobre a ocorrência de evidências que apresentem convergência para um modelo puramente transpressivo, com partição da deformação $X$ evolução de cisalhamento de baixo ângulo para uma deformação transpressional, de alto ângulo.

Parece provável que a aplicação generalizada do modelo da tectônica de placas para explicar todas as feições geológicas levou a alguns autores construir modelos prematuros ou testar hipóteses de trabalho dissociados de dados qualitativos ou quantitativos confiáveis. Por conseguinte, a ampla gama de interpretações permitidas pela conceituação tectônica de Sengör (1990), levou autores a interpretar orogêneses tendo por base apenas o aspecto geoquímico de maciços ou corpos graníticos. Exemplos da aplicação desse critério são as orogêneses Cunhaporanga e Três Córregos (Reis Neto, 1994), tendo por base apenas a filiação calci-alcalina dos mesmos.

\subsection{MODELOS ESTRUTURAIS PROPOSTOS E PROBLEMAS PENDENTES}

Diversos mecanismo ou modelos foram propostos para explicar as feições estruturais e metamórficas presentes na Cinturão Ribeira, em sua porção paranaense e vale do Rio Ribeira do Iguape, na porção paulista, como segue:

(1) Intensa deformação tangencial oriunda de um cavalgamento obliquo, com transporte para norte ou noroeste, do bloco Vitória sobre o bloco São Paulo (Hasui et al., 1986 e Ebert et al., 1988);

(2) Tectônica de baixo ângulo, com geração de estruturas do tipo duplex, envolvendo o transporte de unidades geológicas através de grandes distâncias numa bacia do tipo back arc (Fiori et al., 1987; Fiori, 1990 e 1992); 
(3) Cisalhamento de baixo ângulo, com componente direcional, gerada em rampa oblíqua com escape de material através do eixo Y, igualmente numa bacia do tipo back arc (Ebert et al., 1988; Spoladore, 1993);

(4) Colisão continental frontal entre as placas do São Francisco e do Congo, com escape tectônico da litosfera em direção a sudoeste, resultando na estruturação das Faixas Ribeira e do Oeste-Congo. Essa interpretação foi suportado pelo modelo de indentação de Tapponnier \& Molnar (1976) proposto para a colisão das placas entre a Índia e Eurásia. (Vauchez et al., 1992, 1994).

Porém, diversas feições observadas nos litotipos aflorantes nessa faixa não são convenientemente explicados por esses mecanismos e/ou modelos acima citados, como segue:

(1) Pequeno número de fechamentos de dobras em escala de afloramento, quando ocorre variação de mergulho da foliação principal com ângulo de até 45 graus, numa distância de aproximadamente 50 metros;

2 Predomínio do mergulho da foliação de alto ângulo com valores entre $50^{\circ} \mathrm{e} 90^{\circ}$, na maioria dos afloramentos;

3 Presença de foliações protomiloníticas, miloníticas e ultramiloníticas verticalizadas na borda do Complexo Granítico Três Córregos, além da orientação magmática de minerais ou de agregados minerais, com direção nordeste e mergulhos subhorizontais;

4 As poucas dobras fechadas (ou apertadas?), quando presentes, apresentam-se com flancos rompidos - um ou ambos - pela foliação de alto ângulo;

5 Ausência de camadas sedimentares invertidas na grande maioria dos afloramentos, aspecto este esperado no modelo de cavalgamentos;

6 Valores de deformação relativamente baixos, da ordem de 3,0 para a Formação Água Clara; 1,2 a 2,5 para a Formação Votuverava; e ao redor de 1,0 para a Formação Antinha (Spoladore, 1993). Estes valores são relativamente baixos para se constituir no registro da presença de uma 
tectônica com intenso transporte através de rampas frontais (Fiori, 1990), rampas oblíquas (Ebert et al., 1988; Spoladore, 1993), com escape de material através do eixo Y;

( Descrição de intensa deformação cisalhante, com transporte tectônico de material ao longo de grandes distâncias e, consequente, encurtamento substancial da bacia, além de metamorfismo de baixo grau para o Grupo Açungui. Estas características são interpretadas como pertencentes a uma bacia do tipo back arc, embora essas feições estejam associadas, de forma mais comumente, a complexos de subducção ou de colisão (cunhas de acresção);

8 Ocorrência de indicadores cinemáticos em metapelitos e metamargas com sentido de transporte opostos, estruturados em tramas estruturais distintas, presentes na mesma amostra ou até no mesmo corte. Além disso, a ocorrência de sentidos de transporte opostos, gerados pela presença de fragmentos rígidos dentro de uma matriz incompetente, associados a uma trama específica, conforme indicado por Harnmer (1990), Bjornerud (1990) e discutido por Spoladore (1993) e Spoladore \& Hackspacher (1994). Na região de São Silvestre - São Pedro, corresponde a transportes para noroeste e sudeste;

9 Geometria simétrica das unidades com maior deformação e metamorfismo em torno do Complexo Granítico Três Córregos, características que diminuem simetricamente nas unidades com referência ao referido complexo. Desta forma, a Formação Água Clara aflora nas bordas sudeste e noroeste deste complexo; a Formação Votuverava a sudeste, estando ausente na porção noroeste do mesmo; a Formação Capirú, situada a sudeste, e a Formação Itaiacoca, a noroeste.

A tectônica de cavalgamentos normalmente gera a inserção, de forma aleatória, de lascas tectônicas deformadas com maior intensidade por entre os metassedimentos presentes no nível estrutural médio a superior. Neste tipo de modelo, não é comum a ocorrência de simetria.

Deste modo, a proposição do modelo de transpressão (Ver Capítulo 2) para a faixa Ribeira, na altura dos Estados do Paraná e sul de São Paulo, é oportuna, tendo em vista os problemas e as lacunas ora existentes. É provável que esse modelo não venha solucionar todos os problemas estratigráficos existentes, porém explica, de forma coerente, muitos dos aspectos não solucionados pelos outros modelos, constituindo-se, assim, num modelo alternativo para ser testado doravante. 


\subsection{O CINTURÃO RIBEIRA NO CONTEXTO REGIONAL}

A faixa de metassedimentos em que o Grupo Açungui está inserido, estende-se desde a região nordeste da Bahia $\left(11^{\circ} \mathrm{S}\right)$, até o Rio Grande do Sul/Uruguai $\left(30^{\circ} \mathrm{S}\right)$, tendo uma orientação geral NE/SW (Figura 5.1).

Diversas denominações foram atribuídas a esta faixa, entre elas, Faixa e Cinturão Paraíba (Ebert, 1962 e Cordani et al., 1968), Faixa Paraibídes (Ebert, 1971), Cinturão Atlântico (Ferreira, 1972), Cinturão Ribeira (Hasui et al., 1975), Região de Dobramentos Sudeste (Almeida et al., 1976), Província Mantiqueira (Almeida \& Hasui, 1984) e, mais recentemente, Cinturão de Cisalhamento Atlântico (Machado \& Endo, 1993). Tudo indica que a denominação de Cinturão Ribeira deva prevalecer, dado pela sua generalizada utilização e aceitação pela comunidade geológica.

Trata-se de uma faixa linear, relativamente estreita, disposta de forma paralela a costa sulsudeste do Brasil, com extensão superior a $2.900 \mathrm{~km}$ (Machado \& Endo, 1993).

As características distintas paleogeográficas e estruturais da Faixa Ribeira, levaram Fragoso Cesar (1993) a identificá-la como uma placa tectônica, inserida num contexto de aglutinação colisional oblíqua entre diversas placas do sul e sudeste do Brasil (Placas Sanfranciscana, Paraná, Luiz Alves, Rio de La Plata, Piratini, Rio Vacacaí e Pampeana. Neste sentido, uma provável subducção(?)-colisão entre as placas do Congo, a leste, e Sanfranciscana/ Paraná/São Paulo, a oeste, teriam deformado os metassedimentos da micro-placa Ribeira, através de uma colisão tangencial, com caráter transpressional, conforme proposto por Machado \& Endo (1994).

Este aspecto transpressional foi anteriormente identificado no lineamento LancinhaCubatão por Ebert et al. (1988), Ebert \& Hasui (1989), Fassbinder (1990) e, no segmento AlémParaíba (Vale do Rio Paraiba do Sul - Estado Rio de Janeiro), por Ebert et al. (1991, 1993), e Endo \& Machado (1993), na forma de uma estrutura-em-flor positiva. Porém, a utilização do conceito de transpressão por Ebert et al. (1993) e Endo \& Machado (1993), difere basicamente devido ao modelo tectônico empregado. Por exemplo, os primeiros autores reconhecem as placas tectônicas de Brasília, Vitória e São Paulo, delimitadas por suturas mascaradas, as quais teriam sofrido uma colisão pretérita Norte-Sul. Na seqüência da história deformacional, estas placas teriam participado da geração de uma nova tectônica, na forma de uma obducção com colisão obliqua, com tensores leste-oeste, e com a geração de cavalgamentos e imbricamentos ao longo de zonas de cisalhamento dúcteis de baixa ângulo. Os autores admitem, ainda, um progressivo 


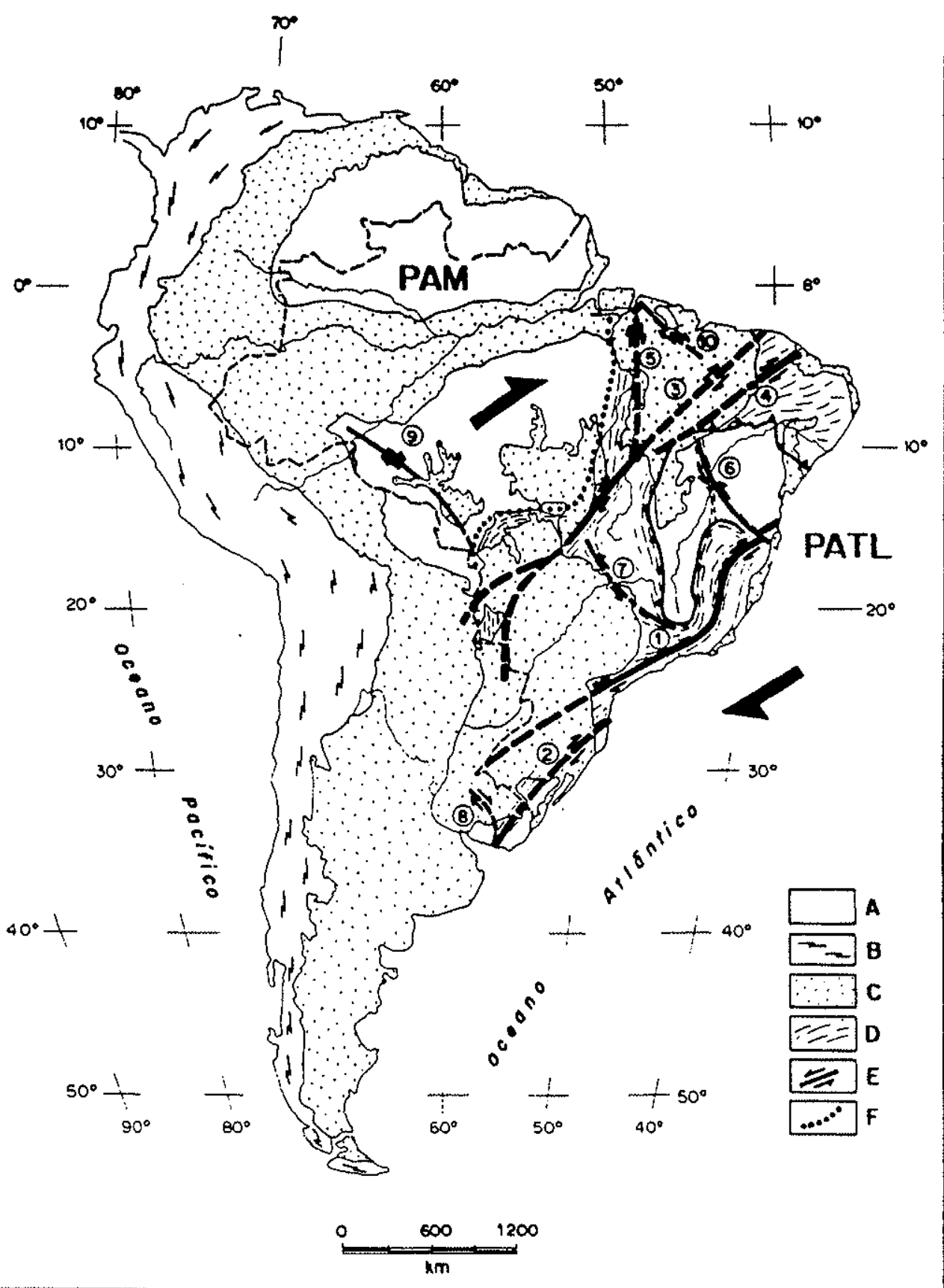

Figura 5.1 - O Cinturão Ribeira ou Atlântico. segundo proposição de Endo \& Machado (1993).

A-Embasamento, B- Cinturão Orogênico Andino, C- Cobertura Fanerozóica, D-Trajetória da Foliação, E- Zona Axial (ZPDD) dos cinturões e sistemas de cisalhamento onde as setas indicam o sentido de movimento cisalhante, $F$ Limite entre as Provincias Tectônicas do Amazonas (PAM) e do Atlântico (PATL), 1-Sistema de Cisalhamento

Paraiba do Sul (SCPS), 2- Sistema de Cisalhamento Dom Feliciano (SCDF), 3- Cinturão de Cisalhamento Transbrasiliano (CCTB), 4-Sistema de Cisalhamento Senador Pompeu (SCSPO), 5- Sistema de Cisalhamento Tocantins (SCTA), 6- Sistema de Cisalhamento Paramirim (SCPM), 7- Sistema de Cisalhamento Campo do Meio (SCCM), 8- Sistema de Cisalhamento Sarandi Del Yí (SCSDY), 9- Sistema de Cisalhamento Guaporé (SCGP), 10Sistema de Cisalhamento Tentugal (SCT). 
encurtamento e espessamento crustal, com a evolução da tectônica tangencial para uma tectônica direcional, expressa através de extensas zonas de cisalhamento dúcteis-rúpteis de médio a alto ângulo, que cortam a região sudeste (Lineamentos Lancinha-Cubatão, Morro Agudo, Ribeira, etc.). Além disso, Ebert et al. (op. cit.) interpretam a foliação metamórfica principal (no Grupo Açungui), $s_{1}$, como tendo sido desenvolvida com disposição de baixo ângulo ao longo de rampas laterais, fracamente oblíquas, durante a deformação direcional.

Enquanto isso, Endo \& Machado (1993) postularam que a Província Tectônica do Atlântico (Faixa Ribeira), a qual se constitui num domínio móvel, com características transpressionais, situado entre dois blocos rígidos: o Cráton Amazônico e o Cráton do Congo.

Os autores admitiram, ainda, uma provável colisão continental oblíqua entre as placas Amazônica e do Congo, com uma convergência tectônica próxima de E-W. Neste contexto, os mecanismos transpressionais presentes na faixa Ribeira desempenhariam um papel fundamental na acresção e na colagem continental. É provável que a foliação metamórfica principal ( $s_{1}$ no Grupo Açungui) tenha sido originada num regime transpressional, com a geração da partição da deformação em componentes de cisalhamento puro (thrust faults) e cisalhamento simples (transcorrências).

A interpretação do Cinturão Ribeira segundo os modelos tectônicos de Endo \& Machado (op. cit.) e Fragoso Cesar (1993), apesar das diferenças, parecem ter consistência, quando observados em escala regional, no âmbito da região sudeste do Brasil (Ver Figura 5.1). O referido cinturão apresenta disposição linear, na forma de uma faixa estreita, disposta entre blocos rígidos, do Congo (e/ou Vitória), a leste e, Brasília (Sanfranciscana), a oeste, podendo ter sido deformado por esforços transpressionais durante as fases de deformação e metamorfismo associadas ao ciclo Brasiliano, através de colisão obliqua de placas.

Embora os dados de lineações minerais e de estiramento mineral, além de outros indicadores cinemáticos seguros ainda estejam restritos a trabalhos pontuais no contexto regional, é provável que tenha havido uma colisão continental entre as placas de Brasilia (Sanfranciscana)/ Paraná e do Congo, conforme admitido por Soares et al. (1990), Ebert et al. (1993) e Endo \& Machado (1993). Com o prosseguimento da tectônica colisional, é possivel que a placa São Paulo, com transporte de oeste para leste tenha acentuado o caráter oblíquo da colisão em relação a placa do Congo, gerando assim o Cinturão Móvel Atlântico (Cinturão Ribeira), com características essencialmente transpressivas. Nesta estruturação, teria se desenvolvido, ainda, uma rede de lineamentos de alto ângulo (Zonas de Cisalhamento com predominio de componentes de empurrão e transcorrentes), com caráter dúctil, em litologias do Embasamento 
Cristalino, de Complexo Pré-Setuva e do Grupo Açungui. Estas estruturas teriam atingido provavelmente a base da crosta. Estes lineamentos incluem as falhas de baixo ângulo caracterizadas por Fiori et al. (1987) e Fiori (1990), as quais poderiam corresponder a falhas de empurrão ou reversas de baixo ângulo, além das Zonas de Cisalhamento Além Paraíba-CubatãoLancinha, Juiz de Fora-Jaguari-Taxaquara e Niterói, estas últimas reativadas por tensores NorteSul (Machado \& Endo, 1994).

Os resultados obtidos por Ebert et al. (1993) a partir de modelagens com silicone e areia, com a simulação de uma colisão frontal entre as Placas Brasília, São Paulo e Vitória, mostraram a possibilidade de que tenha ocorrido uma colisão oblíqua entre estas placas, dependendo apenas da geometria das bordas colidentes e dos vetores cinemáticos envolvidos. Idênticos experimentos foram anteriormente realizados por Vauchez et al. (1992), simulando através de programas gráficos de computador, uma colisão frontal entre a porção leste do cráton de São Francisco, e a margem oeste do cráton do Congo, postulando um escape da litosfera em direção a sudoeste (a qual poderia corresponder as faixas Ribeira e oeste-Congo). Em ambos os experimentos, os autores partiram do princípio de que a colisão entre os continentes tenha sido frontal, com base no modelo de indentação proposto por Tapponnier \& Molnar (1976). Para os autores, "em uma colisão continental, um continente pode indentar outro, e blocos litosféricos podem ser expulsos lateralmente, com uma direção de transporte paralela às margens dos continentes", a exemplo do modelo de colisão entre Índia e Eurásia, concebido pelos últimos autores. Porém, numa colisão frontal, é necessário que diversas variáveis que controlam uma colisão, sejam conhecidas e quantificadas, elementos ainda não disponiveis no conhecimento geológico regional. Desta forma, simulações deste tipo são estimulantes para a discussão e entendimento das feições geológicas, porém é indispensável estimar o grau de confiabilidade das variáveis empregadas e dos resultados obtidos, evitando assim a difusão de idéias, muitas vezes especulativas. Neste sentido, estes modelos não partem de uma realidade geológica, mas sim de hipóteses de trabalhos previamente concebidos na sua elaboração. Deste modo, o resultado final do modelo está intrinsicamente ligado com as premissas em que o modelo foi concebido. Dentro deste enfoque, as colisões proposta por Vauchez et al. (1992), Ebert et al. (1993) e Endo \& Machado (1993) pode ser testados pela capacidade de explicar um maior número de feições geológicas presentes nas áreas estudadas.

Em consequência dos aspectos acima expostos, assim como por entender que a possível colisão entre os continentes não teria ocorrido obrigatoriamente de forma frontal, o que se constitui nos dias de hoje mais como exceção do que na regra geral (Woodcock, 1986). Neste 
sentido, procurou-se demonstrar, neste trabalho, que as estruturas presentes são produzidas por deformação num regime transpressivo, resultante de uma colisão obliqua e não de uma colisão frontal, seguindo-se o modelo geral proposto por Machado \& Endo (op. cit.). Este modelo torna-se viável na medida em que possibilita explicar um maior número de feições geológicas presentes na porção paranaense do Cinturão Ribeira ou Paraíba do Sul, em comparação com o modelo de colisão frontal, conforme será discutido a seguir.

\subsection{PORÇÃO CENTRAL DA ZONA DE CISALHAMENTO (TRANSPRESSIONAL)}

Diversos autores tentaram explicar o Cinturão Ribeira e a granitogênese a ele associada, segundo a ótica dos modelos Himalaiano e/ou Andino de Tectônica de Placas, a exemplo de Soares (1987), Campanha et al. (1987), Fiori (1990), Campanha (1991), entre outros. Porém, a aplicação deste modelo, de forma direta, não parece muito evidente, pois são elaborados com base nas cadeias modernas, as quais são reflexo da própria evolução da crosta no tempo geológico, relacionadas sobretudo com o fluxo térmico. Neste sentido, diversos modelos alternativos de tectônica de placas foram propostos, como os de Porada (1979), Kröner (1977 e 1981), Etheridge et al. (1987), entre outros. Exemplos da aplicação do modelo Himalaiano são aquele de duas bacias retro-arco propostas por Soares (op. cit.), para explicar as distintas bacias Setuva e Açungui, as quais, segundo o autor, teriam sido geradas e deformadas no préCambriano médio e superior, respectivamente; o modelo de Campanha (op. cit.), na tentativa de reconhecer um ambiente colisional (cunha de acresção) na Formação Votuverava, propõe uma suposta sutura ao longo dos Lineamentos de Morro Agudo e Figueira.

Por outro lado, a não comprovação de restos de crosta oceânica no Cinturão Ribeira, poderia ser indicativo da operação de um outro modelo, diferente do modelo de subducção do tipo B, conforme tem sido proposto pela maioria dos autores. Neste sentido, a proposicão de um modelo de tectônica transpressional torna-se oportuno, pois além de sugerir um mecanismo deformacional alternativo, trata-se de uma nova hipótese de trabalho para a colocação dos 45 corpos graniticos conhecidos no estado do Paraná, incluíndo os complexos graníticos Três Córregos e Cunhaporanga (?).

A identificação da presença de uma zona de cisalhamento de alto ângulo nas imediações da localidade de Cerro Azul, com a geração de protomilonitos, milonitos e ultramilonitos paralela a borda sudeste do Complexo Três Córregos, sugere um controle de 


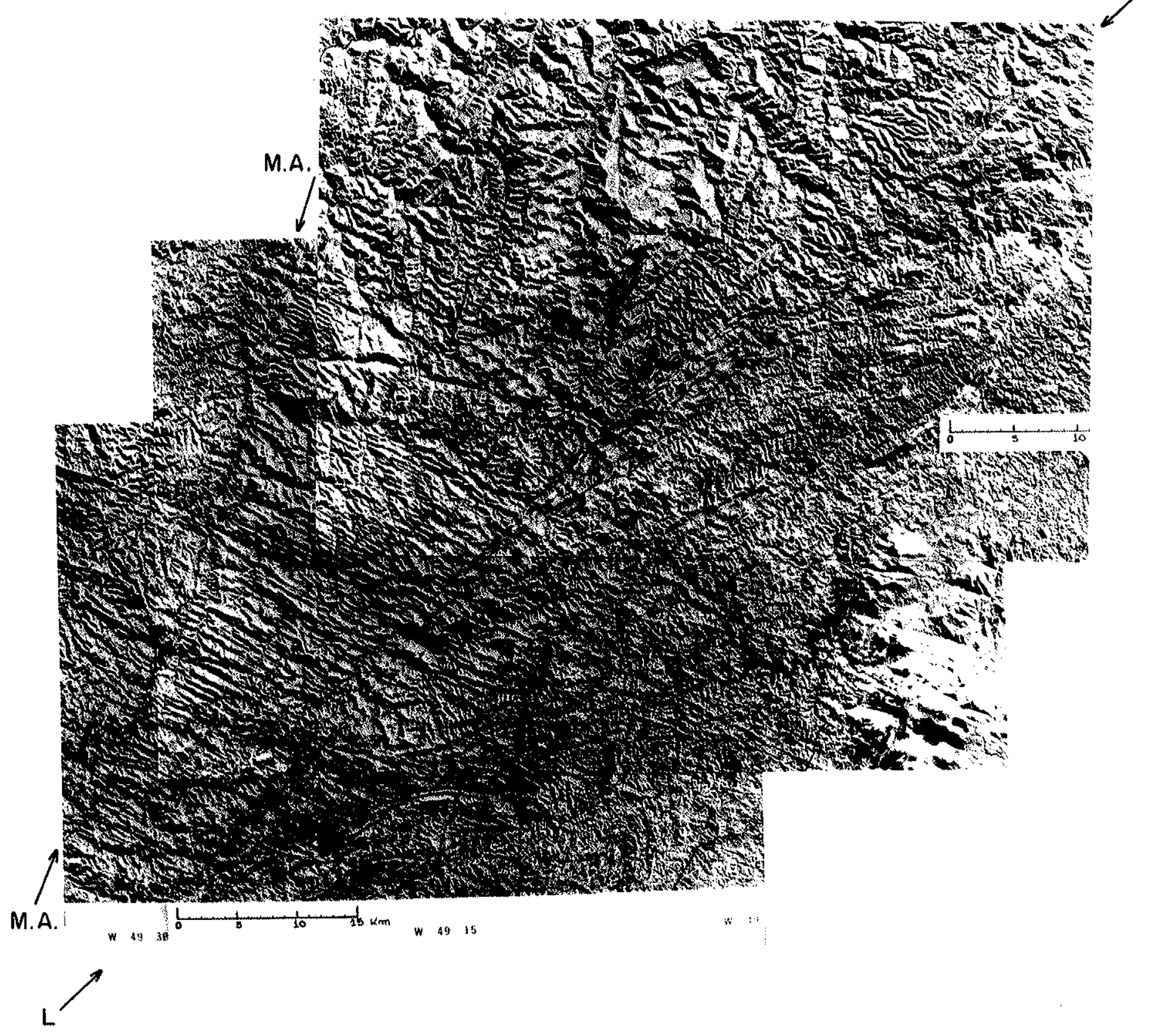

Fotografia 5.1 - Mosaico de fotografias mostrando as estruturações das Zonas de Cisalhamento Lancinha (L) e Morro Agudo (M.A) à norte e noroeste da cidade de Curitiba. FONTE: Imagens de Satélite Landsat, escala 1:100,000, reduzidas para escala 1:417.000.

LEGENDA: $\quad$ L = Zona de Cisalhamento da Lancinha: M.A. = Zona de Cisalhamento Morro Agudo 
colocação deste maciço, pelo menos nesta região, de forma sin a tardi-cinemática a esta zona. Neste sentido, a orientação magmática dos megacristais de feldspato de potássio ao longo de planos com direção N35-50E/78NW, nas imediações da borda do referido complexo, corroboram a hipótese de que o Granito Três Córregos tenha sido colocado no centro de uma zona de cisalhamento, conforme proposição de Machado \& Endo (1993). Desta forma, a colocação dos corpos graníticos poderia ocorrer no período de distensão do cinturão, logo após a fase de transpressão, lateral esquerda (ou direita), gerada por tensores leste-oeste ou noroestesudeste. Ainda no período de distensão, teria ocorrido a sedimentação das Sequências Lajeado, no Estado de São Paulo, e Antinha, no Estado do Paraná (Associação Litológica Vuturuvú de Fiori, 1990). A ausência de uma foliação penetrativa paralela ao acamamento sedimentar, de dobras intrafoliais, lineações mineral e de estiramento mineral, mostra que estas sequências não foram afetadas pelas deformações transpressionais ativas no periodo pré-intrusões. A presença de dobras suaves a abertas, com uma clivagem de fratura plano-axial em leque, além de um anquimetamorfismo, mostram que estas sequências foram deformadas de forma rúptil-dúctil a rúptil, pelas zonas de cisalhamento de alto ângulo, segundo o seu pulso de estruturação lateral direita, presentes no atual nível de exposição das litologias, e de forma dúctil ao longo do Complexo Três Córregos, exposto por transpressão.

Assim, os Complexos Três Córregos e Cunhaporanga(?) teriam sido colocados na parte central da citada estrutura, enquanto os corpos menores seriam formados pela migração de magmas graniticos e se colocado em dobras escalonadas através dos lineamentos Lancinha (Granito do Cerne) e Morro Agudo (Granitos Piedade, Morro Grande e Varginha) (Fiori, 1985d), segundo a componente direcional, lateral direito, de num evento de deformação transpressional. Esta superposição cinemática, lateral direita, teria deformado a borda dos granitos Três Córregos, gerando protomilonitos, milonitos e ultramilonitos, e estirando corpos menores segundo o eixo $X$ do elipsóide de deformação, com direção média N33E. A disposição atual dos corpos graníticos e do Sistema de Cisalhamento Lancinha-Cubatão-Além Paraíba, marcaria o registro do paroxisma desta reativação lateral direita, com uma estruturação segundo lineações bem marcantes e proeminentes sobre as litologias do pré-Cambriano, conforme pode ser observado em mosaico de fotografias obtidas a partir de imagens de satélite Landsat, na escala 1:100.000. (Fotografia 5.1).

A constatação de Reis Neto (1994) de que as rochas gnáissicas e graníticas dos Complexos Cunhaporanga e Três Córregos apresentam uma idêntica filiação geoquímica, com mesmo ambiente tectônico e profundidade de colocação, pode ser utilizado como argumento em 
favor da hipótese de que estes gnaisses correspondam, na verdade, a granitos miloníticos (Quadro 5.1 e 5.2). Datações obtidas por Reis Neto (1994), embora de referência, indicam que ocorreu um pulso de colocação dos granitos miloníticos por volta de $746 \pm 45 \mathrm{Ma}$., seguido por outro pulso mais novo, agora com ausência de deformações expressivas, por volta de $658 \pm 49 \mathrm{Ma}$. Estes dados são concordantes com as idades Rb-Sr de Gimenez Filho (1993), obtidos para o Complexo Três Córregos, no intervalo de $665 \mathrm{Ma}$ (Granito Córrego do Butiá) e de 790 Ma (granitóides orientados), interpretados como a idade de geração do "Arco Magmático Três Córregos".

Dados petrográficos obtidos por Reis Neto (op. cit.), mostram, ainda, que os gnaisses Cunhaporanga e Três Córregos são ortoderivados, e que suas paragêneses magmáticas (plagioclásio + quartzo + hornblenda + FK + titanita) foram parcialmente transformadas em paragêneses metamórficas (quartzo + clorita \pm epidoto $\pm($ FK?) \pm sericita) (Quadro 5.3 e 5.4). Estes dados, ao contrário da interpretação de Reis Neto (op. cit.) como gnaisses de alto grau, são compativeis com a interpretação dada neste trabalho, de rochas miloníticos, formadas a partir de um protólito granítico, devendo corresponder, em parte, aos granitos orientados de Gimenez Filho (op. cit.). Evidências de campo, obtidas na borda sudeste do Complexo Três Córregos, nas proximidades da localidade de Cerro Azul, parecem confirmar esta hipótese. Neste sentido, o autor salienta ainda a presença no mesmo complexo de foliações miloníticas, com estiramento de quartzo e extinção ondulante em plagioclásio.

$O$ centro da Zona de Cisalhamento estaria situado entre os lineamentos Além ParaíbaCubatão-Lancinha e Juiz de Fora-Jaguari-Taxaquara, esta última prolongando-se para o Estado do Paraná através do lineamento Itapirapuã, conforme mapa esquemático de Machado \& Endo (1993) (Figura 5.2). O periodo transpressional, lateral direito, teria deformado e alçado os Complexos Três Córregos e Cunhaporanga, com as litologias da Formação Água Clara dispostas na margem sudeste e noroeste do centro da estrutura, além das demais unidades do Grupo Açungui, conforme será discutido mais adiante. Por outro lado, a Figura 5.3 sugere que o Complexo Cunhaporanga esteja inserido na aba noroeste da citada estrutura. Esta observação permite a formulação de duas novas hipóteses de trabalho:

(1) O Complexo Cunhaporanga representaria um arco magmático, gerado a partir da subducção de crosta oceânica, por volta de $746 \pm 45 \mathrm{Ma}(\mathrm{RI}=0,70698)$, reforçando assim a proposição de Gimenez Filho (1993); enquanto o Complexo Três Córregos seria o reflexo da atuação de zonas transtracionais/transpressionais que teriam permitido sua colocação e ascensão por volta de $658 \pm 49 \mathrm{Ma}(\mathrm{RI}=0,7098)$, conforme datações $\mathrm{Rb} / \mathrm{Sr}$ de Reis Neto (1994). 


\begin{tabular}{|c|c|c|c|c|c|c|c|c|c|}
\hline & & \multicolumn{4}{|c|}{ GEOQUÍMICA } & \multicolumn{4}{|c|}{ GEOLOGIA ISOTOPICA E GEOCRONOLOGLA } \\
\hline & & $\begin{array}{l}\text { COMPOSICAOO } \\
\text { QUIMICA } \\
\text { (elementos maiores) }\end{array}$ & $\begin{array}{l}\text { PROCESSO DE } \\
\text { GERAÇÃO } \\
\text { (elementos traços) }\end{array}$ & $\begin{array}{l}\text { AMBIENTE } \\
\text { GEOTECTÔNICO } \\
\text { (terras raras) }\end{array}$ & $\begin{array}{l}\text { COLOCAÇÁAO } \\
\text { (pré-sin-pós tect.) } \\
\text { PROFUNDIDADE }\end{array}$ & MÉTODO & $\begin{array}{l}\text { COMENTARIOS } \\
\text { SOBRE AS } \\
\text { ISÓCRONAS }\end{array}$ & $\begin{array}{l}\text { ORIGEM DO } \\
\text { MAGMA }\end{array}$ & $\begin{array}{l}\text { PROVAVEL } \\
\text { FONIE }\end{array}$ \\
\hline $\begin{array}{l}T \\
R \\
\hat{E} \\
S\end{array}$ & GNAISSES & $\begin{array}{l}\text { CÁLCIO-ALCALINA } \\
\left(\mathrm{K}_{2} \mathrm{O} \mathrm{Na}_{2} \mathrm{O}\right) \\
\text { TRONDHJEMFIICA- } \\
\text { GRANíTICA } \\
\left(\mathrm{Na}_{2} \mathrm{O} \times \mathrm{Ca}_{2} \mathrm{O} \times \mathrm{K}_{2} \mathrm{O}\right) \\
\text { Composiçăo sódica) } \\
\\
\\
\mathrm{K}_{2} \mathrm{O} \mathrm{Na}_{2} \mathrm{O}: 0,6 \text { (Paina) } \\
\mathrm{K}_{2} \mathrm{O}: \mathrm{Na}_{2} \mathrm{O}: 1 \mathrm{O} \\
\quad \text { (Rio Morœego) }\end{array}$ & $\begin{array}{l}\text { CRISTALIZAÇÃo } \\
\text { FRACIONADA } \\
\text { (Gn. Paina) } \\
\text { FUSÃO PARCIAL } \\
\text { (Gnaisse } \\
\text { Rio Morcego) }\end{array}$ & $\begin{array}{l}\text { VAG (Arco } \\
\text { Vulcan.) } \\
(\mathrm{Rb} \times \mathrm{Y} \times \mathrm{Nb}) \\
\text { VAG + Sin-COLG } \\
(\mathrm{Nb} \times \mathrm{Y}) \\
\text { VAG + OFG } \\
\text { (Arco Vulc. + } \\
\text { Fundo Oceânico) } \\
\text { (Hf } \times \text { Ta*.3 } \mathrm{x} \\
\mathrm{Rb} / 10)\end{array}$ & $\begin{array}{l}\text { INDEFINIDO } \\
\text { Os portos situam- } \\
\text { se sobre os campos } \\
\text { do Pré, Tardi- } \\
\text { colisão, e anatético. } \\
>30 \mathrm{Km} \\
(\mathrm{Rb} / \mathrm{Sr}) \text {. }\end{array}$ & $\begin{array}{l}\mathbf{R b} / \mathrm{Sr} \\
658 \pm 49 \text { Ma. } \\
\mathrm{RJ}=0,7098 \\
\text { M.S.W.D. }= \\
2,55 \text { (Gnaisses } \\
\text { P.AINA) } \\
\\
\text { Ph/Pb } \\
\mathbf{7 7 8} \pm 266 \mathrm{Ma} . \\
\text { USD =0,3613 } \\
\text { M.S.W.D. = } \\
\text { 0,1305 }\end{array}$ & $\begin{array}{l}\text { IDADE Rb/Sr } \\
\text { de } 651 \mathrm{Ma.} \\
\text { obtida por SOUZA } \\
\text { (1990) em rochas } \\
\text { graniticas foliadas } \\
\text { do Maciço Córrego } \\
\text { Butiá. }\end{array}$ & $\begin{array}{l}\text { M (Manto) } \\
\text { (Gnaisses Paina) } \\
\text { entre S \& K e M } \\
\text { (Gr. Rio Morcego). } \\
\text { (não formeceu uma } \\
\text { isćcrona ou } \\
\text { errócrona) }\end{array}$ & IDEM \\
\hline $\begin{array}{l}R \\
E \\
G \\
o \\
S\end{array}$ & GRANITOS & $\begin{array}{l}\text { CACIO-ALCALINA } \\
\mathrm{K}_{2} \mathrm{ONa}_{2} \mathrm{O}=1,0\end{array}$ & $\begin{array}{l}\text { CRISTALIZAÇÃO } \\
\text { FRACIONADA } \\
\text { m?? }\end{array}$ & $\begin{array}{l}\text { VAG } \\
\left(\mathrm{Hf} \times \mathrm{Ta}^{*} \cdot 3 \times\right. \\
\mathrm{Rb} / 10) \\
(\mathrm{Rb} \times \mathrm{Y} \times \mathrm{Nb}) \\
\text { VAG }+ \text { Sin-COLG } \\
(\mathrm{Nb} \times \mathrm{Y})\end{array}$ & $\begin{array}{l}\text { Pôs- } \\
\text { COLISIONAIS } \\
\left(\mathrm{Rb} / \mathrm{Zr} \times \mathrm{SiO}_{2}\right) \\
\\
>30 \mathrm{Km} \\
(\mathrm{Rb} / \mathrm{Sr})\end{array}$ & $\begin{array}{l}\text { Rb/Sr } \\
509 \pm 31 \mathrm{Ma} \\
\mathrm{RI}=0,71285 \\
\text { M.S.W.D. = } \\
0,35 \\
\text { (PSEUDO- } \\
\text { ISÓCRONA). }\end{array}$ & $\begin{array}{l}\text {-OCORRE HETE- } \\
\text { ROGENEIDADE } \\
\text { ISOTÓPICA - os } \\
\text { pontos dos } 2 \text { aflora- } \\
\text { mentos não se "mistu- } \\
\text { ram", podendo ser } \\
\text { traçado pseudo- } \\
\text { isócronas distintas. }\end{array}$ & entre $\mathbf{S} \& \mathbf{K}$ e $M$ & IDEM \\
\hline
\end{tabular}

Quadro 5.1 - Principais características geoquímicas. isotópicas e geocronológicas do Complexo Três Córregos, segundo Reis Neto (1994). 


\begin{tabular}{|c|c|c|c|c|c|c|c|c|c|}
\hline & & \multicolumn{4}{|c|}{$\overline{\text { GEOQUIMICA }}$} & \multicolumn{4}{|c|}{ GEOLOGLA ISOTÓPICA E GEOCRONOLOGLA } \\
\hline & & $\begin{array}{l}\text { COMPOSICÁO } \\
\text { QIIIMICA } \\
\text { (elementos maiores) }\end{array}$ & $\begin{array}{l}\text { PROCESSO DE } \\
\text { GERACCÁ } \\
\text { (elementos traços) }\end{array}$ & $\begin{array}{l}\text { AMBIENTE } \\
\text { GEOTECTÓNICO } \\
\text { (terras raras) }\end{array}$ & $\begin{array}{l}\text { COLOCAÇÁO } \\
\text { (pré-sin-pós } \\
\text { tectônico)/ } \\
\text { PROFUNDIDADE }\end{array}$ & MÉTODO & $\begin{array}{l}\text { COMENTARIOS } \\
\text { SOBRE AS } \\
\text { ISÓCRONAS }\end{array}$ & $\begin{array}{l}\text { ORIGEM DO } \\
\text { MAGMA }\end{array}$ & $\begin{array}{l}\text { PROVÁVEI } \\
\text { FONTE }\end{array}$ \\
\hline $\begin{array}{l}C \\
U \\
N \\
H \\
A \\
P \\
O\end{array}$ & GNAISSES & $\begin{array}{l}\text { CALCIO-ALCALINA } \\
\left(\mathrm{K}_{2} \mathrm{O} \mathrm{Na}_{2} \mathrm{O}\right) \\
\text { TONALITO- } \\
\text { GRANITICA } \\
\left(\mathrm{Na}_{2} \mathrm{O} \times \mathrm{CaO} \times \mathrm{K}_{2} \mathrm{O}\right) \\
(\text { enriquecimento } \mathrm{K} . \mathrm{Ca}) \\
\mathrm{K}_{2} \mathrm{ONa}_{2} \mathrm{O}>1\end{array}$ & $\begin{array}{l}\text { FUSÃO PARCIAL } \\
\text { E/ou } \\
\text { CONTAMINAÇÃO } \\
\text { CRUSTAL } \\
(Y / Z r \times Y) \\
\text { - ocorre variaçãona } \\
\text { relaçăo YiZr. }\end{array}$ & $\begin{array}{l}\text { VAG } \\
\text { (Arco Vulcânico) } \\
\left(\mathrm{Hf}_{\mathrm{f}} \mathrm{Ta}^{*} \cdot 3 \times\right. \\
\mathrm{Rb} / 10) \\
(\mathrm{Rb} \times \mathrm{Y} \times \mathrm{Nb})\end{array}$ & $\begin{array}{l}\text { INDEFINIDO } \\
\text { - São rochas mais } \\
\text { diferenciadas). } \\
>30 \mathrm{Km} \quad(\mathrm{Rb} / \mathrm{Sr})\end{array}$ & $\begin{array}{l}\mathrm{Rb} / \mathrm{Sr} \\
\mathfrak{t}=746 \pm 45 \\
\mathrm{Ma} \\
\mathrm{RI}=0,70698 \\
\text { M.S.W.D. }= \\
11.79 \\
\text { (ERRÓCRON } \\
\text { A) }\end{array}$ & - ERRÓCRONA & $\begin{array}{l}\text { OR (Crosta } \\
\text { Orogênica) } \\
\text { ou } \mathbf{S} \& \mathbf{K} \\
\text { (evolução das } \\
\text { rochas a partir de } \\
\text { uma crosta já } \\
\text { diferenciada, no mi- } \\
\text { nimo em } 2 \text { estágios). } \\
\text { ( }{ }^{206} \mathrm{~Pb} / 204 \mathrm{pb} \text { ) }\end{array}$ & $\begin{array}{l}\text { CROSTA } \\
\text { ou } \\
\text { MANTO } \\
\text { SUBCON- } \\
\text { TINENTAL. }\end{array}$ \\
\hline $\begin{array}{l}A \\
N \\
G \\
A\end{array}$ & GRANITOS & $\begin{array}{l}\text { CALCIO-ALCALINO } \\
\mathrm{K}_{2} \mathrm{ONa}_{2} \mathrm{O}>1\end{array}$ & $\begin{array}{l}\text { CONTAMINAÇÃo } \\
\text { CRUSTAL ?? } \\
\text { (não foi bem } \\
\text { definido } \\
\text { pelo gráfico). }\end{array}$ & $\begin{array}{l}\text { VAG (Arco Vulcâ- } \\
\text { nico (Hf } \times \text { Ta*.3 } \\
\text { Rb } 10 \text { ); } \\
\text { VAG + Sin-COLG } \\
\text { (Arco Vulcânico } \\
\text { sin-colisional). (Rb } \\
\times \mathrm{Y} \times \mathrm{Nb} \text { ) (Nb } \times \text { Y) }\end{array}$ & $\begin{array}{l}\text { PÔS - } \\
\text { COLISIONAIS } \\
\left(\mathrm{Rb} / \mathrm{Sr} \times \mathrm{SiO}_{2}\right) \\
>\mathbf{3 0} \mathrm{Km} \quad(\mathrm{Rb} / \mathrm{Sr})\end{array}$ & $\begin{array}{l}\text { Rb/Sr } \\
617 \pm 406 \mathrm{Ma} \\
\mathrm{RI}=0.7164 \\
\text { M.S.W.D. }= \\
0,51 \\
\text { (ISÓCRONA) }\end{array}$ & $\begin{array}{l}\text { MARGEM DE ERRO } \\
\text { MUTTO GRANDE: } \\
\text { Pequena variação } \\
\text { da ražo } 8 / \mathrm{Rb} /{ }^{86} \mathrm{Rb} \\
\text { (entre } 1,6 \text { e } 1,7 \text { ). } \\
\text { - IDADE MINIMA!!! }\end{array}$ & $\begin{array}{l}\text { OR } \\
\text { ou } \\
\mathrm{S} \& \mathrm{~K} \\
\left.{ }^{206} \mathrm{~Pb} /{ }^{204} \mathrm{~Pb}\right)\end{array}$ & IDEM \\
\hline
\end{tabular}

Quadro 5.2- Principais características geoquímicas, isotópicas e geocronológicas do Complexo Cunhaporanga, segundo Reis Neto (1994). 


\begin{tabular}{|c|c|c|c|c|c|c|c|c|c|}
\hline \multirow{2}{*}{\multicolumn{2}{|c|}{$\begin{array}{l} \\
\text { COMPLEXO/ } \\
\text { TIPO DE ROCHA }\end{array}$}} & \multicolumn{8}{|c|}{ CARACTERISTICAS GEOLOGICAS E PETROGRAFICAS } \\
\hline & & COMPOSIÇĀO & $\begin{array}{l}\text { ESTRUTU- } \\
\text { RAS }\end{array}$ & $\begin{array}{l}\text { BANDA- } \\
\text { MENTO } \\
\text { GNÁIS- } \\
\text { SICO }\end{array}$ & $\begin{array}{l}\text { PARAGÊNESES } \\
\text { MAGMÁTICAS }\end{array}$ & $\begin{array}{l}\text { DERIVAÇÃO: } \\
\text { ORTODERIVADA }\end{array}$ & $\begin{array}{l}\text { PARAGÊNESES } \\
\text { METAMÓRFICAS }\end{array}$ & $\begin{array}{l}\text { METAMOR- } \\
\text { FISMO }\end{array}$ & DEFORMAÇĀO \\
\hline $\begin{array}{c}T \\
R \\
\hat{E} \\
S \\
\\
C \\
\dot{o} \\
R\end{array}$ & GNAISSES & $\begin{array}{l}\text { DIORÍTICA } \\
\text { GRANITICA } \\
\text { GRANODIORÍTICA }\end{array}$ & $\begin{array}{l}\text { Rochas } \\
\text { homogêneas, } \\
\text { com uma } \\
\text { discreta } \\
\text { foliação. }\end{array}$ & $m ?$ & $\begin{array}{l}\text { PLAGIOCLASIO + } \\
\text { QZO + HORNBL } \pm \\
\text { FK } \pm \text { TITANITA }\end{array}$ & $\begin{array}{l}\text { - Hornblendas com hábíto } \\
\text { subédrico; } \\
\text { - Tendência para a formação } \\
\text { de mega-cristais (feno- } \\
\text { cristais) de plagioclásio e } \\
\text { homblenda; } \\
\text { - Plagioclásio com freqüentes } \\
\text { zonaçöes e geminaç̄̄es } \\
\text { magmáticas (reliquiar) do } \\
\text { tịo Albita/Carlsbad; } \\
\text {-Microclinio è o FK } \\
\text { predominante. }\end{array}$ & $\begin{array}{l}\text { QZO + CLORITA } \pm \\
\text { EPIDOTO } \pm \text { FK (?) } \pm \\
\text { SERICITA. }\end{array}$ & $\begin{array}{l}\text { FÁCIES } \\
\text { XISTO } \\
\text { VERDE } \\
\\
\text { ZONA DA } \\
\text { CLORITA }\end{array}$ & $\begin{array}{l}\text { FOLIAÇĀO } \\
\text { MILONÍTICA, } \\
\text { heterogênea, com } \\
\text { estiramento de } \\
\text { quartzo e extinģăo } \\
\text { ondulante no } \\
\text { plagioclasio. }\end{array}$ \\
\hline $\begin{array}{l}R \\
E \\
G \\
O \\
S\end{array}$ & GRANITOS & $\begin{array}{l}\text { MONZOGRANITO } \\
\text { porfiritico. com fenocristais } \\
\text { dc Fi: } \\
\text { Matriz: MONZOGRA- } \\
\text { NITICA a DIORÍTICA. } \\
\text { - Fácies equigranular: } \\
\text { GRANODIORITICO a } \\
\text { SIENOGRANÍTICO }\end{array}$ & MACIÇA & $\begin{array}{l}\text { AUSEN- } \\
\text { TE }\end{array}$ & $\begin{array}{l}\text { MICROCLINIO + } \\
\ldots\end{array}$ & & AUSENTE & AUSENTE & $\begin{array}{l}\text { Orientaçăo } \\
\text { preferencial de } \\
\text { fenocristais. } \\
\text { Foliação } \\
\text { cataclástica } \\
\text { superposta. }\end{array}$ \\
\hline
\end{tabular}

Quadro 5.3 - Características geológicas e petrográficas do Complexo Cunhaporanga, segundo Reis Neto (1994). 


\begin{tabular}{|c|c|c|c|c|c|c|c|c|c|}
\hline \multirow{2}{*}{\multicolumn{2}{|c|}{$\begin{array}{l}\text { COMPLEXO/ } \\
\text { TIPO DE ROCHA }\end{array}$}} & \multicolumn{8}{|c|}{ CARACTERISTICAS GEOLOGICAS E PETROGRAFICAS } \\
\hline & & COMPOSIĆÁO & $\begin{array}{l}\text { ESTRUTU- } \\
\text { RAS }\end{array}$ & $\begin{array}{l}\text { BANDAMENTO } \\
\text { GNÁISSICO }\end{array}$ & $\begin{array}{l}\text { PARAGÊNESES } \\
\text { MAGMÁTICAS }\end{array}$ & $\begin{array}{l}\text { DERIVAÇĀO: } \\
\text { ORTODERIVADA }\end{array}$ & $\begin{array}{l}\text { PARAGÉNESES } \\
\text { METAMÓRFICAS }\end{array}$ & $\begin{array}{l}\text { METAMOR } \\
\text { FISMO }\end{array}$ & DEFORMAÇĀO \\
\hline $\begin{array}{l}C \\
U \\
N \\
H \\
A \\
P\end{array}$ & GNAISSES & $\begin{array}{l}\text { DIORITICA a } \\
\text { MONZO- } \\
\text { GRANÍTICA }\end{array}$ & $\begin{array}{l}\text { Rochas } \\
\text { Homogêneas, } \\
\text { com uma } \\
\text { estrutura do } \\
\text { tipo banda- } \\
\text { mento } \\
\text { gnáissico. }\end{array}$ & $\begin{array}{l}\text { Fino, bem desen- } \\
\text { volvido; } \\
\text { Intercalaç̃̃es de } \\
\text { niveis quartzo- } \\
\text { feldspáticos, mm a } \\
\mathrm{cm}, \text { com niveis de } \\
\text { minerais máficos. }\end{array}$ & $\begin{array}{l}\text { PLAGIOCLASIO + } \\
\text { HORNBLENDA + } \\
\text { BIOTITA + QZO + } \\
\text { FK + TITANTTA }\end{array}$ & $\begin{array}{l}\text { - Häbito subédrico a } \\
\text { euédrico das } \\
\text { homblendas; } \\
\text { - Zonaçãa composicional } \\
\text { do plagioclásio (centro } \\
\text { para a borda do cristal); } \\
\text {-Textura granular } \\
\text { hipidiomórfica. }\end{array}$ & $\begin{array}{l}\text { CLORITA } \pm \text { EPIDOTO } \\
\pm \text { SERICITA } \pm \text { QZO. } \\
\text { BIOTITA } \Rightarrow \text { CLORITA } \\
\text { PLAGLASIO } \Rightarrow \text { EPI- } \\
\text { DOTO (Saussuritizaşa). }\end{array}$ & $\begin{array}{l}\text { FÁCIES } \\
\text { XISTO } \\
\text { VERDE } \\
\text { ZONA DA } \\
\text { CLORITA }\end{array}$ & ??? \\
\hline $\begin{array}{l} \\
R \\
A \\
N \\
G \\
A\end{array}$ & GRANITOS & $\begin{array}{l}\text { MONZOGRANÍ- } \\
\text { TICA e SIENO- } \\
\text { GRANITICA } \\
\text { com fenocristais de } \\
\text { microclinio. } \\
\text { GRANODIORÍ- } \\
\text { TICA.com xenólitos } \\
\text { dioriticos. }\end{array}$ & MACIÇA. & AUISENTE & $\begin{array}{l}\text { QUARTZO + } \\
\text { MICROCLINIO + } \\
\text { PLAGIOCLÁSIO + } \\
\text { BIOTITA + } \\
\text { MÁFICOS. }\end{array}$ & & AUSENTE & AUSENTE & $\begin{array}{l}\text { Orientaçào } \\
\text { preferencial de } \\
\text { fenocristais em } \\
\text { alguns pontos. }\end{array}$ \\
\hline
\end{tabular}

Quadro 5.4 - Características geológicas e petrográficas do Complexo Três Córregos, segundo Reis Neto (1994). 


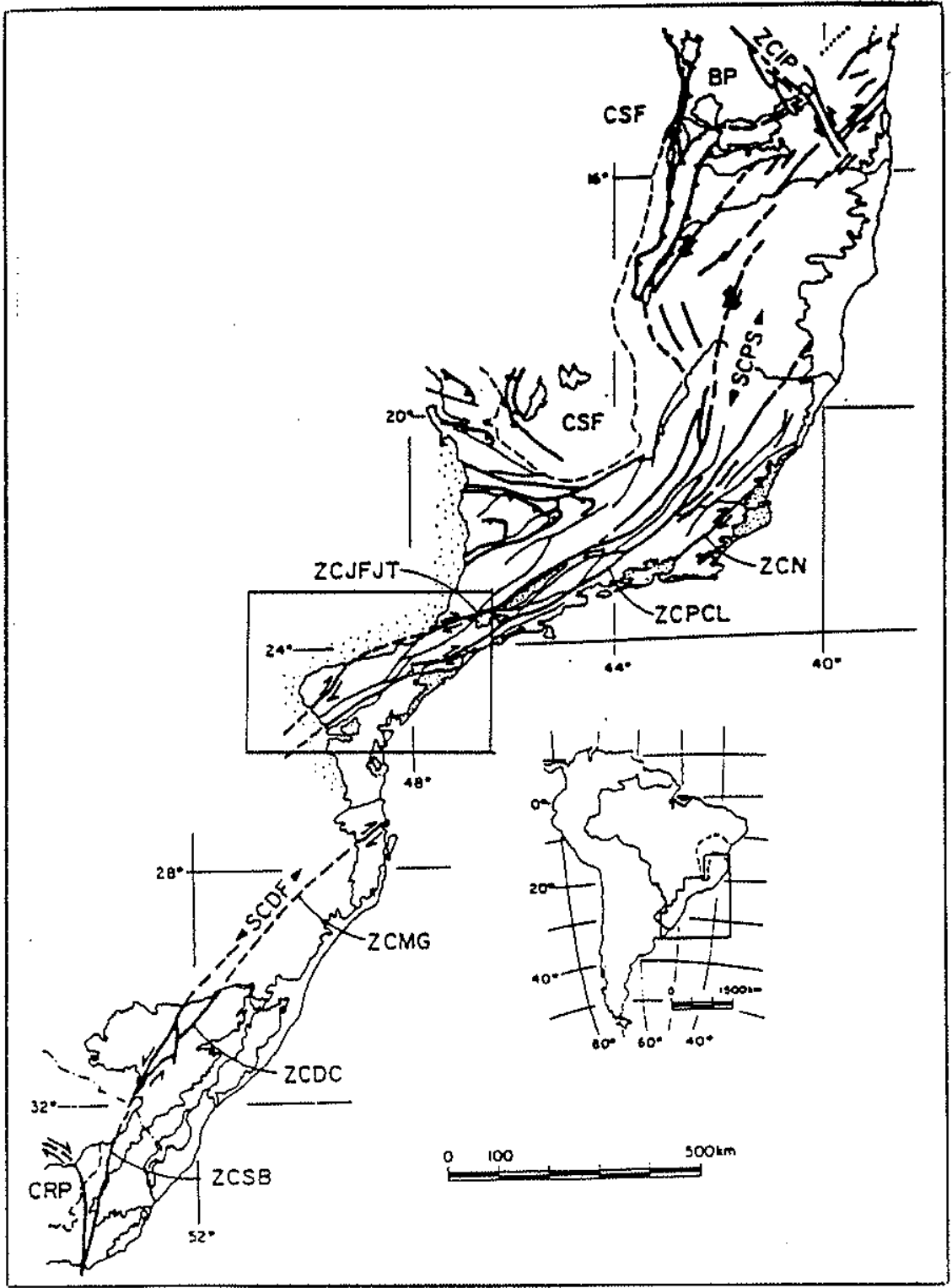

\section{E G E N D A}

CCA - CINTt R.̃o dE CISALHAMENTO ATLÁnTICO, SCPS - SISTEMA DE CISAl HAMENTO PARAíba DO SUL. ZCJFJT - ZONA DE CISAlHaMENTo JUIZ DE FORA-JaguaRI-TaxaquARA, ZCPCL - ZONA DE CISAlHAMENTO ALÉM PARAiba-CUBATÁO-LANCINHA, ZCN - ZONA DE CISALHAMENTO NITERÓI. SCDF SISTEMA DE CISALHAMENTO DOM FELICIANO, ZCMG - ZONA DE CIS ALHAMENTO MANOR ERCINO, ZCDC ZONA DE CISALHAMENTO DORSAL DO CANGUÇU, ZCSB - ZONA DE CISALHAMENTO SIERRA BALLENA. ZCIP ZONA DE CISALHALENTO ITAPEBI-PIRAMIRIM. CSF - CRATON DO SÃO FRANCISCO. CRP - CRÁTON RIO DE LA PLATA. COBERTURAS FANEROZÓICAS EM LEGENDA PONTILHADA.

Figura 5.2 - Estruturação do centro da Zona de cisalhamento transpressional. entre os lineamentos Juiz de Fora-Jaguari-Taxaquara e Além Paraiba-Cubatão-Lancinha. a qual teria permitido o alojamento da granitogênese no pré-Cambriano do Estado do Paraná.

FONTE: Machado \& Endo (1993). 


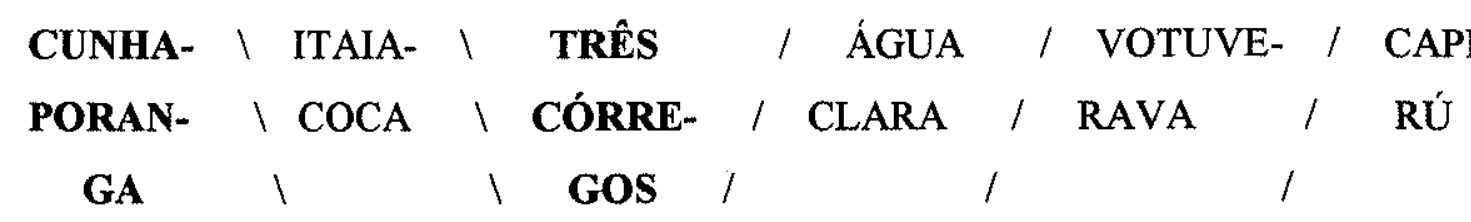

Figura 5.3 - Disposição das Unidades do Grupo Açungui em torno do Maciço Três Córregos, à nortenoroeste da cidade de Curitiba, segundo uma seç̧ão esquemática NW-SE.

Esta hipótese encontra respaldo no comportamento isotópico do $\mathrm{Pb}$ em diagrama $207 \mathrm{~Pb} / 204 \mathrm{~Pb}$ $\mathrm{x}{ }^{206} \mathrm{~Pb} /{ }^{204} \mathrm{~Pb}$, com as amostras situando-se próximas da curva Or (crosta orogênica), no Complexo Cunhaporanga (Stacey \& Kramers, 1975, in: Reis Neto, 1994), enquanto no Complexo Três Córregos, os dados isotópicos situam-se nas imediações da curva do Manto (Zartman \& Doc, 1981, in: Reis Neto, 1994) (Figura 5.4).

(2) $O$ Complexo Cunhaporanga teria sido alojado através de uma tectônica transtracional/transpressional, por volta de $746 \pm 45 \mathrm{Ma}$. $O$ centro desta zona teria migrado para sudeste e possibilitado a colocação do Complexo Três Córregos por volta de $658 \pm 49 \mathrm{Ma}$ próximo ao valor $\mathrm{Rb} / \mathrm{Sr}$ de $665 \mathrm{Ma}$. de Gimenez Filho (1993) e do próprio Reis Neto (1994). Esta segunda hipótese encontra amparo na falta de evidências concretas de restos de crosta oceânica subductada, cunhas de acresção, metamorfismo de alta pressão, suturas típicas, zoneamento magmático típico de acresção (toleitos de arco, cálcio-alcalinos e shoshonitos, esperados a partir da zona de subduç̧ão em direção o arco magmático). O predomínio do magmatismo calci-alcalino em ambos os complexos graníticos, é sugestivo de que a origem de seus magmas tenha sido similar, possivelmente do tipo subcontinental, conforme proposto por Reis Neto (1994). É possivel, ainda, interpretar o magma que deu origem ao complexo Cunhaporanga com comportamento segundo a curva de S \& K (reservatório condrítico) (Stacey \& Kramers, 1975 in: Reis Neto, 1994). Desta forma, a geração dos magmas que deram origem aos complexos graníticos não teriam se dado na crosta superior ou crosta orogênica, mas sim a partir de um reservatório condritico ou do manto. Esta hipótese é confirmada pela ausência de 


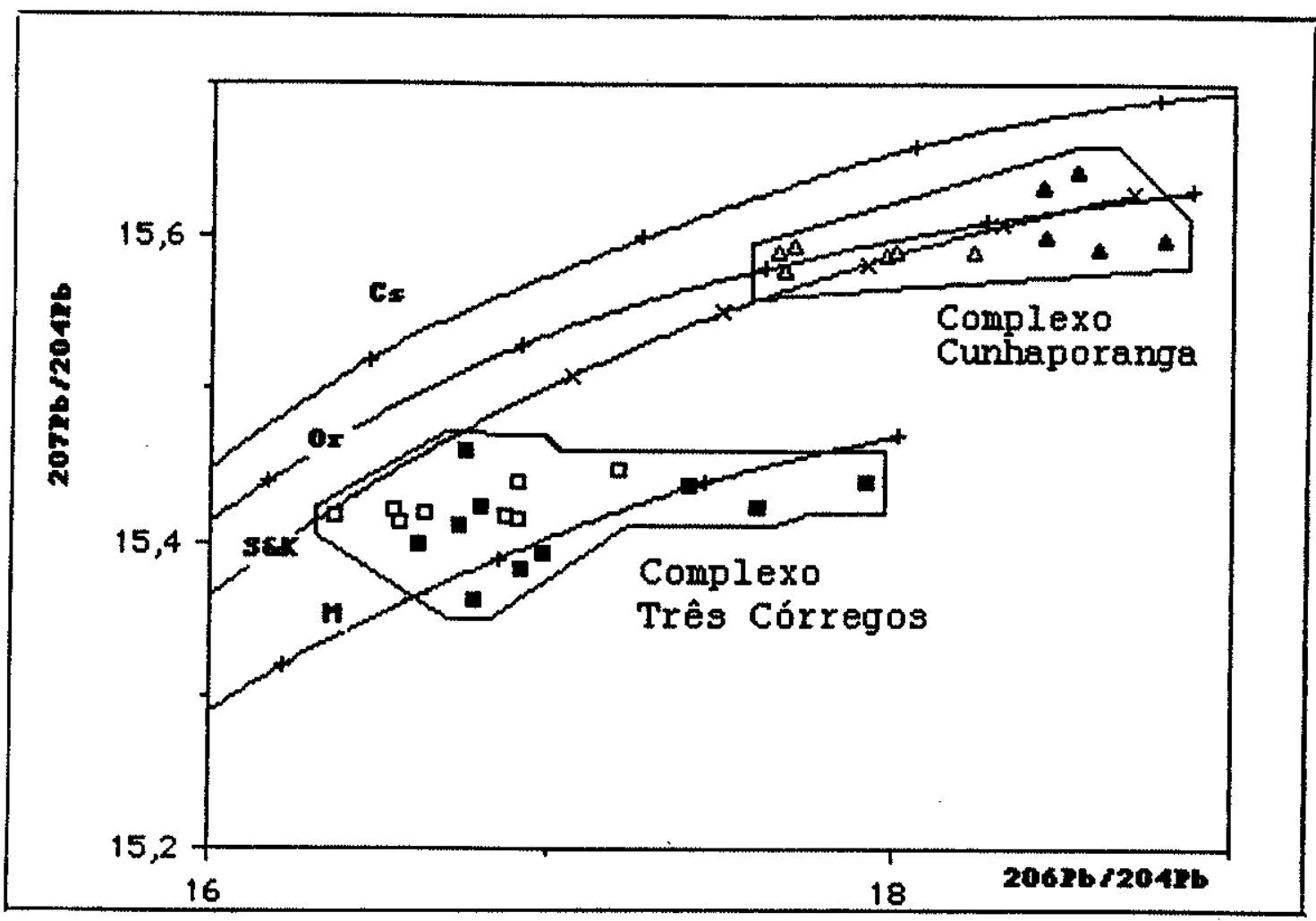

Figura 5.4 - Diagrama de ${ }^{207} \mathrm{~Pb} /{ }^{204} \mathrm{~Pb} \times{ }^{206} \mathrm{~Pb} /{ }^{204} \mathrm{~Pb}$ mostrando a composição isotópica do $\mathrm{Pb}$ para os Complexos Cunhaporanga e Três Córregos. Fonte: Reis Neto (1994).

anomalia negativa de európio na maioria das amostras analisadas, com excessão de duas amostras que apresentam leve anomalia negativa de $\mathrm{Eu}$. Desta forma, à luz dos presentes dados, a interpretação dos complexos graniticos como um arco magmático (Soares 1987, Gimenez Filho, 1993, Reis Neto, 1994) dificilmente pode ser sustentada. Além disso, o Complexo Três Córregos é interpretado por Gimenez Filho (op. cit.) com magmatismo tipo Caledoniano, o qual é característico de ambientes tardi a pós-colisionais.

(3) Os complexos Cunhaporanga e Três Córregos seriam cogenéticos, e marcariam o centro de uma zona transtracional/transpressional, gerada por volta de $746 \pm 45 \mathrm{Ma}$ e reativada em torno de 658+49Ma. Ambos os complexos estariam ligados em subsuperficie, por debaixo da Faixa Itaiacoca.

Esta hipótese encontra subsidios nas datações dos gnaisses (prováveis granitos miloníticos), com idades $\mathrm{Pb} / \mathrm{Pb}$ de $778 \pm 266 \mathrm{Ma}$ e $\mathrm{Rb} / \mathrm{Sr}$ de $746 \pm 45 \mathrm{Ma}$, representativas do primeiro regime transtrativo/transpressivo (Ver Quadros 5.1 e 5.2). Uma nova fase transtrativa teria possibilitado a colocação dos granitos maciços por volta de $658 \pm 49 \mathrm{Ma}(\mathrm{Rb} / \mathrm{Sr})$, indicado 
pela rehomogeneização isotópica dos gnaisses Paina e Três Córregos, além das idades $\mathrm{Rb} / \mathrm{Sr}$ com $617 \pm 406 \mathrm{Ma}$ e $509 \pm 31 \mathrm{Ma}$ para rochas dos Complexos Cunhaporanga e Três Córregos, respectivamente. Idade idêntica foi encontrada por Souza (1990) nas rochas graníticas foliadas do Maciço Córrego Butiá, com valor de $651 \mathrm{Ma}$. Idades $\mathrm{Rb} / \mathrm{Sr}$ mais jovens de 480Ma, são referidas por Gimenez Filho (1993) para granitos pós-tectônicos, associados ao Complexo Três Córregos.

As datações de Reis Neto (op. cit.) apresentem diversos problemas com relação ao significado de algumas isócronas, assim como erros elevados (Ver Quadros 5.1 e 5.2). Tais dados podem ser interpretados como idades de referência, e neste sentido podem traduzir cogeneticidade entre estes complexos, características estas que são corroborados pelos dados petrográficos e geoquímicos dos mesmos (Ver Quadros 5.3 e 5.4).

\subsection{DISCUSSÃO SOBRE A DISPOSIÇÃO SIMÉTRICA DAS UNIDADES}

A relação entre a disposição das unidades do Grupo Açungui em torno do Complexo Três Córregos (Ver Figura 5.3), com a sua estratigrafia original, tem sido uma questão em discussão desde a década de 70 , por diversos autores.

Neste sentido, Bigarella \& Salamuni $(1956,1958)$ empilharam as unidades da "Série Açungui" com a Formação Setuva, na base, sendo sobreposta pela Formação Capirú e, no topo, a Formação Votuverava (Ver Anexo 1 - Colunas Estratigráficas). Esta mesma disposição foi identificada por Marini et al. (1967), porém com o desmembramento da Formação Água Clara a partir da Formação Votuverava, passando a primeira a ocupar uma posição de topo da coluna. Desta forma, a unidade localizada mais a noroeste foi interpretada como topo e aquela situada a sudeste, como da base da coluna estratigráfica, na seqüência indicada pela Figura 5.3. Este posicionamento estratigráfico foi, provavelmente, induzido pela disposição da foliação metamórfica principal, a qual tem o predomínio com mergulhos para noroeste. Campanha (1991) seguiu o mesmo raciocínio, adicionando o Grupo Itaiacoca no topo, logo acima da Formação Água Clara, seguida pelo Grupo Votuverava, Formação Capirú e Grupo Setuva, na base. Esta organização estratigráfica apresenta, porém, um forte controle tectônico, desde a estruturação dos contatos entre as unidades, bem como a inserção da Formação Água Clara no topo ou próximo a ele, apesar do maior grau metamórfico e deformacional comparado com as Formações 
Votuverava e Capirú. Porém, tendo em vista que os contatos tectônicos entre as unidades apresentam mergulhos para noroeste desde o Complexo Três Córregos até o Embasamento Cristalino (Figura 5.5), numa possível convergência dos mergulhos para o centro de uma estrutura-em-flor, o que é compatível com a justaposição de unidades mais antigas ou mais deformadas próximas ao citado complexo granítico, efeito este que deve diminuir à medida em que nos afastamos do centro da estrutura. Esta disposição geométrica pode ser observado numa estrutura-em-flor teórica (Ver Figura 2.4), onde ocorre um alçamento com maior intensidade, da coluna original, em torno do centro da estrutura e, conseqüentemente, com exposição de litologias mais antigas nesta região. Este efeito sofre uma diminuição em direção às suas bordas, quando deformações transpressivas vão diminuindo progressivamente de intensidade, enquanto fatias de rochas experimentam um alçamento progressivamente menor, até o momento em que a transpressão tornar-se nula.

Este alçamento diferencial em torno do centro da estrutura gera uma justaposição de pacotes sedimentares, os quais passam a ocupar posições diferentes na coluna original, por ocasião da exposição de um nível idêntico de erosão (Ver Figuras 2.4 e 5.5).

Este mecanismo transpressional teria alçado a Formação Água Clara, expondo a base da Bacia Açungui, em torno do Complexo Granito Três Córregos (Ver Figura 5.5), por meio de falhas de empurrão. As Formações Votuverava e Capinú teriam sido alçadas igualmente na aba sudeste da estrutura, porém com uma intensidade progressivamente menor do centro da mesma até o embasamento. Esta exposição de um nível mais profundo da Formação Votuverava em relação a Formação Capirú foi identificada anteriormente por Marini (1970), tendo sua explicação relacionada ao lineamento Lancinha por Fassbinder (1990).

$\mathrm{Na}$ aba noroeste da estrutura-em-flor, a Formação Votuverava parece estar ausente, passando a Formação Itaiacoca a ocupar uma posição simétrica à Formação Capirú, na aba SE. Neste sentido, é provável que estas formações tenham ocupado idêntico nível estratigráfico na Bacia Açungui (ocupando, respectivamente, as bordas NW e SE desta bacia), num período de sedimentação pré-colocação ao Complexo Três Córregos, conforme pode ser deduzido pela geometria transpressional. As similaridades entre estas unidades sedimentares têm levado diversos autores a propor uma equivalência entre elas, porém correspondendo a fácies distintas dentro de uma mesma bacia. A expressiva contribuição vulcânica nos sedimentos da Formação Abapã (Grupo Itaiacoca) (Reis Neto, 1994) e, de forma mais restrita, na Formação Capirú (Juliani, comunicação verbal), juntamente com a presença de estromatólitos - embora de gêneros distintos presentes na Formação Bairro dos Campos e Formação Capirú - constituem-se em 


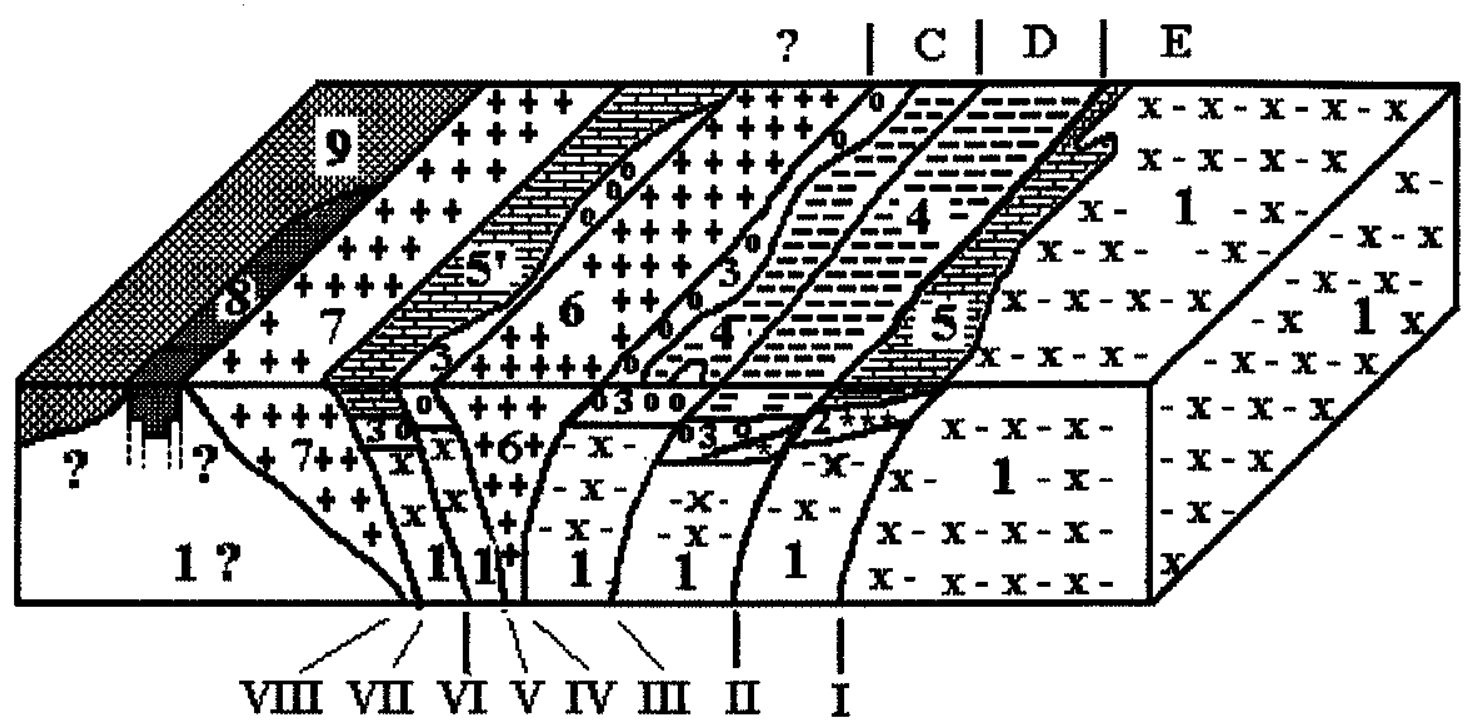

\begin{tabular}{|c|c|c|c|}
\hline \multicolumn{4}{|c|}{$\begin{array}{lllllll}\mathbf{L} & \mathbf{E} & \mathbf{G} & \mathbf{E} & \mathbf{N} & \mathbf{D} & \mathbf{A}\end{array}$} \\
\hline SIMBOLOGIA & UNIDADES TECTÔNICAS & SIMBOLOGIA & $\begin{array}{l}\text { LINEAMENTOS E BLOCOS } \\
\text { TECTONICOS }\end{array}$ \\
\hline 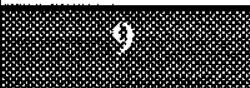 & BACIA DO PARANÁ & $\bar{I}$ & $\begin{array}{l}\text { CONTATO DA BACIA ACUNGUU COM } \\
\text { O EMBASAMENTO CRISTALINO }\end{array}$ \\
\hline 8 & BACIA DE CASTRO & II & LINEAMENTO LANCINHA \\
\hline $\begin{array}{l}++7++ \\
++++++\end{array}$ & COMPLEXO CUNHAPORANGA & III & LINEAMENTO MORRO AGUDO \\
\hline $\begin{array}{l}++6++ \\
++++++\end{array}$ & COMPLEXO TRÊS CÓRREGOS & IV - V & $\begin{array}{l}\text { ZONA DE CISALHAMENTO CERRO } \\
\text { AZUL (BORDA NW E SE DO } \\
\text { COMPLEXO TRÊS CÓRREGOS) }\end{array}$ \\
\hline$-5 \mid-1$ & $\begin{array}{l}\text { FORMAÇÃO CAPIRÚ } \mathbf{( 5 )} \text { E } \\
\text { FORMAÇÃO ITAIACOCA (5') }\end{array}$ & VII & LINEAMENTO ITAPIRAPUÃ \\
\hline $\begin{array}{l}--4=-- \\
--------\end{array}$ & FORMAÇÃO VOTUVERAVA & VI - VIII & NÃO DEFINIDOS \\
\hline $\begin{array}{l}003000 \\
000000\end{array}$ & $\begin{array}{l}\text { FORMAÇÕES ÁGUA CLARA } \\
\text { PERAU E SÃO SEBASTIÃO }\end{array}$ & $\bar{C}-\mathbf{D}-\mathbf{E}$ & $\begin{array}{l}\text { BLOCOS TECTÔNICOS DEFINIDOS } \\
\text { POR GÓIS ET AL (1985). }\end{array}$ \\
\hline $\begin{array}{l}* * * * * * * \\
* * * 2 * *\end{array}$ & $\begin{array}{l}\text { GRUPO SETUVA PRESENTE } \\
\text { ANTICLINAL DO SETUVAE NÚCLEO } \\
\text { BETARA }\end{array}$ & & \\
\hline $\begin{array}{l}x-1-x-x \\
x-x-x-x\end{array}$ & $\begin{array}{l}\text { COMPLEXO PRE-SETUVA E } \\
\text { EMBASAMENTO CRISTALINO }\end{array}$ & & \\
\hline
\end{tabular}

Figura 5.5 - Seç̧ão esquemática. mostrando a disposição das unidades do Grupo Açungui, expostas por uma estrutura-em-flor. positiva. 
argumentos que reforçam esta hipótese.

A coluna estratigráfica original presente em cada fatia de rocha, deduzida pela geometria da zona transpressional, sugere a Formação Água Clara como base do Grupo Açungui, seguida pelas Formações Votuverava e Capirú, com esta última no seu topo, correspondendo assim a uma ordem estratigráfica inversa daquela proposta normalmente para a região. Coluna estratigráfica similar foi obtida por Fiori $(1990,1992 a)$, com base no modelo de cavalgamentos ou duplex de Boyer \& Elliot (1982). Contudo, o referido autor não discutiu a Formação Água Clara. Neste sentido, as falhas de baixo ângulo, reconhecidas por Fiori (op. cit.), correspondem a componente de cisalhamento puro (Thrust faults) da partição da deformação.

\subsection{COLUNA ESTRATIGRÁFICA ORIGINAL}

A estrutura anticlinal da Serra do Cadeado, inserida no bloco tectônico identificado pela letra "D" por Góis et al. (1985), e gerada pelas Zonas de Cisalhamento Lancinha-Cubatão, na forma de dobras escalonadas, expôs a coluna estratigráfica original na região da Mina do Perau. Esta seqüência, denominada de "Perau" por Piekarz (1981) e Silva et al. (1982), apresenta-se assentada diretamente sobre os gnaisses do Complexo Pré-Setuva, sendo constituída por quartzitos na base, seguido por rochas carbonáticas impuras, mineralizadas em $\mathrm{Cu}, \mathrm{Pb}, \mathrm{Zn}, \mathrm{Au}$, intercaladas por metatufos. No topo da sequência, intercalam-se metapelitos e anfibolitos, com estes últimos tendo sido denominados de Formação São Sebastião por Veiga \& Salomão (1980).

A Formação Votuverava acha-se sobreposta a Seqüência Perau, compreendendo metapelitos intercalados por sills básicos, indicando sentido de topo da coluna estratigráfica do Grupo Açungui.

Diversas observações de campo mostram similaridades entre a Seqüência Perau e a Formação Água Clara, esta última aflorante em torno do Complexo Granítico Três Córregos. Estas observações, sugerem tratar-se de uma mesma sequiência deposicional, exposta por esforços transpressionais em torno do Complexo Três Córregos e, por dobramento antiformal, na Serra do Cadeado, expondo a base da Bacia Açungui. Os principais argumentos que suportam esta conclusão estão relacionados aos aspectos litológicos, estruturais e metamórficos, como segue. 
(1) LITOLÓGICAS - A Formação Água Clara é constituída de metamargas com formações ferríferas associadas, além de pacotes subordinados de metarenitos e metapelitos intercalados, exibindo similaridades litológica e deposicional com as unidades da Seqüência Perau;

(2) METAMORFISMO - Minerais metamórficos como cummigtonita, estaurolita, granada, indicativos da fácies xisto-verde alto, início da fácies anfibolito, são características comuns de ambas as unidades.

(3) TRANSIÇÃO METAMÓRFICA - Na coluna estratigráfica presente na região da mina do Perau, parece ocorrer transição metamórfica desde a unidade de base (Formação Perau), até a unidade de topo, representada pela Formação Votuverava. Assim, na base da coluna ocorrem minerais metamórficos como estaurolita, os quais vão sendo sucessivamente substituídos por granada, biotita e sericita, na medida em que se vai subindo na coluna estratigráfica, cuja espessura é da ordem de 800 e 1000 metros. Embora não seja possível observar as litologias da Formação Água Clara, por meio de uma secção vertical, pois a exposição é restrita e presente num mesmo nível estrutural, é provável que esta transição metamórfica também ocorra em seus domínios.

(4) ESTRUTURAIS - Os dados obtidos a partir de observações estruturais, como $\mathrm{n}^{\circ}$ de foliações, lineações de intersecção, lineações minerais e de estiramento mineral, geometria das dobras e intensidade da deformação, mostram novamente uma similaridade entre as duas unidades;

(5) MINERALIZAÇÕES - Importantes anomalias geoquímicas de $\mathrm{Au}, \mathrm{Cu}, \mathrm{Pb}$ e $\mathrm{Zn}$ na região de São Pedro e São Silvestre, obtidos através de sedimentos de corrente, mostram similaridades com aquelas mineralizações presentes na Seqüência Perau;

Com base na discussão acima, conclui-se que a Formação Água Clara/São Sebastião/. Perau ocupa a base do Grupo Açungui (Figura 5.6). As denominações São Sebastião e Perau, propostos por Veiga \& Salomão (1980) e Piekarz (1981), com conotações locais, deverão ser abandonadas em favor da denominação Água Clara, proposta por Marini et al. (1967), ou talvez considerá-las como fácies da Formação Água Clara. 


\begin{tabular}{|c|c|c|}
\hline & SUPER GRUPO & GRUPOS \\
\hline \multirow{3}{*}{$\begin{array}{l}\text { SUPRA- } \\
\text { ESTRUTURA }\end{array}$} & \multirow{3}{*}{$\begin{array}{l}\text { SUPER GRUPO } \\
\text { ACUNGUI }\end{array}$} & GRUPOS CAPIRÚ E ITAIACOCA \\
\hline & & GRUPO VOTUVERAVA/LAJEADO (ANTINHA?) \\
\hline & & GRUPO ÁGUA CLARA \\
\hline $\begin{array}{l}\text { INFRA- } \\
\text { ESTRUTURA }\end{array}$ & $\begin{array}{l}\text { COMPLEXO } \\
\text { PRÉ-SETUVA }\end{array}$ & GNAISSES \\
\hline
\end{tabular}

Figura 5.6 - Coluna proposta para o Pré-Cambriano dos Estados do Paraná e sul de São Paulo.

Segue-se a Formação Votuverava, com transição estrutural e metamórfica a partir da Formação Água Clara, na região da Mina do Perau. Seguindo-se na coluna, deveria aparecer a Formação Capirú, a qual não é registrada na mina do Perau, em virtude do soerguimento transpressional e, consequente, erosão. Porém, aparece numa posição mais afastada do centro da zona transpressional, a sudeste da Zona de Cisalhamento Lancinha, onde os esforços transpressionais foram mais brandos. As Formações Lajeado e Antinha aparecem logo acima, tendo sido depositadas provavelmente durante o período transtracional que permitiu a colocação de corpos graníticos na Faixa Ribeira. Tais formações, acham-se deformadas apenas pelas transcorrências, lateral direita. Esta observação, reforça a proposição de Soares (1987), o qual considera as Sequências Antinha/Lajeado como depositadas num ciclo sedimentar pós-Açungui, pois não apresentam as deformações e metamorfismo característicos do Grupo Açungui. As Formações Antinha/Lajeado, Capirú/Itaiacoca, Votuverava e Água Clara/Perau devem ser elevadas a categoria de Grupos, e o Grupo Açungui a Super Grupo, conforme proposta de Hasui et al. (1989), seguida por Souza (1990, 1992), Campanha (1991), Reis Neto (1994) e também proposta neste trabalho (Ver Figura 5.6).

O Grupo Setuva, aflorante basicamente no Anticlinal do Setuva, não foi investigado neste trabalho. Este Grupo, descrito por Bigarella \& Salamuni $(1956,1958)$ e, posteriormente, discutido por Ebert (1971), parece não possuir similaridades com a Sequência Perau aflorante na Mina homônima ou nos domínios tradicionais da Formação Água Clara. Estudos mais detalhados são necessários para a elucidar esta questão. 


\subsection{LOCALIZAÇÃO DO GRUPO AÇUNGUI NA ESTRUTURA TRANSPRESSIONAL}

Dados de 32 análises de deformação obtidas por Kops (1994) nas Formações Água Clara (5 amostras), Votuverava ( 3 amostras) e Formação Antinha (25 amostras), foram lançados nos Diagramas de Flinn (Rxy x Ryz) e de Hossack (Figuras 5.7 e 5.8), mostrando caracteristicas oblatas para o conjunto das análises. Apenas uma das amostras situou-se no campo da deformação prolata. Estes resultados indicam uma componente de achatamento das elipses.

Estas constatações quando transportadas para o modelo teórico de Sanderson \& Marchini (1984), mostram que o atual nível de exposição da Faixa Ribeira corresponde a uma zona intermediária a inferior.

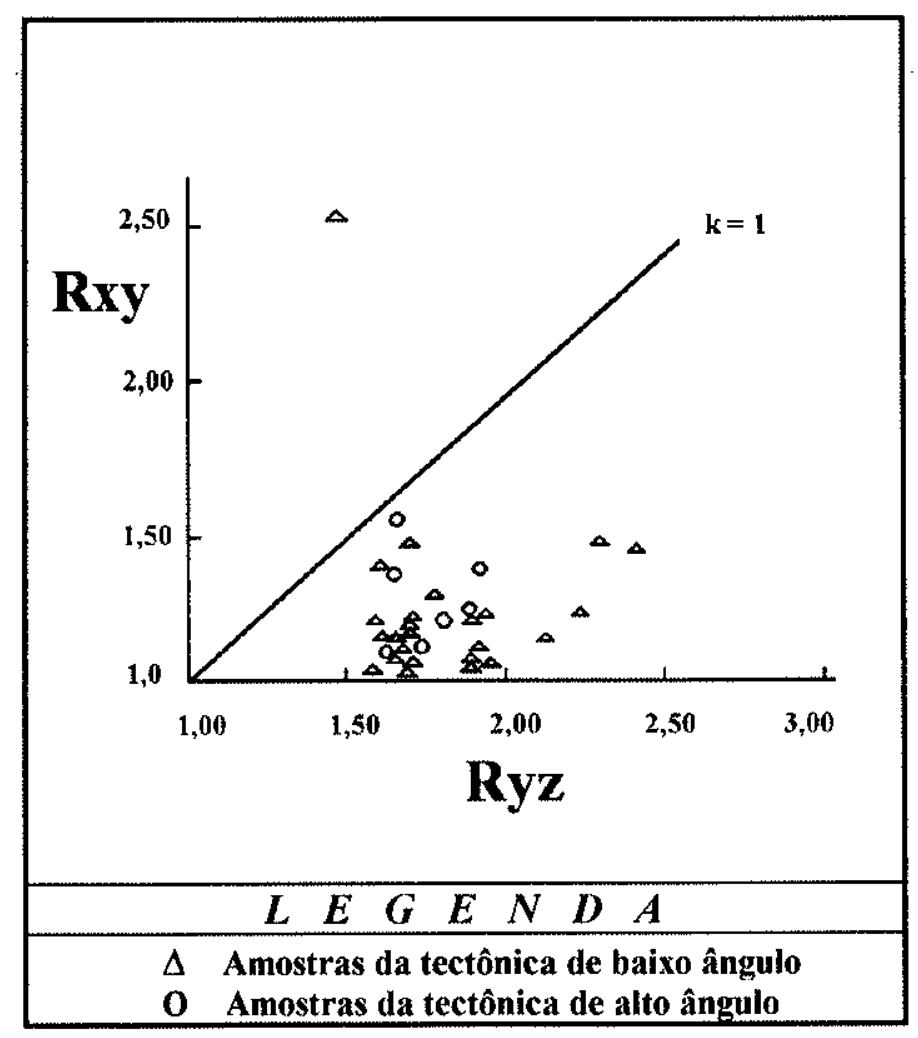

Figura 5.7 - Representação no diagrama de Flinn de valores de $\mathbf{k}$ provenientes das Formações Água Clara. Votuverava e Antinha, segundo Kops (1994).

\subsection{MECANISMOS DE GERAÇÃO DA FOLIACÃO $\mathrm{S}_{1} / / \mathrm{S}_{0}$}

Diversos mecanismos foram propostos para explicar o paralelismo da foliação $S_{1}$ com o acamamento sedimentar no Grupo Açungui e correlatos. 


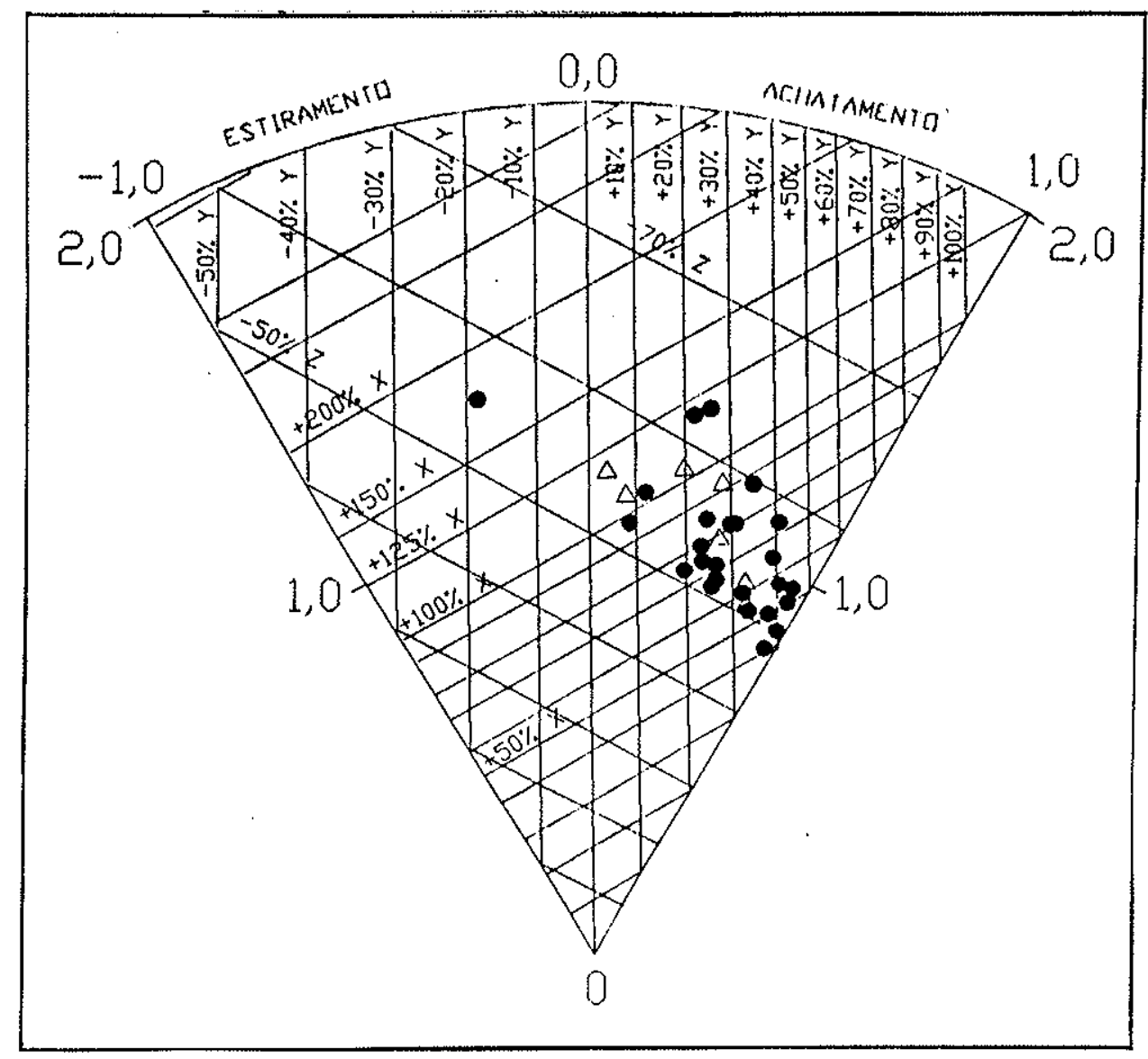

Figura 5.8 - Resultados obtidos por Kops (1994) no Diagrama de Hossack que relaciona os valores de intensidade de deformação (Es) e tipos de elipsóides de deformação (v), para as Formações Água Clara, Votuverava e Antinha.

\subsubsection{MECANISMO CLÁSSICO DE "BUCKLING"}

Dobras isoclinais recumbentes sofreriam uma total transposição na forma de uma foliação e/ou bandamento metamórfico, resuitando numa estrutura planar com disposição paralela ao acamamento sedimentar. Este mecanismo de deformação coaxial foi aplicado até o início da década de 80 por diversos autores (Fritzsons Jr. et al., 1982, Pontes, 1982, entre outros), para explicar a deformação presente na Formação Água Clara. Porém, a falta de fechamentos de dobras em escala regional, e a preservação de estruturas sedimentares em alguns niveis estratigráficos, contrapõem-se a esta interpretação. 


\subsubsection{CISALHAMENTO SIMPLES, NO SENTIDO DE RAMSAY(1980)}

A verificação da ocorrência de deformação não-coaxial nos metassedimentos do Grupo Açungui por Fiori et al. ( 1987c) e Fiori $(1990,1992 b)$ levou a uma modificação substancial do entendimento dos mecanismos de geração deste paralelismo. Entre os principais mecanismos destacam-se os cavalgamentos de baixo ângulo de Boyer \& Elliot (1982), os quais teriam se instalado de forma paralela a subparalela ao acamamento sedimentar. Este mecanismo foi aplicado por Fiori et al. (op. cit.) e Fiori (op. cit.) no modelo de colisão continental frontal, enquanto que Ebert et al. (1988) reconheceu estas mesmas feições ao longo de prováveis colisões com rampas oblíquas de baixo ângulo.

\subsubsection{MODELO TRANSPRESSIONAL}

No modelo transpressional, presente ao longo de colisão oblíqua de placas tectônicas, ocorre partição da deformação, segundo as componentes de cisalhamento puro (thrust fault) e simples (transcorrência). As foliações de baixo ângulo, dispostas de forma paralela a subparalelas ao acamamento sedimentar, são geradas pela componente de cisalhamento puro, responsável pelo encurtamento da bacia. $\mathrm{O}$ mecanismo de geração deste paralelismo é idêntico a aquele proposto por Fiori et al. (1987c) e Ebert et al. (1988).

\subsection{CONTATO ENTRE AS UNIDADES}

O contato entre as unidades do Grupo Açungui vem sendo descrito tradicionalmente como sendo de natureza tectônica. Neste sentido, Marini (1970) reconheceu que o único critério que pudesse indicar uma discordância entre as Formações Água Clara e Votuverava seria estrutural, na forma de uma "aparente falha". Enquanto isso, Hasui et al. (1984c) abordaram a dificuldade em reconhecer a estratigrafia interna das sequências aflorantes no Anticlinório da Serra do Cadeado (Anta Gorda), devido as estruturas de deformação como transposições, lenticularizações, recristalizações, remobilizações internas e contatos tectônicos entre as sequências.

Contatos tectônicos foram também descritos por Fiori (1990) para praticamente todas as unidades do Grupo Açungui, através de falhas de baixo ângulo, no sentido de Boyer \& Elliot 
(1982). Estes contatos foram reconhecidos, pelo autor, pelo truncamento de camadas mais competentes ao longo do seu traçado em fotografias aéreas ou, ainda, pela intensificação da deformação ao longo da sua ocorrência no campo, podendo culminar com uma nova foliação. Idênticos truncamentos foram observados por Fiori (op. cit.) e Fassbinder (1990) e Fassbinder et al. (1994b) ao longo de zonas de cisalhamento de alto ângulo, a exemplo das Falhas da Lancinha, Morro Agudo, Itapirapuã, entre outras.

\subsection{INTENSIDADE DA TRANSPRESSÃO}

No primeiro evento de transpressão, responsável pela geração das principais estruturas tectônicas no Grupo Açungui, a deformação parece não ter sida muito intensa. Valores de razões da deformação, obtidos por Spoladore (1993), Kops (1994) e Fiori (comunicação verbal), por meio da quantificação do estiramento de minerais, seixos e sombras de pressão, indicam, para a Formação Água Clara, valores entre 1.84 e 3,80. Estes valores decrescem na Formação Votuverava/Lajeado, onde estão situados no intervalo de 1,2 e 2,5, podendo, localmente, atingir valores superiores ou até praticamente nulos na Formação Antinha e, localmente, alcançando valores de 3.37 (Tabela 5.1). Estes valores, além de indicar uma maior deformação nos metassedimentos da Formação Água Clara, o que é esperado para uma unidade situada num nível estrutural mais profundo do que das unidades sobrepostas (Formações Votuverava e Capirú), podem também indicar que o provável transporte tectônico das fatias de rochas ocorreu ao longo de distâncias relativamente pequenas.

\begin{tabular}{|l|l|l|}
\hline FORMAÇÕES & SPOLADORE (1993) & KOPS(1994) \\
\hline ÁGUA CLARA & 2,0 a 3,0 & 1.84 a 3.80 \\
\hline VOTUVERAVA & 1,2 a 2,5 & 1.76 a 2.16 \\
\hline ANTINHA & 1,0 (NULOS) & 1.55 a 3.37 \\
\hline
\end{tabular}

Tabela 5.1 - Valores de razões de deformação encontrados por Spoladore (1993) e Kops (1994) nas Formações Água Clara. Votuverava e Antinha. no Grupo Açungui. 
Por outro lado, a segunda fase transpressiva teria sido responsável pela "ejeção" de blocos tectônicos rígidos ao longo da estrutura transpressional. Desta forma, a base da bacia Açungui (Formação Água Clara) foi exposta em torno do Complexo Granítico Três Córregos, até o efeito transpressivo tornar-se nulo na borda da faixa Ribeira, expondo sucessivamente as Formações Votuverava e Capirú, ao longo da aba sudeste da estrutura. Durante este evento, teria ocorrido, ainda, a estruturação final do lineamento Lancinha-Cubatão, com movimentação lateral direita, com dobras escalonadas e demais estruturas de Riedel associadas (Fassbinder, 1990; Fassbinder et al. 1994b).

É interessante observar que praticamente todas as camadas metassedimentares apresentam-se com disposição normal. Desta forma, não teriam ocorrido significativas inversões de flancos de dobras e/ou ejeções de camadas sedimentares através de falhas reversas de baixo ângulo, em ambas as fases transpressivas. 


\section{EVOLUÇÃO GEOLÓGICA}

A atuação da tectônica formadora e a sedimentação do Grupo Açungui, segundo os dados de isótopos estáveis de ${ }^{18} \mathrm{O}$, comparados com a escala mundial (Torquato, 1980), ocorreu num intervalo de tempo menor que $1.3 \mathrm{Ga}$ e maior que $0.7 \mathrm{Ga}$. Ao valor de $1.3 \mathrm{Ga}$, obtido na Formação Água Clara, deve ser deduzido o efeito do metamorfismo, tornando a idade, provavelmente, menor. A idade da Formação Votuverava, de $0.90 \mathrm{Ga}$, deve estar mais próxima do seu valor real, devido a interferência pequena ou nula do metamorfismo. Por outro lado, a idade de $0.70 \mathrm{Ga}$, da Formação Capirú, deve ser maior, devido ao efeito da dolomitização. É provável que o mesmo fenômeno tenha ocorrido na Formação Itaiacoca, uma vez que os dados isotópicos obtidos por Frascá (1992) são idênticos àqueles da Formação Capirú.

Os dados de ${ }^{18} \mathrm{O}$ sugerem que estas unidades foram depositadas em intervalos de tempo independentes, ocorrendo assim a superposição de bacias distintas, entremeadas por períodos de estabilidade tectônica e possível erosão. Exemplo deste tipo de evolução foi observado na evolução tectono-sedimentar da Bacia do Paraná, durante o período de 430 Ma., por Figueiredo \& Raja Gabaglia (1986).

A coluna estratigráfica do Grupo Açungui, indicada por estes dados, é formada pela Formação Água Clara, na base, seguida pela Formação Votuverava e, no topo, as Formações Capirú e Itaiacoca. O empilhamento das Formações Votuverava e Capirú é idêntico àqueles obtido por Fiori (1990) e difere daquele do Grupo Itaiacoca (Reis Neto, 1994), pela inversão das Formações Bairro dos Campos e Serra dos Macacos, esta última passando para o topo.

Após um último período de estabilidade tectônica da Bacia, teve início o processo de inversão tectônica, ocasião em que a mesma sofreu encurtamento. Nesta etapa ocorreu a instalação das foliações $\mathrm{Ss}_{(1)}$ e $\mathrm{Sc}_{(1)}$, paralelas a subparalelas às camadas sedimentares.

Com a evolução da deformação no Grupo Açungui, ocorreu o encurtamento da bacia com o aparecimento de estruturas dúcteis e mais deformadas na sua base, típicas do nivel estrutural inferior a médio, no sentido de Mattauer (1971). Assim, na Formação Água Clara desenvolveram-se dobras cerradas a isoclinais, as quais são geralmente rompidas na 
base ou no topo, por ocasião da intensificação da foliação $\mathrm{Sc}_{(1)}$. Estas dobras foram desenvolvidas por mecanismos de cisalhamento puro, segundo os conceitos de Sanderson \& Marchini (1984) Fossen \& Tikoff (1993) Tikoff \& Fossen (1993) e Tikoff \& Teyssier (1994) entre outros. Na Formação Votuverava estas dobras são, em geral, fechadas a cerradas, com raras isoclinais (Spoladore, 1993); na Formação Capirú elas são, geralmente, fechadas (Fiori et al., 1987b), cuja geração se deu num nível estrutural médio a superior.

A intensificação da foliação, nestes três niveis, na base com biotitas e, no topo, com serecitas, levou ao rompimento das dobras, com nucleação de dobras-falha, evoluíndo para a formação de falhas de baixo ângulo. Exemplos destas estruturas são as falhas do Setuva, do Queimadinho, Tranqueiras, morro Grande, Almirante Tamandaré, do Betara, do Votuverava, do Bromado, do Brejal, entre outras (Fiori, 1992a,b; 1993a,b).

A culminação do processo de cisalhamento, envolvendo formação de pares SC de foliações, com dobras e falhas associadas, propiciou $o$ desenvolvimento de descontinuidades, juntamente com dobras sem raízes (rootless folds).

A continuidade deste processo de deformação é marcada pela nucleação de novas dobras, agora como produto de deformação da superficie metamórfica subhorizontal $\left(\mathrm{Sc}_{1}\right)$. Estas estruturas são novamente rompidas na base, a exemplo da Sinforme de Morro Grande (Fiori, 1990). Porém, como as bordas das placas convergem como movimentos oblíquos, a componente de cisalhamento puro, responsável pelo encurtamento perpendicular ao orógeno, não acomodou toda a deformação. Deste modo, surge uma nova componente, de cisalhamento simples, a qual acomodou a outra parte da deformação, ao longo de transcorrências. Este mecanismo que fraciona a deformação em duas componentes, é denominada de partição da deformação (Richard \& Cobbold, 1990). Assim, enquanto que a componente de cisalhamento puro promoveu o encurtamento da bacia, a de cisalhamento simples iniciou um processo de verticalização das estruturas, conduzindo a reorientação de foliações, ou o desenvolvimento de novas foliações. Este processo, de intensidade variável, atuou com pequena intensidade nas litologias da Formação Água Clara (região de São Pedro/São Silvestre) e de grande intensidade, em outras regiões (Fragoso Cesar, 1996), dificultando deste modo a recuperação do registro da componente de cisalhamento puro.

Durante a atuação da componente de cisalhamento simples, foram geradas estruturas secundárias de Riedel, como dobras escalonadas, falhas sintéticas e antitéticas, fraturas $R, T$, 
X (Fiori, 1985a; Fassbinder, 1990, 1994b). Exemplos de dobras escalonadas são as antiformas do Cerne, Caetê, Rio Abaixo, Anta Gorda, Núcleo Betara, entre outros; e falhas sintéticas do Ribeira e do Cerne. Durante a atuação desta componente foram alojados corpos graníticos em dobras escalonadas (Fiori, 1985d), ou segundo um mecanismo transpressional/transtracional (Hackspacher, 1996).

Ambas as componentes que derivam da partição da deformação, formam dobras por processos de cisalhamento simples segundo o conceito de Ramsay (1980). Tais dobras não apresentam continuidade lateral (dobras sem raiz - rootless folds - e escalonadas). As dobras escalonadas dispõem-se ao longo dos lineamentos, tendendo a desaparecer lateralmente.

No final do ciclo da deformação ocorreu um evento transtrativo (transtração), que foi acompanhado de aumento de volume, o qual se desenvolveu no campo rúptil/dúctil da deformação. Os espaços formados neste evento foram, em parte, preenchidos por magma granítico, resultando os complexos Três Córregos e Cunhaporanga (?). Posteriormente, ocorre um novo evento transpressivo, ainda num campo rúptil/dúctil da deformação, com partição da deformação. A componente de cisalhamento simples reativou os atuais lineamentos da Lancinha, Morro Agudo, Itapirapuã, do Ribeira, entre outros, e deformado as bordas do Complexo Três Córregos, gerando protomilonitos a ultramilonitos.

E a segunda componente da partição, de cisalhamento puro, promoveu a instalação de uma estrutura-em-flor positiva. No centro desta estrutura foram alçados, com maior intensidade, o Complexo Três Córregos e a Formação Água Clara. Lateralmente, com intensidade média, foi também alçada a Formação Votuverava, na porção sudeste da estrutura. Para as bordas da estrutura-em-flor, a sudeste e noroeste, com intensidade mais baixa, aparem às Formações Capirú e Itaiacoca, respectivamente.

Este último evento transpressivo teria promovido a movimentação subvertical de grandes blocos tectônicos, porém sem ocasionar a inversão de camadas (meta)sedimentares. Deste modo, ocorreu uma superposição cinemática de estruturas dúcteis, geradas no primeiro evento transpressivo, por dúcteis/rúpteis.

Nesta estrutura transpressional, acham-se expostas as rochas graníticas, com textura inequigranular grosseira e porfirítica, as Formações Água Clara, Votuverava e Capirú, estas últimas sucessivamente mais afastadas de parte central da estrutura. O predomínio de mergulhos para noroeste das foliações e das principais falhas da estrutura-em-flor, levou 
Campanha (1991) a realizar um empilhamento invertido das unidades, com o topo a noroeste, e a base para sudeste, com a seguinte estratigrafia: o Grupo (ou Formação) Itaiacoca no topo, seguido pela Formação Água Clara, Votuverava, Capirú e o Grupo Setuva, na base. Porém, os dados de isótopos e os argumentos apresentados anteriormente, sugerem, que a Formação Água Clara ocorre na base do Grupo Açungui, seguido da Formação Votuverava, e no topo, as Formações Capirú e Itaiacoca. 


\section{CONCLUSÕES}

1. As litologias organizadas em torno de 40 colunas estratigráficas do pré-cambriano dos Estados do Paraná e sul de São Paulo, podem ser agrupadas em torno de termos consagrados na literatura, como Embasamento Cristalino, Complexo Pré-Setuva, e dos Grupos Setuva e Açungui.

2. As Formações Água Clara, Votuverava e Capirú estão estruturalmente organizadas por componentes da deformação que sofreram partição: Falhas de baixo ângulo (cisalhamento puro) e, transcorrências (cisalhamento simples), geradas num ambiente de transpressão.

3. No ambiente transpressivo, que deformou, pelo menos, o sul do Cinturão Ribeira, houve predomínio do cisalhamento puro, tendo esta componente se desenvolvido inicialmente. Com a evolução da convergência obliqua, ocorreu a partição da deformação, ocasião em que passaram a se desenvolver, de forma contemporânea, estruturas perpendiculares (empurrões) e paralelas (transcorrências) às margens transpressionais.

4. O registro de estruturas de baixo ângulo ficou bem preservada da ação deformadora da componente de cisalhamento simples, em litologias da Formação Água Clara, aflorantes na região de São Pedro/São Silvestre. Esta última componente é mais intensa nas Formações Votuverava e Capirú.

5. A componente de cisalhamento puro desenvolveu os sistemas de deformação $\mathrm{SD}_{1}, \mathrm{SD}_{2}, \mathrm{SD}_{3}$, durante o mesmo evento metamórfico, traduzindo assim, uma clara superposição cinemática.

6. No sistema de deformação $\mathrm{SD}_{1}$ foram desenvolvidas as foliações $\mathrm{Ss}_{1} \mathrm{e} \mathrm{Sc}_{1}$, dobras cerradas a isoclinais, lineações mineral e de estiramento mineral, assim como de intersecção ( $\mathrm{Li} \underset{S c}{S s}$ ). Este sistema foi gerado por cisalhamento, em condições dúcteis, constituindo-se no evento mais penetrativo nas Formações Água Clara, Votuverava e Capirú. O transporte tectônico deste sistema de deformação é para S-SE.

7. No sistema $\mathrm{SD}_{2}$ foram desenvolvidas as foliações $\mathrm{Ss}_{2}$ e $\mathrm{Sc}_{2}$, com redobramento da foliação $\mathrm{Ss}_{1}$, e transporte tectônico para norte. A implantação desta nova trama estrutural seguiu os 
planos de fraqueza da foliação anterior $\left(\mathrm{Sc}_{1}\right)$, constituindo-se numa reativação da matriz estrutural pré-existente.

8. Seguiu-se um novo evento deformativo, com a instalação do sistema $\mathrm{SD}_{3}$, composto por uma foliação $\mathrm{Sc}_{3}$, disposta com ângulo de $30-40^{\circ}$ em relação às foliações anteriores, $\mathrm{Sc}_{1} \mathrm{e} \mathrm{Sc}_{2}$, gerando localmente uma foliação $\mathrm{Ss}_{3}$.

9. Posteriormente, porém em continuidade a deformação $\mathrm{SD}_{3}$, ocorreu um período transtrativo, durante o qual foram alojados corpos graníticos associados ao Complexo Três Córregos e, possivelmente, ao Complexo Cunhaporanga.

10. Nova fase de convergência (transpressão) foi instalada, a qual foi acompanhada por uma segunda partição da deformação, em resposta a um rearranjo das placas em colisão obliqua.

11. A componente de cisalhamento puro foi responsável pela formação de estrutura-em-flor positiva, no campo rúptil/dúctil da deformação. Em consequência disso, diversos blocos tectônicos foram alçados ao longo desta estrutura, sendo com maior intensidade no centro da mesma, com decréscimo em direção às bordas. Esta deformação expôs, com inversão, os diferentes níveis estratigráficos da coluna original do Grupo Açungui. Nesta fase, aparentemente, não ocorreu inversão estratigráfica das camadas metassedimentares.

No centro da estrutura foram alçados o Complexo Três Córregos e a Formação Água Clara, este último nas bordas do primeiro; numa posição intermediária, na aba sudeste da estrutura, aparece a Formação Votuverava, sendo suas bordas ocupadas pelas Formações Capirú, a sudeste, e Itaiacoca, a noroeste. A disposição horizontal, simétrica das unidades geológicas em torno do centro da estrutura-em-flor, mostra o registro de uma transição deformacional e metamórfica pretérita, vertical.

12. A componente de cisalhamento simples promoveu a deformação da borda do Complexo Três Córregos, com a formação de protomilonitos, milonitos e ultramilonitos. Nesta fase, ocorreu a instalação da atual trama de falhas transcorrentes, a exemplo das Falhas da Lancinha, Morro Agudo, Itapirapuã, Ribeira, Cerne e Figueira, entre outras. 
13. A coluna sedimentar original do Grupo Açungui tem, na base, a Formação Água Clara, seguida pela Formações Votuverava, e no topo, Capirú e Itaiacoca. Isótopos de ${ }^{18} \mathrm{O}$ indicam que a sedimentação da Formação Água Clara é mais jovem do que $1.3 \mathrm{Ga}$, a Formação Votuverava com idades em torno de $0.90 \mathrm{Ga}$, enquanto as Formações Capirú/Itaiacoca sugerem idades mais antigas do que $0.70 \mathrm{Ga}$. Caso estas diferenças de idades venham a ser confirmadas pelos futuros estudos geocronológicos, isto implicaria na existência de bacias superpostas (Água Clara, Votuverava, Capirú/Itaiacoca.

14. Finalmente, considera-se que a Formação Água Clara ocupa a base do Grupo Açungui. Esta formação apresenta metamorfismo e deformação progressiva mais intensos do que as demais formações, referidas como Formações Votuverava, Capirú/Itaiacoca. Estas formações foram posteriormente seccionadas pela estrutura-em-flor. Estas unidades apresentam estruturas tectônicas equivalentes, diferindo apenas por serem melhor desenvolvidas na Formação Água Clara. 


\section{GLOSSÁRIO}

\subsection{FASE DE DEFORMAÇÃo}

Designa um evento único, penetrativo e característico dentro da evolução estrutural de uma determinada área (Fiori, 1990).

\subsection{SISTEMA DE DEFORMAÇÃO}

Esta designação abriga todas as estruturas formadas num mesmo regime tectônico, compreendendo diversas estruturas planares e lineares, dobras e falhas em diversas escalas, desenvolvidas contemporaneamente ou quase. Algumas dessas estruturas nem sempre são penetrativas na área, podendo ocorrer de forma localizada, ora associada a alguma estrutura maior, ora representando anomalias do desenvolvimento estrutural regional.

Esse conceito apresenta um significado mais amplo comparado a definição de "fase de deformação" (Fiori, 1990).

\subsection{SUPERPOSIÇÃO CINEMÁTICA}

É utilizado neste trabalho, quando ocorre superposição de estruturas geradas pela mudança de vetores cinemáticos com orientações distintas, de forma análoga como aplicado por Machado \& Endo (1994). 


\section{REFERÊNCIAS BIBLIOGRÁFICAS}

Algarte, J.P. et al. (1974) Projeto sudeste do Estado de São Paulo. São Paulo, Convênio DNPM/CPRM, relatório final.

ALMEIDA, F.F.M. (1944) Collenia itapevensis sp, um fóssil Pré-Cambriano no Estado de São Paulo. Boletim de geologia da Faculdade de Filosofia, Ciências e Letras da USP, 45(1):89-106.

ALMEIDA, F.F.M. (1956) Novas ocorrências de fósseis no pré-cambriano Brasileiro. Anais da Academia Brasileira de Ciências, 28(4):XLIV-XIV (Resumo de Comunicações).

ALMEIDA, F.F.M. (1957) Novas ocorrências de fósseis no Pré-Cambriano brasileiro. Anais da Academia Brasileira de Ciências, 29(1):63-72.

ALMEIDA, F.F.M. de (1967) Origem e evolução da Plataforma Brasileira. Boletim da Div. Geol. Min., DNPM, (Rio de Janeiro), $\mathbf{n}^{\circ} 241$.

ALMEIDA, F.F.M. \& HASUI, Y. (1984) O Pré-Cambriano do Brasil. São Paulo, Edgard Blücher, 378p.

ALMEIDA, F.F.M.; HASUI, Y.; NEVES, B.B.B. (1976) The Upper Precambrian of South America. Boletim IG-USP 7:45-80.

ALMEIDA, M.A. (1990) Geologia da Formação Água Clara na Região de Araçába-SP. São Paulo, Universidade de São Paulo, 184p. (Dissertação de Mestrado-Instituto de Geociências/USP).

ALMEIDA, M.A. (1993) Uma megaestrutura S-C na Formação Água Clara, região de Araçaiba,SP. In: SIMPÓSIO SUL BRASILEIRO DE GEOLOGIA, 4, Curitiba, 1993. Atas... Curitiba, SBG v.1, p.15.

ALTHOFF, F.J. (1989) Geologia Estrutural da Antiforma do Setuva - Pr. Belém, Universidade Federal do Pará, 147p. (Dissertação de Mestrado - Univ. F. do Pará).

BARboSA, O. (1941) Geologia e Petrologia na Região de Apiaí, Estado de São Paulo. São Paulo, Universidade de São Paulo, 76p. (Tese para concurso da cadeira de Geologia, Petrografia e Mineralogia - Escola Politécnica/ USP).

BARBOSA, O. (1948) A chamada Série Ribeira. Min.Metal., São Paulo, 13(75): 187-189.

BATOLlA Jr, F; SILVA, A.T.S.T.; ALGARTE, J.P. (1981) O Pré-Cambriano da Região SulSudeste do Estado de São Paulo e Este-Nordeste do Estado do Paraná. In: SIMPÓSIO REGIONAL DE GEOLOGIA, 3, Curitiba, 1981. Atas... Curitiba, SBG v.1, p.94-108.

BELL, T.H. (1978) Progressive deformation and reorientation of fold axes in a ductile mylonite zone: the Woodroff Thrust. Tectonophysics, 44:285-320. 
BELL, T.H. (1985) Deformation partitioning and porphyroblast rotation in metamorphic rocks: a radical re-interpretation. J. Metamorphic Geol., 3, p. 109-118.

BELL, T.H. \& ETHERIDGE, M.A.(1973) Microstructure of mylonites and their descriptive terminology. Lithos, 6:337-348.

BELL, T.H. \& HAMMOND, R.L. (1984) On the internal geometry of mylonites zones. J. Geology, 92:667-86.

BELL, T.H. \& JOHNSON, S.E. (1992) Shear sense: a new approach that resolves conflicts between criteria in metamorphic rocks. J. Metamorphic Geol., 10:99-124.

BELL, T.H; JOHNSON, S.E.; DAVIS, B.; FORDE, A.; HAYWARD, N.; WILKINS, C. (1992) Porphyroblast inclusion-trail orientation data: eppure non son girate. $\mathbf{J}$. Metamorphic Geol., 10:295-307.

BERTHÉ, D. \& BRUN, J.P. (1980) Evolution of folds during progressive shear in the South Armonican Shear Zone, France. J. Struct. Geol., 2:127-134.

BERTHÉ, D.; CHOUKROUNE, P.; GAPAIS, D. (1979) Ortho-gneiss, mylonite and non-coaxial deformation of granites: the exemple of the South Armorican Shear Zone. Jl. Struct. Geol., 1:31-42.

BLUMENFELD, P. \& BOUCHEZ, J.L. (1988) Shear criteria in granite and migmatite deformed in the magmatic and solid states. J. Struct. Geology., 10:361-372.

BIGARELLA, J.J. (1947) Estudos preliminares na Série Açungui. 1: Brecha Calcária de Toquinhos. Arq. Biol. Tecnol., IBPT Curitiba, 2:41-61.

BIGARELLA, J.J. \& SALAMUNI, R. (1956) Estudo preliminar da Série Açungui.

Estruturas Organógenas nos dolomitos da Formação Capirú (Pr). Dusenia, 7(6):317-332.

BIGARELLA, J.J. \& SALAMUNI, R. (1958) Estudos preliminares da Série Açungui. VIII: A Formação Votuverava. Bol. Inst. Hist. Nat. Geol., 6p, Ctba-Pr.

BIGARELLA, J.J. \& SALAMUNI, R. (1967) Geologia do Pré-Devoniano e Intrusivas Subsequentes da Porção Oriental do Estado do Paraná. Boletim Paranaense de Geociências, 23 a 25.

BIONDI, J.C. (1983) Mapa Geológico da área do embasamento do Estado do Paraná, escala 1:250.000. Mineropar, Curitiba-Pr.

BIONDI, J.C.; CAVA, L.T.; SOARES, P.C. (1989) Mapa Geológico do Estado do Paraná, escala 1:650.000, Mineropar, Curitiba-PR.

BJORNERUD, M. (1990) Toward a unified conceptual framework for shear-sense indicators. Jl. Structural Geology, Vol. 11, $n^{\circ}$ 8, p.1045-1049. 
BOUCHEZ, J.L.: LISTER, G.S.; NICOLAS, A. (1983) Fabric Asymmetry and Shear sense in movement zones. Geol. Rundschau, 72:401-419.

BOULLIER, A.M.(1986) Sense of shear and displacement estimates in the Abeibara-Rarhous late Pan-African shear zone, Adrar des Ifora, Mali. J. Struct. Geol., 8:47-58.

BOUMA, A.H. (1962) Sedimentology of some flysch deposits.Amsterdam, Elsevier, 168p.

BOYER, S.E. (1986) Styles of folding within thrust sheets; examples from the Appalachian and Rocky Mountains of the USA and Canadá. J. Struct. Geol., 8:325-339.

BOYER, S.E. \& ELLIOT, D. (1982) Thrust Systems. Am. Assoc. Petrol. Geol. Bull, 66:1196-1230.

BRYANT, E. \& REED JR, J.C. (1969) Significance of lineation and minor folds near major thrust faults in the Southen Appalachians and the British and Norwegian Caledonides. Geol. Mag., 106:412-429.

BRUNEL, M.(1986) Ductile in the Himalayas: shear sense criteria and stretching lineations. Tectonics, 5:247-265.

BURG, J.P. \& LAURENT, ph (1978) Strain Analysis of a shear zone in a Granodiorite. Tectonophysics, 47:15-42.

BURG, J.P.; BALE, P.; BRUN, J.P.; GIRARDEAU, J. (1987) Stretching lineations and transport directions in the Ibero-Armorican arc during Siluro-Devonian collision. Geodinamica Acta, 1:71-87.

BUTLER, R.W.H. (1982) The terminology in thrust zones. J. Struct. Geol., 4:239-245.

CAMPANHA, G.A.C. (1980) O lineamento de Além Paraíba na Área de Três Rios-RJ. São Paulo, Universidade de São Paulo, 109 p. (Dissertação de Mestrado - Instituto de Geociências/USP).

CAMPanha, G.A.C. (1991) Tectônica Proterozóica no Alto e Médio Vale do Ribeira, Estados de São Paulo e Paraná. São Paulo, Universidade de São Paulo, 296p. (Tese de Doutoramento - Instituto de Geociências/USP)., 2 volumes.

CAMPANHA, G.A.C.; BISTRICHI, C.A.; ALMEIDA, M.A. (1987) Considerações sobre a organização litoestratigráfica e evolução tectônica da faixa de dobramentos Apiai. In: SIMP.SUL BRAS.GEOL.,3,Curitiba,1987. Atas... Curitiba, SBG v.2, p.725-742.

CAMPANHA, G.A.C.; ESCUDERO, O.B.; SADOWSKI, G.R. (1993) Análise da Geometria e Cinemática da Zona de Cisalhamento do Lineamento Ribeira, SP e PR. In: SIMPÓSIO NACIONAL DE ESTUDOS TECTÔNICOS, 4, Belo Horizonte, 1993. Atas... Belo Horizonte, SBG Bol. 12, p.347-351. 
CAMPANHA, G.A.C. et al. (1985) Geologia das folhas Iporanga (SG.22-X-B-V-2) e Gruta do Diabo (SG.22-X-B-VI-1), Estado de São Paulo. São Paulo, Contrato IPT/Pró-Minério (IPT, Relatório 22.352, inédito).

CAMPANHA, G.A.C.; GIMENEZ FILHO, A.; CAETANO, S.L.V.; PIRES, F.A.; DANTAS, A.S.L.; TEIXEIRA, A.L.; DEHIRA, L.K.; (1986) Geologia e estratigrafia da região das folhas Iporanga e Gruta do Diabo, Vale do Ribeira, São Paulo. In: CONGRESSO BRASILEIRO DE GEOLOGIA, 34, Goiânia, 1986.Anais...Goiânia, SBG v.2, p. 1058-1073.

CAMPOS, J.M. (1937) Estudos petrográficos de algumas rochas da Série Açungui no Estado do Paraná. Boletim do DNPM (Serviço Geológico e Mineralógico do Brasil), 71:27-29.

CAMPOS NETO, M. da C. (1983a) Contribuição à litoestratigrafia do Grupo Açungui no sudeste do Estado de São Paulo. In: SIMP. REGIONAL DE GEOLOGIA, 4, São Paulo, 1983. Atas... São Paulo, SBG v.1, p.103-112.

CAMPOS NETO, M. da C. (1983b) Os gnaisses do Alto Rio Jacupiranguinha e os xistos Cajati: relações estruturais e estratigráficas. In: SIMP. REGIONAL de GEOLOGIA, 4, São Paulo, 1983. Atas... São Paulo, SBG v. 1, p.91-102.

CAMPOS NETO, M. da C. (1993) Contribuição à litoestratigrafia do Grupo Açungui no sudeste do Estado de São Paulo. In: CONGR. REG. GEOL., 4, São Paulo, 1983. Atas... São Paulo, SBG, p. 103-112.

CARVALHO, P.F. \& PINTO, E.A. (1937) Reconhecimento Geológico na Série Açungui. Bol. DNPM, Div. Geol. Min., (71):29p.

CHEENY,R.F.(1983)Statistical methods in Geology.London,Georg Allen \& Unwin,169p.

CHEMALE JR., F.; HARTMANN, L.A.; SILVA, L.C. (1994) Tectonic evolution of southern Brasil in the Brasiliano Cycle. In: CONGR. BRAS. GEOLOGIA, 38, Camboriú, 1994. Bol. de Resumos Expandidos... Camboriú, SBG v.1, p. 626-627.

CHIODI FILHO, C. et al. (1982) Geologia e mineralizações da região que abrange as minas do Rocha, Paqueiro e Barrinha, Vale do Ribeira, PR e SP. In: CONGR.BRAS.GEOL., 32, Salvador, 1982. Anais...Salvador, SBG v.3, p.1037-1049.

CHIODI FILHO, C. (1984) Contribuição à geologia das regiões sul paulista e leste paranaense Grupos Açungui e Setuva. In: CONGRESSO BRASILEIRO de GEOLOGIA,33, Rio de Janeiro, 1984. Anais...Rio de Janeiro, SBG v.5, p.2394-2406.

CHOUKROUNE, P.; GAPAIS, D.; MERLE, O. (1987) Shear criteria and structural symmetry. Jl. Struct. Geol., 9:525-530.

COBBOLD, P.R. \& QUINQUIS, H. (1980) Development of shear folds in shear regimes. J. Struct. Geol., 2:119-126.

COBBOLD, P.R. \& GAPAIS, D. (1987) Shear criteria in rocks: an introductory review. J. Struct. Geol., 9:52l-523. 
COBBOLD, P.R.; GAPAIS, D.; MEANS, W.D.; TREAGUS, S.H. (Eds) (1987) Shear criteria in rocks. J. Struct. Geol. (Sp. Issue) (9):521-778.

COOK, H.E \& MULLINS, H.T. (1983) Basin Margin Environment. In: SCHOLLE, P.A.; BEBOUT, D.G.; MOORE, C.H. ed. Carbonate Depositional Environments. Oklahoma, Am. Assoc. of Petroleum Geologists, Memoir, 33, p.539-618.

CORDANI, V.G. \& KAWASHITA, K. (1971) Estudo geocronológico pelo método Rb-Sr de rochas graníticas intrusivas no Grupo Açungui. In: CONGR.BRAS.GEOL., 25, São Paulo, 1971. Anais... São Paulo, SBG v.1, p.105-110.

CORDANI, U.G.; MELCHER, G.C.; ALMEIDA, F.F.M. (1968) Outline of the Precambrian geochronology of South America. Canadian Journal of Earth Sciences, 5:629-632.

CORDANI, U.G.; TEIXEIRA, W.; TASSINARI, C.C.G; KAWASHITA, K.; SATO, K. (1988) The growth of the Brazilian shield. Episodes, 11:163-167.

COWARD, M.P. (1980) Shear Zones in the Precambrian Crust of Southern Africa. J. Struct. Geology, 2:19-27.

CRAIG, H. (1953) The geochemistry of the stable carbon isotopes. Geochim. Cosmochim. Acta, 3:53-92.

CRAIG, H. (1961) Isotopic variations in meteoric waters. Science, 133:1702-1703.

DAHLSTROM, C.D.A. (1970) Structural geology in the eastern margin of the Canadian Rocky Mountains. Bul. Canadian Petroleum Geol., 18:332-406.

DAVIS, G.H.(1984) Structural geology of rocks and regions. New York, J.Wiley, 492p.

DENNIS, A.J. \& SECOR, D.T. (1990) On resolving shear direction in foliated rocks deformed by simple shear. Geol. Soc. Am. Bull., 102:1257-67.

DERBY, O. (1878) Geologia da Região Diamantífera da Província do Paraná do Brasil. Arquivo do Museu Nacional, 3:89-96.

DEWEY, J.F. \& BIRD, J.M. (1970) Mountain belts and the new global tectonics. Journal of Geophysical Research, 75(14):2.625-2.647.

DIAS, M.V.F. \& SALAZAR JR, O. (1983) Geologia e potencialidades econômicas da Sequência Antinha. Curitiba, Mineropar, Secretaria da Industria e Comércio do Paraná (Relatório Interno).

DIAS, M.V.F. \& SALAZAR JR, O. (1987) Geologia da Sequência Antinha - Grupo Açungui, PR. In: SIMP. SUL BRAS. GEOL., 3, Curitiba, 1987. Atas...Curitiba,SBG v.1, p.263-279.

EBERT, H. (1962) Baustil und regional metamorphose in präkambrischen Grundgebirge Brasiliens. Mineral. Petrog. Mitt., 8:49-81. 
EBERT, H. (1971) Observações sobre a litologia e subdivisão do "Grupo Setuva" no Estado do Paraná. In: CONGR.BRAS.GEOL., 25, São Paulo, 1971. Anais... São Paulo, SBG v.1, p.131-165.

EBERT, H.D. \& HASUI, H. (1989) Tectônica transpressiva no sub bloco Tunas, Vale do Ribeira-PR. In: SIMP. GEOL. NORDESTE, 13, Fortaleza, 1989. Atas...Fortaleza, SBG v.11, p.255-257.

EBERT, H.D. \& MÜLLER, G. (1989) Dados petrológicos e litogeoquímicos dos metamorfitos da região da Mina do Perau no Vale do Ribeira, Paraná. In: SIMPÓSIO de GEOLOGIA do SUDESTE, 1, Rio de Janeiro, 1989. Boletim de Resumos... Rio de Janeiro, SBG, p. 124-125.

EBERT, H.D.; HASUI, Y.; QUADE, H. (1988) Aspectos da evolução estrutural do Cinturão Móvel Costeiro na região da Mina do Perau, Vale do Ribeira. In: CONGR.BRAS.GEOL., 35, Belém, 1988. Atas... Belém, SBG v.5, p.2318-2331.

EBERT, H.D.; HASUI, Y; SENA COSTA, J.B. (1991) O carater transpressivo do cinturão transcorrente Rio Paraíba do Sul. In: SIMP. NAC. EST. TECTÔNICOS, 3, Rio Claro, 1991. Atas... Rio Claro, SBG, p.139-141.

EBERT, H.D.; NEVES, M.A.; HASUI, Y.; SZATMARI, P.; AIRES, J.R. (1993) Evolução dos Cinturões de Cisalhamento entre os Blocos São Paulo, Vitória e Brasilia através da Tectônica Colisional Oblíqua: uma modelagem fisica. In: SIMPÓSIO NACIONAL de ESTUDOS TECTÔNICOS, 4, Belo Horizonte, 1993. Atas... Belo Horizonte, SBG Bol. 12, p.254-268.

EBERT, H.D.; ARTUR, A.C.; CHEMALE JR., F.; BABINSKY, M.; VAN SCHMUS, W.R. (1994) Regimes tectônicos e idades U/Pb em zircão do Complexo Socorro no contexto da Faixa Ribeira: um exemplo de magmatismo transpressivo. In: CONGR.BRAS.GEOL., 38, São Paulo, 1994. Boletim de Resumos Expandidos... Camboriú, SBG v.1, p.260-261.

ELLIS, M. \& WATKINSON, A.J. (1987) Orogen-parallel extension and oblique tectonics: the relation between stretching lineations and plate motions. Geology, 15:1022-1026.

ENDO, I. \& MACHADO, R. (1993) Sistema de cisalhamento Transatlântico: um modelo tectônico transpressional para o Neoproterozóico do Brasil oriental. In: SIMP. NACIONAL de ESTUDOS TECTÔNICOS, 4, Belo Horizonte, 1993. Atas... Belo Horizonte, SBG Bol. 12, p.356-359.

EOROLA, T.T. (1994) Proterozoic to eo-paleozoic supracrustal sequences of the Rio Grande do Sul Shield and contemporaneous glaciogenic record of the SW Africa: possible tectonic, paleogeographic and paleoclimatic implications. In: CONGR.BRAS.GEOL., 38, Camboriú, 1994. Boletim de Resumos Expandidos... Camboriú, SBG v. l, p.624-625.

EPSTEIN, S. \& MAYEDA, T.K. (1953) Variations of the ${ }^{18} \mathrm{O} /{ }^{16} \mathrm{O}$ rations in natural waters. Geochim. Cosmochim. Acta, 4:213-224. 
ETHERIDGE, M.A.; RUTLAND, R.W.R.; WYBORN, L.A.I. (1987) Orogenesis and tectonic process in the Early to Middle Proterozoic of Northern Australia. In: KRÖNER, A. (ed.) Proterozoic lithospheric evolution. Boulder, American Geophysical Union, p.131-147. (Geodynamics Séries, 17).

FASSBINDER,E. (1990) Análise Estrutural da Falha da Lancinha no Estado do Paraná. São Paulo, Universidade de São Paulo, 165p. (Dissertação de Mestrado - Instituto de Geociências/USP).

FASSBINDER, E.; FUMAGALLI, E.; FIORI, A.P. (1985) Estudo preliminar sobre lineamentos tectônicos, intrusões e possíveis mineralizações associadas no Pré-Cambriano Paranaense. In: SIMP. SUL BRAS. GEOL., 2, Florianópolis, 1985. Atas... Florianópolis, SBG v.1., p.172-183.

FASSBINDER,E.; MACHADO, R.; FIORI, A.P. (1993) A unidade Água Clara e o Grupo Açungui no Estado do Paraná: possibilidades de Correlação. In: SIMP. SUL BRAS. GEOL., 5, Curitiba, 1993. Boletim de Resumos... Curitiba, SBG, p.11.

FASSBINDER, E.; MACHADO, R.; FIORI, A.P. (1994a) Evolução estrutural e cinemática da unidade Água Clara, no Estado do Paraná. In: CONGR. BRAS. GEOL., Camboriú, 1994. Boletim de Resumos Expandidos... Camboriú, SBG v.2, p.265-266.

FASSBINDER, E.; SADOWSKI, J.R.; FIORI, A.P. (1992) Análise Estrutural da Falha da Lancinha no Estado do Paraná. In: CONGR. BRAS. GEOL., 37, São Paulo, 1992. Boletim de Resumos Expandidos... São Paulo, SBG v.2, p.362.

FASSBINDER, E.; SADOWSKI, J.R; FIORI, A.P. (1994b) Modelo de Riedel aplicado no Lineamento Lancinha, no Estado do Paraná. Boletim Paranaense de Geociências, núm. 42, p.173-184.

FERREIRA, E.O. (1972) Nota explicativa da carta tectônica do Brasil. Boletim do Dep. Nac. Prod. Min, 1. Rio de Janeiro.

FIGUEIREDO, A.M. de \& RAJA GABAGLIA, G.P.(1986) Sistema classificatório aplicado às bacias sedimentares brasileiras. RBG, Vol. 16, núm. 4, p. 350-369.

FIORI, A.P. (1985a) As Falhas da Lancinha e de Morro Agudo e Estruturas Secundárias associadas. In: SIMP. SUL BRAS. GEOL., 2, Florianópolis, 1985. Atas... Florianó-polis, SBG v.1, p.146-158.

FIORI, A.P. (1985b) A Falha da Lancinha no Pré-Cambriano Paranaense: reflexo de uma falha profunda? Bol. Paranaense de Geociências, 36:3-14.

FIORI, A.P. (1985c) Avaliação preliminar do deslocamento dúctil das Falhas da Lancinha e de Morro Agudo no Estado do Paraná. Bol. Paranaense de Geociências, 36:15-30.

FIORI, A.P.(1985d) Aplicação do modelo de cisalhamento simples na análise da deformação dúctil de alguns granitos Paranaenses. Bol.Paran.Geociências, 36:31-40. 
FIORI, A.P. (1989) Mapa Geológico-Estrutural da Região de Rio Branco do Sul. Curitiba, Convênio UFPR-MINEROPAR, escala 1:100.000 (inédito).

FIORI, A.P. (1990) Tectônica e Estratigrafia do Grupo Açungui à norte de Curitiba. São Paulo, Universidade de São Paulo, 261p. (Tese de Livre Docência - Instituto de Geociências/USP)

FIORI, A.P. (1992a) Tectônica e Estratigrafia do Grupo Açungui, PR. Boletim IG-USP, Série Científica, 23:55-74.

FIORI, A.P. (1992b) O Grupo Açungui a norte de Curitiba. In: CONGR. BRAS. GEOL., 37,São Paulo, 1992. Boletim de Resumos Expandidos...São Paulo, SBG v.1, p.279.

FIORI, A.P. (1993a) O Sistema de cavalgamento Açungui (PR). Geociências, São Paulo, 12(1):187-208.

FIORI, A.P. (1993b) O Sistema de dobramentos Apiaí, Estado do Paraná. Revista Brasileira de Geociências, 23(1):5-17.

FIORI, A.P. (1996) Introdução à análise da deformação. Curitiba, Editora da UFPr, 300p. (no prelo).

FIORI, A.P. \& GASPAR, L.A. (1993) Considerações sobre a estratigrafia no Grupo Açungui (Proterozóico Superior), Paraná, Sul do Brasil. Boletim IG-USP, Série Científica,24:1-19.

FIORI, A.P.; FASSBINDER, E.; GÓIS, J.R.; FUMAGALLI, C.E. (1987a) Compartimen-tação tectônica do Grupo Açungui à norte de Curitiba. In: SIMP. SUL BRAS. GEOL. 3, Curitiba, 1987. Atas...Curitiba, SBG v.1, p.183-196.

FIORI, A.P.; FUMAGALLI, C.E.; GÓIS, J.R; SALAMUNI, E. (1987b) As principais estruturas dobradas do Grupo Açungui na região de Rio Branco do Sul - Bocaiúva do Sul. In: SIMP. SUL BRAS. GEOL., 3, Curitiba, 1987. Atas... Curitiba, SBG v.1, p.281-301.

FIORI, A.P.; SALAMUNI, E.; FASSBINDER, E. (1987c) Geologia da Região de BateiasBocaiúva do Sul. In: SIMP.SUL BRAS.GEOL., 3, Curitiba, 1987. Atas... Curitiba, SBG v. 2, p. $773-787$.

FIORI, A.P.; CAMARGO, E.C.; MONASTIER, M.S.; LIMA, R.E.; FUMAGALLI, C.E.; SALAMUNI, E; FASSBINDER,E; GÓIS, J.R. (1984) Lineamentos Tectônicos e Possíveis Mineralizações Associadas no Pré-Cambriano Paranaense. Curitiba (PR), Convênio UFPR-MINEROPAR, Vol. 1 (Texto Final) (Anexos: Mapa de Lineamentos Tectônicos do Pré-Cambriano Paranaense, escalas 1:250.000 e 1:500.000), 26lp.

FLINN, D. (1962) On folding during three dimensional progressive deformation. Quart. J. Geol. Soc., 118:385-433.

FOSSEN, H. \& TIKOFF, B. (1993) The deformation matriz for simultaneous simple shearing, pure shearing and volume change, and its applications to transpression-transtension tectonics. Jl. Struct. Geol., 15(3-5):413-422. 
FRAGOSO CESAR, A.R.S. (1993) As Placas Brasilianas do Sul e Sudeste da Plataforma SulAmericana. In: SIMP. NACIONAL de ESTUDOS TECTÔNICOS, 4, Belo Horizonte, 1993. Atas... Belo Horizonte, SBG Bol. 12, p. 183-188.

FRAGOSO CESAR, A.R.S. (1996) The Neoproterozoic Brazilides collage in the southern south American Plataform. In: CONGRESSO BRAS. GEOLOGIA, 39, Salvador, 1996. Resumos Expandidos... Salvador, SBG v.6, p.9-10.

FRASCÁ, M.H.B. de (1992) Petrografia e Geoquímica de rochas carbonáticas précambrianas do Estado de São Paulo. São Paulo, Universidade de São Paulo, 168p. (Dissertação de Mestrado - Instituto de Geociências/USP).

FRITZSONS JR., O.; PIEKARZ, G.F.; FALCADE, D. (1982) Geologia e potencial econômico do Grupo Setuva(PR). In: CONGRESSO BRAS, GEOL., 32, Salvador, 1982. Anais... Salvador, SBG v.3, p.987-1001.

FUCK, R.A.: TREIN, E.; MARINI, O.J. (1971) Geologia do Leste Parananese.In: CONGR.BRAS.GEOL.,25,São Paulo,1971. Anais... São Paulo, SBG v.1, p.121-130.

GHOSH, S.K.; SENGUPTA, S. (1984) Sucessive development of plane noncylindrical folds in progressive deformation. J. Struct. Geol., 6:703-709.

GIMENEZ FILHO, A. (1993) Evolução da Complexo Granítico Três Córregos a noroeste de Apiaí - SP. São Paulo, Universidade de São Paulo, 118p. (Dissertação de Mestrado Instituto de Geociências/USP).

GÓIS, J.R; SALAMUNI, E; FIORI, A.P. (1985) Lineamentos e Compartimentos Tectônicos do Pré-Cambriano Paranaense. In: SIMP. SUL BRAS. GEOL., 2, Florianópolis, 1985. Atas... Florianópolis, SBG v.1, p.159-171.

GOLDSTEIN, A.G. (1988) Factors affecting the kinematic interpretation of asymmetric boudinage in shear zones. J. Struct. Geol., 10:707-715.

HACKSPACHER, P.C. (1996) Tectônica Transtensiva/Transpressiva e alojamento de rochas plutônicas, à exemplo da Folha Cabreúva (SP) 1:50.000. Rio Claro, Universidade Estadual Paulista, 203p. (Tese de Livre Docência - Instituto de Geociências e Ciências Exatas/UNESP).

HANMER, S. (1986) Asymmetrical pull-apparts and foliation fish as kinematic indicators. J. Struct. Geol., 8:111-122.

HANMER, S. \& PASSCHIER, C.W. (1991) Shear-sense indicators: a review. Geol. Surv. Can. Pap., (90-17):72p.

HARLAND, W.B. (1971) Tectonic transpression in Caledonian spitsbergen. Geol. Mag., 108:27-42.

HARNMER, (1990) Natural rotate inclusions in non-ideal shear. Tectonophysics, 176:245-255. 
HARTMANN, L.A.; CHEMALLE Jr., F.; SILVA, L.C. (1994) Mantle plume tectonics in the Brasiliano cycle of the Dom Feliciano Belt, Southern Brazil. In: CONGR. BRAS. GEOL., 38, Camboriú, 1994. Boletim de Resumos Expandidos... Camboriú, SBG v.1, p.623.

HASUI, Y. (1973) Tectônica da área das folhas de São Roque e Pilar do Sul, São Paulo. São Paulo, Universidade de São Paulo, 190p. (Tese de Livre Docência - Instituto de Geociências/USP).

HASUI, Y. (1975a) Geologia da Folha de São Roque. Bol. IG-USP, 6:157-183.

HASUI, Y. (1975b) Evolução polifásica do pré-Cambriano a oeste de São Paulo. Boletim IGUSP, 6:95-108.

HASUI, Y. (1982) The Mantiqueira Province: Archean structure and proterozoic evolution. Revista Brasileira de Geociências, 12(1-3)167-171.

HASUI, Y. (1986) Novo modelo geológico do Vale do Ribeira. São Paulo, IPT, Relatório núm. 23.742.

HASUI, Y. \& COSTA, J.B.S. (1988) Curso de Zonas e Cinturões de Cisalhamento. Belém, 35 Congresso Brasileiro de Geologia, SBG, 86p.

HASUI, Y. \& MIOTO, J.A. (Coords.) (1992) Geologia Estrutural Aplicada. São Paulo, ABGE/VOTORANTIM, 459p.

HASUI, Y. \& SADOWSKI, G.R. (1976) Evolução geológica do pré-Cambriano na região sudeste do Estado de São Paulo. Rev. Bras. Geoc., 6(3):182-200.

HASUI, Y; ALMEIDA, F.F.M.; BRITO NEVES, B.B. (1978) As estruturas brasilianas. In: CONGR.BRAS.GEOL., 30, Recife. Anais... Recife, SBG v.6, p. 2423-2437.

HASUI, Y; CARNEIRO, C.D.R.; COIMBRA, A.M. (1975) The Ribeira Folded Belt. Revista Brasileira de Geociências, 5(4)257-266.

HASUI, Y.; CREMONINI, O.A.; BORN, H. (1984a) O "Granito Três Córregos" revisado e o maciço Catas Altas. In: CONGR.BRAS.GEOL., 33, Rio de Janeiro, 1984. Anais... Rio de janeiro, SBG V.7, p.3023-3031.

HASUI, Y.; CREMONINI, O.A.; BORN, H. (1984b) Considerações sobre o Grupo Açungui em São Paulo e porção adjacente do Paraná. In: CONGR.BRAS.GEOL., 33, Rio de Janeiro, 1984. Anais... Rio de Janeiro, SBG v.7, p.3297-3306.

HASUI, Y.; HARALY, N.L.E.; MIOTO, J.A.; SAAD, A.R.; CAMPANHA, V.A.; HAMZA, V.M.; GALLI, V.A.; FRANGIPANI,A.; PULEGHINI Filho,P. (1989) Compartimentação estrutural e evolução tectônica do Estado de São Paulo. São Paulo, SCTDE/PróMinério, relatório interno IPT, $\mathrm{n}^{\circ} 27.394$. 
HASUI et al. (1981) O embasamento pré-Cambriano e eopaleozóico em São Paulo. In: ALMEIDA, F.F.M. et al. Ed. Mapa geológico do Estado de São Paulo, escala 1:500.000. São Paulo, IPT, Monografia, 6, Publicação, 1184, v.1, p.12-45.

HASUI et al. (1984c) A parte central da região de dobramento Sudeste e o Maciço Mediano de Guaxupé. In: SCHOBBENHAUS Filho, C. et al. Ed. Geologia do Brasil. Brasília, KKE/DNPM, p.307-329.

HEILBRON, M.; VALERIANO, C.; ALMEIDA, J.C.H.; VALLADARES, C.; TUPINAMBÁ, M. (1994) Segmento central da Faixa Ribeira, exemplo de colisão continental oblíqua no evento termo-tectônico Brasiliano. In: CONGR. BRAS. GEOL., 38, Camboriú, 1994. Boletim de Resumos Expandidos... Camboriú, SBG v. 1, p.263-264.

HIGGINS, M.W. (1971) Cataclastic rocks. Washington, Geological Survey Proffessional Paper $687,97 \mathrm{p}$

HOBBS, B.E.; MEANS, W.D.; WILLIAMS, P.F. (1976) An Outline of Structural Geology. $1^{\circ}$ ed. New York, John Wiley and Sons, 571p.

HUDLESTON, P.J. (1989) The association of folds and veins in shear zones. J. Struct. Geol., 11:949-957.

HUMBERT, L. (1976a) Éléments de pétrologie dynamique des systèmes calcaires. Tome 1: Description macroscopique et microscopique; Diagenèse, Applications. Paris, Technip, $213 \mathrm{p}$.

HUMBERT, L. (1976b) Éléments de pétrologie dybanuqye des systèmes calcaires. Tome 2: Atlas photographique. Paris, Technip.

ILDEFONSE, B.; \& CARON, J.M. (1987) The significance of stretching lineations in terms of progressive deformation and finite strain. Geodinamica Acta, 1:161-170.

INGLES, J. (1983) Theoretical strain patterns in ductile zones simultaneouly undergoing heterogeneous simple shear and bulk shortening. J. Struct. Geol., 5(3/4):369-381.

INSTITUTO DE PESQUISAS TECNOLÓGICAS DO ESTADO DE SÃO PAULO (1982) Modelos metalogenéticos e possibilidades de mineralizações no Pré-Cambriano no Estado de São Paulo. São Paulo, IPT, Relatório n ${ }^{\circ} 17.818$.

JAMISON, W.R.(1992) Stress spaces and stress paths. J. Struct. Geol.,14(10):1111-1120.

KAUFMAN, A.J.; HAYES, J.M.; KNOLL, A.H.; GERMS, G.J.B. (1991) Isotopic compositions of carbonates and organic carbon from Upper Proterozoic sucessions in Namibia: stratigraphic variation and the effects of diagenesis and metamorphism. Precambrian Res., 49:301-327.

KAWASHITA, K. (1996) Rochas Carbonáticas Neoproterozóicas da América do Sul: Idades e Inferências Quimioestratigráficas. São Paulo, Universidade de São Paulo, 126p. (Tese de Livre Docência - Instituto de Geociências/USP). 
KEITH, M.L. \& WEBER, J.N. (1964) Carbon and oxygen isotopic composition of selected limestones and fossils. Geochim. Cosmochim. Acta, 28:1787-1816.

KINGSTON, D.R.; DISHROOM, C.P.; WILLIAMS, P.A. (1983) Global Basin Classification System. American Association of Petroleum Geologists Bulletin, 67(12):2175-2193.

KNIPE, R.J. (1989) Deformation mechanisms - recognition from natural tectonites. J. Struct. Geol., 11: 127-146.

KOPS, P.T. (1994) Geologia das Formações Antinha, Votuverava e Água Clara a sudeste do Complexo Granítico Três Córregos. Rio Claro, Universidade Estadual Paulista/UNESP, 132p. (Dissertação de Mestrado-Instituto de Geociências e Ciências Exatas/UNESP).

KOPS, P.T. \& EBERT, H.D. (1993) Evolução Tectônica das Formações Antinha, Votuverava e Água Clara, a sudeste do Complexo Granítico Três Córregos, Estado do Paraná. In: SIMP. NACIONAL de ESTUDOS TECTÔNICOS, 4, Belo Horizonte, 1993. Atas... Belo Horizonte, SBG Bol. 12, p.322-324.

KOPS, P.T.; SPOLADORE, A.; FUMAGALLI, C. (1993) Lineamento Morro Agudo: zona de cisalhamento transpressiva dúctil-rúptil. In: SIMPÓSIO SUL BRASILEIRO DE GEOLOGIA, 5, Curitiba, 1993. Boletim de Resumos... Curitiba, SBG, p. 22.

KRÖNER, A. (1977) The precambrian geotectonic evolution of Africa plate accretion versus plate destruition. Precambrian Reserch, 4(4):311-338.

KRÖNER, A. (1981) Precambrian plate tectonics. In: A. KRÖNER (Ed.), Precambrian plate Tectonics. Elsevier, Amsterdam, p. 57-90.

LEONARDOS, O.H. (1934) Nota sobre a geologia do distrito de Iporanga, SP. Rio de Janeiro, DNPM, relatório, 564p.

LEONARDOS, O.H. (1941) Notas petrográficas sobre a Série Ribeira do Sul do Estado de São Paulo. Boletim da Faculdade de Filosofia, Ciências e Letras da USP $n^{\circ}$ 21, Mineralogia, 4, p. $7-13$.

LIMA, R.E. de; REIS NETO, J.M.; MONASTIER, M.S. (1993) Geologia e depósitos de Talco da Faixa Itaiacoca. In: SIMP. SUL BRAS. GEOL., 5, Curitiba, 1993. Roteiro de Excursões... Curitiba, SBG.

LIN, S. \& WILLIAMS, P.F. (1992) The geometrical relationship between the stretching lineation and the movement direction of shear zones. J. Struct. Geol., 14(4):491-497.

LISTER, G.S. \& SNOKE, A.M. (1984) S-C milonites. J. Struct. Geol., 6:617-638.

LOWE, D.R. (1982) Sediment gravity flows: II. Depositional models with special reference to the deposits of high-density turbidity currents. J.Sedimentary Petrology, 52(1):279-297. 
MAAC, R. (1947) Breves notícias sobre a geologia dos Estados do Paraná e Santa Catarina. Arq. Biol. Tecn., 2:63-154.

McCREA, J.M. (1950) On the isotopic chemistry of carbonates and a paleotemperature scale. J. Chem. Physics, 18(6):849-957.

MACHADO, R. \& ENDO, I. (1993) A Megaestrutura em Flor Positiva do Vale do Rio Paraíba do Sul no Rio de Janeiro e suas implicações tectônicas regionais. In: SIMPÓSIO de GEOLOGIA do SUDESTE, 3, Rio de Janeiro, 1993. Boletim de Resumos... Rio de Janeiro, SBG, p.58.

MACHADO, R. \& ENDO, I. (1993) Cinturão de Cisalhamento Atlântico: um exemplo de tectônica transpressiva neoproterozóica. In: SIMP. NACIONAL de ESTUDOS TECTÔNICOS, 4, Belo Horizonte, 1993. Atas... Belo Horizonte, SBG Bol. 12, p. 189-191.

MACHADO, R. \& ENDO, I. (1994) Superposição cinemática Brasiliana no Cinturão de Cisalhamento Atlântico e na Cunha de Guaxupé. In: CONGR. BRAS. GEOL., 38, Camboriú, 1994. Boletim de Resumos Expandidos... Camboriú, SBG v.1, p. 269-270.

MALAVIELLE, J. \& LACASSIN, R. (1988) "Bone-shaped" boudins in progressive shearing. Journal Structural. Geology, 10:335-345.

MANIESI, V. \& OLIVEIRA, M.A.F. (1994) Aspectos petrológicos dos corpos anfibolíticos das regiões de Adrianópolis, Campo Largo e Rio Branco do Sul - Pr. In: CONGR. BRAS. GEOLOGIA, 38, Camboriú, 1994. Boletim de Resumos Expandidos... Camboriú, SBG v.3, p.11-12.

MARINI, O.J. (1970) Geologia da Folha de Rio Branco do Sul-PR. Rio Claro, Faculdade de Filosofia, Ciências e Letras, 190p. (Tese de Doutorado - Faculdade de Filosofia, Ciências e Letras).

MARINI, O.J. \& BIGARELLA, J.J. (1967) Rochas calcárias do Grupo Açungui. In: BIGARELlA, J.J.; SALAMUNI, R.; PINTO, V.M. (ed.) Geologia do Pré-Devoniano e Intrusivas Subsequentes da Porção Oriental do Estado do Paraná. Boletim Paranaense de Geociências, 23-25:157-181.

MARINI, O.J. \& BOSIO, N.J. (1969) Estromatólitos algaceos em dolomitos do Grupo Açungui. Ciênc. e Cult., 21:219-220.

MARINI, O.J.; TREIN, E.; FUCK, R.A. (1967) O Grupo Açungui no Estado do Paraná. In: BIGARELLA, J.J; SALAMUNI, R; PINTO, V.M. ed. Geologia do Pré-Devoniano e Intrusivas Subsequentes da Porção Oriental do Estado do Paraná. Boletim Paranaense de Geociências, 23-25:43-103.

MARTINS, G.R. (1938) Recursos minerais do Ribeira de Iguape. Min. Metal., (São Paulo), 3:13. 
MATTAUER, M. (1972) La deformation des roches: de la microtectonique a la chaine de montagne. In: ALLEGRE \& MATTAUER, M, ed. Structure e Dinamique de la lithosphère. Paris IV, Hermann, p. 199-264.

MELFI, A.J.; CORDANI, U.G.; BITTENCOURT, J. (1965) Reconhecimento fotogeoló-gico de parte do Grupo Açungui. Bragantia, Campinas, 24(34):447-474.

MELCHER, G.C. et al (1973) Geologia e petrologia das rochas metamórficas e graníticas associadas ao Vale do Rio Ribeira de Iguape, SP e PR. Revista Brasileira de Geociências, 3(2):97-123.

MONTEIRO, L.V.S.; MARTIN, M.A.B.; JULIANI, C.; CAMPOS NETO, M.C. (1994) Contribuição à geologia do Núcleo Betara (Pr). In: CONGR. BRAS. GEOL., 38, Camboriú, 1994. Boletim de Resumos Expandidos... Camboriú, SBG v.2, p.62-63.

MANTOVANI, M.S.M.; HAWKESWORTH, C.J.; BASEI, M.A.S. (1987) Nb and Pb isotope studies bearing on the crustal evolution of southeastern Brazil. Revista Brasileira de Geociências, 17:263-268.

MORAIS REGO, L.F. de (1933) Contribuição ao estudo das formações pré-Devonianas de São Paulo. São Paulo, Instituto Astronômico e Geofísico de São Paulo, 60p.

MORALES, N. (1994) Evolução Tectônica do Cinturão de Cisalhamento Campo do Meio na sua porção central. Rio Claro, UNESP- Campos de Rio Claro, vol I (texto) 174p., vol II (ilustrações) 125p. (Tese de Doutoramento - Universidade Estadual Paulista/Campos de Rio Claro).

MORALES, N. \& HASUI, Y. (1993) Evolução tectônica da porção ocidental do cinturão de cisalhamento Campo do Meio. In: SIMP.NAC.EST.TECTÔNICOS, 4, Belo Horizonte, 1993. Atas... Belo Horizonte, SBG Bol. 12, p.292-296.

MORALES, N.; SIMÕES, L.S.A.; VALERIANO, C.M.; GODOY, A.M. (1991) Boudinagem e estrutura de constrição associadas a dobras em bainha. In: SIMP.NAC.EST.TECTÔNICOS, 2, Fortaleza, 1991. Atas... Fortaleza, SBG Bol. 11, p.221-224.

MORGENTAL, A. et al (1975) Projeto Sudelpa; relatório final, geologia. São Paulo, Convênio SUDELPA/CPRM, 18 vol.

MORITZ JR., A.R. \& FIORI, A.P. (1987) Análise de seixos deformados da Formação Camarinha. In: SIMP. SUB BRAS. GEOL., 3, Curitiba, 1987. Atas... Curitiba, SBG v.l, p.107-121.

NAYLOR, M.A.; MANDL, G.; SIJPE STEIJN, C.H.R. (1986) Fault geometries in basement induced wrench faulting under different initial stress states. Jl. Struct. Geology, 8(7):737752.

NARDI, L.V.S. (1994) Evolução do magmatismo neoproterozóico sintranscorrente no sul do Brasil: implicações geotectônicas. In: CONGR. BRAS. GEOLOGIA, 38, Camboriú, 1994. Boletim de Resumos Expandidos...Camboriú, SBG v.1, p.137-138. 
NICOL, A. (1993) Conical folds produced by dome and basin fold interference and their application to determining strain: exemples from North Canterbury, New Zealand. J.Struct.Geol., 15(6)785-792.

O'BRIEN, D.K.: WENK, H.R.; RATSCHBACHER, L, YOU, Z.(1987)Preferred orien-tation of phyllosilicates in phyllonites and ultramylonites. J. Struct. Geol., 9:719-730.

OLIVEIRA, E.P. (1916) Geologia do estado do Paraná. Boletim do Ministério da Agricultura e Industria e Comércio $5(1): 77-143$.

OLIVEIRA, E.P. (1925) Mapa Geológico do Estado do Paraná. Escala 1:1.000.000, Serviço Geológico Mineral do Brasil.

OLIVEIRA, E.P. (1927) Geologia e Recursos Minerais do Estado do Paraná. Rio de Janeiro, Serv. Geol. Mineral do Brasil, Monografia 6, 178p.

OLIVEIRA, E.I. \& LEONARDOS, O.H. (1943) Geologia do Brasil. Rio de Janeiro, Minist. da Agricultura-Imprensa Nacional, 782p (Série Didática, 2).

OLIVEIRA, M.A.F.; GODOY, A.M.; HACKSPACHER, P.C.; MORENO, M.M.T. (1994) Novos dados geoquímicos para rochas anfibolíticas do Grupo São Roque nas regiões de Cabreúva e Sorocaba, SP. In: CONGR. BRAS. GEOL., 38, Camboriú, 1994. Boletim de Resumos Expandidos... Camboriú, SBG v.3, p.165-166.

PAIVA, I.P. et al (1977) Projeto Leste do Paraná, Folha Apiaí (SG 22-X-B-IV), relatório final. São Paulo, DNPM/BADEP/IGUFP/CPRM (inédito).

PASSCHIER, C.W. \& SIMPSON, C. (1986) Porphyroclast system as kinematic indicators. Journal Structural Geology, 8:831-843.

PASSCHIER, C.W.; TROUW, R.A.J.; ZWART, H.J.; VISSERS, R.L.M. (1992) Porphyroblast rotation: eppur si muove? J. Metamorphyc Geol., 10:283-294.

PETRI, S. \& SUGUIO, K. (1969) Sobre os metassedimentos do Grupo Açungui no extremo sul do Estado de São Paulo. São Paulo, Convênio USP-DAEE, 98p.

PIEKARZ, G.F. (1981) Reconhecimento de unidades correlacionáveis a Sequência Mineralizada do Perau(PR). In:SIMP.REG.GEOL.,3,Curitiba, 1981. Atas...Curitiba, SBG v.1, p.148-155.

PIEKARZ, G.F. (1984) Geologia e resultados preliminares da pesquisa no Núcleo Betara da Formação Perau (PR). In: CONGR.BRAS.GEOL., 33, Rio de Janeiro, 1984. Anais... Rio de Janeiro, SBG v.7, p.3682-3696.

PLATT,J.P.(1983) Progressive refolding in ductile shear zones. J.Struct.Geol., 5:619-622.

PONTES, J.B. (1981) Geologia e Potencialidades Econômicas da Formação Água Clara (PR). Curitiba, Relatório Interno da MNEROPAR. 
PONTES, J.B. (1982) Geologia e Potencialidades Econômicas da Formação Água Clara-PR. In: CONGR. BRAS.GEOL., 32, Salvador, 1982. Anais... Salvador, SBG v.3, p.1002-1016.

PONTES, J.B. \& SALAZAR JR., O. (1982) Geologia e Potencialidades Econômicas da Região de São Silvestre (PR). Curitiba, Relatório da MINEROPAR, 128p.

POPP, J.H.; ANGULLO, R; BIGARELLA, J.J. (1979) Geologia. In: BIGARELLA, J.J. ed. Recursos Naturais, Folha de Ouro Fino. Curitiba, COMEC, p.22-26.

PORADA, H. (1979) The Damara-Ribeira orogen of the Pan-African-Brasilian Cycle in Namibia (Southwest Africa) and Brazil as interpreted in terms of continental collision. Tectonophysics, 57: 237-265.

RAGAN, D.M. (1973) Structural Geology: an introduction to geometrical tecnhiques. 2.ed. John Wiley \& Sons.

RAJLICH, P. (1993) Riedel shear: a mechanism for crenulation cleavage. Earth-Science Reviews, 34:167-195.

RAMSAY, J.G. (1967) Folding and fracturing of rocks. New York, McGraw-Hill,568p.

RAMSAY, J.G. (1980) Shear zone geometry: a review. J. Struct. Geol., 2:83-89.

RAMSAY, J.G. \& GRAHAM, R.H. (1970)Strain variation in shear belts. Can.J.Earth Sci., 7:786-813.

RAMSAY, J.G. \& HUBER, M.I. (1983) The techniques of modern structural geology, volume 1: strain analysis. London, Academic Press, 307p.

RAMSAY, J.G. \& HUBER, M.I. (1987) The tecchniques of modern structural geology, volume 2: folds and fractures. London, Academic Press, 700p.

READING, H.G. (1980) Characteristics and recognition of strike-slip faut systems. Spec. Publ. International Association of Sedimentologists 4:7-26.

REIS NETO, J.M. (1994) Faixa Itaiacoca: registro de uma colisão entre dois blocos continentais no neoproterozóico. São Paulo, Universidade de São Paulo, 253p.(Tese de Doutorado - Instituto de Geociências/USP).

REIS NETO, J.M. \& SOARES, P.C. (1987) Um estudo de caracterização termo-dinâmica de micro-estruturas dos Grupos Açungui e Setuva (PR). In: SIMP.SUL BRAS. GEOL., 3, Curitiba, 1987. Atas... Curitiba, SBG v. 1, p.147-165.

RICHAR, P. \& COBBOLD, P. (1990) Experimental insights into partitioning of fault motions in continental convergent wrench zones. Annales Tectonicae, Special issue, 4(2):35-44. 
RIDLEY, J. (1986) Parallel stretching lineations and fold axes oblique to a shear displacement direction: a model and observations.J. Struc. Geol, 8:647-653.

ROBERT, F. (1993) The geometrical relationship between the stretching lineation and the movement direction of shear zones: Discussion. J. Struct. Geol., 15(2)239-240.

RUTTER, E.H. (1993) Rheology, deformation mechanisms and microstructures - an illustration by reference to the mechanical behaviour of calcite rocks. In: SIMP.NAC.EST.TECTÔNICOS, 4, Belo Horizonte, 1993. Atas... Belo Horizonte, SBG Bol.12, p.148-155.

SADOWSKI, G.R. (1983) Sobre a geologia estrutural de cinturões de cisalhamento continentais. São Paulo, Universidade de São Paulo, 108p. (Tese de Livre Docência Instituto de Geociências/USP).

SALAMUNi, E. (1991) Análise Estrutural do Núcieo Betara, Rio Branco do Sul-PR. Rio Claro, UNESP, 147p. (Dissertação de Mestrado - UNESP).

SALAMUNI, E.; FIORI, A.P.; WERNICK, E. (1992a) Evolução Tectônica e Estruturação do Núcleo Betara, Arredores de Curitiba-PR. In: CONGR.BRAS.GEOL., 37, São Paulo, 1992. Boletim de Resumos Expandidos... São Paulo, SBG v.1, p. 280.

SALAMUNI, E.; WERNICK, E.; FIORI, A.P. (1992b) Tectonoestratigrafia do Núcleo Betara sudoeste de Rio Branco do Sul, PR. In: CONGR.BRAS.GEOL., 37, São Paulo, 1992. Boletim de Resumos Expandidos... São Paulo, SBG v.2, p.123.

SANDERSON, D.J. \& MARCHINI, W.R.D. (1984) Transpression. J. Struct. Geol., 6(5):449-458.

SCHIDLOWSKI, M; EICHMAN, R.; JUNGE, C.E. (1975) Precambrian sedimentary carbonates: carbon and oxygen isotope geochemistry and implication for the terrestrial oxygen budget. Precambrian Res., 2(20):01-69

SCHMID, S.M.; PANOZZO, R.; BAUER, S. (1987) Simple shear experiments on calcite rocks: rheology and microfabric. J. Struct. Geol., 9:747-778.

SCHÖLL, W.U. (1981) Geologia do Grupo Açungui na Região a noroeste de Rio Branco do Sul, PR. In: SIMP.REG.GEOL., 3, Curitiba, 1981. Atas... Curitiba, SBG v. 1, p. 170-184.

SCHÖLL, W.U.; SILVA, A.C.G.A.; MONASTIER, M.S. (1982) A Formação Setuva do PréCambriano do Estado do Paraná - uma revisão crítica. In: CONGR. BRAS. GEOL,32, Salvador, 1982. Anais...Salvador, SBG v.1, p.55-63.

SCHÖLL, W.U.; LOPES, O.F.; SILVA, A.C.G.A.; PROZZI, C.R. (1980) Geologia do PréCambriano da Região do Anticlinal do Setuva (município de Bocaiúva do Sul e Rio Branco do Sul-PR). In: CONGR. BRAS. GEOL., 31, Camboriú, 1980. Anais... Camboriú, SBG v. 5, p. 3003-3012. 
SHACKLETON, R.M. \& RIES, A.C. (1984) The relation between regionally consistent stretching lineations and plate motions. J. Struct. Geol, 6:111-117.

SCHOLLE, P.A.; ARTHUR, M.A.; EKDALE, A.A. (1983) Pelagic environment. In: SCHOLLE, P.A.; BEBOUT,D.G.; MOORE,C.H. (ed.) Carbonate Depositional Environments. Oklahoma,Am.Assoc.of Petroleum Geologists,Memoir,33,p.619-692.

SENGOR, A.C.M. (1990) Plate tectonics and orogenic research after 25 years: a Tethyan perspective. Earth- Science Reviews, 27:1-201.

SIBSON,R.H.(1977) Fault rocks and fault mechanisms. J.Geol.Soc.London, 133:191-213.

SILVA, A.T.S.F. et al (1977) Projeto Santos-Iguape, relatório final de geologia. São Paulo, Convênio DNPM/CPRM.

SILVA, A.T.S.F. et al (1978) Geologia integrada das folhas Iguape e Cananéia. In: CONGR.BRAS.GEOL., 30, Recife, 1978. Anais... Recife, SBG v.1, p. 222-235.

SILVA, A.T.S.F. \& ALGARTE, J.P. (1981a) Contribuição à geologia da Sequência TurvoCajati entre o Rio Pardo e Pariquera-Açu, estado de São Paulo. 1: Litologia e petrografia. In: SIMP. REGIONAL DE GEOLOGIA, 3, Curitiba, 1981. Atas... Curitiba, SBG v.1, p.109-120.

SILVA, A.T.S.F. \& ALGARTE, J.P. (1981b) Contribuição à geologia da Sequência TurvoCajati entre o Rio Pardo e Pariquera-Açu, Estado de São Paulo. 2: Estrutura, metamorfismo e evolução tectônica. In: SIMP. REGIONAL GEOLOGIA, 3, Curitiba. Atas... Curitiba, SBG v.1, p.121-132.

SILVA, C.R. et al. (1982) Geologia e mineralizações da região Perau-Água Clara, Vale do Ribeira, PR. In: CONGRESSO BRASILEIRO DE GEOLOGIA, 32, Salvador, 1982. Anais... Salvador, SBG v.3, p.1024-1036.

SILVA, D.C.; FELIPE, R.S.; PONTES, J.B. (1981) Notas sobre as ocorrências de fluorita do Vale do Ribeira (PR). In: SIMP. REGIONAL de GEOLOGIA, 3, Curitiba, 1981. Atas... Curitiba, SBG v1, p.83-89.

SILVA, M.E. (1981)Análise Estrutural das faixas ectiníticas associadas ao Falhamento de Cubatão entre as regiões de Juquiá e Pedro Barros, Estado de São Paulo. São Paulo, Universidade de São Paulo, 118p. (Dissertação de Mestrado - Instituto de Geociências/USP).

SILVA, M.E. (1996) Zona de Cisalhamento de Alta Temperatura - O Lineamento de Além Paraíba (RJ) (Petrotrama de Plagioclásio - Anisotropia Física - Reologia da Litosfera Continental). São Paulo, Universidade de São Paulo, 226p. (Tese de Livre Docência Instituto de Geociências/USP). 
SILVA, M.E.; SADOWSKI, G.R.; TROMPETTE, R.R. (1982) Modelo Geométrico e Cinemático para os falhamentos de idade Brasiliana da Faixa de Dobramentos Ribeira, Estado de São Paulo, Brasil. In: CONGR. LATINO AMERICANO DE GEOLOGIA. Anais... tomo II, p.11-21.

SIMPSON, C. (1986) Determination of movement sense in mylonites. J. Struct. Educ., 34:246-261.

SIMPSON, C. \& SCHMIDT, S.J. (1983) An evolution of criteria to deduce the sense of moviment in sheared rocks. Geol. Soc. Am. Bull., 94:1281-1288.

SOARES, P.C. (1987) Sequências tecto-sedimentares e tectônica deformadora no centro-oeste do escudo Paranaense. In: SIMP.SUL BRAS.GEOL., 3, Curitiba, 1987. Atas... Curitiba, SBG v.2, p.743-772.

SOARES, P.C. (1988) Tectônica colisional em torno do Bloco Paraná, Brasil. In: CONGR. LATINO AMERICANO GEOL., 7, Belém, 1988. Anais... Belém, SBG, p.63-79.

SOARES, P.C. (1992) Algumas observações sobre as faixas proterozóicas e seus sistemas colisionais no sul do Brasil. In: CONGR.BRAS.GEOL., 37, São Paulo, 1992. Boletim de Resumos Expandidos... São Paulo, SBG v.1, p.277-278.

SOARES, P.C. \& FIORI, A.P. (1976) Lógica e sistemática na análise e interpretação de fotografias aéreas em geologia. Notícias Geomorfológicas, 16(32):71-104.

SOARES, P.C. \& GÓIS, J.R. (1987) Geologia do Granito Passa Três (PR) e suas mineralizações auríferas. In: SIMP.SUL BRAS.GEOL., 3, Curitiba, 1987. Atas... Curitiba, SBG v.2, p.497-514.

SOARES, P.C.; FIORI, A.P.; CARVALHO, S.G. (1990) Tectônica colisional oblíqua entre o Bloco Paraná e a margem sul do Cráton do São Francisco, no Maciço de Guaxupé. In: CONGR.BRAS.GEOL., 36, Natal, 1990. Anais... Natal, SBG v.6, p.2723-2724.

SOARES, P.C.; CARVALHO, S.G.; FIORI, A.P. (1991) Evolução tectônica dos terrenos máficos-ultramáficos na margem sul do Cráton do São Francisco. In: SIMPÓSIO NACIONAL ESTUDOS TECTÔNICOS, 3,Rio Claro,1991. Atas...Rio Claro,SBG,p.66-68.

SOARES, P.C.; STEVANATO, R.; CAMARGO, C.R. (1987) Geologia do noroeste da Faixa Itaiacoca-PR. In: SIMP.SUL BRAS.GEOL., 3, Curitiba, 1987. Atas... Curitiba, SBG v.1, p. 245-262.

SOARES, P.C.; FIORI, A.P.; CARVALHO, S.G. (1990) Tectônica colisional obliqua entre o Bloco Paraná e a margem sul do Cratón São Francisco, no Maciço de Guaxupé. In: CONGR. BRAS. GEOLOGIA, 36, Natal, 1990. Anais... Natal, SBG v.6, p.2723-2734.

SOUZA, A.P. (1990) Mapa geológico na escala 1:50.000 e esboço da evolução tectônica e sedimentar do Grupo Itaiacoca, nas folhas Barra do Chapéu e Ouro Verde-SP/PR. São Paulo, Universidade de São Paulo, 200p. (Dissertação de Mestrado - Instituto de Geociências/USP). 
SOUZA, A.P. (1992) Litoestratigrafia e Tectônica da Faixa Itaiacoca. In: CONGR. BRAS. GEOL., 37, São Paulo, 1992. Boletim de Resumos Expandidos... São Paulo, SBG v.1, p.281-282.

SOUZA NETO, J.A; HACKSPACHER, P.C.; LEGRAND, J.M. (1994) Progressão da tectônica de alto para baixo ângulo na zona do lineamento Patos, NE do Brasil - Região de Catingueira - PB. In; CONGR. BRAS. GEOLOGIA, 38, Camboriú, 1994. Boletim de Resumos Expandidos... Camboriú, SBG v.2, p.288-289.

SPOLADORE, A. (1993) Caracterização da história deformacional das rochas proterozóicas da região de Bromado, Paraná. Rio Claro, Universidade Estadual Paulista - Campos de Rio Claro, 157p. (Dissertação de Mestrado - Instituto de Geociências e Ciências Exatas/UNESP - Campos de Rio Claro).

SPOLADORE, A. \& HACKSPACHER, P.C. (1993a) Geologia do Grupo Açungui na Região de Bromado, PR. In: SIMPÓSIO SUL BRASILEIRO DE GEOLOGIA, 5, Curitiba, 1993. Boletim de Resumos... Curitiba, SBG, p.1.

SPOLADORE, A. \& HACKSPACHER, P.C. (1993b) Evolução deformacional progres- siva brasiliana do Grupo Açungui na região de Bromado, PR. In: SIMPÓSIO SUL BRASILEIRO DE GEOLOGIA, 5, Curitiba, 1993. Bol. de Resumos...Curitiba, SBG, p.13.

SPOLADORE, A. \& HACKSPACHER, P.C. (1994) Tipologia de sombras de pressão e sua utilização para o diagnóstico de diferentes comportamentos reológicos em uma história tectônica progressiva. In: CONGR. BRAS. GEOLOGIA, 38, Camboriú, 1994. Boletim de Resumos Expandidos... Camboriú, SBG v.1, p.668-669.

SUGUIO, K.(1980) Rochas Sedimentares, propriedades/gênese/importância econômi-ca. São Paulo, Editora Edgard Blücher/Editora da Universidade de São Paulo, 500p.

TAKAGI, H. \& ITO, M. (1988) The use of asymmetric pressure shadows in mylonites to determine the sense of shear. J. Struct. Geol., 10(4):347-360.

TAKAHASHI, A.T.; FERREIRA, J.C.G.; THEODOROVICZ, A. (1984) Projeto Guapiara. Relatório Final. São Paulo, contrato CPRM/Pró-Minério.

TAKAHASHI, A.T. et al. (1986) Projeto Engenheiro Maia-Ribeirão Branco. Relatório Final. São Paulo, contrato CPRM/Pró-Minério.

TANAKA, H. (1992) Cataclastic lineations. J. Struct. Geol., 14(10):1239-1252.

TAPPONIER, P. \& MOLNAR, P. (1976) Slip line field theory and large-scale continental tectonics. Nature, 264:319-324.

TAPPONIER, P.; PELTZER, G.; ARMIJO, R. (1986) On the mechanics of the collision between India and Asia. In: COWARD, M.P. \& RIES, A.C. ed. Collision Tectonics. London, Blackwell, p.115-157. 
TASSINARI, C.C.G.; BARBOUR, A.P.; DAITX, E.C.; SATO, K. (1990) Aplicação dos isótopos de $\mathrm{Pb}$ e $\mathrm{Sr}$ na determinação da natureza das fontes das mineralizações de Chumbo do Vale do Ribeira - São Paulo e Paraná. In: CONGR. BRAS. GEOLOGIA, 36, Natal, 1990. Anais... Natal, SBG v.3, p. 1254- 1266.

THEODOROVICZ, A.; CÂMARA, M.M.; TAKAHASHI, A.T; MORAES, S.M.; GODOY, H.K. (1988) Geologia do Pré-Cambriano das folhas Engenheiro Maia e Ribeirão Branco, São Paulo. In: CONGR. BRAS. GEOL., 35, Belém, 1988. Anais...Belém, SBG v.6, p. $2713-2726$.

TIKOFF, B. \& FOSSEN, H. (1993) Simultaneous pure and simple shear: the unifying deformation matriz. Tectonophysics, 217:267-283.

TIKOFF, B. \& TEYSSIER, C. (1994) Strain modeling of displacement-field partitioning in transpressional orogens. J. Structural Geology, 16(11):1575-1588.

TORQUATO, J.R.F. (1980) Aplicação dos isótopos estáveis de carbono e oxigênio ao estudo do Pré-Cambriano Brasileiro. (Tese para Professor Titular apresentada ao Departamento de Geociências da Universidade Federal do Ceará), 268p.

TREIN, E.; REIS NETO, J.M.; BIONDI, J.C.; MONASTIER, M.S. (1985) Revisão da Formação Itaiacoca: identificação de uma sequência metavulcano-sedimentar em Abapã (PR). In: SIMP.REG.GEOL., 5, São Paulo, 1985. Atas... São Paulo, SBG v. 1, p. 169-182.

TUPINAMBÁ, M. \& TROUW, R.A.J. (1994) Evidências de evolução metamórfica e estrutural anterior à tectônica transpressiva na Faixa Ribeira. In: CONGR. BRAS, GEOLOGIA, 38, Camboriú, 1994. Boletim de Resumos Expandidos... Camboriú, SBG v.2., p.75-76.

TURNER, F.J. (1981) Metamorphic Petrology. New York, McGraw-Hill, 524p.

TURNER, F.J. \& WEISS, L.E. (1963) Structural analysis of metamorphic tectonites. New York, McGraw-Hill, 545p.

UREY,H.C.(1948) Oxygen isotopes in nature and in the laboratory. Science, 108:489-496.

VAN DEN DRIESSCHE, J. \& BRUN,J.P. (1987) Rolling structures at large shear strain. J. Struct. Geol., 9:691-704.

VAUCHEZ, A.; TOMMASI, A.; SILVA, M.E.; TROMPETE,R. (1992) Tectônica de escape na terminação de um craton: a Faixa Ribeira. In: CONGR. BRAS. GEOLOGIA, 37, São Paulo, 1992. Boletim de Resumos Expandidos... São Paulo, SBG v.2, p.373-374.

VAUCHEZ, A.; TOMMASI, A; SILVA, M.E. (1994) Self-indentation of a heterogenous continental lithosphere. Geology, 22:967-970.

VEIGA, H.R. \& SALOMÃO, E.L. (1980) A Formação São Sebastião e sua importância econômica. In: CONGR.BRAS.GEOL., 31, Camboriú, 1980. Anais... Camboriú, SBG v.2, p. 826-831. 
VEIZER, J. \& GARRET, D.E. (1978) Secular variation in the composition of sedimentary carbonaterocks I. alkali metals. Precambrian Res., 6:367-380.

VEIZER, J. \& HOEFS, J. (1976) The nature of ${ }^{18} \mathrm{O} /{ }^{16} \mathrm{O}$ and ${ }^{13} \mathrm{C} /{ }^{12} \mathrm{C}$ secular trands in sedimentary carbonate rocks. Geochim. Cosmochim. Acta, 40:1387-1395.

WALKER, R.G. (1975) Generalized facies models for resedimented conglomerates of turbidite association.Geol. Soc. Americ. Bull., 86:737-748.

(1977) Deposition of upper mesozoic resedimented conglomerates and associated turbidites in suthwestern Oregon. Geol. Soc. America Bull., 88:273-285.

(1978) Deep-water sandstone facies and ancient submarine fans: models for exploration for stratigraphic traps.Am.Assoc.Petroleum Geologists Bull,62:932-966.

WEBER, J.N. (1964) Trace element composition of dolostones and dolomites and its bearing on the dolomite problem. Geochim. Cosmochim. Acta, 28;1817-1868.

WENK, H.R. \& CHRISTIE, J.M. (1991) Review paper: comments on the interpretation of deformation textures in rocks.J. Struct. Geol., 13:1091-1110.

WENK, H.R.; TAKESHITA, T.; BECHLER, E.; ERSKINE, B.G.; MATTHIES, S. (1987) Pure shear and simple shear calcite textures. Comparison of experimental, theoretical and natural data. J. Struc. Geol., 9:731-745.

WERNICK, E.; HASUI, Y.; NEVES, B.B. de B. (1978) As regiões de dobramento sudeste e nordeste. In: CONGR. BRAS. GEOLOGIA, 30, Recife, 1978. Anais... Recife, SBG v.6, p.2493-2507

WILLIAMS, G.D. \& CHAPMAN, T.J. (1979) The geometrical classification of noncylindrical folds. Jl. Struct. Geol., 1(3):181-185.

WINKLER, H.G.F. (1977) Petrogênese das rochas metamórficas. São Paulo, Editora Edgard Blücher, 254p.

WOODCOCK (1986) The role of strike-slip fault at plate boudaries. Philosophical Transactions Royal Society of London, v. A317, p.13-29.

ZAGORCEV, I.S. (1993) The geometrical classification of foldsand distribution off old types in natural rocks. J. Struct. Geol., 15(3-5):243-251. 


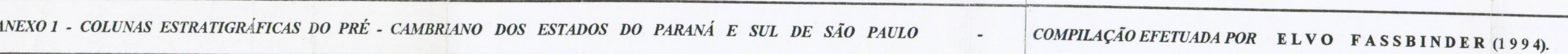

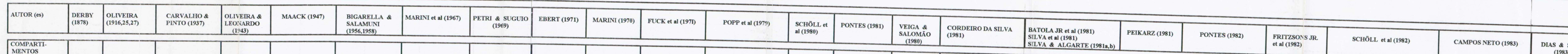

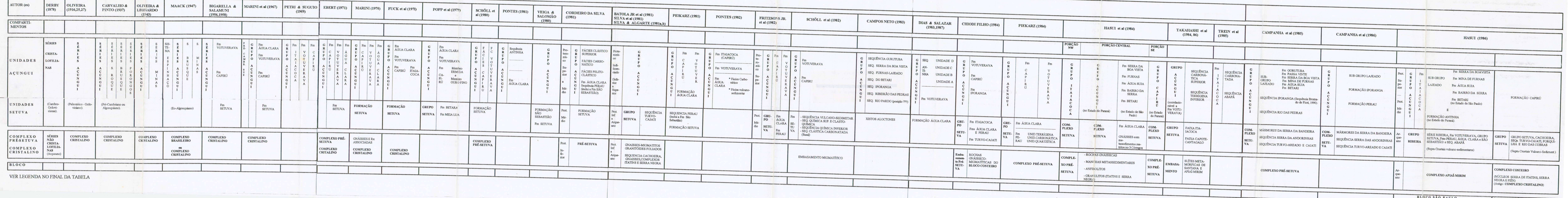




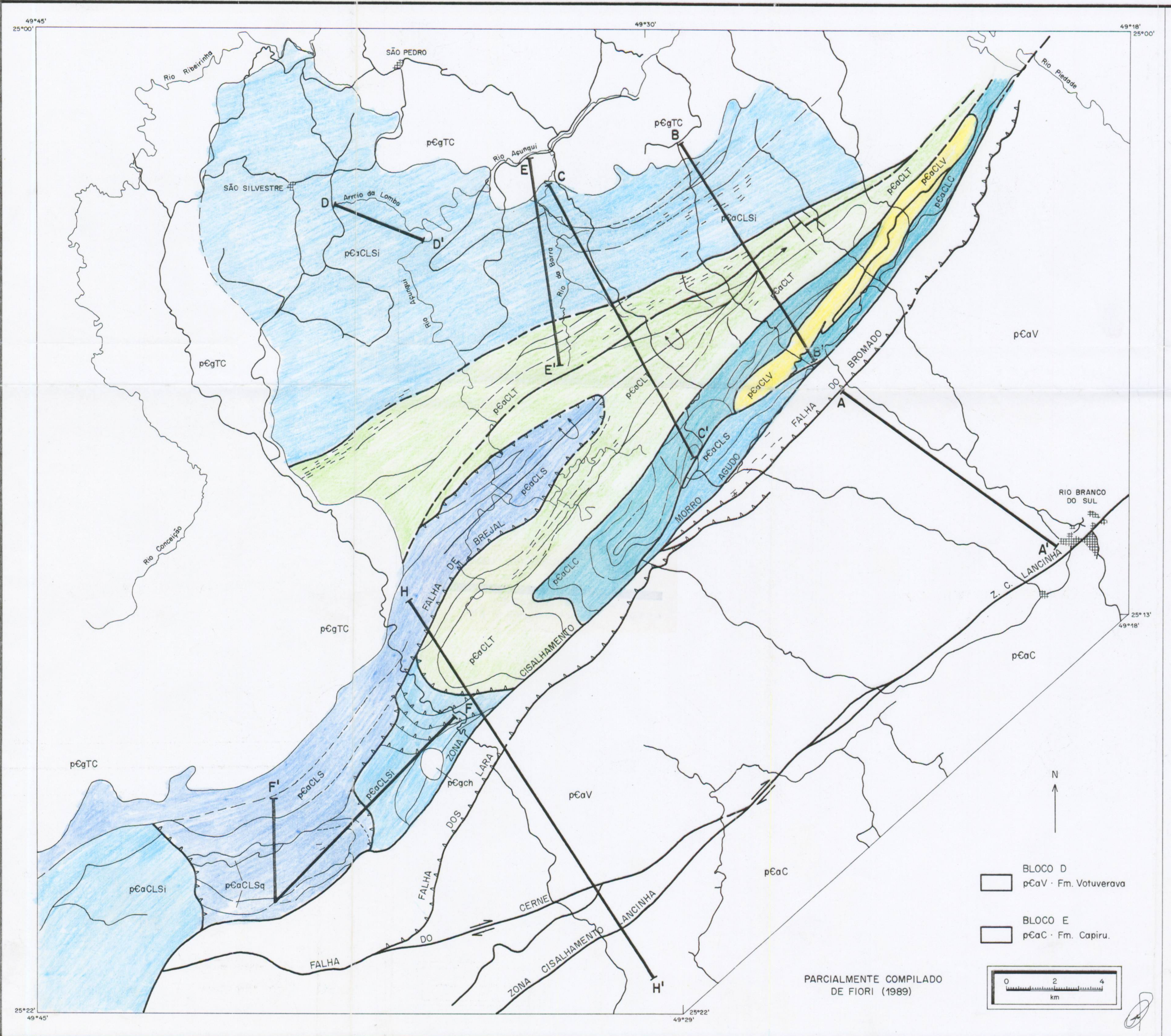

BLOCO C

$\square \quad \begin{gathered}\text { peg. GRANTO } \\ \text { TRES CORRECOS (TC), CHACRINHA (Ch) }\end{gathered}$

GRUPO AÇUNGUI

FORMAÇ̃̃O ANTINHA (SUB-GRUPO LAJEADO).

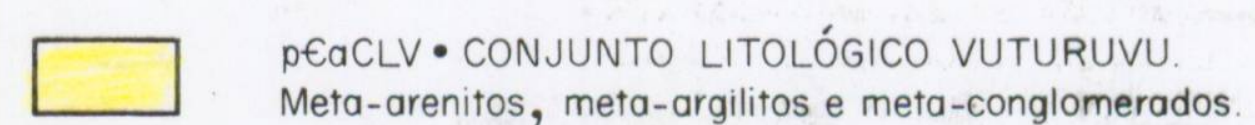

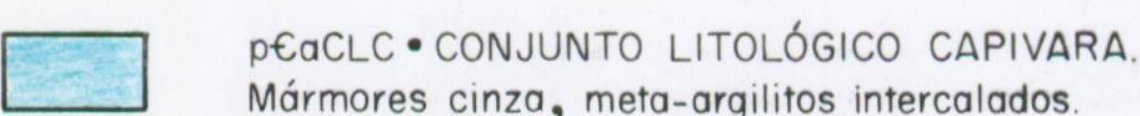

PefaCLT - CONJUNTO LITOĹGICO TACANIÇA. FormaĢ̄óo ÁGUA CLARA

pEaCLS• CONJUNTO LITOLÓGICO SERRINHA

Marmores e meta-margas com intercalaçees de

peacisi con

peaCLSi $\bullet$
Meta-pelitos, meta - psamitos, meta-margas,
meta-carbonatos e meta- vulcânicas.

CONVENÇŌES

GEOLÓGICAS

II Falhas de cavalgamento.

Falhas transcorrentes.

Lineaçōes fotogeológicas.

tos fotogeológicos.

Contato geológico.

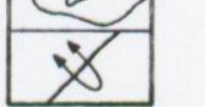

Antiforme com flanco invertido.

TOPOGRÁFICAS

Cidade

En Estrada secundári

Drenagem.

ARTICULACĀO DOS BLOCOS TECTÔNICOS

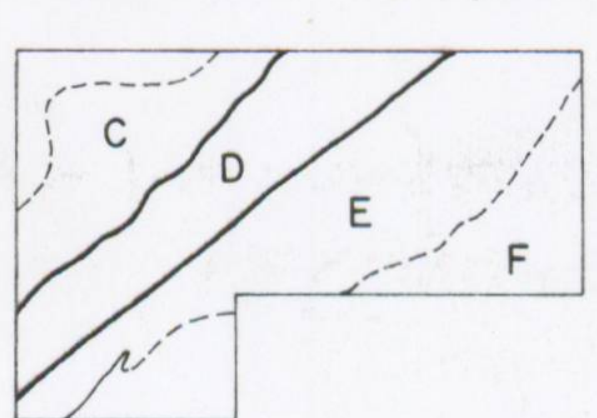

BASE TOPOGRÁFICA (Escala $1 / 50.000$

COMEC, SG-22-X-C-III-2,

$$
\begin{aligned}
& \text { SG }-22-X-C-111-4 \\
& \text { SG }-22-X-D-1-1 \\
& \text { SG }-22-X-D-1-3
\end{aligned}
$$

ANEXO II

MAPA FOTOGEOLÓGICO DA REGIĀO DE SĀO PEDRO • SĀO SILVESTRE

\begin{tabular}{|ll|l|}
\hline Autor: & ELVO FASSBINDER & Data: \\
\hline Orientodotor: & Prof. Dr. RÔMULO MACHADO & Escala \\
\hline
\end{tabular} NSTITUTO DE GEOCIENNCIAS - USP 


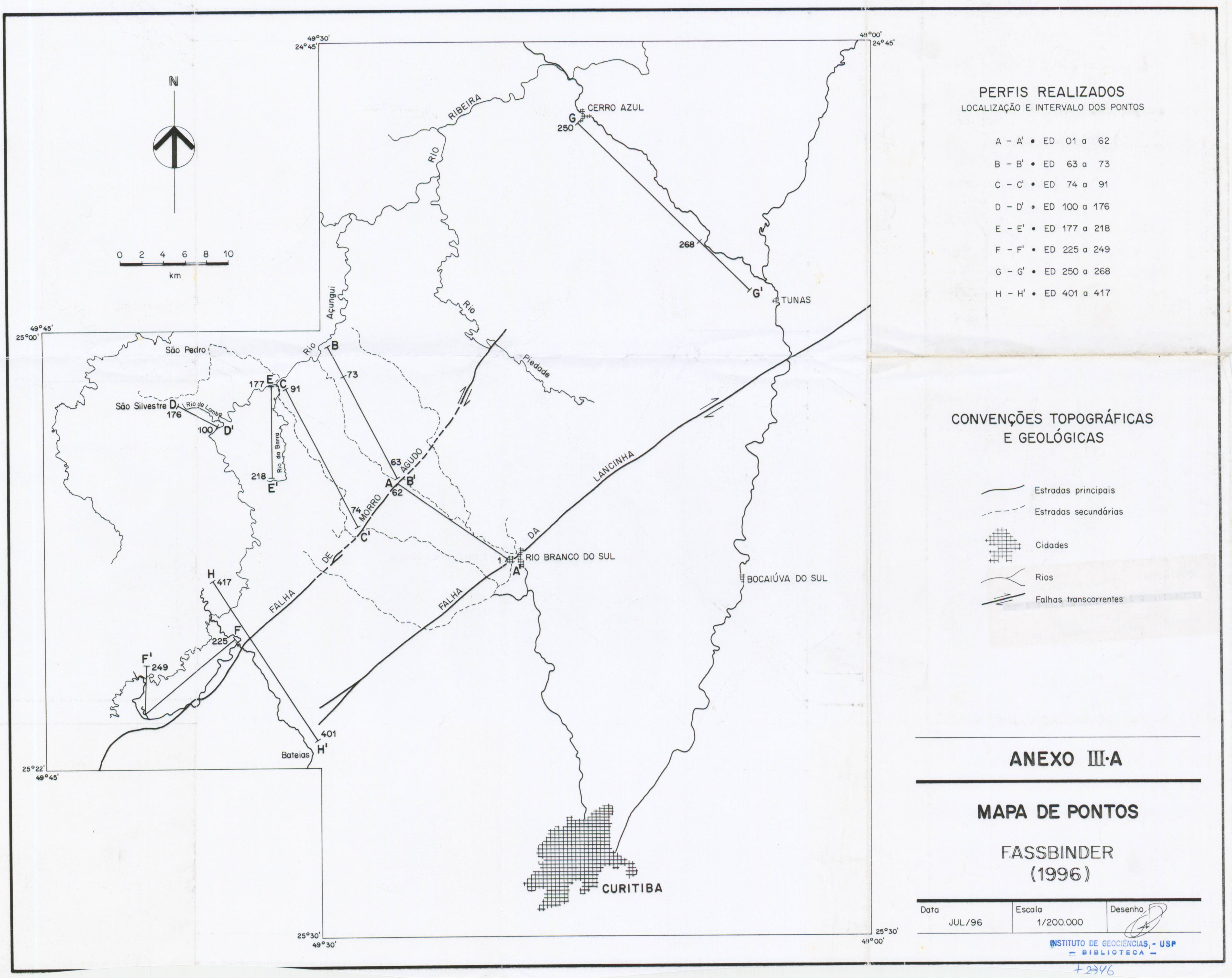

